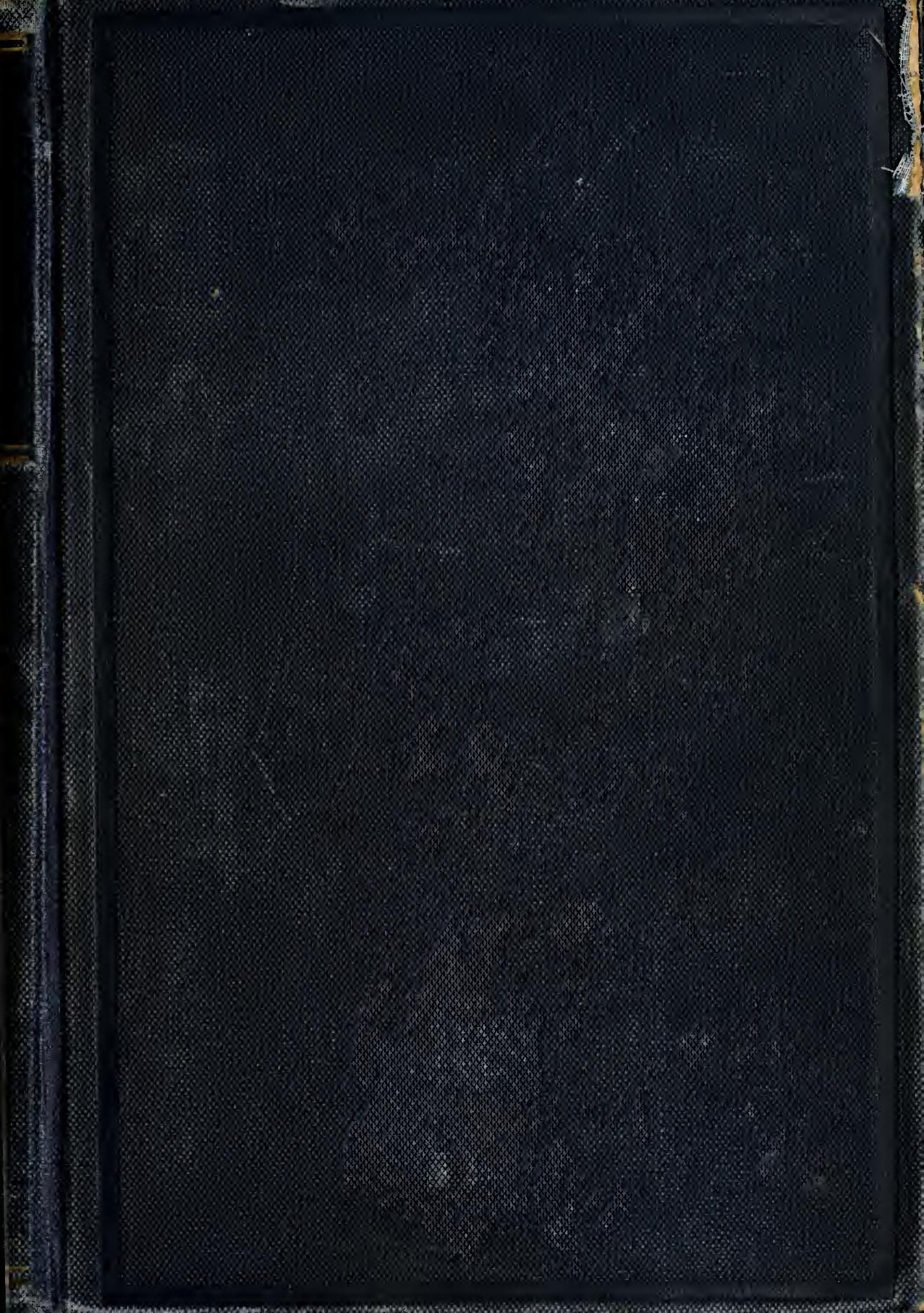




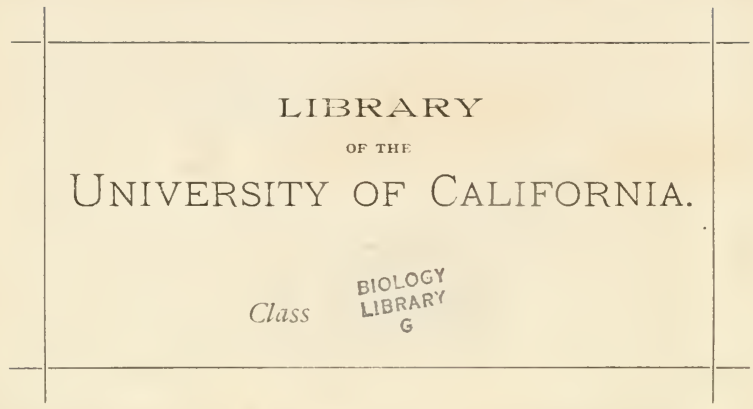


Digitized by the Internet Archive in 2008 with funding from Microsoft Corporation 



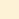

- 



\section{THE PATHOLOGY}

AND

\section{DIFFERENTIAL DIAGNOSIS}

OF

\section{INFECTIOUS DISEASES OF ANIMALS}

By VERANUS ALVA MOORE, B.S., M.D.

Professor of Comparative Pathology, Bacteriology and Meat Inspection,

New York State Veterinary College, Cornell University, lthaca, New York.

With An lntroduction by

DANIEL ELMER SALMON, D.V.M.

Former Chief of the Bureau of Animal Industry, United States

Department of Agriculture.

THIRD EDITION REVISED AND ENLARGED

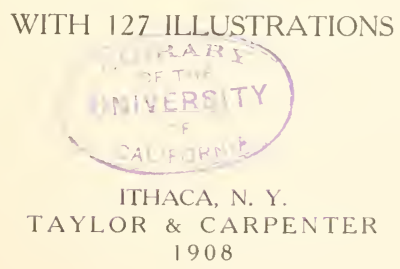




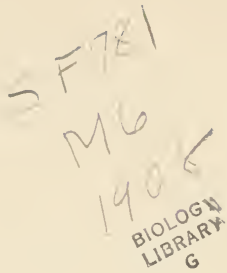

\section{SENERAL}

COPYRIGHT IgOS

BY VERAXUS ALYA MOORE 


\section{TO DANIEL, EI,MER SALMON}

LARGELY THROUGH WHOSE IABORS THERE, WAS ESTABLISHED IN THE UNITED STATES DEPAR'TMENT OF AGRICULTURE THE BLREAT OF ANIMAL INDUSTRY WHICH HAS MADE POSSIBLE EXTENSIVE INVESTIGATIONS INTO THE NATURE OF EPIZOÖTIC DISEASES IN AMERICA AND WHO FOR TWENTY-ONE YEARS DIRECTED THESE INVESTIGATIONS

THIS VOLUME IS DEDICATED. 


\section{PREFACE}

The activity in the study of the infectious diseases of animals has brought out many new facts pertaining to them since the publication of the second edition of this volume. This rapid increase of new knowledge and the elimination of previously employed methods and interpretations render thepr eparation of a text-book suitable for student use more and more difficult.

In the present revision, the general plan of the arrangement of subject matter and the classification of the diseases followed in the previous editions have not been changed. The gromping of the infectious diseases in accordance with the classification of their etiological factors is for student purposes at least proving to be satisfactory. The rapid accumulation of literature on the subject matter of this elementary work precludes the publication of a bibliography. The appending of a few references after the discussion of each disease to some of the more important articles has, however, proven to be of much assistance to students just beginning the study of infectious diseases.

I desire to express my appreciation of the kind reception accorded to the second edition and the helpful reviews and criticisms that it has received. It is hoped that this edition will be of still greater aid both to the student and practitioner than the former ones. My thanks are especially due to Drs. S. H. Burnett and $W^{T}$. J. Taylor of this department for helpful suggestions and for assistance in reading proof.

$$
\text { V. A. II. }
$$




\section{PREFACE TO THE FIRST EDITION}

The literature on infection and the etiology and morbid anatomy of infectious diseases of animals is exceedingly rich in the results of new discoveries and important investigations. However, students just beginuing this study and following a prescribed curriculum have not the time nor are they prepared to read with profit the detailed records of original research. Such publications seen to be better adapted for those doing advanced or graduate work. Furthermore many of these publications are out of print and are only available for consultation. For these reasons it is believed that a volume containing the rudiments of the subject will be of use to the student and an aid to the teacher. It is also believed that such a work will be of assistance to practitioners.

In preparing this volume the aim has been to bring together in a concise form the fundamental facts in the pathology of the more common infectious diseases of animals, especially those existing in the United States, with which sanitarians and the practitioners of comparative medicine must contend. To this end the current literature, the reports of the investigations made at various Institutions and Experiment Stations, as well as the standard works on comparative pathology have been freely drawn upon, to all of which full acknowledgment is hereby made.

In order to bring into consideration the clinical value of a knowledge of morbid anatomy a few of the symptoms or antemortem manifestations have been included. It is hoped that this correlation of symptoms and lesions will stimulate a deeper interest in the study of comparative pathology and thus render it of more permanent and practical value for those entering into the practice of veterinary medicine.

In selecting the subject matter care has been taken to avoid, as far as possible, the introduction of results concerning 
which there are controversies. It has seemed best to deal with those facts about which at the present time there is little or no doubt. After the discussion of each disease a few references to the literature are appended. These are intended simply to bring the attention of the student to a few publications respecting the cause and morbid anatomy, considered in the light of modern etiology, of the disease in question and to a few articles containing the results of original research.

In order not to complicate or unnecessarily expand this text, a knowledge of general pathology and the principles of bacteriology has been taken for granted.

The difficulties involved in the preparation of such a text are both numerous and obvious. The indication of errors or omissions with any other criticisms that will tend to better the volume and increase its efficiency for the student will be thankfully received. 


\section{TABLE OF CONTENTS.}

PAGE:

LIST OF ILIUSTRATIONS _.......

LIST OF REFERENCE BOOKS _... Xiii

IXTRODLCTION_._._.

CHAPTER I.

GENERAL CONSIDERATION OF ETIOLOGY, INFECTION AND SPECIFIC INFECTIOUS DISEASES.

Etiology

Infection

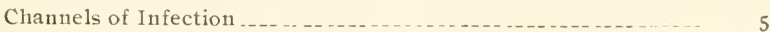

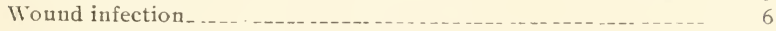

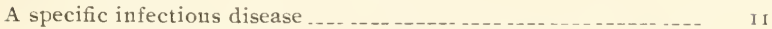

The differential characters of a specific infectious or epizoötic

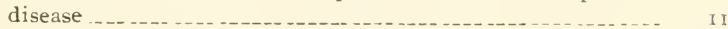

Dissemination of infections diseases _... . . . . . . . . . . . . . . .

Cause of variations in the course of an infectious disease ....... 15

Classification or grouping of infectious diseases _._...... I6

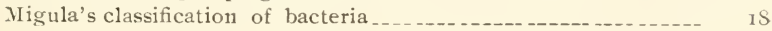

CHAPTER II.

DISEASES ATTRIBUTED TO WOUND INFECTION,

Botryomycosis.

Omphalophlebitis ....

White scours in calves

Infectious suppurative cellulitis _._.

Fistulous withers and poll-evil ....................... $3 \mathrm{I}$

Infectious mastitis

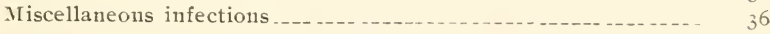

CHAPTER III.

DISEASES CAUSED BI BACTERIA-GEXY'S STREPTOCOCCUS.

General discussion of streptococci .......... 38

Strangles _..

Equine contagious pleuro-pneumonia

Apoplectiform septicemia in chickens _._._. 57

Streptococcus mastitis............................................ 60

CHAPTER IV.

DISEASES CAUSED BI BACTERIA-GENT'S MICRUCOCCI'S.

Takosis 
CHAPTER V.

DISEASES CALSED BN BACTERIA-GENUS BACTERIUN.

Pasteurelloses

Swine plague

Hemorrhagic septicemia in cattle

Fowl cholera

Goose septicemia _._._.

Fowl typhoid

Swine erysipelas . .

Anthrax _.

Glanders .

Tuberculosis _...

Avian tuberculosis. ... _... 203

Johne's disease _._.

Ovine caseous 1ymph-adenitis.............. 234

Asthenia in fowls and pigeons _................ 243

Diphtheria in calves and swine _...

CHAPTER VI.

DISEASES CAUSFD BY BACTERIA-GENL'S BACILLIS.

Hog cholera ...

Tetanus _._. .

Black leg - .

Foot-rot in sheep

Miscellaneous infections with bacilli _....................... 29 I

CHAPTER VII.

DISEASES CALSED BY BACTERIA-FAMILY SPIRILIACE.E.

Diseases of fowls caused by spirilla _..

Disease of pigs caused by spirochaetes _._.

CHAPTER VIII.

DISEASES CAUSED BY FUXGI.

Actinonyycosis_._.

Actinobacillosis__._. 317

Leeches _... - .

Pneumonomycosis _... 333

Epizoötic lymphangitis_......... 342

Farcy in cattle... 346

Mycotic stomatitis _.. 347

Blastomycetes, infection in horses................. 348

CHAPTER IX.

DISHASES CALSED BV PROTOZOA-GENUS PIROPLASMA.

Texas fever 


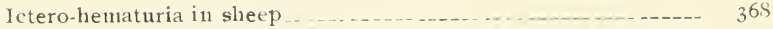

Fquine malaria _..._._. 369

Canine malaria _._._._._._._. 372

CHAPTER $\mathrm{X}$.

DISEASES CAITSED BY PROTOZOA-GENUS AMEBA.

Infectious entero-hepatitis in turkeys

CHAPTER XI.

DISHASES CAUSED BY PROTOZOA-GENUS TRSPANOSOMA.

Classification of Trypanosoma

Surra .... . .

Dourine ........................ 410

Mal de caderas .... .

Nagana ....

CHAPTER XII.

INEFCTIOLS DISEASHS POR WHICH THE SPHCIFIC CAUSE IS NOT YET DETERMIED.

Rinderpest

Contagious pleuro-pneumonia in cattle ................. $44 \mathrm{I}$

Foot and mouth disease.... . . . . . . . . . . . 454

Rabies .... _.

Diphtheria in fowls _...

Influenza _. _ . .

Dog distemper. ...

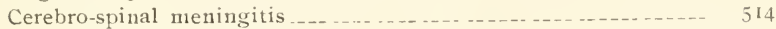

Cornstalk disease in cattle _... . . 517

Infectious abortion ... 523

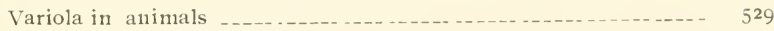

Epitheliona contagiosa

Infective sarcomata in dogs ....... $5+2$

Fowl pest.

CHAPTER XIII.

IMMUNITY AND PROTECTIVE INOCILATION.

Natural immunity _._. 545

Artificial immunity _._. 547

Hemolysins _._.

Protective inoculation _._. _ _ _... 555

Prevention _.

CHAPTER XIV.

DISINFECTION.

Disinfection _....

Disinfection of stables 


\section{ILLUSTRATIONS.}

PLATES.

Tuberculosis of lung, pig -

FIGLRES IN TEX'T.

PAGE

I. Purulent infiltration

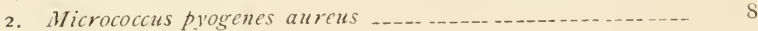

3. Streptococcus pyogenes........ 9

4. Abscess in partially immunized rabbit _............... I7

5. Streptococcus of mastitis ............ 32

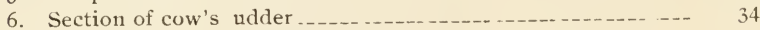

7. Morphology of streptococcus ._.

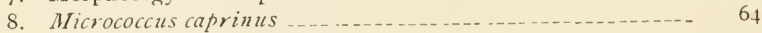

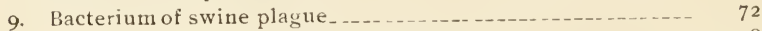

10. Lung showing emphysema in interlobular spaces......... 78

I1. Right lung of pig showing areas affected with swine plague $\quad 79$

I2. Portion of lung showing liemorrhagic interlobular infiltration 82

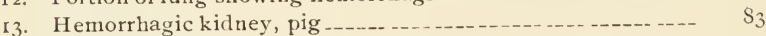

14. Hemorrhagic heart, cow

15. Bacterium sanguinarium._._._._._. 115

16. Temperature chart of fowls affected with fowl typhoid..._ 116

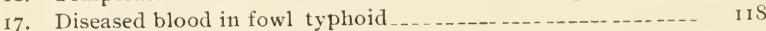

IS. Congested liver in fowl typhoid .............. Iis

19. Phagocytic action of leucocytes on the red blood corpuscles_ $\quad$ I2O

20. Bacteriun of swine erysipelas ... 124

21. Anthrax bacteria from an impression preparation $\ldots+\ldots . . .130$

22. Cover-glass preparation from anthrax blood_.......... 132

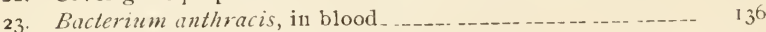

24. Nasal septum and turbinated bone, glanders ._._._._._. 156

25. Nasal septum, advanced glanders.......................... 157

26. Nasal septum, showing scars, glanders _...

27. Glandered lung ... I59

28. Section of glandered nodule ... 161

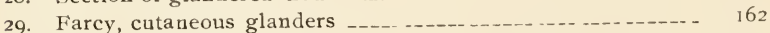

30. Mallein reaction.

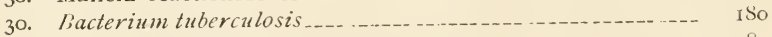

31. Lymph glands on side of cow's head _................... I $\mathrm{S}_{3}$

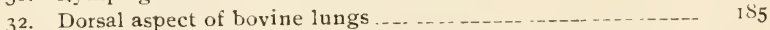

33. Bovine tracheal and bronchial lymph glands _.......... IS6

34. Posterior mediastinal glands ........... 187

34. Section of very young tubercles 
36. Tuberculous heart, cow _............. 190

37. Tuberculous focus in cow's lung .............. 192

$3 \mathrm{~S}$. Section of tuberculous lung, cow _................. I93

39 Tubercular pleura . . _._.

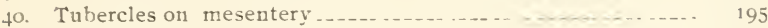

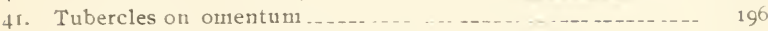

42. Tuberculous ulcers, intestine, cow ........ I97

43. Section of a tuberculous ulcer ......................... I9S

44. Tuberculous spleeli, pig .............................. $20 \mathrm{I}$

45. Avian tubercle bacteria

46. Culture of avian tubercle _..._. 205

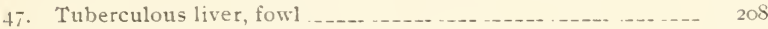

48. Section of a tubercle, fowl ............ 209

49. Tuberculous mesentery, fowl 210

50. Tuberculous skin, fowl ............ 211

5t. Teniperature curve, tuberculin _..._. . . 221

52. Chart showing the effect of cold water on temperature ...... $22 \mathrm{t}$

53. Tuberculin curve of pig _........ 222

54. Non-tubercular temperature reaction.......... 223

55. Chart showing tuberculin reaction .... _... 224

56. Bacterium of Preisz _._. 236

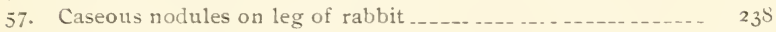

58. Lung of sheep with nodules.......... 239

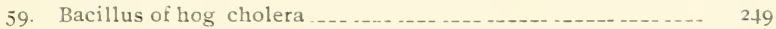

6o. Ulcerated intestine in hog cholera .................... 254

6r. Spleen of pig, normal and with hog cholera ............ 255

62. Bacillus of tetanus _._._. 266

63. Bacillus of black leg ............... 279

64. Bacillus of malignant edema _._ _._. 287

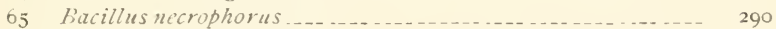

66. Necrotic area, liver, rabbit ..._._. 290

67. Spirochaete anserina _._ _... 294

68. Spirochaetes from pig ............. 296

69. Ray fungus _..... 30r

70. Section of young actinomycotic growth _............. 302

71. Giant cells in actinomy cotic growth 302

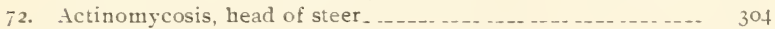

73. Young actinomycotic growth

74. Actinomycotic jaw, cow _... 307

75. Section of actinomycotic jaw ....... 308

76. Actinomycosis of upper jaw 309

77. Actinomy cosis in tongue ........... 310

78. Actinonycosis in cow's lung ....... 312

79. Actinobacillosis____._. 318

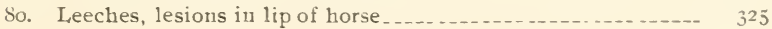


81. Various formis of fungus _._.

82. Leeches, lesions in lip of horse ................. 327

83. Isolated nodule from lesion ............ 328

84. Club-like ends of hypliae fungus, "leeclies" .......... 329

85. Section through nodule, "leeches" _......... 330

86. A spergillus fumigatus _... . . . . . . . . . . . 334

87. Section of lung showing aspergillus _._. 336

88. Necrosis, kidney of rabbit _._. 340

S9 Piroplasma bigeminum _................... 353

90. Coccus form of Piroplasma bigeminum 353

91. Texas fever parasite in blood of kidney _...... 354

92. Coccus form of Texas fever parasite in kidney .......... 354

93. Invasion of corpuscles with Piroplasma bigeminum ...... 355

94. Adult male tick, Soöphilus annulatus _............. 355

95. Bull suffering from Texas fever.................... 356

96. Adult feulale tick, lioöphilus annulatus _........... 357

97. Eggs and young tick, boöphilus annulatus.......... $35^{8}$

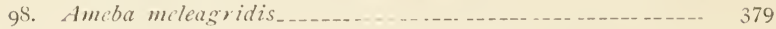

99. Ceca of turkey with lesions of entero-hepatitis ......... $38_{3}$

100. Cecum showing ulcers, in entero-hepatitis........ 384

I01. Liver of turkey affected with entero-hepatitis ............ 385

102. Farly lesions in entero-hepatitis _...

103. Trypanosoma liruci _... _................ 392

104. Tripanoplasma liorelli _............. 392

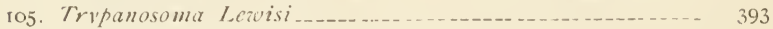

106. Map showing distribution of trypanosomiasis ........... 396

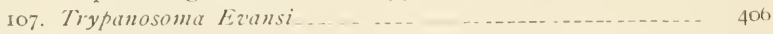

10S. Trypanosma cquiperdum _........ 112

109. Trypanosoma equiperdum, dividing _............. +13

110. Negri bodies._....... 462

II . Section of normal plexiform ganglion, dog ........... 480

I12. Section of plexiform ganglion from a case of rabies....... 4 So

113. Diphtheria in fowls, eye _._. $4 \mathrm{~S}_{7}$

II4. Diphtheria in fowls, sinus_ _._. $48 \mathrm{~s}$

Ir5. Early stages of diphtheritic necrosis_........ 489

I16. Advanced stage of diphtheritic exudate _... .......... 490

117. Diphtheritic exudate, throat of pigeon _... 492

I1S. Diphtheritic exudate, larynx, fowl _........... 493

119. Diphtheritic exudate, laryıx and trachea, fowl ........ 493

120. Sections of heads of normal and diphtheritic fowls_..._. 496

12r. Fipitheliona contagiosa, fowl ...

122. Ehrlich's figures, complement _._. 554

I23. Ehrlich's figures, various receptors _... 554

124. I ihrlich's figures, free receptors ..__._. 554

I25. Elurlicis's figures, anti-complement 


\section{A LIST OF REFERENCE BOOKS.}

BOtLEY ET REYNAL. - Nouveau Dictionaire pratique de Médecine de Chirurgie et d'Hygiène Vétérinaires.

ĊDÉac.-Encyclopédie Vétérinaire.

DiEckerhoFf.-Lehrbuch der speciellen Pathologie und Therapie fuir Thierärzte.

ELLENBERGER, SCḦ̈TZ LND BAUM.-Jahresbericht über die Leistungen auf dem Gebiete der Veterinär-Medicin.

FLEMING - A manual of veterinary sanitary science and police.

FRIEDBERGER UND FRöHxER. - Lehrbuch der speziellen Pathologie $u$. Therapie der Haustiere.

GALTIER.-Traité des maladies contagieuses et de la police sanitaire des animaux domestiques.

HUTYRA IND MAREK.-Spezielle Pathologie und Therapie der Haustiere.

KITT.-Lehrbuch der pathologischen Anatomie der Hausthiere.

KOLLE UAD WASSERMANX.-Handbuch der pathogenen Mikroorganismen.

LAW.-Veterinary Medicine. (Especially Vol. IV.)

LUBARSCH UND OSTERTAG. - Ergebnisse der allgemeinen Pathologie und Pathologischen Anatomie des Menschen und der Tiere.

NoCARD ET LECLAIXCHE.- - Les maladies microbiennes des animaux.

OSTERTAG. - Handbook of meat inspection. Authorized translation by E. V. Wilcox.

REYxAL - Traité de la Police Sanitaire des Animaux Domestiques. Schnerdevithr.-Lehrbuch der vergleichenden Pathologie und Therapie des Menschen und der Hausthiere.

WALLEY.-The four bovine scourges.

For bibliography on all medical subjects, see Index-catalogue of the Library of the Surgeon-General's office.

Annual reports, Special Reports and Bulletins on Animal Diseases issued by the Bureau of Animal Industry, U. S. Department of Agriculture, Washington, D. C.

Proceedings of the American Veterinary Medical Association.

The Bulletins on Animal Diseases issued by the various State Agricultural Experiment Stations. 


\section{INTRODUCTION.}

An elementary treatise on the pathology of the infectious diseases of animals - a treatise that states briefly, clearly and comprehensively all that is known, and excludes all that is not known-has long been needed not only by the students who are beginning this interesting subject, but by members of the veterinary profession who, as practitioners, investigators or teachers, wish to learn in the shortest time the present condition of our knowledge. A work which supplies this need will be welcomed and appreciated.

There are few subjects more important to Americans than a thorough comprehension of the infectious diseases of animals. An enormous amount of money is invested in the domesticated animals in the United States, and the security of this investment depends very largely upon our ability to protect these animals from infectious diseases. There are many diseases of this class which spread among animals as smallpox, bubonic plague or cholera spreads among mankind; and it requires a thorough knowledge of all the characteristics of such diseases to guard against them, to recognize them when they appear or to control them.

For a period already too long, exact knowledge of these diseases has been confined to a comparatively small number of men; but with the great property interests at stake it is extremely desirable that this information should be distributed, that not only responsible officials but every practitioner should share it. With not far from three thousand million dollars worth of farm animals in this country, and with a single disease that sometimes destroys a hundred million dollars worth 
of property in a year, it is not difficult to see the value of that precise knowledge which is required to deal promptly and efficiently with these plagues.

It is a narrow and incorrect view to hold that the farmer who owns these animals is the only one who suffers from the ravages of the diseases which destroy them. Animal products constitute a large part of the national food supply. If this food supply is diminished, made dearer and more difficult to obtain, want, misery, disease and death among mankind increase. At first the effects of a scarcity of the food supply may be almost inappreciable and felt only by the very poor: but as the conditions of famine are approached, suffering is multiplied and intensified until whole communities are prostrated or destroyed. An abundant supply of wholesome and nutritious food is therefore an essential condition of the welfare and prosperity of the people.

The great commercial operations of nations also depend to a great extent upon the good condition of animals. When all of the horses are disabled by an epizoötic, as they have been on rare occasions by influenza, the delivery of purchased goods has nearly ceased, the shipments of flour, iron, maclinery and other products have been temporarily arrested and business has been almost at a standstill. Again, it should be remembered that we export annually from the United States forty million dollars worth of live animals, one hundred million dollars worth of meats, fifty-five million dollars worth of lard, tallow and other animal fats, and nine million dollars worth of dairy products. Let this traffic be stopped by the shortage of supplies or by prohibitive orders of other nations on account of the unrestrained prevalence of infectious diseases, and the earnings of steamships, and railroads, and banks, and commission houses, are at once diminished; men 
employed in these enterprises are discharged, and in innumererable ways the welfare of people who have no part in the ownership of any of these animals or their products is affected.

Finally the most serious of all is the case in which the animal plague, in addition to being destructive to animal life, is communicable to and fatal to man, as is true of anthrax, rabies and tuberculosis. Such diseases destroy property, disturb business, lessen the food supply, and directly threaten human life. What more is needed to impress upon the reader the supreme importance of studying and understanding the infectious diseases of animals?

The pathology of these diseases is in itself a large subject. Investigations concerning it have extended over more than a century of time and the literature of the subject is enormous. To concentrate this knowledge, to select the truth and discard the errors, and to develop a concise and systematic treatise is a task of great magnitude and one which has required much labor and thought. The writer has not seen the manuscript, but, from his long and intimate acquaintance with the author, he feels sure that the work has been patiently, carefully, intelligently and thoroughly done, and that it will be favorably received.

D E. SALMON. 
CHAPTER I.

\section{GENERAL CONSIDERATION OF ETIOLOGY, INFECTION AND SPECIFIC INFECTIOUS DISEASES.}

$\$$ 1. Etiology. The development of the science of bacteriology, together with a knowledge of the parasitic protozoa; has already demonstrated that a large number of the infectious diseases are the direct result of the invasion of the animal body by certain species of microörganisms. A specific etiology which teaches that for each of the various epizoötics we have a single, definite cause has become recognized and been accepted by all pathologists. Although there are a number of distinct diseases for which such a specific agent has not been found, the evidence in the very nature of the maladies is conclusive that for each of these such an etiological factor exists.

In studying the pathology of infectious diseases the idea of a definite and adequate cause should be kept in mind. It is no longer justifiable to attribute them to an unfavorable environment, poor hygiene, or improper sanitation, conditions which may aid the specific cause but which cannot supplant it. It is often a troublesome task to differentiate between the morbid affections, often fatal in their results, brought about by improper care and fond, and the maladies dependent upon a specific cause. The reason why many of the former theories accepted unsanitary conditions, certain kinds of food or other similar agencies as the etiology of distinct, infectious diseases, is found in the fact that the infectious microörganisms. were and still are often transmitted to the individual through such channels. It is important, therefore, that the limitations of both the exciting cause and the environment should be fully taken into account. Although for certain diseases such as rinderpest we do not know just what the specific cause is, 
the fact that its location in the body of the diseased animal is known, that with the morbid tissues the disease can be produced in healthy animals and that without this definite infection, no matter what the conditions are, the malady cannot be made to develop, argues against extraneous conditions as exciting causes.

The mystery which formerly surrounded the origin, the course and the disappearance of animal plagues has in a large degree been cleared away; and in its place we are confronted with the problems involved in the life history and the possibilities of invading microörganisms. In fact during the last few years the biological sciences have been brought into immediate use by the pathologists. Ettiology has become permanently linked to microbiology so that in seeking for the specific cause of an infectious disease we look for some species of organic life which may belong either to the animal or to the vegetable kingdom. The fact that certain microscopic animals and plants have become, if they were not in the beginning, parasitic on larger and higher forms of life has long been recognized; but the idea came later, that the various infections giving rise to a wide series of phenomena, known as symptoms and morbid anatomy, were actually and simply the results of the invasion of the individual with living microscopic plants (bacteria) or animals (protozoa). It is likewise true that for many of the disorders consisting of changes recognized in the terms of general pathology, the cause may be found in the conditions of life under which the individual has been forced to exist. Etiology, therefore, in a broad sense, includes both the infecting microörganisms that produce the specific infectious diseases and poor hygienic, unsanitary conditions and physical forces which may produce non-specific morbid changes often sufficient to cause death.

$\$ 2$. Infection. The term infection has come to be generally understood to mean the entrance into the animal body, from without, of living microörganisms capable of multiplying within the living tissues and of producing in consequence of this multiplication a local or a general diseased condition and 
possibly the death of the individual. The invading microörganisms may belong to any one of the three great groups of microscopic life, namely, bacteria, higher fungi, and protozoa. It is customary and convenient, if not altogether logical, to limit the term microörganisms to these forms, excluding altogether the entozoa and other animal parasites, most of which are not microscopic in size.

A diseased condition produced by substances not capable of reproducing themselves, as, for example, organic or inorganic chemical compounds, is an intoxicative process. In an infection, the immediate cause of the symptoms and morbid changes in the tissues is an intoxication due to the action of the metabolic products (toxins) of the invading microörganisms. The theories of their mechanical interference with the normal functions of the body or that they absorb the nutriment, thus depriving the tissues of necessary food, wait for demonstration. The results of infection vary in their manifestations.

I If the invading organisms remain at the point of entrance and produce local tissue changes, the condition is spoken of as a wound infection.

? If the invading bacteria become widely distributed in the circulation and tissues, the condition is known as septicemia or bacteremia.

If the infecting bacteria remain at the point of entrance and multiply there, elaborating a toxin which is absorbed and which causes symptoms and possibly death, the condition is a toxemia.

If there is a febrile condition, resulting from the absorption of the products of putrefaction caused by saprophytic bacteria, the condition is called sapremia.

If the invading organism is one possessed of definite pathogenic properties, such as the bacterium of anthrax, giving rise to a definite series of symptoms and lesions, the affection is designated a specific, infectious disease.

Through the agency of metastasis, invading microörganisms may be carried from the point of introduction to other 
parts of the body, where they may become localized, multiply, and give rise to any one of many forms of lesions. It may happen that the point of entrance is so obscure that the resulting morbid changes are not easily traced to an external infection. There are many illustrations of this in comparative pathology, such for example as suppurative cellulitis. For convenience in discussion, infections may be divided into two clinical groups, namely: wound infections and specific infectious diseases, although in certain instances they cannot be separated.

In arriving at a clear understanding of the nature of infections, it is well not to be too closely circumscribed by classifications. It is better to look upon them as a series of processes going on in the animal world due to the artivities of infecting or parasitic microörganisms. In other words, the lesions following an infection are simply the results of parasitism.

In the study of the various forms of infection in the lower animals, lesions have been found to contain, apparently as their causative factors, bacteria which suggest at least that certain of the supposed saphrophytic organisms may, under certain conditions, become parasitic and cause infections resulting in more or less local or general disturbance. Many lesions seem to be produced by bacteria which are harbored normally upon the skin. When these organisms are introduced by accident into the living tissues they multiply and acquire, if they did not already possess it, the power to produce tissue changes. We cannot, therefore, dismiss the subject of infection without a passing consideration of the possible etiological significance, under certain conditions, of many species of bacteria ordinarily considered harmless with which the animal body is constantly surrounded. In the search for the cause of many lesions supposed from their nature to be infectious, or in applying methods for their prevention, it is well to take into consideration all microörganisms which might possibly be the causative factors and not limit the search to the detection of the already recognized pathogenic species. Recent investigations point to the conclusion that domesticated animals frequently suffer as the 
result of the invasion of bacteria at present not listed anong the pathogenic microörganisms, and what is true in this regard for bacteria, may be hypothetically applied to the higher fungi and to the protozoa.

\$ 3. Channels of infection. There are a number of ways by which microörganisms may be introduced into the living tissues of the animal body. The more common of these are as follows, namely :

I: Through the digestive tract. Bacteria gain entrance into the tissues from the digestive tract where they have been bronght with the food or water. It is not clear in all cases how the invading organisms get into the tissues from the intestine. It has been demonstrated that tubercle bacteria will pass through the mucosa with fat globules in the process of digestion and absorption.

2. Through the respiratory tract. Bacteria are taken into the lungs with the inhaled atmosphere. Pulmonary tubercular affection is often brought about in this way.

3. Through abrasions of the skin or intestinal mucosa. The wide distribution of bacteria in nature renders it highly. probable that in all wounds of the integument microörganisms will reach the fresh tissues. They may come from the cutting or tearing implement, the particles of dirt which may fall into or upon the cut surface, or from the ducts of the glands of the skin itself. It may happen that the fresh tissues thus exposed are infected with one or several species of bacteria. It may be that one or more of these species may be destroyed by the living juices of the body or by the leucocytes, or again it is possible that, from their saprophytic nature, they may not be able to multiple in this new environment; in either case the infection is of no significance and clinically would not be recognized. It may happen that only one species of the infecting bacteria multiplies and produces the morbid changes. This would be a single infection. If, however, two or more species coöperate in the production of the lesions, it is called a mixed infection. This term is often used to designate the 
condition where one species may be responsible for the tissue clianges, although other bacteria are present but only in an accidental or passive way.

4. Through the generative organs. Infection of the reproductive organs takes place in certain instances where they are the seat of the disease. This is especially true in case of maladie du coit.

5. Through the agency of insects. Some insects carry the virus of certain diseases from the infected and introduce it into the susceptible individuals. Thus the mosquito carries the plasmodium of human malaria, the cattle tick the piroplasma of Texas cattle fever, and flies are often the introducers of pathogenic bacteria, such as those of anthrax. In certain instances, as with malaria, a part of the life cycle of the microorganism takes place in the body of the carrying insect.

6. Transmission of the rinus from the parent to the fetus. Occasionally the young of diseased parents are born infected with the disease with which one or both of its parents were suffering. In these cases the specific bacteria were transmitted either from the sire at the time of coition, or later to the fetus in the uterus from the dam. It is important not to confuse these rare cases with those in which the offspring are born uninfected but subsequently contract the disease. Many of the so-called hereditary diseases are the result of post-natal infection.

\$ 4. Wound Infection. Wound infections are the direct results of the entrance of certain microörganisms into traumatisms and operative incisions. They fall very naturally into two classes:

I. Those infections producing local, acute or more chronic inflammatory processes usually leading to suppuration and finally healing by granulation. This is the form most frequently encountered clinically. The tissue changes are those of acute or chronic inflammation.

2. Infections which may in the beginning appear like 
the first or cause so little disturbance as to be unnoticed at the time, but sooner or later result in a local or remotely situated lesion or lesions. Frequently these are recognized as distinct diseases although in some cases, such as scirrhous cord, the origin is easily traced to an operation where infection was possible. This group of wound infection lesions, $\mathrm{such}$ as scirrhous cord, botryomycosis, infectious cellulitis of cattle and sheep and still other disorders may not appear to be dependent upon wound infection ; but the results of recent investigations suggest this as their primary cause. These affections will be treated sepa rately in subsequent paragraphs but their relation to wound infection renders them worthy of note in this connection.

In wound infection, the invading organism is not always of the same species. It is because of the fact that wound in-

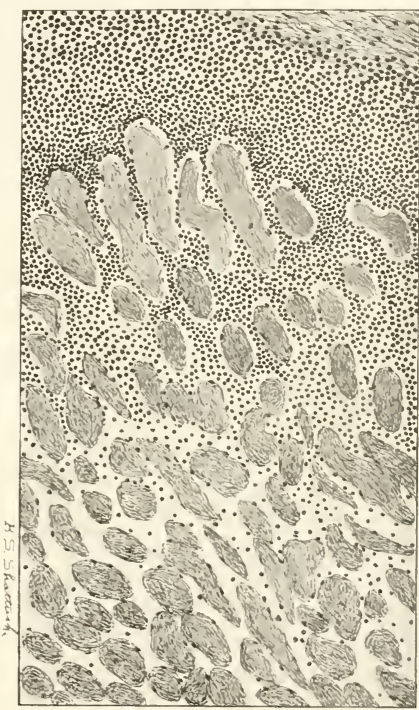

Fig. I. Hound infection. Purulent infiltration from the wall of an abscess in a horse showing the infiltration of the intermuscular tissue with puscorpuscles. Drawing made with 1 inch ocular and 2-3 objective. fection lesions of a similar character anatomically may be caused by a number of different bacteria that they cannot be classed among the specific infections diseases. It is observed further, that in many of these lesions two or more species have been responsible for the results. There is no symptom, or manifestation of tissue changes, by which one can determine 
the specificity of the exciting cause. If this is done, it requires a bacteriological examination.

Another class of diseases that are sometimes called wound infections should be mentioned, namely, those specific diseases, such as tetanus and symptomatic anthrax, where the virus is supposed always to be introduced through a wound either in the skin or mucous membranes.

Bacteria causing wound infection. A large number of species of bacteria and a few fungi are included among the

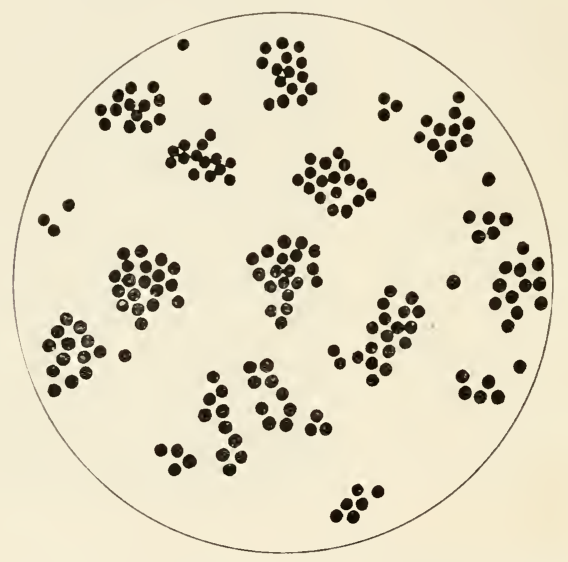

FIG 2. Micrococcus pyogenes aureus. Drau'ing from a coverglass preparation of a bouillon culture. Highly magnified.

organisms which are known to produce wound infections in animals. Usually, however, the forms encountered are micrococci, especially those belonging to the staphylococcus group, streptococci, Bacillus pyogenes (Bacillus pyogenes bovis (Grips) Bacillus pyogenes suis (Künnemann)), a few other bacilli, especially those belonging to the colon group and a few species of the genus pseudomonas. Fungi and protozoa 
are rarely found in acute wound infection lesions excepting in specific diseases which they cause and where their entrance is through injuries or by means of the bites of insects. Many of the specific pathogenic bacteria may be introduced through wounds. As a rule, it seems to be true that in the domesticated animals, as in man, the pyogenic bacteria are the most common and important wound infecting microörganisms. In open wounds these are, of course, associated with a very large number of ordinary saprophytic bacteria. Frequently in closed lesions nonpathogenic organisms are present in addition

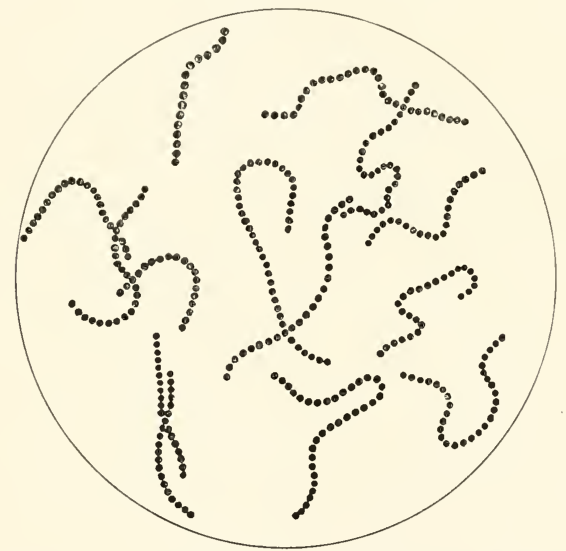

Fig. 3. Streptococcus pyogenes. Drazing made from a coz'er-glass preparation from a bouitlon cutture. Highly magnified.

to the seemingly causative factors. It is worthy of note that it appears to be impossible to predict from the general character of the lesions, the kind of bacteria which are producing them, except it be in case of infections like tuberculosis or actinounycosis. These bacteria are usually recognized without trouble in cover-glass preparations made from the lesions. 
Their species can also be easily determined by cultivating them on artificial media. ${ }^{1}$

Morbid anatomy of infection. The tissue changes resulting from an infection of the body with various microörganisms belong with those considered in general pathology under the headings of inflammations, degenerations, other retrograde disturbances and regenerative processes. The pathology of infection, therefore, is not a discussion of new deviations or disturbances of cells and fibers, but rather a grouping or combining of disturbances already recognized as the selective results of the activities of the particular invading organisms. Thus in ordinary wound infections the morbid changes are those of an acute inflammation leading to suppuration, necrosis or gangrene; sometimes they are chronic in nature, resulting in formative changes, and again in the various forms of exudation. In other instances infection results in hemorrliages of varying degrees. Occasionally the lesions may become localized, as in pneumonia, lymphangitis, intestinal ulcers, nephritis, hepatitis, splenitis and the like. The morbid anatomy of infection introduces few if any changes not known to general pathology. Because of this, the emphasis of the pathology of infection rests on the etiology and the possible variety and distribution in the body of the tissue changes. It has been shown that certain infections are slow in bringing about tissue changes and consequently many lesions resulting from wound infection may, when they appear, be considered as distinct maladies.

Prezention of infection. In surgical operations, wound infection may be prevented where uninfected lesions are involved by disinfecting the field of operation. This is a much more difficult task than it appears. The habit of bacteria of growing down into the hair follicles, sweat glands and beneath the dead epithelial cells on the surface, renders it necessary to use a disinfectant of much penetrating power in order to

${ }^{1}$ For the specific cultural characters of each of the wound infection bacteria the student is referred to manuals of bacteriology. 
sterilize the skin. In case of traumatic infection the wound itself must be disinfected.

5. A specific infectious disease. A specific infectious disease is the result of the multiplication within the animal ${ }^{1}$ body of a single species of microörganism. The lesions may be local or general, but the cause producing them is always the same. Thus, Bacterium anthracis will produce a disease which is called anthrax, no other cause can produce it, and no matter how much the lesions may vary in different individuals if they are produced by this species of bacteria the disease is anthrax. It is clear, therefore, that there is no hard and fast line between a simple (single) wound infection and a recognized infectious or epizoötic disease, except in the nature of the invading organism. The course of the disease may vary in different individuals and usually it does, especially if in different species of animals. If a man receives accidentlly a cut from a knife with which he is making a post-mortem on an animal dead from anthrax, the lesion is liable to be restricted to the point of inoculation, and while it is anthrax (malignant pustule) it would often be recognized as a simple wound infection. If this accidental inoculation should occur in a guinea pig, the disease would not be recognized as a local lesion; but the animal would develop septicemia.

As a class the specific diseases are differentiated from the lesions known clinically as wound infections in a number of ways. The bacteria of the epizoötic diseases do not ordinarily produce wound infections following accidental injuries or surgical operations, although there are exceptions. Again, there is usually a difference in the mode of infection. The virus of the epizoötic diseases is ordinarily introduced through the digestive or respiratory tract or by means of insects, while in wound infection the virus is introduced, as the term implies, through the injured integument or mucosa.

$\leqslant 6$. The differential characters of a specific infec-

${ }^{1}$ Plants suffer from specific infectious diseases caused by bacteria and fungi, quite as much as animals. 
tious or epizoötic disease. It is very important not to mistake for an infections disease some form of body disturbance due to a local cause or condition. Animals often suffer from improper food and the conditions of life under which they are compelled to live. It frequently happens that as all of the animals in a given herd are subjected to like conditions, a number of them, perhaps all, will manifest very similar symptoms and more or less of them die. Such an occurrence often gives rise to the supposition that the cause of death is some form of infection. Deaths from such causes or under such couditions should be carefully distinguished from an epizoötic. In differentiating a non-infectious disorder from a specific disease, it is important, and usually sufficient, to take into account the appended characteristics of an infectious disease.

I. Cause. An infectious disease is caused by a specific agent. This necessitates as the first requisite an exposure to and an infection with the specific organism.

2. Period of incubation. The infection must be followed by a certain period of incubation before the development of symptoms. This is the time necessary for the invading microorganisin to become established in the body and to bring about the first symptoms of the disease. The incubation period varies in different diseases, and to a certain degree in the same disease, according to the mode of infection and the resistance of the individual. Usually the incubation period of a given disease is practically the same for all individuals of the same species when subjected to the same mode of infection. Exceptions, however, are not rare.

3. Lesions. The morbid anatomy of an infectious disease is usually nearly the same in animals suffering in the same outbreak, especially when they were infected at or about the same time. It is more common for only a few individuals in a herd to be infected in the beginuing and from these first cases for other animals to contract the disease. In many epizoötics, the disease appears in an acute form in the first animals attacked while those infected later in the course of the outbreak suffer from a chronic form of the affection. In other outbreaks, 
the first cases are chronic in nature and the later ones acute.

4. Duration. In aninals, as in man, most of the infectious diseases are self limiting, but, as a rule, the percentage of fatal cases is much larger among animals than in the human species. The period of convalescence is not so well marked in the lower species as in man. It frequently happens that the course of the disease is so changed that an acute case which appears to recover, or at least to pass into the stage of convalescence, becomes chronic or subchronic in nature and eventually terminates in death. The lateness in the development of the modified lesions often causes the nature of the terminal disease to go unrecognized.

5. Transmission by inoculation. Finally, it is necessary in making a positive diaguosis to find the specific organism, or to prove the transmissibility of the malady from the sick or dead to healthy animals. The extent of the spread of the virus of the disease through the available channels for its dissemination will also aid in determining the infectious or noninfectious nature of the malady in an outbreak among animals.

In diagnosing an epizoötic disease investigations have shown that too much reliance can not be placed on the period of incubation, or the morbid anatomy. There are many possibilities, therefore, that an erroneous diagnosis may be made when the clinical and post-mortem evidences of the disease are alone considered. It has also been determined that certain non-infectious disorders often assimilate, in their more general manifestations, the characters of infectious maladies. This fact necessitates much care in the differentiation of outbreaks of animal diseases.

The dietary and other non-infectious disorders do not exhibit definite, uniform differential characters excepting perhaps in case of those caused by a few mineral poisons or by eating certain plants. As examples of these, lead poisoning and the Pictou or Winton disease of horses and cattle caused by eating a ragwort (Senecio jacoboea) may be mentioned. The non-infectious disorders are differentated from the infec- 
tious ones largely by eliminating the characters of the latter and finding, if possible, the causative agent.

The necessity for an early and positive diagnosis in all outbreaks of epizoötic disease, is to assure the enforcement of all possible measures to prevent its spread. The essential problem for the practitioner or sanitarian in the presence of these diseases, is to restrict the number of cases to the individuals already infected. In order to do this, it is of much importance that modified or chronic cases of any infectious disease should not escape detection if there is danger of their spreading the virus or exposing susceptible animals.

$\$ 7$. Dissemination of infectious diseases. A1though the discussion of the means by which each of the various diseases are disseminated will be found under the considerations of the individual affections, it is important to consider the general ways and means by which these different vital causative factors are spread from an infected individual to a non-infected one in the same herd and from one herd to another. As we understand them at the present time, each virus is dependent for its perpetuation upon its escape from one host (sick or dead) to another. As these organisms are without power of their own for such migration, they are dependent upon other forces and carriers to take them. In finding the cause of their spread, we must consider first how they escape from the infected individual and secondly how they are carried rom one individual to another.

1. Escape of vinus from infected individuals. The infecting organisms escape from the living body either with (a) the excreta, (b) the external discharge of ulcers and abscesses or both, and (c) the blood by sucking and possibly biting insects. After the death of the host they can escape only by the disintegration of the dead body or by its being consumed by other animals or birds. The bacteria of several diseases can pass through the digestive tract of such animals uninjured.

2. Dissemination of infecting organisms. Pathogenic 
bacteria are spread after they escape from the body in many ways, the following being the 1110st common:

(a.) By direct contact.

(b.) They are carried on the hands, shoes or clothing of attendants, and on farm implements, such as shovels and hoes.

(c.) They are carried in streams receiving the excreta or disintegrating bodies of the infected.

(d.) They are scattered with the excreta of birds that feed upon the dead carcasses. Other animals, such as dogs and foxes, are also charged with the scattering of the virus by the same method.

(e. The virus is often carried from one herd to another by introducing chronic cases or those already infected in which the symptoms have not yet appeared.

(f.) Animals are often infected by shipping them in cars or crates that have previously contained diseased animals and that have not been thoroughly disinfected.

(g.) The pathogenic protozoa are transferred from infected to non-infected individuals by means of insects. They are carried from place to place in infected animals.

$\$ 8$. Cause for the variations in the course of an infectious disease. It is a recognized fact that there is much variation in the course of infectious diseases in different epizootics and often marked individual variations occur in the same outbreak. In explaining this interesting phenomenon, it is important to take into account the question of individual resistance or immunity,-partial or more complete. It was found in case of certain diseases that when an individual was partially immunized and then infected, that the lesions were very much modified. The teachings of a specific etiology point to this phenomenon as a result of certain biological or vital differences existing either in the parasite or in the host, possibly in both. The results of the investigations already made along this line suggest as a probable explanation, that 
the course of the disease varies on the one side with the resistance of the host and on the other with the degree of virulence of the infecting microörganism. This has been expressed in the formula

$$
D=\frac{V}{R}
$$

in which $\mathrm{D}=$ the disease, $\mathrm{V}$ - the virulence of the infecting organism, and $\mathrm{R}=$ the resistance of the host or the individual attacked. As $\mathrm{V}$ or $\mathrm{R}$ change the disease is modified. For example, rabbits that are partially immunized against swine plague bacteria, when inoculated with a virulent culture of that organism, will live for several days and perhaps for weeks, and then die of peritonitis, pleuritis or extensive pus formations, instead of perishing within twenty-four hours with septicemia as they would if they had not been protected against this organism. In chronic cases of swine plague, as found in certain outbreaks, the bacteria are often attenuated so that when inoculated into susceptible rabbits the result is the same as when the rabbits protected by partial immunization were inoculated with virulent cultures. The above simple formula which was worked out and demonstrated for certain swine diseases seems to apply to infectious diseases generally.

S. Classification or grouping of the infectious diseases. It will be found in the study of the morbid anatomy of the various specific maladies that the lesions in a given disease vary in different species and in individuals of the same species to a marked degree. This fact precludes the possibility of classifying or arranging them after their morbid anatomy, if the idea of a specific etiology is to be adhered to. If the infectious diseases are to be considered as parasitisms, as they appear to be, the only logical method of classifying them, according to the writer's opinion, is the one suggested by their etiology, namely, that they shall be placed in groups corresponding to their causes. Thus a single lesion found in the glands of the head, in the lungs, in the liver, in the mesenteric 


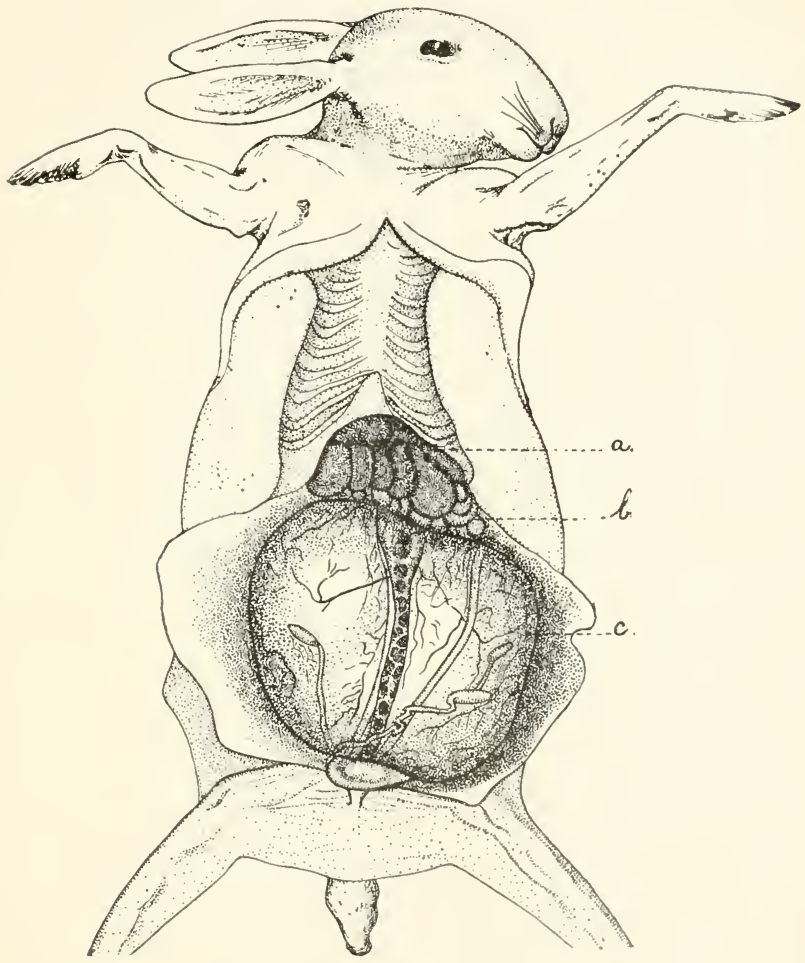

Fir: 4. Large abscess in partially immunized rabbit caused by su'ineplague bacteria. This rahbil lived 37 dars after its inoculation with virulent swine plague bacteria. At death its a'eight was rgio grams, the tumor itself weighing goo grams. The ahscess formed dorsad of the peritoneum. (a) Cecum, (b) intestines, (c) absiess. The control rabbit of same weight and age died of septiccmia in 16 hours. 
glands, in the skin, in the joints, or in the generative organs, would be called tubercular if the bacteria of tuberculosis could be demonstrated to be its cause. The same conclusion would be maintained regardless of the character of the lesion, whether cellular, purulent, caseous or calcareous. These facts are enough to suggest that the most direct method of arranging these diseases for purposes of study is in groups composed of like generic etiological factors.

Most of the known specific causes of the infectious diseases of animals are bacteria. It is necessary, therefore, in carrying out this plan to choose from among the numerous classifications one to be followed in grouping the diseases according to the genera of bacteria producing them. Of the various systems, the one by Migula seems to be the simplest and most natural and consequently it is selected. The only radical difference between it and the others, so far as pathology is concerned, rests in the fact that the old genus Brcterium is revived, but with a new meaning. All rod-shaped, nonmotile bacteria are placed in this genus. This causes a change of the generic name from Bacillus to Bacterium of a number of pathogenic bacteria, such as those of tuberculosis, anthrax, swine plague and others of less importance.

Because of the few species of fungi and protozoa that are pathogenic for animals, systematic classifications of these organisms are not introduced. For such classifications the student is referred to the various works'on mycology for the fungi and the excellent work by Calkins, - "The Protozoa" for the protozoa. In this elementary pathology, all that seems to be necessary concerning the biology and classification of the pathogenic protozoa will be given in connection with genera and species under the "etiology" of the diseases they produce.

The chapter on diseases caused by fungi naturally follows those on the bacterial diseases.

§ 10. Migula's classification of bacteria. The genera of the five families are incladed. 


\section{MIGULA'S CLASSIFICATION}

LOWER BACTERIA

COCCACEAE

Streptococcus

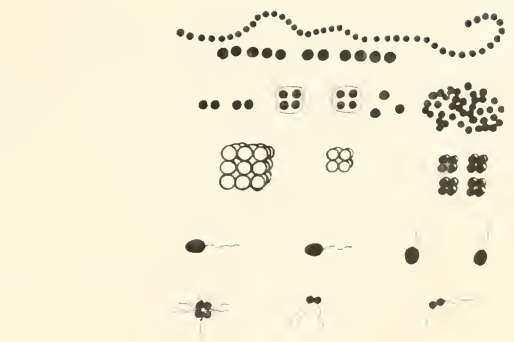

Micrococcus

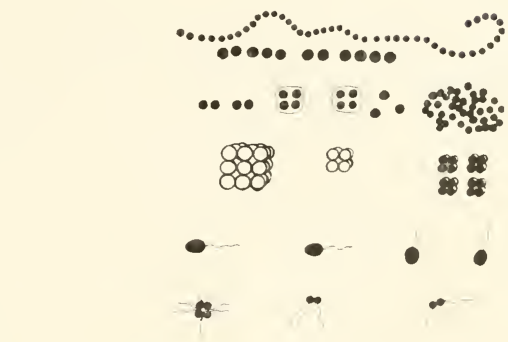

Sarcina

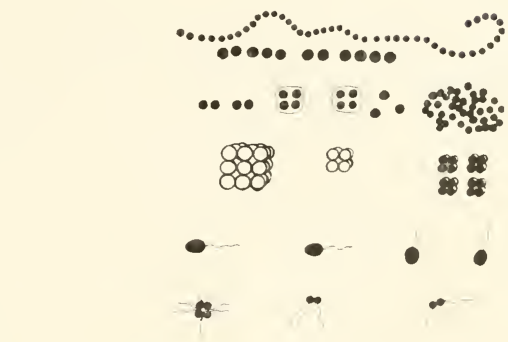

Planococcus

Planosarcina

BACTERIACEAE

Bacterium

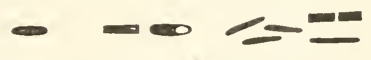

Bacillus

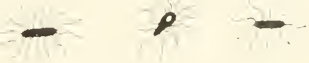

Pseudomonas

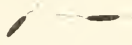

SPIRILLACEAE

Spirosoma

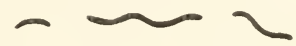

Microspira

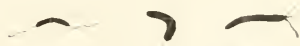

Spirillum

Spirochaeta

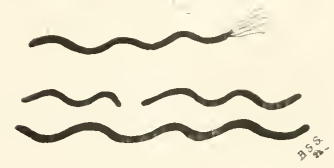


FAMILIES.

I. Cells globose in a free state, not elongating in any direction before division into $\mathrm{I}, 2$, or 3 planes.............. I. Coccacer.

II. Cells cylindrical, longer or shorter, and only dividing in I plane, and elongating to twice the normal length before the division.

(I) Cells straight, rod-shaped, without sheath, non-motile, or motile by means of fla-

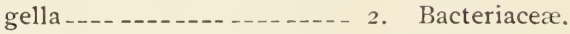

(2) Cells crooked without sheath 3. Spirillaceæ.

(3) Cells enclosed in a sheath .... + Chlamydobacteriaceæ.

(4) Cells destitute of a sheath, united into threads, motile by means of an undulating membrane_._._._._._._. 5. Beggiatoaceæ.

\section{Coccacere.}

Cells without organs of motion.

a. Division in I plane-..- I. Streptococcus.

b. Division in 2 planes__._ 2. Micrococcus.

c. Division in 3 planes_--- 3. Sarcina.

Cells with organs of motion.

a. Division in 2 planes _-_- 4. Planococcus.

b. Division in 3 planes.-.- 5. Planosarcina.

\section{Bacteriacer.}

Cells without organs of motion. I. Bacterium.

Cells with organs of motion (flagella). 
a. Flagella distributed over

the whole body 2. Bacillus.

b. Flagella polar-....... 3. Pseudomonas.

3. Spirillacee.

Cells rigid, not snakelike or flexuous.

a. Cells without organs of motion ........... Spirosoma.

b. Cells with organs of motion (flagella).

I. Cells with one, very rarely 2.3 polar flagella_._._._._._. 2. Microspira.

2. Cells of polar flagella, in tufts of from 5-20-- 3. Spirillum.

Cells flexuous_..._......... 4. Spirochæeta.

\section{Chlamydobacteriaceae.}

Cell contents without granules of sulphur.

A. Cell threads unbranched.

1. Cell division always only in I plane.......... 1. Streptothrix.

2. Cell division in 3 planes previous to the formation of conidia.

a. Cells surrounded by a very delicate, scarcely visible $\mathrm{sheath}$ (marine) -........ 2. Plragmidiothrix.

b. Sheath clearly visible (in fresh water) .... 3. Crenothrix. 
B. Cell threads branched

(pseudo-branches) -.---- 4. Cladothrix.

Cell contents containing sulphur granules...-..... 5. Thiothrix.

5. Beggiatoaceae.

Only one genus known (Beggiatoa Trev.), which is scarcely separable from Oscillaria. Character as given under the family.

\section{REFERENCES.}

I. BERGER. Vergleichende Untersuchungen über den Bacillus pyogenes bovis und den Bacillus pyogenes suis. Zeitsch $f$. Infektionskrankh. parasitare Krankh. und Hygiene der Haustiere, Bd. III (1907), S. IOI.

2. GRIPS. Ueber eine mit multipler Abszessbildung verlaufende Pleuritis und Peritonitis der Schweine und deren Erreger. Zeitschr. $f$. Fleisch-u. Milchhygiene, 1898 .

3. GRIPS. Ueber einen pyogenen Mikroorganismus des Schweines. Inaugural-Dissertation. Giessen, 1902.

4. KÜNNEMANN. Ein Beitrag zur Kenntnis der Eitererreger des Rindes. Arch. f. wiss. u. prakt. Tierheilk., 1903.

5. Migula. System der Bacterien. 1897.

6. SMITH AND MOORE. On the variability of the infectious dis. eases as illustrated by hog cholera and swine plague. Bulletin No. 6 . U. S. Bureau of Animal Industry, r894. p. 81.

7. WeLch. General bacteriology of surgical infections. Dennis' System of Surgery. Vol. 1, p. 249. 


\section{DISEASES ATTRIBUTED TO WOUND INFECTION.}

$\S$ I1. Lesions which may be caused by several organisms that are recognized as distinct maladies. It has already been stated that the lesions following wound infections may be brought about by a variety of bacteria and also that certain of these disease processes are sometimes recognized as distinct maladies. There are a number of affections which belong to this class. From some of these, such as botryomycosis, a supposedly specific organism has been isolated and described. A number of workers, however, have found that other bacteria may produce apparently the same morbid conditions. The more important of the affections which seem to be directly traceable to wound infection will be briefly described in the light of recent investigations. It should be stated, however, that the amount of work that has been done on these subjects is not sufficient to preclude the possibility of a specific etiological factor, but rather to suggest the lines along which valuable and more conclusive findings may be expected in the future.

I .

\& 2. Botryomycosis. This name has been given to a variety of lesions found more commonly in the horse but occurring also in cattle, swine and other animals. The thickened spermatic cord (scirrhous cord) which sometimes follows castration is the most common form of this disease. Practitioners often designate as botryomycosis certain closed abcesses occurring in the subcutaneous or intermuscular tissue. Abscesses and nodules found in the internal organs have been included under this caption. Several investigators have isolated from 
these lesions a species of microörganism which appeared to stand in a causative relation to them. It was first described as Zoögloca pulmonis equi, in I870, by Bollinger who found it in the nodules in the lungs of a horse. More recently he renamed it Botryococcus ascoformans. Rivolta designated it Discomyces equi. Rabe proposed the name. Nicrococcus botryogenes and Johne has called it $M$. ascoformans. The results of other investigations throw some doubt upon the specific nature of these lesions. Kitt, Hell, deJong, Gay and others have found in them micrococci which do not differ from. M. pyogenes aureus. The writer has failed to find $M$. ascoformans but has isolated in its stead pyogenic micrococci and streptococci. In one very interesting case of thickened cord, the writer found masses of a fungus resembling that of actinomycosis within the pockets of spongy tissue sprinkled throughout the thickened fibrous cord. Bacteria was not found in this case.

In the closed abcesses in the connective tissue, pyogenic bacteria have been found, excepting in certain cases of long standing where the cultures give negative results. Investigations which have been made into the bacterial flora of the skin of the horse show that pyogenic bacteria are frequently present in the deeper layers of the epidermis, in ducts of glands and about the hair shafts. With the possibility of infection from the integument plus all the other chances of having members of this and other groups of bacteria introduced into the body there seems to be abundant opportunity for infection with a variety of species. The evidence at hand points to the conclusion that botryomycosis is the result of wound infection, and that several species of nicroörganisms are capable of producing it, especially the form known as scirrhous cord.

The source of infection in the cord is to be found in the unsterilized or non-disinfected skin, improperly sterilized instruments, dressings, and hands of operator. For precautions to be observed in disinfecting the skin see chapter on disinfection. The fact is worthy of note in this connection, that septicemia, peritonitis, and other more distantly localized lesions occasionally follow such infections. 
I 1 .

S 13. Omphalophlebitis. This affection which is commonly called navel-ill, consists of suppurative lesions in young animals caused by pyogenic bacteria. In the horse they are most often localized in the joints of the limbs. In certain other species the lesions are quite as likely to be situated elsewlere in the body. In some cases the morbid changes are restricted to subcutaneous and intermuscular suppurative cellulitis.

The infection takes place in the nmbilicus. As the cord is severed in the field or stable many species of bacteria may gain access to the end of the exposed and freshly severed cord. In the colt a streptococcous seems to be the most common species of bacteria capable of producing the joint abscesses. In the lamb, a variety of the colon bacillus has been associated, apparently as the etiological factor, with the subcutaneous cellulitis. The lesions resulting from navel infection illustrate in a most excellent manner the extent to which certain pyogenic bacteria gaining access to the body may extend by metastasis to places remote from their entrance and produce diseased foci.

In the case of navel-ill, the umbilical vein contains a large number of bacteria. The writer has found that in colts very few if any of the bacteria (streptococci) producing the joint lesions could be found in the parenchymatous organs. Occassionally one or two of many tubes of media inoculated from the liver would develop into cultures of the infecting organism. In this disease, where many species of bacteria come into competition, one is impressed with the fact that seemingly very few of the ordinary bacteria are capable of gaining an entrance into the circulation or, at least, are possessed of vital powers sufficient to resist the destructive forces of the living animal body. A brief description of a case with the bacterial findings will illustrate this point. The case referred to was from I)r. Villiams' clinic.

A colt, about three years old. It was in good condition and seened to be perfectly well excepting for the diseased joints. It was killed for 
examination. The umbilical ven, from the umbilicus to the liver, was distended with blood, pus cells and bacteria. All the internal organs appeared to be normal. In both knee joints and in one hock joint there was extensive suppuration. A bacteriological examination showed the umbilical vein to contain many species of bacteria, among which may be mentioned $B$. coli communis, Micrococcus pyogenes aureus and a streptococcus. One of several tubes of nedia inoculated from the liver developed the streptococcus, the others remained clear. All media inoculated from the heart blood, spleen, kidney and glands remained sterile. All of the media inoculated with the pus from the diseased joints gave pure cultures of the streptococcus.

The treatment in these cases is limited to the prevention. The proper disinfection and dressing of the umbilicus at the time it is severed prevent this trouble. It is the only preventative measure known to us.

I I I.

S 14. White scours or diarrhea in calves. This is a disease affecting calves from a few hours to as many days old, with a mortality ranging from 50 to 90 per cent. The investigations which have been made in this country, especially those at the New York State Veterinary College, have suggested that it is due to certain forms of the colon bacillus. In these investigations characteristic lesions were not found.

Nocard reported the results of his investigation of apparently a similar disease of calves in Ireland. He found that they usually die during the first week. In the more chronic cases, lung lesions were found. His inquiries tend to show that this is primarily due to a wound infection. He states in his report concerning the nature of this disease that it nsually lasts from 3 to 6 days and is characterized by an intense intestinal discharge. The discharges are always of the nature of a diarrhea, white and frothy. The calves lose flesh rapidly, their flanks are hollow, abdomen retracted, back arched, eyes sunken, and hair dull; they make violent expulsive efforts, the nose is hot and dry with slight discharge of mucus, and the temperature is elevated.

In other cases, but not so commonly, the symptoms are 
less severe and recovery seems to take place; but most of the calves die several weeks later witl pulmonary lesions.

Nocard states that it is not rare to see, in these cases, the discharges mixed with blood in various quantities. In more chronic forms it is not rare to observe acute, multiple and very painfui arthritis.

The lesions found at the autopsy vary according to the course of the disease. Usually the umbilicus is large and the umbilical blood vessels have indurated walls, and contain blood clots which may be soft and purtulent. Bloody extravasations are observed, sometimes very extensive, along the umbilical vessels and the urachus, extending sometimes to the posterior third of the bladder.

In rapidly progressing cases, lesions of true hemorrhagic septicemia are found. All the organs are congested; their surface is covered with petechiae, ecchymoses or sub-serous blood infiltrations; the capillary network of the peritoneum, the omentum, the pleura and the pericardium is very much injected.

Nocard describes the lungs and articular lesions as follows :

"The lungs are rarely entirely healthy; most often they present here and there little diffuse centers of catarrhal pneumonia, nodular broncho-pneumonia or only of atelectasis. The lesions are much more constant, extensive and dense when the animals have resisted longer; they represent then the transition between the simple atelectasis of the beginning and the suppurative lesion of lung disease.

"Articular lesions, when they exist, are very interesting. The periarticular tissues are infiltrated with yellowish and somewhat gelatinous liquid; the synovial serous membrane is covered with a rich vascular injection, which seems to extend to the borders of the cartilages of the articular surfaces; the culs-de-sac of the synovials are distended by a great quantity of thick and limpid synovia, strongly yellow or reddish in color, and in which more or less dense and abundant clots of fibrinous exudate are floating. When the lesion is older, instead of synovia, there are thick, dense, and firm fibrinous 
exudates, which fill the culs-de-sac of the serous membrane and are infiltrated between the articular surfaces. In these cases the lesion resembles exactly those of peripneumonic arthritis of sucking calves.'

He found a microörganism (Pasteurella) in the organs and blood of the calres, with which he was able to produce the disease. After convincing himself that he had found the cause, he sought for the source of infection, which he found in the umbilicus. He advances three suppositions concerning the time and mode of entrance: I. intra-uterine, 2. vaginal, 3. after delivery when the calf drops on the ground or floor and when the ruptured cord comes in contact with the fecal matter or dust of the stable. The latter he believes to be the actual method. His conclusion concerning infection after delivery may be summarized in the following observation which he makes :

"We have witnessed in a well kept farm a case of labor in a cow. She was in an ordinary barn. Nothing had been prepared to receive the new-born. The calf was dropped on a bedding soiled with feces; he only fell back a little, and there during 15 or 20 minutes, we watched him making his efforts to get up, falling back here and there to the right and to the left or on his belly, dragging the stump of his cord on the ground, in the urine, or even in the fecal matter. It was only after the mother had well licked her little one, well covered with salt, that the cord was ligated. I am not sure that the umbilicus was cleaned.

"White scours is ordinarily the result of umbilical infection which takes place at the time of delivery, by the way of the wound made by the rupture of the cord."

He states that this trouble can be prevented if the person in charge of the animals at the time of their delivery takes certain precautions to prevent infection.

This disease described by Nocard does not seem to differ in many respects from the diarrhea in young calves in this country. Lesage and Delmar have described the disease in France. Ward and Fisher tested Nocard's method with quite 
satisfactory results In our cases the lung complications did not occur. Our bacteriological examination of a number of young calves that died of this trouble showed that their blood and organs were teeming with a variety of $B$. coli communis. I have not found Bact. sept. hemorrhagice (Pasteurella) in any of our cases. This suggests the possibility of serious umbilical infection with members of other groups of bacteria. The important finding of Nocard should stimulate further investigation into this important trouble in this country. As the remedy which he recommends, and which has given good results, is simply one to prevent infection of the ruptured cord, the conclusion of the wound infection origin of this disease is strengthened.

IV.

\$15. Infectious suppurative cellulitis. Cattle and sheep suffer from more or less extensive inflammatory conditions of the subcutaneous tissues, especially of the lower extremities. Frequently the morbid process extends beneath the hoof, causing it to slough or to undergo resulting disintegration changes. When this condition exists, the affection is usually called "foot rot." If the inflammatory process attacks the skin also, the condition is often designated erysipelas. If it becomes circumscribed, resulting in a local suppuration, an abscess or an ulcer is the result. The investigations which have been made concerning the cause of these lesions point to the conclusion that they result from an infection, probably through some slight abrasion of the skin. Thus far, the results show streptococci 1 to be the etiological factors in the majority of these cases. It frequently happens that a number of animals subjected to the same conditions are attacked at the same time, giving rise to a condition resembling an epizoötic.

* Lucet has reported the results of bacteriologic examınations of fifty-two abscesses in cattle. From nine of these steptococci were obtained in pure culture, and in ten cases they were associated with other bacteria. - Annales de l' Institut Pasteur. Vol. I'II (IS9.3), p.32t. 
In cattle,-cases studied by the writer, - the lesions were, within certain limits, uniform in all of the affected animals. Usually but one foot or leg was attacked, although there were numerous exceptions. The first symptom noticed was a swelling. which usually appeared in the lower part of the leg, most often in the pastern. In some animals the swelling was restricted to a small area, but often it extended up the leg to and even above the knee or hock joint. There was eridence of pain. As the inflammatory process continued, the subcutaneous tissue became indurated, the skin thick and dry, and later it would crack, usually but not always, below the dew claws, and a thick creamy pus would be discharged. After discharging, the swelling subsided and the normal condition was rapidly restored. The time necessary for the suppurative process and recovery to take place varied in different animals, but as a rule from ten to fifteen days were required. The exceptions were largely in those cases where the inflammatory process extended down to the coronary cushion. In these there was more or less sloughing of the hoof. These cases were the most serious.

In the so-called foot-rot of sheep, we have, in the cases which have come to our notice, conditions similar to those found in the cattle which were suffering from suppurative cellulitis. It may be of interest to cite a specific case with the result of the bacteriological examinations.

Nay, I 899, two sheep that were suffering from so-called foot-rot were brought to Dr. Law's clinic. They came from a large flock in which forty or more animals were reported to be similarly affected.

No. I. An adult female in very poor condition. All four feet and legs were affected and the nails on one foot were quite loose. There was a purulent discharge from openings either between the claws or in the skin just above the hoof. The microscopic examination of the pus from this opening showed a number of bacteria, but streptococci were especially numerous. They were not isolated in pure culture. The left knee was badly swollen and from the lower side of the swelling there was a discharge of thin purulent substance which contained strep- 
tococci in large numbers. A few other bacteria, mostly nicrococci, were associated with them.

No.2. An adult female, black, emaciated, but in nuch better flesh than No. 1. The two fore feet and the left hind one were affected. The hind foot and the right fore one were discharging. The left fore foot was badly swollen above the hoof but the swelling did not extend high up the leg. Fluctuation was marked. The skin was shaved, washed, disinfected and the abscess opened. A thick creamy pus was expressed. From this a number of tubes of media were inoculated and in each a streptococcus developed in pure culture. The pus from the discharging feet contained a streptococcus with other bacteria. The feet were treated locally with disinfectants by Dr. Law. In recovering there was considerable thickening of the interdigital tissue. In this case the suppuration had not extended under the nails.

V.

$\$$ 16. Fistulous withers and poll-evil. Recent investigations indicate that these very common and troublesome local diseased conditions are either directly or indirectly the result of bacterial invasion. This conclusion is tentatively drawn from the fact that the bacteriological examinations made from the pus and from recent lesions in these affections invariably reveal the presence of streptococci or micrococci, or both. Gay found a streptococcus in each of seven cases of common fistulous withers and in two cases of poll-evil. It was invariably associated with a micrococcus. He found in five cases of deep seated shoulder abscesses $M$. pyogenes aureus only. It is instructive to note, that bacteria closely resembling this organism have frequently been found in the deeper layers of the skin. The mechanical injuries commonly attributed as the primary cause consist usually of little more than skin irritation from ill fitting harnesses, saddles or from blows. While these are mechanically not extensive, they are sufficient to liberate into the juices of the subjacent tissues the bacteria deeply seated in the integument. The inflammatory process leading to suppuration, the formation of fistulae, the new formation of fibrous tissue in the affected parts, and even the bone necrosis occasionally seen are all possible and rational results of the activities of the pyogenic bacteria found in the lesions. There is 
nothing in their character to suggest causative agencies other than microörganisms. The tissue changes involved in the deposition of fibrous tissue and the abscess formation are known as the results of infection and the inflammatory processes following them. These affections are mentioned in this connection simply because the accumulating evidence tends to strengthen the working hypothesis that they are the result of bacterial invasion.

VI.

$\$$ 17. Infectious mastitis. Cattle suffer frequently from an acute inflammation of the udder as the result apparently of an invasion by a number of bacteria. The results of the investigation of this affection thus far reported suggest that the form which is transmitted from animal to animal is caused by

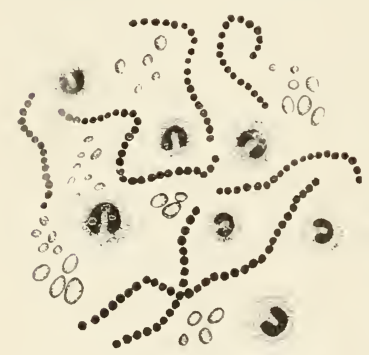

FIG. 5. Streptococcus from a case of infectious mastitis.

a streptococcus. It is, however, difficult to distinguish between this affection and those caused by certain other bacteria. It seems likely that many cases are primarily brought about by mechanical injuries which render possible the entrance into the fresh tissues of the bacteria of the skin or of the milk ducts. Other cases may be due to infection through the teat of bacteria capable of producing, by means of their metabolic products, the inflammatory condition without a distinct injury to the mucous membrane. The former view that there was a sphincter muscle near the base of the teat which closed the duct sufficiently to prevent the entrance of bacteria to the secreting portions of the gland was not well founded upon anatomical facts (Fig. 6).

The acute and more chronic inflammatory affections of the udder fall very naturally into two groups, namely: (1) those in which the parenchyma is most affected and (2) those in 
which the stroma or fibrous tissue is iuvolved. The form of mastitis more frequently encountered as an infectious (transmissible) disease is characterized by very marked changes in the milk, accompanied by the usual symptoms of parenchymatous inflammation of the gland itself. The discharge from the udder usually contains flaky masses held in suspension in the clear or perhaps cloudy serum. The color varies, and occasionally the fluid is blood-stained. The microscopic examination shows the presence of agglutinated fat globules, pus cells and often red blood corpuscles.

A number of bacteria* considered of more or less etiological value have been found associated with lesions of doubtful specific origin. The results of Kitt, Nocard, Mollereau, Guillebeau, Zschokke, Bang and still others, in which a Bacterium, a Bacillus, a Micrococcus, a Staphylococcus, and a Streptococcus have been found and reported as standing in a causal relation to the trouble, indicate that a variety of microörganisms are active in producing those affections which are frequently grouped without distinction as infectious mastitis. The review of much of the literature on this subject shows that a number of cases reported as infectious were isolated or sporadic ones, i.e., they were in dairies where the disease did not spread to other animals. While these may be truly infectious in their nature they should be differentiated from the rapidly spreading phlegmons which are easily recognized as infectious (contagious).

If we take into account the variety of anatomical changes which have been described in the various udder affections, we can reasonably admit that different agencies may have been instrumental in their production. The various species of bacteria which have been isolated from the udder lesions may very

*Among the bacteria which have been found in udder trouble and described as a possible or perhaps the more probable cause the following species may be mentioned: Bacterium phlegmasic uberis, Streptococcus agalactic contagiosce, Staphylococcus mastitidis, Galactococcus iersicolor, G. fulvus, G. albus. 


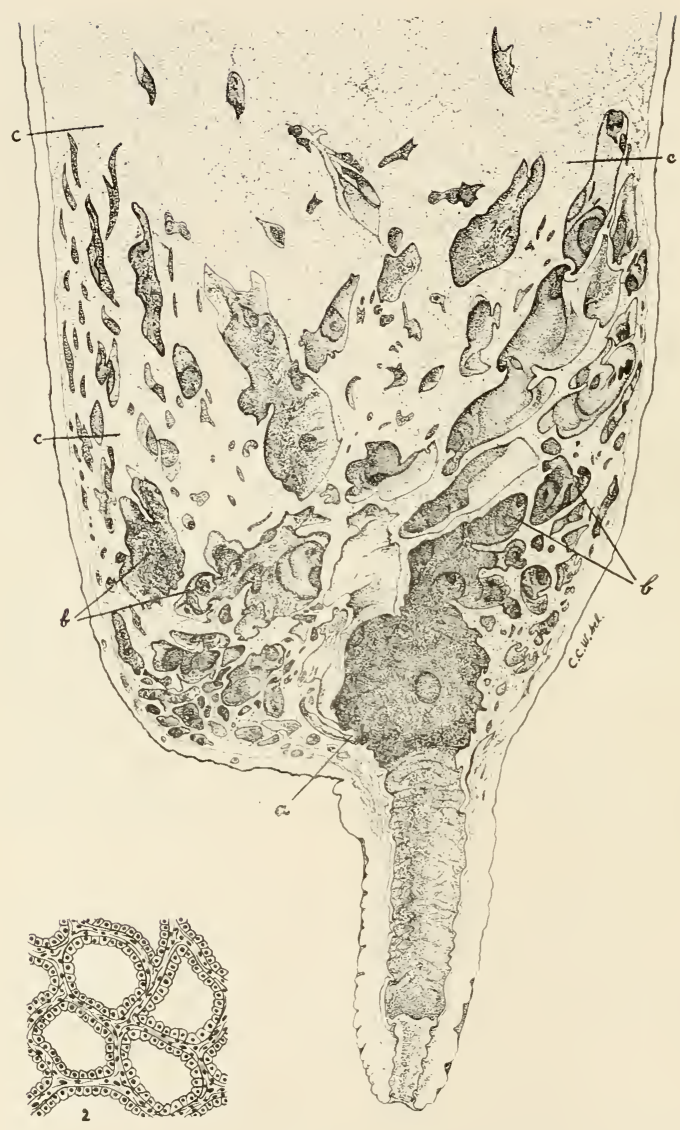

FIG. 6. Section of a quarter of a cou's udder through one teat; (a) cistern, (b) larger milk ducts, (c) secreting portion of mammary gland. 2, drawing of secreting portion of gland, enlarged. 
likely have been of etiological importance in their respective cases.

Already the facts have been pointed out, that the udder is normally more or less extensively invaded with bacteria and that certain species of bacteria seem to persist in the milk ducts of the glands when once they become lodged there. If these results apply to cows generally as rigidly as they did to those examined, an explanation for the presence of a variety of bacteria in the affected udders is not difficult to find. Whether these particular organisms, under certain conditions, would become primarily responsible for udder disease is not known. The evidence suggests that a number of the bacteria, heretofore described as the cause of mammitis, were in the affected glands by virtue of their presence in the normal udder. Concerning these points additional investigations are much needed.

The writer has examined the milk secretions from the affected cows in two quite serious outbreaks of mastitis. In the first, the milk was drawn in sterile bottles after the udders and the hands of the milker had been thoroughly washed in a I to rooo solution of corrosive subimate. In all, there were eight samples of milk taken from as many different cows. In six of the eight specimens streptococci appeared in pure culture. In the other two cases micrococci were associated with the streptococcus. In the second outbreak, the milk from four diseased udders was drawn with aseptic precautions directly into tubes containing slant agar and promptly sent to the laboratory, where it was carefully examined. From two cases pure cultures of streptococci were obtained, while tlose from the others were impure. The streptococci obtained from the twelve cases appeared to be identical and the clinical aspect of the disease in the different animals was the same.

In a dairy that was under close observation by Ward, one cow was found to be troubled in one quarter of the udder with an inflammatory process which produced thickened masses in the blood-stained milk. From this milk a streptococcus was isolated in pure culture. It could not be differentiated from 
the one isolated from the cows in the outbreaks mentioned. Another cow in this herd was found to have her udder permanently infected with a streptococcus. Another animal in the same dairy suffered repeatedly from acute streptococcus mastitis.

There are a large number of morbid conditions more or less frequently encountered in domesticated animals, which seem to be due to infection of some kind but which are not demonstrated to be of such an origin. These will continue to be attributed by some to infection and by others to various general causes until the truth concerning their etiology is revealed.

VII.

\$18. Miscellaneous infections. Attention should be called to the many morbid conditions, resulting from infection, that are encountered in different species of animals and are liable to be attributed to other agencies. Usually such lesions are referred to general pathological conditions, but a more careful inquiry will reveal the presence of infection. Among these, may be mentioned pericarditis in cattle, so frequently associated with punctures by foreign bodies. The extensive exudative inflammations in these cases are frequently associated with micrococci. The same has been true of certain cases of localized endocarditis resulting in the formation of fungoid, purulent, or necrotic masses about the valves of the heart. When one considers the possibilities of infection from accidental causes, as well as from surgical interference, together with the agency of metastasis, it is not difficult to understand how such a variety of morbid conditions can come about. Infection, therefore, forms an important part of pathology, outside of those specific organisms that cause epizoötics of greater or less severity.

REFERENCES.

I. Bollinger. Mycosis der Lunge beim Pferd. Archiv für pathol. Anat., Bd. XLIX (1870), S. 583 . 
2. DEJONG. Intersuchungen iiber Botryonyces. Thise de Giessen, 1 S99.

3. Debors. An enzooty of acute streptococcic mamuitis. /our. of Comp. Pathology and Therapentics, Vol. 17 (1904), p. 159.

4. FRöHNer. Ein Fall von generalisirter Botryomykose. Monatshefte für Thierheilk., Bd. VIII (1S97), S. 17 I.

5. GAY. A bacteriological study of fistulous withers, botryomycosis and infected wounds in the horse. Amer. Vet. Revieu, Vol. XXIV (1901), p. 877 .

6. JoHnE. Zur Actinomykose des Samenstranges. Deutsche Zeitschr. für Thierm., Bd. XII (1885), S. 73.

7. Lucer. Ann. de l'Institut Pasteur. Vol. VI (1893) p. 324.

8. M'FADIEAx. Metastatic lesions in Discomycosis. The Jour. Compr. Path. and Thera., Vol. XIII (1900), p. 337.

9. Migur.A. System der Bacterien. 1897.

IO. MOORE. Suppurative cellulitis in the limbs of cattle due to streptococcus infection. Amer. Vet. Review, June, 1898.

II. Nocard. A New Pasteurellose: White scours and lung disease of calves in Ireland. Amer. Vet. Rezieze, Vol. XXY (I9or), p. 326 .

12. SiITH AND DAwson. Injuries to cattle from swallowing pointed objects. Ann. Report I. S. Bureau of Animal Industry, I $893-4$, p. 78 .

13. WARD. The invasion of the udder by bacteria. Bulletin No. I7s, Cornell Univ. Agric. E.rp. Station, I900. 
CHAPTER III.

\section{DISEASES CAUSED BY BACTERIA \\ GENUS STREPTOCOCCUS.}

$\S$ I9. General discussion of streptococci. The confusion which exists concerning species in this group of bacteria and the variety of antistreptococcic serums on the market, render a summary of the present knowledge concerning this group of bacteria somewhat desirable. The genus Streptococcus is based according to Migula on its method of reproduction or division. Streptococci are spherical bacteria that divide in one plane. The segments do not separate but are held together in short or longer chains, although the divisions seem to be complete. Just how the segments are held together is not fully determined. According to older and more commonly encouutered classifications, a streptococcus is simply a number of micrococci (spherical bacteria) united in the form of a chain. In some of the supposedly different species the segments are oblong and vary in size. Frequently, however, the segments vary in size and form in the same chain.

The more usually observed cultural characters and biochemic properties of different streptococci are quite similar, although it is difficult to obtain two cultures that will exactly agree in all of their manifestations when grown on a large number of media. Their disease-producing powers, however, vary within wide limits. While variations in the physiological properties and pathogenesis are true for different cultures (species?), it has been found that there is a possibility of much variation in the subcultures of the same species. As with certain other bacteria, their virulence is the first to suffer change. In differentiating species, therefore, the fact must not be overlooked, that the existing characters and properties 
possessed by the streptoccocus in hand may have been more or less influenced by its conditions of life. When, for example, two streptococci appear to be identical under the majority of tests, a slight deviation in a single property cannot be considered of great differential value especially if this particular manifestation is among those most subject to change. A fundamental difficulty in differentiating species among streptococci seems to be a lack of information concerning the possible variations brought about by different environments. The further difficulty of identifying any of the very large number of forms which have been assigned specific names is due to the brevity

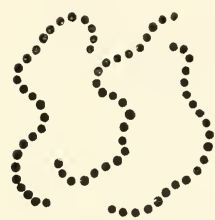

1.

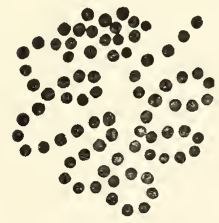

4.

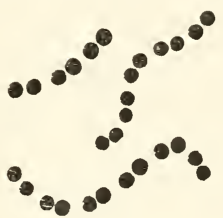

2.

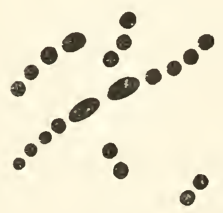

5.

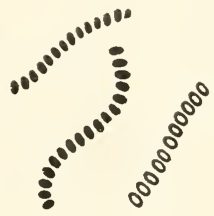

3

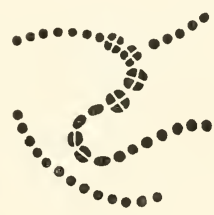

6.

Fig. 7. Six forms of streptococci. I. Long chains consisting of small segments arranged with equal spaces between them. 2. Long and shorter chains in a'hich the segments are arranged in pairs. The size of the indizidual segments is considerably larger than those in the long chains. 3. Short and longer chains where the segments are oval with the long diamcter perpendicular to the long aris of the chain. +. Long interlacing ihains. 5. Short and longer chains with one or more segments very much larger than the others. 6. Chains showing divisions in two planes. This form of dizision has becn obseried in a fea' cases. The dividing in two planes is an exception which is nol satisfactorily explained. $\times$ about rooo. 
of their description and the failure of the author to mention any character or property, or combination of the same, which would distinguish it from others. However, such deficiencies cannot well be avoided in the time of rapid accumulation of observations and the evolution of methods.

$\$ 20$. Classification of streptococci. A few investigators have tried to eliminate the confusion concerning species by classifying streptococci according to distinct morphologic characters and pathogenic properties. Of these classifications the following may be mentioned :

I. The classification of von Lingelsheim. This author divides all streptococci into two groups, or species, namely :-

(a) Streptococcus brevis-which is non-pathogenic.

(b) Strcptococcus longus - which is pathogenic.

This is a combination of pathogenesis and morphology which the author thought applicable to the entire genus. $\mathrm{He}$ worked very largely, however, with the streptococci from the human mouth and throat.

II. The classification of Furth. Kurth worked largely with the streptococci from cases of scarlatina. His system is practically the same as that of von Lingelshein, with the exception that he does not include pathogenesis as necessarily belonging to either group. The divisions are as follows :

(a) Streptococcus rigidi-Streptococci growing in short chains, imparting a uniform turbidity to bouillon.

(b) Streptococcus flexuosi-Streptococci which grow in long interlacing chains forming flocculi in bouillon, leaving the liquid clear.

III. The classification of Pasquale. Pasquale worked with thirty-three streptococci, including nearly all of the then known species. His work was quite exhaustive, but he had to deal with cultures of various generations. He divides them into four groups, as follows :

(a) Short saphrophytic streptococci. 
(b) Long non-virulent streptococci.

(c) Long pathogenic streptococci.

(d) Short higlly infectious streptococci.

Group $(d)$ pertains largely to bacteria which are no longer recognized as streptococci, for example, the diplococcus (.1/icrococcus lanceolatus) of pneumonia. It is now known that streptococci which grow in short chains are often virulent. This is especially true of the pyogenic forms.

The study of streptococci from various sources, more especially from tissues of diseased animals, suggests the desirability of delaying a further classification until more definite data are obtained concerning the natural history, not only of these, but also of the species normally present on the mucous membranes of animals and in nature generally. The specific name is, pathologically or even biologically speaking, of little moment unless we can attach a certain definite meaning to it concerning the morphologic characters, cultural manifestations and the degree of disease-producing power possessed by the organism designated. In a group of twenty-eight streptococci previously studied, the writer found the pathogenic forms, $i$. $e$. those able to produce disease in rabbits, guinea pigs, or mice, about equally divided between the long and short chains. Of the twenty-eiglit, nine possessed a certain amount of virulence for one or more of these animals.

$\$ 21$. Distribution of streptococci in nature. The fact has been pointed out in many publications that streptococci are quite widely distributed in nature. The results of the bacteriologic examinations of normal mucous membranes show that they are frequently included in the bacterial flora of the mouth, throat, nares, intestines, vagina, and in a few cases they have been found in the bronchioles of the horse and rabbit They are also present in greater or less numbers on the skin, especially in the deeper layers, presumably in the ducts of the sweat and sebaceous glands and along the hair shafts and follicles. They exist in soil and in water, and occasionally these forms are quite as delicate in their morphology and 
equally as sensitive to the influence of environment as those isolated from diseased animal tissnes. In view of this wide distribution, the presence of a streptococcus in any abuormal condition cannot be considered necessarily a specific infection from a previous case of the same kind. In many affections where the specific organism has been demonstrated, such for example as diphtheria, tuberculosis and hog cholera, streptococci frequently appear in the lesions. In these cases, they are considered as accidental or secondary invaders, although in some of these maladies, such as tuberculosis, they are believed to be of more or less secondary importance. When, however, the specific canse of the disease is not positively known, and streptococci which possess certain pathogenic powers for experimental animals are constantly present and seem to stand in a causal relation to the disease, the pathologist is confronted with a puzzling problem in trying to determine the source and the etiological importance of the organism in hand. In cases of infection leading at once to septicemia, peritonitis or suppuration, the explanation is more simple than in the epizoötic diseases, such as Brustseuche, where the constant presence of streptococci in the lesions can be quite as easily explained on the ground of their invasion of the parts affected from a normal habitat as on the hypothesis of a specific infection. It is in these instances that we are seeking for the crucial test.

We have found in a few test experiments that when certain of the delicate streptococci which exist (are found) in external nature (soil or water) are introduced within the tissues of certain animals they become, by reason of their activities, a source of irritation which causes local tissue disturbances. In a few cases they have produced septicemia with fatal results.

In cases of infection resulting in septicemia, or in those where the disease is more localized, as in strangles or mastitis, and possibly in others where the affection spreads more or less rapidly, we cannot well escape from the feeling that the streptococci, present in such large numbers, must either stand in a causal relation to the disease or be accounted for by their 
rapid proliferation in native soil made favorable for their excessive increase by the conditions produced by the true etiological factors. Their natural distribution is so wide and their virulence so capricious that a secondary invasion, which seems always to be possible, renders the fixing of etiological responsibility upon a streptococcus isolated from any diseased tissue a somewhat difficult task. The problems in this connection whicl concer11 us most and which need more extended investigation pertain ( 1 ) to the determination of the parasitic possibilities of streptococci existing in nature, $i$. $e$, those ordinarily considered as saprophytes and (2) to the distinction, if it exists, between streptococci that are able to produce local inflammatory processes leading to suppuration and those which produce highly infective and rapidly spreading diseases, such as erysipelas and strangles.

In view of the confusion respecting species in this genus, the identity of streptococci isolated from the lesions in the various diseases which have been attributed to streptococci is, at the present time, a matter of some uncertainty. There is also considerable skepticism concerning the primary etiological significance of the streptococci in a number of diseases in which they have, heretofore, been assigned as the cause. Recent investigations, especially those of Lignières, tend to the conclusion that they are often secondary invaders in certain of these diseases. Petruschky has pointed out analogous cases in human infections in slowing that streptococci play an important rôle as secondary invaders in human diphtheria, scarlatina and tuberculosis.

Pathogenesis. In the absence of verified results to prove the non-specific relation of streptococci to the diseases which have with reasonable certainty been attributed to the activities of this genus of bacteria, these affections are tentatively included among the specific streptococcic maladies. It is very important, especially when the use of antistreptococcic serums are in question, to take into account the apparently large number of forms, or species, commonly included in the general statement of a streptococcus disease or infection. In I897, 
Van de Velde, in a very exhaustive series of experiments, showed that an antitoxin produced from one streptococcus will not immunize against another, save to a very slight degree. Better results are reported by the use of polyvalent serums.

There are a number of acute local disorders, such as vaginitis in cows, that have been attributed to this genus.

REFERENCES.

I. Krein. Serenteenth Annual Report of the Local Government Board. Supplement containing report of Medical Officer. London. 1887, p. 256.

2. KuRTH. Arbeiten a.d. Kaiserlichen Gesundheitsante, Bd. VII (189I), S. 389 .

3. MoOrE. Bulletin No.3. U. S. Bureau of Animal Industry, I 893 , p. 9.

4. Pasquale. Beitrïge zur path. Anat. u. zur allgemeinen Pathologie, Bd. XII ( I893), S. 433.

5. Petruschky. Zeitschriftf. Hygiene, Bd. XVII, S. 59.

6. Von LiNGelshen. Zeitschrift f. Hygiene, Bd. X (1891), S. 331 .

7. Werch. The Amer. Jour. of Hed. Sciences, Vol. CII (I89I), p. 439 .

STRANGLES.

Synonyms. Adenitis equorum; Coryza contagiosa equorum; Distemper; Gourme; Druse.

\$ 22. Characterization. Strangles is an infectious disease of horses, asses and their hybrids occurring sporadically and in epizoötics. It is characterized principally by a fever, followed by an acute catarrh of the mucosa of the upper air passages especially of the nares, and a suppurative inflammation of the lymph glands of the submaxillary and pharyngeal regions. The lesions, however, are not restricted to these parts. It is a disease of young animals.

S23. History. Strangles was among the first equine diseases to be recognized. In I664, Solleysel gives an account of it and points to the fact that it had been known for a long 
time. Its infectious (contagious) nature was determined experimentally in 1790 by Lafosse and since that time by a number of other investigators. In 1873 , Rivolta found in the pus of the abscesses a micrococcus which appeared in chains of from three to five segments. Baruchello, in 1887 , described as its cause an organism, which he designated as Bacillus adenitis equi. Strangles has been thought by some to be identical with scrofula and measles. Sacco and Nasbot considered it as horse pox. Viborg and Toggia and more recently Nasbot advocated the inoculation of horses with the lymph of horse pox as a prophylactic measure against strangles. Delamotte demonstrated that this procedure was of little or no preventive value. The supposed specific cause (Streptococcus equi) of strangles was described first by Schütz and later by Sand and Jensen in the same year (1888). This discovery has been confirmed by Poels, Lupka and others. More recently Lignières has discovered a "coccobacillus" which he believes to be the primary cause. He considers the streptococcus of Schütz as a secondary invader of no specific value. His conclusions do not appear to have been confirmed.

$\$$ 24. Geographical distribution. Strangles is a wide spread disease among horses. It appears to stand in equine pathology very much as measles do in human medicine,-a disease of early life and consequently more prevalent where there are more young. It seems to exist in all countries where the horse kind are raised and to be more prevalent in breeding districts than elsewhere.

$\$$ 25. Etiology. Strangles is caused by Streptococcus equi, first described by Schütz in I888. With pure cultures of this organism Schuitz was able to produce the disease in healthy horses. It is fatal to mice, a maximum virulent virus destroying life in three days. In the writer's experience streptococci only have been found in the abscesses.

The period of incubation varies, from four to eight days is the most usual time.

\$ 26. Symptoms. The first indication of this disease 
is a rise of temperature. There is loss of appetite, depression, and often great weakness. The general symptoms may continue for a few days before the localization of the lesions is apparent. The first local manifestation consists usually in a catarrh of the nasal mucosa or swelling of the sub-maxillary and pharyngeal lymplatic glands. The nasal discharge is at first serous and somewhat viscid, but in from 3 to 5 days it becomes purulent and of a yellowish green color. The catarrhal condition may exist in one or both nostrils. It may extend into the pharynx, larynx, trachea and even to the bronchi. In most cases, swelling of the sub-maxillary glands appears concurrently with the purulent nasal catarrh. The spreading of the inflammation to the connective tissue which surrounds the glands, and the stasis of the lymph in the efferent lymph vessels, often cause the development, from the sub-maxillary lymph glands, of very extensive swellings that may occupy the entire inter-maxillary space, and may spread even to the outer side of the maxilla. Abscesses form in most cases.

In exceptional cases, strangles may present catarrhal symptoms without suppuration of the lymph glands. Jensen states that it may first assume the form of pharyngitis, purulent pneumonia, and pleuritis without any well marked morbid affection of the lymph glands. The urine generally remains alkaline; it frequently contains a considerable quantity of albumen.

At times, strangles is accompanied by a cutaneous exanthema which takes the form of an eruption of wheals, nodules, vesicles and even pustules; these may appear, chiefly on the sides of the neck, shoulders and sides of the chest. These exanthemata are characterized by their sudden appearance, and often by their equally rapid disappearance. An eruption of vesicles may break out on the nasal mucous membrane. The contents of the vesicles is at first limpid, but later it becomes purulent. Rabe states that the streptococcus of strangles can produce ulcers on the nasal mucous membrane.

\$ 27. Morbid anatomy. The lesions in strangles are 
interesting from the fact that in the beginning the disease is general but later in its course it becomes a series, exceedingly variable in different individuals, of localized morbid foci. The lymphatic glands seen to suffer most, althouglı any organ may be involved. As indicated by the symptoms, the lesions in most cases are characterized by an acute inflammatory process followed by suppuration.

The glandular swellings about the head usually terminate in suppuration, the pus discharging either externally or into the oral cavity. In other cases the pus undergoes caseation. Frequently the inflamed glands become confluent, resulting in a single large abscess. Small abscesses may occur under the pharyngeal mucosa.

The inflammation may extend to the superficial lymph vessels of the skin, especially of the head, resulting in the formation of a large number of small abscesses. This may be followed by a diffuse phlegmonous swelling of the parts. Metastatic abscesses are liable to occur in a great variety of organs. The metastasis seems to take place through both lymph and blood vessels althongh the lymphatic glands are most often affected. Suppurating foci have been described in nearly every lymphatic gland in the body. The discharge of pus from the bronchial, mesenteric or other glands, within or adjacent to the pleura or peritoneal cavities, may give rise to a fatal pleuritis or peritonitis. There is no organ of the body free from possible suppurative lesions as a result of metastasis.

Strangles may become chronic, especially when the nasal catarrh extends into the sinuses of the head, in the guttural ponches, or pharyngeal cavity. In these cases the animal becomes emaciated. The lesions in these cases resemble somewhat those of chronic glanders. Many complications are liable to arise. Mixed infections and secondary lesions often occur. The prognosis, however, is favorable.

Death from strangles is caused usually by either septicemia, pyemia, pleuritis, peritonitis or suppurating (metastatic) pneumonia.

The duration of the disease varies according to its severity 
and the localization of the lesions. In mild cases convalescence begins in a few days, but in other cases restoration may require weeks and even months.

The mortality, according to available statistics, does not exceed three per cent.

$\$ 28$. Differential diagnosis. Strangles is to be differentiated from :

I Punlcnt nasal catarrh. In this affection, there is rarely suppurating sub-maxillary glands, although occasionally these glands may be swollen.

2 Glanders. In glanders, the tissue changes are more persistent and the skin lesions, if they exist, do not heal as rapidly as in strangles. In chronic cases, the diagnosis is quite difficult. Here animal inoculation must be resorted to. Mice inoculated subcutaneously with the nasal discharge succumb to the streptococcus of strangles but they are resistant to the bacterium of glanders. Guinea pigs inoculated in a like manner will, in case of glanders, develop that disease from the lesions of which pure cultures of Bacterium mallei may be obtained.

3 Parotiditis. In this affection the swelling is localized and suppuration does not of ten occur.

4 Abscesses due to pyogenic bacteria. The cases are rare where there would be any question as to diagnosis. The bacteriological examination including the inoculation of animals would give positive aid unless the pyogenic organism happened to be a virulent streptococcus in which case a differentiation might be difficult.

$\$$ 29. Prevention. Isolation of the infected and removal of healthy animals from the place where the diseased animals came down. If in stables the stalls should be thoroughly disinfected before being used for well animals.

\section{REFERENCES.}

1. LIGNIÈRES The etiology of equine influenza as infectious pneumonia. Jour. Compr. Path. and Thera., Vol. XI (I898), p. 312. Translated from Recueil de Miéd. Vét., Vol. IV ( I897). 
2. PoLks. Die Mikrokokken der Druse des Pferdes. Fortschr. der Med., Bd. VI (18S8), S. 4.

3. REEKS. Intracranial strangles, abscess in a mare. Jour. Compr. Path. and Thera., Vol. XII (1S99), p. 178.

4. Sand and Jensen. Die Aetiologie des Iruse. Deutsche Keit. für Thiermed., Bd. XIII (ISS8), S. 437.

5. Schütz. Der Streptococcus der Druse des Pferdes. Arch. für Thierheilkunde, Bd. XIV (1SS8), S. 172.

EQUINE CONTAGIOUS PLELRO PNELMONIA.

Synony'ms. Pleuro-pneumonia contagiosa equorum; stable pneumonia; pneumoenteritis; Brustseuche.

30. Characterization. This disease known as contagious pneumonia or contagious pleuro-pneumonia in the horse is characterized by a high temperature, rapid pulse, but occasionally without definite lung disturbances. Like strangles, both the symptoms and the lesions vary to such a degree that it is difficult to single out diagnostic features.

\$ 31. History. In earlier times, influenza and contagious pleuro-pneumonia of the horse were not distinguished as separate diseases. Falke differentiated the disease formerly known as influenza into contagious pleuro-pneumonia and influenza. Since his time they have been recognized as distinct diseases.

\$ 32. Geographical distribution. Contagious pnenmonia, like strangles, is widely distributed. It appears in epizoötic form, although in certain places it is reported to be almost enzoötic. It prevails most extensively where large numbers of horses are congregated. It has frequently been reported as the cause of much trouble among the horses in the European armies. In the eastern part of the United States, it appears from time to time in more or less serious epizoötics. It is quite common among horses shipped from the West. In these cases, it is designated as "western" or "stable" fever. 
\$3. Etiology. There is some question concerning the specific cause of this disease. A large number of suspected microörganisms have been isolated and described, but the streptococcus of Schütz seems to be the only one with which the disease has been produced experimentally.

In I 887, Schütz published the results of his investigations into the cause of Brustseuche. He described an organism which appeared as a diplococcus in tissues, but in bouillon cultures it grew in flocculi. From the description, it appears that this organism was a streptococcus, notwithstanding the fact that in the tissues it appeared more often as a diplococcus. In cultures, he speaks of it as chains growing in masses. He mentions a capsule, but in the cases described it does not seem to be invariably present and it is not mentioned in preparations made from cultures. Chantemesse and Delamotte, Galtier and Violet, aud Cadéac found streptococci in the lesions of animals suffering from this disease. Although differences seem to exist in the streptococci isolated and studied by these investigators, there is a striking similarity between them. It is not at all unlikely that difference in methods may explain the variations mentioned.

According to Schütz, cultures inoculated into horses produce the disease when injected directly into the lungs by means of a hypodermic syringe. The resulting contagious pleuro-pneumonia exhibits the same symptoms and runs a like course to those observed in cases of the disease contracted in the natural or common manner. The essential changes shown on post-mortem examination were multiple gangrenous patches in the lungs with parenchymatous degeneration of the most important organs. The inoculated streptococci were found in the tissues of the artificially produced disease. According to Schütz, the bacteria of contagious pleuro-pneumonia are found most numerously in the lungs or the exudate on the pleurae. They are also met with in the nasal discharge and in expired air (Rust). Nothing positive is known concerning the life history of the streptococci outside the animal body. They are supposed not to be able to live longer than six weeks within 
the animal body ; but in certain cases, especially in encysted deposits in the lungs, the virus may remain active for a much longer time.

Baumgarten and Hell oppose the view that Schüz's streptococcus is specific, while Rust and Fiedler support it. Hell maintains that with our present means of investigation, the bacteria of contagious pleuro-pneumonia cannot be differentiated from the pyogenic streptococci or from the streptococcus of erysipelas In fact, Hell believes that the streptococcus of Schütz has a pathogenic effect in horses affected with pleuro-pneumonia; but as there is no positive proof of its being specific, he maintains that we are justified in supposing that this ubiquitous microörganism simply has an injurious influence on the course of the disease, contributing to the production of the secondary lesions. Hell further states that protective inoculation with Schïtz's bacteria, which at first promised good results, has not proven to be satisfactory. Fiedler, on the other hand, has obtained the same bacteriological results and has arrived at the same conclusion as Schütz. $\mathrm{He}$ also states that he has experimentally produced pleuropneumonia in a horse by inoculation of cultivations of these bacteria.

Lignières believes that his cocco-bacillus stands in an etiological relation to this disease and that here, as in strangles, the streptococcus is a secondary invader. This view has not been confirmed.

The writer made a bacteriological examination of the organs from five cases of fatal contagious pneumonia of the horse. In each case, the lungs were more or less hepatized, but the other organs were nearly normal in appearance. Without exception, a streptococcus appeared, usually in pure culture, from the lungs. The inoculated media from the other organs (liver, spleen, and kidney) remained clear. The streptococci isolated from the different cases were identical in their norphology, cultural manifestations and pathogenesis. A microscopic study of the lungs from the different horses showed streptococci singly, in pairs and occasionally in short 
chains. Distinct capsules were not observed. In bouillon cultures, however, they appeared in long chains, leaving the liquid clear, as described by Schütz.

This streptococcus did not grow in gelatin, or on serum, or on potato. It would not derelop in acid media. On agar the colonies were small and characteristic of streptococci, i. e., with a thickened, convex, grayish center surrounded by a thin, spreading bluish border, nearly equal in width to the diameter of the central portion. It fermented dextrose, lactose and saccharose, with the formation of acids but no gas. Milk remained unchanged in appearance.

In mice and rabbits, it produced a rapidly fatal septicemia, but guinea-pigs were unaffected. A horse inoculated in the pleural cavity with a small quantity of the culture was killed ro days later. At the point of inoculation and extending over an area equal to one-half of the lung, there were strong adhesions between the lung and parietes. The subjacent lung tissue was hepatized. Pure cultures of the streptococcus were obtained from the exudate and from the hepatized lung.

Although a few discrepancies exist between the description of Schiitz's organism and this streptococcus, in the more essential features they seem to be identical. The cases were examined before the publication of Lignières' results, and the methods employed did not meet the requirements of those used in isolating his cocco-bacillus. Although a very careful histological study of the pneumonic tissue was made. Lignière's organism was not detected. It is known that a bacterium. resembling that described by Lignières, exists normally in the upper air passages of a certain number of horses.

The poriod of incubation is given as varving from one to fourteen days, but nsually from four to ten days elapse from the time of exposure to the derelopment of the first symptoms.

$\$ 34$. Symptoms. The symptoms vary to a marked degree. When preumonia develops early in its course, the disease may appear suddenly; and in addition to the elevation of temperature there is a cough with difficult breathing. Often 
the symptoms differ from those of fibrinous pneumonia by the absence of distinct evidences of local lesions which are found in that disease. The first regular symptom is a rapidly increasing temperature frequently accompanied by a chill. The pulse rate is increased. There is general depression, usually loss of appetite and muscular weakness; the conjunctivae and other visible mucous membranes become congested. There may be from the beginning marked indications of localized lesions in the lungs, or the general symptoms may continue without evidence of pronounced lung disturbance. The duration of the disease depends almost entirely upon its course. In the moretypical cases, the fever lasts from 5 to 8 days. The period of convalescence is much longer, lasting from two to three weeks. Many symptoms may be exhibited, corresponding to the variations in the morbid processes. If the heart, digestive tract, liver, kidneys or brain become the localized seat of the disease, syuptoms referable to impaired functions of these organs are in evidence. The septicemic form has been described as being followed by localized suppurative lesions.

$\$$ 35. Morbid anatomy. The morbid changes in the tissues and organs vary according to the course of the disease, which is exceedingly irregular. It may exhibit a regular form of lobar inflamation of the lungs or the disease may run an atypical, complicated, acute, chronic, and not infrequently an abortive course. Further, authorities agree that many complications may arise modifying or changing completely the morbid anatomy of the disease from the conditions found in the more typical cases. In the few cases examined post-mortem by the writer, the gross lesions were restricted to the lungs. They were either in a state of congestion, or exhibited changes of fibrinons pneumonia in the cephalic (anterior) portions of one or both organs. Pneumonia is the most common localized lesion. Several quite distinct forms of lung disturbances are described.

In the lobular form of pleuro-pneumonia, which it is 
stated furnishes the largest number of subjects for post-mortem examination, there are many hemorrhagic foci, possibly gangrenous pneumonia with secondary pleuritis. Parenchymatous degeneration of other vital organs is reported. Areas of the lung tissue of greater or less size are thickened and hepatized. These are located more especially near the base of the lungs and in the lower (ventral) portions. Bright foci which are distinctly defined from the neighboring tissues are scattered through the hepatized areas and appear on the surface of sections of the hepatized parts. Uusually several of these foci are present. They vary in size from a millimeter to 20 or more centimeters in diameter. In recent lesions, these areas are very small, of a grayish-red color and surrounded by a grayish zone consisting of leucocytes. In more advanced lesions they become yellowish, necrotic and finally cavities are formed varying from the size of a pea to that of a hen's egg. These cavities are surrounded by a smooth capsule. There are other foci which contain greasy, fetid, watery pus (gangrene of the lungs), by reason of the necrotic part of the lung undergoing liquefaction in consequence, it is stated, of the admittance of air. The lungs often contain suppurating foci composed of a whitish pus mixed with necrotic lung tissue. It sometimes happens that the foci just described are absent in the lungs, although during life distinct symptoms of such a localized affection may have been present. In these cases, it is assumed that absorption of the necrotic tissue has taken place. The remaining tissue of the lungs is more or less hyperemic or edematous.

The pleurae show signs of a diffuse, exudative inflammation, the starting point of which in the large majority of cases is from necrotic deposits which are situated in the periphery of the lungs. Pleuritis may occur, however, apparently as a primary lesion without the necrotic foci being present. The contents of a necrotic deposit in the lungs rarely break through into the pleural cavity. In some cases, the visceral and costal layers of the pleurae are congested, diffusely or in spots, and are sprinkled with hemorrhages. Frequently the 
plenrae are covered with soft red granulations orer which are layers of a yellowish exudate which are partly nembranous and partly coagulated in a reticular manner, and which can usually be easily removed. The pleural cavities generally contain a considerable quantity of fluid. Dieckerhoff states that from $30-40$ liters of a serous fluid are occasionally present. The exudate is usually turbid and of an orange, grayish-red, brownish-red, or dirty-grayish color. It is generally mixed with numerous yellowish colored flakes which form a sediment when the liquid is allowed to stand in a glass. The pleuritic exudate sometines consists of pure pus and less frequently of blood. The plenritic exudate when present in large amount compresses the lungs and pushes them away from the thoracic walls. In cases of recovery, the pleuritic exudate may become organized, binding the lungs to the costal walls and diaphragm. Various forms of fibrous, villous growths develop on the pleurae.

The records show that the other organs of the body are usually in a state of parenchymatous inflammation and fatty degeneration. The muscular tissue of the heart is, as a rule, brownish-gray in color, soft, and suffers from cloudy swelling. In severe cases, it shows well-marked fatty degeneration, is of a clay color, and is occasionally sprinkled with a large number of small, yellowish-white foci. The liver is enlarged, of a clay color or sometimes icteric, and presents signs of fatty degeneration. The spleen is flaccid, its pulp increased and often sprinkled with hemorrhages. The kidneys may be swollen, friable and sometimes show numerous hemorrhagic foci. The lymph glands, especially the bronchial and mediastinal glands, are enlarged. softened, and exhibit on section a grayishred color. The muscles of the body are soft, and of a yellowish-brown color. Small hemorrhages under the serous membranes are frequentiy reported. Slight endocarditis may occur. The blood suffers less change than any of the solid organs. It contains an excess of polynuclear lencocytes.

The mucous membranes of the stomach and intestines are frequently hyperemic, swollen, sprinkled with hemorrhages, 
and sometimes even ulcerated. The bronchial mucous membrane is swollen and inflamed.

In other cases, the lesions are those of lobar pneumonia, in which the stages of hyperemia, red hepatization, gray hepatization and resolution (in favorable cases) follow each other in regular order. In a fatal case post-mortemed by the writer the right lung was entirely involved, the left one being but slightly hyperemic. In non-fatal cases, the crisis is reached on the 5 th or 6 th day, after which resolution begins.

As already stated the lesions in this disease are so exceedingly variable that, in addition to the more typical pneumonia, almost any modification can be found. The detailed description of many of these variations as described by Dieckerhoff are worthy of careful study.

The duration of the disease is from two to three weeks. If there are complications the course may be much longer.

The mortality is often very high. The literature shows it to vary from one to thirty per cent. It frequently leaves animals practically worthles because of pleural adhesions and other complications.

\$ 36. Differential Diagnosis. This disease is to be differentiated from several disorders.

I. Influenza. In the general form, where the localization of the lesions in the lungs does not occur, it is often con fused with influenza.

2. Bronchial pneumonia. The pneunonia which often follows colds must be differentiated from the epizoötic form.

3. Aspiration pneumonia. The pneumonia following the introduction of foreign substances into the lungs, as ofien happens in giving medicines, must be distinguished. The history, course of the disease, and the spread to other animals will do much to settle the diagnosis. In case of post-mortem, streptococci are often found in all the pneumonias. We have no positive lesion or organism by which to determine the diagnosis.

s 37. Prevention. The short period of incubation and 
the high temperature as the early symptom render it an easy task to detect the appearance of the disease. The well animals should if possible be removed at once to other stables. The stalls occupied by the infected animals should be disinfected before being used for other animals. Isolation and disinfection are the important factors in checking the spread of this, as of other infectious diseases.

To prevent the introduction of this malady, all horses brought from a distance should be kept isolated for at least a week before allowing them to come in contact with the home animals.

\section{REIFRENCES.}

I. CADÉAC. Contributions à l' etiologie de la pneumonie contagieuse du cheval. Compt. rend de la Soc. de Biol., r889, p. 316.

2. Finming. Infectious pneumonia of the horse. The Veterinary Jour., Vol. XXXIII, p. I.

3. Schütz. Die Ursache der Brustsenche der Pferde. Virchoze's Archiz', Bd. CVII, S. 356 .

4. Scнǘt\%. Die genuine Lungenentzündung der Pferde. Archiv fur wissen. u. prak. Thierheilkunde, Bd. VIII.

5. SiEDAMGrotzky. Ueber infectiöse Pneumonien bei Pferden. Dentsche med. Hochenschrift, ISS2, S. 668.

6. Willians. Contagious pleuro-pneumonia of the horse. Amer. Vet. Review, Vol. XVI (1892), p. 3or.

APOPLECTIFORM SEPTICEMIA IN CHICKENS.

$\$ 38$. Characterization. A rapidly fatal septicemia in chickens caused by a streptococcus.

\$ 39. History. This disease was recently discovered and described by Nörgaard and Mohler. Although the symptoms and lesions given correspond somewhat closely to those mentioned by Mazza and Rabieux, there is a marked difference in the etiological factor. The newly discovered disease is based upon the findings and investigations following a single epizoötic among fowls. Thus far it lias been identified in one other locality. 
\$4. Geographical distribution. The only locality from which it has been described is Loudoun Co., Va. It was observed and a few cases studied by Moore and Mack in an epizoötic among fowls in the northern part of New York in 1905.

\$ 4I. Etiology. This disease is stated to be due to a streptococcus which grows in short or longer chains with segments varying from 0.6 to $0.8 \mu$ in diameter. In some cases elongated forms are observed. It is an ærobe, and a facultative anrobe. When cultivated on artificial media it does not liquefy gelatin, it does not change the appearance of milk, but causes slight acidity and thickening of the lower stratum without coagulation of the casein. The reaction of alkaline bouillon is changed to an acid one. It does not give a visible growth on potato. It stains by Gram's and Gram-Weigert's methods. In bouillon it grows in somewhat flaky masses while the medium remains clear. It was fatal to fowls, mice, rabbits and swine; guinea pigs, dogs and sheep were not destroyed by inoculation. This organism has not been specifically named.

$\$ 42$. Symptoms. It is not at all uncommon to find the fowls dead and lying under the roosts. Occasionally capons were observed to be sick for from 12 to 24 hours prior to death. In these cases the feathers become ruffled and the fowl showed evidence of extreme depression. The onset of the disease is very sudden and its course a very rapid one, usually terminating in death.

$\$$ 43. Morbid anatomy. The authors describe the morbid anatomy as follows: "The spleen is more or less enlarged, showing hyperplasia of the Malpighian corpuscles. The pulp contains numerous areas of extravasated blood. When a stained section is examined by means of a hand lens a number of circular semi-transparent foci, the size of a pin hole, may be noted. These are found on microscopic examination to be centers of necrobiosis, consisting of parenchyma which has undergone coagulation necrosis, and surrounded by a more or 
less well defined capsule of embryonic and further developed connective tissue cells and filaments.

"On microscopic examination, the kidney's show slightly swollen epithelial cells of a beginning parenchymatous degeneration to well pronounced disintegration of tle renal epithelium of acute nephritis. The degree of degeneration depends, as a rule, upon the course of the disease. If a bird succumbs suddenly or in the course of a few hours the morbid changes are either not apparent at all or but slightly pronounced, while, on the other hand, the duration of three or four days to a week results in an acute exudative nephritis. The swollen or degenerate epithelium of the tubules surrounds irregular masses of coagulated exudate and white blood corpuscles, among which are numerous short chains of streptococci. In very acute cases with sudden death the liver shows extreme hyperemia. The cells have a slightly granular appearance in addition to the fatty infiltration usually seen in the liver of well kept fowls. When death does not occur until after twenty-four hours the liver cells also show parenchymatous or fatty degeneration; their outlines become indistinct, the body very granular, and the nucleus takes the stain but faintly. Interlobular and intralobular collections of round cells and leucocytes appear, and in more chronic cases centers of coagulation necrosis may be seen. The lungs become hepatized. The walls of the bronchioles are thickened and the streptococci may be seen in the minute capillaries. The air cells are filled with plasma, red blood corpuscles and epithelium, among which the nicroörganism is easily detected."

$\$$ 44. Differential diagnosis. This affection must be differentiated from fowl typhoid and chicken cholera. The positive diagnosis of each must rest with the etiological factor. A number of diseases of fowls have been described from various places in Europe and Africa, but none of them seem to be caused by a streptococcus.

$\S 45$. Prevention. The separation of the well from the diseased fowls and placing them in uninfected houses or yards 
is of the first importance. Nörgaard and Mohler found that immunity may be produced in susceptible animals by the filtrate of bouillon cultures, by sterilized bouillon cultures of the specific streptococcus, and with the serum of artificially immunized animals.

REFERENCES.

NÖRGAARD AND MOHLER. Apoplectiform septicemia in chickens. Bulletin No.36, U. S. Bureau of Animal Industry, 1902.

\section{STREPTOCOCCUS MASTITIS.}

$\$ 46$. Characterization. The term "streptococcus mastitis" has been given to an infectious disease of the udder of cows caused by a streptococcus. It is characterized by hard foci in the gland.

$\$ 47$. History. As early as $18+8$, Brennwold observed in Switzerland an enzoötic mastitis that was difficult to cure. The affection was called "gelber Galt." Since that time this affection has been found in nearly all if not all countries. Among the more recent writers on this subject may be mentioned Hess and Borgeand in Switzerland, Nocard and Mollereau in France, and Zschokke in Vienna. In America it does not appear to have been studied independently of the infectious form of mastitis described in $\$$ I 7 . The epizoötic mastitis occasionally reported in this country may be identical with this supposed distinctively specific disease. Zschokke found the streptococcus in 297 of the 444 cases of altered milk examined.

5 48. Geographical Distribution. This affection has been reported from nearly every country where cows are kept.

$\$ 49$. Etiology. The organism that causes this disease was described by Kitt, as Strcpiococcus agalactia, and Guillebeau as Streptococcus contagiosa. It enters the udder through the ducts of the teats.

The writer has been unable to differentiate this strepto- 
coccus from the one he has found in cases of mastitis, and also in the milk of cows with healthy udders. Ward and Reed produced mastitis in a healthy udder with the streptococcus that they had isolated from a normal udder.

The period of incubation is very short, one to three days in the produced cases.

$\$$ 50. Symptoms. The first symptom is the diminution in the quantity of milk, usually in but one quarter of the udder. This is quickly followed by indurated foci in the affected glands. The part becomes inflamed. The discharge or secretion is thin, more or less colored, and contains pus cells and clumps of streptococci. The lesions develop slowly, and one quarter after another of the udder becomes involved. Later the milk secretion is liable to stop entirely.

$\$$ 51. Morbid Anatomy. The tissue changes are described as those of catarrhal inflammation of a mucous surface, followed by the development of new formed tissue and atrophy of the parenchymatous tissue. The gland is hard and in time becomes enlarged, due to the new formed tissue. The microscopic examination shows a thickened intertubular tissue, and the epithelial cells more or less disintegrated and sloughed from the tubular walls. The lymphatic glands and other organs of the body are not involved. The lesions are localized in the udder.

The period of duration is variable, but always long.

The prognosis is grave for the gland itself, but is rarely fatal to the animal.

$\$$ 52. Differential Diagnosis. The diagnosis is made by finding the streptococcus in pure culture. It is to be differentiated from the sporadic cases of mastitis caused primarily by some injury, and the infectious mastitis caused by other bacteria, largely micrococci. This can readily be done from a bacteriological examination of the udder secretions.

$\$$ 53. Prevention. This disease is spread from the infected to the non-infected largely by the hands of the 
milkers. Recognizing this fact, the spread can be stopped by disinfecting (washing in a disinfectant) the hands of the milker after each animal. The diseased animals should be isolated from the others. It is one of the easiest infections to control.

\section{REFERENCES.}

I. Brenswald. Chronische Euterentzündung, Archiv'f. Thierheilk. Bd. X (1848), S. 40.

2. Dubois. An Enzoöty of Acute Streptococcic Mammitis. Jour. Comp. Path. and Thera. Vol. XVII (1894), p. 159.

3. Nocard E'T Mollereau. Sur une mammite contagieuse des vaches laitières. Bulletin de la Société centr. de Méd. vét., 1884, p. 188. Ibid. Ann. de l'Institut Pasteur, Vol. I (1887), p. 109.

4. REED AND WARD. The significance of the presence of streptococci in market milk. American Medicine, Vol. VII (1903), p. 256.

5. ZScHOKKE. Weitere Untersuchungen über den gelben Galt. Schweizer-Archiv für-Thierheilk., Bd. XXXIX (1897), S. 145. 


\section{CHAPTER IV.}

\section{DISEASES CAUSED BY BACTERIA GENUS MICROCOCCUS.}

$\$ 54$. General discussion of the genus Micrococcus. The genus Micrococcus includes the spherical bacteria that divide in two planes. The micrococci, therefore, may be single spherical organisms or they may be united in pairs (diplococcus), in fours (tetracoccus), or in small clumps or masses (staphylococcus). This genus contains many important species but they are largely among those forms producing wound infection, such as Micrococcus pyogenes aureus. These infections are not characteristic in their manifestations and consequently the disturbances they produce have not been classed among the specific infectious diseases. At present, we seem to have recognized but one specific malady of animals attributed to them. In the human species they cause a number of diseases.

TAKOSIS.

$\S 55$. Characterization. Takosis, meaning to waste, is a destructive, infectious disease of angora goats. It is characterized by great emaciation and weakness, with symptoms of diarrhea and pneumonia.

$\$ 56$. History. The name Takosis was given to this disease of goats by Mohler and Washburn in 1903. They investigated the disease, described its symptoms and morbid anatomy. They found a micrococcus which they believed to be its cause and which they named $M$. caprinus.

In 1875 , a disease was reported among angora goats in Virginia which may have been this infection. Pegler describes it somewhat fully in his work entitled, "The book of the goat" 
as "a disease peculiar to goats." The identity of this disease and the various affections of goats, largely pneumonia, described by Duquesnoy, Hutchens, Pusch, Steele and others is not established. Mohler and Washburn seem to be the only investigators in this country who have carefully studied this affection.

\$ 57. Geographical Distribution. Takosis is reported from a number of localities in this country, more especially in the Northern States.

$\$ 58$. Etiology. According to Mohler and Washburn this disease is caused by $M$. caprinus. It is pathogenic for goats, chickens, rabbits, guinea pigs and white mice, but not for sheep, dogs or rats. It usually appears in pairs. It has been isolated in pure culture from the heart's blood,spleen, kidneys and pericardial fluid. It was not obtained in cultures from the spinal cord.

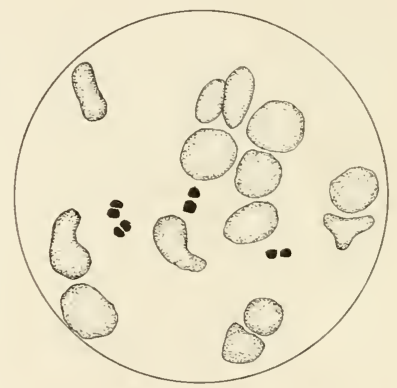

FIG. 8. Micrococcuscaprinus from the blood of an angora goat (Mohler).

\$ 59. Symptoms. The first observable symptom is a listless and languid appearance of the animal. The affected goats lag behind the flock. Frequently there is drooping of the ears and a drowsy appearance of the eyes. There is slight elevation of the temperature in the beginning, but later in the course of the disease it becomes subnormal. As the disease advances the goats move about in a desultory manner, the back arched, neck drawn down toward the sternum, and the gait staggering. Rumination is seldom impaired. The appetite is usually good but capricious. The exposed mucous membranes are pale. The respirations are accelerated and labored. The affected animals soon become so weak that they can stand with difficulty, and often they are knocked down 
and trampled by their companions. They slirink often to nearly half their normal weight. There is usually a fluid discharge from the bowels of a very offensive odor during the last few days. The goat groans occasionally and the head is usually bent around to one side. Death follows in from eight days to ten weeks. Recoveries have not been observed. The young are reported to be more susceptible to the disease than the older animals.

S6. Morbid anatomy. Emaciation and anemia are the most striking lesions. The lungs usually contain areas of pneumonia. Their surface is mottled by areas of congestion and iron gray patches. On section these areas show a frothy mucus in the bronchioles. The heart muscle is pale, dull, soft and flabby. Inflamed hemorrhagic areas may appear on the epicardium. Sometimes they are preseut in the endocardium especially that lining the ventricles. The pericardium is slightly thickened and usually contains a small quantity of blood-stained fluid. The gall bladder is frequently distended with a pale-yellow watery bile. The liver appears to be unaffected. The kidneys are anemic and softened. The cortex is pale and contrasts strongly with the dark pyramids. The capsule is easily removed. The spleen appears to be atrophied and indurated, the fibrous portions exceeding the spleen pulp. The spleen may be attached to the diaphragm or neighboring organs by adhesions. The mucosa of the intestines gives the appearance of a chronic catarrh associated with necrosis of the mucosa.

The microscopic study showed the terminal bronchioles and alveolar passages to have swollen walls and to contain various amounts of mucus and desquamated cells as a result of the catarrhal inflammation. The blood vessels in the interalveolar tissue are distended and surrounded by migrated leucocytes. The kidneys show a catarrhal or parenchymatous nephritis with the most pronounced changes occurring in the cortex. The intercapsular space is dilated and contains an albuminous exudate. The convoluted tubules show the epithelium to be swollen and granular and occasionally desqua- 
mated. The tubules may contain an albuminous deposit. As the specific micrococcus has not been found in the kidneys, Mohler and Washburn considered the lesions in this organ to be of toxic origin.

The heart shows parenchymatous degeneration of isolated fibers or groups of fibers. The spleen shows an increase in fibrous tissue. Sections of the intestines, especially of the duodenum, show a productive inflammation with exudation. There is ofte1 desquamation of the mucosa.

The blood count in experimental cases shows an increase in the number of red corpuscles. Mohler and Washburn report the examination of the blood in two such cases and one of natural infection as follows:

No. I. Red corpuscles I I, 190,000, white corpuscles 20,560 per cubic millimeter.

No. 2. Red corpuscles I 2, I60,000, white corpuscles 20,000 per cubic millimeter.

No. 3. (Natural infection) red corpuscles $10,208,000$, white corpuscles $\mathrm{I}_{4}, 860$ per cubic millimeter.

They give the normal red corpuscles as 9,976,000, white corpuscles 9,200 per cubic millimeter.

The increase in the white cells they state is due to an increased number of polymorphonuclear leucocytes and eosinophiles. They found the specific gravity of the blood to be I.031 and hemoglobin 56 .

$\$$ 6r. Differential Diagnosis. Takosis is to be differentiated from the morbid condition resulting from various animal parasites, anemia caused by some previously existing disease such as chronic pneumonia, or poor food and starvation; watery cachexia and hydremia, and contagious pneumonia.

The positive diagnosis is made from the infectious nature of takosis, and by finding the specific organism, M. caprinus in the tissues. The symptoms caused by parasites frequently resemble quite closely those of takosis. In takosis symptoms of pneumonia will frequently be noted, especially the labored breathing or rapid respiration. The luster of the fleece is less 
affected in takosis, while diarrhea is more frequently noted. Continuous coughing and snuffling, while diagnostic of the presence of lu11g worms, are not characteristic of takosis.

The anemia due to other causes is not common. Hydremia usually results from poor feeding or pasturing on low ground. The symptoms are weakness, exhaustion, rapid respiration and palpitating heart. The mucosa of the eyes, nose and mouth are pale and swollen. The edema about the head, neck and abdomen will differentiate this condition from takosis.

Hutcheon writes concerning the contagious pneumonia of goats as follows :

"It was a specific infectious form of pleuro-pneumonia, affecting goats only. Cattle and sheep remaining free from infection although constantly exposed to it. The disease was introduced into Cape Colony by a shipload of angora goats from Asia Minor, where the disease is represented as being indigenous."

\$62. Prevention. The study of this disease by Mohler and Washburn brought out very clearly certain preventive measures that should be carefully noted.

I. The most destructive outbreaks have occurred among goats that had recently been shipped from a Southern locality to a Northern latitude. Sudden climatic changes should be avoided. Hobson states that the natives of Asia Minor assert that the goat cannot be transported from one village to another of higher altitude without suffering some deterioration.

2. Angora goats should be provided with stables that are perfectly dry. These should be accessible to them at all times, as rains are very injurious to them. So averse are they to wetting that they will seldom be caught out in a shower if shelter is within reach.

3. Careful feeding.

4. When the disease appears, remove all well animals from the sick ones.

Immunity seems to have been established by the injection 
subcutaneously of sterilized cultures of the specific organism. The method, however, is still in the experimental stage.

\section{REFERENCES.}

I. Hobson. Angora goat farming. Agricultural Journal, Cape Colony, Vol. VIII (is94), p. 8I.

2. HOLZENDORFF. Lungen-Brustfellentzündung bei Ziegen. Archiv für Thierheilk., Bd. XXII (IS96), p. 345.

3. HuTCHEON. Contagious pleuro-pneumonia in Angora goats. The Veterinary Journal, Vol. XIII (I88I), p. I7r.

4. Hutcheon. Contagious pleuro-pneumonia in goats at Cape Colony, South Africa. Ibid. Vol. XXIX (I8S9), p. 399.

5. Mohler and WAShburn. Takosis, a contagious disease of goats. Bulletin No. 15, U. S. Bureau of Animal Industry, Washington, D. C., 1903 .

6. NiCOL ET RÉFIK-BEY. La pneumonie des chèvres d'A natolie. Ann. de l'Inst. Pasteur, Vol, X (IS86), p. 321.

7. PEGLER. The book of the goat. 1885 . 
CHAPTER I".

\section{DISEASES CAUSED BY BACTERIA GENUS BACTERIUM.}

\$63. General discussion of the genus bacterium. The genus Bacterium includes all the rod-shaped, non-motile bacteria. The absence of motility appears to be a logical, natural and sufficient reason to place these organisms in a genus by themselves. The only objection, that can be reasonably urged against it from the pathologist's point of view, is the changing of the generic name of a number of important pathogenic bacteria, such as those of anthrax, glanders, tuberculosis and others, from Bacillus to Bacterium.* This, however, is not serious but should be gladly welcomed if it enables us to bring into groups for study diseases that are etiologically more closely related. It is for this reason that the classification is adopted. The further subdivision of the non-motile, rod-shaped bacteria into several genera, as found in more recent classifications, suggests the possible desirability of a more restricted grouping of diseases for study and comparison, than Migula's classification permits. Several writers have already proposed a more limited grouping, such as is found in the Pasteurelloses.

$\$ 64$. Pasteurelloses. Lignières $\dagger$ has introduced the term Pasteurelloses to include a group of diseases in different species of animals caused by the bacteria represented by the

* It is important not to confuse the genus bacterium as revived by Migula with the same genus of earlier writers who characterized it as composed of non-spore bearing, rod-shaped organisms.

† Lignières. Contribution a l'étude et a la classification des septicemies hemorrhagiques les "Pasteurelloses." Ann. de l'Instit. Pasteur. Vol. XV (190I), p. 734. 
bacterium of fowl cholera, first described by Pasteur. Trevisan gave the generic name Pasteurella to this group of organisms. Hueppe designated them under the heading of Bacillus septicemiae hemorrhagicae. He seems to have taken for his type the bacillus of schweineseuche of Loeffler and Schütz.

In order to simplify the nomenclature, Lignières has grouped the diseases caused by the Pastcurella Trev, as indicated below. This plan was adopted by Nocard and Lèclainche.

I. Pasteurellose of birds. Fowl cholera.

2. Pasteurellose of rabbits. Rabbit septicemia.

3. Pasteurellose of guinea-pigs.

4. Pasteurellose of wild animals. Wildseuche.

5. Pasteurellose of sheep. Pneumo-enteritis of sheep.

6. Pasteurellose of goats. Infectious pneumonia.

7. Pasteurellose of cattle. Septicemia hemorrhagica, septic pleuro-pneumonia of calves, diarrhea of calves (white scours) and entéqué (a disease of cattle in Argentine Republic, characterized by a state of progressive cachexia.)

8. Pasteurellose of buffalo. Barbone, an infectious disease of buffalo characterized by acute fever and edematous engorgement of various organs.

9. Pasteurellose of swine. Swine plague.

Io. Pasteurellose of horses. Infectious pneumonia or typhoid ferer of horses.

I I. Pasteurellose of dogs. Maladie des chiens (distemper) and typhus du chien (malady of Stuttgart, hemorrhagic gastro-enteritis.)

The very interesting and far reaching findings of Lignières relative to the distribution of this genus of bacteria and the diseases produced by its different species are worthy of careful consideration. If his results are verified, this grouping will do much to simplify both the nomenclature and the de- 
scriptions of the various maladies caused by this group of bacteria. We already have a similar grouping in tuberculosis, where the disease bears the name of its cause, no matter in what species of animals it exists or in what form it manifests itself. Such a simplying process is hoped for but at present it seems desirable to retain the names of the diseases that are now recognized.

SWINE PLAGIE*

Synonyms. Infectious pneumo-enteritis. Pasteurellose of swine; septicemic duporc; pneumonie contagieuse; Schweineseuche.

\$65. Characterization. Swine plague is an infectious disease of swine occurring sporadically and in epizoötics. It appears usually as a septicemia, or a pneumonia in which there is marked consolidation of the ventral and cephalic lobes and the cephalic portion of the principal lobe of one or both lungs. There may or may not be pleuritis. There may be marked changes in the intestine, consisting of superficial necrosis of the mucosa especially in the ileum and cecum. On this account it has been considered an infectious pueumo-enteritis.

$\$$ 66. History. In 1886 , Smith found in a pig in the state of Illinois a disease which differed from hog cholera, and from the lesions he isolated an organism which differed from the bacillus of hog cholera. Later other cases of this disease were found in considerable numbers not only in the state of Illinois but in various places in the eastern part of the United States. Prior to this, Loeffler in Germany had described an organism which he had found to be the cause of an infectious pneumonia in swine (Schweineseuche) and with which Smith was able to identify the organism he had discovered. The first publication on this disease in the United States is in the

* For an explanation of the confusion existing concerning the nomenclature of swine plague and hog cholera see hog cholera. 
Annual Report of the Bureau of Animal Industry for 1886 .

Smith described swine plague as an independent disease, although it is often associated with hog cholera in the same animal. On account of its frequent association with hog cholera, it has been thought by some investigators to be a secondary infection only. In 1895 the writer investigated several outbreaks of this disease in southern Minnesota where it occurred uncomplicated with hog cholera. More recently two epizoötics of swine plague have been studied in New York State where no evidence was found of its being a secondary infection but where in every particular its independent nature was indicated.

$\$ 67$. Geographical distribution. Swine plague is a wide spread disease in this country. It seems to occur more or less frequently in every state in the Union. It is quite

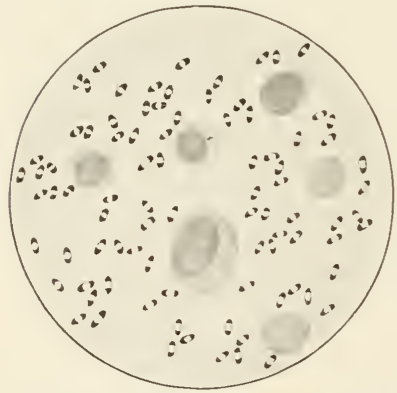

Fig. 9. Bacterium of suine plague from a cover-glass preparation of a rabbit's liver.

Hutyra has found a filterable virus in the blood and other parts of pigs suffering with Schweineseuche. The possibility of a mixed infection in this case is not excluded. Other European observers have reported similar findings.

The bacterium of swine plague and its varieties have not been systematically studied and classified. It has already 
been noted that the bacteria of rabbit septicenia, fowl cholera and Wildseuche are closely related to it.

Becker has described a pleuro-pneumonia in lambs and Evans has recently observed a septicenlia hemorrhagica in elephants caused by this species of bacteria. The infection took place through wounds.

The pathogenic organism associated with the lesions in certain forms of broncho-pneumonia in cattle differs very slightly from this. In human pathology, we find a striking resemblance in Micrococcus lanceolatus to the swine-plague bacterium, especially in its manifold and varied pathogenic possibilities and its frequent presence in normal saliva.

The fact should be recognized that experimentally the different varities or forms of this group (Bacterium septicemiae hemorragicae Hueppe, Pasteurella Trev.) are not interchangeable in their pathogenesis except for the rabbit. Thus an epizoötic fornı of fowl cholera has not been produced with the swine plague or rabbit septicemia organism. Further, it has been shown that in the npper air passages of healthy swine, cattle, loorses, cats and dogs $*$ there are bacteria not distinguishable in their cultural characters and their effect upon rabbits from the swine plague bacterium. The presence of this organism in the trachea of healthy pigs has been suggested as the source of the cause of sporadic cases of swineplague. It explains the frequent association of this bacterium with log cholera and otler maladies. What tle conditions are by which this organism is enabled to produce disease in its host have not been clearly pointed out.

If the rabbit is taken as the animal on which to test the pathogenesis of the bacteria belonging to the swine plague group, we find that those from different sources are very similar. In nature, the bacteria of swine plague, rabbit septicemia, fowl cholera, and those located in the normal upper air passages of the various species of animals mentioned exist,

*The investigations thus far made show these bacteria to be present in 48 per cent of healthy swine, So per cent of cattle, 50 per cent of sheep, 16 per cent of horses, 90 per cent of cats, and 30 per cent of dogs. 
possessed of marked variation in virnlence, that is, there are those that will kill a rabbit in from 16 to 24 hours when inoculated subcutaneously with a pure culture and those that require from 3 to ro days, or even weeks, to destroy life. With the variations in the time period, we have corresponding differences in lesions. The virulent forms produce septicemia while the attenuated varieties excite a serere purulent infiltration about the place of inoculation and exudates on one or more of the serous membranes. Conversely, it has been shown that rabbits possessed of a certain amount of natural or artificially produced resistance will, when inoculated with a virulent culture, die after the same period of time and with lesions similar to those produced by the attenuated virus in the susceptible rabbit.

- The fact that this organism is not frequently described in our works on bacteriology and because of some confusion existing concerning it and the bacillus of hog cholera, it is deemed best to insert a short description of it here.

$\$ 69$. Brief description of the bacterium of swine plague.

Morphology. A non-motile, rod-shaped organism varying from o.S to 2.0 microns in length and from 0.4 to 1.2 microns in breadth. The ends are oval, and the shorter forms resemble micrococci. The size depends upon the medium and the stage of development of the individual bacteria. A capsule has not been demonstrated, although often there appears to be one in preparations made directly from tissues. Il is not observed in cultures. Spores have not been seen. Involution forms are not uncommon in old cultures. They are especially numerous in the organs of a rabbit when it is allowed to lie for some hours after death before it is examined. It exhibits, when stained in cover-glass preparations made directly from animal tissues, a light center with deeply stained extremities (polar stain). In preparations made directly from cultures this character is much less marked. It stains readily with the basic aniline dyes. It does not retain the coloring matter when stained after Gram's method.

Cultural and biochemic properties. - This organism is less liardy than the bacillus of hog cholera, and on certain of the media used it grows very feebly or not at all. It requires a temperature of above $37^{\circ}$ C. although it develops very slowly at the room temperature. 
Agar.-The growth on this medium is not vigorous. It is of a neutral grayish color, with a glistening, moist appearing surface. It is slightly viscid and adheres to the agar surface. Isolated colonies vary from 1 to $2 \mathrm{~mm}$. in diameter, nearly round, convex, with smooth and sharply-defined margins. The condensation water becomes faintly clouded with a grayish sediment which becomes viscid. Within the agar the colonies appear as minute grayish dots. In agar, especially in plates (Petri dishes), it enits a peculiar, disagreeable, pungent odor.

Gelatin.-Ordinarily it does not grow in gelatin. (Dr. Theobald smith found that certain cultures grew in this medinm.)

Potato.-It does not grow on potato.

Bouillon.-Alkaline, peptonized bouillon becomes uniformly clouded in 24 hours when kept at a temperature of $36^{\circ} \mathrm{C}$. Occasionally cultures are obtained in which the growth appears in the form of flocculent masses, but usually after a few generations these disappear and the liquid becomes uniformly cloudy. If the bonillon contains any dextrose or muscle sugar, its reaction hecomes acid in 24 to 48 hours, owing to the fermentation of the carbohydrate. With the virulent cultures the liquid clears within a few days. The small amont of grayish sediment becomes viscid after some days, and upon agitation it is forced up, appearing as a somewhat twisted, tenacious cone, with its apex at or near the surface of the liquid. Frequently a thin, grayish, somew hat viscid band composed of bacteria is found on the sides of the tube at the surface of the liquid. It will not grow in acid bouillon. If the bouillon contains from $\mathrm{I}$ to 2 per cent. glucose, the growth is slightly more vigorous.

Effects on sugars. - In the fermentation tube, alkaline bouillon containing sugars becomes uniformly clouded in both branches. Gas is not produced. In bouillon containing dextrose and saccharose the reaction becomes strongly acid in 24 hours, but the reaction of alkaline bouillon containing lactose is not changed.

Milk.-Milk inoculated with this organism remains unchanged in appearance for several weeks. When boiled, after this period, the casein is not coagulated.

Indol.-This organism grows feebly in Dunham's solution; some cultures have given a decided indol reaction, but others have not. The production of indol is reported to be one of the properties of the German swine plague. Smith* obtained only a trace of indol in one out of four cultures of swine-plagne bacteria.

Phenol.-This was fonnd by Lewandowski'st method in all of the

*Special report on swine plague, 1891, 1. S9.

†Deutsche med. Wochenschrift, I890, S. I I86. 
cultures tested by Smith. I have failed to obtain the reaction in a few cultures, but usually it appears.

Thermal death point.-This organism is destroyed in bouillon at $58^{\circ} \mathrm{C}$. in ten minutes. A temperature of $56^{\circ} \mathrm{C}$. for this time did not destroy its vitality.

Effect of drying.-These bacteria cannot stand drying. The bacteria in a drop of bouillon dried on a cover-glass and kept at the room temperature are destroyed in 24 to 36 hours. In similar preparations made from agar cultures they resist drying from five to eight days. The difference in the time between the two cultures is probably due to the thicker layer in case of the agar preparations.

Persistence of vitality in water and soil.-Experiments to determine the length of time this organism will live in water and in the soil show that it is destroyed in water in test tubes in from nine to eleven days. In the soil it was not found after eight days. Dr. Smith states that it is destroyed in the soil after four days.

Power to resist disinfectants. - The bacterium of swine plague is very sensitive to the action of disinfectants. A large number of these agents have been tested. The following are among the more important :

Commercial sulphuric acid, 7/s per cent. kills in 30 minutes.

Commercial hydrochloric acid, $1 / 4$ per cent. kills in Io minutes.

Lime, lime water kills in I minute.

Lime, 0.015 per cent. kills in 30 minutes.

Carbolic acid, $\mathrm{I}_{2}$ per cent. kills in 60 minutes.

Carbolic acid, I per cent. kills in 5 minutes.

Carbolic acid, 2 per cent. kills in I minute.

Formalin, solution $\mathrm{r}: 2000$ kills in 5 minutes.

Trikresol, 1/2 per cent. kills in 5 minutes.

Pathogenesis.-This organism is pathogenic for rabbits, guinea pigs and mice among the smaller experimental animals and for swine. With the virulent form rabbits inoculated either subcutaneously or in the vein with very small, o.00I c. c. doses, die of septicemia in from 16 to 24 hours. Cruinea pigs are slightly less susceptible. When inoculated subcutaneously with 0.1 to 0.2 c. c. of a bouillon culture, they die in from 30 to 72 hours. Mice succumb in about 24 hours when inoculated with a drop of the culture. Pigs inoculated intravenously usually die from acute septicemia in from 18 to 36 hours. If they live longer there may be decided lung lesions. (See report on swine plague, Smith)

$\$ 70$. Symptoms. It is frequently difficult to recognize symptoms distinctive of swine plague. The peculiarities of swine render it exceedingly difficult to obtain evidence on physical examination of lung disease. Sometimes this affec- 
tion runs a very rapid course, the animal dying of septicenia. Usually it is more protracted, lasting from a few days to a week or longer. Animals affected with the more chronic form, where there are lung lesions, eat very little or refuse food altogether. They cough considerably, especially when forced to run. The back is usually arched and the groins sunken. The whites of the eyes are reddened. The skin over the ventral surface of the body, nose and ears is frequently flushed. The cough, however, is the most reliable indication we have of swine plague; but in some cases of hog cholera the coexistence of broncho-pneumonia also causes the animal to cough when forced to move rapidly.

$\$ 71$. Morbid anatomy. There are many known variations in the appearance of the internal organs of hogs which have died of swine plague. The characteristic lesions are, as previously stated, to be found in the lungs. Frequently the abdominal viscera appear to be normal, althougli a careful examination will usually reveal slight changes. In the lungs, however, the disease is ordinarily obvious.

The variety of lesions produced by the inoculation of swine plague bacteria is not so great as that observed in the naturally contracted disease. While there are outbreaks in which considerable uniformity is observed, there are others in which each animal is a surprise to the pathologist. In general it may be stated that the lungs and the digestive tract are the chief seats of the disease, though other organs, notably the lymphatic glands, are secondarily involved. The disease is localized in the lungs and in the digestive tract probably because the bacteria gain entrance through the respiratory and digestive passages.

The lungs have been found diseasec in nearly every outbreak which has been investigated. In some outbreaks the lung lesions predominated and pneumonia was the direct cause of death. In individual cases, pneumonia is absent but pleuritis and interlobular edema are generally present. In a few instances interlobular emphysema of the lungs has been observed. With pneumonia the seat of the lesion varies: 
usually the ventral lobes are first attacked, then the cephalic and azygos, and lastly the principal lobes. This movement of the disease seems to depend on gravity, inasmuch as the diseased parts are marked off from the healthy portion by a nearly

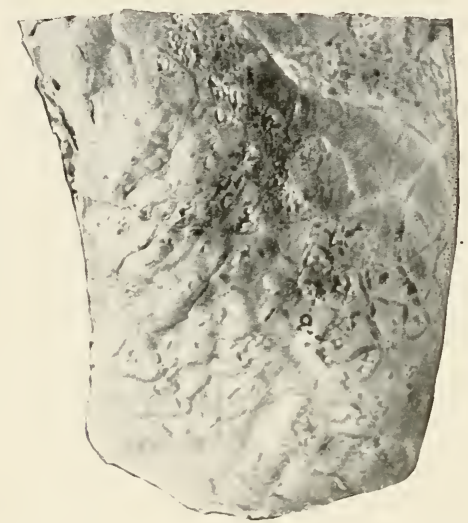

Fig. Io. Portion of a pig's lung showing emphysema. horizontal line. I $n$ other words, the most dependent portions of the lungs are the ones affected first, and as the disease progresses upwards only a small portion of the principal lobe directly under the back of the animal remains pervious, provided the life of the animal is maintained up to this point. In cases where disease is caused by lung worms or by embolism, the pne u monia involves portions of the principal lobes not contiguous to the ventral lobes.

Two kinds of pneumonia are encountered, namely, lobar and catarrhal or broncho-pnenmonia. In the former the vesicular portion of the lung substance is chiefly affected; in the latter the smaller bronchioles are primarily attacked and the alveoli secondarily. In croupous-pneumonia, there is, following the stage of congestion, an emigration of red blood corpuscles, some leucocytes, and an exudate of fibrin into the air spaces. These elements are firmly matted together by the coagulating fibrin, making the diseased lung firm to the touch. In broncho-pneumonia the catarrhal condition of the smaller airtubes makes them impervious to air. The lung tissue which they supply is gradually emptied of air and assumes the appearance of red flesh, owing to the collapse of the walls of 
the alveoli and the distended condition of the capillary network. Subsequently the inflammation extends into the alveoli, which then become distended with cellular masses.

The nature of the lung disease will depend more or less upon the mode of entrance of the virus. If it enters only by way of the air tubes it will appear perhaps as a bronchopneumonia. If it enters the lung tissue through the circulation we may have more or less scattered centers of hepatiza-

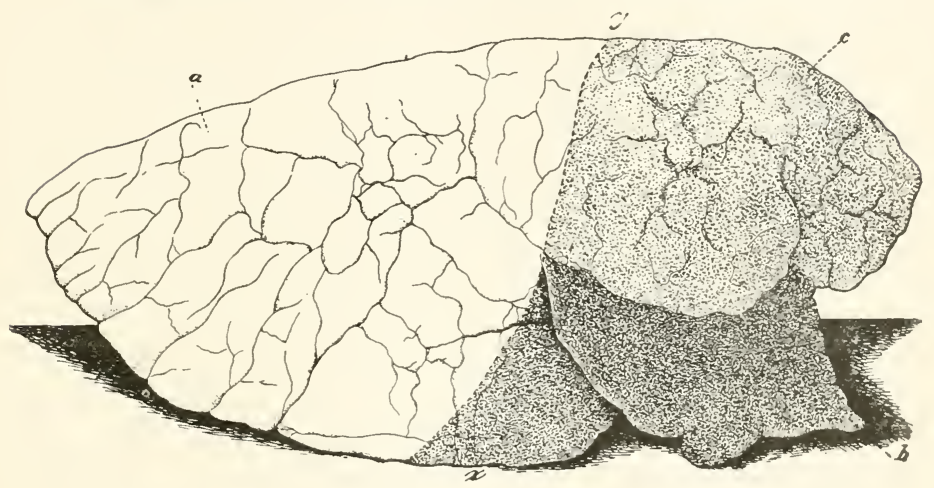

FIG. II. Right lung of pig. The stippled portion is usually involied in cases of infectious pneumonia or suine plague. (b) ientral lobe, (c) cephalic lobe, (a)principal lobe. The ventral lobe is usually the seat of the more advanced disease and consequently the first to become hepatized. The cephalic portion of the principal lobe $\left(x^{*}\right)$ is usually hepatized and the remaining portion deeply reddened.

tion (embolic pneumonia). If it enters by way of the pleura, the virus will creep along the interlobular and peribronchial tissue before it invades the parenchyma proper.

In natural infection of swine plague, bacteria seem to enter the lung tissue chiefly by way of the air tubes. At the same time it is not improbable that occasionally they may enter the serous cavities first, $i . \ell$., invade the pleural cavities and thence the lungs. This probability is shown by inocula- 
tion in which intravenous injections produced exudative pleuritis and pneumonia of the most dependent portions of the lungs covered by the pleural exudate. It is not improbable that even in the natural disease the bacteria which have gained access to a portion of the lung tissue by way of the air tubes reach the pleura covering this portion, and may then by this route invade other portions of the lungs. It may be that in this way a pneumonia originally single may become double. It has been observed that the first pneumonic infiltration of the principal lobe was at the point of contact with the diseased ventral lobe, and that the resting of a lobe against an inflamed serous surface, such as the pericardium, caused a pneumonic infiltration at the point of contact.

The character and seat of the lung lesions are somewhat variable. It is difficult to find two lungs exactly alike so far as gross appearances go. This to be sure may be due largely to the fact that animals die in different stages of the disease. Yet there are differences evidently not dependent on this fact, which must be left for special pathological investigation.

In general the cephalic (anterior) half of a swine-plague lung is hepatized, of a dark-red or grayish-red color and firm to the touch. The pleura is more or less thickened and opaque, and possibly covered with easily removable, friable, false membranes. In the more recently affected regions a faint but quite regular, delicate mottling with yellow is observed to shine through the pleura when not thickened. These minute hazy, yellowish dots usually occur in groups of four. Occasionally whitish or yellowish patches varying much in size are seen, perhaps more frequently in the ventral lobes. These correspond to homogeneous dead masses of lung tissue.

When such lungs are cut open, the section presents much the same appearance, both as regards color and mottling, as when viewed from the surface, excepting that the details are less distinct. In some cases, in the most recently invaded territories in the principal lobe and nearer the dorsum in the other lobes, the dark or grayish-red cut surface shows grayish 
lines usually arranged in curves and circles. These, so far as determined, represent the cut outlines of the interlobular and peribronchial tissue infiltrated with cells. It has already been stated that these lines may represent the paths along which the swine-plague bacteria invade the lungs from the pletral surface.

The cut ends of the bronchi of the ventral lobes are frequently occluded with thick, whitish pus; in the other lobes a reddish froth is usually present. Rarely they also contain thick glairy mucus in which particles of dry pus and lung worms are imbedded. The contents of the air tubes in the ventral lobes may have been derived from the overdistended alveoli, or else a broncho-pneumonia may have preceded the swine-plague pneumonia.

In microscopic sections of diseased lung tissue the alveoli and smallest air tubes are found distended with cell masses consisting chiefly of leucocytes. Usually there is very little fibrin and very few red corpuscles in the alveoli, even in cases in which the disease was quite recent. It may be that the stage represented in ordinary croupous-pneumonia by the presence of fibrin in connection with the cellular elements is very brief, and that it is speedily replaced by large numbers of leucocytes. The large predominence of these elements in some portions of the lungs, as well as beginning fatty degeneration, is probably the cause of the regular mottling of the lungs, as seen from the surface. The little yellowish hazy dots represent alveoli surrounded by the hyperemic walls.

The necrotic and caseous changes so frequent in swine plague are most interesting. The latter are usually quite small and disseminated in large numbers over the diseased lobes. The former represent larger masses from a marble to a horsechestnut in size. They represent tissue which has been destroyed by the rapid multiplication of swine-plague bacteria in particular localities. Hence they are found in all stages of the pneumonia. The large caseous masses may be considered as the result of a slow death of larger areas of lung tissue, due primarily to the gradual overdistention of the tissue by leuco- 
cytes, and hence the gradual cutting off of the blood supply. One is a rapid death due directly to highly virulent bacteria, the other a slow death, or a kind of dry suppuration in the later stages of the pneumonia, characteristic of the pig, and

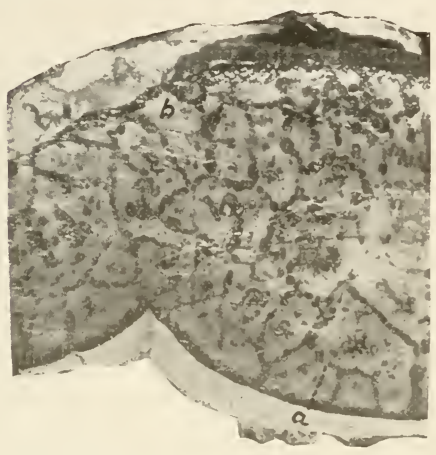

FIG. 12. Hemorrhage in the interlobular tissue of a saine-plague lung: (a) hemorrhage, (b) hepalized lobules. due indirectly to the irritation of perhaps more attenuated races of bacteria. In some cases there are extensive hemorrhages in the interlobular connective tissue.

The inflammation of the pleura frequently extends to the pericardium. This membrane is opaque, thickened and its resse $1 \mathrm{~s}$ distended. It may be glued to the contiguous lobes of the lungs and covered by a false membrane, smooth or roughened, which extends upon the large vessels emerging at its base.

Disease of the digestive tract in a considerable proportion of animals inoculated with swine-plague cultures consisted $n$ a severe catarrhal inflammation of the lining membrane of the stomach. The hyperemia was very intense, bordering on hemorrhage. Occasionally the extension of the peritonitis, produced by intra-abdominal inoculation along the mesentery, causes a severe inflammation, with exudation on the mucosa of the small intestine. A case is reported where all the Peyer's patches of the small intestine were in a hyperemic and partly hemorrhagic condition.

In the naturally contracted disease extensive hyperemia of the mucosa of the large intestine, bordering on a hemorrhagic condition, has been observed. In other cases a peculiar 
croupous exudation appeared, which seeningly resulted from the effect of swine-plague bacteria in the large intestine.

The production of intestinal disease by swine-plague bacteria may be supposed to go on as follows: the bacteria first attack the lung tissues and there produce more or less hepatization. The blood through the lungs finds its path partly obstructed. This reacts on the blood in the right sicie of the heart and the venous blood entering it. Hence there may be more or less stasis of blood in the portal circulation which in turn impairs the digestive functions of the stomach. The

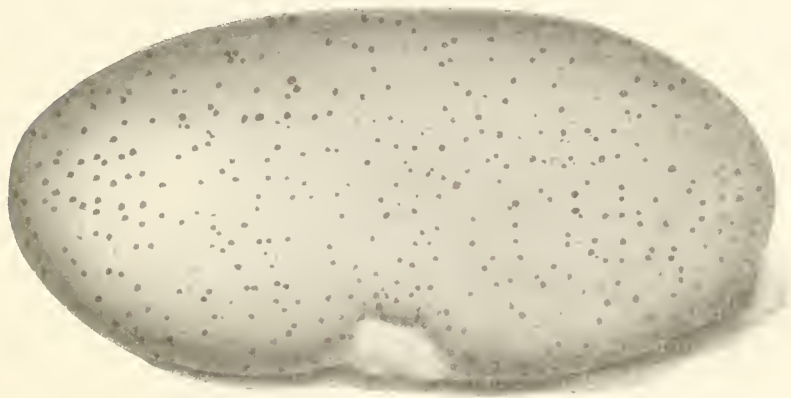

FIG. 13. Kidney from a case of acute swine plague, showing punctiform hemorhages.

swine-plague bacteria in the lungs in the later stages of the pneumonia may be coughed up in the contents of the bronchial tubes, swallowed and passed through the impaired stomach unharmed into the intestines. The stagnation of the feces in the large intestine furnishes the bacteria an opportunity to cause inflammation with exudation on the mucous membrane. The tendency of swine-plague bacteria to cause fibrinous inflammatory deposits on serous membranes may serve to explain such action on mucous membranes.

There is general congestion with resulting degeneration of the parenchyma of the spleen, kidneys and liver in the acute septicemic forms of the disease. In these cases the specific 
bacterium is easily obtained from the abdominal organs. In brief, the lesions of swine plague as they appear in various outbreaks may be summarized in four classes, namely :

I. The acute septicemic form in which the lesions are characterized by a general hyperemic condition of the serous membranes and parenchymatous organs. Not infrequently hemorrhages, especially the punctiform variety, occur. No localized lesions.

2. Cases of pueumonia with or without pleuritis. The other organs remained normal in appearance.

3. Cases where either in addition to, or possibly in the absence of, the lung lesions there are marked anatomical changes in the mucosa of the digestive tract and possibly in the lymphatic glands.

4. Cases of mixed infection, especially with hog cholera, where in addition to the swine-plague lesions which may be more or less modified, there are those, especially of the digestive tract, characteristic of the accompanying disease.

In order to present as clear a picture as possible of the findings in a case of this disease, the published autopsy notes of one animal are appended.

"Pig died yesterday, put on ice. Weight about 30 pounds. Skin on ventral aspect of body more or less reddened; over the sternum a few excoriations. The enlarged inguinal glands show as lumps under the skin. On section they present a mottled gray and red surface, the red limited chiefly to the cortex. Edema of the subcutis over right knee.

"False membrane covers the left half of the mass of intestines and the spleen; consists of an elastic, rather firm yellowish white layer. Spleen firmly glued to the surrounding intestines, slightly enlarged, dark, softened. Liver firm, cut with considerable difficulty. Kidneys in condition of parenchymatous degeneration. One hemorrhagic spot in medullary portion of the kidney. Pelvis contains a whitish glairy liquid.

"Digestive tract. Two superficial necroses on the inner surface of lower lip in front, one on the upper lip and on edge of tongue near tip. Stomach contains a little deeply bile-stained fluid. II ucosa sprinkled with red spots of a washed-ont appearance, most numerous in fundus and near pyloric valve. Hyperemia of duodenum begins sharply at 
pyloric valve. From the opening of bile duct a few drops of thick bile can be expressed. Remainder of small intestine not markedly changed. The Peyer's patch in lower ileum has some of its follicles enlarged from which caseous masses can be expressed.

"Large intestine contains much sand and gravel. Mucosa of ciccum of a dark slate color. The sumuit of the folds of a purplish hue. Free edge of valve bordered by a thin slough. On Peyer's patch near valve areas of necrotic tissue of a yellowish color, resting on a firm, yellowish-white base three-sixteenths of an inch thick. Upper colon has its mucosa of the same dark slate color, merging into a wine red. Two ulcers one-eighth of an inch in diameter observed. In lower colon congestion slight and gradually disappearing towards rectum. A small number of circular whitish erosions, apparently associated with the solitary follicles.

"Thorax. On the left lung, the ventral and cephalic lobes are interspersed with small regions of collapse. The remainder of the lobes very emphysematous and hyperemic. Of the right lung, the anterior half $(i . e$, including cephalic, ventral, and adjacent portion of principal lobes) hepatized, covered by a thin false membrane, gluing the various lobes lightly to each other and to chest wall. The diseased lobes show the regular mottling in the upper, dorsal portion. As we proceed towards the ventral portion the mottling is less distinct, the tissue firmer and interspersed with small, irregular, necrotic foci. The smaller bronchi contain a thick, whitish pus. In ventral lobe a portion of the parenchyma as large as a marble completely converted into a grayishyellow homogeneous mass. Of the principal lobe about one-third or one-fourth hepatized. The mottling of surface very regular. On section grayish, circumscribed areas one-half an inch in diameter interspersed. Over tnese masses the pleura is converted into a wrinkled, roughened, hide-like membrane.

"Trachea and bronchi contain small quantities of foamy liquid intermingled with yellowish particles. Bronchial glands barely enlarged, firm ; some lobules pale, others reddened.

"Bacteriological notes. At the autopsy an agar tube was inoculated with a platinum loop lightly rubbed over the pleural exudate. On the following day a thin grayish growth with condensation water clonded. Examination of hanging drop and stained cover-glass preparations shows only swine-plague germs.

"In cover-glass preparations of hepatized lung tissue a large number of germs resembling swine-plague bacteria were seen.

"With a bit of hepatized lung tissue, a rabbit was inoculated subcutaneously at 2 P. .1 . The rabbit was dead next morning at 8 A. ..., $i$. e., in less than is hours. In spleen, liver, and blood preparations numer- 
ous polar-stained swine-plague germs present. An agar culture from heart's blood contained only swine-plague germs.

"From the peritoneal exudate of pig, consisting of cells and fibrin and numerous bacteria of several varieties, two agar plate cultures were made. On Place A one large colony of spore-bearing bacilli and one small colony of swine-plague germs. Plate B, completely overgrown by the spore-bearing bacillus.

"A bouillon culture from the exudate contains streptococci and swine-plague bacteria. Agar plate cultures were made therefrom and both germs isolated.

"At the same time a large rabbit was inoculated subcutaneously with a bit of the exudate. Dead in 18 hours. Stained cover-glass preparations of blood from heart, spleen and liver tissue show polarstained swine-plagne germs. An agar culture from the blood contains only swine-plague germs.

"From the spleen, after thoroughly scorching through the exudate, two agar plate cultures and a bouillon culture were made with bits of spleen pulp. The bouillon culture contained only swine-plague germs.

"The swine-plague bacteria were thus obtained from lungs, pleura, spleen, and peritoneal exudate, while hog-cholera bacilli, which were looked for with the greatest care, could not be found." (Smith, Report on Swine Plague, p. 62.)

The course of the discase varies in acute cases from one to three weeks. In chronic or complicated cases it is indefinite.

The prognosis in swine plague is very unfavorable. Most of the affected animals die, and those that recover are usually not thrifty.

\$ 72. Differential diagnosis. In sporadic cases, swine plague is to be differentiated from broncho-pneumonia due to other causes than the swine-plague bacterium. Pneumonia of a non specific nature is often associated with deaths due to dietary or other causes. It frequently causes death in chronic cases of other diseases (terminal pneumonia).

In epizoötics or outbreaks, it is to be distinguished from hog cholera when there is accompanying catarrhal pneumonia. To make a positive diagnosis, it is usually necessary to depend upon the results of the bacteriological examination.

Pneumonia resulting from lung worms (Strongylus paradoxus) can be distinguished by a careful examination of the contents of the bronchioles. 
In case of coexistence of hog cholera and swine plague a bacteriological examination is necessary to determine the presence of the two diseases, owing to the possibility of an accompanying or terminal pneumonia with hog cholera.

The question has arisen as to whether the presence of Bact. septicemiae hemorrhagicae in the hepatized lung constitutes a diagnosis of swine plague. As understood at the present time it would seem that the presence of this species of bacteria would indicate the nature of the disease. It must be remembered, however, that bacteria not readily distinguishable from swine-plague organism exists in the normal upper air passages, from whence it could be brought into the lung and in such a case it might appear as a secondary invader only, or it might have been primarily the cause of the lesions. It is not improbable that epizoötics may start from these sporadic cases, although conclusive proof of this is still wanting. It seems, however, that the presence of this organism in the lung tissue of a sporadic case should be considered in the light of the distribution of these organisms and not necessarily as the starting of an epizoötic.

$\$$ 73. Prevention. Recent investigations show that outbreaks of swine plague are much more extensive than heretofore supposed. The present knowledge of this disease indicates that the adoption of measures for its prevention is quite as important as for hog cholera. In general the measures to be adopted and followed and the rules to be observed in the prevention of epizoötic swine plague are practically the same as those for the prevention of hog cholera. It will be seen from a comparison of the two species of bacteria that the bacillus of hog cholera is a more hardy organism thain that of swine plague. Thus the swine-plague bacterium is destroyed more rapidly by drying and will live a much shorter time in the soil. Howerer, the channels through which it may gain access to a herd are practically the same, and every precaution suggested in reference to hog cholera, is applicable to swine plague. It is beliered that the time during which a field, hog 
yard or pen should be kept free from swine after the appearance of the disease can, with safety, be shorter after swine plague than after hog cholera. In any case several months should elapse before the yards or pens are reoccupied. If the disease appears, the well animals should be promptly separated from the sick and placed in suitable pens or yards, protected against subsequent infection, and given an abundance of wholesome food and water. It is well to remove the sick animals to other pens. The thorough disinfection of the infected pens should be insisted upon before they are again occupied.

$\$$ 74. Specific treatment. For a number of years investigations were almost constantly under way in the United States Bureau of Animal Industry, for the purpose of finding some method by which the disease could be successfully and specifically treated. Drugs and medicines have been tried, preventive inoculations and injections of toxins have been made. The serum therapy which has effected relief in certain other diseases has been and is now being tested with somewhat favorable results, by a few European workers, yet we do not see that a specific therapeutic agent has been demonstrated. In view of this, it becomes necessary to apply with renewed zeal our present knowledge of the nature of the malady and endeavor to prevent its occurrence or reappearance by keeping the animals under the best possible conditions. Prevention of this disease is more promising than its treatment.

75. The effect of swine-plague bacteria in rabbits. In 1894, Smith and Moore described the appearance of the effect of swine-plague bacteria in rabbits and also the effect of resistance on the part of the rabbit on the form of the resulting lesions. As this disease is caused by a bacterium belonging to the septicemia hemorrhagica group, it seems desirable that the results above referred to should be restated. The appended paragraphs are taken from the report of these investigations.

Among the forms of disease observed after the subcu- 
taneous inoculation of rabbits with swine-plague bacteria from different sources (epizoötics) are the following :

I. Septicemia.

2. Peritonitis.

3. Pleuritis (usually with pericarditis).

4. Pleuritis (usually with pericarditis and peritonitis).

5. Local lesion only.

In septicemia, death ensues within eighteen or twentyfour hours. The local lesion produced at the seat of inoculation is slight. Bacteria are abundant in the parenchyma (blood vessels) of the various organs. In the form characterized by peritonitis death ensues in three to seven days. The local lesion, which in all these forms of diseases increases in extent with the prolongation of the life of the animal, is here characterized by more or less suppurative infiltration of the skin and the subcutis. The peritonitis in its earlier stages is characterized by punctiform hemorrlages on the cecum and a fibrinous or cellular exudate. It always contains immense numbers of bacteria. When pleuritis is also present the exudate usually involves the pericardium as well. It varies in amount according to the duration of the disease and is essentially the same as the peritoneal exudate.

The form characterized by pleuritis and pericarditis without peritonitis is interesting in so far as the seat of inoculation does not explain the localization, for, in every case, the inoculation was made in the region of the abdomen. The lungs may become hepatized secondarily through invasion from the pleura if the animal lives long enough.

Lastly, the form of disease in which the only localization is a very extensive suppurative infiltration associated with hemorrhage and edema of the subcutaneous tissue is not common.

It should be stated that the cultures from the same outbreak continued to produce the same form of disease in rabbits until modified by age. The maintenance of a certain uni- 
form virulence for years is well exemplified by a variety isolated in the summer of 1890 . This variety was fatal to rabbits within twenty hours when first isolated and this degree of virulence maintained itself for a period of nearly four years.

$\$ 76$. Modifications of the septicemic type by increasing the resistance of rabbits. By the injection of sterilized cultures which increase the resistance of rabbits, Smith and Moore were able to produce nearly all the pathological variations which follow the inoculation of natural races of swine-plague bacteria as isolated from outbreaks. This modification of the septicemic type is not fortuitous, for among the large number of rabbits inoculated during three and onehalf years with the culture employed, none survived twenty to twenty-four hours. Whenever the course of the inoculation disease in rabbits departed from this rapidly fatal type, it was due to some preliminary treatment of the rabbit.

The degree of resistance determined quite regularly though not invariably the form of the disease. This degree was measured by the relative quantity of the protective material (sterilized cultures, sterilized blood, and blood serum) injected. The grades of disease induced range themselves in the following order :

I. No resistance-acute septicemia.

2. Slight resistance-peritonitis.

3. Increased resistance-pleuritis and pericarditis with or with out secondary pneumonia.

4. Higher degree of resistance--pleuritis and peritonitis.

5. Still greater resistance-irregular lesions in the form of abscesses, subcutaneous and subperitoneal.

6. Nearly complete immunity. Very slight reaction at the point of inoculation.

Most of the cases cited below as illustrating these modified forms of the septicemic type belong to the series of immunizing experiments of the preceding article. To this the reader is referred for additional illustrations. 
First degree of resistance-peritonitis.--Rabbit No. I2 received $7 \mathrm{cc}$. of bouillon culture of swine-plague bacteria sterilized by heat. Subsequently with a control rabbit it was inoculated with a minute dose of swine-plague bacteria under the skin. The control died within eighteen hours, the treated rabbit in three days. The macroscopic changes were linited to the point of inoculation and the peritoneum. At the former there was a purulent infiltration of the subcutis, $1.5 \mathrm{~cm}$. in diameter, with a dilation of surrounding blood vessels. The peritonitis was characterized by an exudate of a slightly viscid character covering liver, spleen, and cecum, and made up of fibrin, leucocytes and immense numbers of bacteria.

Second degree of resistance-pleuritis and pericarditis.-Rabbit No. $3^{8}$ was treated before inoculation with 4.5 cc. of a sterilized suspension of agar cultures of swine-plague bacteria in 3 doses. Together with a control rabbit, it received under the skin the equivalent of 0.00 I cc. of a fresh bouillon culture of swine-plague bacteria. The control died in twenty hours. The treated rabbit died six days after inoculation. At the point of inoculation there was a purulent infiltration of the subcutis $3 \mathrm{~cm}$. in diameter. The abdomen and abdominal viscera were free from macroscopic changes. In the thorax, the pleural cavity was lined with a grayish, friable exudate consisting of round cells and bacteria. Lungs hyperemic and only partly collapsed. Pericardium also covered with a slight exudate.

Third degree of resistance-pleuritis (pericarditis) and pcritonitis. - Rabbit No. 15 received in the ear vein a total of I 2 cc. of a sterilized bouillon culture of swine-plague bacteria. It was inoculated subcutaneously with virulent swine-plague bacteria May 26, and died June 3 , eight days later. The control rabbit died within eighteen hours. The following changes were observed :

A purulent infiltration into the subcutaneons tissue at the point of inoculation extending over an area $6 \mathrm{~cm}$. in diameter. The superficial layer of the subjacent muscle discolored. Surrounding the area of infiltration the blood ressels were injected. The cecum and liver were covered with a very thin grayish exudate, which also ap- 
peared on and between the coils of the intestine. Spleen not enlarged.

The right lung and chest wall covered with a thin grayish exudate. In the cephalic lobe, two small areas of consolidation; principal lobe hyperemic. The left pleural cavity lined with a quite thick membranous exudate, which covered the entire surface of the lung. On the dorsal surface of the principal lobe a mass of lung tissue $2 \mathrm{~cm}$. in diameter, firm and of a yellowish-gray color. The remaining portion of the principal lobe hyperemic; cephalic lobe in a state of collapse.

Pericardium covered with a thin cellular exudate.

Higher degrees of resistance.-None of the treated animals which have come under our observation have succumbed to a mere extension of the lesion produced at the point of inoculation as is occasionally observed after inoculation with certain varities of swine-plague bacteria found in nature. There have been noticed, however, certain peculiar localizations resembling those produced in the subcutis after inoculation, and in a few cases the local lesion persisted a considerable length of time. It was quite severe in all fatal cases in which the disease was prolonged several weeks after inoculation, although the real cause of death was due in all such cases to localizations on one or more of the serous membranes. The peculiar forms of disease may be grouped as follows:

(a) Persistence of local lesions.--Rabbit No. 50 received in the abdominal cavity $3.5 \mathrm{cc}$. of the sterilized suspension of agar cultures in 3 doses. It was subsequently inoculated beneath the skin with 0.00 I cc. of a bouillon culture of swine-plague bacteria which produced a large local swelling. On February 25, IS92, nearly eight months after its inoculation, it was chloroformed. The only lesion found was in the subcutaneous tissue. At the point of inoculation the skin was sloughed over an area $3 \mathrm{~cm}$. in diameter. The denuded surface was covered with a thick scab. The subcutis beneath the scab and surrounding the ulcer was infiltrated with pus. A stained cover-glass preparation showed swine-plague bacteria. No other lesions were found.

(b) Sub-peritoneal abscess.-Rabbit No. I6 was injected intravenously with $16 \mathrm{cc}$. of sterilized bouillon cultures of swine-plague bacteria. After some days it was inoculated beneath the skin with o $001 \mathrm{cc}$. of a fresh bouillon culture of virulent swine-plague bacteria. The control rabbit died within twenty hours. Rabbit No. I6 showed no ill effect from the inoculation for several months, when it was noticed that it was becoming emaciated. It died June $I 1,1892$, one year and six days after its inoculation, with a subperitoneal abscess. 
(c) Multiple abseesses under the skin. - Rabbit No.439 received into the ear vein in three injections $4 \mathrm{cc}$. of sterilized blood fron a swine plague rabbit. Later it was inoculated subcutaneously with o.oor cc. of a bouillon culture of virulent swine-plague bacteria. The control rabbit died within twenty hours. Two months after the inoculation it was noticed that this rabbit with others was suffering from a large number of subcutaneous abscesses.

\section{REFERENCES.}

I. DE SCHWEInitz. Serum therapy. Proceedings Society for the Promotion of Agricultural Science, 1896, p. 47.

2. DE SCHWEINITZ. The serum treatment of swine plague and hog cholera. Bulletin No. 23, U. S. Bureau of Animal Industry, 1899.

3. Evans. Hämorrhagische septikämie des elephanten. The Jour. of Tropical l'et. Science, Vol. 1, p. 283.

4. JoEst. Schweineseuche und Schweinepest. Jena, rgo6.

5. LOEFFleR. Arbeiten a. d. Waiserlichen Gesundheilsamte, Bd. I ( $\left.\mathrm{IS}_{5}\right)$, S. $5 \mathrm{r}$.

6. MOORE. Pathogenic and toxicogenic bacteria in the upper air passages of domesticated animals. Bulletin No.3. U. S. Burcau of Animal Industry, iS93.

7. MOORE. Concerning the nature of infectious swine diseases in the State of New York with practical suggestions for their prevention and treatment. Report of the New rork State Commissioner of Agriculture, 1897 .

S. Smith. Preliminary investigations concerning infectious pneumonia in swine (Swine plague). Ann. Rpt. Bureau of Animal Industry, L. S. Dept. of Agriculture, 1856, p. 76.

9. Surth. Special report on swine plague. Bureau of Animal Industry, U. S. Dept. of Agriculture, ISgr.

10. SMITH AND MOORE. Experiments on the production of immunity in rabbits and guinea pigs with reference to hog-cholera and swine-plague bacteria. Bulletin No. 6, Bureau of Animal Industru, U. S. Dept. of Agriculture, 1 S94, p. 65.

II. WELCH AND CLEMENTS. Remarks on hog cholera and swine plague. First International Congress of America. Chicago. IS93. 
HEMORRHAGIC SEPTICEMIA IN CATTLE.

Synonyms. Wild und Rinderseuche; Pasteurellosis bovum; Séptucémie hémorrhagique du boeuf.

\$77. Characterization. Hemorrhagic septicemia in cattle is determined by an acute attack usually running a rapid course and terminating fatally. The lesions consist largely of hemorrhagic areas more or less widely distributed throughout the body and due to the presence of a specific microörganism.

58. History. In 1878 , Bollinger described under the name of IVild und Rinderseuche an epizoötic disease which killed a large number of wild boars and deer in the Royal game preserves of Munich. After the disease in these animals had died out, the domestic cattle in the neighborhood began to die of the same or a very similar affection. He reports it to be sudden in its onset and rapidly fatal in its course, with a mortality of 90 per cent. Death occurred in from 12 hours to a few days after the appearance of symptoms.

An exanthematous and a pectoral form are described. In the exanthematous form there are large and small hemorrhages disseminated throughout the muscles and viscera. The intestines exhibit large numbers of ecchymotic areas, while the submucous tissue is infiltrated with a serous exudate. Large hemorrhagic tumors infiltrated with serum are abundant in the subcutaneous tissue, often extending into the muscles. The mucous membranes of the tongue, larynx and pharynx, and the lymphatic glands of these regions, are swollen and infiltrated with more or less bloody serum. In the pectoral form, there is a hemorrhagic lobular pneumonia, with considerable infiltration into the interlobular tissue of a serofibrinous exudate. The pleura is infiltrated and inflamed and covered with a fibrinous exudate. The pleural cavities contain from two to twenty-five litres of liquid. At the same time there exist a certain degree of hemorrhagic enteritis and the widely disseminated hemorrhagic lesions common to the preceding form. 


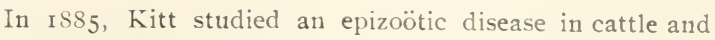
swine in Sincbach. From this disease he isolated a short, polar staining, non-motile, rod-shaped organism, fatal to cattle, horses, pigs, sheep, goats, dogs and rabbits. In the following year Oreste and Armanni reported a destructive disease of young buffaloes in Italy with symptoms and lesions similar to those reported by Bollinger and Kitt. This disease had been known in Italy for a century or more, where in certain districts it is reported to have recurred with great regularity, destroying both old and young animals. In the same year ( $188_{5}$ ) Poels described a septic pleuro-pneumonia in calves which prevailed in the vicinity of Rotterdam. It was of a septicemic nature. From the organs he obtained an organism belonging to the Bacillus septicemiae hcmorrhagicue group of bacteria. In I889, Jensen described a similar disease affecting calves in Jutland. In the same year Piot reported the presence of "barbone" in the buffaloes and domestic cattle in Egypt. In some districts 40 per cent. of the horned cattle are said to have died in a single year. It is reported as being more prevalent in the wet season.

In I890, Van Ecke described a hemorrhagic septicemia in cattle in Dutch India, particularly in Java, the lesions of which were similar to those first described by Bollinger. The specific organism was virulent for rabbits, mice, turtle dores, calves, horses and swine; sheep and asses were almost immune. In the following year Galtier described the same disease imported from Algiers to Lyons. A number of other investigators have studied and reported cases of this disease. In 1890 , Nocard isolated from cases of broncho-pneumouia in American cattle landed at La Villette, France, an organism similar to that described as the cause of septicemia hemorrhagica. In 1896 , Smith called attention to a similar organism which he found in cases of sporadic pneumonia in cattle; he does not think, however, that this organism was primarily the cause of the disease. giving it a secondary place in the etiology. As early as IS9I, Smith published the discovery of the presence of an organism morphologically and in its cultural 
characters identical with that of swine plague in the upper air passages of healthy swine. The same year Moore reported the presence of a like organism in the upper air passages of cattle, horses, sheep, dogs and cats. The following year, Fiocca described a pathogenic bacterium resembling that of rabbit septicemia in the saliva of healthy cats and dogs.

Hueppe proposed the name Bacillus septicemiae hemorrhagicae for this group of organisms and septicemia hemorrhagica for the disease they produce. Lignières has designated the diseases caused by this group as Pasteurelloses. While there may be objections to this unifying name, there seems to be no serious reason for not accepting it as a working hypothesis. In 1898, Fennimore described under the name of "Wild and Cattle Disease" a malady occurring in Eastern Tennessee. Its serious nature caused an investigation to be made by the Tennessee Agricultural Experiment Station. Nörgaard, who assisted in this investigation, recognized it as the same disease as that described by Bollinger in 1878 . Fennimore states that it has occurred to a considerable extent in his practice. In Igor, it was carefully studied by Wilson and Brimhall for the Minnesota State Board of Health. They report 64 cases of this affection which they have examined in cattle in the state of Minnesota. In 1903 , Reynolds described an investigation into several outbreaks of this disease in the same state. It is from the two latter reports that we draw very largely for the symptoms and morbid anatomy of this disease in cattle.

$\$ 79$. Geographical distribution. It will be seen from the history that this disease is a wide spread malady occurring in nearly every country. It appears to be quite prevalent in the western and northern parts of the Mississippi valley. It occurs in other localities more rarely.

\$ 8o. Etiology. Septicemia hemorrhagica in cattle is caused by an organism belonging to the group of bacteria designated by Hueppe as the hemorrhagic septicemia group and specifically named Bacillus bovisepticus by Kruse. This, according to Migula's classification, should be Bacterium 
horisepticum. A brief description of the organism as given by Wilson and Brimhall is appended.

"The organisn has a strong tendency to show polar staining in tissues and to form chains of much shortened individuals in liquid media, which causes it to be mistaken in examinations of a single specimen for a diplococcus or a streptococcus. Sometimes in cover-glass preparations from solid organs and very frequently in those from body fluids and liquid cultures, the bacteria were found in chains of three to twelve individuals. In cover-glass preparations the bacteria are from $0.6 \%$ to o. $8 /$ broad and from I.O to I. $5 /$ in length. In tissues which have heen fixed in $9^{6}$ per cent. alcohol, they are somewhat smaller. In cultures, especially in fluid media, they are apt to be much smaller and approach diplococci in appearance. The ends are rounded. In stained preparations directly from the tissues most of the bacteria have the ends intensely stained and the central portion but faintly so. In some chains in rapidly growing broth cultures this is not the case, many of the individual bacteria being evenly stained throughout and some what pointed at the ends. They do not retain the stain by Gram's method. The organism is non-motile. It is aërobic, but prefers the depths rather than the surfaces of the media. It grows best at the body temperature and more slowly at room temperature. In plain and dextrose broth a growth appears in 24 hours. In Dunham's solution a small amount of indol is formed in $t^{S}$ hours. No coagulation of milk. On Lïffler's blood serum, direct from the diseased tissues, it failed to grow well. On potato no appreciable growth has been obtained. In gelatin plates small, granular, white to slightly yellowish colonies appear after $4 \mathrm{~S}$ hours. In gelatin stab cultures a light growth occurs on the surface, while along the needle tract numerous colonies like those in the deep portions of the plate cultures derelop. The bacteria are destroyed in fluids at $58^{\circ} \mathrm{C}$. in 7 or $S$ minutes, by I to 5,000 mercuric chloride in one minute, and by a solution of lime water as weak as 0.04 per cent. almost immediately."

The period of incubation is supposed to be very short. The method of infection is not known.

$\$ 8$ r. Symptoms. There is little opportunity to determine the symptoms. The animals observed at the onset of the disease by Wilson and Brimhall appeared to be dumpish and out of sorts. There is sudden stopping of the milk secretion in milch cows. As a rule the affected animals refuse food. Of the few that make an attempt to eat, those with affected throats are unable to swallow except with much difficulty. These 
cases also breathe very heavily. The animals show marked disinclination to move and when incited to do so, exhibit stiffness, and in some instances actual lameness. Animals have been observed to drop to the ground and die in a short time, apparently without pain. Other animals live for several hours in great pain as indicated by groans and spasms of the muscles. The paroxysms of pain are apparently intermittent. There is extremely rapid loss of flesh in the animals that are sick for any length of time.

Reynolds has observed the symptoms in a few cases. He describes three stages. First (24-36 hours) general dullness and checking of milk secretion. Second, diarrheal discharge dark in color, and of disagreeable odor. The breath was noticed to be offensive. In some cases nervous symptoms developed. The temperature remained about normal during this period. Third, in this stage the eyes are wild, there is grinding of the jaws, convulsions of the face and neck muscles followed by a period of intense restlessness and activity.

$\mathrm{He}$ also records the observation that the cases that appeared to be the worst in the beginning lived longer than those that appeared to be mild.

Opportunities for the accurate determination of temperature at the beginning of the disease have been very few. An initial temperature of $105.6^{\circ} \mathrm{F}$. followed by a rapid decline has been observed. Painful edematous swellings about the legs, shoulders and under the throat are noted as early symptoms. The intestinal discharges are often streaked with blood. In other cases the feces are black, tarry or of a bloody, serous nature. Bloody urine and a bloody serous discharge from the nose have been present in some cases. The vaginal and rectal mucous membranes are intensely congested.

The marked swelling of the face, stomatitis, glossitis, and convulsive movements of the jaws in the pneumonic form of the disease, described by European writers, more especially Bollinger, were not observed by Wilson and Brimhall or by Reynolds. 
The duration of the disease is short. Often the animals are found dead.

The prognosis is unfavorable. The mortality is placed at from so to go per cent of the animals affected.

$\$$ 82. Morbid anatomy. The characteristic lesions of the disease are widely distributed areas of hemorrhage, varying in size from a pin point to several centimeters in diameter. They vary in color from light red to almost black. They are frequently accompanied with a sero-fibrinous exudate, usually yellow, but occasionally dark red in color. The hemorrhagic areas in the animals just dead are not so dark as those in animals that have been dead for some hours. The large areas, some centimeters in diameter, are apparently due, in some instances at least, to single hemorrhages, infiltrating an extensive mass of tissue, and in others to a number of minute hemorrhages closely placed and partially coalescing. Gas is not present in the subcutaneous connective tissue except in cases where extensive post-mortem changes have occurred.

There is extensive fullness of the vessels of the subcutaneous connective tissue in the acute cases, especially in those animals which are not killed by bleeding. In animals which live until emaciation is marked, there is no engorgement of the vessels.

Reynolds reports one outbreak in which meningitis involving the spinal cord, brain or both of these organs were invariably present.

All cases show some hemorrhagic areas in the subcutaneous tissue, though the number and size of these vary greatly in the different cases. Some animals show not over a dozen areas between two and three centimeters in diameter, though many minute cnes are present. In other animals, on removing the skin, hemorrhagic areas are found in great numbers and so extensive that a large fraction, possibly one-eighth, of the body surface appears to be involved. The large hemorrhages in the subcutaneous connective tissue appear to be of the composite type noted above. 
The location of the superficial lesions varies in different animals. In most cases the parts about the shoulder are most affected. A few animals show marked lesions in the gluteal and inguinal regions.

At first sight the muscle tissue in some cases seems to be

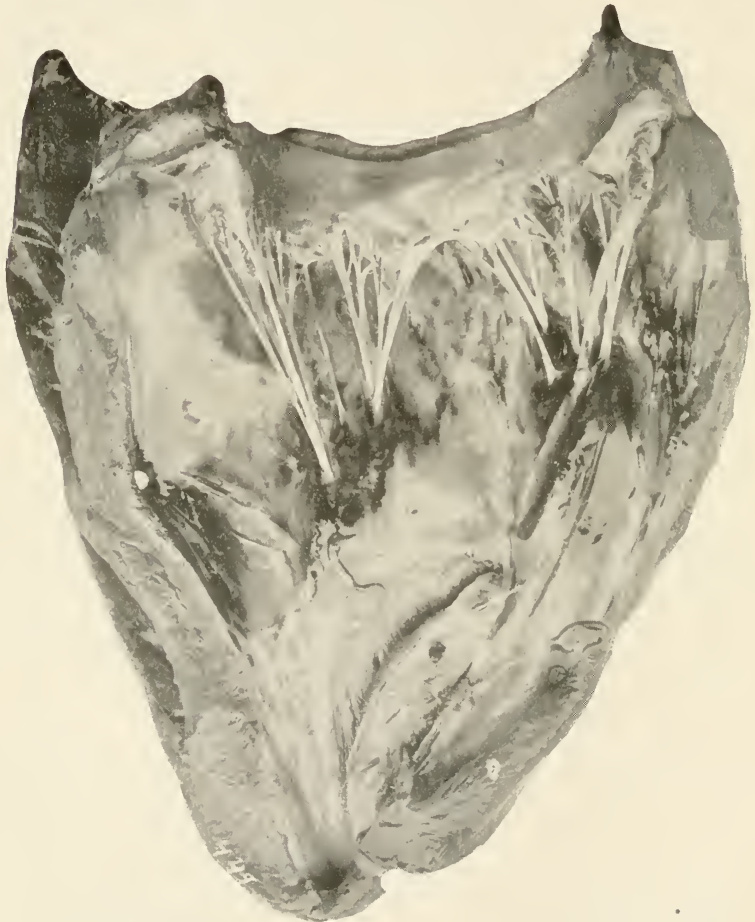

Fig. 14. Photograph showing hemorrhages bencath the endocardium of the right z'entricle (Revnolds).

much involved. A closer examination, however, usually shows that while some of the minute hemorrhages are in the 
muscle proper, the larger ones are in the intermuscular connective tissue. They are usually accompanied by a considerable quautity of yellowish or blood-stained serous exudate. The intermuscular connective tissue appears to be quite as much involved as the subcutaneous connective tissues.

The lymphatic glands are frequently though not uniformly nor constantly enlarged. Those that are enlarged are edematous and often hemorrhagic. The cervical and prescapular glands are most serionsly affected.

The nasal mucous membrane in some cases is congested, and a bloody serous discharge from the nostrils is present. The tissues around the lary $\mathrm{nx}$ are hemorrhagic and infiltrated with blood-stained serum. The mucous membranes of the larynx and trachea are nore or less congested and covered with a frothy mucus, sometimes streaked with blood. In some instances no lesions are observable in these organs. The lungs are in general almost fere from eridence of disease. Occasionally there are a small number of hemorrhagic areas, pyramidal in shape with their base on the pleura. In most cattle the parietal pleura is studded with small hemorrhages. The diaphragm sometimes contains very large hemorrhagic areas.

The pericardial sac usually shows small, sometimes very numerous, hemorrhages in the walls, and in many instances contains a blood-stained serum.

The heart walls, with but few exceptions, contain ecchy. moses and petechiae. These sometimes extend deep into the muscle. Similar areas of hemorrhage are also visible in the endocardium. The heart usually contains post-mortem blood clots.

The blood, in animals just dead, is said to be somewhat lighter than normal in color. When post-mortem changes set in, the blood is darker in color, but reddens on exposure to the air.

The spleen shows on its surface a few small hemorrhagic areas. It is usually normal in size, color and consistency, except where post-mortem changes have taken place. 
Stomatitis and glossitis are rarely observed. The pharynx is usually congested.

The stomach walls contain a few or many hemorrhagic areas. These are sometimes extremely large, especially on the third stomach. As a rule the larger hemorrhages penetrate the entire thickness of the walls The smaller ones are confined to the subserous or mucons coats. The stomach contents are apparently normal.

The intestinal walls are constantly affected. Hemorrhagic areas involving all the coats are frequently present. Smaller ones, visible only from the inner or outer surface, are always present. General enteritis and peritonitis are constantly observed. Localized enteritis is frequent.

The bowel contents are in some cases dark and tarry : in others the feces are apparently normal in color and consistency but streaked with bloody mucous.

The kidneys are usually but slightly affected. When lesions are present they are hemorrhages but pin point in size and mostly confined to the cortical substance, though a few are found in the walls of the pelvis and ureters. The urine is bloody in some instances.

The vaginal mucous membrane is congested in many cases. Wilson and Brimhall saw one animal that was four months pregnant which exhibited small hemorrhagic areas in the placental membranes.

The udder is congested in some cases. It may be hemorrhagic.

The central nervous system occasionally shows heniorrhages in the dura. A few cases are reported of hemorrhages on all of the joint surfaces. Brimhall recently reported an outbreak where the autopsies showed very few hemorrhagic areas in the subcutis and internal organs. There were lesions in its spinal cord. The spleens were enlarged. In nine outbreaks Bact. boi'isepticum was present.

Wilson and Brimhall fixed portions of the subcutaneous tissue, skeletal muscles, lymphatic glands, lung, heart wall, stomach wall, and spleen in 95 per cent. alcohol and in 4 per 
cent formaldehyde solution and stained by various methods. In general the lesions found were enormous extravasations of blood, some recent and some showing coagulation of fibrin. In the areas of less recent hemorrhage, the surrounding tissues showed varying degrees of ordinary coagulation necrosis. This was particularly marked in the affected muscles, lymph glands and portions of the lungs. In the borders of such necrosed areas leucocytic infiltration was not infrequent. In the spleen, in which the hemorrhagic areas were neither numerous nor large, there was in some instances an apparent destruction or shrinkage of the parenchyma.

A very important feature in this disease has been brought out, namely, that it is necessary, in order to obtain cultures of the bacterium producing it, that the media shouid be inoculated at once. It is evident from the literature, that with this precaution cultures should invariably be obtained.

s 83. Differential diagnosis. Septicemia hemorrhagica in cattle must be differentiated from anthrax, symptomatic anthrax, and the affection known as "corn-stalk disease." Death from this disease must also be distinguished from those due to certain accidental causes, poisoning, or the effect of over eating of grain or green fodder (hoven). The suddenness with which the animals may die from all of these causes renders the symptoms, should they be observed, of very little value in making a diagnosis. It is necessary, therefore, that in all cases, especially with the first animals to die, careful post-mortem and bacteriological examinations should be made.

In case of septicemia hemorrhagica, the cultures will usually reveal the presence of Bact. bovisepticum. The lesions will be hemorrhagic in nature.

In case of the " cornstalk disease" the lesions may consist of small hemorrhages (petechix) especially of the serous membranes and heart. The cultures will be negative.

With anthrax and symptomatic anthrax, their specific bacteria will be found.

$\leq 84$. Prevention. When this disease occurs it is im- 
portant to remove the unaffected animals to other fields or enclosures. It is well to divide them into small groups if possible. The carcasses of animals that die should be burned or buried deeply with a good covering of a disinfectant, such for example, as quick lime. Should death occur in a stable, all contaminated litter should be burned and the floors, mangers and walls thoroughly disinfected.

Experiments directed towards protective inoculation have been made, but thus far the results have not been sufficiently satisfactory to warrant the recommendation of the methods.

REFERENCES.

I. BOLliNitir. Teber eine neue Wild und Rinderseuche. München. 1878 .

2. Brimhatr. Haemorrhagic septicemia in cattle. Amer. Vet. Reä., Vol. XXVII (1903-4), p. IO3.

3. FENNIMRE. Wild and cattle disease. Jour. of Comp. Med. and Vet. Archiz', Vol. XIX (ISgS), p. 625.

4. GALTIER. Nouveaux faits tendant à etablir que la pueumoenterite infectieuse existe sur les grands et les petits ruminants en algerie. Kecneil de .hîd. Vít., 7 serie, Vol. VIII (1891), p. 97.

5. HufPPE, Ueber die Wildseuche. Berlin klinische Wochenschrift, ISS6, S. 753 .

6. KITT. Leber eine Experimentelle,der Rinderseuche(Bollinger) ähnliche Infectionskrankheit. Sitzungsberichte der. Gesellschaft fü, Morphologie und Physiologie in München, I. $188_{5}$, S. 240.

7. Piot. Le Barbone du Buffle. Bulletin d l'Instut. Egyplien, I889.

8. Poks.s. Septische Pleuropneumonie der Kälber. Fortschr. $d$. Med., rS86, S. 3 SS.

9. Reviolds. Hæmorrhagic Septicrmia. Am. Vet. Reriew. Vol. XXVI (I902), p. 819.

10. REY Yol Ds. Hemorrhagic Septicirmia. Bulletin No. S2, Hinn. Agric. Erperiment Stalion, I903.

II. WILsON AND BRIMHALL. Sixty-four cases of hemorrhagic septicemia in cattle due to bacillus bovisepticus. Report State Board of Health of Minnesota, Igor. (Very full bibliography.)

12. WOOLSEY AND JOBLING. A report on hemorrlagic septicemia in animals in the Philippine Islands. 1903. No.9. Bureau of Goz'ernment Laboratories, Manila, P. I. 
FOW', CHOLERA.

Synony'ms. Chicken cholera; cholera gallinarmm; Hühner cholera; Pasteurellosis avium; cholira des poules.

$\$ 85$. Characterization. This is an infectious disease of fowls caused by bacteria, and transmissable by cohabitation and inoculation. It is determined by a high fever, great weakness and prostration, and usually terminates in the death of the affected bird. It is reported that it attacks all varieties of domesticated poultry (chickens, ducks, geese, pigeons, turkeys), and caged birds such as parrots and canaries. It also attacks some species of wild birds. It is communicable by inoculation to rabbits and mice. Guinea pigs are not very susceptible.

\$ 86. History. This disease is mentioned in some of the oldest works treating of the diseases of animals. Fowl cholera was studied by Chabert in 1782 , who regarded it as a form of anthrax. Since 1825 , it has been frequently observed in France where it caused enormous losses in 1830 , in 1850 and in 1860. About 1830, it became known in Russia, Bohemia and Austria. In 1851 , Benjamin considered it to be a contagious disease but remarked that people and dogs might consume with impunity the meat of affected fowls. Delafond observed that it might be transmitted to birds and rabbits by using blood, secretions, and portions of the flesh. It was also recognized that the excrement plays an important part in the dissemination of the virus.

During recent years it has been observed in nearly all of the countries of Europe as well as in the United States. It has been reported from many places in the United States, but its presence seems to have been determined by scientific investigation in but a very few of these. Salmon investigated it in South Carolina in $1879-80$, and Higgins in 1898 reported it from Canada. Salmon gave special attention to raccination and the effect of disinfectants in destroying the virus. In I904. Ward reported an outbreak in California. 
Perroncito was among the first to describe the specific cause of the disease. This was followed by the contributions of Pasteur, who, in 1880 , cultivated the bacterium in chicken broth and showed that its virulence might be reduced to such an extent that it could safely be used for vaccination. This is the first case in which a virulent organism was successfully modified in a laboratory and made to act as a vaccine. It was the forerunner of the preparation of vaccines for a number of diseases, more particularly for anthrax, black quarter, and rabies.

$\leqslant 87$. Geographical distribution. Fowl cholera seems to be widely distributed in Europe and it has been found in a few localities in the Inited States and in Canada. In Germany it is the cause of heavy losses among poultry. In I903 it is reported to have killed over 48,000 fowls and 23,000 geese besides other poultry.

\$ 88. Etiology. Fowl cholera is caused by a specific bacterium (Bacillus (bipolaris) avisepticus, Pasteurella avium) which is not distinguishable morphologically or in its cultural mauifestations from the other members of the group of bacteria of which Bact. septicemiae hemorrhagicae is the type. In this group are the bacteria of rabbit septicemia, swine plague, and Wildseuche. It is a small, slightly elongated organism with rounded ends. In stained preparations from the tissues it exhibits a pronounced polar stain.

The period of incubation is placed by European writers at from is to 48 hours. In the case of 40 fowls inoculated by Salmon, it varied from + to 20 days, the average period being 8 days. Ward fed viscera of dead fowls to so healthy ones. They died in from 24 hours to 6 days.

\$ 89. Symptoms. The symptoms described for this disease in Europe differ somewhat from those reported by Salmon. Usually the appetite is lessened. Occasionally they continue to eat almost to the time of death. The earliest indication of the disease is a yellow coloration of the urates. In 
health, these are a pure white though they are frequently tinted with yellow as the restult of disorders other than cholera.

Occasionally the first symptom is a diarrhea in which the excrement is passed in large quantities and consists almost entirely of white urates mixed with colorless mucus.

Very soon after the first symptoms appear the bird separates itself from the flock, it no longer stands erect, the feathers are roughened, the wings droop, the head is drawn down towards the body and the general outline of the bird becomes spherical or ball-shaped. At this period there is great weakness, the affected bird becomes drowsy and may sink into a sleep which lasts during the last day or two of its life, and from which it is almost impossible to arouse it.

The crop is nearly always distended with food and apparently paralyzed. There is in most cases intense thirst. If the birds are aroused and cansed to walk, there is at first an abundent discharge of excrement followed at short intervals by scanty evacuation.

With the beginning of diarrhea the body temperature rises to 109 to $110^{\circ} \mathrm{F}$. Ward states that in advanced stages it ranges from 109 to 1 I $2^{\circ} \mathrm{F}$. The comb loses its bright hue and becomes pale and bloodless. European writers describe the comb as dark blue, purple, or black, and some writers in the United States have referred to it in the same terms. Salmon reports that he never observed it.

Diseased birds rapidly lose in weight. They become so weak that they walk with great difficulty, a slight touch causes them to fall over. The fowls become very much emaciated. Death may occur without a struggle or there may be convulsive movements and cries.

This disease may run rapidly through a flock destroying the greater part of the birds in a week, or it may assume a more chronic form, spreading slowly, and remain upon the premises for several weeks or months.

$\$$ go. Morbid anatomy. The comb is pale and bloodless. The superficial blood vessels usually contain but little blood. 
The liver is usually enormously enlarged, softened, and the blood ressels are engorged. The gall bladder is distended with thick, dark bile.

The crop is usually distended with food. The stomach often presents externally a number of circular discolorations, about three millimeters in diameter, which on section are found to be extravasated blood. The small intestines are congested.

The rectum and cloaca usually present deep, red lines upon their mucous membrane, evidently the first stage of inflammation, which results, in chronic cases, in thickening of the walls, especially of the rectum, the desquamation of the mucous membrane and the formation of large ulcerated surfaces.

The mesentery is generally congested, often greatly thickened and reddened, and rendered opaque by inflammation. The ureters are distended with vellow urates; the kidneys seem engorged, and on section accumulations of the tenacious, yellow urates are frequently seen. The spleen is generally normal in size and appearance, though frequently enlarged and softened.

The pericardium is sometimes distended with effusions, in which case there is noticeable hyperemia of the surface of the heart. The lungs are often, though not generally, engorged with dark blood; they are seldom, if ever, hepatized.

The blood vessels are sometimes filled with a firm clot, and contain but little liquid; at other times the blood does not coagulate at all. It seems to be those cases in which the duration of the disease is the longest, that the blood loses its power to coagulate.

Ward has summarized the morbid anatomy in the fowls examined by him as follows :

"At death, or some hours previous, the comb frequently takes on a dark purple color, but this does not always occur. Very often the comb is pale and bloodless. The skin of the breast and abdomen is frequently reddened.

"In post-mortem examinations a congestion of the blood ressels of the liver, kidney, mesentery, or intestines is noticeable to some degree 
in all eases Punctiform henorrhages are foum upon the heart with almost absolute uniformity. The liver is very frequently marked with punctiform whitish areas of recrosis. Stained sections show these necrotic foci thronghout the substance of the liver, and besides reveal a congestion of the blool vessels of that organ. The next most striking lesions occur in the first and second duodenal flexures. The nucosa is deeply reddened and studded with hemorrltages varying in size, but seldom exceeding one millineter in dianeter. These involve the intestinal coats to an extent that makes them distinctly visible on the peritoneal surface. The contents of the luodenum consist of a pasty mass, more or less thickly intermingled with blood clots. The intes tinal contents sometimes consist of a cream-colored pasty mass, or may be brownish red or even green in color. Lesions are very rarely observed in other portions of the intestines. The ureters are noticeable in practically all cases by reason of the yellow-colored urates that they contain. The nasal cavity, pharynx and oral cavity frequently contain a viscous mucous fluid, probably regurgitated from the crop.

"The field notes on twenty-one post-mortem examinations refer to hemorrhages in the lieart in twenty-one cases; punctiform necroses in the liver, fifteen cases; lremorrhages in duodenum, seven cases; the discoloration of the skin in six cases. The presence of a gelatinous exudate within the pericardium was noted twice. A fibrinous exudate in the pericardium occurred the same number of times. Hemorrhages in the peritonemu other than those visible through the mucosa of the duodenum occurred but twice. In one case hemorrhages were abundantly scattered throughout the muscles of the trunk and legs.

"Fowls inoculated subcutaneously with cultures exhibit on postmortem examination the punctiform henorrhages on the heart and the hemorrhages in the mucosa of the duorenum exactly as in cases infected naturally."

BLOOI COLXTS (I: FOWLS INFECTHE BI INGISTION AND

INFFCTEI NATIRAI,1,

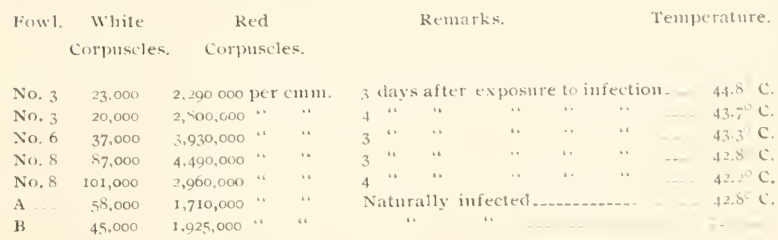


BL,OOD COUNTS OF APPARENTIY HEALTHY FOWLS.

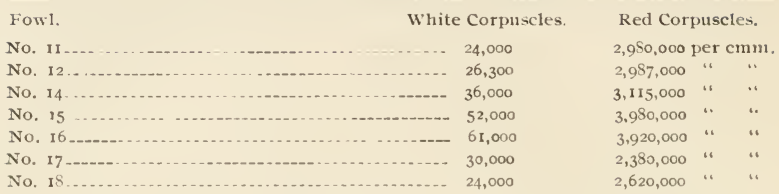

The duration of the disease varies from a few hours to several days.

The prognosis is unfavorable. The mortality is very high, often roo per cent.

$\$ 91$. Differential diagnosis. Fowl cholera is to be differentiated from :

1. A number of dietary disorders which cause the death of a large number of fowls. Such cases are often thought to be chicken cholera and so reported by the owners. A diagnosis is to be made from the bacteriological findings.

2. It is to be differentiated from fowl typhoid. There There are a number of resemblances in the clinical history of the two diseases but there are marked differences in both the morbid anatomy and etiology. For a comparison of the lesions and specific bacteria of these two diseases see fowl typhoid.

\$ 92. Prevention. Pasteur introduced a preventive inoculation or vaccine for this disease. Kitt has found that the eggs of fowls unknown to this disease possessed a substance somewhat similar to antitoxin. He immunized fowls by injecting them simultaneously with from four to eight cubic centimeters of the whites of such eggs. While exceedingly interesting this method does not seem practicable. More recently he has obtained a horse serum that promises to be of immunizing value. Good sanitary conditions, isolation of the well from the sick fowls and thorough disinfection seems to be the most satisfactory procedure. It is important not to introduce the disease with newly purchased fowls or to expose healthy ones to the disease either at or in transportation to various poultry exhibits. 
REFER I:NCHS.

1. Higgins. Notes on an epidenic of fowl cholera and upon the comparative production of acid by allied bacteria. Jowr. of Experimental Medicine, Vol III (1S98), p. 65 I.

2. Kiтr. Die Serumimpfung gegen Geflügelcholera. Nonatshefte für praktische Tierheilk., Vol. XVI (1904), s. I.

3. Perroncito. Arch. für wiss. u. praikt. Thierheilk., 1879, \$. 4.

4. Pasteur. De l'attenuation du virus du cholera des poules. Comptes rendus des Seances de l'Academie des Sciences, Vol. XCI (I8So), p. 673 .

5. PASteur. Sur les maladies virulentes, et en particulier sur la maladie appalée vulgairement choléra des ponles. Ibid. Vol. XC (ISSo), p. 239.

6. SAlmox. Annual Reports of the U. S. Commissioner of Agriculture, $1880-82$.

7. SALMON. The diseases of poultry. Washington, D. C. I889, p. 232 .

8. IVARD. Fowl cholera. Bulletin No. 156. College of Agric., Calif. Agric. E.rp. Station, 1904.

GOOSE SEPTICEMIIA.

S 93. Characterization. The disease is an acute septicemia causing the death of the infected goose in a few hours after there are evidences of sickness.

S 94. History. In 1902, Curtice described this disease as causing considerable loss in Rhode Island. The following note by T. Smith, dated October 3I, 1900, quoted by Curtice, is significant in explaning the condition under which the disease disappeared.

"Geese born in April and May and collected during the summer and fall for fattening, kept in opew yards, crowded together but able to move about; about 500 in a pen. Fed on a mixture of corn meal and meat and beef scraps. Epidemic began in midsummer. Deaths up to twenty a day (one workman says sixty one day); about 3,000 lost to date."

$\S$ 95. Etiology. The cause of this disease is a bacterium belonging to the septicenia hemorrhagica group. It is stated 
to have "the characters of the fowl cholera type." It killed rabbits when they were inoculated with $0.2 \mathrm{cc}$. of a bouillon culture.

$\leqslant$ 96. Symptoms. The symptoms are indefinite. In the outbreak described the geese were often found dead. The description of the disease by Curtice is appended.

"Few symptoms of disease were seen, those noted pertaining mainly to the death struggles. Very few that died were noticed to be sick more than an hour or two before death, and, as the experimental investigation demonstrated, the disease could not have lasted, in the majority of the geese, more than thirty-six hours. An uncertain gait, a burrowing of the head in the dirt, twisting it around, or actions indicating spasms of the throat, were the earliest symptoms. Some geese were observed to die within five minutes or after the first seizure." There are few chrouic cases and recoveries are not recorded. Some show no other symptom than being slower in action, and separating themselves somewhat from the flock. However, this sign is quite important when the wild nature and gregarious habit of the goose are taken into account.

$\leqslant$ 97. Morbid anatomy. The tissue changes, as given by Curtice, are as follows :

" There was considerable mucus in the throat and mouth, and a very tenacious mucus in the nose. The veins of the head were usually congested, as though the animal had died of asphyxia. This, together with spasm of the throat, indicates a spasmodic closure of the glottis. The digestive tract was found to be full of food in nearly all stages of digestion. In some cases the catarrhal products of the intestines contained petechiae. Sometimes these points were collected in more or less extensive patches. Perhaps more than half of the livers showed yellow spots of from a pin point to a pin head in size. These discolorations were found on section to extend into the substance of the liver, and were evidently dead tissue, or necroses. In one example the heart disclosed severe inflam- 
mation, both epicarditis and pericarditis being present. In one case the lungs were affected. In all, fifteen cases were examined, and from these this composite description of the postmortem appearances is drawn."

Hemorrhages on the serous membranes and punctate necroses in the liver seem to be quite characteristic lesions.

Post mortem notes.-These are a few taken from curtice's publication.

"Goose No. I. Died last night; quite fat. Right lung, ventral portion quite firm, whitish. Some flocculi of exudate in peritoneal cavity. Liver shows numerous point-like necrotic foci. Blood thick, blackish and tarry. Mucus glassy on dusky mucosae of nose and throat.

"Goose No. 2. Died last niglit. Somewhat thinner than No. I. Eicchymoses on fat in abdomen and gizzard and on heart muscle; necrosis in liver. Blood thick, tarry. Mucus in nasal passages.

"Gander No. 7. Died last night ; now cold. No well nuarked hemorrhagic lesion in pleuroperitoueal cavity. Whitish points in liver. Hemorrhagic or extremely hyperemic condition of duodenum. Jejunum, or second coil of intestine, filled with a glairy mucous fluid in which are suspended shreds and patches of food (?). Few if any necroses in liver."

$\$ 98$. Differential diagnosis. The disease here described is caused by Bacterium septicemiac hemorrhagicae which resembles that of fowl cholera and other members of that group of bacteria. A diagnosis, therefore, is made positive by finding this organism in the tissue of the sick and dead geese.

M'Fadyean has described a disease under this title causing the death of many geese in which he found the blood swarming with bacteria suggesting Bact. septicemiae hemorrhagicae but morphologically different, but which he could not induce to grow on any of several media in cultures under both aërobic and anaërobic conditions. It appears that this is a different disease from that described by Curtice.

59. Prevention. The procedure that can be suggested at present is isolation of the well from the sick, repeating the separations as often as new cases appear. The infected pens should be thoroughly disinfected before being reoccupied. 
REFERFNCES.

I. Curtice. Goose septicemia. Bulletin No. s6, R. I. Agr. Exp. Station. 1902.

2. M'FADYEAN. A remarkable outbreak of goose septicemia. lour. Compar. Path. and Therap., Vol. XV (I902), p. 162.

FOWL, TYPHOID.

- Ioo. Characterization. A specific disease of fowls caused by Bacterium sanguinarium. It is not known whether or not other species of domesticated birds are susceptible.

\$ 101. History. 'This disease was briefly described by Moore in 1895 . At that time it had been studied in but a few fowls and these the last to die in their respective flocks. In the following year other fowls were examined very carefully from two outbreaks of the disease and it is upon the data obtained in their investigation together with those procured from many produced cases that the description of the disease is based. It was described as an infectious leukemia. Further investigation, however, has shown that the excess of white corpuscles was due to a leucocytosis brought about by the infecting organism and that the disease is not a true leukemia.

It was found by Smith in I894, on Block Island, R. I. In 1898 , Dawson found it to be the cause of very serious losses among poultry near Baltimore, Md. In all of the outbreaks studied, the owners of the fowls first reported the disease as chicken cholera. In I902, Curtice investigated an outbreak in Rhode Island.

\$ I02. Geographical distribution. It was first studied in fowls taken from an outbreak in Virginia. Since then, it has been identified in Maryland, the District of Columbia, and the State of Rhode Island. There is good evidence in the numerous reports of destructive fowl diseases to believe that it is quite widespread in the United States. Thus far, there seems to be no reports of its extent in other countries. 
$\leqslant$ 103. Etiology. Moore isolated and described a pathogenic bacterium which he designated Bacterium sanguinarium. With this organism the disease has been produced in healthy fowls both by feeding cultures and by intravenous injections. Its etiological relation to the disease is, therefore, quite clearly established. It is possible that certain accompanying conditions may be necessary in conjunction with the organism to cause the disease to spread rapidly in a flock. Experimentally it did not spread from diseased (inoculated or fed) to healthy fowls when kept in the same yard.

\section{Symptoms. From the}

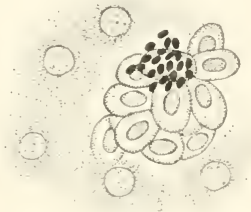

FIG. 15. A clump of Bacterium sanguinarium in a blood space in the lizer (much enlarged). statement of the owners of the diseased fowls in the different outbreaks and from the appearance of those in which the disease was artificially produced, little can be positively stated concerning the early symptoms. There is a pronounced auemic condition of the mucosa of the head. An examination of the blood shows a marked dininution in the number of red corpuscles and an increase in the number of white ones. In the disease produced artificially by feeding cultures of the specific organism there are, in most cases, a marked drowsiness and general debility manifested from one to four days before death occurs. The period during which the prostration continues varies from a few hours to two days. The mucous membranes and skin about the head become pale. There is an elevation of from $\mathrm{I}$ to + degrees in temperature. The fever is of a contintrous type, as shown in the appended temperature chart of two fowls in which the disease was produced artificially.

Although the course of the disease in different fowls is usually constant, there are many variations. The time required for fatal results is from three to fifteen days, but ordinarily death occurs in about eight days after feeding the cultures. The rise in temperature can be detected about the third 
day and external symptoms about the fifth or sixth, occasionally not until a few hours before death. The symptoms observed in the cases produced by feeding correspond with those described by the owners of affected flocks.

As indicated in the inoculation experiments, the symptoms following the intravenous injection of the virus were, as

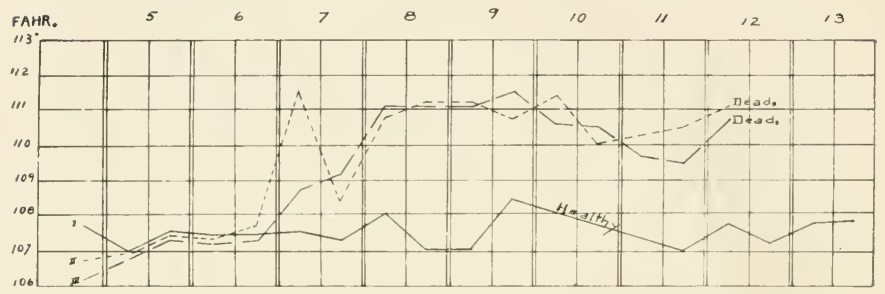

Fic, 16. Temperature chart of two fatal cases artificially produced in fouls.

would be expected, considerably modified from those fowls which contracted the disease by the ingestion of cultures of the specific bacterium.

$\leqslant$ 105. Morbid anatomy. The only constant lesions found in the fowls which contract the disease naturally, as well as in those fed upon the virus, are in the liver and blood. The liver is somewhat enlarged and dark colored. A close inspection shows the surface to be sprinkled with minute grayish areas. The microscopic examination shows the blood spaces to be distended. The hepatic cells often stain very feebly. Not infrequently the cells are isolated and their outlines indistinct. Occasionally foci are observed in which the liver cells appear to be dead and the intervening spaces infiltrated with round cells. The changes in the hepatic tissues are presumably secondary to the engorgement of the organ with blood.

The rareness with which the intestinal tract is affected in both the natural and artificially produced cases is exceedingly 
interesting and important for the differential diagnosis. There is in most cases a liyperemia of the n11ucous membrane of the colon, but this condition is not uncommon in the healthy individual. The kidneys are generally but not uniformly pale. They are streaked with reddish lines, due to the injection of blood vessels. In section the tubular epithelium appears to be normal. The kidneys seem to be, from the number of bacteria in the cover-glass preparations, especially favorable for the localization of the specific organism. The spleen is rarely discolored or engorged with blood. The lymphatic glands were not appreciably enlarged in any individual examined. The lungs except in chronic cases are normal. The brain and spinal cord are unaffected.

The heart muscle is usually pale and sprinkled witl grayish points, due to cell infiltration and necrosis. These lesions are so common that it seems safe to consider them characteristic manifestations. Death usually occurs in systole, the auricles containing very thin, unclotted blood.

The most important alterations are found in the blood. These consist, in the progress of the disease, of the gradual disappearance of the red corpuscles and increase in the number of white ones, as determined by blood counts made daily or every other day, from the time of inoculation, or of feeding the virus, until the day of death.

The dininution in the number of red corpuscles and the increase in the number of white ones are illustrated in the blood count of two cases of artificially produced disease.

In carefully heated cover-glass preparations of healthy fowl's blood stained with methylene-blue and eosin, the nuclei are colored a deep blue, and the cellular protoplasm surrounding the nuclens is stained by the eosin. In similar preparations made from the blood of the affected fowls there are a greater or less number of cells which do not take the eosin stain. These were called spindle cells by Van Recklinghausen, blood plates by Bizzozero, and hematoblasts by Hayem. More recently Dekhuyzen has called them thrombocytes. In these the portion of the cell body surrounding 
the nucleus remains unstained or becomes slightly tinted with blue. Occasionally they contain one or more vacuoles, and the margin is frequently broken. The apparent dissolving away of the red corpuscles

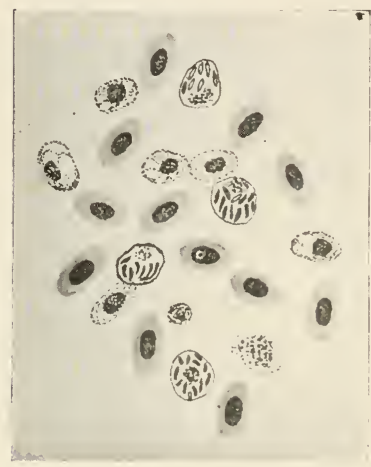

FIG. I7. Blood from a well advanced case of fowl typhoid showing red corpuscles, blood plates and increase in the number of leucocytes. has been frequently observed and corpuscles showing the intermediate stages are readily detected in carefully prepared specimens. These must be differentiated from the blood plates.

The cause of the destruction of the red corpuscles is not satisfactorily explained. In his report on fowl cholera, Salmon illustrates lencocytes surrounding the red corpuscles, but the marked diminution of the red cells was not determined. $\mathrm{He}$ speaks, however, of the pale color of the blood. In fresh preparations of the blood, portions of red cells may be seen within the leucocytes, those containing spindle shaped granules. The determination of the extent of this mode of destruction of the red corpuscles necessitates further investigation.

TABLE SHOWING CHANGES IN THE NUMBER OF CORPUSCI,

Fowl No. 82, inoculated in the wing vein, February 6.

\begin{tabular}{|c|c|c|c|c|}
\hline Date & $\begin{array}{l}\text { Tempera- } \\
\text { ture }\left(\mathrm{F}^{\circ} .\right)\end{array}$ & $\begin{array}{l}\text { Number of } \\
\text { red cor- } \\
\text { puscles. } \\
\text { per c. } 111 \mathrm{~m} \text {. }\end{array}$ & $\begin{array}{l}\text { Number of } \\
\text { white cor- } \\
\text { puscles } \\
\text { per c. } 111 \mathrm{~m} \text {. }\end{array}$ & Remarks \\
\hline Feb. 6 & 107.4 & $3,744,444$ & 21,222 & Well. \\
\hline 7 & 109 & $3,417,391$ & 26,087 & Apparently well. \\
\hline 8 & 108.2 & $2,784.700$ & 55,000 & Do. \\
\hline 9 & 108.4 & $2,807,692$ & 76,925 & Do. \\
\hline II & 107.4 & $3,481,518$ & 90,909 & Feathers ruffled; refuses food. \\
\hline 13 & 110.2 & $2,133,333$ & 100000 & Very quiet; comb pale. \\
\hline 14 & 108 & $2,530,000$ & 140,000 & Fowl died later in the day. \\
\hline
\end{tabular}


Fowl No. 5or, fed culture March 26.

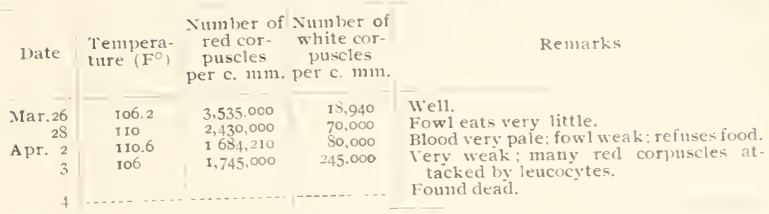

In fresh preparations of the blood of affected fowls examined in Toisson's fluid, red corpuscles which take the violet stain more or less intensely throughout are frequently observed.

In the blood of poultry two distinct classes of white corpuscles are conspicuous. The first which predominates in numbers, contains nuclei with from one to four lobes, and the cytoplasm is sprinkled with a variable number of round, elongated, or spider-shaped bodies. In the fresh condition they are highly refractory. They stain with eosin, and if the preparations are heated sufficiently they will retain certain of

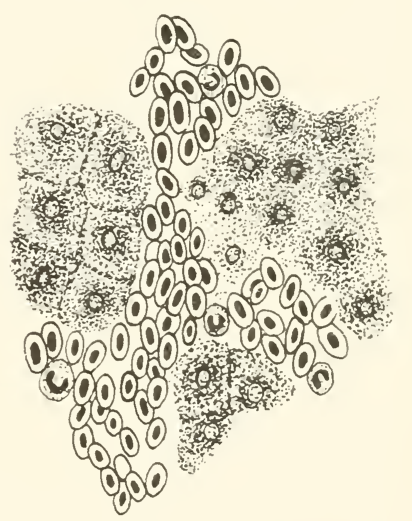

FIs. 18. Section of chicken's lizer showing blood engorgement. the aniline dyes. The other class consists of round or nearly round cells which takes the blue stain feebly. 'Tsually it is difficult to detect the nucleus, although it is occasionally distinct. Between these two types there are many varieties. The leucocytes containing the spindle-shaped bodies appear to be the phagocytes, as they were the only ones which were observed to engulf the red corpuscles. Bacteria have not been demonstrated in these cells, although their presence has, in 
several cases, been suspected. From the appearances observed in the red blood corpuscles it seems highly probable that phagocytosis plays a comparatively large part in their destruction. Another hypothesis is also suggested, namely, that a toxin produced during the multiplication of the specific organ-
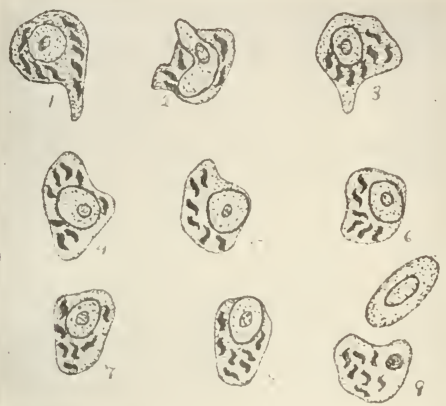

FIG. 19. The phagocytic action of the white blood corpuscles upon the red ones in advanced cases. The changes represented fron $I$ to 9 took place in 35 minutes.

these changes are entirely attributable to the phagocytes is an open question.

In the blood from healthy fowls it is comparatively rare to see one of the white corpuscles engulfing a red one. As the disease progresses, however, this warfare becomes very conspicuous, owing perhaps to the increased number of the colorless cells. Up to the present the study of these corpuscles has not been extended beyond the observations of the general ap pearance of these structures, and no attempt is made to explain the apparently marvelous increase in the number of the leucocytes. It is an interesting and as yet unexplained fact that the increase in the corpuscles is apparently restricted to those containing the spindle shaped bodies.

\$ I06. Differential diagnosis. Intestinal disturbances, 
especially diarrhea and fowl cholera, are the diseases liable to be mistaken for fowl typhoid.

A comparison of the important changes in the morbid anatomy in fowl cholera, as described by European writers, and in the disease under consideration, can be made from the appended columns, in which their more characteristic lesions are contrasted :

\section{Lesions in fowl cholera.}

I. Duration of the disease from a few hours to several days.

2. Elevation of temperature.

3. Diarrhea.

4. Intestines deeply reddened.

5. Intestinal contents liquid, mucopurulent, or blood stained.

6. Heart dotted with ecchymoses.

7. Lungs affected, hyperemic or pnenmonic.

8. Specific organisms appear in large numbers in the blood and organs.

9. Blood pale (canse not determined).

ro. Condition of leucocytes not determined.

\section{Lesions in fow'l typhoid.}

r. Duration of the disease from a few hours to sereral days.

2. Elevation of temperature.

3. Diarrhea not common.

4. Intestines pale.

5. Intestinal contents normal in consistency.

6. Heart usually pale and dotted with grayish points, due to cell infiltration.

7. Lungs normal, excepting in modified cases.

8. Specific organisms comparatively few in the hlood and organs.

9. Blood pale, marked diminution in the number of red corpuscles.

10. Increase in the number of lencocytes.

Attention should be called to the fact that as yet there seems not to have been a careful study of the condition of the blood in fowl cholera. Salmon observed many changes which may have been similar to or identical with those herein recorded. Ward found an increase in the number of white corpuscles and in some cases a decrease in the number of red ones in cases of fowl cholera.

The difference between the specific organism of these two diseases can be readily appreciated by a comparison of the 
more diagnostic properties of each; they are arranged in parallel columns, as follows :

Bacterinm of foul iholera.

Bacterium sanguinarium.

I. Bacterium short, with oval

I. Bacterium short, with ends ends. oval or more pointed.

2. It usually appears singly in tissues.

2. It usually appears in pairs united end to end or in clumps in tissues.

3. Ordinarily it exhibits a polar stain (from tissue).

3. It gives a light center, with uniformly stained periphery (from tissue). Rarely a polar stain is observable.

4. Frows feebly or not at all on gelatin.

5. It does not change milk.

4. Decided growth on alkaline gelatin.

6. Resists drying from one to three days.

7. Kills rabbits inoculated sub. cutaneously in from eigh. teen to twenty-four hours.

8. It kills fowls when injected subcutaneously in small quantities.

5. Saponifies milk.

6. Resists drying from eight to twelve days.

7. Kills rabbits inoculated intravenously in from three to five days. Rabbits inoculated subcutaneously remain well or die in from six to ten days.

8. It does not kill fowls when injected subcutaneously in small quantities.

While there are many similarities in the symptomatology of these two diseases, there are pronounced differences in the morbid anatomy and in the specific microörganisms. These facts render positive differentiation dependent upon a careful bacteriological and pathological examination. In fowl cholera the course of the disease is more rapid than in fowl typhoid.

S 107. Prevention. Prompt isolation of the well from the sick fowls and thorough disinfection of the houses and yards.

In reference to preventing its introduction, Curtice makes the following observation : 
"Inasmuch as one possible method of introducing the disease is through purchases, it will always be necessary for purchasers to enquire into the history of the flock from which additions are to be made, and especially to examine into the condition of the fowls. It is better in any case to keep new purchases by themselves for some weeks or until it is apparent that they are healthy."

\section{REFERENCES.}

1. Curtice. Fowl typhoid. Bulletins s. Agr. Exp. Station of the R. I. College of Agric. and Mech. Arts, 1902.

2. DAwson. Infectious leukemia. Annual Report of the Burean of Animal Industry, U. S. Dept. Agric., 1898 .

3. NOORE. A study of a bacillus obtained from three outbreaks of fowl cholera. Bulletin No.s, U.S. Burean of Animal Industry, I895.

4. MOORE. Infectious leukemia in fowls-A bacterial disease frequently mistaken for fowl cholera. Annual Report of the Bureau of Animal Industry, IS95-96.

\section{SWINE ERISIPELAS.}

Symony'ms. Red fever of swine; rouget; Rotlauf.

s 108 . Characterization. This disease, peculiar to swine, is determined by a rise of temperature, cerebral disturbances and pronounced reddening of areas of the skin. It is a disease of adult life. It is stated that pigs are rarely attacked under three months or over three years of age. Lydtin and Schottelius found some differences in the degree of susceptibility of certain breeds of swine. The common country pig was least susceptible.

$\$$ rog. History. This disease has been known in Europe for many years. Smith found a bacterium in rabbits inoculated with the organs of pigs that had died of an undetermined disease in Minnesota, which was either the bacterium of swine erysipelas or of mouse septicemia. The latter organism had been recorded on two previous occasions from pigs in this country. 
S 110. Geographical Distribution. Swine erysipelas is an infectious disease that occurs enzoötically and in epizoötics in most of the countries of Europe. It was formerly restricted in Bavaria to the districts along the Danube, and was entirely unknown in southern Bavaria (Kitt). It is stated that the disease tends to become enzoötic chiefly in valleys and low-lying plains which have slow-flowing streams and heary, damp, clay soil; and that sandy and granite soils are comparatively free from it. It occurs chiefly during the nonths of July, August and September, although it appears sporadically during the winter months. It has not been described from the United States.

S III. Etiology. Loeffler and Schütz

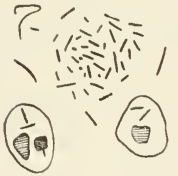

FiG. 20. Bacterium of swine erysipelas, showing free organisms and also the ir presence a'ithin the cells. pointed out in 1885 that swine erysipelas was caused by a very slender bacterium (Bact. erysipelatis suis) I to $2 \mu$ long and 0.3 to $0.4 \mu$ broad, straight or slightly curved, ends not rounded and in cultures often appearing in filaments. It is very closely related to the bacterium of mouse septicemia described by Koch in 1878 . In Europe, where the bacterium of mouse septicemia is quite common, swine erysipelas prevails. There is much uncertainty concerning the relationship of the bacterium of mouse septicemia to that of this disease. Smith has suggested that possibly the bacterium which has been found in this country may gain virulence sufficient to produce epizoötics, if such is not already the case. It is exceedingly important that careful search be made for this organism in the outbreaks among swine where the nature of the disease is not clearly determined. House mice and pigeons are susceptible to the bacteria of swine erysipelas ; guinea pigs and fowls are immune. Rabbits suffer from erysipelatous swellings when inoculated subcutaneously in the ear. The bacterium of swine erysipelas is to be differentiated from that of mouse septicemia. 
The period of incubation is stated to be at least three days. It is apparently longer than that in many cases.

S I12. Symptoms. The disease usually begins suddenly and violently. The animal refuses food, makes efforts to vomit, has a rise of temperature, manifests severe nervous disturbance, is very weak, torpid and indifferent to its surroundings. When approached it tries to hide itself under its bedding. The hind quarters become weak and paralyzed. Muscular spasms and grinding of the teeth are sometimes observed. At first there is constipation, the conjunctiva is of a dark red or brownish-red color, and the eyelids are sometimes swollen. Isually a day or two after the first symptoms develop or, perhaps, from the first, reddish spots appear on the thin parts of the skin, such as the region of the navel, lower surface of the chest, perineum, inner surface of the thighs, ears and throat. These spots, which at first are bright red and about the size of a man's hand, become, later on, dark red or purple, and soon unite into large, irregularly-shaped patches. As a rule, they are neither painful to the touch nor prominent, but sometimes they show a slight inflammatory swelling. The skin of the red spots, especially of the ears, may suffer from an eruption of vesicies and may even slough. The reddening of the skin may be very slight in serere cases, or may appear only immediately before, or even after, death. Death takes place usually on the third or fourth day. In the very serere form, the animal may die in twenty-four hours, otherwise the disease requires a week or longer to run its course.

Jensen considers that this disease, instead of being uniform in its clinical aspects, manifests itself in the following forms, which differ from each other by well-marked peculiarities. The forms recognized as varieties of this disease but more generally considered as distinct maladies and known by different names are as follows :

I. True erysipelas.

2. Swine urticaria. 
3. Erysipelas without redness of the skin.

4. Diffuse necrotic erysipelas of the skin.

5. Endocarditis of erysipelas.

He also maintains that there may sometimes be transitional forms between the respective varieties which he enumerates. Different forms of epizoötic erysipelas have also been described by Cornevin, Hess and others.

\$113. Morbid anatomy. In the ordinary form of epizoötic erysipelas there is a septicemic condition without any well marked morbid changes of separate organs. In less acute cases the septicemia may give way to hemorrhagic and diphtheritic gastro-enteritis, considerable swelling of the lymphatic system, hemorrhagic or parenchymatous nephritis, and hepatitis, acute swelling of the spleen and myositis. The hemorrhagic gastro-enteritis consists at first of excessive inflammation of the mucous membrane of the stomach in the region of the fundus. The mucosa shows a dark-red discoloration which is partly diffuse and partly in spots. The cells suffer from cloudy swelling and the mucous membrane is covered with a viscid layer of mucus. The intestinal mucous membrane is swollen, especially on the top of the folds and in the neighborhood of Peyer's patches. It is infiltrated with blood and sometimes shows superficial scabs. Less frequently, circumscribed parts of the mucosa of the cecum and the anterior parts of the colon suffer from a diphtheritic affection.

The solitary follicles and Peyer's patches appear as prominently raised patches. Sometimes they are infiltrated with blood and surrounded by a reddish band. There is ulceration and cicatrization of the solitary and agminated follicles. The mesenteric glands become more swollen than the other glands of the body, of a dark red color, and show softening. The surface of fresh sections is dun-colored with interspersed darkred areas. The paraglandular tissue is hyperemic and infiltrated with blood.

The kidneys are enlarged, the cortex of a grayish-red and 
the medullary portion of a very dark-red color. Frequently catarrhal nephritis occurs as a complication.

The acute swelling of the spleen arises in consequence of an acute hyperemia, with an increase of the cellular constituents of the pulp, in which case the organ is enlarged, but not softened as in anthrax. The pulp is of a purple color, moderately soft and free from hemorrhages.

There is cloudy swelling and enlargement of the liver. The surface of sections has a grayish-brown color, and the acini are widened. The muscles are gray in color, soft, flaccid, watery, glistening and sometimes they are sprinkled with hemorrhages. They give the general appearance of boiled flesh. The myocardium shows similar spotted changes, and punctiform hemorrhages beneath the endocardium. In the abdominal and thoracic cavities and pericardium, there may be found small quantities of an orange-colored, clear fluid, which may be mixed with a flaky coagulum.

Many English veterinarians regard the occurrence of more or less luxuriant vegetations on the valves of the heart to be so common that it is to be considered almost diagnostic. It would appear from the literature that this endocarditis is not nearly so common in continental Europe. The lungs remain unchanged, or at most exhibit a post-mortem edema. By microscopic examination, the specific bacteria are found everywhere in the body, especially in the spleen and kidneys, and to a less extent in the blood.

The duration of the disease varies from I to ro days. In types of moderate severity it runs from 3 to 4 weeks.

The prognosis is unfavorable. There is from 20 to 80 per cent mortality.

§ I14. Differential diagnosis. Swine erysipelas is to be differentiated from :

I. Hog cholera and swine plague. The frequent reddening of the skin in these diseases together with the modified lesions so frequently observed may cause confusion. The 
bacteriological examination will enable the positive diagnosis to be made. (See hog cholera and swine plague.)

2. Anthrax, which is very rare in swine. Here, too, the bacteriological examination discloses the true nature of the disease.

3. Erythemata due to various dietary causes.

The significance of a deep reddening of the skin about the head, abdomen and thighs of pigs is not fully determined. It is clear, however, that such a condition often occurs in the absence, so far as present knowledge goes, of a specific infection. It is frequently found in pigs suffering from digestive troubles, or poisoning from eating decomposed offal.

$\$$ II5. Preventive inoculation. Pasteur's preventive inoculation was until recently the chief prophylactic means employed against epizoötic erysipelas. Metchnikoff found that the blood of immunized rabbits was antitoxic, and Lorenz maintains that the serum of swine that have recovered from swine erysipelas is also antitoxic, and will produce immunity in other animals. The treatment introduced by Lorenz is to inject the inmunizing serum in the proportion of $\mathrm{I}$ cc. to every Io kilograms of the body weight of the animal. Two days afterward 0.5 to I.O cc. of virulent culture is injected, and after twelve days the dose is doubled. The use of the immunizing serum is reported to be very successful.

REFERENCES.

I. BAxG. Leber Rotlauf-Endocarditis bei schweinen. Deutsche Zeitschr.f. Thiermed., Bd. XVIII (1891), s. 27.

2. JeNSEx. Die Aetiologie des Nesselfiebers und der diffusen Hautnekrose des Schweines. Deutsche Zeitschr. f. Thiermed., I892, S. 278 .

3. LOEFFLER. Experimentelle Untersuchungen über SchweineRotlauf. Arbeiten ausd. Kaiserlichen Gesundheitsamte, Bd. I (I885), S. 46 .

4. LoRExz. Die Schutzimpfung gegen Schweinerotlauf mit Anwendung eines aus Blutserum immunisirter Thiere hergestellten Impfstoffes. Deutsche Zeitschr. f. Thiermed., Bd. XX (1894), S. I. 
5. LOREN\%. Die Veterinärpolizeiliche Behandlung des Schweinerothlaufes und die Schutzimpfung. Berliner thierarz. Wochen., 1897, ง. 574 .

6. LOREN\%. Schutzimpfungen gegen den Rotlauf der Schweine. lbid, 1897 , S. Iog.

7. MOORE: Monse septicemia bacilli in a pig's spleen witl some observations on their pathogenic properties. Jour. of Comp. Med. and Vet. Archives, Vol. XIII (1892), p. 333.

S. PASTEUR HT THUILLIER. La vaccination du rouget des porcs à Paide du virus mortel attenué de cette maladie. Comp. rondus liad. des. Sciences, Vol. XCVII ( $\left.\mathrm{IS}_{3}\right)$, p. I $6_{3}$.

9. Schit\%. Leber den Rotlauf der Schweine und die Impfung mit demselben. Arbeit a. d. Kaiserichen Gesundheistamte, Bd. I $(1885)$, S. 56 .

I0. Snuтн. An Examination of Pastenr's Vaccine for Ronget. Annual Report $U$. S Bureau of Animal Industry, IS85, p. I 87 .

11. Surrt. Swine erysipelas or mouse septicemia bacilli from an outbreak of swine disease. Annual Rept. U. S. Burean of Animal Industry, i $895-96$, p. 166.

\section{ANTHRAX.}

Synony'ms. Splenic fever; splenic apoplexy; wool sorters' disease; malignant pustule; anthracemia; mycosis intestinalis ; charbon; Milsbrand.

s I6. Characterization. Anthrax is an infectious disease occurring sporadically and in epizoötics in herbivora and omnivora and communicable to nearly all warm-blooded animals, and to man. It is characterized by the presence in the diseased tissues or liquids of Bacterium anthracis, by an enlarged spleen, blood extravasations and by local gangrene. It usually occurs in the acute form.

$\S$ II7. History. Anthrax is among the oldest of the known infectious diseases of animals. Descriptions of epidemics and epizoötics of this disease are given by Homer, Plutarch, Livy and other writers before the Christian Era. The Arab physicians designated it as "Persian Fire." Extensive outbreaks are mentioned in the literature of the fifteenth, sixteenth, seventeenth, eighteenth and nineteenth centuries. 
Chabert pointed out in 1780 that the various kinds or forms of the disease, which had previously been described as independent affections, were all one disease. As late as 1805, Kausch gave a good description of anthrax but denied its contagiousness. Delafond and Gerlach thoroughly investigated ovine anthrax in 1854 and its contagiousness was experimentally shown by Gerlach. In 1850 , Heusinger published a very comprehensive treatise on anthrax which deals at length with its history and geographical distribution.

Much new information concerning the nature of anthrax was acquired during the fifth decade of the last century.

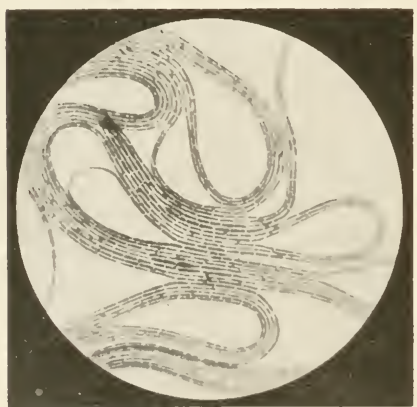

FIG. 21. Anthrax bacteria in an impression preparation made from a colony on an agar plate culture. In i 855 , Pollander announced the discovery, which he first made in 1849 , of $\mathrm{m}$ in ute unbranched rod-shaped bodies in the blood of cattle dead of anthrax. Davaine observed simi1 ar bodies in 1850 . Then followed a long series of observations and somewhat controversial discussions on the bacterial origin of the disease, culminating by Robert Koch's careful description of the morphology of its specific organism including the spore formation in 1876 (I877 Pasteur). Cohn, however, seems to have been the first to have called the organism a Bacillus and to have suspected the existence of spores. Toussaint, in 1880 , and Pasteur in I88 I, published results of investigations directed toward protective inoculation. Since that time, the literature on the cause, morbid anatomy and prevention of anthrax has become very extensive. 
S I18. Geographical distribution. Anthrax is a widely disseminated disease. The continent of Eiurope has perhaps suffered most from its ravages. It occurs, also, in Northern, Eastern and Central Africa, where in recent years it has become a great plague. In Siberia, it has caused fearful destruction, and in that country it is still known as the "Siberian Plague." It has frequently appeared in England. Russia, India and Australia are also infected. South America is also reported to suffer much from its ravages. In the United States it has been reported from at least fifteen states. In fact there are very few, if any, countries where this disease has not been found. A knowledge of its specific cause, with the methods of properly disposing of dead animals, isolation and disinfection, as well as the preventive inoculations now in vogue, have made it possible to prevent wide-spread epizoötics. In America it is looked upon as a comparatively rare disease, excepting in certain infected districts.

s Irg. Etiology. Anthrax is due to the presence of a microörganism known as Bacterium anthracis. This organism is found in the diseased tissues and organs of affected animals. On account of its spores, it is very resistant to the normal destructive agencies in nature. Consequently when it is once introduced into a locality it tends to remain there for many years, possibly causing from time to time a few cases of authrax or serious epizoötics or epidemics. The spores are also fre. quently carried in the wool, hair, hides, hoofs and horns taken from animals sick or dead of anthrax. Thus the affection has been introduced into far distant localities.

Bacterium anthracis is a rod-shaped organism varying in length from in to $4 \mu$, but having a quite uniform breadth of about one micron. In a suitable medium it grows out in long flexible filaments which combine to form thread-like bundles. When examined, the ends of the rod seem to be square cut. In preparations from animal tissues there appear sometimes to be slight concavities in the ends of the segments when two of them are united. In cultures spores are formed. These are 
oval, highly refractive bodies held within the cellular envelopes of the filaments, but later they are set free by the

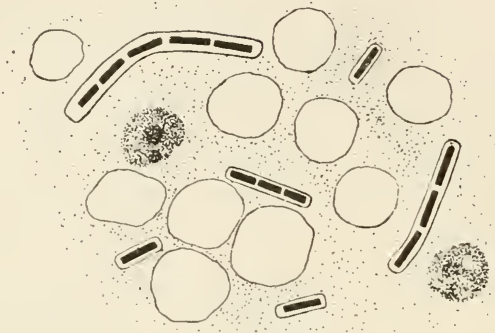

FIG. 22. Anthrax bacteria in a cover-glass preparation of blood shoa'ing chains and capsules.

dissolution of this membrane. They stain readily with the aniline dyes and also by Gram's method.

The bacterium of anthrax itself is not an especially hardy organism. On the contrary it is easily destroyed by weak disinfectants and it has a low thermal death point. Its spores, however, are among the most hardy of bacterial life to resist chemical and thermal agents. They resist drying for months or years and often boiling for a half-hour or longer does not destroy them. On this account it is very difficult to eliminate the virus from infected pasture lands, especially if they are wet or marshy.

As the spores may remain on the soil in a dormant condition for many years, it sometimes happens that the disease does not appear until long after the introduction of the virus. Anthrax has been known to break out among cattle grazing on a field in which the carcasses or hides from affected animals were buried many years before. Through some means the spores seem to be able to get to the surface and contaminate the grass. The virus may be introduced with blood or bone 
fertilizers, hides, hair or wool from infected countries. When the extent of this traffic is realized, it is easy to understand how anthrax has been brought to this country and why it occasionally appears here and there over a large part of the continent. Many outbreaks, as well as isolated cases, illustrating this common method of dissemination are on record.

The period of incubation is very short. In inoculated animals it ranges from $I$ to 5 days.

I20. Animals attacked. Nearly all species of animals suffer from anthrax. The herbivora and rodents are most susceptible. Horses and mules often suffer from it. M'Fadyean has reported outbreaks aggregating $5+$ cases, of which 49 were cattle, 4 horses and I pig. He states also that for a period of 5 years there had been reported 192 cases in horses and $3.390 \mathrm{in}$ cattle. It is interesting to note that the Algerian race of sheep are immune. A satisfactory explanation for this striking exception has not been recorded. It has been stated that a single bacterium introduced into the subcutaneous connective tissue of a guinea pig or mouse is sufficient to kill it. Cats, tame and wild rabbits and hares are the next most susceptible species. It is stated that $\operatorname{dog} s$, pigs and foxes are very slightly susceptible. Rats, fowls and pigeons are reported to be immune. Fish and amphibia are rarely attacked.

S I2I. Channels of infection. Three common modes of infection are recognized for anthrax, namely : through the digestive tract, by the skin and by the lungs. In cattle the infection seems to be largely through the alimentary canal; in horses and sheep by the skin or digestive tract; in men through wounds of the skin and the respiratory tract. Although these are the usual methods there are many exceptions with each species.

I. Infection through the alimentary canal. This is the more common mode of infection in cattle. The resulting disease has been designated by various names, among which are "intestinal anthrax," "fodder anthrax," "spontaneous 
anthrax," internal anthrax," "anthrax fever," and anthrax without external manifestations. In these cases the infecting organisms, either the spores or the vegetating bacteria themselves, are taken into the body with food or drinking water. M'Fadyean has recently shown that infected food stuffs are often responsible for the infection. It is stated that the infection takes place in most cases in the small intestine, the mucosa of which, it is stated, need not necessarily be injured. It is highly probable that the gastric juice destroys most of the bacteria while the free spores are not injuriously affected by it. In the infected districts, the spores exist at or upon the surface of the soil and possibly on the blades of grass, from which they are easily taken up by grazing animals. In lands thus infected, the specific organism has been introduced at some previous time either by the burying of anthrax animals in these fields, by the use of infected tannery or slaughter house refuse as fertilizers, by flooding from infected streams, or by the bringing of the organism in the droppings of birds or other small animals which have fed upon anthrax carcasses. It is reported that the spores will find their way to the surface even when the dead animals have been buried at a considerable depth. There has been some controversy in the writings of Pasteur, Koch and Bollinger concerning the method by which the spores reach the surface. Pasteur supposed that they were brought by earth worms from the buried carcasses. Koch believed this impossible because of the low temperature of the ground at the depth at which the animals are buried. Bollinger has shown experimentally the possibility of Pasteur's views. Karliniski and others have found that the spores of anthrax may be disseminated by slugs, insects and larvae which are found on untanned infected skins.

2. Infection through the skin. In animals, this mode of infection occurs less frequently than in man. Anthrax produced in this way is usually characterized by local manifestations known as "carbuncle disease," or "'malignant pustule." In this mode of infection the bacteria penetrate through wounds in the skin and exposed mucous membranes into the 
living tissues by means of infected utensils, the use of infected instruments, and insects, especially the house fly (Musca domestica.) Dalrymple has called attention to the spread of this disease among animals in the lower Mississippi Valley by means of the horse fly (Tabanidac). In man many cases of the disease occur from the injuries or cuts made at the postmortem of anthrax animals or by the infection of skin wounds while handling infected hides or wool. Malignant pustule is reported to be quite common among the employes of certain tanneries and upholstering establishments where hides and hair imported from infected districts or countries are used.

3. Infection through the respiratory tract. Faser, Buchner, Lemke, and other writers have shown experimentally that the disease can be produced by the inhalation of spores. In man this form of infection is quite common among the wool sorters. In Great Britain, where much foreign wool is handled, it has been reported as causing as many as 500 deaths annually. It is known as "wool-sorters' disease."

\$ 122. Symptoms. In antlirax, the symptoms vary not only in different species of animals but also in different individuals according to the location of the disease. Again there is often considerable variation when the lesions are apparently the same. The most characteristic features of the disease are the suddenness of the attack, the grave general disturbances, high elevation of temperature, a tendency to ecchymoses of the mucous membranes and local manifestations, such as carbuncles and edema of the skin, digestive disturbances, brain complications and difficult respiration.

Anthrax has been classified according to its course as peracute, acute and subacute. It has also been divided according to the site of its manifestations as anthrax with visible localization and anthrax without visible localization.

Inthrax without visible localization. This form is generally due to ordinary infection presumably by spores. It includes the peracute, acute, and subacute.

I. The peracute or apoplectic anthrax gives rise to 
symptoms of cerebral apoplexy. The animal becomes suddenly ill, staggers about for a brief period and falls. There is often a bloody discharge from the mouth, nostrils and anus. Death usually ensues in from a few minutes to an hour.

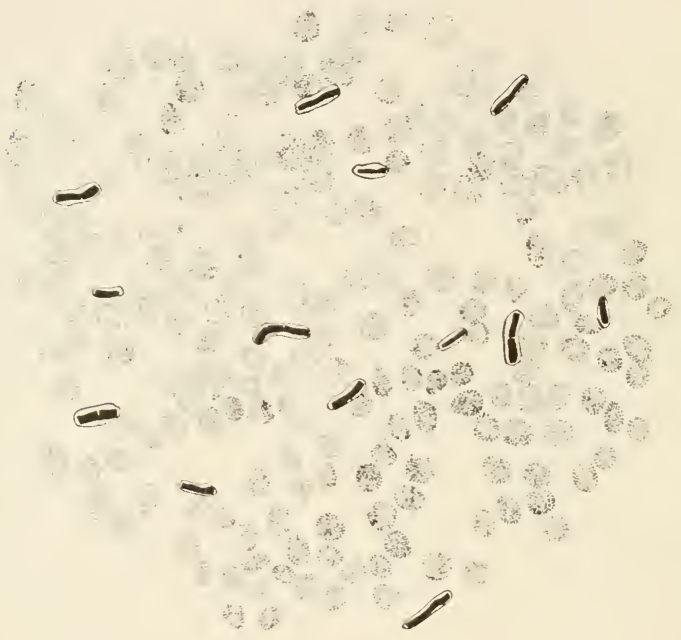

Fig. 23. A camera lucida drawing of a field in a preparation of blood from a case of acute anthra.r, much enlarged (Burnett).

Usually there are convulsions. Sheep and cattle suffer most frequently with this form of the disease. They are often found dead. This is especially true in the beginning of an epizoötic.

2. In the acute form, the disease runs a somewhat slower course, lasting usually not to exceed twenty-four hours. The temperature rises rapidly to from 105 to $\operatorname{IO}^{\circ} \mathrm{F}$. With this there are signs either of congestion of the brain or of the lungs. If the brain is affected the animal becomes restless, excited, stamps the ground, rears in the air, bellows, runs to 
and fro and finally goes into convulsions followed by stupor and death. If the lungs are congested there is difficulty in breathing, more or less wheezing, panting, groaning, palpitation of the heart, small and frequent pulse, cyanosis of the mucosa of the head, bloody discharges, hematuria, staggering and finally convulsions and death from suffocation. Occasionally there is a partial remission of the symptoms, followed by relapse. It has been observed that occasionally there are premonitory symptoms preceding the acute attack, consisting of slight digestive disturbances and diminished vivacity. Burnett found the anthrax bacteria in large numbers in the blood during this stage. He likewise found them to be present in the blood of the more chronic cases during the febrile period.

3. The subacute form is known as anthrax fever or intermittent anthrax. The symptons are the same as in the other forms, except that they are more sharply defined and the course is longer. The disease lasts from one to seven or eight days, the average being about forty-eight hours. The high temperature, the congestion of the lungs or brain complicated with intestinal disturbances, especially colic, are usually well marked. In epizoötics where the peracute or acute form ushers in the disease, the later cases usually are of the subacute variety.

Anthrax with visible localization. These forms usually result from infection of the skin and mucous membranes. The lesions are spoken of as carbuncles and often there is marked local edema of the skin. This form is common in many horses and sometimes it occurs in cattle. It is reported to occur in other species. The carbuncles are circumscribed, cutaneous swellings which are at first hard, hot and painful. Later they become cold and painless, with a tendency to become gangrenous. The edematous tissue becomes doughy, cold to the touch and painless. Frequently fluctuating swellings of the skin occur. The duration of this form of the disease varies from four to fifteen days. Ordinarily it is not so fatal as internal anthrax.

When the infection is on the mucous membrane the 
animal suffers from fever, dyspnea, difficulty in swallowing and cyanosis, together with the immediate local effects. Death occurs much sooner than when the disease is located on the skin. It is stated that dogs and swine suffer from this form more than from the acute types.

In horses, anthrax usually runs an acute or subacute course. The first symptom is rise of temperature with a rapid, feeble pulse. There may be chills and muscular spasms. The mucosa of the head becomes cyanotic and lacrymation is often present. The animal has a dull, stupid look, appears to be stunned and walks with a staggering gait. In some cases there are symptoms of cerebral congestion, such as restlessness or convulsions. Colic is a very characteristic symptom in the horse, otherwise the symptoms are the same as in cattle. Infection of the skin usually occurs on the hypogastrium, lower part of the breast, inner surface of the fore and hind quarters. Swelling of the hind quarters often causes lameness. Carbuncles of the mucous membrane of the tongue are said to be rare in this species.

In sheep and goats the disease is usually of the acute or apoplectic form. The animals appear as if suddenly stricken with apoplexy. If death does not occur within a very short time, symptoms already described for this form of the disease may be recognized. Subacute anthrax is said to be very rare in sheep.

In swine, anthrax is ordinarily characterized by local lesions on the mucous membrane of the larynx and pharynx. The animals have a rise of temperature and the intermaxillary space is generally swollen. The swelling may spread along the trachea, giving rise to difficulty in swallowing, hoarseness, cyanosis of the mucosa of the mouth, dyspnea and rapid breathing. The animal shows signs of paralysis. Death occurs from suffocation. Frequently the tongue becomes the seat of the disease. Carbuncles occurring on the skin, especially of the back, have been described in this species.

In dogs and cats, the disease usually runs a very rapid course. The fact that they are usually infected by eating the 
meat of animals dead of anthrax causes them to suffer largely from the intestinal form. It has been stated that probably much of the so-called anthrax in dogs is simply cases of ptomaine poisoning.

It is reported that iu birds anthrax usually runs a very rapid and usually fatal course. Toward the end they stagger, tremble, or go into convulsions and die with bloody discharges from the month, nostrils and anus. From the first the birds are depressed, weak, and their feathers ruffled. There is evidence of dyspnea. Carbuncles are said to appear on the comb, wattles, conjunctiva, tongue and extremities.

It has been stated that the milk from cows suffering with anthrax contains Bact. anthracis. The writer found in the examinations made in one epizoötic that the anthrax bacteria were present in considerable numbers in the milk just before or immediately after death, but they were not found in the milk of animals in the earlier stages of the disease.

\$ 123. Morbid anatomy. The nature and extent of the tissue changes depend upon the course of the disease. When experimentally produced it is ordinarily a septicemia. This form often occurs in domesticated animals when they contract the disease naturally. The more common anatomical changes, except in the most acute cases and in the strictly localized lesions or carbuncles, are :

Hemorrhages varying in amount from petechiae to blood extravasations, with more or less serous, gelatinous and hemorrhagic infiltration of the submucous, subserous and subcutaneous tissue.

The capillaries are distended and frequently there are hemorrhages beneath the epidermis. The subcutis is sprinkled with ecchymoses. Frequently there are gelatinous effusions of a rather firm consistency and of varying size. The color also differs, ranging between a deep yellow and a yellowish brown. Often these edematous areas are sprinkled with hemorrhagic foci. A simple serous edema may occur.

The lymphatic glands may be hemorrbagic, edematous 
or both. An edema of the connective tissues of the neck or about the trachea is often very marked.

The muscles vary in color but usually they are darker than normal, and like the skin, they often become sprinkled with ecchymoses. The heart muscle suffers from parenchymatous changes.

In the larger cavities of the body, a sanguinolent fluid is found in moderate quantities. Blood extravasations of different sizes are seen under the serous membranes, particularly on the mesentery and mediastinum. The subserous connective tissue, especially on the mesentery, anterior mediastinum and in the neighborhood of the kidneys, is often infiltrated with a gelatinous substance. On this account the neighboring lymph glands are considerably swollen, filled with serum and sprinkled with hemorrhages. The internal organs contain a large quantity of blood. All the larger veins and the heart are filled, while the surrounding tissues show sanious imbibition.

The spleen is usually considerably enlarged (two to five times its normal size), either uniformly or by prominent tumor-like protuberances. The pulp is soft, more or less fluid, and stained a dark red color. The capsule is always very tense. It is frequently sprinkled with ecchymoses. Occasionally this organ is slightly affected.

The liver and kidneys are highly congested and somewhat enlarged. The parenchyma contains areas of blood infiltration and the cells themselves manifest various kinds of degeneration. The portal lymph glands often appear to be enlarged, and the retroperitoneal tissue may be infiltrated with a serous, gelatinous fluid. The subperitoneal tissue of the intestines and of the abdominal walls may be similarly affected.

The nature of the lesions of the intestinal canal varies according as the disease is intestinal anthrax, or anthrax caused by inoculation. In case of inoculation anthrax, the intestine is frequently normal. In other cases there may be submucous and subserous hemorrhages, or swelling of the 
mesenteric glands. The principal changes in intestinal anthrax are always found in the small intestine, chiefly in the duodenum. In the milder cases of intestinal anthrax the mucous membrane is affected by circumscribed or diffuse swellings. The bacteria are often found in very large numbers on the surface of the mucous membrane. Necroses and ulcers appear in those parts where the bacteria are most thickly congregated. In very severe cases, the abomasum or the true stomach may be affected with a gelatinous and sanious infiltration of the mucous membrane. The mucosa of the abomasum, and especially of the duodenum, is, in consequence of excessive hyperemia, dark red or almost black, and is covered with erosions and ulcers or necroses, which may extend down to the submucosa. The contents of the intestine are bloody, and the submucosa is infiltrated with a serous, gelatinous, or hemorrhagic exudate, so that the mucous membrane often projects, in the form of large tumors, into the lumen of the intestine. On the site of Peyer's patches and the solitary follicles we may find flat or prominent nodules, the surface of which are covered with diphtheritic crusts.

The lungs are greatly congested, edematous and show areas of ecchymoses. The entire respiratory mucous membrane is considerably reddened and ecchymotic. The mucous membrane of the pharyn and opening of the larynx is often so edematous that stenosis of the larynx takes place. The contents of the trachea and the bronchi consist mostly of bloody froth or mucus.

The brain is often studded with ecchymoses. The surface of its membranes often exhibits hemorrhages with an accumulation of sanious serum in the ventricles. Extravasations of blood sometimes occur in the anterior chanber of the eye and under the retina. All the other organs may contain hemorrhages, and the urine frequently contains blood.

The blood is usually dark. It has a tarry or varnish-like lustre, and shows little tendency to coagulate. It does not assume its normal red color when exposed to the air. Burnett studied the blood of a few cases of anthrax in r9o4. The appended tables are taken from the results of his examinations. 
RESULT OF THE EXAMINATION OF THE BLOOD OF FIVE CASES OF ANTHRAX IN CATTLE.

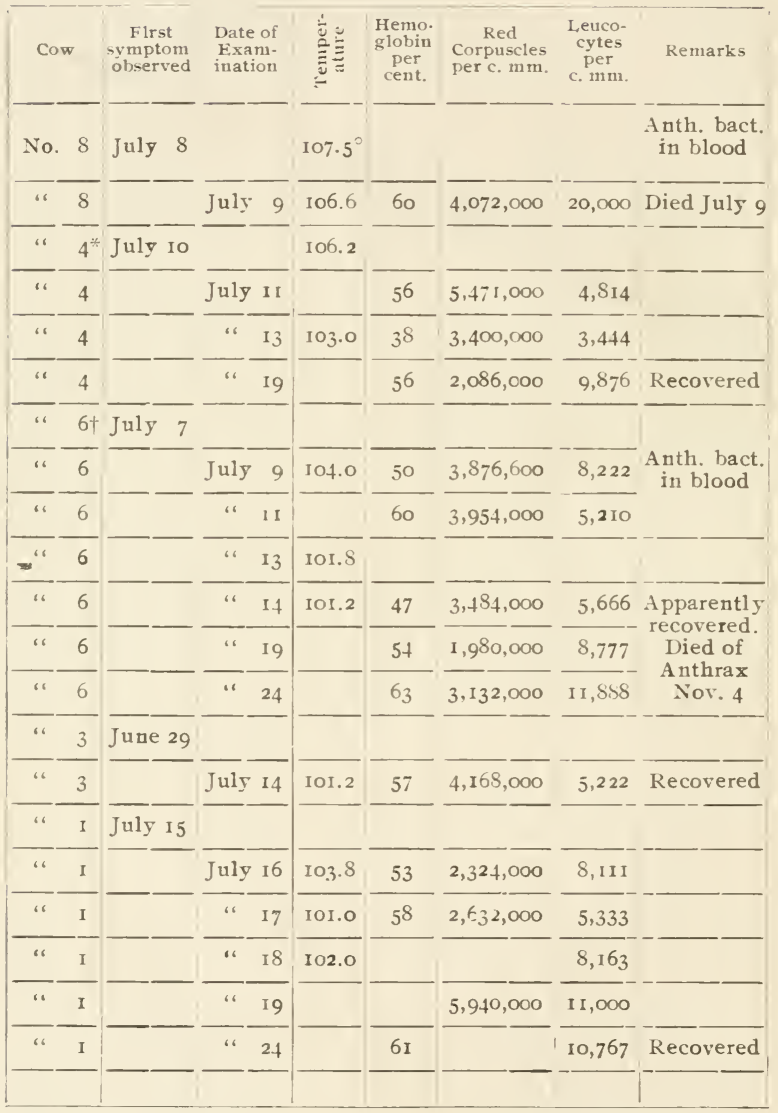

*Temperature July 8, I02, ${ }^{\circ}$. $\div$ Temperature July $S$, $107.4^{\circ}$.
Temperature July 10, $100.0^{\circ}$. Temperature July 9, $103.0^{\circ}$. 
THE DIFFFRENTIAI, COUNT OF TIE LEUCOCYTES IN FIVE CASHS OF ANTHRAX IN CATTLE.

\begin{tabular}{|c|c|c|c|c|c|c|c|c|c|c|c|c|c|}
\hline \multirow[t]{2}{*}{ Cow } & \multirow{2}{*}{\multicolumn{2}{|c|}{ Date }} & \multirow{2}{*}{ 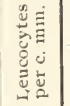 } & \multicolumn{2}{|c|}{$\begin{array}{c}\text { I.ympho. } \\
\text { cytes }\end{array}$} & \multicolumn{2}{|c|}{$\begin{array}{c}\text { Iarge Mono } \\
\text { nuclear }\end{array}$} & \multicolumn{2}{|c|}{$\begin{array}{l}\text { Polyunc- } \\
\text { lear }\end{array}$} & \multicolumn{2}{|c|}{$\begin{array}{l}\text { Eosino- } \\
\text { philes }\end{array}$} & \multicolumn{2}{|c|}{$\begin{array}{l}\text { Mast } \\
\text { Cells }\end{array}$} \\
\hline & & & & No. & $\%$ & No. & $\%$ & No. & $\%$ & No. & $9 / 0$ & No. & $\%$ \\
\hline $\begin{array}{l}\text { Soper } \\
\text { No. } 8\end{array}$ & July & 9 & 20000 & 7050 & 35.4 & 2200 & I I.O & 7120 & 35.6 & 3520 & 17.6 & 80 & 0.4 \\
\hline " 4 & " & IO & & & 27.4 & & 5.2 & & 64.8 & & 2.8 & & 0.2 \\
\hline 64 & " & I I & $4 \mathrm{~S}_{\mathrm{I}} 4$ & 1670 & $34 \cdot 7$ & $34 \mathrm{I}$ & $7 \cdot 1$ & 2200 & $45 \cdot 7$ & 548 & I I. 4 & 48 & 1.0 \\
\hline "6 6 & $" 6$ & I3 & 3444 & 1432 & 41.6 & $26 \mathrm{I}$ & 7.6 & 1667 & 48.4 & 75 & 2.2 & 7 & 0.2 \\
\hline "6 "6 & "، & 19 & 9876 & 4257 & $43 . I$ & 273 & 2.7 & 4696 & $47 \cdot 5$ & 636 & 6.4 & I I & 0.2 \\
\hline " 6 & $" 6$ & 9 & 8222 & 3930 & 47.8 & 296 & 3.6 & 3436 & 41.8 & 5 IS & 6.3 & $4 \mathrm{I}$ & 0.5 \\
\hline "6 6 & "6 & II & 5210 & 2287 & 439 & $33^{8}$ & 65 & 2 I I 5 & 40.6 & $43^{2}$ & 8.3 & 36 & 0.7 \\
\hline 66 & $"$ & 13 & & & 40.1 & & 4.0 & & 47.2 & & 7.8 & & 0.7 \\
\hline " C & "، & 14 & 5666 & 833 & 50.0 & I 19 & 2. I & 2221 & 39.2 & 430 & 7.6 & 62 & I. I \\
\hline 66 & “6 & 19 & 8777 & 3747 & 42.7 & 263 & 3.0 & 2800 & 31.9 & 1930 & 220 & 35 & 0.4 \\
\hline $6 \quad 6$ & $" ،$ & 24 & 11888 & 6033 & 50.7 & 698 & 5.8 & 3120 & 26.2 & I946 & I6.3 & Sg & 0.7 \\
\hline " 3 & "6 & I 4 & 5222 & $335^{2}$ & 64.2 & $26 I$ & 5.0 & I 45 I & 27.8 & 146 & 2.8 & IO & 0.2 \\
\hline $\begin{array}{c}\text { Bradish } \\
\text { No. I }\end{array}$ & $"$ " & 16 & 8 I I I & 3528 & 43.5 & I 54 & I. 9 & 3033 & 37.4 & 1330 & 16.4 & 65 & o. \\
\hline " & " & I 7 & 5333 & 2832 & 53.1 & 256 & 4.8 & I 368 & 29.4 & 640 & 12.0 & 36 & o. 7 \\
\hline " " " & " & I 8 & $8 \mathrm{I}_{3}$ & 6375 & 78.1 & ${ }_{13} 8$ & I. 7 & $9 I_{4}$ & IX.2 & 734 & 9.0 & & \\
\hline " " & $" 6$ & 19 & IIOOO & 66 II & 6o. I & 253 & $2 \cdot 3$ & 2585 & 23.5 & 1496 & I 3.6 & 55 & 0. \\
\hline " " & a & 24 & 10767 & 159 & 54.9 & 484 & 4.5 & 2186 & 20.3 & & 19.5 & 186 & \\
\hline
\end{tabular}

He found that the number of red corpuscles and the percentage of hemoglobin are reduced. In the chronic cases they tend to return to the normal condition. There was an increase in the number of lymphocytes and a decrease in the number of polynuclear leucocytes. In some cases there was a 
marked increased in the number of eosinophiles. No change from the normal was noted in the large mononuclear lencocytes or in the mast cells.

The bodies of animals which have died from anthrax are often well nourished. Rigor mortis is absent and they decompose quickly. Very frequently blood flows from the natural openings of the body, and the rectum is sometimes prolapsed.

All the foregoing lesions may be absent in very acute apoplectic cases. The specific organism is, however, always present in the cadaver. It is important to note that occasionally the usual changes indicated by the symptoms and the duration of the disease are not found on post-mortem examination. In one epizoötic, the writer saw an animal dead from subacute anthrax in which the blood and tissues were teeming with anthrax bacteria, yet the organs examined macroscopically appeared to be normal. Other animals in the same outbreak exhibited the more usual anatomical changes.

The period of duration varies from a few hours to a week or even longer.

The prognosis is unfavorabie. In some herds the mortality is 100 per cent while in others a number of animals may recover. The average mortality is placed at about 70 per cent in animals. In the human species many persons recover from its local form (malignant pustule).

I'Fadyean has reported this disease in 39 consecutive outbreaks in which a total of 54 animals died. In New York the disease existed in $190+$ in 15 herds in one locality. There were more than 30 deaths. In one herd of 21 animals, 20 had the disease, 16 died and 4 recovered. In another dairy 4 out of 7 died, but in the others one or two animals in each was affected. In 1906 anthrax occurred on 84 different farms in the same county. There were r 70 fatal cases of which 33 were in horses, I 23 in cattle, I I in sheep, and 3 in hogs (Burnett). These facts are interesting in showing that the disease does not a1ways cause heavy losses in the infected herds. 
I24. Differential diagnosis. It is important not to confuse anthrax with a number of non-specific disorders and accidental causes of death. The suddenness of the attack, and in very virulent cases, the short duration of the disease may tend to the mistaking of it for poisoning, cerebral apoplexy, pulmonary congestion, heat apoplexy, death from lightning, or acute gastro-intestinal inflammation. The affection known as corn-stalk disease is not infrequently taken for anthrax and iice versa. In all of these cases the doubt following the postmortem can be easily settled by a bacteriological examination which, with genuine anthrax, will reveal the presence of $\mathrm{Bac}$ terium anthracis. It is believed by those who have dealt most with anthrax, that the specific organisms are always in the circulating blood before death. The putrefactive organisms that resemble Bacterium anthracus morphologically do not appear in the cutaneous blood as quickly after death as they do in the organs.

There are, however, certain specific diseases from which anthrax must be differentiated. The most important of these are symptomatic anthrax (black leg), malignant edema, and septicemia hemorrhagica. Rabies is not infrequently taken for anthrax. If the diagnosis cannot be determined by the anatomical changes (which can be relied upon only in somewhat typical cases) the positive diagnosis can be made only with the finding of the anthrax bacteria. In animals just dead, where decomposition has not begun, these organisms can usually be found in properly stained cover-glass preparations made directly from the blood or tissues. After decomposition begins to take place, a putrefactive organism, that is not easily distinguished from that of anthrax, often appears in the tissues. It is, therefore, necessary in such cases to resort to culture methods before a positive statement can be made. As the bacilli of malignant edema and symptomatic anthrax are anaërobes, they will not develop in aërobic cultures, such as on slant agar or in bouillon. The bacterium of septicemia hemorrhagica, being a small oval organism, is easily told from that of anthrax. It is important to recognize the possi- 
bility of error, if the conditions restrict the examination to the study of the microscopic preparations.

Differential stain. II'Fadyean has described a peculiar staining reaction, first pointed out by Heins, which he considers of value for the microscopic diagnosis of this disease. The reaction is in evidence when films of blood, exudates, or tissue juice containing the bacteria are stained with a simple aqueous solution of methylene blue. The method as applied to blood is as follows:

Place a drop of the blood on a clean slide. The size of the drop should be about $2 \mathrm{~mm}$. in diameter. It is spread quickly with a platinum needle until it covers an area about I $2 \mathrm{~mm}$. in diameter. Protect from dust and allow the slide to remain until all evidence of moisture has disappeared. When dry, heat the preparation by lowering it film upwards into the flame of a Bunsen burner or au alcohol lamp for a second. Repeat this three times or until the glass is too hot to be borne by the skin in the palm of the hand. Allow the slide to cool and then cover the film with I per cent aqueous solution of methylene blue. After a few seconds pour off the free stain and wash the slide thoroughly in tap water. Dry the slide by pressing it gently between two layers of bibulous paper, and then more thoroughly by holding it in the current of hot air above the Bunsen flame. Finally, mount in Canada balsam.

The microscopic examinations ( $x 800$ to 1000 ) will show an occasional leucocyte and the anthrax bacteria. There will appear no other visible formed elements. The nuclei of the corpuscles generally exhibit a greenish-blue tint, the anthrax rods are stained blue. The intensity of the stain depends upon the length of time after death before the films were made. Usually the segment character of all but the shortest rods will be apparent. If they are deeply stained this is not very distinct. The peculiarity in the reaction lies in the color of the amorphous material which is present between and around the bactcria. This material presents itself under the form of coarse or fine granules of a violet or reddish-purple color, which is in sharp contrast to the tint of the bacteria or cell nuclei, espec- 
ially with brilliant lamp or gas light. These violet granules differ a good deal in form and size; sometimes they are very minute, and at others coarsely granular. When the bacteria are arranged in clumps the violet material is often in greatest amount about them. Free-lying anthrax rods will be surrounded by a thick envelope of the same substance. M'Fadyean states that he has never found this reaction in animals dead from other diseases. The peculiar coloring, he states, in some cases may be observed without the aid of the microscope.

125. Protective inoculation. Toussaint was the first to make use of protective inoculations in anthrax. He heated defibrinated anthrax blood to a temperature of 50 to $55^{\circ} \mathrm{C}$. for from 15 to 20 minutes, then injected it as a protective agent. Pasteur, however, was the first to prove that immunity could be obtained by the use of cultures of attenuated bacteria. Several methods of attenuating the specific organisms have been proposed by Pasteur, Toussaint, Chaveau, Chamberland, Arloing and others.

Pasteur's method consists in inoculating the animal with a small quantity of culture which has been grown at a high temperature- $t^{2}$ to $43^{\circ} \mathrm{C}$. - for several days. This deprives the bacteria of their virulence. To strengthen the resistance, the animals are again inoculated with a stronger virus. After the two inoculations, they are said to be protected against the most virulent anthrax; but the immunity is of short duration. Chamberland reported in 1894 that a total of $1,988,677$ animals had been treated by this method in France, and that the loss from anthrax had diminished from ro per cent in sheep and 5 per cent in cattle to less than I per cent. Cope, in his report to the English Board of Agricuiture, regards the conclusions of Chamberland as somewhat fallacious, because in order to prove that the animals inoculated received immunity, it should be shown that they were subsequently exposed to the risks of natural infection. The excellent work which has been done by Neal and Chester, at the Delaware College Experiment 
Station, has shown the possible efficiency of this method. Of the 331 cows which they vaccinated against anthrax, two died of the disease, giving a death rate of less than I per cent and this in a territory so saturated with the virus that it was practically impossible to keep cattle at all before its use.

A more critical study of the reports on the use of this vaccine shows that while success can not be denied, failures must be admitted. It is reported both in England and Germany that the Pasteur vaccine has not been a marked success. In England, Klein, who tested the raccine used in that country, found that if the animals did not die from the effect of the vaccine, they did when exposed to the disease. The German veterinarians and agriculturalists agree that the first vaccine is mild and harmless, but that the second vaccine, even in the hands of experts, is dangerous and often fatal. In the state of Illinois a number of cattle died of anthrax inmediately after receiving the second vaccine, and in Manitoba a large number (about 500) of sheep died after the second vaccination (Higgins). In these cases the vaccine used was not sufficiently attenuated. In a recent outbreak in the state of New York the animals that were vaccinated, but not carefully isolated from the infected pastures, continued to die of the disease after the second vaccination. This was due to the excessive attenuation of the vaccine. In the summer of rigo 7 a large number of cattle in an infected territory were vaccinated with very good results. On a few farms, all of the unvaccinated cattle died of anthrax, while the vaccinated ones reniained well. It is reported to have been demonstrated by experiment that the virulence of the attenuated virus can be easily restored. Again, it has been shown by the investigations of Chester and Neal, of the Delaware College Agricultural Experiment Station, that a vaccine which succeeded at one time subsequently proved fatal. The vital objection to this method is, that it requires the use of the living bacteria, which later may become virulent and consequently cause a subsequent outbreak. The scattering of pathogenic organisms, even in an attenuated condition, should be avoided if possible. 
It must be admitted, however, that Pasteur's method has done much good and helped to rob anthrax of much of its former terror, especially for the farmers of Europe. In America the spread of anthrax has been checked in many districts by its use. Dalrymple has pointed out its success in the lower Mississippi valley. Notwithstanding, it is highly probable that the spreading of a knowledge of the specific cause of this disease with that of the proper disposition of dead animals has also exerted much influence for good in checking its ravages.

In Germany and England the stamping-out system is considered superior to vaccination. According to Crookshank, in England it is regarded as the only reliable means of suppressing the disease. To this end rigid laws have been enacted. In this country as rigid measures as possible for its eradication seem infinitely better than the general adoption of methods for establishing a tolerance for its existence.

s 126. The simultaneous method. This method which consists in the injection of anthrax antitoxin or serum together with a small quantity of virulent anthrax bacteria, has proven to be very satisfactory. It has the advantage of being administered at one time. This method of protection against anthrax seems to have been first proposed by Sobernheim in 1899 . Since that time Sclavo in Italy and others have published on the method. Sobernheim reports excellent results by the use of this method in immunizing cattle against anthrax in South America. The serum is now produced in large quantities in Germany. In this country, it is just beginning to receive attention.

$\$$ 127. Prevention. In all cases the well animals should be removed from the barns or yards containing the sick ones and from pasture lands on which the sick became infected. The temperature of healthy and uninfected animals should be taken morning and evening for from one to two weeks after they are removed and all of those showing an elevation of temperature should be isolated. By careful isolation and safe disposition of the dead animals the spread of the disease can be 
checked. Animals do not, as a rule, spread the virus when the first symptom (rise of temperature) can be detected. All infected stables and yards should be thoroughly disinfected.

The disposition of dead animals in an outbreak of anthrax is a matter of much importance. In all cases they should be burned if possible, if not, they should be buried deeply and covered with quick lime before the dirt is replaced. The ground over the place where they are buried should be fenced in to prevent other animals from grazing over it, and the surface should be burned annually for some years to destroy spores should they be brought to the surface.

\section{REFERENCES.}

r. Burnitit. On the control of an outbreak of anthrax. $A m$. l'et. K'er'iezi'. 1908.

2. Chester. Anthrax, bacteriological work. Report Del. Agr. E.1.pt. Station, 1895, p. 64 .

3. Chester. Protective inoculation against anthrax. Proceedings of the Society for the Promotion of Agricultural Science, 1Sg6, p. 52.

4. DALRYMPLE. Anthrax and protective inoculation in Louisiana. Proceedings of the Am. Vet. Med. Assn., 1901, p. 147.

5. Davaine. Recherches sur les infusoires du sang dans la maladies connue sous le nom de sang de rate. Compt. Rend. de l' Acad. des $S_{c} .1863,1864,1865$.

6. Koch. Die Aetiologie der Milzbrand-Krankheit begründet auf die Entwickelungsgeschichte des Bacillus Anthracis. Cohn's Beitr. zur Biol. der Pflanzen, Bd. II (1876), \$. 277 .

7. M'Fadvean. Anthrax. Jour. Compar. Path. and Ther., Vol. XI (I898), p. 51 .

8. MFADYEAN. A peculiar staining reaction of the blood of animals dead of anthrax. Jour. of Compar. Path. and Ther., Vol. XVI (I903), p. 35 .

9. M'FADYEAN. Extraneous sources of infection in outbreaks of anthrax. Jour. Compar. Path. and Ther., Vol. XVI, p. 346.

IO. MoOre. Report of an outbreak of anthrax. Annual Report, Commissioner of Agriculture of the State of New York. I897.

I1. PASTEur, Chanberland ET Rovx. De l'attenuation des viruset de leur retour à la virulence. Comp. Rend. de ' Acad. des Sc., Vol. NCII (I88I), p. 427. 
12. PASTECR. La vaccin du charbon. Ibid. p. 666.

13. RisSELL. Outbreak of anthrax fever traceable to tannery refuse. The I,th annual report of the Wis. Agric. E.tp. Station, 18sig.

14. SOBERNHE1M. Ueber das Milzbrandserum nnd seine praktische Anwendung. Deut. med. Wochenschr., 1904. No. 26 11. 2\%. (First publication. Zeit. für Hrgiene, IS99. Bd. 31 ).

\section{GLANDERS}

Sinony'ms. Malleus; farcy ; mor'e; Rotzkrankheit.

\$ 128. Characterization. Glanders is one of the most important diseases of horses, asses and mules and when transmitted to man, one of the most fatal diseases of the human species. It runs an acute or chronic course, attacking the lymphatic system more especially in the upper air passages, lungs or skin. The disease is characterized by a strong tendency to the formation of small neoplasms or nodules which are likely to degenerate into ulcers from which exudes a peculiar sticky discharge. In the very acute cases a considerable rise of temperature and general debility may accompany the formation of the lesions. Glanders of the skin is known as farcy.

By direct inoculation several species of animals may be infected. Thus the disease has been reported in goats, rabbits, sheep, guinea pigs, field mice, and several of the wild animals, especially those of the cat tribe. Swine and pigeons are very slightly susceptible. Cattle, white mice, rats and domestic fowls seem to be immune.

I29. History. The theory of the contagiousness of glanders was much doubted at the begiuning of this century. The view taken by the veterinarians at the Alfort Veterinary College was that glanders might arise spontaneously from an attack of strangles. This view was far more widely accepted than the theory of its contagiousness, which was stoutly supported by the authorities at the Veterinary College of Lyons. It was not until Rayer (1837) had demonstrated the transmissibility of glanders to man, and Cliauveau (I86S) had 
shown that the virus was contained chiefly in the firm component parts of the infective material, that the fact of the infectious nature of the disease was accepted.

The theory of the spontaneous origin of glanders was widely accepted in Germany. Sixty years ago it was believed that glanders could be produced by the injection of pus, and that strangles could develop into glanders. Glanders was looked upon as a tubercular disease, scrofula, pyemia, diphtheritis, general dyscrasia and cachexia respectively. Virchow was the first to declare that the nodules of glanders were independent, anatomical formations, which he placed under the heading of granulation tumors. Gerlach was the strong adrocate for the exclusively infectious origin of the disease. Leisering appears to have been the first to give an accurate description of the lesions.

The first biological researches into its nature were made in 1868 by Zurn and Hallier, who found a fungus which they believed to be its cause. In 1882, Loeffler and Schütz succeeded in finding the bacterium of glanders, in cultivating it, and in transmitting the disease to other animals by inoculating them with pure cultures of the organism. Their researches furnished the positive proof that glanders is a specific, infectious disease, produced exclusively by Bacterium mallei.

\$ 130. Geographical distribution. Glanders exists in the greater part of the civilized world. It is more common in the temperate zones, where traffic in horses is active. In the United States it was largely confined to the Northern States before r 86 r, but it spread over the South in connection with the civil war. It is said to have entered Mexico with the American cavalry in 1847 . Similarly, Portugal is said to have been exempt until the invasion by Napoleon in 1797 . Central Hindoostan was said to be free from it until the war with Afghanistan in 1878 . In all these cases, the movements of cavalry, artillery and of commissary trains were responsible for the introduction of the disease into new territory. In our own case the sale of horses and mules at the close of the civil 
war produced a very general diffusion of this disease, from which the country is still suffering.

Insular places, especially if far from the main land and free from importation of horses, usually escape. Thus glanders is very rare in Iceland and in the Faroe islands. In Australia, Tasmania and New Zealand it is reported to be unknown.

S 131. Etiology. Bacterium mallei, the specific cause of glanders, was discovered and isolated in pure culture almost at the same time ( 1882 ) by Loeffler, Schüt $z$, Israel, Bouchard, Charrin. Weichselbaum, Kauzfeld and Kitt. It is found in the recent nodules, in the discharge from the 11ostrils, pus from the specific ulcers, and occasionally in the blood of animals affected with glanders.

Morphologically it is a small organism with rounded or pointed ends. It varies in breadth from $0.25 \mu$ to $0.4 \mu$ and from $1.5 \mu$ to $3 \mu$ in length. It is usually single but pairs and long filaments, especially on potato cultures, are not rare. It frequently breaks into short, almost coccus-like elements. Galli-Valerio found great variations in its morphology when grown under certain different conditions. Branching forms were numerous.

It stains with some difficulty. Of the aniline colors, the best results are obtained with the aqueous solutions, when they are made feebly alkaline. It is decolorized by Gram's method.

It grows well, but slowly, at the body temperature on glycerin agar, in acid-glycerin bouillon, on blood-serum aud on potato.

Of the test animals, guinea pigs and field mice are the most susceptible. In guinea pigs, subcutaneous injections are followed in four or five days by swelling at the point of inoculation and sloughing of the skin, which are followed by the formation of a chronic, purulent ulcer. The ly mphatic glands become inflamed and symptoms of general infection develop in from two to four weeks; the glands suppurate and in males the testicles are involved. A purulent inflanmation of the joints may occur. The formation of the specific ulcers upon 
the nasal mucous membrane, which forms one of the characteristics of the disease in the horse, rarely occurs in the guinea pig as a result of inoculation. The disease is often prolonged for several weeks or months. Guinea pigs succumb usually in from eight to ten days when injected into the peritoneal cavity with a virulent culture. In males, the testicles are invariably affected.

The period of incubation is not generally known. It evidently varies from a few to many days.

532. Symptoms. Two forms of glanders have been recognized, namely, acute and chronic.

Acute glanders. Acute glanders is common in the ass and mule, but infrequent in the horse. After a short period of incubation the animal has a chill, elevation of temperature, a profuse muco-purulent, sticky discharge, sometimes mixed with blood, from the nose. Particles of food arrested in the pharynx occasionally appear in the nasal dișcharge. If unilateral the margin of the nostril swells, the mucosa is dark red, infiltrated, marked with pea-like, yellowish elevations with red areolæ, which in a few days become eroded, thus forming spreading ulcers. The submaxillary lymphatic glands on the affected side become enlarged. There may, however, be a uniform swelling of the intermaxillary space. The course is rapid and death ensues in from the sixth to the fifteenth day. The acute form rarely if ever becomes chronic.

Chronic glanders. In the horse, this form of the disease may begin with a chill but usually the onset is very insidious. There may be a muco-purulent, sticky discharge, sometimes streaked with blood, from one or both nostrils. There may be intermittent or continued lameness, arthritis, edema of a limb, swelling of a testicle, cough, or epistaxis. There is usually a nodular but comparatively painless swelling of the submaxillary lymph gland on the affected side. On palpation the swelling imparts a sensation suggestive of a number of peas. They are adherent to the adjacent structures. The nasal mucosa is congested, of a dark reddish color and 
sprinkled with superficial or deep ulcers either clean or covered witl crusts.

Rarely the submaxillary glands only are apparently diseased. In other cases, there is only a congh, the latent lesions being confined to the lungs. In still other cases, the lesions are restricted to one or both testicles, the spleen, or some other internal organ. Objective symptoms may or may not be present. Chronic glanders may terminate in the acute form.

In chronic, cutaneous glanders, with or without edema of the limbs, there may be one or many nodules on the fetlock, or elsewhere on the line of the lymphatic ressels, with induration of the lymphatics extending from it. The nodules may be suppurating and discharging, or they may be closed.

\$ 133. Morbid anatomy. In chronic glanders the most frequent locations of the lesions are on the respiratory mucous membrane, in the lungs, $1 \mathrm{ymph}$ glands and skin. M'Fadyean states that he has never seen a case of glanders in which the lungs were not affected if any lesions were found. Other organs are more rarely invaded. The mucous membrane of the upper respiratory passages is the usual seat of the lesions. Glanders occurs in two forms, (I) as circumscribed nodules with the formation of ulcers and cicatrices; and (2) as diffuse or infiltrated lesions.

In nodular glanders, which is the common form, the lesions are most frequently situated on the upper portion of the nasal septum and in the cavities of the turbinated bones. The affection begins with the appearance of nodules varying in size from a grain of sand to a millet seed. They are more or less translucent, of a roundish or oval shape, and of a dirty gray or grayish-red color. The nodules, which may attain to the maximum size of a pea, project somewhat above the surface of the mucous menbrane. They are surrounded by a reddish ring. Some of them are isolated and others are arranged in groups. Microscopically they cousist of a large number of lymphoid cells, which disintegrate in the centre of the nodule. In consequence of the central fatty and purulent 
degeneration, the nodules become yellowish in color, discharge and form ulcers. These ulcers are sometimes super-

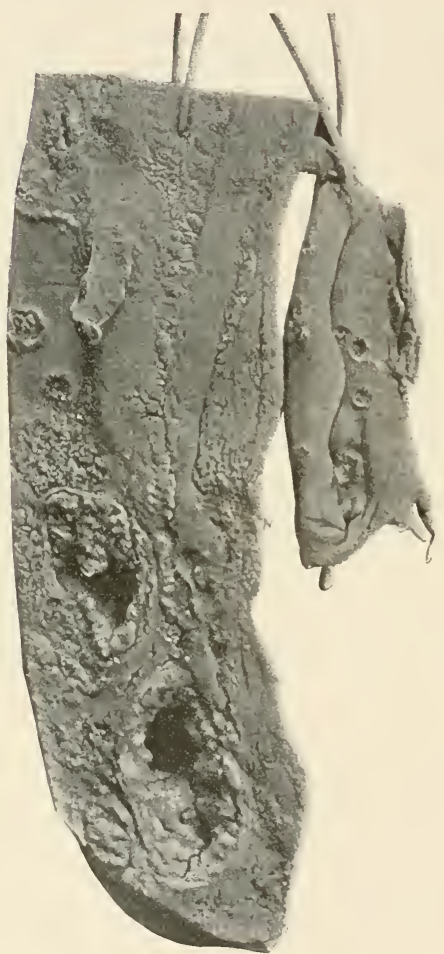

FIG. 24. Nasal septum and portion of turbinated bone showing glanders ulcers with two perforations (W'illiams). ficial, sometimes deep, lenticular or crateriform, surrounded by a hard, indurated edge, and frequently becoming confluent, with irregularly serrated and eroded edges. They are sometimes corered with a brownish crust. The ulcers may increase in area or in depth and may even involve the underlying cartilage or bone, causing perforation of the septum nasi, and distensions of the maxillary or exostoses on the turbinated bones. The shallow lenticular ulcers may heal without leaving any visible changes; but the deeper ones, after granulating, leave a radiating, star-shaped cicatrix which is either smooth or horny, and which, according to the shape of the ulcer, may be of an irregular or oblong form. The nasal septum is frequently covered with these scars. The ulcers and cicatrices are some- 
times found in the maxillary and frontal sinuses, in the guttural pouches and in the eustachian tubes. They may also occur in the larynx, especially in the region of the vocal

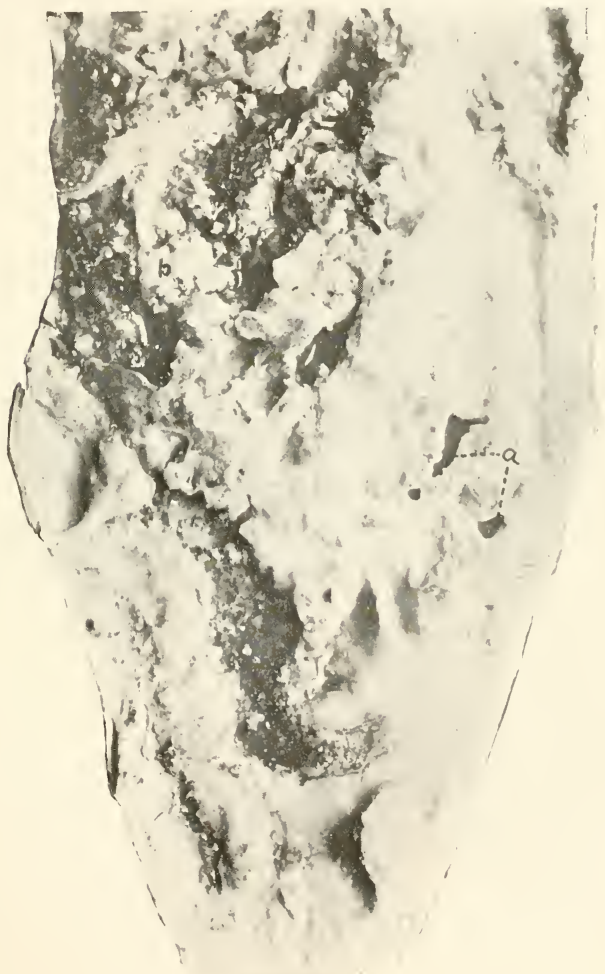

F16. 25. Photograph of a portion of a nasal septum shou'ing ulcers in advanced glanilers: (a) perforations of septum, (b) conflucnt ulcers and necrotic tissue. 
chords. In the trachea and even in the bronchi, particularly

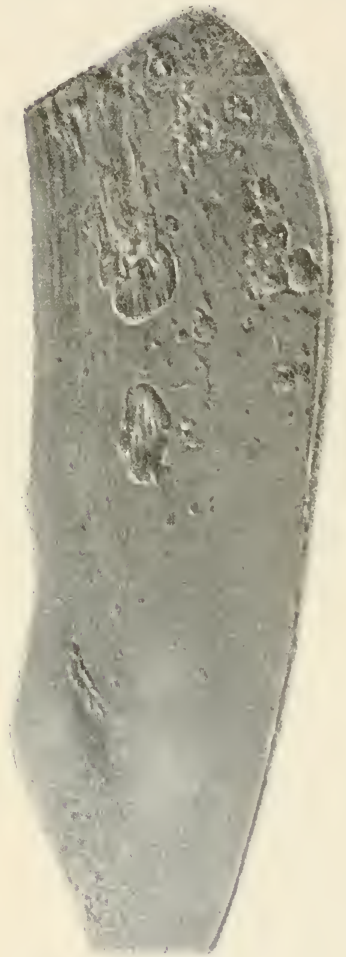

FIG. 26. Nasal septum from a glandered horse showing two large scars and several smaller recent healing ulcers and scars (Williams). on the anterior surface, numerous long, oval ulcers or long, pointed, serrated scars are frequently found. In addition to the ulcers, a catarrhal inflammation of the mucous membrane is very apt to be present.

Diffuse glanders manifests itself as a diffuse catarrh of the inucous membrane of the nasal and neighboring cavities, with superficial ulceration, thrombosis of the veins, inflammatory infiltration of the submucosa. considerable thickening of the mucons membrane and the formation of a peculiar, radiating cicatrix.

Both the nodular and infiltrated forms are found in the lungs.

In the nodular form, the lungs contain nodules* varying in size from a millet seed to a pea. They are gray by transmitted

*Nocard showed that when glandered horses are treated with mallein, a certain proportion of them recover, in which case nodules that are present in the lungs cease to contain living bacteria, a fact he has fully proved by inoculation. On postmortem examination the nodules may be readily felt by passing the hand with firm pressure over the surface of the lung, which, when badly diseased, will feel like a bag full of shot or peas. 
light, glassy and pearl gray by reflected light, and are surrounded by a congested or a hemorrliagic ring. The center of the nodules shows a pale yellow point in consequence of caseation and disintegration of the innermost cells. These nodules are of different sizes, of varying numbers, and of different ages. The formation of a capsule by a comnective tissue membrane is induced by a reactive inflammation in the tissue surrounding the nodule. The nodules may be of an embolic

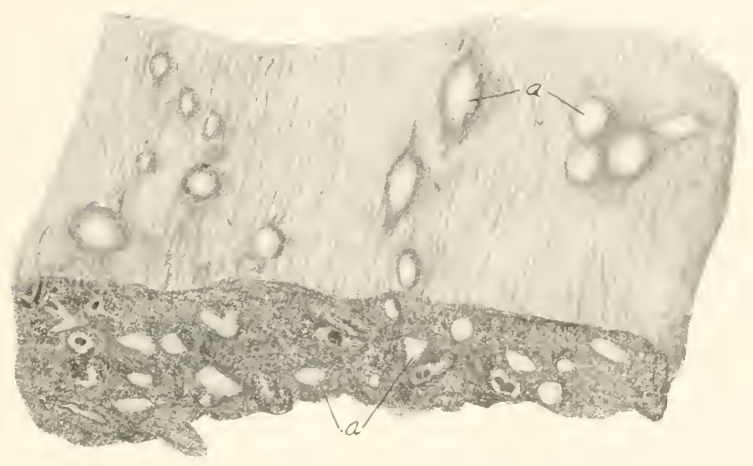

FIG. 27. Drawing of a horse's lung containing glanders nodules (a). They appear on both the plenral and cut surfuces.

origin, situated principally in the periphery of the lung, their structure being the same as that of the nodules in the nasal mucosa. Sometimes the lung nodules represent lobular pneumonic foci, in which the alveoli are filled with red and white blood corpuscles and with desquamated epithelium of the lungs. Central disintegratiou occurs very early. These areas are surrounded by a membrane resulting fron a reactive inflammation which manifests itself and out of which a connective tissue capsule develops later on. There are tro theories concerning the structure of the early nodules. One is, that the first cells are epithelial in nature, thus closely resembling 
a tubercle. The other is that the first stage of the nodules consists of air cells filled with leucocytes.

II'Fadyean has called attention to the structure of the lung nodules, in which he finds a central part composed of leucocytes that have filled the air spaces, the walls of which have disappeared as if by liquefaction. This is surrounded by a zone of epithelioid cells. A third zone surrounds this, in which the walls of the air resicles are recognizable. The walls are thickened. The fourth zone is composed of air vesicles filled with a fibrinous exudate, which entangles a few leucocytes. Frequently the exudate is free from red blood corpuscles, but at times it contains l11uch blood. In older nodules the third and outermost zone is composed of cirrhotic lung tissue, in which can be distinguished the remains of the air cells. This zone passes gradually into the normal tissue. In the last stage the central area shrinks and becomes calcified, while the other zones become converted into a distinct fibrous capsule. Other observers have not reported the calcification. It has not occurred in the writer's observation. The cell necrosis in glanders has been designated by Unna as chromatolasis which consists in the disintegration of the nucleus before the destruction of the cell body and the retention of the staining property of the broken, nuclear chromatin. This gives the dark color in the central part of a stained nodule.

Besides these nodules, there are often chronic bronchitis, peribronchitis, parabronchitis, atelectasis, inflammation of the tissue of the lung and less frequently circumscribed or exudative pleuritis.

Infiltrated glanders of the lungs form tumors from the size of a walnut to that of a child's head, consisting of a diffuse glanderous infiltration of the alveoli and of the interstitial connective tissues. Frequently on section the infiltrated parts of the lungs resemble very closely a soft sarcoma. They are of a dirty white color, of a gelatinous, juicy consistency and irregular in shape. They may either become indurated so as to form hard, connective tissue-like new growths (fibroma-like tumors of glanders, according to Gerlach), or they may become 
gangrenous. In nodular and in infiltrated glanders of the lungs, the bronchial glands and frequently the mediastinal glands become enlarged, indurated and studded with small foci of cell infiltration.

In glanders of the skin (farcy) the nodules are found in the papillary layer, in the cutis and in the subcutaneous and superficial intermuscular tissue. The cutaneous nodules vary in size from a hemp seed up to a pea. They suppurate rapidly and form small ulcers. The nodules in the subcutis are inflammatory (metastatic) tumors from the size of a pea to that of a hen's egg. They change into large abscesses and discharge externally. In the region of the nodules the lymphatic vessels are inflamed, swollen, and frequently resemble a rosary or knotted cord. Ulcers often develop from these secondary nodes. The neighboring lymph glands are at first swollen and soft,

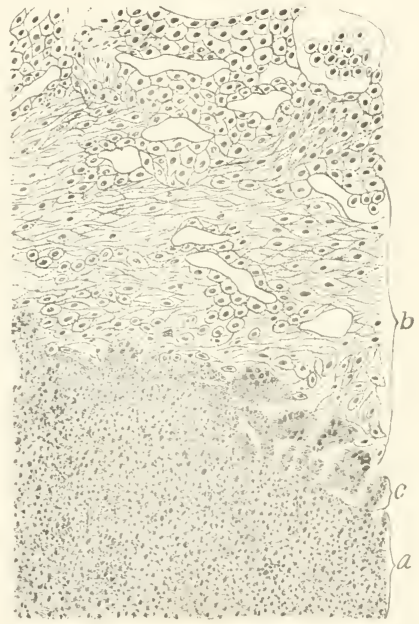

FIG. 2S. Section of a glanders nodule in the lung of a horse: (a) necroticienter. (c) zone of giant iells, (b capsule surrounding the nodule (Sinutz). but later they become indurated by the growth of connective tissue and studded with dirty white nodules about as large as a pin head, or with yellow foci of caseation. The capsule around the lymph glands becomes infiltrated with small cells and subsequently thickened. In rare cases secondary chronic farcy occurs. It is marked by a large, diffuse new growth of connective tissue with nodular thickening of the skin. This 
condition is termed glanderous elephantiasis or pachyderma. It chiefly affects the limbs and head.

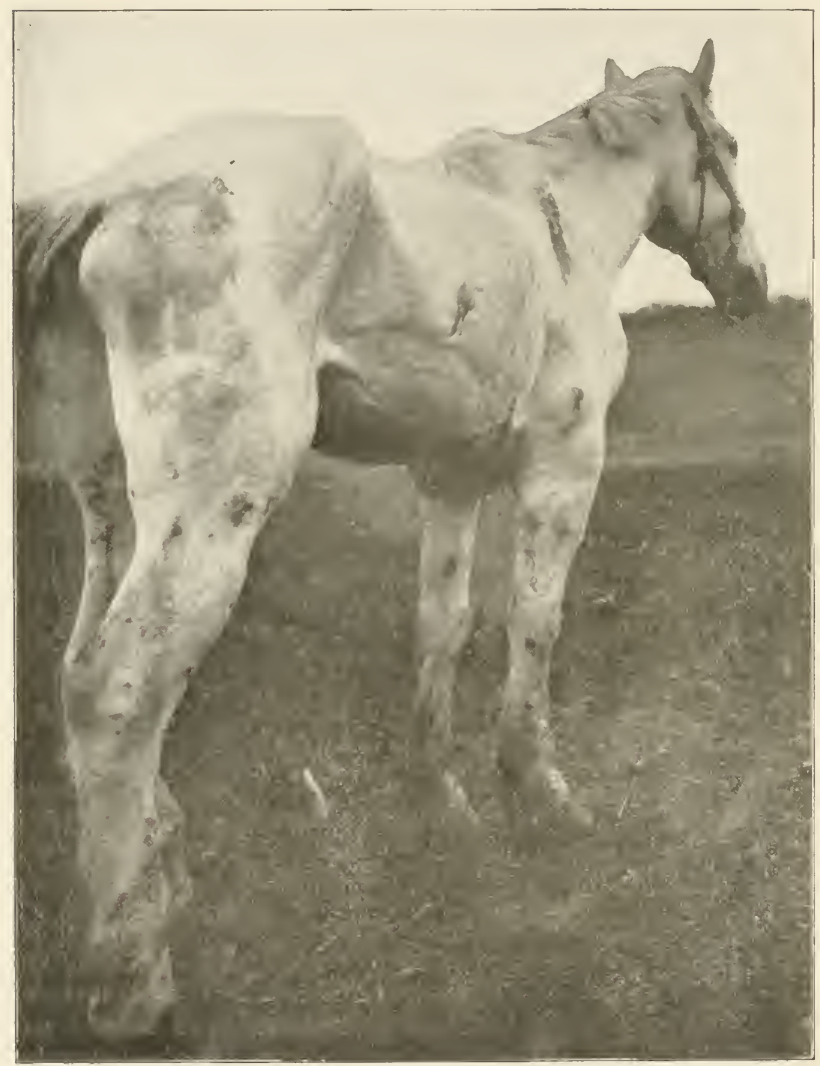

FIG. 29. Photograph showing cutaneous glanders or farcy buds. (Photograph by kelly'). 
Of the abdominal organs, the spleen is most frequently attacked. It then contains embolic nodules, which vary in size and either suppurate or become calcareous. Similar nodules occur, though not so often, in the liver, kidneys, testicles, brain, muscles, heart and bones. In the bones, the lesions consist of a cellular infiltration of the medulla and purulent breaking down of the osseous tissue. Ulcers are very rare on the mucous membranes of the eyes, stomach and vagina. The blood shows sigus of slight leucocytosis. The specific bacteria are found in the blood only in cases of acute general infection.

The anatomical changes in acute glanders consist chiefly in a disintegration of the respiratory mucous membrane, in a serous infiltration of the submucosa, subcutis, and intermuscular tissue, with inflammation and suppuration of the lymph vessels and lymph glands. There are also metastatic formations in the skin and lungs. The nasal mucous membranes are covered with rapidly spreading ulcers with considerable infiltration into the submucosa. The mucous membrane of the larynx and pharynx may be swollen and corered with ulcers. The lungs are studded with purulent metastatic foci or fresh nodules. The skin is excessively swollen and covered with glanderons nodes. Sometimes diffuse gangrene of the skin occurs.

\$ 134. Glanders in man. The symptoms of glanders in man are of much importance to the veterinarian. Although the susceptibility to the disease is usually not very great, cases of human glanders unfortunately occur, especially anong veterinary surgeons and those having the care of horses. Human glanders is reported to be quite common in Russia. The parts usually first affected are the hands, nasal mucous membrane, lips and conjunctiva. After a period of incubation of from three to five days the infected part becomes swollen and painful, with subsequent inflammation of the lympl ressels and swelling of the glands. Fever is often the first symptom, and it is nearly always followed by a nasal dis- 
charge, ulcers on the nasal mucous membrane, pustules and abscesses in the skin, ulcers in the oral cavity, larynx, and conjunctiva, articular swellings, and grave general disturbances. Sometimes there is intense gastro-intestinal trouble. Nodules occur in the lungs in some cases. As a rule, death takes place in from two to four weeks, and occasionally in a few days. In other instances, the disease becomes chronic, lasting for months or years. Bact. mallei has been found in the blood in cases of acute glanders. The positive diagnosis depends on the possibility of infection having taken place, on inoculation in guinea pigs, or the proof of the presence of Bact. mallei. Treatment is usually of no avail. The only hopeful cases are those that are purely local in their manifestation. A few of these are reported to have been cured by applying deep cauterization.

$\$$ 135. Differential diagnosis. Glanders is to be differentiated from a variety of nasal and lymphatic disorders more or less common in the horse kinc. Before the discovery of the specific bacterium of glanders or of mallein, it was necessary to determine as closely as posible the differential anatomical characters between glanders and those of other affections, such as chronic nasal catarrh, strangles, lymphangitis, follicular ulceration of the nasal mucosa, cancer, sarcoma, actinomycosis, melanosis and the like. Strong has described a disease in the Philippine Islands, which first appears in nodules, that resemble those of glanders very closely. It is caused by a blastomyces. It occasionally attacks cattle as well as horses. The disease most liable to be mistaken for farcy or skin glanders is epizoötic lymphangitis caused by a yeast-like fungus (Saccharomyces farciminosus). This disease has recently been discovered by Pearson in Pennsylvania.

Since the discovery of practically positive means of diagnosis, it does not seem wise to speculate upon the chances of a correct differential determination by obscure clinical evidences. If the diagnosis of glanders can not be made from the symptoms and lesions in evidence three reliable diagnostic 
procedures are available. These are animal inoculation, the use of mallein and the agglutination or serum test.

Animal inoculation. Nale guinea pigs should be used. The material for inoculation usually consists of the nasal discharge from the suspected glandered horse, bits of scrapings from the ulcers, or pieces of other diseased tissue. The method to be followed is precisely the same as with the subcutaneous inoculation of tuberculous material. In these cases there is liable to be a local swelling and abscess. The first symptom of glanders noticed is usually orchitis. The lymphatic glands in the groin are also enlarged. After the orchitis becomes well advanced, the guinea pig may be chloroformed and examined. Pure cultures of the specific organism can be obtained in most cases from the suppurating foci in the testicle. The spleen is usually enlarged and sprinkled with grayish nodules. Other organs may be involved. The diagnosis by the inoculation of a male guinea pig is known as the Strauss method.

Mallein. Mallein is prepared in the same way as tuberculin. It consists of the glycerinated bonillon in which the glanders bacteria have grown and in which are the products resulting from their multiplication. It has a somewhat fetid odor. In applying the mallein test the horse is injected usually in the neck with the required amount ( 0.5 to $2 \mathrm{cc}$.) of mallein, the quantity depending upon the degree of concentration. If a concentrated mallein is used it should be diluted with a I per cent carbolic acid solution to at least $2 \mathrm{cc}$. The reaction is as follows. In a few hours there forms at the place of injection a hot, inflammatory swelling. It is very painful and in case of glanders quite large. From all sides of the swelling there may radiate wavy lines consisting of swollen lymphatics, hot and painful when touched, extending toward the adjoining glands. When the mallein injection is made aseptically, this swelling never suppurates, but it increases in size during a period of from $2+$ to 36 hours and persists for several days, when it gradually diminishes and finally disappears at the end of eight or ten days. With the appearance 
of the local swelling the patient becomes dull and dejected, the eyes have an anxions expression, the coat is lusterless, the flanks contracted, the respiration hurried and the appetite is impaired. Frequent shudders are observed to pass through the muscles of the fore legs and sometimes the trunk is subject to violent convulsive movements. The most active and fractious horses become listless and indifferent to their surroundings. These general phenomena constitute what the French call the "organic reaction," but they are not always so clearly marked. Differences in their intensity are observed but they are never completely absent.

The temperature reaction never fails to show itself. In about eight hours after the injection the temperature of a glandered horse gradually rises $1.5^{\circ}, 2^{\circ}$ or $2.5^{\circ} \mathrm{F}$., and eren more above the normal. The rise in temperature usually attains its maximum between the tenth and twelfth hour, occasionally not till the fifteenth, and more rarely not until about the eighteenth hour. An important fact to note is that the reaction called forth in glandered horses by the injection of mallein persists for from $2+$ to 48 hours and in some cases the temperature remains above the normal for even a longer time. In practice it is advisable to take the temperature of the suspected animals two or three times before the injection of the mallein, and every two hours, beginning at the eighth and going to the twentieth hour after the injection. It is often sufficient for diagnostic purposes to take the temperature but four times, viz., at $9,12,15$, and 18 hours after the injection.

In healthy horses the injection of mallein, even in a much larger dose, produces no effect on the temperature or the general condition of the animal. There is produced, however, at the point of injection, a small edematous swelling, somewhat hot and painful to the touch, but the edema instead of increasing, diminishes rapidly and disappears in less than 24 hours.

The reaction called forth by the injection of mallein in a glandered animal is quite specific. When it occurs one is enabled to state at once and with certainty that glanders exists, although the lesions may be quite minute or obscure. When 
the reaction does not take place it is generally considered that the animal tested is not glandered, although the physical examination may suggest it. Notwithstanding the specific action of mallein, its administration can give really useful

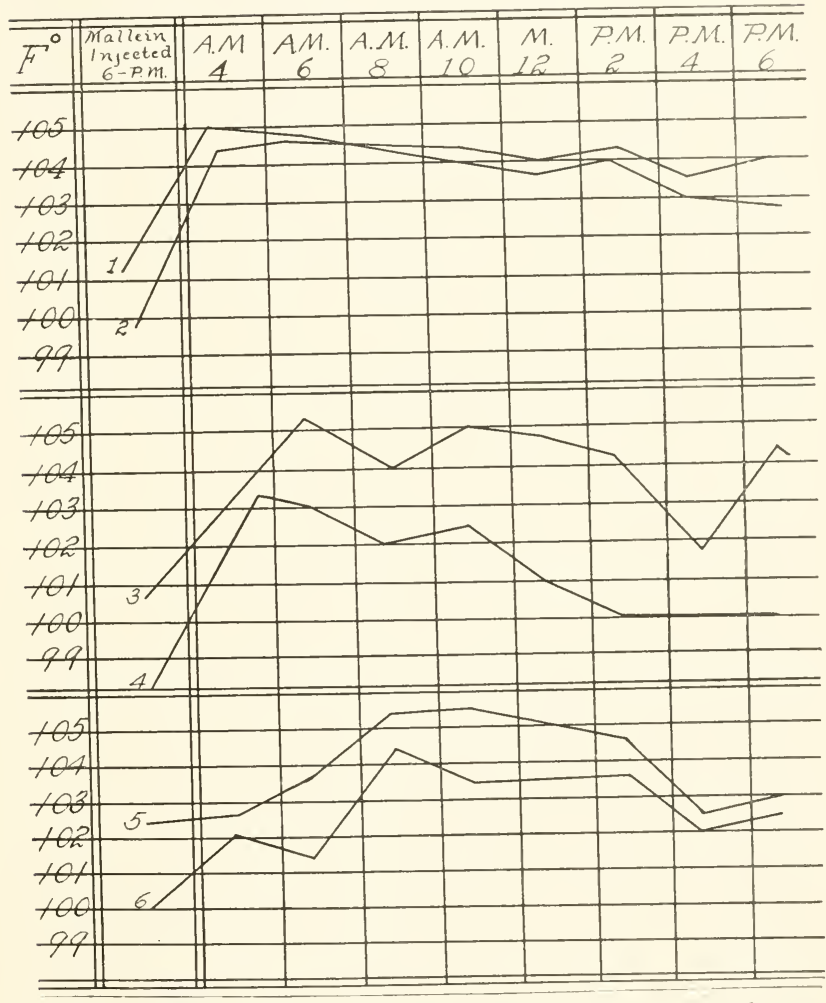

Ficr. 30. Mallein reaction. Temperature curces of sir horses for 3 howrs after injecting mallein. The horses a'ere in one stable from aihich a well developed case of glanders hat been remozed. 
indications according to Nocard "only when, and as far as, we can remove the causes of error that have been pointed out by experience." For example, it would be imprudent to use mallein in case of animals already suffering with an abnormally high or low temperature. The further precautions should be taken that the animals subjected to the test are removed as far as possible from atmospheric variations and the influence of strong sunlight, fog, rain and currents of air. If it be true that the majority of horses are not susceptible or slightly so, to these influences, there are still some that are affected by them. A rise of 1.5 or 2 degrees in temperature would not necessarily indicate a reaction. Again, it must not be forgotten that certain diseases, strangles for instance, frequently produce great daily variations in the temperature; therefore, when there is reason to believe in the presence of a disease of this kind, it is necessary to make sure that the increase of temperature consequent on injection of mallein is persistent, and that the organic reaction is clearly present.

The agglutination method or serum diagnosis. Rabieaux found that the difference which exists between the agglutinating power of a serum from a glandered and from a healthy horse may be used as the basis of a method or diagnosing glanders. He collected the serum as pure as possible, diluted it with sterile, distilled water to $I$ in 10 , or to $I$ in 500 . The diluted serum was then mixed in a small sterile tube with an equal volume of a 24 to 72 hour culture of Bact. mallei in peptonized bouillon (without glycerine). The mixture was placed in an incubator at a temperature of $35^{\circ}$ to $37^{\circ} \mathrm{C}$. and examined at variable times under the microscope. In dilutions of from $I$ in 10 to $I$ in 50 the agglutination occurred in 20 minutes to 3 hours. In serum of a non-glandered horse from 2 to 6 hours were required to produce the agglutination. In weaker dilutions the differences were more marked. The derelopment of the method can be followed from the writings of M'Fadyean, Bourget and Méry, Arpàd, Fedorowsky, Reinecke, Bonome, Schütz and Miessner, Schnïrer and Moore, Taylor and Giltner. 
The method consists in the preparation of a test fluid from a suitable culture of Bact. mallei to which is added the diluted serum.

The "test-fluid" is prepared by washing the growth from a 72 hour acid-agar culture by the aid of a sterile wire loop into distilled water containing 0.85 per cent sodium chloride and 0.5 per cent carbolic acid crystals. This suspension is then placed in a thermostat at $60^{\circ} \mathrm{C}$. for two hours, which kills the bacteria. Three cubic centimeters of the "test-fluid" are placed in each of several small test-tubes. With a sterile pipette, the diluted serum is added to the tubes of test-fluid and thoroughly mixed. In making the different dilutions, the amount of diluted serum to be used is readily ascertained by the following table:

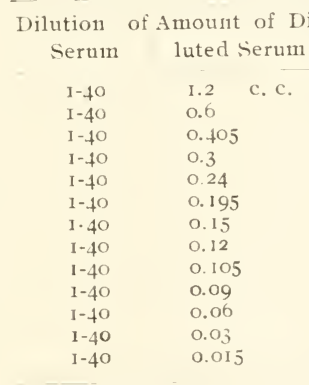

Amount
Test Flui
3 c. c.
3
3
3
3
3
3
3
3
3
3
3
3

Dilution

$$
\begin{aligned}
& I-100 \\
& 1-200 \\
& I-300 \\
& 1-400 \\
& I-500 \\
& I-600 \\
& I-500 \\
& I-1,000 \\
& I-1,200 \\
& 1-1,500 \\
& I-2,000 \\
& I-4,000 \\
& I-S, 000
\end{aligned}
$$

Where dilutions greater than $\mathrm{I}-1000$ are nuade, a serum diluted I-80 may be used to better advantage, unless the pipette employed is very finely graduated. In this case the amount of diluted serum for a certain dilution must be double that indicated in the table.

The mixture thus prepared is placed in an incubator at $37^{\circ} \mathrm{C}$. for $24-30$ hours. A temperature higher than $37^{\circ} \mathrm{C}$. interferes with the agglutination.

The reaction consists of a layer of the agglutinated bacteria covering the entire convexity at the bottom of the tube. 
This film-like sediment may become so dense that it rolls in at the periphery. The supernatant fluid becomes clear in the lower dilutions, but in the higher ones the clarification may not be complete, showing that all the bacteria have not become agglutinated. This is further evidenced by the fact that the layer is less dense in the higher dilutions. The reaction may begin in six hours, but cannot be considered complete until 24 to 36 hours have elapsed. If no reaction appears in 24 hours it cannot be considered negative, as it may occur in from 30 to to hours after setting. Often, however, a reaction appears in less than 24 hours.

After the agglutination is completed, further standing produced no visible change in the test fluid.

A negative result shows a small round concentrated spot of sediment in the center of the convexity at the bottom of the tube, the test fluid remaining apparently unchanged even after several weeks. Animals whose blood serum agglutinates in dilutions of $\mathrm{I}-500$ are suspicious and a reaction in dilutions of I-SOo or higher indicates an infection with Bact. mallei.

As pointed out by Bonone and confirmed by Taylor, there seems to be little or no change produced in the precipitating power of the serum of the blood taken before, during or after the mallein reaction but the agglutinating power as determined microscopically is very much increased during the mallein reaction.

This is shown by the appended table: 
Table showing hoth macroscopically and microscopially the agylutination of dead glanders bacteria with blood serum from hor ses taken before, during and after the mallein reaction.

Blood taken the day pre- Blood taken during vious to malleination Feb. 2I. the reaction

Feb. 22.
Blood taken after the temperature had returied to normal Mar. 2.

\begin{tabular}{|c|c|c|c|c|c|c|}
\hline No. & $\begin{array}{l}\text { Macro- } \\
\text { scopic }\end{array}$ & $\begin{array}{l}\text { Micro- } \\
\text { scopic }\end{array}$ & $\begin{array}{l}\text { Macro- } \\
\text { scopic }\end{array}$ & $\begin{array}{l}\text { Micro- } \\
\text { scopic }\end{array}$ & $\begin{array}{l}\text { Macro- } \\
\text { scopic }\end{array}$ & $\begin{array}{l}\text { Micro- } \\
\text { scopic }\end{array}$ \\
\hline I & I-Soo & $1-1000$ & I $-\$ 00$ & I-I Soo & I-Soo & 1- 1000 \\
\hline 4 & I 800 & $I-1200$ & I-1000 & I- 2000 & $I-1000$ & I -1500 \\
\hline 5 & $1-1500$ & $1-1600$ & I-I 500 & $I-2500$ & $I-1000$ & $1-1200$ \\
\hline 6 & $I-I 200$ & $1-1500$ & I -1200 & I-2000 & I-ISOO & $1-1800$ \\
\hline 7 & $I-1000$ & $I-1200$ & $I-1000$ & I-ISOO & $I-1000$ & $I-1400$ \\
\hline 8 & $I-500$ & $I-500$ & I-Soo & $1-1600$ & $I-500$ & I-60o \\
\hline 9 & I-SOO & $I-I 000$ & I-Soo & $1-1400$ & $I-500$ & I-8oo \\
\hline 10 & $I-500$ & $I-600$ & $I-500$ & $1-1000$ & $1-500$ & $1-800$ \\
\hline I 2 & $1-200$ & $1-300$ & $I-500$ & $\mathrm{I}-\mathrm{SoO}$ & $I-500$ & $1-75^{\circ}$ \\
\hline 13 & $1-1000$ & $1-1200$ & $\mathrm{I}-500$ & I-IOCO & $1-S 00$ & $1-1000$ \\
\hline 14 & $I-500$ & $1-600$ & $1-500$ & $\mathrm{I}-800$ & $1-500$ & I-Soo \\
\hline I 5 & $I-I 200$ & $1-1+00$ & $J-1200$ & $1-2500$ & $I-1200$ & $1-1800$ \\
\hline 16 & $\mathrm{I}-\mathrm{I} 000$ & $\mathrm{I}-\mathrm{I} 2 \mathrm{OO}$ & $\mathrm{I}-\mathrm{IOOO}$ & I -2400 & I-IOUO & $I-2200$ \\
\hline 17 & $I-500$ & 1-Soo & $1-S 00$ & $1-1500$ & $\mathrm{I}-\mathrm{S} 0 \mathrm{O}$ & $I-1400$ \\
\hline 18 & $1-1000$ & $1-1,400$ & I-IOOO & $1-1500$ & I-Soo & $1-1500$ \\
\hline 19 & $1-1000$ & I-IOOO & I-80o & $1-1200$ & I-IOOO & $1-1200$ \\
\hline 20 & $\mathrm{I}-500$ & $I-600$ & $\mathrm{I}-500$ & I-Soo & $\mathrm{I}-500$ & $1-800$ \\
\hline $2 \mathrm{I}$ & I -500 & $\mathrm{I}-75 \mathrm{O}$ & $1-500$ & $I-1000$ & I-Soo & I-1 200 \\
\hline 22 & $1-1000$ & I-I 400 & $1-1000$ & $1-2500$ & $1-800$ & I -2200 \\
\hline 23 & I-200 & $\mathrm{I}-200$ & I -200 & I-IOOO & I-80o & $1-1000$ \\
\hline 2.4 & $1-1000$ & $1-1200$ & I-IOOO & I-2200 & I -1200 & I -2000 \\
\hline 25 & $1-800$ & $1-800$ & $\mathrm{I}-500$ & $I-1200$ & 1-Soo & $1-1000$ \\
\hline 26 & $I-1200$ & $1-1500$ & $1-1000$ & I -2200 & I -1200 & I -2000 \\
\hline 27 & $\mathrm{I}-500$ & $I-I 000$ & I -1000 & I-I Soo & I-SoO & I-2000 \\
\hline 28 & $1-500$ & $I-600$ & $\mathrm{I}-500$ & $\mathrm{I}-\mathrm{I} 200$ & $1-1000$ & I 1500 \\
\hline 29 & $1-800$ & I -1000 & $\mathrm{I}-500$ & I -1200 & $I-1200$ & I -2000 \\
\hline 30 & I-IOOO & I-I 200 & $\mathrm{I}-\mathrm{SOO}$ & I-1S0O & I-\$்o & $I-1600$ \\
\hline 31 & $1-500$ & $I-600$ & I- 800 & $1-1400$ & $1-1000$ & $I-I 500$ \\
\hline
\end{tabular}

The agglutination in higher dilutions with the living organisms as determined microscopically was pointed out by Taylor. A comparison of the agglutination of the living and killed bacteria with the serum from glandered horses, as shown by the mallein reaction, is given in the appended table: 
Macroscopic and microscopic agglutination of Bacterium mallei zeith horse serum by the use of killed and living cultures.

\begin{tabular}{|c|c|c|c|}
\hline $\begin{array}{l}\text { Number } \\
\text { of } \\
\text { Horse }\end{array}$ & $\begin{array}{l}\text { Macroscopic. } \\
\text { Dead bacteria, } 24 \\
\text { hours at } 37^{\circ} \mathrm{C} \text {. }\end{array}$ & $\begin{array}{l}\text { Microscopic. } \\
\text { Dead bacteria, I2 } \\
\text { hours at } 37^{\circ} \mathrm{C} \text {. }\end{array}$ & $\begin{array}{l}\text { Microscopic. } \\
\text { Live bacteria, }{ }^{12} \\
\text { hours at } 37^{\circ} \mathrm{C} \text {. }\end{array}$ \\
\hline I & I -8000 & $1-12000$ & $I-30000$ \\
\hline 2 & $1-2000$ & $1-3000$ & $1-12000$ \\
\hline 3 & I-Soo & $1-1000$ & $1-10000$ \\
\hline 4 & $I-1600$ & $1-\mathrm{I} S 00$ & $I-6000$ \\
\hline 5 & I-500 & I -600 & $I-5000$ \\
\hline 6 & I-IOOO & $I-1250$ & $I-25000$ \\
\hline 7 & I-Soo & $1-1000$ & I- 8000 \\
\hline$\dot{S}$ & I-80o & I-I 200 & $I-12000$ \\
\hline 9 & $I-1600$ & I-I 800 & $1-24000$ \\
\hline IO & $1-500$ & I-SOO & $\mathrm{I}-7500$ \\
\hline
\end{tabular}

The method as pointed out by Schütz and Miessner is a macroscopic one. It depends upon the precipitation of the agglutinated masses of bacteria. Normal horse's serum agglntinates glanders organisms in high dilutions as determined microscopically. This, however, does not appear to be of diagnostic value.

Disposition of reacting horses. The question arises whether animals found by the help of mallein or the agglutination test to be glandered ought to be immediately slaughtered. Nocard said no. The experience of the last few years goes to prove that among the animals that react there are some which, when removed from the infected center and thereby withdrawn from all chance of new contamination, recover. "We ought therefore," he continues, "to confine ourselves to the destruction of those which in addition to the reaction, present some clinical indication of the disease, such as ulceration of the nose, indurated glands, suppurative lymphatics or other pronounced manifestation of the disease. The animals showing physical signs of infection must simply be removed from among the healthy horses and subjected from time to time, say every two months, to the mallein test. If any of these should eventually show the clinical signs of glanders, it should be slaughtered at once. On the other hand, those animals which have stood two successive doses of mallein without reacting ought to be 
considered definitely cured, restored to their places and put to the free disposal of the owners."

The views advocated by Nocard are not universally entertained in this country. It has been shown repeatedly that a good reaction, following the injection of mallein, was a sure indication of glanders as revealed by post-mortem. The question, however, concerning the necessity of immediate slaughter for purposes of protection, where there are no eridences of lesions on physical examination, seems to be an open one. This question which pertains to sanitary police rests, until the results of conclusive investigations a re recorded, with those entrusted with the protection of animals and men from this disease. However, the results of certain experiments in the use of mallein as a therapeutic agent and the fact that certain animals recover when kept in quarantine are very suggestive. Certainly further investigations are needed to determine the safe and equitable disposition of animals devoid of all symptoms and obvious lesions of glanders, but which give a reaction to the mallein or agglutination test.

$\S$ 136. Prevention. Isolation of the healthy animals from the infected ones and thorough disinfection of the stable are important. It is also desirable not to bring strange horses in close contact with home animals, until their freedom from this disease is determined.

REFEREXCES.

1. BABEs. (Observations sur la morve. Arth. de lid. erpir. el d'Anat. path., Vol. III (1S9I), p. 619.

2. BERNS AND WAY. Practical Application and Results of the Agglutination Method of Diagnosing Glanders in One Hundred and Fifty-two Cases. Amer. Vit. Re'?, Vol. XXX (1906), p. \$22.

3. Boxomf. Leber die schwankungen des Agglutinin und Präzipitingehaltes des Blutes während der Rotzinfektion, Centralbl.f. Bakt., Bd. XXXVIII. (1905), S. 601.

4. Bourget tit Mirs: Sur le séradiagnostique de la morve, $L a$ Semaine .1\%ed., 1Sgs, p. 6r. 
5. Butrer. Glanders. Bulletin No. I6. Wiss. Agr. Exp. Station, rigr.

6. CARY. Glanders. Bulletin No. 35. Ala. Agr. Expt. Station of the Agricultural and. Wechanical College, Jan. 1892.

7. Dawson. Equine glanders and its eradication. Bulletin No. 77. Florida Agric. Exp. Station, 1905.

8. DE SCHWEINITZ AXD KILBORNE. The use of mallein for the diagnosis of glanders in horses and experiments with an albumose extracted from cultures of bacillus mallei. Am. V'et. Reziea', Vol. XYI $(1 \$ 92)$, p. 439.

9. Fraxcis. Glanders, tests with mallein. Bulletin No. 30. Teras, Agri. Exp. Station, i894.

ro. FROTHINGHAM. The diagnosis of glanders by the Strauss method. Jour. of Medical Research, Vol. VI (rgoi), p. 33 r.

II. GALLI-VALERIO. Contribution à l' ètude de la morphologie du Bacillus mallei. Centralb. für Rakt., Bd. XXVI (1899), S. I77.

12. Higgixs. Glanders and mallein. Proceedings Amer. I'et Med. Asso., r9o4, p. 135 .

13. LANGER. Untersuchung über die differential diagnostische Bedeutung der Rotzagglutination u. s. w. Monatshefte fïr prak. Tierheilkunde, Bd. XVI (1905), S. $24 \mathrm{I}$.

14. LOEFfin Axi Schitiz. On the bacillus of glanders. Diwtsche Med. Hochenschrift, Dec. ISS2. Translated, Vol. CXV, New Sydenlam Society.

15. M'FADYEAN. The pulmonary lesions of glanders. Jour. of Compar. Path. and Thera., Vol. VIII (1895), p. 5 o.

16. IIPAdreax. Glanders. Jour. Compar. Path. and Thera., Vol. XVII (1904), p. 295.

17. MoORE, TaYlor AND GILTNER. The Agglutination Method for the Diagnosis of Glanders. Amer. Veter. Rev., Vol. XXX (1906), p. $\mathrm{SO}_{3}$.

IS. NOCARD. The value of mallein as a means of diagnosis in doubtful cases of glanders. Jour. Compar. Path. and Thera., Vol. VIII (I895), p. 227.

19. Rabieacx. Serum diagnosis of glanders. Abstract Jour. Compar. Path. and Thera., Vol. XVI (1903), p. 59. Orig. Jour. de Jíd. V'it., I9o2.

20. REYNoLDS. State control of glanders in Minnesota. Jour. of Compar. Med. and vet. Archizes, Vol. XX (1899).

21. Rutherford. Glanders. Proceedings Am. Vet. Med. Asso., I906, p. 215. 
22. Sichiт\%. A contribution to the subject of glanders. four. of Compar. Path. and Thera, Vol. XI (1S98), p. 1.

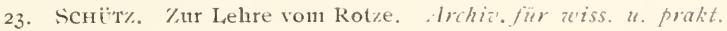
Thierheilkunke, Bd. XXIV (1sgs), S. I.

24. Schüt\% UND MIESSNER. \%ur Serodiagnose der Rotzkrankheit. Archiv. fur wiss. u. prakt. Tierhielkunde, Bd. XXXI (1905), S. 353.

25. Sмrтн. On the influence of slight modifications of culture media on the growth of bacteria as illustrated by the glanders bacillns. Journal of Comparalive Medicine, (1890), p. 15 s.

26. Strong. Preliminary report of the appearance in the Philippine Islands of a disease clinically resembling glanders. $1902, \mathrm{No} . \mathrm{T}$ Bureau of Goiernment Laboratories, Manila.

27. STrAuss. Sur nn moyen diagnostique rapide de la morve. Arch. de Med. erper. et de Anat. path., Vol. III (1889), p. 460.

28. WAY. The practical application of the agglutination nethod for the diagnosis of glanders. Am. l'ct. Rezicui, Vol. XXXI (1907), p. 709 .

29. WHERRY. Glanders: Its diagnosis and Prevention. Bulletin No. 27. Bureau of Government Laboratories. Manila. (1904'.

3o. Wildidus. (ilanders. Bul. No.f. Mont. Agr. E.1p. Stat., iSg4.

3I. WRIGHT. The histological lesions of acute glanders in man and of experimental glanders in the guinea pig. Jour. of E.ip. Med., Vol. I ( 1896 ), p. 577 .

\section{TUBERCULOSIS}

Synonyms. Consumption ; pearl disease ; grapes; plithisis ; scrofula ; tabes; 'The great white plague.'

\$ 137. Characterization. Tuberculosis is an infectious disease from which the human species, cattle and swine suffer very extensively and which, under favorable conditions, attacks nearly if not all species of animals including fish. It is a disease of slow development, involving either primarily, or in association with other organs, the lymphatic system. It is characterized by the formation of nodules, or tubercles, in consequence of the activities of Bacterium tuberculosis. It does not destroy life by acute toxemia, but by a chronic and long continued systemic poisoning and by the morbid changes brought about through the localization of these lesions in organs necessary to life. 
$\$$ 138. History. Tuberculosis is one of the oldest diseases affecting cattle of which there are identifying records. It seems to have been known to the Jewish people during their Egyptian captivity and the ecclesiastical laws for many centuries contained numerous enactments against the consumption of flesh from tuberculous animals. In 1370 , it was forbidden in Munich to have on sale the flesh of animals affected with tuberculosis. A number of other cities passed similar ordinances. In I702, Florinus described the disease and emphasized the then existing opinion that it was identical with syphilis. This led to the practice of destroying all tuberculous animals. In $1_{7} 8_{3}$, the Berlin Board of Health rejected the theory of the connection of tuberculosis and syphilis and declared the flesh of affected animals to be fit for food. This led finally to the cancelling of all laws throughout Prussia against the use of flesh for food trom animals affected with the disease. Tscheulin, in 1816 , recognized in reference to the infection of meat, three degrees of bovine tuberculosis, viz: $\mathrm{I}$, in which the tubercles were to be removed; 2 , in which the diseased parts were to be destroyed and the meat sold at a low price; and 3 , those cases in which the lesions were so extensive that the whole carcass must be rejected.

The study of the lesions themselves gave rise to a number of beliefs concerning their nature. Thus, Virchow, Schüppel and others declared that the tubercles in cattle were lympho-sarcomata. Leisering considered them simply as sarcomata. Spinola and Haubner maintained that human and bovine tuberculosis were identical.

In 1865 , Villemin showed that tuberculosis was due to a specific infection. He produced the disease in rabbits by inoculating them with tuberculous material from human subjects. He also produced the disease by feeding experimental animals and by causing them to inhale tuberculous material. Chauveau, in the same year, produced the disease in cows. These results were soon confirmed by Klebs, Cohnheim and Gerlach. These experiments, in which the disease was produced in one species with tuberculous material from another, 
followed by the discovery by Koch of the specific bacterium of the disease, led to the view that tuberculosis in all species of mammals was identical. This generally accepted belief caused sanitarians to look upon tuberculosis in cattle as a great menace to public health. The result was that during the closing decade of the last century, this disease in cattle was treated more vigorously as a menace to the human species than as a destructive disease of animals.

In 1896 , Dr. Theobald Suith pointed out that for certain animals the tubercle bacteria from cattle were more virulent than those from man and further that there were certain morphological and cultural differences existing between them. In 1898 , he published the results of a more extended series of investigations. Since that time a number of investigators have arrived at the same conclusion. The fact has come to be well known that certain differences exist between the bacteria of tuberculosis found in the human and in the bovine species. Koch's experiments reported at the tuberculosis congress in London in July, rgor, give additional evidence of a difference in virulence for experimental animals of the bacteria of human and of borine tuberculosis. To what extent the human species becomes infected from the borine kind cannot be stated, but the accumulating evidence tends to the conclusion that bovine tuberculosis is of less significance in its influence upon public health than has heretofore been thought, and of more importance as a rapidly spreading and destructive disease among cattle. It is not proven, however, that the human species is not affected with the bacteria of bovine tuberculosis. The investigations of the last five years have shown that not infrequently human tubercle material will produce tuberculosis in cattle. The interim reports of the Royal Commission appointed in I9OI are important in this connection. Salmon has published an important paper on the relation of human and bovine tuberculosis in reply to Koch's paper of I gor. Concerning its transinission, the conclusion seems to be warranted, that the virus of tuberculosis spreads very largely among men and cattle from individual to individual of the 
same species rather than from one species to the other. A number of cases of tuberculosis in man seems to have been caused by the bovine type of the tubercle bacterium. According to Smith there are forty to fifty such cases on record.

\$139. Extent of tuberculosis especially among cattle and swine. The committee on cattle diseases and animal food of the American Public Health Association for I 90 I reported the appended statistics concerning the extent and increase of tuberculosis in cattle and swine in various countries.

"The slaughter house statistics of Prussia show I +6 per cent of the cattle and 2. I + per cent of the swine to be tuberculous. In Saxony the percentage is 29.13 with cattle and 3.10 with swine. In the city of Leipzig the figures are 36.4 for cattle and 2. 17 for swine (Siedamgrotzky). Of 20,850 animals in Belgium tested with tuberculin in $1896,48.88$ per cent reacted. Of $25,+39$ tested in Denmark from 1893 to 1895 , 49.3 per cent reacted; and of 67,263 tested from 1896 to 1898 , 32.8 per cent reacted (Bang). An examination of 20,930 cattle in Great Britain, either slaughtered and examined postmortem or tested with tuberculin, showed 5,441 or 26 per cent affected with tuberculosis. M'Fadyean estimates that 30 per cent of the cows in Great Britain are tuberculous. Figures a vailable in the United States do not cover a sufficient area of our territory to allow us to make a reliable estimate of the extent of tuberculosis in milch cows.

"Our beef cattle as they come to the large packing houses are as yet comparatively free from tuberculosis. Of 4, 84 I, I 66 cattle slaughtered in the year 1900 , under Federal meat inspection, but 5,279 or O. I I per cent were sufficiently affected to cause the condemnation of any part of the carcass. Of 23,336 ,884 hogs similarly inspected, $5,+40$ were sufficiently affected to cause a condemnation of some part of the carcass. This is equal to 0.023 per cent, or slightly more than one-fifth the proportion found in beef cattle.

"The slaughter house statistics of all countries show that the percentage of affected hogs increases as the disease becomes 
more common in cattle, so that we must consider not only the effect of the disease upon beef and milk producing animals but also upon swine. Tuberculosis is more acute with hogs than with cattle, and there is a much greater tendency to generalization, consequently the parts used for human food are more likely to be affected, and if there is a possibility of communicating the virus through the meat the danger is increased by this peculiarity of the disease in swine." The statistics of the last few years show a rapid increase in the amount of tuberculosis in swine. In I905 64,919 carcasses of hogs and I 42, 105 parts were condemned for tuberculosis.

I40. Geographical distribution. Tuberculosis is an exceedingly wide spread disease. In earlier times it was quite prevalent among cattle in Central Europe. It seems to have existed in Western Asia and Northern Africa at an early date. From these centers it has spread to nearly every cattle raising country of the world. Its rapid spread during the last fifty years is attributed to the increase in cattle exchange resulting in the introduction of tuberculous animals into healthy herds. It is stated that in many countries, and in large districts within others, tuberculosis did not exist until it was introduced within recent years by the importation of diseased animals.

In countries where there has been little or no importation of cattle, and in which the native breeds still exist unchanged, as in many parts of Russia, Austria and Spain, in the northern part of Sweden and Norway, and in parts of Africa, tuberculosis is practically unknown. This is true of the cattle on the island of Jersey, where for more than a hundred years foreign cattle have not been introduced.

In the United States, the disease is very widely distributed. It is found to a considerable extent in certain localities where the climatic conditions seem to be beneficial for tuberculous people. The explanation for this seems to be that tuberculous animals have been introduced into certain herds in these districts. There are, however, large areas in which it is practically unknown. The Western steers that are killed in the 
slaughter houses of Kansas City, Omaha, Sioux City and Chicago are practically free from this disease. Tuberculosis exists, however, in many places where beef cattle are raised, as the result of the introduction of affected breeding stock. In many localities, especially where there is an extensive interchange of animals, a large percentage of the herds are more or less affected.

S 141. Etiology. Tuberculosis is caused by a rod-shaped organism known as Bacterium tuberculosis. It was discovered

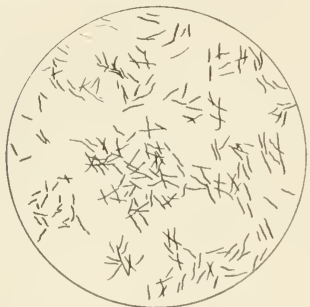

FIG. 30. Bacterium tuberculosis.

by Robert Koch in 1882. Schiiller and Toussaint had previously studied growths which seem, from the results of their inoculation experiments, to have been this organism. The bacterium of tuberculosis is a slender, rod-shaped organism with rounded ends, from 2 to $5 \mu$ in length and from 0.3 to $0.5 \mu$ broad. The rods are straight or slightly curved, and occur singly, in pairs or in small bundles. Frequently they cross one another. They do not produce spores, but vacuoles are often observed and branching forms have been described.

The bacterium of tuberculosis is readily cultivated on artificial media such as blood serum, glycerinated agar and bouillon after it has been adapted to such artificial conditions. * It is, however, not easy to cultivate it directly from ordinary

*To accomplish this necessitates a very special and careful procedure. Dr. Theobald Smith, of Harvard University (Jour of Exp. Med., Vol. III., 1898 , p. 451), has the credit of formulating a method by combining details in such a manner that the procuring of cultures is, in most cases, possible. Dog serum is used. The method, as he gives it, is as follows:

"The dog was bled under chloroform and the blood drawn from a femoral artery, under aseptic conditions, through sterile tubes directly into sterile flasks. The serum was drawn from the clots with sterile pipettes and either distributed at once into tubes or else stored with 0.25 
tuberculous lesions. Although at the time of their discovery, the tubercle bacteria from man and from animals were believed to be identical, they have been found to possess slightly different characters and properties. Smith pointed out in 1898 , that morphologically those from cattle were shorter and thicker than those from man, that the growth was slightly different on blood serum, and that they were much more virulent for cattle and rabbits than those from the human species. Since that time his conclusions have been confirmed by a number of investigators. Koch obtained like results. At present, therefore, we must look upon the tubercle bacteria coming from these different species as possessing races or varieties which, perhaps, are the result of their different conditions of life. The investigations which have been made with the decidedly different forms of this organism found in tuberculosis of fowls and of fish have led a few experimenters to believe that they are simply varieties of the organism first described by Koch. Further inquiries are necessary to fully satisfy bacteriologists that all of these forms are thus related to the one species.

to 0.3 per cent chloroform added. Discontinued sterilization was rendered unnecessary. The temperature required to produce a sufficiently firm and yet not too hard and dry serum is for the $\operatorname{dog} 75^{\circ}$ to $76^{\circ} \mathrm{C}$. For horse serum it is from $4^{\circ}$ to $5^{\circ}$ lower. The serum was set in a thermostat into which a large dish of water was always placed to forestall any abstraction of moisture from the serum. About 3 hours suffice for the coagulation. When serum containing chlorofor $\mathrm{m}$ is to be coagulated, I am in the habit of placing the tubes for an hour or longer in a water bath at $55^{\circ}$ to $60^{\circ} \mathrm{C}$, , or under the receiver of an air pump, to drive off the antiseptic. This procedure dispenses with all sterilization excepting that going on during the coagulation of the serum. It prevents the gradual formation of membranes of salts, which, remaining on the surface during coagulation, form a film unsuited for bacteria. Tubes of coagulated serum should be kept in a cold closed space where the opportunities for evaporation are slight. They should always be kept inclined.

"The ordinary cotton-plugged test tubes I do not use, because of the rapid drying out permitted by them, as well as the opportninities for infection with fungi. Instead, a tube is used which has a ground glass cap fitted over it. This cap contracts into a narrow tube plugged with glass worl. This plug is not disturbed. The tube is cleaned, filled, and 
There seems to be no reason for doubting that the bovine and human forms are varieties or races of the same species. The difference in the conditions of life under which they exist in the bodies of men and of cattle are quite enough to explain resulting differences in the bacteria.

S 142. Symptoms. The symptoms vary according to the course of the disease. There is a chronic form, which is most common, and an acute form or miliary tuberculosis.

The symptoms of chronic tuberculosis depend upon the location of the lesions and their extent. When the lesions are situated deeply and are not of great extent, they may not exhibit visible evidence of their presence. In such cases, the infected animal may present the picture of perfect health and show no disturbance of function. Indeed some animals, in which the lesions are both extensive and widely distributed and which have never presented noticeable signs of the disease, are slaughtered for beef without a suspicion of the presence of tuberculosis until they are examined post-mortem.

inoculated by removing the cap. With sufficient opportunity for the interchange of air little evaporation takes place, and contamination of the culture is of very rare occurrence. In inoculating these tubes, bits of tissue, which include tuberculous foci, especially the most recent, are tor1 from the organs and transferred to the serum. Very little crushing, if any, is desirable or necessary. I think many failures are due to the often futile attempts to break up firm tubercles. Nor should the bits of tissue be rubbed into the surface, as is sometimes recommended. After a stay of several weeks in the thermostat, I usually remove the tubes and stir about the bits of tissue. This frequently is the occasion for a promptappearance of growth within a week, as it seems to put certain still microscopic colonies in or around the tissue into better coudition for further development. The thermostat should be fairly constant, as urged by Koch in his classic monograph, but I look upon moisture as more important. If possible, a thermostat should be used which is opened only occasionally. Into this a large dish of water is placed, which keeps the space saturated. Ventilation should be restricted to a minimum. As a consequence, moulds grow luxuriantly and even the gummed labels must be replaced by pieces of stiff manila paper fastened to the tube with a rubber band. By keeping the tubes inclined, no undue amount of condensation water can collect in 
Since the lesions of tuberculosis vary so mucl in different cases, it is not possible to give a description of what can be designated the characteristic or even the usual symptoms of this disease. There are, however, certain general manifestations that appear in most of the advanced cases, such as emaciation while the appetite continues good. This is always a suspicious indication and especially if accompanied by cough, rough coat and tight, harsh skin. Rough or 1 o u d respiratory sounds are suspicious, and, in a d va nced cases, it is often found that the animal groans when pressure is brought to bear upon the chest wall. Many cases bloat habitually. Hard, painless swellings (enlarged lymphatic glands) beneath the skin in the region

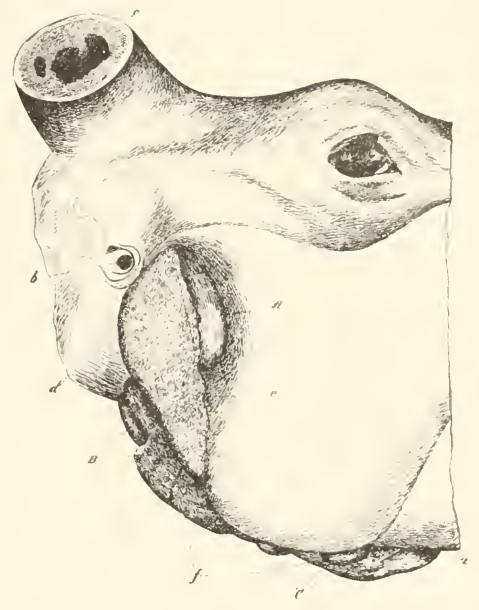

FIG. 31. Right lateral aspect of posterior half of steer's head. (a) Lower jaw, (b) ear passage, (c) horn, (d) styloid process of ocipital bonc, $(e)$ parotid gland. ( $f)$ submaxillarygland. A. Right parotidlymph gland. B. Right post ma.iillary lymph gland. C. Right suhmaxillary lymph gland. These glands are often the seat of tubercular deposits (Smilh). of the escutcheon, flank, shoulder or throat are suspicious.

the bottom, and the upper portion of the serum remains moist. The only precaution to be applied to prevent infection with moulds is to thoroughly flame the joint between tube and cap as well as the plinged end, before opening the tube. When test tubes are employed it is well to dip the lower end of the plng into sterile molten paraffin and to cover 
In tuberculosis of the lungs, it may be said that coughing is the most noticeable symptom. It is most common after feeding, drinking, or after rapid moving following a period of repose, but sometimes it occurs without any apparent cause. The cough is usually strong, dry and frequently of a high pitch. Sometimes it is very violent, accompanied by protrusion of the tongue. Auscultation reveals modified and abnormal sounds of different kinds in the lungs; sibilant, sonorous and mucous rales are most common. A dull sound is often detected on percussion. It is also to be noted that this condition is of slow development and long duration, thus aiding one to distinguish it, in many cases, from bronchitis or pneumonia.

Where the mediastinal lymphatic glands are enlarged and press upon the esophagus, it is stated that the animal bloats habitually. Chronic or habitual bloating accompanied by a good appetite and no other evidence of disease of the digestive tract, especially if there is shortness of breath and cough, may be looked upon as strongly indicative of tuberculosis with enlarged mediastinal lymphatic glands. Enlarged tubercular glands along the esophagus may press upon that organ causing obstructions and preventing the escape of gases from the stomach. This often gives rise to lymphangitis.

Sometimes large tubercular masses develop on the pleura. In such cases the principal symptom is a friction sound that is heard most distinctly during inspiration. If the masses are large enough they give rise to a dull sound upon percussion. In tuberculosis of the stomach and intestines, digestion is interfered with. This gives rise to poor appetite, frequently to diarrhea and sometimes to alternation of diarrhea and constipation. In tuberculosis of the peritoneum or of the lining of the abdominal cavity, the lymphatic glands of the

the tube with a sterilized paper cap. The white bottle caps of the druggist ale very serviceable."

While the tuberculous material is perfectly fresh (uncontaminated) and in the early stages of the disease, it is safer to inoculate a guinea pig, and after the lesions begin to develop to chloroform it and make the cultures from the recently affected liver or spleen. 
flank are often enlarged and hard. Sometimes this condition can be diagnosed positively by a rectal examination and the discovery of the hard, nodular masses. 'Tuberculosis of the liver does not give rise to obvious symptoms unless the disease is far advanced, in which case jaundice may be observed.

In animals in which the postpharyngeal lym1phatic glands are enlarged from tuberculosis, $\quad \mathrm{th} \mathrm{e}$ breathing is liarsh and noisy. In this condition there is sometimes difficulty in swallowing, a nd particles of chewed up food are occasionally expelled from the moutl, either voluntarily when it is found that they cannot be swallowed conveniently, or by the coughing they occasion upon reaching the pharynx. These en larged glands may some-

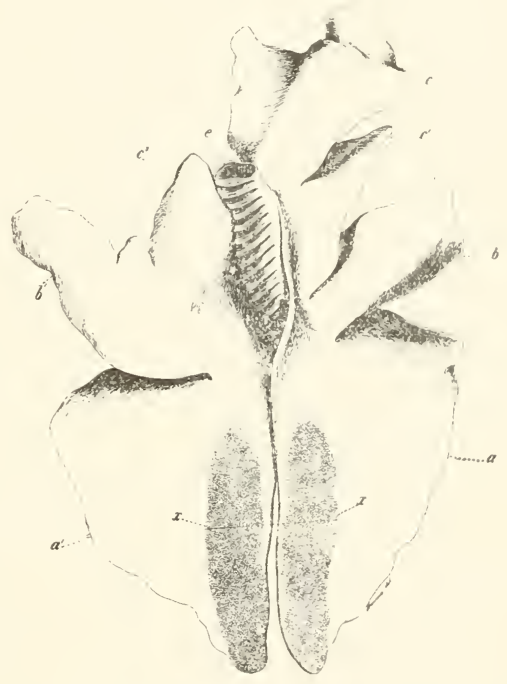

Fig. 32. Dorsal a spect of bovine lungs. (a-a $a^{1}$ right and leit caudal lobes, $\left(b-b^{1}\right)$ r. and l. ventral lobes, $\left(c-c^{1}\right)$ first and second right cephatic lobes, $\left(c^{-}\right)$left cephalic lobe, $(e)$ trachea, $\left(x^{*} x^{*}\right)$ region most frequently involved in the earliest stages of pulmonary tuberculosis. The lesions at this stage are nsully embedded in the lung tissue (Smith). times be detected by palpation accomplished by placing one hand on each side of the throat above the laryux and then pressing from opposite sides. 
Tuberculosis of the udder is detected by an enlargement and hardening of the affected part, usually by the absence of

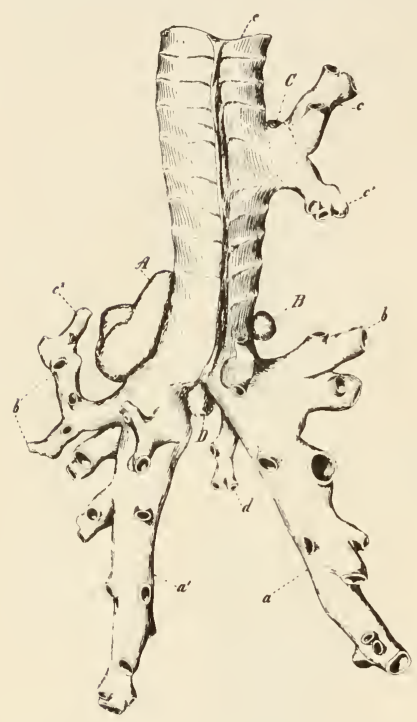

Fig. 33. Trachea and bronchial tubes of bozine lungs showing attached bronchialglands. $\left(a-a^{1}\right)$ Supply right and left caudal lobes, $\left(b . b^{\mathrm{x}}\right)$ supply $r$. and l. ventral lobes, $\left(c-c^{\mathrm{T}}\right)$ branches of the right supernumerary bronchus, $\left(c^{2}\right)$ supply left cephalic lobe, (d) branch to azygous tobe, (e) trachea. A. Left bronchial lymph gland. $B$. Right bronchial lymph gland. C. Lymph gland base of supranumerary bronchus. D. gland often between bronchi. The glands $A$. to D., are often involved (Smith). pain and the fact that the secretion is not altered until the part has been diseased for some time. In advanced cases, instead of milk, the udder secretes a yellowish, cloudy and sometimes flocculent liquid. In acute, rapidly developing cases, there may be pain and edema of the skin. In nearly all cases of udder tuberculosis the supramammary lymphatic glands situated above the udder in the middle of the escutcheon, are enlarged and hard. If there is doubt as to the character of the disease of the udder, the milk, or possibly a piece of excised udder tissue, may be examined bacteriologically.

In tuberculosis of the brain, the animal is unsteady and uncertain in its movements. It lies down much of the time, is usually subject to occasional cramps and is apt to carry the head in an unusual position. Such cases are inclined to advance rapidly and terminate in death following coma or convulsions. 
In tuberculous disease of the bones and joints, the parts are enlarged, there is loss of motion, pain and usually abscess formation followed by the discharge of thick yellow pus. In tuberculosis of the uterus or ovaries and sometimes in peritoneal tuberculosis of the cow, the subject is almost continually in heat. In tuberculosis of the uterus, there is sometimes a discharge of thick, yellowish material mixed with mucus. In tuberculosis of the testicles the orgaus become enlarged and hard.

In all advanced cases, the nutrition of the animal is interfered with and, sooner or later, the "tuberculous cachexia" appears. It is, however, in many cases remarkable to note the extent of lesions in animals that are well nourished and present no external signs of disease. Animals killed in prime condition by the butcher are sometimes found to contain extensive and widely. distributed lesions of tuberculosis. In general tuberculosis, 
many of the symptoms described above may occur simultaneously. The symptoms of acute miliary tuberculosis, "galloping consumption," are rapid loss of flesh, depression, poor appetite, cough, weakness, rapid breathing, harsh respiratory sounds, some elevation in temperature, increased pulse rate and, sometimes, enlarged lymphatic glands. The course of this form of tuberculosis is always rapid and terminates in death. Acute miliary tuberculosis occurs when large numbers of tubercle bacteria are discharged into the blood or lymph currents. They are then carried to other parts of the body, filtered out in the capillaries of the lungs, liver, spleen, kidneys and elsewhere, causing tubercular lesions in each of these localities. The lesion from which the infectious material entered the circulation may have been a comparatively small nodule. This form of the disease is more likely to appear in young animals than in adults, and is more common among swine than in cattle.

S 143. Morbid anatomy. The usual direct anatomical changes following the invasion of tubercle bacteria are the formation of nodules or tubercles. A tubercle has been defined as, " a small nonvascular nodule composed of cells varying in form and size with some basement substance between them and with an inherent tendency to undergo central necrosis." In a large number of cases the individual tubercles are distinct and easily recognizable, while in others they are coalesced, forming a mass of necrotic tissue. The lesions vary, therefore, from well isolated minute or larger nodules to masses or cavities containing a purulent, caseous, or calcified substance.

The location of the primary lesion depends upon the channel of infection. If the specific organisms are lodged in the oral cavity or pharynx they may, through an accidental abrasion of the mucosa, be taken to some of the lymphatic glands about the head; if they are taken directly through the respiratory passages into the lungs they either develop nodules in the lung tissue proper, or they are carried through 
the lymphatic system to the lymph glands draining the lungs where the lesions first appear. If the specific bacteria are first lodged in the intestinal mucosa, primary tuberculous ulcers may develop or they may pass into the mesenteric lymphatics or the portal vein. It may happen that the bacteria may be carried by means of the lympli or blood stream and lodged in any part of the body, such as the brain, kidneys, spleen, testes, ovaries, bones, joints, and subcutaneous and intermuscular glands and serous membranes. The evidence at hand,

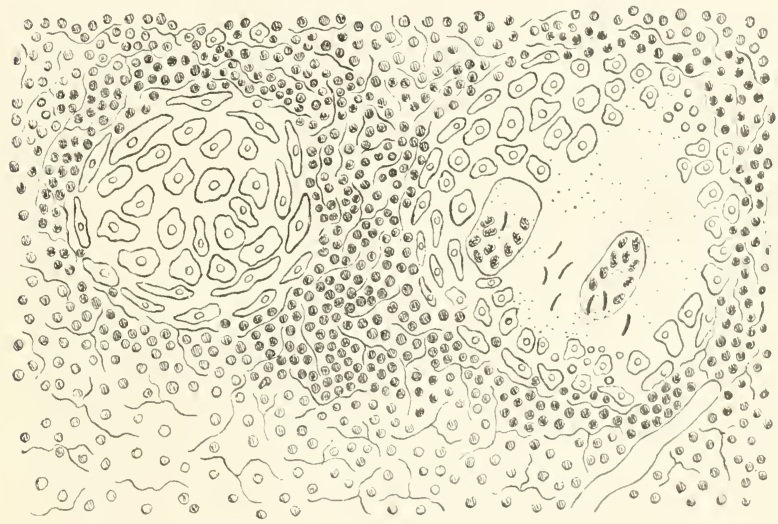

FIG. 35. Adrawing of a section of very young tuhercles in spleen (Thoma).

however, seems to show that in a large majority of cases the primary lesions are located in one of the five following organs: (1) in the lungs or the lymphatic glands draining them, (2) in the lymphatic glands about the head, (3) in the mesenteric glands and intestines, $(4)$ in the portal glands or liver substance itself, and (5) in the generative organs and udder.

It not infrequently happens that the apparent prinary lesions occur on the pleura, peritoneum, meninges or synovial membranes while the organs remain free from disease. In such cases the lesions consist of many tubercles varying from 


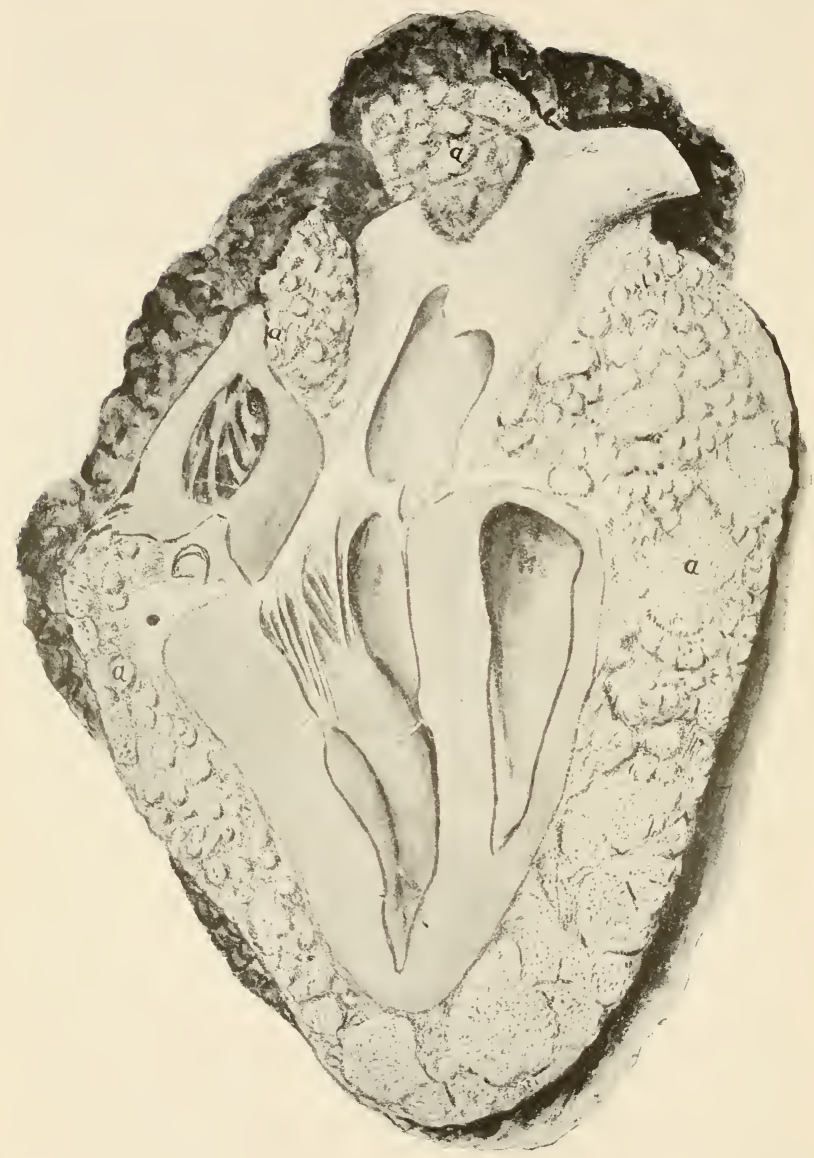

FIG. 36. Section of a tuberculous heart of a cow. (a) tuberculous deposit surrounding the heart muscle and base of the larger blood vessels. 
one to ten or more millimeters in diameter or of bunches of closely set tubercles which are more or less flattened or irregular in sliape, owing to their nutual pressure. Sometimes these tubercles are attached to the serous membrane by a small, tough, fibrous pedicle; frequently, however, this is absent and the nodules rest bodily upon the membrane.

The structure of the tubercle consists in the beginning of a few cells surrounding the invading specific organisms. These are soon encased by a zone of epithelioid cells and giant cells which is soon surrounded by an outer layer of round or lymphoid cells. The central portion becomes necrosed and as the nodule enlarges the central necrotic portion becomes correspondingly large.

This histological structure of the tubercle is typically illustrated in the beginning avian tubercle. In cattle there is a strong tendency for the necrotic tissue to become infiltrated with lime salts and encapsulated. In certain species a deposit of fibrous tissue in the outer zone of the tubercle has been observed. In the smaller and more susceptible experimental animals such as the guinea pig and rabbit and frequently in swine, the lesions are of a more diffuse nature infiltrating the interstitial tissue with the tuberculous mass and gradually encroaching upon the parenchyma. Circumscribed tubercles may also be present.

In secondary or generalized tuberculosis one or more of the organs, such as the omentum, serous membranes, or lymphatic system, may become more or less thickly sprinkled with minute grayish nodules about the size of a millet seed. These tubercles are at first almost the color of mother-of-pearl but later as the central caseous degeneration begius they become grayish. Giant cells are usually numerous.

In studying the lesions in a fatal case of tuberculosis one may find with varying modifications one or more of the following conditions :

I. The primary lesion may be found in any one of the organs or membranes. Its comparative age is determined by the character of the anatomical changes. It may be entirely 
encysted, easeous or calcareous and dead. In addition to the primary focus, there may be a succession of tubercles of various ages distributed in one or more organs.

2. The lesions may be restricted to one organ, as the liver, in which the primary focus has spread by continuity due to its infiltrating nature until the destruction of the tissues of the organ has become so extensive that death results. Such

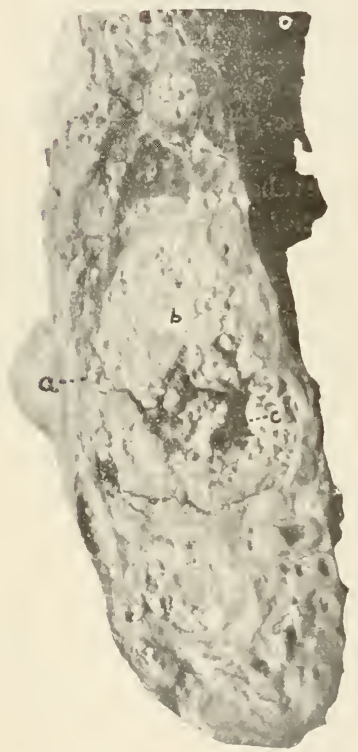

Fig. 37. Tuberculous focus in lung showing areas of, (a) caseation, (b) calcification, and (c) liquefaction. cases do not seem to be common.

3. The primary lesion may be well marked and accompanied by miliary tubercles sprinkled extensively throughout the organs and tissues of the entire body.

4. The lesions througliout the body may resemble each other very closely, so that difficulty nay be experienced in determining the primary focus.

In the lungs, two distinct forms of lesions are observed. (1) The air cells may be infiltrated with the tuberculous mass spreading directly from the primary focus. This may be purulent, caseous or calcareous. The color may be whitish, gray or of a yellowish tinge. (2) The lesions may consist of miliary tubercles. In later stages these nodules, more or less translucent, may become yellowish, caseated and calcareous in their centers. Large tubercular nodules are frequently formed by the massing of several of these minute tubercles.

When the luugs are primarily attacked the caudal (principal) lobes are most frequently involved. Smith considers 


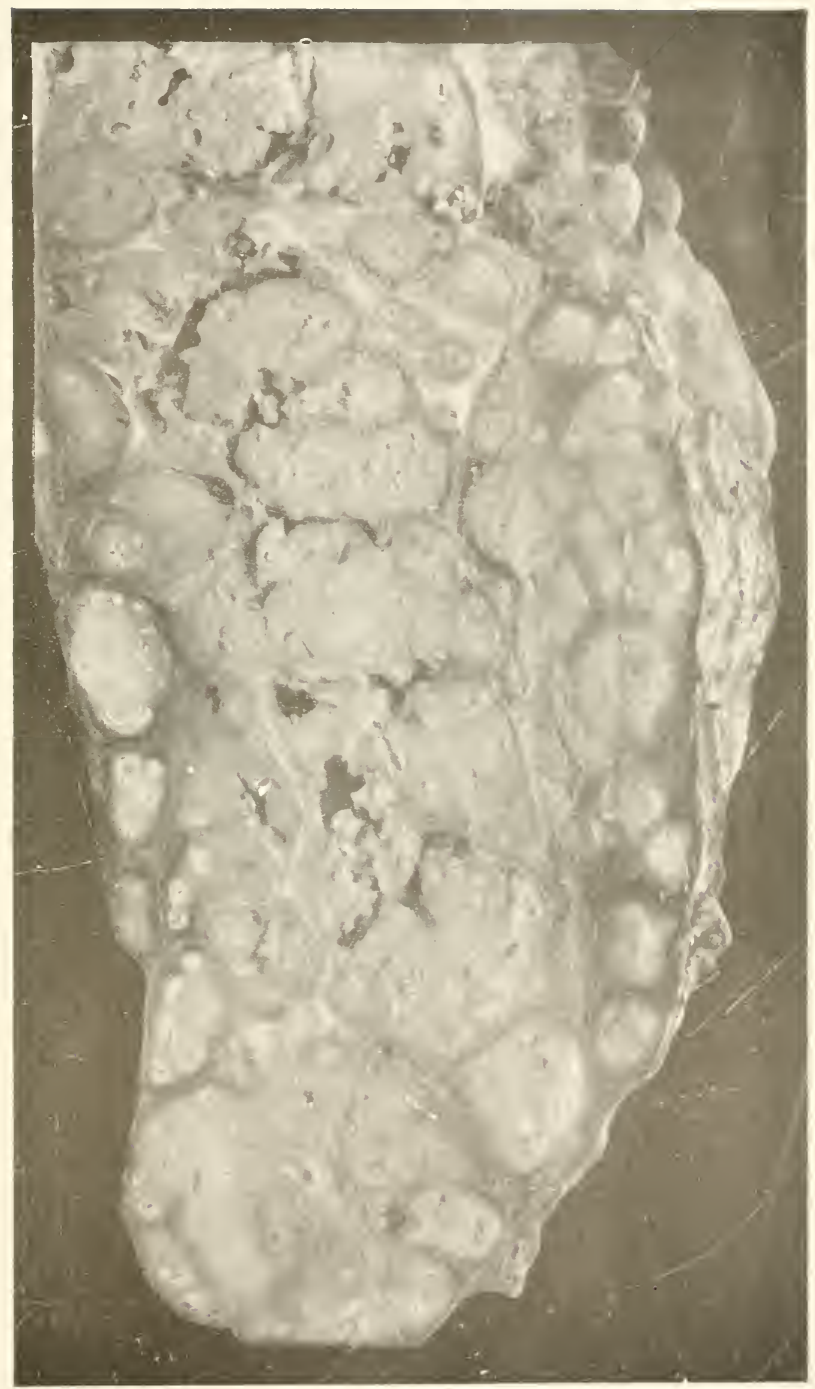

Fig. 38 . Photograph of a section from anterior lobe at tubarculous lung of a cow, showing tubernious infiltration and calcified areas. 
the seeming predilection for the larger lobes to be due to mechanical conditions. The writer has found, however, that in certain herds that have been killed after the tuberculin test,

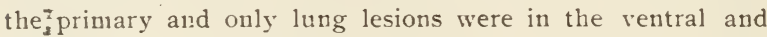
cephalic lobes. It is important to note that usually the bronchial glands are also involved. When the pleurae are affected the lesions consist of nodules varying in size from that of a millet seed to a large pea, sprinkled more or less thickly on one or both of the visceral or parietal surfaces. These form

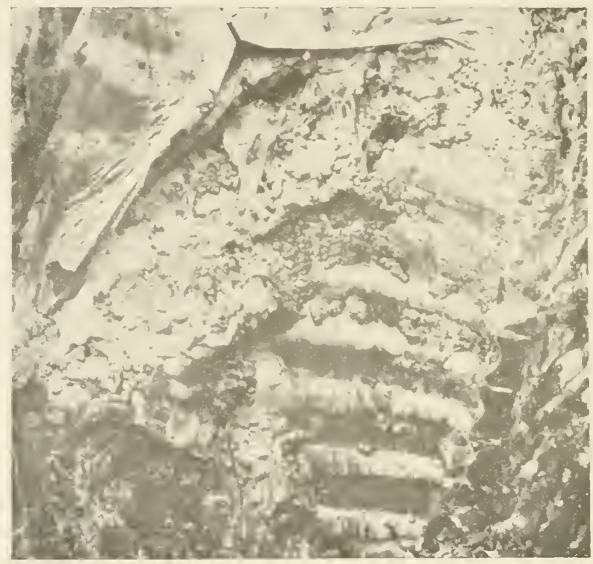

FIG. 39. Photograph of pleura shouing small tuherculous nodules.

the "pearl disease" Perlsucht of the German and the "grape disease" of the English writers. If they become confluent, large masses are found.

Tuberculosis of the thoracic glands is very common and usually accompanies lesions in the lungs; but the lungs may be healthy and the glands involved. (See figures for location of glands.) The primary lesions may be and often are found in the lymphatic glands about the head. 
In the abdominal cavity the organs most frequently involved are the peritoneum, mesenteric lymph glands, portal lymph glands and liver. The kidneys, spleen, ovaries and uterus are more rarely the seat of tuberculous tumors. Ulcers in the intestine have not been conmon in the writer's observation. The ulcers in the cases observed have been isolated

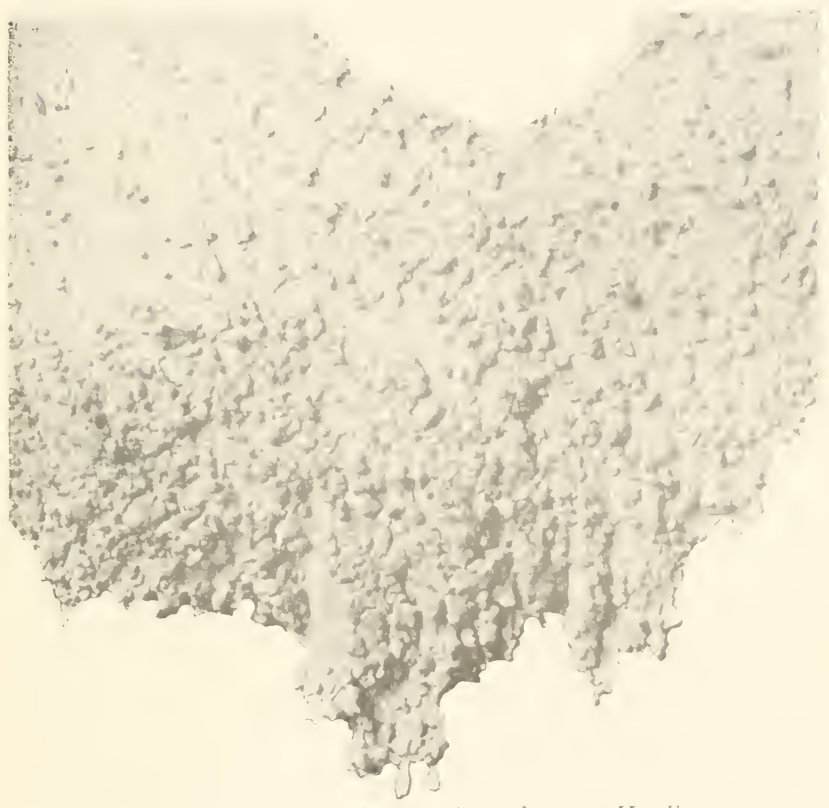

FIG. 40. Tubercles on the mesentery of a cou' (Harding).

with elevated borders and a depressed center. Sections show that the tuberculous infiltration extends outward and to a certain extent undermines the mucosa. Tuberculosis of the testis is sometimes found. The udder becomes the seat of tuberculous deposits in a small percentage of cases. It is 
more often affected in cases of generalized tuberculosis. When the primary infection is restricted to a single focus the disease is said to be localized. When the specific bacteria

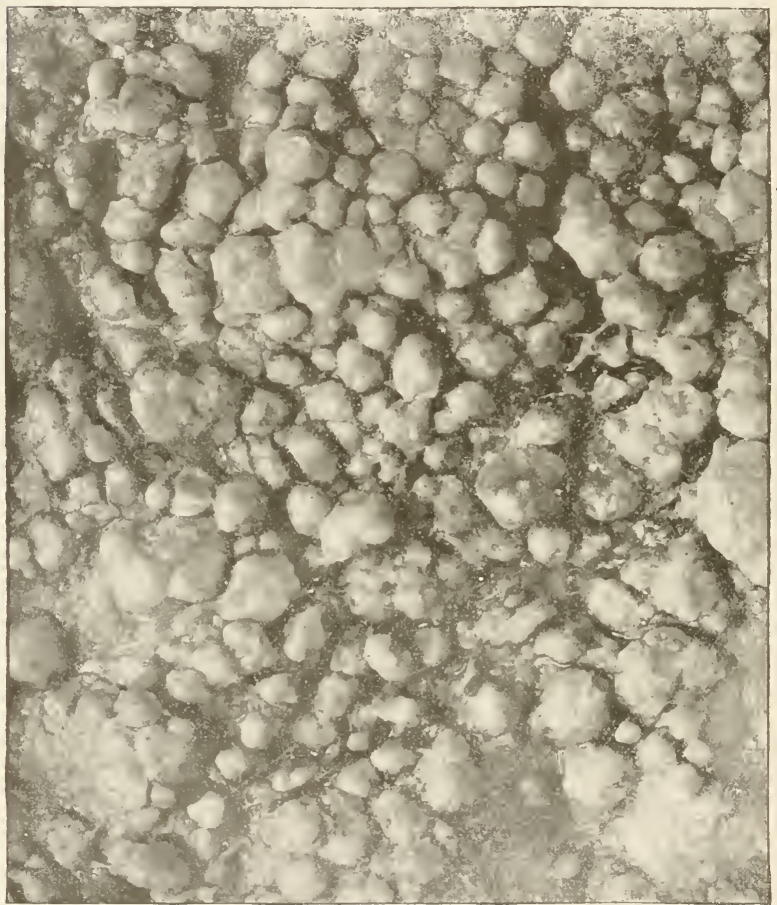

Fig. 4I. A photograph of the tuberulous nodules on the omentum from an advanced case of veneralized tuberulosis.

are spread from the primary lesions through the agency of the lymph and blood streams, sprinkling other organs with the infecting bacteria, each of which becomes the starting point 
for the development of a new tubercle, the disease has become generalized.**

It was formerly considered that when the lesions existed in both of the large (abdominal and thoracic) cavities of the body the disease was generalized. It is possible, however, for it to be generalized when the lesions are restricted to the organs of one cavity, as the secondary seeding with the bac-

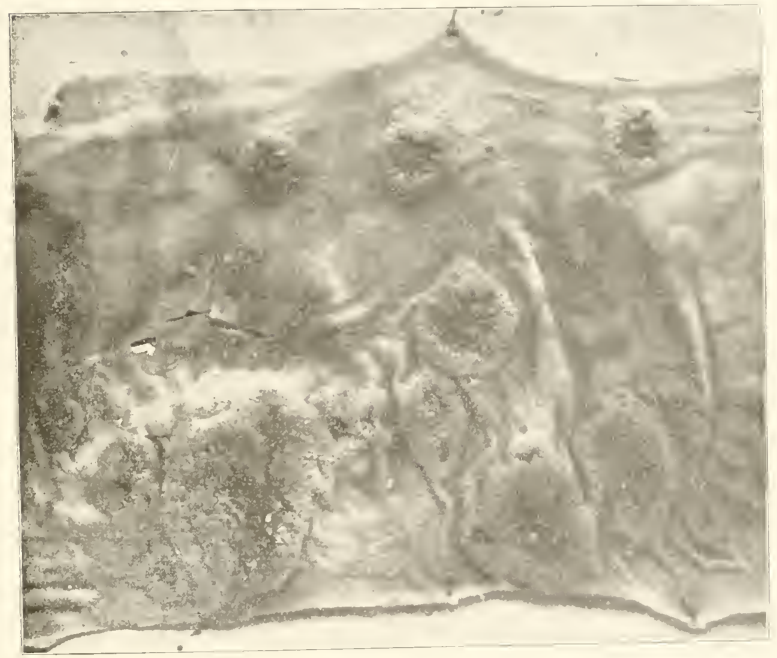

FIG. 42. A photograph of seieral tuberulous ulcers in the intestine of a cori.

teria that have escaped from a primary focus through the circulation may be restricted to the cavity in which the first lesion developed. It seems better, therefore, to accept Ostertag's views and classify local and generalized tuberculosis

*The Federal meat inspection regulations state that animals affected with "extensive or generalized tuberculosis" are to be condemned. 
in accordance with the nature of the lesions rather than their distribution in the body.

The fact is worthy of consideration, that very often cattle killed after reacting to tuberculin do not show extensive dis-

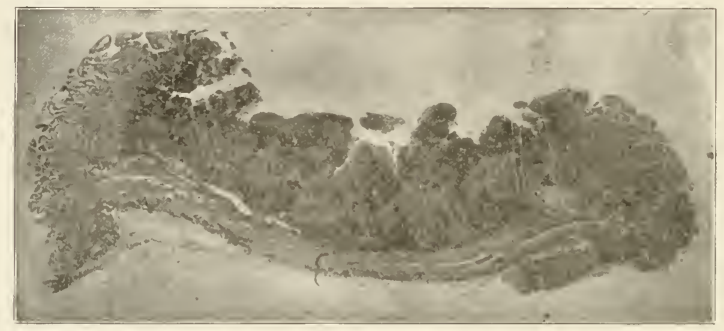

FIc. 43. A photograph of a section of a tuberculous ulcer, from a coa's intestine, showing infittration under the marginal mucosa.

tribution of lesions. Frequently animals are killed soon after infection has taken place, in which case the lesions are restricted to a single lymphatic gland or other organs. In other cases old lesions of considerable proportion are found as shown in Fig. 36, where the heart muscle is entirely encased in a thick calcareous tuberculous deposit. In this case, the animal was in good flesh and killed for beef without a suspicion that it was in any way diseased.

\section{TLBERCULOSIS IN SWINE}

I44. Channels of infection. It is stated that among swine young animals belonging to the precocious breeds seem to be more liable to tuberculosis than others. In nine eases out of ten the animals are infected by ingestion. The pig easily becomes tuberculous when fed on material rich in tubercle bacteria. If pigs are fed on the refuse from dairies and cheese manufactories in districts where there is much tubercu- 
losis in cattle or on tuberculous viscera they readily become infected. Mohler found that when hogs were fted on tuberculous milk for three days, and killed and examined post-mortem I07 days later that 83.3 per cent were tuberculous. Hogs that received infected milk for 30 days and were allowed to live fifty days thereafter loo per cent were affected. Infection through the respiratory tract, while it is certainly possible, seems to be rare. The piggeries where the refuse from butter and cheese factories is fed and those which join abattoirs supply the majority of swine found on post-mortem to be tuberculous.

Ostertag has called special attention to this disease as existing among swine in certain parts of northern Denmark and Germany, where there was much tuberculosis in cattle, and where the swine were fed the slime from creamery separators. Experiments show the possibility of infection by means of the sputum of tuberculous people.

In the cases which have come to notice there is very strong eridence that the swine were infected by being fed the milk from tuberculous cows. In one of these cases, the tuberculin test showed that a large number of the cows from which the milk was obtained were affected.

I45. Symptoms. In most cases tuberculosis of the pig is first recognized at the abatton. Sometimes, however, it causes local and general troubles, which vary according to the organ or system attacked. The following symptoms have been noted.

Its localization in the abdominal organs causes the arrest of fattening and the progressive wasting of the subject. The mucous membranes become pale, the hide becomes dirty and there is usually either constipation or diarrhea. The animal is in low spirits, the corkscrew of its tail is straightened, the abdomen is pendulous and the eyes are sunken. Palpation of the abdomen is painful and may reveal more or less voluminous masses, due to the changes in the mesenteric glands. It is common to find glandular tumors in the submaxillary region or at the thoracic inlet. In this form, the malady may 
last several montlis, but death supervenes rapidly if the lesions become generalized by the scattering of the bacteria through the blood stream. Primary pulmonary tuberculosis is very rare but sooner or later luug lesions complicate abdominal tuberculosis. They betray themselves at the outset by a short, dry, abortive cough and by difficult respiration. The cough soon becomes paroxysmal and painful and is often followed by vomiting; the respiration becomes hurried and gradually painful and more difficult, wasting is very rapid, and death supervenes in a few weeks.

The scrofula of swine (glandular tuberculosis) usually shows itself by a puffing up of the face, which a careful examination shows to be lifted up by the subjacent glands, these being enlarged, indurated, still fairly mobile and free from heat or tenderness. The retro-pharyngeal, superior cervical and sublingual glands are usually affected, forming a kind of necklace of unequal and knotty tumors, reaching from ear to ear and becoming larger under the neck between the rami of the lower jaw. Similar tumors may be developed at the thoracic inlet, behind the shoulder or in the groin, which, as they increase in size, becone harder and more adherent to the neighboring tissues. Sometimes, however, a slight fluctuation is perceptible. The tumor may suppurate and discharge a small quantity of a thick and grumous pus, but the glandular tumor does not disappear and the opening into the abscess remains for a long time as a fistula.

There may be swellings of the bones, causing a true tuberculous arthritis when the lesions happen to be situated at the level of an epiphysis. Persistent lameness, fistulous wounds suppurating indefinitely, necrosis and caries, are the complications of the lesions of the bone, the development of which is always extremely slow.

5 146. Morbid anatomy. The manifestations of tuberculosis in swine are exceedingly interesting. Nocard found the lesions to consist of miliary granulations which rapidly become caseous, as in cattle, but which more rarely 
Plate I.

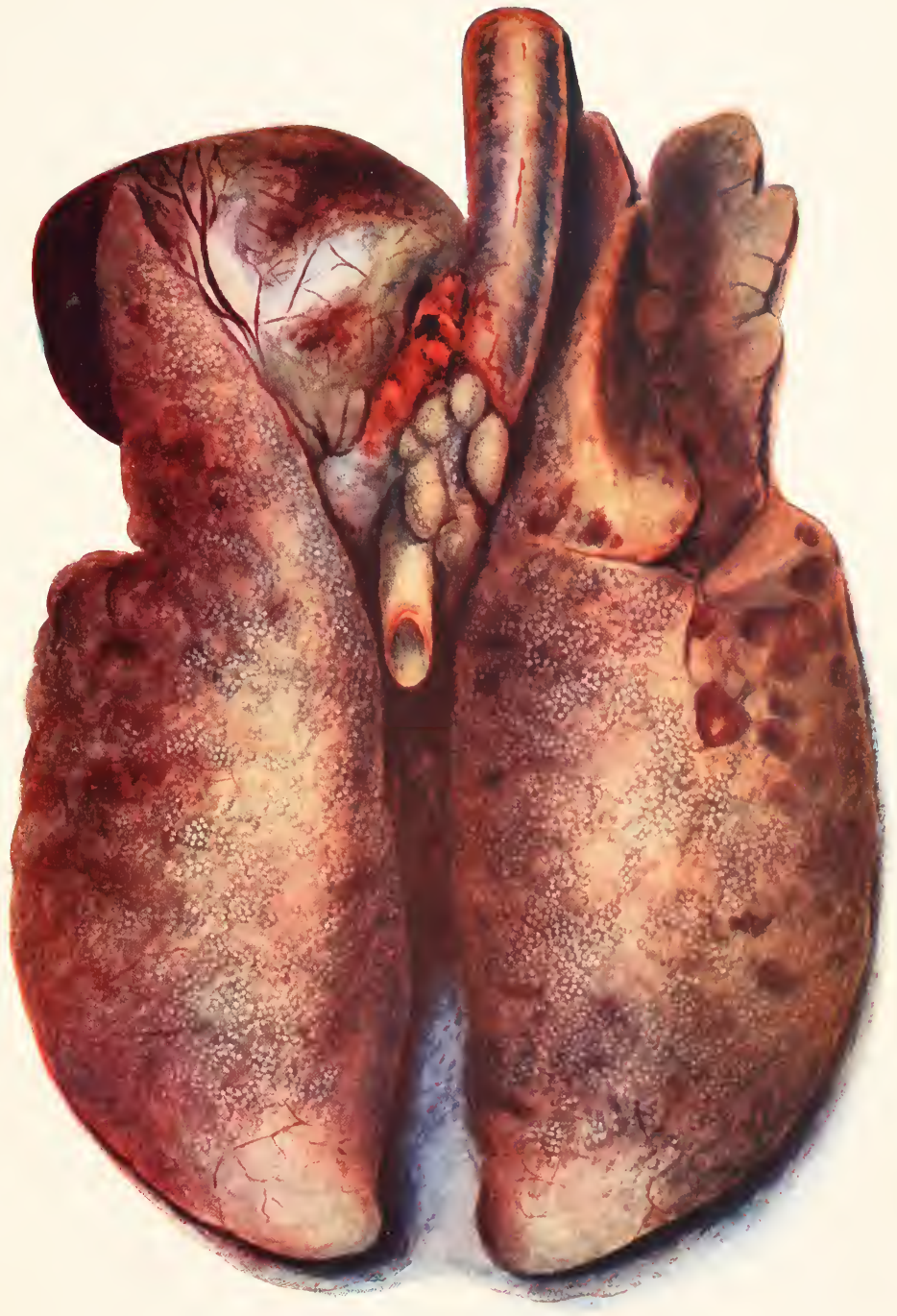

TUBERCULOUS LUNGS OF HOG 

contain calcareous salts. Generalization is common, in which case the viscera are thickly sprinkled with gray granulations which are translucent thronghout, or opaque in their centers, and quite analogous to those found in tubercular lesions in other animals.

As the disease most often results from ingestion of the virus, the digestive apparatus and the corresponding lymphatic glands ( $\mathrm{sub}$ maxillary, parotid, pharyngeal, superior cervical, mesenteric, sublumbar, etc.) may be decidedly diseased, while the other organs remain practically intact. Lesions of the small intestine and of the cecum are common and take the form of ulcers of the mucous membrane, of miliary nodules or of tuberculons infiltrations, involving at once the mucous, the muscular, and subserous tissues. The lesions in the liver take the form either of miliary granulations, which are yellow and caseous and scattered in great numbers through the thickness of the organ, or else of rounded nodules which are yellowish white in color, varying in size from that of a pea to a hazel nut and of a tough consistency. On section they appear sometimes to be firm, homogeneous and fibrous; sometimes softened in the center,

often infiltrated with calcareous salts. The peritoneum and the

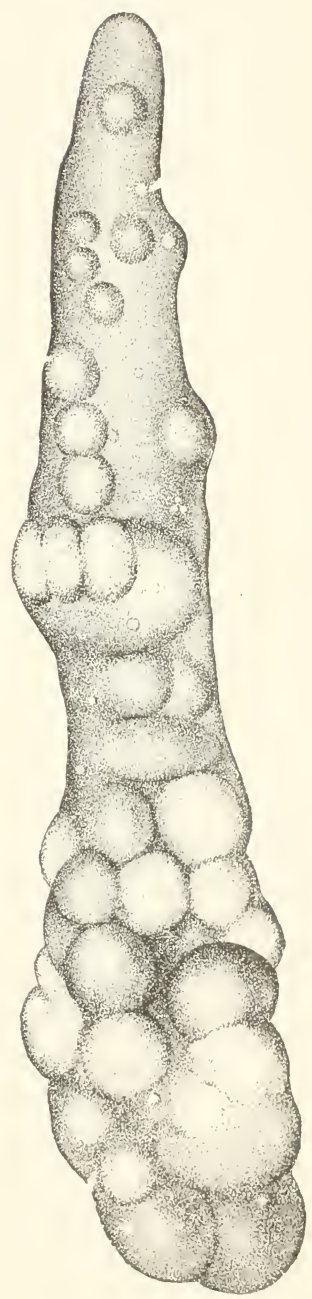

Fig. 4t. Tubiriuleus splien. fiom "pig. 
pleura are sometimes the seat of an eruption of fine granulations which remain in a state of miliary nodules. Lesions like those in the liver may exist in the lungs, but generally there is found in these organs an innumerable number of minute, translucent, gray granulations, caused by the dissemination of tubercle bacteria through the blood stream, in which case the liver, the spleen, the kidneys, the medulla of the bones, and the mammae may be infiltrated with similar growths.

Mohler has reported the results of the examination of I 20,000 infected hogs of which 93.3 per cent had tuberculous glands.

It is common to find lesions localized in one or several lymphatic glands. The pharyngeal and submaxillary glands are the ones most often affected. They become voluminous, hard and knotty, as they have undergone a true fibrous transformation and, consequently, are difficult to cut. This is shown by the creaky sound under the cutting instrument. In section they have the appearance of old fibrous tissues; here and there small yellow foci are seen of a softer consistency, almost caseous; sometimes veritable purulent collections are found, either encysted or in communication with the exterior. If one submits the caseous or purulent matter to a bacteriological examination, tubercle bacilli are not usually found. The bacterium, however, is present and if this matter is inoculated into the peritoneal cavity or the subcutaneous tissue of guinea pigs it will produce tuberculosis.

These chronic glandular lesions, with their very slow progress, have long been looked upon as constituting the scrofula of swine, and to scrofula was also assigned the tuberculous lesions of bones (ribs, vertebrae, articulations, shoulder blades, hip bones) which are common in pigs, both young and old.

The older authors noted that the ancient scrofula was often accompanied by visceral tuberculosis, but they refused to admit the identity and even the relationship of the two affections.

The generalization of the disease, especially in the muscular tissue, is reported by several observers. Moulé called at- 
tention to this peculiarity of the disease. Stocknan shows that while the disease is ordinarily generalized, muscular lesions may exist in swine in the absence of generalization. Zschokke has called special attention to the localization of tuberculous lesions in the head of swine, especially in the nares and brain.

TLBERCLLOSIS IN OTHER MAMMALS

$\$$ 147. Genera affected. It is stated that all species are sometimes attacked. Tuberculosis in the horse is rare, although a total of many cases have been reported. Bang has collected twenty-nine cases. In Saxony .os per cent of the horses $(3,500)$ that were slaughtered were tuberculous. In this and most countries there are no reliable statistics respecting the extent of the disease in this species. M'Fadyean has pointed out the fact that in a considerable number of cases of equine tuberculosis, where the horses have been fed milk from tuberculous cows, the morbid anatomy differs but slightly from that in tuberculous cattle. Recently several authors have reported isolated cases in Europe. In this country horses are practically free from it.

Sheep and other domestic animals are reported to suffer more or less extensively from this disease. All of the so-called tuberculosis in sheep that I have examined proved not to be tuberculosis but the "nodular disease" caused by an animal parasite, (Oesopagostoma Columbianum). A few cases, however, liave been reported.

Tuberculosis in dogs and cats is quite rare but several cases in each genus are on record.

\section{AVIAN TIBBERCLLOSIS}

148. History. In America, tuberculosis in fowls was described by Pernot in Oregon in I 9oo. In I 903 Moore and Ward found the disease in California, where in certain flocks it was 
very destructive. It was recognized by the owners as " spotted liver," going light, and rheumatism. In rgoo it was described by Burnett from northern New York. In Europe it has

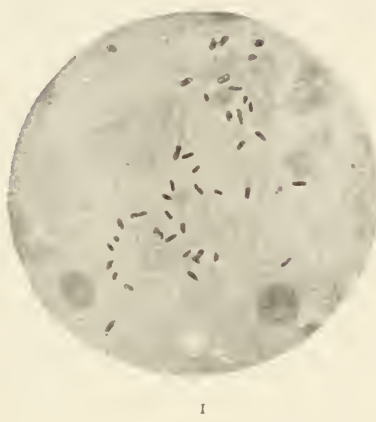
been known for a long time.

$\leqslant$ 149. Symptoms. The symptoms described as quite constant are emaciation, which in advanced cases becomes extreme, and anemia. The comb, the skin, and the visible mucosa about the head are usually pale. As the course of the disease advances the feathers become ruffled and the fowls are weak, dumpish and more about very little. The eres are bright in most cases until the end is near.

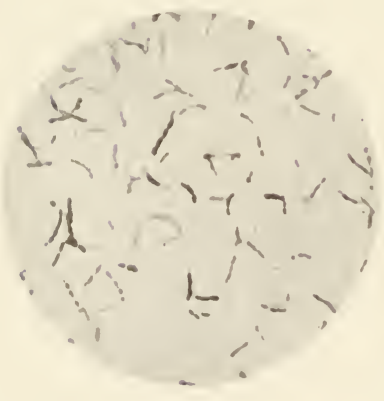
The appetite is good, and the fowls eat ravenously until a few days before death. The temperature is in most cases within the normal limits. rarely it is subnormal. The blood is pale. The hemoglobin varies from thirty-five to serenty per cent as tested with Gowers' hemoglobinometer. The red blood corpuscles vary from $\mathrm{I}, \mathrm{OIO}, 000$ to 2,600,000 per cubic milliFIG. 45. Avian tubercle bateria. (1) from liver tissue of a fou'l, (2) a photograph from a preparation from a glycerine agar culture. $\times$ about 600 . meter. There appears to be a slight increase in the number of white corpuscles, especially of the eosinophiles.

Tuberculous fowls are often lame. Pernot mentions this as one of the important symptoms in the cases he observed. 
It is due to joint lesions in some cases. to be due to extensive lesions in the viscera.

S 50 . The avian tubercle bacteria. These organisms resemble quite closely those of the human and borine varieties in their size and general morphology as they are found in the tissues of the fowl. A measurement of over two hundred individual organisms in cover glass preparations made directly from organs of fowls gave the following: In the liver the length varied from 1.2 to $3.5 \mu$, in the spleen and in the skin they varied from $I$ to $+\mu$ in length. A general average gave a length of $2.7 \mu$. They often appear in these preparations in dense masses. Chains made up of a number of short elements are rarely present. Granules are occasionally ouserved. In the preparations from the skin a considerable number of them contain polar granules and not infrequently three such bodies were noticed in a single indiridual. Perliaps the most striking feature concerning these organisms in the tissues is their enormous! numbers. Sibley has called attention to the similarity of arian tubercle bacteria to those of leprosy in that they multiply to such enormous numbers without a pronounced breaking down of the tissues.

This variety is more easily obtained in pure culture from the lesions than the human or bovine forms. Moore obtained pure cultures in abont 20 per cent of
In others it appears
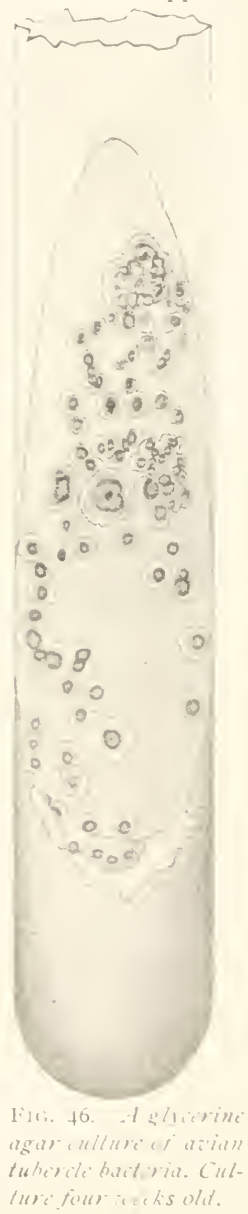
serum tubes inoculated directly from tuberculous lesions in fowls. It grows readily on glycerin agar, Dorset's egg medium, potato and in glycerin bouillon.

The colonies on glycerin agar vary from one to three millimeters in diameter. The central portion is raised and of a slightly yellowish tint as observed under a hand lens. This central part is surrounded by a flat expansion, about two-thirds the thickness of the center, varying from one-half to one millimeter in width, with ray-like projections radiating from it and extending into the outer and very thin band of growth with a lobulated margin. On the egg medium of Dorset the growth is not more vigorous thau that upon glycerin agar. Potato cultures are quite vigorous, wrinkled and of a yellowishbrown color.

Fowls inoculated in the abdominal cavity or subcutaneously with from one-half to one cubic centimeter of a glycerin bouillon culture develop either localized or generalized tuberculosis in from six weeks to three months, but a much longer time is necessary to destroy them.

Rabbits and guinea pigs are not readily infected by the inoculation of pure culture. Moore and Ward failed to produce any tuberculous lesions in these species.

S I1. Morbid anatomy. The lesions are widely distributed, and vary much in their location in different individuals. The liver is most frequently involved. The spleen, intestines, mesentery, kidneys, lungs and skin are affected in order mentioned. The appended table gives the distribution of the lesions in 7 cases observed by Moore. 
TABLE SHOWING THI JISTRIBUTION OF LESIONS IN TI IBER-

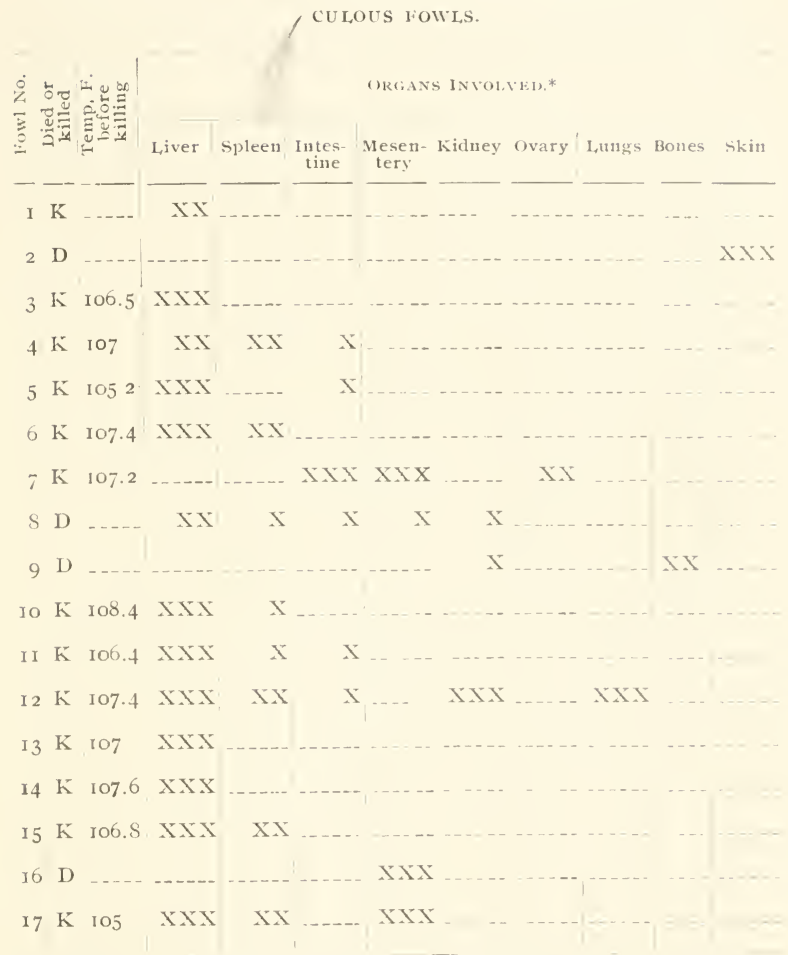

*The relative numbers of tubercles are indicated by the number of Xs. XXX indicates an extensive invasion, $X X$ a less number of tubercles, and $X$ very few, Figures 47 and 48 show extent of lesions represented by Xxx.

The tubercles, especially in the liver, in the earlier stages of the disease, are small greyish points varying from 0.25 to I.o millimeter in diameter. In advanced cases they are larger. They have a cheesy consistency, and are easily removed from 
the surrounding tissue. The remored, necrotic nodules have a roughened surface. The color is greyish or whitish in the early stages, but in the later ones it changes to a yellowish tint. Occasionally there are two distinct crops of tubercles,

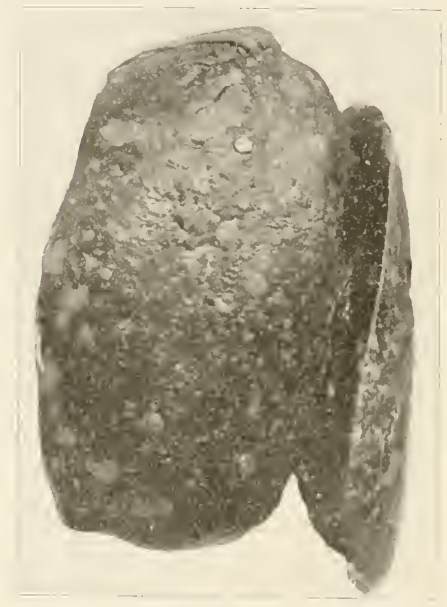

FIG. 47. A photograph of a tuherulous lizer from a fow'. one consisting of nodules + to 6 millimeters in diameter and separated by a centimeter or more, and the other of closely set grayish tubercles 0.25 to $0.5 \mathrm{~mm}$. in diameter. In some cases the tubercles are few in number but larger in size. The liver cells between the tubercles are usually in a state of more or less degeneration, and frequently fat globules are numerous. The blood spaces are more than normally distended with blood.

The lesions in the spleen, like those in the liver, consist of minute or larger tubercles of a grayish or of a yellowish tint. The central portions of the larger tubercles are often homogeneous, darker in color and more or less hyaline in appearance and consistency.

The tubercular growths in the intestine start in the walls of the intestine. They present a glistening appearance, grayish in color and firm to the tonch. Frequently they are confluent. When single they vary from $\mathrm{I}$ to $\mathrm{IO} \mathrm{mm}$. in diameter. They are usually sessile on the intestine but on the mesentery they are frequently pedunculated, varying from 
2 to $5 \mathrm{~mm}$. in length. On section the young tubercles exhibit a grayish, glistening surface, but the more advanced nodules contain recognizable necrotic centers. In the larger tubercles on the intestines the necrotic centers frequently open into the lumen.

The skin lesions consist of a cellular infiltration usually about the root of the feathers. Frequently the nodules be-

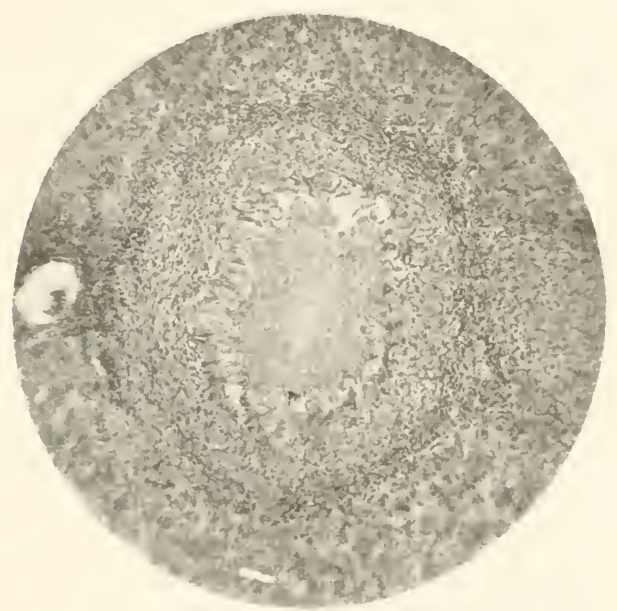

FIG. 45. I photograph of a section of tubercle from a fowl, showing the necrotic cinter and surrounding zones. Enlarged.

come confluent. They may or may not involve the subcutaneous connective tissue.

The microscopic examination of the tubercles of the liver shows them to consist of a necrotic center surrounded by an irregular zone of epitlielioid and giant cells. This is surrounded by a band of tissue consisting for the greater part of liver cells more or less disintegrated, free nuclei and a few infiltrated round cells. This zone is circumscribed by a nar- 
row reactionary band consisting very largely of round cells. The structure is constant in both small and large tubercles, and not strikingly different from the structure of tubercles in

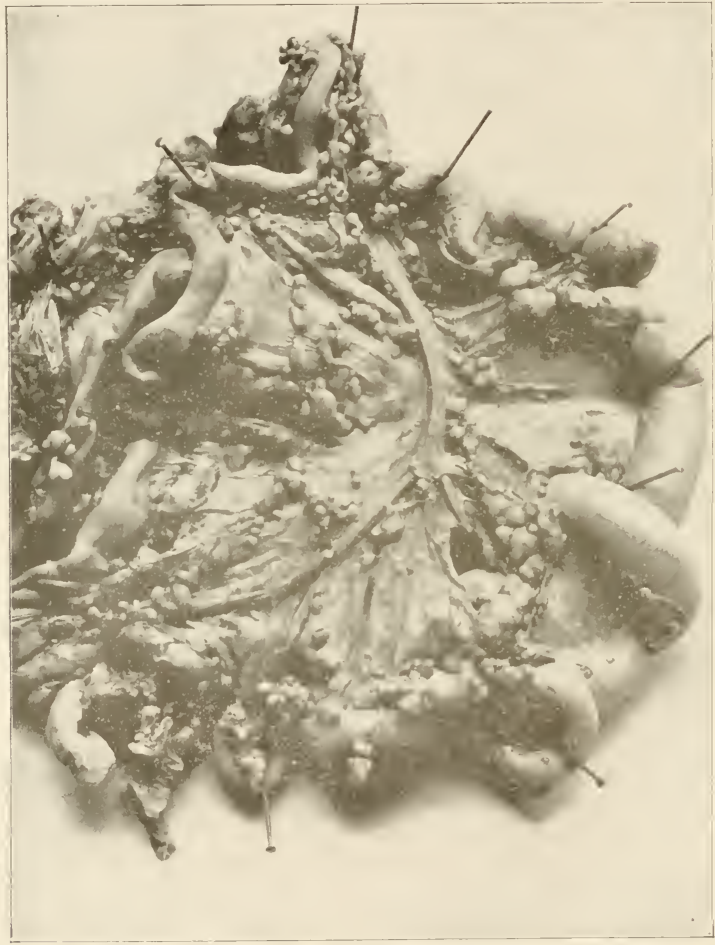

Fig. 49. A photograph of a tuberculous mesentery of a foul. There are a fea small tubercles on the intestine.

certain of the mammals. The larger nodules seem in some instances to be the result of a continuous growth of a single 
tubercle, and in others to have resulted from the coalescence of a number of small ones. The necrotic center and reactionary zone of round cells are beautifully demonstrated by their reaction to nuclear stains.

\$52. Differential diagnosis. Tuberculosis in cattle

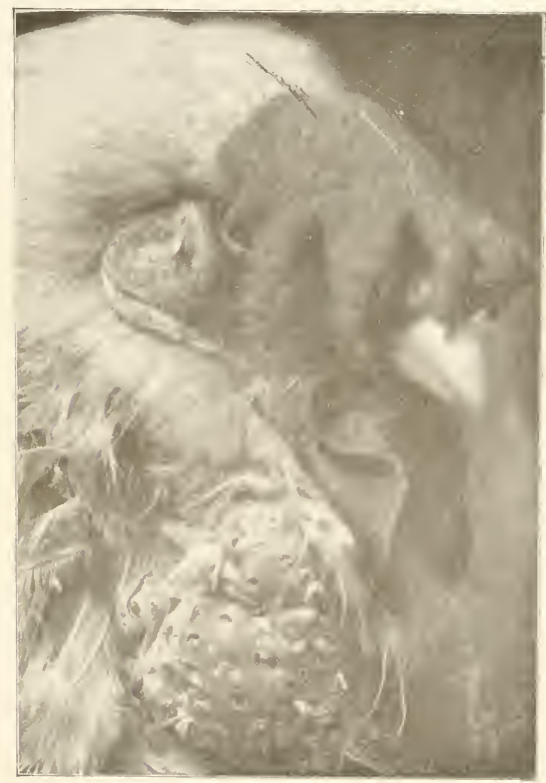

Fig. 50. A photograph of the head and part of the neik of a tubiculous fowl.

and swine is to be differentiated from actinomycosis, glanders, and various parasitisms resulting in nodules largely in the walls of the intestine. In cattle the nodules are produced by an Oesophagostoma. In sheep the nodules are caused by 
O. Columbianum Curtice. In chickens a nodular taeniasis of the intestine is not infrequently mistaken for tuberculosis. Abscesses and necrotic foci due to various agencies must also be distinguished from tuberculous lesions. Enlargement of the lymphatic glands may be due to Hodgkin's disease.

In cases of actinomycosis, the ray fungus can usually be detected on a microscopic examination. Bacterium mallei can be found either in cultures or by guinea pig inoculations in cases of glanders, and in parasitic diseases the specific animal parasite can be found if diligently sought. A careful study of the recent lesions, especially in the nodules cansed by the animal parasites, will slow that they are not structurally like the tubercle as described above.

From the symptons and morbid anatomy it is clear that hard and fast lines for diagnosing tuberculosis cannot be laid down. As a rule the lesions are characteristic, although there are many exceptions. In making a positive diagnosis one must rely upon the discovery microscopically of the specific bacterium, the result of animal inoculation or the effect of tuberculin.

The tubercle bacteria can be found by making and properly staining cover-glass preparations from the tuberculous tissues or discharges in a certain number of cases. When these tuberculous lesions open into the respiratory tract the specific bacteria can almost always be found in the expectoration. This is especially true in men, and Ravenel and others have shown that it is often true in cattle. In old and in the very recent tuberculous lesions, it is not so easy to detect these organisms microscopically. When there is doubt animal inoculation gives quite prompt results.

Tuberculosis in fowls is to be differentiated from certain other affections, such as lymphadenoma and sarcoma of the liver, asthenia, nodular taeniasis and excessive infestion with the air sac mite (Cytodites nudus). Because of a close similarity in the general symptoms, and, in certain cases, of the gross lesions, between tuberculosis and certain other affections, the findings of a somewhat careful examination are necessary 
to warrant a positive diagnosis. In the living fowl it seems as yet to be impossible to fix upon any diagnostic symptoms. At post-mortem, however, properly stained cover-glass preparations from the tubercles will reveal the presence of tubercle bacteria. This renders the positive diagnosis in the dead fow 1 a comparatively easy task.

The positive diagnosis of tuberculosis rests in :

1. Finding the tubercle bacterium on a microscopic examination of the lesions.

2. The production of tuberculosis in experimental animals by inoculating them with the suspected tuberculous material.

3. Obtaining a typical reaction after the injection of tuberculin.

S 153. Microscopic examinations. The diagnosis by microscopic examinations is possible when one has the discharge from a lesion, such as the sputum when the lungs are involved. In case of tubercular abscesses, the examinations should be made from the scrapings of the walls of the abscess rather than from the purulent contents. It is often possible to find tubercle bacteria in sections of the diseased organs.

A method for staining tubercle bacteria. Stain the cover-glass with fresh carbol fuchsin. Place a few drops of the stain on the film side of the cover-glass preparation and hold it over a flame with forceps until steam is given off. Allow the hot stain to act for from 3 to 5 minutes, or the preparation may be floated on the carbol fuchsin in a watch glass without heat. In this case it is allowed to act for from lo to 15 minutes. The preparation is then riused in water and decolorized by treating it with a $10 \%$ solution of nitric or sulphuric acid for from 't to I minute. It is again rinsed in water, when it is ready for examination. It can be dried and mounted permanently in balsam. The tubercle bacteria should be stained a deep redilish color. All other bacteria or animal tissue in the preparation should be nearly or quite decolorized. If desired, a counter-stain, such as alkaline methylene blue, may be used after decolorizing; that is, the preparation should be again stained for about I minute in alkaline methylene blue, rinsed in water, and examined as before. In these preparations the tubercle bacteria are red and the other organiams and cells are blue. A counter-stain is of little value in preparations made for simple diagnostic purposes. IThen a 
counter-stain is desired Gabbett's decolorizing and counter-staining solution is very convenient.

G.ABBETT'S SOLUTION

Methylene blue (powder) . . . . . . . 2 grams
soo cc.

After staining with the carbol fuchsin treat the preparations with this mixture until the film has a faintly bluish tint. This solution decolorizes and counter-stains at the same time. Care must be taken not to confuse the other acid fast bacteria with those of tuberculosis. The acid fast bacteria other than tubercle, are decolorized witl acidulated alcohol ( 3 per cent hydrochloric acid in 95 per cent alcohol).

154. Animal inoculation for purposes of diagnosis. Guinea pigs are preferable, although rabbits may be used. With tuberculous tissue either of the two methods described below may be employed.

I. A small piece (about the size of a pea or bean) of the tissue may be inserted under the skin by first making an incision with a sharp scalpel through the skin and superficial fascia, and then witl a pair of fine forceps insert the bit of tissue well under the skin and close the opening with one or more sutures.

2. The tissue may be crushed in a mortar and thoroughly mixed with a few cubic centimeters of sterile water or bouillon and then injected with a hypodermic syringe. The needle should be of large calibre. If it is suspected milk, it may be injected into the audominal cavity. If the material is tuberculous and contains living tubercle bacteria, the death of the animal follows in from three weeks to four months. Usually the lymphatic glands in the groin and axilla are enlarged and often caseons. If a guinea pig is used, the liver, spleen, lungs and kidneys are liable to be affected, in the order named; if a rabbit, the lungs are often the first of the viscera to be attacked.

In avian tuberculosis it is necessary to use chickens instead of guinea pigs. They may be inoculated subcutaneously or into the abdominal cavity. Several weeks may be necessary for the disease to develop sufficiently to distinguish 
the lesions or to enable one to find the bacteria microscopically.

I55. Tuberculin test. The tuberculin test is the best, and in a large majority of tuberculous cases among animals and in man, the only means of positively detecting the disease in the living individual

Tuberculin. Tuberculin is the concentrated liquid. usually glycerinated bouillon, on which tubercle bacteria have grown until the products resulting from their multiplication have become imparted to the medium in sufficient quantity to inhibit their further development. It is not definitely determined just what these products are or just how they are elaborated. Briefly stated, the preparation of tuberculin consists in the following procedure:

I. The preparation of the culture medium glycerinated bouillon), distributing it in suitable flasks and inoculating it with the growth from a pure culture of tubercle bacteria.

2. The flasks are placed in an incubator at a temperature of about $37^{\circ} \mathrm{C}$. where they remain until the growth ceases, The length of time necessary to accomplish this depends upon the age and condition of the culture from which the inoculations were made. From four to ten weeks are usually required.

3. After the maximum growth is attained, the cultures are sterilized by heat. either by boiling in a closed water bath or heating to a higher temperature in an autoclar.

4. After sterilization, the cultures are filtered to remore all of the dead bacteria. and then the filtrate is evaporated over a water bath to the desired degree.

5. The concentrated liquid is passed through a Pasteur or Berkefeld filter, standardized, bottled and labeled for distribution. It should be perfectly clear although its color may vary. If it is cloudy it should be rejected,

It will be seen from the method of preparation that tuberculin cannot possibly contain living tubercle bacteria. It is 
heated on two occasions to a temperature and for a length of time far in excess of that required to destroy them, besides being passed through a filter capable of removing all bacteria.

The original tuberculin or lymph of Koch was concentrated to one-tentli of the volume of the saturated culture. This gave a thick, syrupy liquid owing to the presence of the glycerin. The diagnostic dose which came to be recommended for cattle of medium weight was 0.25 c.c. On account of its consistency as well as the minuteness of the dose, it was found to be practicable to dilute this quantity with seven parts of a diluent. A weak solution of carbolic acid was ordinarily used. The difficulties and the danger of contamination involved in making the dilutions in the field led to the method of diluting the tuberculin in the laboratory before sending it out. This has been the practice of the Burean of Animal Industry for a number of years. Equally as good results are obtained by concentrating the saturated culture to the point where 2 c. c. contains an equivalent of the 0.25 c. c. of the highly concentrated lymph. This process avoids the necessity of dilutions and, with the addition of a few drops of carbolic acid, the weaker solution keeps perfectly.

Tuberculin in the dose necessary to bring out its diagnostic effect is harmless for healthy animals. Thousands of observations that have been reported assure us of this fact. Tuberculin is in daily use in every state in the Union, in Canada and in every country of Europe, yet so far as can be learned not a single case of injury following its use has been reported. In the tuberculous animal it produces a rise of temperature which, within certain limits, follows a definite course usually terminating in from is to 24 hours after the injection. Occasionally the temperature remains above the normal for a longer time. The temperature usually begins to rise in about eight hours giving a steady but quite rapid elevation for fron I to 3 hours, a continuous high elevation for from 2 to 4 hours, possibly longer, and a gradual decline. This is practically constant, be the raise moderate or extreme. In addition to the elevation in temperature there is sometimes a marked 
nervous chill. Why we get this reaction is not positively determined.

Applying the tuberculin test. In brief, the method for applying the tuberculin test in cattle is as follows:

I. The normal temperature of the animal to be tested must be determined. It is recommended that it be taken hourly or every two hours for the day preceding the test. In practice veterinarians usually take the temperature but once or twice before injecting the tuberculin.

2. The tuberculin is injected subcutaneously in the side of the neck. Care must be taken that the syringe is sterile and the site of injection should be disinfected. The size of the dose depends upon the preparation of tuberculin, that is, the degree of concentration.

"Trudean (Johns Hopkins Hospital Bulletin, J11ly, 1899) gives the following summary of the mechanism of the tuberculin reaction. "The most generally accepted theory at present in regard to it is, briefly, the small dose of tuberculin injected is a partly specific irritaut both to tuberculous foci and to the susceptible organism in general. It produces intense hyperemia of all tuberculous tissue in the body (local reaction), and as the result of this liyperemia much toxin stored up in the tubercles themselves is thrown into the general circulation and produces fever and characteristic symptoms which go to make up what is termed 'a general reaction.' That these poisous stirred up in the tubercles are in part at least derived from the dead or weakened bacilli has been shown by the experiments of Babes and Proca, who found that if two sets of rabbits be injected with equal quantities of living and dead bacilli, the latter react to the tuberculin test at a much earlier period than those inoculated with living germs. This hypothesis that the general reaction is brought about by toxins already stored up iu the tuberculous lesions and exploded as it were by the hyperemia produced about these lesions as the result of the test of injection of tuberculin, is borne out by the fact that a greater annount of albumose can be recovered from the evaporated urine collected during the reaction than was contained in the test injection also by clinical observations which indicate that patients suffering from localized surgical tuberculous processes of limited extent, and where the vascular supply to the part is limited, required a larger test injection to produce the reaction than those who have extensive or scattered visceral lesions in highly vascular organs like the lungs." The reader is referred to this paper for a careful consideration of the vexed questions relating to tuberculin. 
3. Beginning 6 or 8 hours after the injection, the temperature should be taken hourly, or at least every two hours, for fully three-fourths of a day.

4. During the time of testing, the cattle should be kept quiet and free from all exposure, and fed normally.

5. In case of reaction, there should be a rise of at least I. $5^{\circ} \mathrm{F}$. above the maximum individual normal temperature as determined on the preceding day. The elevation should come on gradually, remaining practically at its fastigium for a few hours and gradually subside. Erratic elevations of short duration are to be excluded. In cases of doubt the animals should be retested.

6. Animals advanced in pregnancy and those known to be suffering from any other disease or in oestrum should not be tested. All methods of treatment, including exposure to cold, or kind of food and drink whicls would tend to modify the temperature, should be avoided. Animals in which the disease is far advanced sometimes fail to react.

7. The dose should vary to correspond with the weight of the animal. The dose for an adult cow of average weight is 0.25 c. c. of the concentrated Koch tuberculin. In cases of a second test within a few days, the quantity of tuberculin injected should be larger than for the first test.

Ward has pointed out the fact that fowls do not give a diagnostic reaction to tuberculin made from either the avian or mammalian varieties of the tubercle bacteria.

In cattle there is a marked variation in the normal daily temperature. A fluctuation of two or even three degrees within $2+$ hours is frequently found. Cold water when drunk in considerable quantities lowers the temperature from two to four degrees. A temporary excitement usually causes an elevation of from $\mathrm{I}$ to $\mathrm{I} .5^{\circ} \mathrm{F}$. There are also marked variations in the temperature of the same animal on consecutive days. The temperature at 12 noon and 12 miduight are often the same. In some cases the maximum elevation for the day occurs near midnight and on the following day the minimum temperature appears at that time. It is not uncommon for the maximum 
temperature to occur twice in the same day and occasionally several times within the twenty-four hours. There are marked individual variations in the effect of ordinary conditions upon the temperature, such as food, excitement or temperature of the air. A hot spell causes a rise of two and in some cases four degrees. The average temperature of the animals in three herds tested by Howe and Ryder were $102.5^{\circ}, 102.6^{\circ}$, and $\mathrm{IOI}^{\circ} \mathrm{F}$. respectively.

In a well kept Government herd that was tested with tuberculin, the temperature of part of the animals was taken hourly for 24 and part of them for 16 hours preceding the injection. An examination of the records shows the arerage daily variation of 20 animals in which the temperature was taken for 24 hours to be $2.31^{\circ} \mathrm{F}$. The maximum individual variation in a single day was $4.3^{\circ} \mathrm{F}$, the minimum $0.5^{\circ} \mathrm{F}$. In 25 other animals where the temperature was taken for 16 hours, the average variation was $1.79^{\circ} \mathrm{F}$. In these the maximum variation was $3.2^{\circ} \mathrm{F}$, the minimum $0.6^{\circ} \mathrm{F}$. Ten healthy animals (did not react to tuberculin) in the same herd gave an average variation of $2.08^{\circ} \mathrm{F}$. In these the maximum daily variation was $4.1^{\circ} \mathrm{F}$, the minimum $1^{\circ} \mathrm{F}$. The lowest temperature was usually, but not invariably, in the morning and the highest in the afternoon or evening. I have appended the records of the temperature of two of these animals.

*Bulletin No. 7, Bureau of Animal Industry, U. S. Department of Agriculture, Washington, D. C. The tests were made by Drs. F. L. Kilborne and E. C. Schroeder, under the direction of Dr. Theobald Smith. 
THE INITIAL, TEMPERATURE OF TWO COWS, WITH RATE OF PLI,SE AND NUMBER OF RESPIRATIONS PER MINUTE.

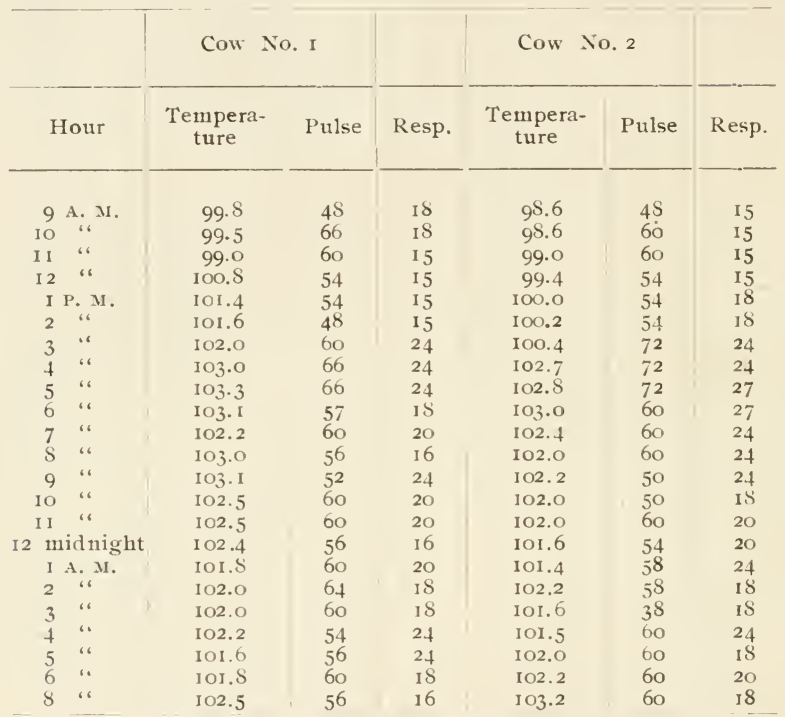

In riew of these normal temperature variations, which often exceed the tuberculin reaction, it is obvious that before applying the test the normal temperature of the animals should be approximately determined and that when they are being subjected to the test they should be cautiously protected, otherwise the comparatively slight elevation necessary to detect the disease may be disguised.

As the reaction seems to be the result of an affinity existing between the tuberculin and the living tuberculous lesion, it is natural to suppose that when the two are brought together in the same animal it would invariably take place. Experience has shown that it almost always does. It is important to 
understand, as far as possible, the reason for the exceptions and the extent to which they occur. The reported failures of the tuberculin tests fall into two distinct classes.

\begin{tabular}{|c|c|c|c|c|c|c|c|}
\hline F & $\delta$ & 10 & $12^{\circ}$ & 14 & 16 & 18 & 20 \\
\hline 107 & & & & & & & \\
\hline$\frac{3}{106}$ & & & & & & & \\
\hline 105 & & & & & & & \\
\hline & & & & & & & 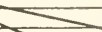 \\
\hline 04 & & & & & & & \\
\hline 103 & 8 & & & & & & \\
\hline & & & & & & & \\
\hline$\frac{12}{5}$ & 1 & & & $=$ & $=$ & & \\
\hline 101 & & & & & & & \\
\hline$\frac{3}{100}$ & & & & & & & \\
\hline
\end{tabular}

FIG. 51. A temperature curve of three cows after injecting tuberulin. I a heatthy cow, 2 and 3 tuberculous ones.

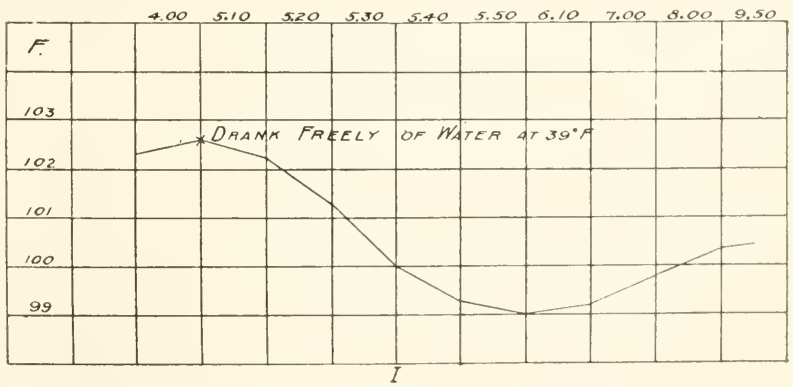

FIG. 52. Chart showing the effect of drinking cold water upon the temperature of a coit.

1. There is a reaction and no disease is found. In explaining this alleged error, the records of the cases which have come to my attention have been so deficient in data concerning the normal temperature variation of the animals, and 
the incompleteness of the post-mortem examinations, that it seems possible for the error to rest with the observer quite as much as with the tuberculin. Unfortunately we are as yet unable to determine by the reaction the extent of the disease, so that a beginning lesion no larger than a walnut may cause a pronounced rise of temperature and such a tubercle may be

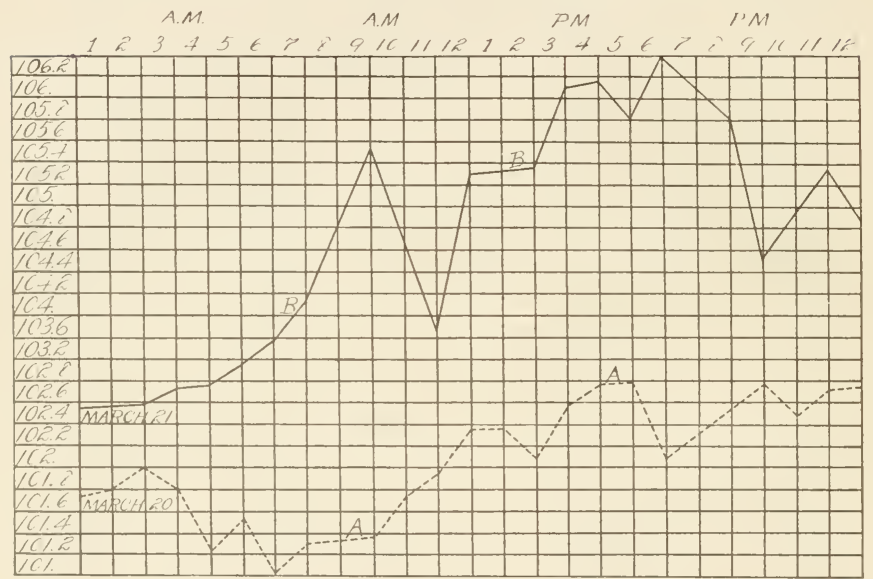

FIG. 53. Temperature curie of a hog. Dotted line -1 represents temperature of a hog for 2 hours before the injection of tuberculin. The full line $B$ represents the temperature of the hog for 27 hours after the injection of tuberculin (Schroeder).

difficult to find, especially if located in the marrow of some bone or in the nervous system.

2. There is no reaction and the disease exists. It is generally admitted that advanced cases often fail to react, but here the test itself is of little importance, as the disease can be detected by the clinician on physical examination. When, however, tuberculin is carefully prepared and scientifically administered, these exceptions are exceedingly rare. It seems to act always in active tuberculosis. 
Tuberculin does not give a reaction during the period of incubation. It does not cause a reaction in many, if not all, cases of temporary arrest or healing of the lesions. This renders it difficult to interpret the negative results especially in herds where there are many positive reactions. In such cases there should be subsequent tests later. For this reason cattle bought on the tuberculin test can not be considered uninfected

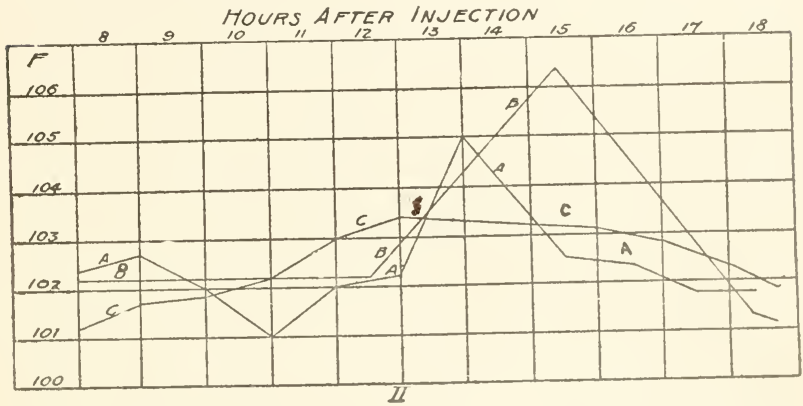

FIG. 54. Irregular temperatures following tuberulin that ari not cansid by tuberculosis (Curtice).

as the result of the first test if they came from herds containing reacting animals.

The practical value of tuberculin lies in its efficiency in the arts of comparative and sanitary medicine. It is in the practical application that difficulties are encountered. The many details and precautions enumerated as absolutely essential to the best results are often considered too tedious and time consuming, and consequently the practice has come too generally into vogue of neglecting or ignoring many of the precautions. In order that the test may be practicable, some practitioners resort to a shorter method of procedure even at the risk of an occasional error.

S 156. Prevention. Tuberculosis, like other infectious diseases, can be very largely prevented. To accomplish this 
it is necessary to keep tuberculous animals from entering the healthy herds. If they are admitted and later the fact is discovered, it is necessary to remove them and to thoroughly disinfect the stable. In eliminating the disease from a herd by means of the tuberculin test, it is necessary to retest the nonreacting animals after six months or a year have passed in

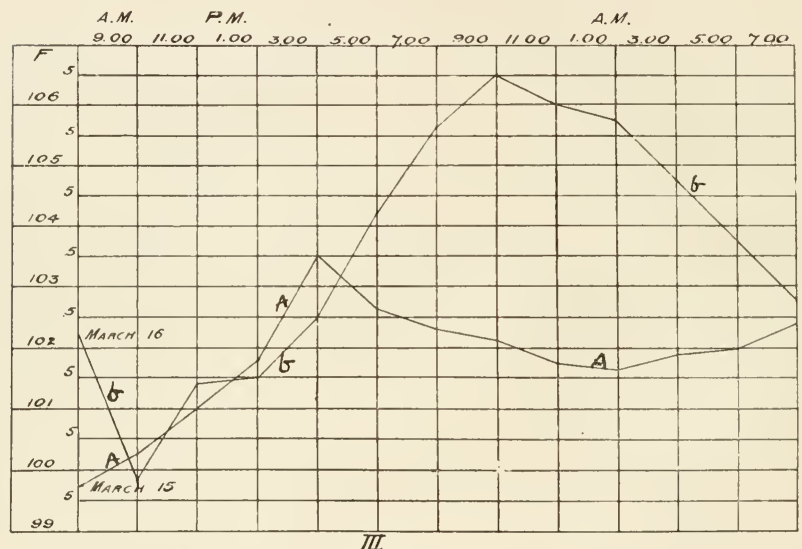

Fig. 55. Temperature curce of a tuberculous cow for ts hours. The line A. A. shows temperature for 24 hours preceding the injection of tuberculin, which was injected at $9 . .1$. 1\%., March $16 ; b, b, b$, show's the temperature for the 24 hours after the tuberculin injection.

order to find any case that might have been infected, but in which the disease had not begun to develop, or cases that were temporarily healed at the time of the first test.

$\S$ 157. The control of tuberculosis in cattle. Several methods have been proposed to eliminate tuberculosis from cattle. The preventing of the spread of the virus from the diseased to the healthy animals is the most important precautions. The system introduced by Prof. Bang of Copenhagen, Denmark, and generally known as the Bang method, has 
proven to be most successful. It consists in the slaughter of the advanced cases and the isolation of the reacting animals, which are kept for breeding purposes. The calves are separated from their dams immediately after birth and fed upon the milk of healthy cows or the sterilized milk of the reacting ones. This method has enabled many owners of infected animals to replenish their herds in from four to six years. In countries where it has been generally applied the percentage of tuberculous cattle has been wonderfully reduced.

The vaccination of cattle against tuberculosis has been proposed as a prophylactic measure. The method has been extensively tried by Pearson in America and von Behring in Germany. Its effectiveness can not be predicted at this time. The results of von Behring's experiments are promising but as yet the vaccinated animals (calves) have not attained to old age so that the length of the resistance that seems to be established by the vaccination is not determined. Several reports on the result of natural exposure to tuberculous cows, after a period of two years, show the vaccinated animals to be nearly as badly infected as the checks. The results reported by Pearson indicate that the attainment of a bacterial immunity against tuberculosis in cattle is not likely to be an easy task. The experiments in this direction are most interesting and many investigators are hopeful for good results. At present it is in the experimental stage.

REFEREXCES.

I. ADAMr. On the significance of bovine tuberculosis and its eradication and prevention in Canada. Canadian Jour. of . Medicine and Surgery, Dec. ISg9.

2. CURTICE. The detection of tuberculosis in cattle. Annual Report, Bureau of Animal Industry. U. S. Dept. Agric., 1S95-g6.

3. DORSET. Experiments concerning tuberculosis. Bulletin $5-$ Bureau of Animal Industry, 1904 .

4. EBER. Suggestions for a uniform system of interpreting the tuberculin reaction in cattle. The Jour. Compr. Path. and Thira., Vol. XVIII (1905), p. 224 . 
5. KocH. The etiology of tuberculosis. Mitt. aus dem. Laiserl. Gesundheitsante, Vol. II (I884). Translated in Vol. CXV, New Sydenham Society.

6. Косн. The combating of tuberculosis in the light of the experience that has been gained in the successful combating of other infectious diseases. Amer. Vet. Rer', Vol. XXV (Igor), p. $44 \mathrm{I}$.

7. MOHLER. Infectiveness of milk of cows which have reacted to the tuberculin test. Bulletin 4t. Bureau of Animal Industry, 1903.

8. MOHLER AND WASHBuRN. A comparative study of tubercle bacilli from varied sources. Bulleting6. Bureau of Animal Industry, 1907.

9. MOHLER. Tuberculosis in hogs, with special reference to its suppression. Amer. Vet. Rev., Vol. XXXII (1907), p. I76.

10. MOORE AND DAwsox. Tuberculosis in swine, the nature of the disease with a report of three cases. Annual Report, Bureau of Animal Industry, U. S. Dept. Agric., 1895-96.

I $\mathrm{r}$. MOORE. The preparation of tuberculin, its value as a diagnostic agent, and remarks on the human and bovine tubercle bacilli. Trans. of the Med. Socicty of the State of $N . Y$., 1900.

12. MoORE. A report on bovine tuberculosis. N'ew York State Dept. of Agric., Igo3.

13. NocARD. The animal tuberculosis. New York.

14. PEARsox. The Pennsylvania plan for controlling tuberculosis of cattle. Proc. Amer. l'et. Med. Assn., ISg9.

15. Pearsox. Tuberculosis in cattle and the Penn. plan of its repression. Bulletin 75. Penn. Dept. of Agric., I901.

16. PEARSON. The repression of tuberculosis in cattle by sanitation. Bulletin 7t. Penn. Dept. of Agric., rgor.

17. PEARsox. The artificial immunization of cattle against tuberculosis. Amer. l'et. Reä., Vol. XXIX (1905), p. 543.

18. RAVENEL. The dissemination of tubercle bacilli by cows in conghing a possible source of contagion. ¿niz' of Penn. Med. Magazine, Nov. 1900 .

19. RAVENEL. The comparative virulence of the tubercle bacillus from human and bovine sources. Univ. of Penn. Med. Bulletin Sept., I90I.

20. RAVENEL. The intercommunicability of human and bovine tuberculosis, The Uniz. of Penn. .Yed. Bulletin May, 1902.

21. REPP. Transmission of tuberculosis through meat and milk. American . Tedicine, Oct. 6, Nov. 2, Igor.

22. SALMON. Legislation with reference to bovine tuberculosis. 
Bulletin 2s. Burean of Animal Industry, U. S. Dipt. of Agrie.. Igor.

23. Sataros. The tuberculin test of imported cattle. Bullelin i2. Bureau of Animal Industry, U. S. Dept. of. Igric., rgor.

24. Samion. Bovine and luman tuberculosis. Procedings Almer. Vet. Hed. 1sso., 1903, p. 436.

25. SALMON. Tuberculosis of the food-producing animals. Bullitin 38. Burean of Animal Industry, 1906.

26. SCHROEDER AND COTTON. The relation of tuberculous lesions to the mode of infection. Bulletin 93. Bureau of Animal Industry, 1906 .

27. SCHROEDER AND COTTON. Experiments with milk artificially infected with tubercle bacilli. Bulletin 86 . Bureau of Animal Industr'y, igo6.

28. SCHROEDER AND MOHLER. The tuberculin test of hogs. Bulletin 8s. Bureau of Animal Industry, 1906.

29. Sirth. Investigations concerning bovine tuberculosis with special reference to diagnosis and prevention. (Pathological part). Bulletin No. 7, Burean of Animal Industry, U. S. Dept. of Agric., IS94.

30. Smirt. A comparative study of bovine tubercle bacilli and of human bacilli from sputum. The Jour. of Exper. Mid., Vol. III ( ISgS).

31. SurTH. The thermal death point of tubercle bacilli in milk and some other fluids. The Jonr. of E.rper. Med., Vol. IV (1899), p. 217 .

32. Surth. The channels of infection in tuberculosis, together with some remarks on the outlook concerning a specific therapy. Trans. Mass. Med. Soc.. 1907.

\section{RFFERENCES TO ATIAN TTBERCULOSIS}

33. BURNETT. Tuberculosis in chickens positively identified in New York. Am. Vet. Kivicz, XXX (1907), p. r3iz.

34. BRar. Tuberculosis in chickens. Jonr. Compar. Med. and Vet. Archizes, XVII (1896), p. 461.

35. Caniot. Sur la tuberculose du cygne. Bul. de la Soc. Cen. et Méd. l'et., Vol. XLIX (1895), p. 570.

36. CADIOT, GILBERT AND ROGER. Inoculation of the tuberculosis of gallinaceous to mammalia. Amer. l'et. R'cuieu', XX (ISg6-7), p. 225 .

37. Cadió, Gilbert hit Rocier. Note sur la tuberculose des volailles. Receuil de Méd. let. Sirvie VII, Vol. VIII (ISgi), p. 22.

38. Cadiot, Gilbert and Roger. A contribution to the study of 
avian tuberculosis. Studies in clinical veterinary medicine and surgery. (1900). (Translated by Dollar.)

39. EBERLEIN. Die Tuberculose der Papageien. Monatshefte für Praktische Thierheilkunde, Bd. V (1894), S. 248.

40. FROEHNER. Zur Statistik der Verbreitung der Tuberculose unter den kleinen Hausthieren. Monatshefte fïr Praktisihe Tierheilkunde, I893, p. 51 .

41. LucEit. Sur un symptome de la tuberculose chez la poule. Recueil de Méd. Vét., Série, VII, Vol. VIII (I891), p. I72.

42. MAFFUCCI. Die Hühnertuberculose. Zeitschr. für Hygiene, Bd. XI ( 1892$)$, p. 445.

43. Moore and Ward. Avian tuberculosis. Proc. Amer. Vet. Med. Asso., I903, p. 169.

44. MoORE. The morbid anatomy and etiology of avian tuberculosis. Jour. of Med. Research, Vol. XI (1904), p. 512 (Bibliography.)

45. Nocard. Sur une tuberculose zoogléique des oiseaux de bassecour. Bul. et Memoires de la Soc. Centrale et Méd. Vít., I885, p. 207 .

46. Nocard. Transmission de la tuberculose des poules et l'homme. V'eterinaire, Vol. III (1886), p. $65^{8}$.

47. PERNoT. Investigations of diseases of poultry. Bulletin No.67. Oregon Agric. Ex.pt. Sta., rgoo.

48. Siblex: Tuberculosis in birds. Jour. of Compar. Med. and Vet. Arch., Vol. XI (1S9o), p. 317.

49. Straus et Gamaleia. La tuberculose humaine, sa distinction de la tuberculose des oiseaux. Archiv. de Méd. Exper., Bd. III (rS9I), p. 457.

50. STRAUS ET IVURTz. Sur la resistance des poules a la tuberculose par ingestion. Congress pour l' étude de la tuberculose, r888, p. 28.

5I. WARD. Tuberculosis in Fowls. Bulletin No. I6I California Agr. Exper. Station, I904.

52. WEBER. Review of the avian tuberculosis. Jour. of Compar. thed. and Vet. Hrch., Vol. XIII (I892), p. 429.

THE FOLLOWING BULLETINS ON TUBERCULOSIS HATE BEEN ISSUED FROI THE VARIOUS STATE AGRICULTURAL EXPERIMENT STATIONS.

BANG. The application of tuberculin in the suppression of bovine tuberculosis. Bulletin $4 \mathrm{I}$. Massachusetts. I896. (A translation).

BFACH. The history of a tuberculous herd of cows. Bulletin 24. Storrs, Conn. 1902. 
Bittrixg. Bovine tuberculosis in Indiana. Bulletin 63. Ind. 1896 .

Breiver. Tuberculosis. Bulletin 4I. Utah. IS9.5.

C.ARY. Bovine tuberculosis. Bulletin 67. Alabama. I895.

Coxs. The relation of bovine tuberculosis to that of man and its significance in the dairy herd. Bulletin 2j. Storrs, Conn. I9O2.

DiNwIDDIF. The relation of virulence for the domestic animals of human and bovine tuberculosis. Bulletin 57. Kansas. IS99.

DIXIDDIE. The relative susceptibility of the domestic animals to the contagia of human and bovine tuberculosis. Bulletin $6_{3}$. Kansas. I900.

Fischer. Bovine tuberculosis. Bulletin 69. Kansas. ISgs.

GLover. Relation of bovine to human tuberculosis. Bulletin 66. Colorado. I9oI.

Graxge. Tuberculosis. Bulletin 133. Michigan. IS96.

HARDixg, SiITH AxD MoORE. The Bang method etc. Bulletin 277. Geneva, N. Y. 1906.

HILl AND RICH. Bovine tuberculosis. Bulletin 42. Vermont. IS94.

LAw. Tuberculosis in relation to animal industry and public health. Bulletin 65. (Cornell), New York. I894.

LAW. Experiments with tuberculin on nontuberculons cows. Bulletin SI. (Cornell), New lork. 1 S94.

L.Aw. Tuberculosis in cattle and its control. Bulletin I50. (Cornell), New York. ISgS.

MARSHALL. A study of normal temperatures and the tuberculin test. Bulletin 159. Michigan. ISgS.

MARSHALL. Killing the tubercle bacilli in milk. Bulletin 173. Michigan. I899.

MAyo. Some diseases of cattle, Texas itch, blackleg, tuberculosis, Texas fever. Bulletin 69. Kansas. IS97.

Moore. Bovine tuberculosis. Bulletin 225. (Cornell), N. Y. I905.

NeLsox. On the use of Koch's lympl in the diagnosis of tuberculosis. Report of the biologist. New Jersey. IS93.

NELSON. Experimental studies of the Koch test for tuberculosis. New Jersey. I\$95.

NELSON. The suppression and prevention of tuberculosis of cattle and its relation to human consumption. Bulletin I18. New Jersey. ISg6.

Nesom. Tuberculosis of cattle. Bulletin 5o. S. C. 1900.

PAIGE. History of tuberculosis in a college herd. Use of tuberculin in diagnosis. Bulletin 26. Massachusetts. IS94. 
Pearsox. Tuberculosis of cattle. Bulletin 29. Penln. IS94.

ReTNolns, Bovine tuberculosis, Bulletin 5r. Lniv. of Minn. Agric. Exp. Station. 1896 .

Risser.L. Tuberculosis and the tuberculin test. Bulletin fo. Wisconsin. IS94.

RuSSEI.I. The history of a tuberculous herd of cows. Bulletin 78. Wisconsin. 1899 .

Russer. A lesson in bovine tuberculosis. Bulletin ir4. Wisconsin. 1904 .

RESSE,L. Two ways of treating tuberculosis in herds. Bulletin 136. Wisconsin. I905.

Russel, AND Hastrags. Bovine tuberculosis in Wisconsin. Bulletin 84 . Wisconsin. Igor.

STALKER AND NII,ES. Investigation of bovine tuberculcsis with special reference to its existence in Iowa. Bulletin IoS. Iowa. IS95.

THORNE. Borine tuberculosis. Bulletin 108. Ohio. I899.

VAx Es. Bovine tuberculosis. Bulletin 77. North Dakota Agricultural Experiment Station. 1907.

WILliAisox AND EMERI: Tuberculosis and its prevention. Bulletin I17. N. C. 1895 .

\section{JOHNE'S DISEASE}

Synonyms. Pseudo-tuberculosis ; chronic bovine pseudotuberculous enteritis ; La diarrhée chronique du boenf.

$\S$ 158. Characterization. Johne's disease is an intestinal disorder supposed to be due to acid-fast bacteria. It is characterized by a diarrhea, gradual emaciation aud the presence of large numbers of acid-fast bacteria on the surface of and in the mucous"membrane of the affected portions of the intestine. The distal part of the ileum is usually the most involved.

§ 159. History. Johne and Frothingham described a disease in 1895 in which the intestinal mucosa contained large numbers of acid-fast bacteria. They thought it was a case of tuberculosis in a cow due to the avian tubercle bacterium. In I903 Markus called attention to its frequent occurrence in Holland. Since that time it has been recognized in Belgium, 
Switzerland, Denmark and England. A few cases have been observed in this country. Sir John M'liadyean lias proposed the name Johne's disease for this affection.

s r6o. Etiology. The cause of this disease is supposed to be an acid-fast bacterium which is found in large numbers in the affected mucosa, and also in the mesenteric and colic lymphatic glands. Norphologically this organism closely resembles the tubercle bacterium. It varies in size from $i$ to $2 \mu$ in length and a few are said to attain to $4 \mu$. It stains uniformly but occasionally the longer forms show alternating stained and unstained segments. It is remarkably acid-fast.

According to M'Fadyean this organism is not inoculable to either guinea pig or rabbits. It has as yet not been cultivated on artificial media.

This bacterinm apparently does not form a strong cell poison and hence the absence of necrosis. On the other hand the tissues appear to be almost powerless to restrain its mnltiplication and invasion.

The period of incubation is not known.

s 161. Symptoms. The first symptom to be observed is a loss of flesh, although the appetite remains normal. The hair becomes roughened and the animal presents an unthrifty appearance. Diarrhea soon sets in. As a rule, the diarrhea is profuse and persistent from the time it begins, although it may sometimes be checked temporarily by giving dry food and by the administration of astringents.

s62. Morbid anatomy. The lesions are primarily in the small intestines, but, as a rule, involving the large intestines, before death takes place. The distal part of the small intestines is most involved. The lesion is in the mucous membrane and even in seriously ill animals it is the only lesion that has been found. In some cases the acid fast bacteria invade the submucosa in which case the wall of the intestine becomes thickened. In proportion to this thickening the mucosa shows more or less coarse wrinkling. [lceration is not observed, and there is very little congestion. 
The mesenteric lymphatic glands may be slightly enlarged. When cut an appreciable amount of water-like liquid exudes from the surface. The absence of congestion has been noted.

The most striking feature of the disease is the slight tissue changes even when the bacteria are exceedingly numerous. In sections made at right angles to the mucous surface of the intestine an irregularity in the size and outline of the villi can be observed. Some of the villi may be partially denuded of epithelium. In the glandular layer the interstitial tissue between the tubular glands may be increased in amount and the glands may show evidence of atrophy. In sections stained by the Ziehl-Neelsen method, with Pappenheim's stain for contrast, M'Fadyean states that those parts in which the bacilli are numerous have an appearance very similar to that of a genuine tuberculous lesion just before the onset of necrosis and caseation, that is, they appear to be mainly made up of the so-called epithelioid cells, with occasionally a well formed giant cell. Sometimes the outlines of these epithelioid cells are distinct, but, as a rule, wherever the bacilli are numerous there appears to have been a partial fusion of the cell bodies, and the appearance is that of a sort of matrix substance with imbedded nuclei. The majority of these nuclei are vesicular but shrivelled or distorted in appearance, and they stain lightly as compared with any of the nuclei in the surroundiug normal tissue. According to M'Fadyean, the important points to notice are that the diseased tissue is never sharply delimited and that there is no actual necrosis, although the appearance of the new tissue may be interpreted as indicating that the cells are on the point of losing their vitality. Within the parts which contain large numbers of bacilli there are also sometimes recognizable small round compact nuclei, apparently belonging to cells of the lymphocyte type, and at their margins there are numerous cells whose bodies stain red with Pappenheim's stain.

The bacilli do not appear to be specially intra-cellular; many of them seem to be lying free, and others appear to be 
situated within the fine reticulum of the villi. The structural alterations are everywhere proportional to the number of bacilli, which indicates that, contrary to what is the case in tuberculosis, the bacilli have little or no tendency to degenerate and disappear from the older lesions. The bacilli when numerous are generally arranged in clumps or groups, and these often form a very large part of the epithelioid areas.

The lesions in the lymphatic glands have a similar histology. They may be present either in the cortex or the medulla, but they are not tuberculons in the anatomical sense. A small number of giant cells may be present.

The course of the disease varies from a few weeks to several months. It seems to be fatal in most cases.

\$ 163. Differential diagnosis. This affection is to be differentiated from tuberculosis and parasitic enteritis. The non-virulence of the organism for guinea pigs is the most reliable differential test between it and the bovine tubercle bacteria. The finding of these acid-fast bacteria and the absence of distinct lesions and parasites wonld distinguish it from the other. As this disease is liable to occur in conjunction with genuine tuberculosis, great care must be exercised in making the diagnosis. In some of these cases reported there appears to have been such a mixed infection.

S 164. Prevention. Johne's disease must be regarded as one which results from infection and from infection only. M'Fadyean states that in all the cases which have come under his observation there was a history of similar cases on the farm, in several instances extending back over a period of many years. During the advanced stages of the disease large numbers of the bacilli must be voided with the feces, and in all ordinary circumstances there are ample opportunities for infection from this source. In this way botl pasture and other materials as well as drinking water may become seriously contaminated. At the present moment there is no knowledge with regard to the resistance of the bacilli outside the body, 
or the length of time that a contaminated pasture may be dangerous.

In the present state of knowledge the question of prevention is an extremely difficult one in the case of farms on which the disease has existed for a number of years. The isolation or destruction of diseased and suspected animals should be practiced. If in stables the feces passed by diseased or suspected animals ought to be burned. Cattle should be kept off from pastures in which such animals have run. As the time during which the bacteria remain alive outside of the body is not known, it is impossible to indicate the period during which infected pastures are dangerous to other cattle.

\section{REFERENCES.}

1. BAxG, Chronische pseudotuberculöse Darmentzündung beim Rinde. Berliner Tierärztliche I'ochenschrift, 1906, p. 759.

2. BORGEAtD. Schweizer Archiv. f. Tierheilk., (1905), p. 22 i.

3. JOHNE AND FROTHINGHAM. Eili eigenthïmlicher Fall von Tuberkulose beim Rind. Zeitschrift für Thiermedicin, Vol. XXI (r894), p. 438 .

4. LIENAUX Axd EEckhot'T. Contribution à l' étude d'une entérite tuberculeuse spéciale et de la diarrhée chronique du boeuf. Annales de Médécine Vetérinaire, Vol. LIV (I905), p. 65.

5. MARKus. Zeitsch.f. Tiermedicin, Bd. VIII (1904), p. 68.

6. M'FADVEAN. Johne's disease; a clironic bacterial enteritis of cattle. Jowr. of Compar. Path. and Thera., Vol. XX (1907), p. 48.

OVINE CASEOUS LYMPH-ADENITIS (PSEUDO-TUBERCULOSIS IN SHEEP).

Synony'ms. Pseudo-tuberculosis ; caseous adenitis.

s65. Characterization. Caseous lymph-adenitis is a disease of adult sheep which until recently was designated as pseudo-tuberculosis. It has been characterized by an enlargement of one or more lymphatic glands, which contain foci of a greenish-yellow, caseous or purulent substance. It is rarely found in young animals. The mortality is very low, due 
perhaps to the fact that the sheep are slaughtered before the disease has time to develop. It does not occur in epizoötic form although it is more prevalent in certain localities than in others.

\$ 166 . History. The name "ovine caseous lymph adenitis" was proposed by Nörgaard and Mohler in I899. These writers found the lesions and the accompanying nicroorganism to correspond with those described by Preisz and Guinard in 189 I as psendo tuberculosis. The bacterium was fully described by Preisz in 1894 . The organism has been found and identified from a large variety of lesions in a number of species of animals. It appears that at least many of the cases of lymphatic gland enlargement in sheep heretofore called pseudo-tuberculosis belong to this disease. Gilruth prefers the name pseudo-tuberculosis. Cherry and Bull describe it as caseous lymphatic glands and Sivori as caseous broncho-pneumonia, the bacterium of Preisz being found as the probable cause in each case.

\$ I67. Geographical distribution. In the United States this disease is quite common in certain districts in the western and southwestern states. It exists in South America, New Zealand, Australia and Europe.

Sivori found that ro per cent of the old sheep killed in Buenos Ayres were affected. The prevalence of the disease in the United States is indicated by the reports of the federal meat inspectors, which show that of $\mathrm{I} 6,000,000$ sheep slaughtered in Chicago, Kansas City and South Omaha 3,236 were condemned for caseous lympl-adenitis or lesions which might be confounded with it. It is reported by an inspector from Los Angeles that of 950 sheep coming from a certain district, 82 were suffering from $l y m p h-a d e n i t i s$.

\$ 168. Etiology. Caseous lymph-adenitis is caused by a specific microörganism first described by Preisz as the bacillus of pseudo-tuberculosis. Its description shows it to vary in size to such a degree that its polymorphism is said to be characteristic. It is non-motile and hence belongs to the 
genus Bacterium. It is aërobic, facultative anaërobic, stains readily and does not produce spores. It derelops readily on agar when this medium is inoculated from the caseous material

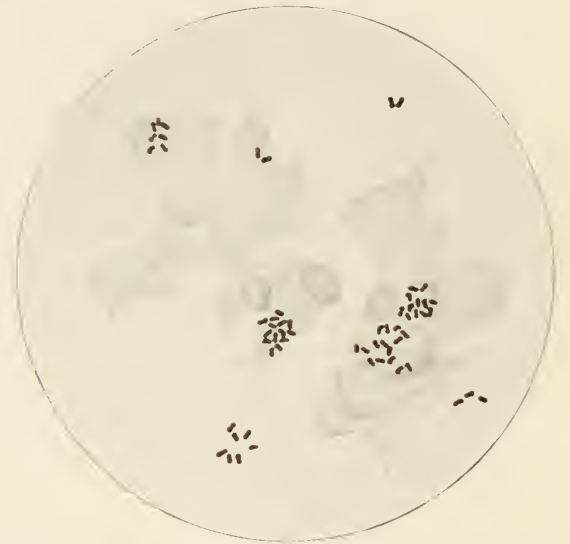

FIg. 56. Bacterium of Preisz. Bactcrium in pus cells $1-12$ obj. 4 ocular (Gilruth).

from the affected glands. It is pathogenic for mice, guinea pigs and rabbits. The organism isolated by Gilruth seems to have been more virulent than the one isolated by Nörgaard and Mohler.

I69. Symptoms. In the majority of cases no symptoms of any importance are observed in the affected animals during life. The conrse of the disease is that of a chronic affection and the pathological changes derelop so slowly that no general or local interference with the health of the affected animals is observed in lambs and sheep that are bred and raised for mutton and are marketed before they are two years old. Only in breeding ewes and wethers does the disease advance to a degree which makes it clinically recoguizable without the aid of manipulation. The affected animals upon 
examination show an enlargement of one or more of the superficial glands, the precrural and the sub-scapular glands being most often involved. The animals thus affected appear in every other respect to be in perfect health. In the older animals, the wethers and breeding ewes, the same glands may be enlarged to a considerable degree, reaching the size of a hen's egg or even larger. Some of these sheep may show a certain degree of unthriftiness or even emaciation. The disease is found in its most advanced stages in the older ewes, which is probably due to the fact that the wethers are generally disposed of before they are three years old, while a good breeding ewe is frequently retained for seven or eight years. In such old animals the superficial lymphatic glands may be enlarged to such a degree as to interfere with locomotion, while the deeper seated glands and those of the body cavities are similarly affected. In the advanced cases the lesions often become disseminated by metastasis to the principal organs of the body. In such cases the disease may assume the appearance of chronic broncho-pneumonia or pleurisy, with occasional cough, slight dyspnea and increasing emaciation and anemia. The course of the disease is exceedingly slow. For this reason owners of affected flocks are often totally ignorant of the presence of the disease. This fact renders it very diffcult to obtain reliable information regarding its prevalence save from the statistics obtained from the slanghter houses. A majority of the inspectors have until recently classified the lesions either as tuberculosis, pyemia or abscesses. In response to inquiries it was found that the majority of cases which had been condenmed under these headings were undoubtedly caseous lymph-adenitis. Several thousand cases are annually observed in the slaughter houses of the United States, but only a fraction of these are advanced to a degree that would warrant a total condemnation of the carcasses. Meat inspectors agree that lambs are very rarely affected, and that the progress of the morbid changes in the majority of cases is coördinate with the age of the animal. 
170. Morbid anatomy. The principal lesions are confined, according to the various descriptions, especially that by Nörgaard and Mohler, to the lymphatic glands. In many cases only a single gland is affected. The relative frequency with which the various glands become the seat of the lesions

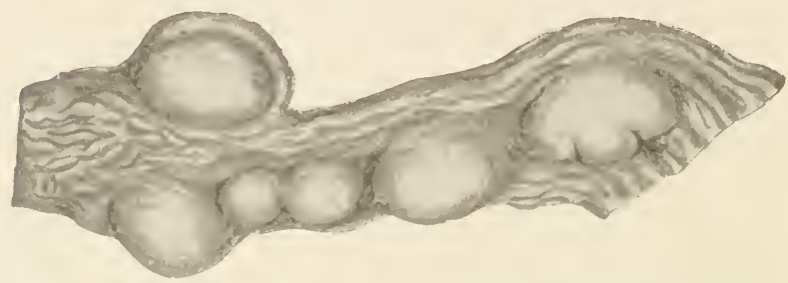

FiG. 57. The leg of a rabbit showing enlarged glands aftcr inoculation with the Bacterium of Preisz (Nörgaard and Mohler).

may be given as follows: prescapular, precrural, superficial inguinal, bronchial, mediastinal, sub-lumbar, deep inguinal, and scrotal. Rarely the suprasternal and mesenteric glands are affected. Sivori mentions the mesenteric glands among those frequently affected. He fails, however, to mention the mesenteric glands as the seat of lesions in the detailed description of twelve typical cases of caseous broncho-pneumonia caused by the bacillus of Preisz.

When first invaded by the bacterium, the adenoid tissue becomes hyperplastic and the gland enlarges to several times its original size. On section the surface is found to be watery, but otherwise the tissue retains its normal appearance. This is followed by the formation of various centers of degeneration which show concentric layers and gradually become confluent. Finally, the total volume of the gland is transformed into a homogeneous, caseous mass. At the same time the distended capsule increases in thickness and forms a sac which confines the semifluid, grumous mass. In rare instances the sac ruptures and when close to the surface the contents will be discharged. Under ordinary circumstances, the caseous contents 
become colesive and sticky and of the consistency of putty. In very old cases the mass becomes dry and mealy, with little or no tendency to calcification. The greenish yellow color of the caseous mass, which is stated to be most characteristic. closely resembles the contents of the intestinal nodules produced by Oesophagostoma Columbianum. In very advanced cases, as for instance those of old breeding ewes, the internal

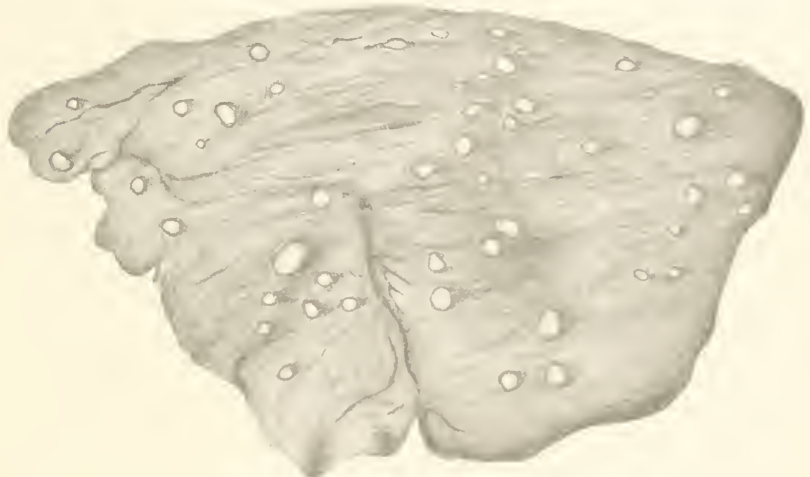

FIG. 58. Lung of sheep studied with nodules (Gilruth).

organs may contain lesions which microscopically resemble those of tuberculosis. The lungs may be studded with small nodules the size of a pea, the spleen, liver and in rare instances the kidneys also may contain one or more foci of the same character, namely, a mass of greenish yellow material, surrounded by a firm, fibrous wall. There seems, however, to be a distinct line of demarcation between the affected and the healthy tissue. The bronchial and the mediastinal glands may be affected to a considerable extent without any lesions being found in the lungs. In some cases the lungs are extensively involved. The lesions consist of nodules varying in size from that of a millet seed to that of a walnut. This condition is, as a rule, accompanied by a chronic pleurisy with 
extensive adhesions and also effusions into the pleural cavities.

In the liver the lesions consist largely of nodules com1posed like those in the lymphatic glands, of a firm white fibrous sac containing a greenish-yellow, cheesy mass of varying consistency. Cases have been reported, however, where the entire organ was filled with miliary nodules.

The kidneys are rarely affected, but when they are the lesions assume the same characteristic appearance of a firm walled abscess protruding on the surface of the organ. As a rule, ouly one or two such foci are observed in each case.

A histological examination of tissues containiug miliary or sub-miliary nodules, shows them to be composed chiefly of leucocytes and nucleated round cells, the greater part of which are irregular in shape, especially toward the center where many of them are transformed into a granular detritus. Among the cells arranged singly or in clumps, are seen the short bacteria which stain irregularly. The shape varies considerably from oval or oblong to a dumb-bell shape.

The bacteria are frequently seen within the degenerated leucocytes, the destruction of which is due, according to Preisz, to the specific chemical products elaborated by these microörganisms.

The microscopic appearance is somewhat similar in all the lesions whether located in the lymph glands, lungs, liver, kidneys or spleen. In the lungs the histolngical picture resembles that of broncho-pneumonia. In the liver the lesions originate in the portal capillaries, where the bacteria cause a proliferation of the endothelial cells, which, together with the accumulation of leucocytes and red corpuscles, cause the obliteration of the vessels. In no case have giant cells been observed. The surrounding hepatic cells become swollen, then granular, and finally they undergo atrophy, leaving open spaces between them. Numerous round cells appear in the periphery of the nodules, which gradually undergo a connective tissue metamorphosis and become organized into an encapsulating membrane.

When a miliary nodule from the liver of an experimental 
animal, which has been destroyed three weeks after inoculation, is examined microsopically the following picture is observed: A caseous center composed of an amorphous material that does not take any of the ordinary stains. Surrounding the center may be seen numerous leucocytes more or less degenerated and frequently containing one or nore bacteria, while clumps of these organisms are scattered among them. External to this is a dense round cell infiltration, the peripheral zone of which is undergoing connective-tissue formation, thus serving as a line of demarcation between the atrophied liver cells and the central cell mass. The process then repeats itself until a connective-tissue barrier strong enough to encapsulate the central part of the nodule and prevent its further growth is obtained. The nodules in the kidneys and lungs present a similar microscopic appearance, excepting that the foci in the lungs are more regular on account of the catarrhal inflammation that accompanies the reaction of the surrounding tissue. The center contains a dense mass of disintegrated cell structures composed of the desquamated and proliferated epithelial cells, degenerated leucocytes and round cells. In experimental animals which succumb quickly to an intravenous injection of virulent material, the lung tissue immediately surrounding the nodules is frequently seen to be hepatized.

According to Gilruth the lesion commences by the arrest of the specific bacterium generally in a lymph-gland where one or more are surrounded by and included within the phagocytes. The micro-organisms multiply within the cell and ultimatelycause the degeneration and death of the latter. Simultaneously a slow chronic inflammation occurs around the focus of attack ; there is proliferation of connective tissue-cells and the formation of more or less new fibrons tissue. As the process spreads ontwardly the centre degenerates, and the protecting wall increases in thickness. In fact, all the phenomena of the pathology of true tuberculosis in a gland occurs, with the exception of the formation of giant cells. The degenerated centre of the nodule assumes a greenish tint, especially distinct at the time of exposure by the knife, but becoming gradually grayer 
afterwards. In the centre of the older purulent or caseous mass (for the consistence varies from that of cream to that of cheese in different tumours) there are usually present no bacilli which can be demonstrated by the microscope or by cultural methods.

\$ I I. Differential diagnosis. This specific lymphatic affection is to be differentiated from :

I. Infections of various kinds, not recognized as specific, which may cause enlargement or suppuration of lymph glands.

2. The specific infectious diseases, such as tuberculosis.

3. Lymphadenoma.

If the diagnosis cannot be made from the gross appearance of the lesions a bacteriological examination will be necessary. The fact should be kept in mind that tuberculosis in sheep is very rare. In lymphadenitis, cultures in ordinary media will give a growth of the bacterium of Preisz. With tuberculosis the results would be negative (see tuberculosis). It is important not to confuse the nodular disease of sheep's intestines with this affection. The location of the lesions in the walls of the intestine will be quite sufficient to determine the nodular disease.

\section{REFERE,ICES}

1. CHERRY AND BLLI. Caseous lymphatic glands (pseudo tuber culosis) in sheep. The Veterinarian, Vol. LXXII, p. 523.

2. ЕвектH. Bacilläre Nekrose der Leber. Virchow's Archiz', Bd. C $\left(I S 8_{5}\right)$, p. 23.

3. Gilruth. Pseudotuberculosis in sheep. (Lymphadenitis). Jour. Compar. Path. and Thera, Vol. XV (1902), p. 324.

4. GILRUTH. Psendo-tuberculosis in sheep. (Lympho-adenitis). Bulletin No. I, Nea' Zealand Dept. of Agriculture.

5. NörgaARD AND MOHLER. The nature, cause, and economic importance of ovine caceous lymph-adenitis. Sixteenth Anmal Report, Bureau of Animal Industry, 1899, p. 638. (Full bibliography).

6. PREisz Axd Guinard. Pseudo-tuberculose chez le mouton. Jour. de méd. de vét. et de zoötech, ser. 3, Vol. XVI (IS9I), p. 563.

7. PREISZ. Recherches comparatives sur les pseudotuberculoses 
bacillaires et une nouvelle espèce de pseudotuberculose. $9 \mathrm{nn}$. de l' Inst. Pasteur, Vol. VIII ( 1894 ), p. 23 I.

8. Sivori. Sur une broncho-pneumonie caseouse du mouton, causée par le bacille de Nocard-Preis\%. R'ev. de méd. vét. ser. 8, Vol. VI (1899), p. 657.

\section{ASTHENIA IN FOWLS AND PIGEONS}

\$72. Characterization. This is a disease especially of chickens and pigeons in which there is marked emaciation and a failure to take on flesh even when fed on the most nourishing food. Because of this, the disease has received the popular name of " going light."

$\$$ 173. History. Although this condition or disease has been recognized for a long time, it seems to have been first described in 1898 by Dawson. He gives a brief account of the symptoms, morbid anatomy, etiology and a somewhat extended description of the specific organism which he isolated from the diseased chickens. The writer has studied this affection in pigeons but did not succeed in finding the organism isolated by Dawson.

S 174. Etiology. Dawson found this disease to be due to the presence of a certain species of bacterium which he obtained in pure culture from the duodenal contents. He described it as Bacterium asthenice. Th1s organism varies from I to $1.3 \mu$ in length and about $0.5 \mu \mathrm{in}$ width with rounded ends. It is reported to possess the peculiarity of vegetating in temperatures varying from 50 to $120^{\circ} \mathrm{F}$. It is fatal to rabbits within 24 hours when inoculated into the abdominal cavity with 0.5 c. c. of a bouillon culture. Chickens 1nocu lated with this organism remained well.

\$ 175 . Symptoms. The ouly symptoms which seem to be in evidence are the gradual loss of flesh and an exceedingly good appetite. It is reported by certain pigeon fanciers concerning pigeons and the fact is reiterated by Dawson, that the 
disease is an exceedingly chronic one, often extending over a period of several months but usually terminating in death. In the cases reported, the fowls were well kept and given an abundance of nourishing food. There seems to be an inability' on the part of the affected animal to assimilate nourishment.

$\$ 176$. Morbid anatomy. The most conspicuous lesion is extreme emaciation. According to Dawson the mucosa of the duodenum contains areas in which the walls are deeply reddened and in which the contents are of a mucoid substance. The writer made a number of post-mortems in pigeons suffering from this disease without finding any gross tissue changes.

The disease needs further investigation, but the fact that an organism has been found in the duodenum in large numbers, where it multiplies and apparently produces by-products that are absorbed and which interfere with the normal metabolism of the body, is of sufficient interest to call attention to the preliminary findings herein mentioned. It is not unlikely that if the present hypothesis concerning the nature of this disease is verified, a number of disorders now attributed to general causes may be traced to some form of intestinal infection.

\section{REFERENCES}

I. DAwson. Asthenia (going light) in fowls. Annual Report of the Bureau of Animal Industry, U.S. Department of Agriculture, I8g8, p. 329.

\section{MISCELLANEOUS INFECTIONS}

$\$$ 177. Diphtheria in calves and swine. Diphtheria of calves is an infectious disease of young calves characterized by the formation of a diphtheritic membrane (necrosis) on a greater or less portion of the mucous membrane of the mouth and throat. It often leads to septicemia and death. It is caused by the Bacterium of necrosis, described by Bang.

The affection is quite common in Europe but it does not seem to be as well known in this country. 
Loeffler, who investigated diphtheria of calves for the Germau Imperial Board of Health, believes that the specific cause of the disease is a bacillus, and not a micrococcus, as Dammann assumed. He found on the edges of the necrotic tissue large long bacteria which formed undulating threads, and which differed entirely from the bacterium of diphtheria of man. Ritter confirmed the observations of Loeffler. On the other hand, Kitt regards the cause of diphtheria of calves to be the bacillus of necrosis.

Swine suffer from a diphtheritic necrosis of the upper portions of the digestive canal and air passages. Johne seems to have been the first to point out the diphtheritic character of this necrosis. He was not able to demonstrate its cause although the bacillus of necrosis was found on the mucous membranes. Swine suffering from hog cholera frequently have areas of necrosis in the gums, tongue and other parts of the mouth.

Kitt believes that there occurs sporadically an independent diphtheria of pigs which has no connection with swine fever. He believes its cause is the bacillus of necrosis, which occurs also in diphtheria in calves. The mucous membrane of the tongue, cheeks, pliarynx and stomach shows yellow-white caseous deposits; and that of the small intestine and colon, diphtheritic necrosis.

The bacterium (bacillus) of necrosis has been found to be pathogenic for many species of animals. Mohler (Pro. Am. Vet. Med. Asso., 1905, p. 181) has pointed out the extent of the pathological activities of this organism in cattle, sheep, goats, antelope, several varieties of deer, horses, asses, hogs, kangaroos, dogs, chickens, pigeons, rabbits, guinea pigs and nice. The extent and variety of the lesions it produces have suggested the term necrobacillosis for the lesions it initiates. 
CHAPTER VI.

\section{DISEASES CAUSED BY BACTERIA GENUS BACILLUS}

$\$ 178$. General discussion of the genus bacillus. The genus Bacillus in Migula's classification includes all rodshaped motile bacteria. In the older classifications it includes both non-motile and motile forms. The fixing upon motility as an essential generic character, and thus restricting the genus Bacillus to motile forms, is the occasion of some confusion between the genera Bacterium and Bacillus as applied to a number of important disease-producing bacteria. It is customary to speak of the Bacillus of anthrax, of tuberculosis and of glanders rather than of the Bacterium of these affections. As in the genus bacterium, there are a number of species of bacilli that are widely separated from each other. The diseases which they produce give very different pictures both clinically and in their morbid anatomy.

\section{HOG CHOLERA}

Synonl'ms.* Swine fever; pneumo-enteritis; pig typhoid; Svinpest.

\$ 179. Characterization. The distinguishing features of this disease are a continuous fever, ulceration of the intes-

*This disease is known popularly by a large number of names and in some works on swine diseases many of them are employed. The more common of these are enteric fever, typhus carbuncular fever, carbuncular gastro-enteritis, carbuncular typhus, pig distemper, blue sickness, blue disease, purples, red soldier, anthrax fever, scarlatina, measles, diphtheria and erysipelas. Many of the terms appear to refer to some one or more of the observed symptoms or lesions. 
tines, and more or less discoloration of the skin, especially over the ventral surface.

$\$$ 18o. History. The earliest outbreak in this country, of which there is knowledge of a disease supposed to be hog cholera, occurred in the state of Ohio in 1833 . It is presumed that it was brought from Europe with some of the animals imported from there for breeding purposes. After being introduced, it spread at first slowly, but later with increasing rapidity along the lines of commerce, until it invaded every part of this country where swine raising had become an industry. The disease was investigated and very carefully described by Dr. C. Sutton, of Aurora, Ind., from 1850 to I858. In I86I, Dr. Edwin M. Snow, of Providence, R. I., contributed an important paper on this disease to the U.S. Department of Agriculture. In I875, Dr. James Law, of Ithaca, N. Y., furnished to the same Department a valuable paper setting forth the symptoms and morbid anatomy of this disease. He believed it to be contagious although the specific organism had not been found. The U. S. Commissioner of Agriculture appointed in 1878 nine men for a period of two mouths each to investigate the disease in various localities. In their report the symptoms and morbid anatomy formerly described were confirmed and two additional features set forth. Law showed that it was transmissible by inoculation to other animals, and Dr. Detmers described a microörganism which he called Bacillus suis and which he believed to be the specific cause of the trouble. Later, Detmers described his organism as a micrococcus. The work of investigation was continued under the direction of the Commissioner of Agriculture and finally, in $188_{5}$, the specific organism was discorered by Salmon and Smith, who described its essential characters and properties. It was called Bacterium of swine plague. Since that time the disease has been under investigation and the Bureau of Animal Industry has during the last few years been actively engaged in the efforts to produce a specific, therapeutic serum.

In 1886, Dr. Theobald Smith discovered another bacterial 
disease among swine. It was found to be similar to the German Schweineseuche both in the morbid anatomy and in the morphology and properties of its specific organism. In naming this disease the Bureau of Animal Industry called it, on account of its similarity to the German Schieineseuche, swine plague and its organism the bacillus of swine plague, and changed the name of the disease described in 1885 to hog cholera and its organism to the bacterium* of hog cholera. The changing of the name of the first disease described from swine plague to hog cholera has been the cause of some criticism and it has been credited with the responsibility of creating confusion. It has, perhaps, led hasty readers to a misinterpretation of these diseases and their relation to those described in other lands under different names. While the names assigned may not have been especially happy ones, the transfer of the term swine plague from the intestinal to the lung disease must be considered as a fortunate occurrence and one which tended to simplify and not to confuse.

Billings, of the Nebraska State Experiment Station, opposed this nomenclature. He not only refused to accept the change and to continue to write about hog cholera under the title of swine plague, but he denied the existence of the swine plague, as described in the reports of the Bureau of Animal Industry for I 886 and subsequently, as an independent disease. The wide dissemination of his publications on this subject has unquestionably been responsible for much of the haziness concerning the distinguishing features of these maladies.

In 1893, Drs. Welch and Clements read a paper before the International Veterinary Congress in which they gave a very clear history of the nomenclature of these diseases and in which they adhered to the one of the Bureau of Animal Industry.

\section{$\$$ 18r. Geographical distribution. Hog cholera is}

*In 1888 the genus Bactorium was changed to Bacillus and this organism is spoken of since that time as the hog-cholera bacillus. 
widely disseminated throughout the central part of the United States. It exists, however, to a certain degree in every state in the Union and in Canada. It has long been known in Great Britain. It prevails to a greater or less extent on the continent of Europe. The confusion that has arisen in the use of the terms swine plague and hog cholera renders it difficult to determine, from the brief description given in a number of reports, the nature of the disease in question.

$\$$ 182. Etiology. The specific disease, here described as hog cholera, is caused by Bacillus cholcrae suis.* A brief description of its morphology, physiological properties and pathogenesis are appended.

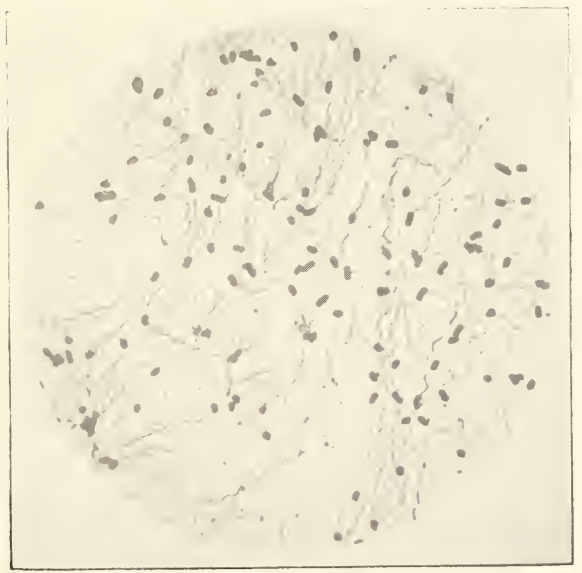

FIG. 59. A photograph of the bacillus of hog chotera with the flugellat stuined. $\times$ about rooo diameters.

* Moore described a bacterium found in a pig, from which the swine plague organism was also obtained, that possessed the cultural and pathogenic properties of the hog-cholera bacillus. More recently, Smith has described a similar organism, which was isolated by Burrell in Illinois. 
Morphology. - A rod-shaped organism varying in size according to the medium in which it is developed. From agar cultures it is from I. 2 to $1.8 /$ long and from .5 to $.8 \%$ broad. The ends are rounded.

Spores have not been observed. It is actively motile. A variable number of flagella have been demonstrated but usually there are from 3 to 5 . The length of the flagella varies. The average seems to be about $7 \mu$ although filaments $55 \|$ with an arerage length of 35 to $40 \mu$ are reported by Ferrier. It stains readily with the aniline dyes. Preparations made from cultures usually stain uniformly; while in the preparations made from the tissue of inoculated animals there is frequently exhibited a light center with a deeply stained periphery.

Cultural characters and biochemic properties. -The bacillus is grown readily on all of the ordinary media used in bacteriological work at a temperature of 30 to $38^{\circ} \mathrm{C}$. It is aërobic and facultative anaërobic.

Agar.-On the surface of inclined agar after 24 hours at a temperature $37^{\circ} \mathrm{C}$. a grayish, glistening nonviscid growth appears. When isolated the colonies are nearly round, convex, 0.5 to $2.0 \mathrm{~mm}$. in diameter. The edges are sharply defined and even. In stab cultures a grayish growth develops along the needle track with a more vigorous growth on the surface about the needle puncture. The growth reaches its maximum in about 48 hours.

Gelatin.-In this medium the growth is moderately feeble, the colonies appearing as grayish dots. When magnified they are finely granular and of a yellowish tint. The quantity and form of growth depend considerably upon the reaction of the gelatin. If decidedly alkaline there is of ten a tendency for the growth to spread. There is no softening or liquefaction of the medium.

Potato.-The growth on potato takes the form of a very thin, glistening layer. It is usually of a faintly yellowish color but this is subject to variation on different potatoes. If the reaction is strongly acid no growth appears.

Bouillon.-In alkaline bouillon it imparts in 24 hours a uniformly cloudy appearance to the liquid. Ordinarily there is no membrane on the surface. After some days' standing the growth begins to settle, forming a grayish, friable sediment. If the bouillon contains muscle sugar the reaction will be changed to acid, in from 24 to 48 hours, due to the fermentation of the sugar. Later, however, the liquid will become strongly alkaline, unless there was too much muscle sugar present. In acid bouillon the growth is less vigorous. It grows better in a bouillon containing peptone than in a simple beef broth.

Milk.-When the milk is acid in the beginning it gradually becomes alkaline. There is no precipitation or coagulation of the casein. After standing for from two to three weeks in an incubator a 
gradually developing opalescence of the milk can be observed. Later it becomes clear, then light brownish in color. If allowed to stand longer in the incubator the volume of the culture shrinks by evaporation and the opalescent liquid becomes quite thick and dark-colored but 110 t viscid. When the opalescence appears the milk is strongly alkaline. The process seems to be a form of saponification of the fat globules due to the presence of the alkali produced by the bacteria.

Indol.-In Dunham's solution the growth is quite feeble. Ordinarily no indol reaction is obtained, although it has been observed in a few cultures ohtained from different epizoötics.

Gas production.-In peptonized bouillon containing I per cent dextrose, gas appears witlin 24 hours and continues to form for from three to five days. During the first day from one-fourth to one-half of the totalquantity is produced. By the end of the second day the gas formation is nearly at an end. The total amount which collects in the closed branch of the fermentation tube is equivalent to about one-half of the capacity of this branch. The gas set free is composed of $\mathrm{CO}$, and an explosive gas which consists largely of $\mathrm{H}$. The ratio of $\mathrm{CO}$., to $\mathrm{H}$ in the fermentation tube is approximately as $1: 2$. The reaction of the liquid becomes strongly acid, which condition checks the multiplication of the bacteria.

Gas is not produced in bouillon containing lactose or saccharose. These sugars are not fermented. Alkaline cultures containing them become more strongly alkaline as the growth continues.

Thermal reactions. - This organism grows very feebly at a temperature of $20^{\circ} \mathrm{C}$. It will not thrive at a temperature above $43^{\circ} \mathrm{C}$. It is destroyed when exposed to moist heat at $5^{\circ} \mathrm{C}$. for ro minutes.

Disinfectants. - This organism is destroyed after an exposure for Io ninutes or less in the following solutions:

Carbolic acid, I per cent. Hydrochloric acid, I-5 of I per cent. Sulphuric acid, I-20 of $\mathrm{t}$ per cent. Suiphate of copper, I-4 of I per cent. Formalin, I to 2,00o. Trikresol, 1-2 of I per cent.

Lime is also a good disinfectant when used in preparations containing about $\mathrm{s}$ per cent $\mathrm{CaO}$.

Drying.-This bacillus resists drying for a variable length of time, according to the amount of protection it lias. In a drop of a bouillon culture dried on a cover-glass and kept under bell jars, the vitality is retained for from 5 to $S$ days. In bits of animal tissue containing the bacilli, the vitality is retained for from 20 to 40 days, according to the quantity of tissue taken.

Pathogenesis.-Subcutaneous injections of from I to 3 c. c. rarely produce fatal results in swine. An intravenous inoculation of 5 c. c., usually produces a septicemia. With smaller doses the "button ulcers" 
characteristic of hog cholera have been produced (Welch). By feeding pigs with pure bouillon cultures the intestinal lesions typical of hog cholera have also been obtained (Smith).

Rabbits inoculated subcutaneously with o.I c. c. of a bouillon culture die in from 5 to 8 days. The essential lesions consist of necrotic foci in the liver and a very much enlarged and dark colored spleen. Guinea pigs are affected similarly to rabbits, but death does not usually occur until from 7 to 12 days. Pure cultures of the bacillus can be obtained from the blood, liver or spleen of the inoculated animals.

While the above description applies to the form most frequently encountered, varieties are not uncommon. In I 894 Smith called attention to several varieties of this species. It is interesting to add, that Reed and Carroll have found the bacillus isolated by Sanarelli, and thought by him to be the cause of yellow fever, to belong to this group of bacteria.

In I903, de Schweinitz and Dorset published the discovery of a disease practically identical in its manifestations with hog cholera of an acute type, but which was produced by a virus that passed through the finest porcelain filters. It is possible, therefore, that the disease now known as hog cholera may be differentiated into two maladies, one caused by $B$. cholerae suis and the other by the "invisible virus", McClintock, Boxmeyer and Siffer report like results in the production of a disease with the filtrate. These authors were unable to find the hog-cholera bacillus in the cases from which they obtained the invisible virus. This suggests that they are dealing with a new disease rather than with a new etiological factor for hog cholera. Until this infectious filtrate is obtained from animals from which pure cultures of $B$. cholerae suis were isolated from the organs, it seems unfortunate to consider it the cause of hog cholera. The experimental results obtained with $B$. cholerae suis are too convincing to relegate it, without sufficient evidence, to the rôle of a secondary invader.

More recently Dorset, Bolton and McBryde have confirmed the earlier publication by de Schweinitz relative to the filterable virus. They state, however, that "it must be admitted that a disease in hogs may exist which is due to $B$. cholerae suis, and which has no connection with the filterable 
virus found by us in the outbreaks we have studied." They believe, however, that such a disease " would be possessed of a low degree of contagiousness."

The period of incubation varies from 7 to 14 days. Berry states that it varies from one to three weeks and perhaps longer.

\$ 183. Symptoms. The symptoms of hog cholera are by no means constant. The best informed writers on the subject agree that hog cholera can not, with certain exceptions, be positively diagnosed from the symptoms. Animals suffering from various intestinal troubles frequently exhibit symptoms which very closely resemble those of this disease.

There are two recognizable forms, namely, the acute, and the chronic or mild form. In the acute disease, the animals die very suddenly after a few hours' or at most a few days' sickness. In the other form, the disease runs a longer course. There is usually a rise of temperature of from $I$ to $3^{\circ} \mathrm{F}$.

The sick animals act dumpish and spiritless and lie quietly in a corner or huddle together, usually concealing the head in the litter. They refuse to move when disturbed and are more or less oblivious to their suffering. The appetite varies. In acute cases the animals may eat quite heartily up to within a few hours before death. In more chronic forms they eat fairly well until the end. There may or may not be diarrhea. Frequently the bowels are costive. It is quite common in these cases to have an active diarrhea during the last few days. The color of the discharge depends largely on the food. Vomiting rarely occurs. The changes in the respiration and the pulse are difficult to determine. There is rarely any cough. Usually there is considerable reddening of the skin on the nose, ears, abdomen and on the inside of the thighs and public region. Occasionally this reddening is very marked. The redness is diffuse and becomes more intense as death approaches. In some cases there is a discharge from the eyes. In the chronic form the animal becomes emaciated. These symptoms vary to such an extent that it is sometimes necessary to make a 
post-mortem examination and even the diagnosis must often be delayed until the results of a bacteriological examination

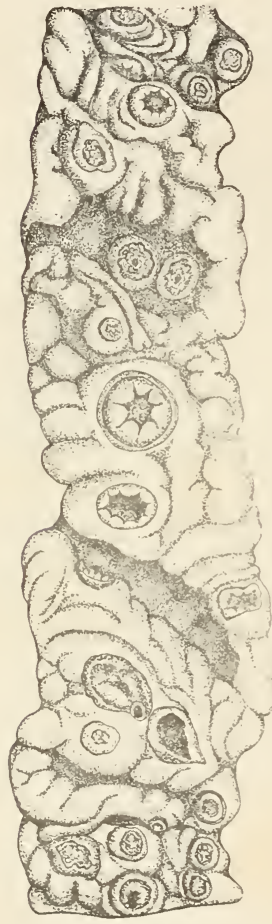

FIG. 6o. Ulcers in the intestine of a pig dead of hog cholera. have been obtained. It not infrequently happens that swine suffering from hog cholera are attacked with swine plague, the two diseases coexisting in the same animal.

s 184. Morbid anatomy. The acute type. This might with equal propriety be called the hemorrhagic or septicemic type, inasmuch as the chief and perhaps the only obvious changes are hemorrhagic in nature. They are more conspicuous when an animal is examined immediately after death. The spleen is variably enlarged, soft, and gorged with blood. Sometimes it is twice as long as normal and the other dimensions are proportionately increased. It may extend across the median line to the right side. Next to the spleen, the lymphatic glands and the serous membranes are most severely involved. The cortex of the glands appears on section as a hemorrhagic line or band, according to the amount of extravasated blood, or the entire gland may be infiltrated with it. Among the glands most commonly hemorrhagic are those of the mesocolon, those at the root of the lungs, and on the posterior thoracic aorta. Besides these, the retro-peritoneal and the gastric glands may be involved. More rarely the mesenteric glands show slight blood extravasations. Hemorrhages are also quite frequent beneath the serous surfaces of the abdomen and thorax. They are most 
abundant as petechiae and larger patches under the mucous membrane of the large and small intestines. They are occasionally found under the peritonenm near the kidneys, the diaphragm and the costal pleura as extravasations nearly an inch in diameter.

The lungs, in a small percentage of cases, show subpleural ecchymoses in large numbers and on section small hemorrhagic foci are observed throughont the lung tissue. In a few cases severe hemorrhages involving one or more lobes have been observed. The kidneys are occasionally the seat of extensive hemorrhagic changes. The glomeruli appear as blood red points; larger extravasations occur in the medullary substance and blood may collect around the apices of the papillæ. The subcutaneous tissue over the ventral surface of the body may be dotted with petechire and occasionally collections of blood (hematomata) are found in the superficial mnscular tissue. The brain and spinal cord have not been generally examined. In one case, petechize were observed on the cerebellum.

The digestive tract usually is the seat of extensive lesions.

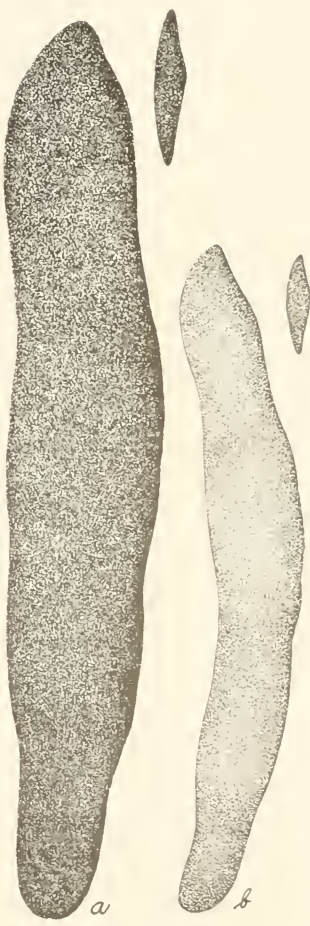

FIG. 6r. Spleins of pigs of the same age; (a) dad from hog cholera, (b) normal (killed in hialth).

The fundus of the stomach is as a rule deeply reddened; there may be more or less hemorrhage on the surface, giving rise to 
larger areas of blood clots. In some cases the small intestine has submucous ecchymoses throughout its entire length. In the large intestines these may be so numerous as to give the membrane a dark red appearance. The intestinal contents are now and then incased in a layer of blood clot.

The chronic form is perhaps the most common, at least in those epizoötics which have been reported. The acute hemorrhagic cases usually die in the beginning of the outbreak and are apt to be overlooked. Following these are the more protracted ones. In these animals the disease may be limited in its manifestations to the large intestine, although the other organs are not exempt from degenerative changes. These are due in part to the impairment of the functions of the large intestine, consequent fermentations and the absorption of the poisonous products elaborated by the specific bacilli in the spleen and other organs.

The lesions of the large intestines are necrotic and ulcerative in character. The ulcers may be isolated and appear as circular, slightly projecting masses, stained yellowish or blackish or both in alternate rings, or they may be slightly depressed and somewhat ragged in outline. When the superficial slough is scraped away many ulcers show a grayish or white base. A vertical section reveals a rather firm neoplastic growth, extending usually to the inner muscular coat. When sections of such an ulcer are stained with aniline dyes and examined under the nicroscope, the submucous tissue is very much thickened, infiltrated with rounds cells and containing a large number of dilated vessels. Resting upon this thickened submucosa, is a line of very deeply stained amorphous matter and upon this is situated the necrotic mass which fails to retain the coloring matter and which is permeated by a very large number of bacteria of various kinds. Frequently the eggs of trichocephalus are imbedded in the slough.

The extent of the submucous infiltration depends upon the age of the ulcer. In old ulcers it contains many newlyformed capillaries, and evidences of the formation of connective tissue are present. The capillaries may extend to the very 
edge of the border where the slough begins. The latter may have been partly shed, leaving a smooth line bounding the cicatricial tissue. The submucous infiltration gradually disappears toward the periphery of the ulcer and slightly outside of the ulcer no inflammation of the membrane exists. Giant cells have been observed in the intertubular tissues at the edge of the ulcer. The depth to which the infiltration extends is not always limited to the submucosa; it may extend into the muscular coats and cause inflammatory thickening and inflammation and the formation of new vessels in the subjacent serosa.

In some cases the necrosis, instead of appearing in circumscribed ulcers from one-sixteenth to one-half inch or more across, involves the whole surface of the mucous membrane, giving it the appearance of a so-called diphtheritic membrane. In such cases the walls of the intestine are very much thickened and so friable as to be easily torn with the forceps in handling them. Such necroses are rare in epizoötic cases, but they frequently appear in animals which have been fed with pure cultures of hog-cholera bacilli.

The distribution of the ulcers varies but slightly. They appear most frequently in the cecum and on the ileo-cecal valve, as well as in the upper half of the colon. The lower half is implicated in severe cases only and then less extensively. The rectum is rarely ulcerated. The lower portion of the ileum is ulcerated in a small percentage of animals, especially when they have been fed with hog cholera viscera or cultures. The stomach is occasionally the seat of slight ulceration. The lymphatic glands of the affected intestine are usually much enlarged, pale, tough and whitish on sections. The spleen is rarely enlarged. The liver shows degenerative changes. The heart and lungs are usually normal. The broncho-pneumonia frequently found in young pigs in the winter months must be ascribed primarily to exposure rather than to the presence of hog cholera.

In some outbreaks the acute and the chronic types are not so clearly separated as indicated in the foregoing pages. 
Frequently recent hemorrhagic lesions seem to be associated with cases presenting extensive ulcerations, which certainly are much older than the extravasations. It may be that the latter are the result of a secondary invasion of the hog-cholera virus, either from the ulcers in the intestine or from without. To illustrate more fully the difference in the lesions of the two forms of the disease, the published post-mortem notes of two cases are appended.

(I) Acute form. Female, two years old, weight about 150 pounds. She had been known to be sick but a few hours. The examination was made two hours after death. A little blood was oozing from the nostrils. The skin was not discolored. Upon section the skin was normal in appearance. The liver was deeply reddened, due to engorgement of the blood vessels. Blood flowed freely upon section. The spleen was slightly enlarged and dark colored The kidneys were hyperemic, especially the medullary portion. In the pelvis of the right kidney there was a large blood clot. The mucous membrane of the intestines was normal with the exception of several irregular areas of hyperemia. In the fundus of the stomach was a large, dark blood clot. No ulcers. The mesenteric glands were enlarged and darker than normal. In a few cases the cortex was hemorrhagic. The right lung was in a state of hyperemia. The heart contained very little liquid blood.

Bacteriologicalexamination.-A few bacteria were found in stained cover-glass preparations from the spleen aud liver. Tubes of slant agar were inoculated with bits of the tissue from the hyperemic lung, liver, spleen and kidueys. These tubes developed cultures of the hog-cholera bacillus. A few of them were pure cultures; the others contained, in addition to the hog-cholera organism, a quite large bacillus. (Report N. Y. State Com. Agric. ISS7).

(2) Chronic form. Small female, weight about 20 pounds, Considerable reddening of the skin over the ventral aspect of the body and limbs; especially marked along the median line. Superficial inguinals enlarged, of a mottled, pale and deep red color on section. Spleen very large, 12 inches long, 2 inches broad, and five-eighths to threefourths inches thick at the hilus; gorged with blood, friable. A small number of punctiform hemorrhages in cortical portion of the kidneys. Glands of mesentery and colon enlarged and congested. Deep reddening of several square inches of mucosa fundus of stomach. Large intestine contains a semi-liquid mass chiefly earth. Four large ulcers in the cecum, one of them at least one inch across, covered by a yellowish slough; the peritoneum covering it is thickened and inflamed. In upper colon there is considerable necrosis, involving the epithelium in 
patches. Lungs normal, excepting the right ventral lobe, which is solid. Bronchi and air cells of this lobe completely occluded by plugs; surface bright red, mottled with yellowish points-the ultinate air cells filled with the cellular exudate. Subpleural ecchymoses over both lungs. From the spleen a liquid and a gelatin culture contained only hog-cholera bacteria. They were very numerous in cover-glass preparations from this organ.

A rabbit inoculated from the consolidated lung tissue died on the seventh day. At the point of inoculation a pasty mass extends to abdomen, only subcutis involved. Spleen engorged. single acini in the liver are completely necrosed, yellowish white. In both organs, hog cholera bacteria. Cultures from spleen pure. (Report on hog cholera, I 889 ).

The duration of the disease varies. In the acute septicemic type it may not be more than a few hours or a day at the longest. In the chronic form it lasts from one to two weeks, sometimes longer.

The prognosis is not good. Berry states that recoveries are not rare. Although there are outbreaks where the mortality reaches from so to roo per cent, there are others of a milder type where the fatalities do not exceed 50 per cent.

\$ 185 . Differential diagnosis. Hog cholera is to be differentiated from a great variety of dietary disorders and poisoning from alkalies and possibly from other chemicals which may get into their food. "Powdered soap has been found to produce, when given in sufficient quantities, a series of symptoms quite similar to those of hog cholera. In addition to the many as yet etiologically undetermined disorders often producing a high mortality and popularly called hog cholera, infectious pneumonia or swine plague and tuberculosis are to be distinguished.

It sometimes happens that swine when kept under good hygienic conditions suffer from disorders which in their symptoms resemble hog cholera, but anatomically the lesions are varied and irregular. A few such enzoötics have been studied. A few have been described. In one instance $B$. coli communis seemed to stand in a casual relation to the trouble. Recently the writer has studied two similar enzoötics where several 
animals died and where the lesions were very few and exceedingly varied. In some of them there were healing, intestinal ulcers. The bacillus isolated belonged to the paracolon group.* It may be supposed that possibly many of these mild cases (enzoötics) are modified hog cholera. At present, however, such a conclusion does not seem to be fully justified.

The dietary disorders are determined by their history, the irregularity of the lesions, and the failure to find the specific organism of hog cholera in the tissues of the dead animals. An important feature is the fact that the trouble does not extend beyond the herd or herds first attacked or animals fed and kept under like conditions. The amount of loss from these troubles is very large. They are very often confused with and mistaken for hog cholera.

Hog cholera must also be differentiated from a new disease recently described by de Schweinitz, which resembles acute hog cholera symptomatically, but which is caused by an unknown organism that passes through a Chamberland filter.

The differentiation of hog cholera from swine plague depends upon the specific bacteria. While in typical, chronic cases the intestinal lesions in hog cholera and the lung affections in swine plague are sufficient to distinguish the nature of the disease, in many cases the variations of the lesions are such that diagnoses must depend upon the bacteriological findings. The essential differences between the two species of bacteria are brought out in the comparison appended.

Bacillus of hog cholera.

I. Rod-shaped organism with ends rounded, $\mathrm{I} .2$ to $2.0 \%$ in length, 0.5 to o $\mathrm{S} \mu$ in width. The size varies according to the stage of growth and division and the culture media.

2. From cultures it stains entirely. In tissues it usually stains around the periphery leaving a light centre.
Bacterium of saine plague.

I. Elongated oval organism 0.8 to $1.5 \mu$ in length, 0.6 to $0.8 \mu$ in thickness. The size varies according to the stage of growth and division and the culture media.

2. From old cultures it usually stains entirely. When in process of division as found in the organs of freshly dead rabbits the extremities stain leaving an unstained central band, "polar stain."

*It differed from the hog-cholera bacillus in not saponifying milk. 
3. Actively motile in liquids.

4. From 3 to 9 flagella are demonstrable.

5. Vigorous growth in alkaline nutrient liquids. Less vigorous if liquids are acid in reaction.

6. Moderate growth on potato. (Varies according to reaction).

7. Distinct growth on gelatin.

8. Saponifies milk in from 3 to 4 weeks.

9. Ferments dextrose with the formation of acids and gas.

10. Does not ferment lactose. Bouillon containing it becomes strongly alkaline. No gas.

II. Does not ferment saccharose. Bouillon containing it becomes strongly alkaline. No gas.

I2. Destroyed by moist heat at $5^{\circ} \mathrm{C}$. in $5_{5}$ minutes.

13. Dies in water in from 2 to 4 months.

I4. It dies in the soil in from 2 to 3 months.

15. Rabbits injected subcutaneously with o.I cc. of a bouillon culture of a virulent bacillus will die in from 5 to 7 days. Enlarged spleen, necrotic foci in liver.

I6. Rabbits inoculated with culture of an attenuated variety live from to to 20 days or recover. The lesions are enlarged spleen and infiltration of the follicles in Peyer's patclies.

17. In guinea pigs the lesions are practically the same as in rabbits. Death occurs in from 7 to $I 2$ days.
3. Not motile in liquids.

4. No flagella have been found.

5. Growth moderate or feeble in alkaline nutrient liquids. No growth if liquids are acid.

6. No growth on potato.

7. Feeble or no growth on gelatin.

8. Produces no apparent change in milk.

9. Ferments dextrose with the formation of acids but no gas.

Io. Does not ferment lactose. No gas.

II. Ferments saccliarose with the formation of acids.

I2. Destroyed by moist heat at $5 \mathrm{~S}^{\circ} \mathrm{C}$. in 7 minutes.

13. Dies in waterin from 10 to 15 days.

14. It dies in the soil in fron 4 to 6 days.

15. Rabbits injected subcutaneously witl o.oI cc. of a bouillon culture of a virulent bacillus will die in from 16 to 20 hours. Septicemia.

16. Rabbits inoculated with a culture of an attenuated variety will live from 4 to 10 days. The lesions are local infiltration of pus cells with pleuritis, pericarditis or peritonitis.

I7. Guinea pigs are slightly less susceptible than rabbits. There is more local reaction. Death occurs in from 1 to 4 days. 
I8. Pigs are not usually affected by subcutaneous injection of small quantities of culture. If the pigs are killed within I to 3 weeks the bacilli are found in the local lesion and certain of the $1 \mathrm{ym}$ phatic glands. Fatal results are reported in a few cases from these injections.

19. Feeding cultures to pigs which have fasted for 24 hours produces extensive intestinal lesions with fatal results.

20. Intravenous inoculation into pigs causes either an acute septicemia or a chronic form of the disease in which are produced quite typical round, firm, elevated ulcers.
I8. Pigs are not usually affecter by the subcutaneous injection of small quantities of culture. The bacilli are not found except in the local lesion. In a few cases fatal results are reported.

I9. Feeding cultures to pigs usually produces no effect.

20. Intravenous inoculation in to pigs usually produces a septic form of the disease $w$ hich kills in from 1 to 2 days. Inoculation into the lungs causes pleuritis, usually accompanied by pneumonia.

Dawson pointed out the serum reaction as a possible means of diagnosis. This test, however, seems of little value until the disease has run a course of many days.

S 186. Prevention. As hog cholera is caused by a specific organism, the first fact to be determined is to find the channel or means by which it can be carried from an infected to a non-infected herd. The thorough investigations which have been made in the United States Bureau of Animal Industry have shed much light upon this subject. The observations of more recent years have confirmed the conclusion reached in the earlier reports of the Bureau concerning the means of spreading this disease. With these results, the pointing out of the ways by which the virus may be disseminated and the methods necessary for checking its spread is no longer questionable and there is a certainty that it can be kept away from individual herds even in the midst of widespread epizoötics. A few of the common means of its dissemination are worthy of note.

1. The virus of hog cholera is frequently introduced into a non-infected locality by the purchase of animals, usually for 
breeding purposes, from herds in which this disease exists or has existed within the preceding few months. These animals are usually placed among the home raised swine without quarantine, thus affording every possible facility for starting up a new outbreak. The reason for this is clear.

2. The bacteria can be carried in the dirt on the animals or, as is most usually the case, the pigs may have been but recently infected and being transferred during the period of incubatiou they derelop the disease later. It not infrequently happens that the purchased animals are actually suffering from a chronic form of the disease, to which they eventually succumb but meantime infect others. In purchasing swine, therefore, it is of the greatest importance that the history of the herd should slow that it had been free from infectious disease for at least one year. In addition to this, newly purchased swine should not be placed immediately after shipment in the pens with the home stock, but they should be kept in a separate enclosure until all danger of the disease has passed.

3. Swine are often shipped in crates, boxes or in open cars in which hogs affected with hog cholera have previously been confined. The history of hog cholera contains many illustrations of this method of contracting the disease.

4. The bacilli of hog cholera live for a considerable time in water. On this account the bacteria from outbreaks which start at or near the source of a creek or small river may be carried in the current and infect animals which wallow in the stream many miles below. By keeping swine in a small enclosure away from infected streams and fields the disease is often prevented.

5. The bacilli of hog cholera can be carried in the dirt which adheres to one's shoes or to farming utensils. It not infrequently happens that the virus of this disfase is carried from farm to farm on the tools taken from an infected place.

6. The virus may be carried by buzzards, crows and other birds. There is no positive proof that the virus has been 
disseminated in this way although there is much evidence to support such a theory, particularly in the South. Several outbreaks have been attributed to this method of introducing the virus. The hypothesis emphasizes the necessity for promptly disposing of the dead animals instead of leaving them as prey for scavengers. If they cannot be burned it is best to cover the bodies with a liberal amount of line and bury them.

When healthy hogs are separated from those suffering with the disease it is a safe precaution to dip them in a disinfectant to kill any hog-cholera bacteria that may be upon the exterior of the body.

5 187. Specific treatment. A large number of investigations have been made to find a protective vaccine for this disease and also to find a specific serum treatment. Thus far satisfactory experimental results have not been obtained. In a number of instances, where the practical application of the "serum treatment" has been made, most satisfactory results followed, but the reports fail to give evidence of an accurate diagnosis of the disease treated. In these cases, the better management of the animals, in addition to the serum, would suffice to check the disease if the trouble was of a dietary nature. There is need for additional investigation along these lines.

\section{REFERENCES.}

1. Berry. Swine fever. Jour. Compar. Path. and Thera., Vol. XV (Ig02), p. I.

2. Burlings. Bulletins Neb. Agric. Expt. Station, isss. Also many special publications and contributions to various veterinary journals.

3. Dawson. The serum diagnosis of hog cholera. New York Med. Jour., Feb. 20, 1897.

4. DE SCHWEINITZ. The production of immunity in guinea pigs from hog cholera by the use of blood serum fiom immunized animals. Annual Report of the Bureau of Animal Industry, U. S. Dept. of Agric, , IS98.

5. DE SCHWEINITZ AND DORSET. A form of hog cholera not caused by the hog cholera bacillus. Circular No. $7^{I}$, U.S. Bureau of Animal Industry, 1903. 
6. DORSET, BOLTUNAND MCBRIDE. The etiology of log cholera. Bulletin No.72. Bureau of Animal Industry, U. S. Dept. Agric., I 905.

7. PETERs. Serum therapy in hog cholera Bulletin No. 77 , Uniz. of Neb. Agric. Exper. Station, 1897 .

8. Salmon and Simith. Annual Reports of the Bureall of Animal Industry, IS85-1 895 .

9. SALMON. Special report on hog cholera, its history, nature and treatment. U.S. Burean of Animal Indnstry, ISS9.

Io. Sistr. Zur Kenntuiss des Hog.cholera Bacillus. Centralblatt fïr Bakter. u. Parasitenkunde, Bd. IX (189I), S. 253.

II. Sirter. Hog cholera group of bacteria. Inulletin No. 6, I . S. Bureau of Animal Industry, 1894, p. 9.

12. SMITH AND MOORE. Experiments on the production of immunity in rabbits and guinea pigs with reference to hog cholera and swine-plague bacteria. Ibid., p. $4 \mathrm{I}$.

13. REED AND CARROLL. Bacillus icteroides and Bacillus cholerae suis. A preliminary note. The Hedical Neas, Apr. 29, 1899.

14. WELCH. Report of investigations concerning the causation of hog cholera. Johns Hopkins Hospital Bullelin, Nov. I, r889.

I5. WELCH AND ChenENTS. Remarks on hog cholera and swine plague. First International I'eterinary Congress of America held in Chicago, Ill., October, I893.

\section{TETANUS}

Synonyms. L,ockjaw; trismus.

\$ 188. Characterization. Tetanus is an infectious disease (toxemia) is which the specific organisnus are localized at the place of inoculation. It is characterized by spasmodic contraction of the muscles referable to the nervous system and by the absence of obvious tissue changes. It is the result of a specific wound infection. All mammalia including man are susceptible. It occurs most frequently in horses, asses and mules; next to them in the smaller ruminants such as the sheep and goat; it appears least often in the dog. It is reported to occur rarely in birds and fowls are supposed to be immune. The human species is very susceptible. 
\$ 189. History. Tetanus is one of the diseases that was recognized and described before the Christian era. It was not clearly differentiated until the discovery of its specific cause in 1884 .

$\S$ rgo. Geographical distribution. Tetanus is reported to be more prevalent in the hot climates than in the temperate ones, while in the very cold latitudes it is rarely if ever encountered. It is more frequently met with in some districts than in others. Although very common in certain localities, it is, on the whole, a somewhat rare disease. There seem to be no statistics by which its frequency can be determined in this country, but in certain of the European armies this has been noted. In the Prussian army, it is reported to occur once in a thousand cases of sickness among horses. At Wiirtemberg, Hering reports it once in 3000 cases of disease among the horses in the cavalry. It has also been noted that in some veterinary hospitals it does not occur for long periods, while at other times several cases may appear in rapid succession. It is, however, a wide spread disease.

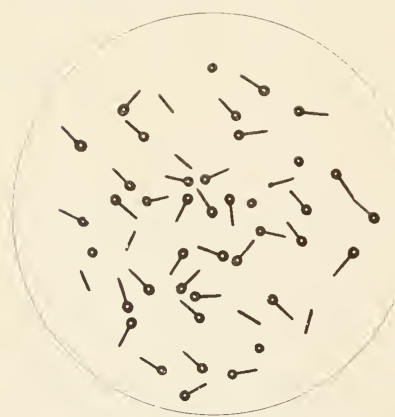

FIG. 62. Bacillus tetani.

S 191. Etiology. Tetanus is caused by a slender bacillus 2 to $5 \mu$ in length. It forms spores which are at the end of the organism giving it somewhat the appearance of a pin. On account of this it has been designated the "pin bacillus." It is anaërobic. This organism was first observed by Nicolaier in 1885 , although Carle and Rattone showed in 1884 that this disease could be transmitted from man to animals by inoculation with the pus from the local lesion. In 1889, Kitasato isolated the bacillus and studied it in pure culture. This 
bacillus stains readily with the aniline dyes, especially with carbolfuchsin. It takes the Gram stain. It grows well in nutrient gelatin, agar or bonillon and on blood serum at the temperature of the body and in an atmosphere of hydrogen or in the absence of air as in deep agar cultures. The addition of a little grape sugar facilitates its growth. It has the distinction of producing the most powerful (poisonous) toxin of any known bacteria, 0.23 of a milligram being estimated as a fatal dose for a mall of 175 pounds weight.

The fact that this bacillus is an anaërobe renders its cultivation of little practical value in diagnosing the disease. Although it is not distributed in the body, it can ustrally be found in cover-glass preparations, made from the local lesion and stained with carbol fuchsin.

Bacillus tetani is found in the soil. It has been found in hay dust, in the mortar of old masonry, in the dust in rooms, barracks and hospitals and in the arrow poison of certain savages in the New Hebrides. They obtain it by smearing their arrow heads with mud from crab holes in the swamps. It is reported that certain savages in Africa destroy their enemies by putting bits of broken glass nixed with certain soils in their shoes. The cause of death is tetanus. Mold rich in horse manure seems to be the most favorable abode for it. It has been stated that it exists in all soils. There are good reasons for believing that this is an over-estimate of the wideness of its distribution. It certainly is more nunerous in some localities than in others.

The tetanus bacillus is very resistant, especially in its spore form, to destructive agents such as drying and the ordinary disinfectants. Kitasato found that a 5 per cent solution of carbolic acid applied for ten hours failed to kill the spores. Tizzoni and Cattani found that mineral and organic acids produced no effect upon the dried spores. von Behring found that iodine trichloride possesses a strong antiseptic effect upon them. They are not affected by the gastric fluids. It has been noted by Kitt that the dried spores in pus have retained their virulence for sixteen months. They are de- 
stroyed when subjected to a temperature of $100^{\circ} \mathrm{C}$. in water or steam for ten minutes. The bacilli in the vegetative state are readily destroyed by the usual strong disinfectants, such as 5 per cent carbolic acid.

A number of bacilli closely resembling $B$. tetani have been described. This renders a careful study of the suspected organism necessary, as it is difficult in some cases to determine $B$. tetani microscopically. The guinea pig inoculation affords a ready means of differentiation whenever fresh material is available.

$\$$ 192. Mode of infection. As the bacillus of tetauus is widely distributed in the soil and consequently on articles contaminated with it, the most common modes of infection are punctures, scratches, and pricks made by splinters, nails or infected instruments (traumatic tetanus). It may follow slight abrasions of the skin where infected earth comes in contact with the lacerated epidermis. Infection through wounds in the intestinal mucosa do not seem to have been clearly demonstrated. The most usual method seems to be by pricks and nail punctures, in which case the virus can be carried well into the living tissue and there is little or no bleeding to wash it out. Infection often occurs in young foals and lambs through the freshly broken umbilical cord (tetanus neonatorum).

The period of incubation. The shortest period which seems to be reported is a few hours and the longest is six weeks. In horses the period of incubation is usually from four to twenty days. After inoculation with pure cultures it is from four to five days and in sheep from two to four days. In guinea pigs inoculated with infected soil the incubation period is usually not over forty-eight hours and often less than that.

Park has found that mice, guinea pigs, rabbits, rats, horses, goats and a few other animals inoculated with pure culture have a period of incubation of from one to three days. In man it varies from one to twenty days. There are, however, a few exceptionally long periods reported. It has been 
noted by Richter and others that the shorter period of incubation the more severe the disease, the mortality being over 90 per cent in the first and about 50 per cent when the symptons were slow in appearing.

$\S$ 193. Symptoms. The first symptoms are often obscure and may be overlooked for several days or they may be ushered in suddenly with violent and extensive tonic spasms. The tetanic spasms usually begin in the muscles of the head and neck, extending from these to the nuscles of the throat, trunk and extremities. It often happens that the spasms first appear in the hind quarters and extend forward. There is stiffness of the parts affected. If in the head, the muscles of mastication are first attacked with spasms, while if the hind quarters are first attacked, there are usually spasms of the muscles of the tail. The muscles at the site of inoculation are frequently the first to show spasms and, if the disease is of a mild type, they may be the only ones to exhibit symptoms. Friedberger and Fröhner have grouped the muscles which are attacked with the more obvious effects upon the appearance of the animal. They are as follows:

1. The muscles of mastication. The contraction of these muscles is called trismus or "lockjaw." According to the degree of contraction, the jaws remain in more or less close contact, rendering prehension or mastication difficult or impossible.

2. The other muscles of the head. These are spasuodically contracted in different degrees. Spasms of the muscles of the ears canse the ears to be "pricked" and their tips to be drawn together; of the recti muscles of the eyes, cause the eyes to be retracted in the orbit with protrusion of the nictitating membrane; of the nose, produce dilatation of the nostrils ; of the dilator of the upper lip, give an abnormal shape to the opening of the mouth. The muscles of the tongue, of deglutition and of the larynx are also usually attacked by spasms.

3. The extensor muscles of the neck. Contraction of these muscles canses a stiff, ontstretched carriage of the head and 
"ewe neck." The muscles of the neck become hard and tense to the touch.

4. The extensor muscles of the back. Spasms of these muscles are manifested by an extremely hard condition of the muscles of the back, loins and croup. Several conditions may arise: orthotonous in which the neck is stretched out and the back and croup are carried horizontally, or opisthotonous in which the head is raised or drawn back and the vertebral column slightly depressed. This is the most common occurrence. There may be a lateral curvature of the cervical vertebrae which is uncommon and also a convex curvature of the vertebrae which is very rarely observed. The tail, especially in horses, is often raised and occasionally said to be straight with the back.

5. The muscles of the limbs. The spasms in these muscles make the limbs stiff and cause the animal to assume an attitude in which the fore legs are extended forward and laterally and the hind ones backward and laterally. They are bent at the joints only with difficulty. The contraction of the muscles of the abdomen gives the animal a tucked up appearance and the spasms of the muscles of respiration render breathing difficult.

Besides the spasms the animal shows an increased reflex irritability and heightened sensibility. These manifest themselves in excitement, timidity and intensified muscular contractions if irritated. Sweating is common, especially in severe cases. In mild cases it may be absent. There is usually little or no change in the internal temperature. In fatal cases the temperature is usually constantly high toward the last. The high temperature $\left(104^{\circ}\right.$ to $106^{\circ} \mathrm{F}$.) usually continues for some time after death. Bayer has observed in a horse, 24 hours before death, a temperature of $\mathrm{IO}^{\circ} \mathrm{F}$.; one and a half hours before death, $105^{\circ} \mathrm{F}$; ; the moment of death, III ${ }^{\circ} \mathrm{F}$. ; and fifty minutes after death, $1 \mathrm{I} 3^{\circ} \mathrm{F}$. There is frequently no increase in the number of pulse beats until severe exacerbation sets in. The frequency of the pulse is much greater in animals which continue recumbent than in those which keep upon their feet. The pulse is often hard and small and the 
walls of the arteries are spasmodically tense. In many cases, however, it is full, soft and easily compressible. There is, as a rule, an increase in the number of respirations, which may become very high if the respiratory muscles are attacked. The number varies according to the excited condition of the animal. The respirations may increase four fold without a corresponding increase in the pulse beat. The breathing may reach from so to 100 per minute. In character the respirations are shallow on account of the fixed condition of the ribs and the spasms of the muscles which compress the abdomen. There may be cyanosis and catarrh of the nasal mucosa, coughing and in fatal cases symptoms of hyperemia and edema of the lungs and often pneumonia (usually aspiration in nature). There is constipation due to lack of peristalsis and the rigid condition of the unuscles which compress the abdomen. Micturition becomes less frequent and more difficult. Complete retention of urine is said to occur in some cases. The urine has a high specific gravity and occasionally contains albumen. Some animals can eat readily while others eat, if at all, with great difficulty. They like to play with drink set before them and often try to satisfy their thirst, which seems to increase as the disease advances. In fatal cases the animals seem to be perfectly conscious to the last. They seem to be possessed of a feeling of terror.

r94. Morbid anatomy. The gross examination of the tissues at post-mortem of animals dead from tetanus is usually negative. It has been pointed out by Goldscheider and Flatau that in experimental animals there are certain characteristic changes in the motor cells of the anterior horns of the spinal cord which in the order of their development depend upon the concentration of the toxin or virulence of the bacteria injected and upon the duration of the disease. The changes are primarily an enlargement of the nuclei, which at the same time become more distinct; then follows an enlargement and disintegration of Nissl's cell-granules with an enlargement of all of the nerve cells. These investigators also 
found that where antitoxin had been used it had a distinct retarding influence upon these changes. They found like lesions in the spinal cord of a human subject dead of tetanus. Very similar results have been obtained by Matthes, Westphal, Goebel and others. The lesions point to the anterior horns of the spinal cord as the primary seat or origin of the tetanic contractions. The changes pointed out above are said by Moschowitz to be characteristic of tetanus and constantly found. The motor ganglia cells of the auterior horns of the spinal cord seem at present, therefore, to be the most likely source of the spasms, due apparently to a specific affinity between those cells and the tetanus toxin. It is possible to explain also the local spasms on this hypothesis as the toxin elaborated by the nerves terminating in the affected region. The experiments of Tizzoni and Cattani suggest the possibility of such a theory. There is, however, need for further investigation on this subject.

A considerable number of lesions may be found elsewhere in the body, none of which can be considered as characteristic of the disease, but which are secondary to the tonic contractions. The blood, owing to lack of oxidation, may be dark colored, tarry, of a greasy appearance and tardy in coagulating. There may be numerous ecchymoses and sanious exudates in the subserous and mucous membranes. The lungs may be variously affected according to the extent of the trouble with the respiratory muscles. Thus congestion, edema, hemorrhages, pneumonia, emphysema and hypostatic congestions have been described. In the heart there are usually epiand endocardial hemorrbages. The muscles may contain hemorrhages. The fibers of the muscles may show cloudy swelling, a loss of the transverse striae and changes 'in the nuclei. The liver may be swollen and abnormally yellow in color. The hepatic cells often show fatty degeneration. The spleen is often swollen, it may be engorged with blood or soft and flabby. The kidneys may or may not show degenerative changes. The bladder is usually distended with urine and its mucous membrane is often sprinkled with ecchymoses. The 
digestive tract may show areas of congestion and ecchymoses.

The duration of the disease varies in different species and in different individuals of the same species. In the horse it may last for two or three days only or it may continue for several weeks. In cattle the course is usually less rapid, but it rarely runs longer than two weeks. In sheep it usually terminates fatally within a week and often in two or three days.

$\leqslant$ 195. Differential diagnosis. Tetanus, while possessing quite characteristic symptoms, may be mistaken for a number of other affections or specific diseases. Among those which should receive special attention are cerebro-spinal meningitis and rabies (for the symptoms and lesions see those diseases), rheumatism, eclampsia, catalepsy, convulsions in the newly born and pyemic polyarthritis in lambs and foals.

The symptoms of tetanus which are perhaps the most diagnostic are (I) the continuous tonic spasms of different groups of muscles, (2) the apparent clearness of mind (if we may attribute such a quality to animals), and (3) the absence of fever in the beginning of the symptoms. The general attitude of the animal is also of much value. If the infected wound can be found, it is often possible to obtain cover-glass preparations in which the tetanus bacilli can be found. Negative results are in this case not to be considered as final, for it is practically impossible to make these examinations sufficiently thorough to be sure of the absence of these bacilli, if they are not found. If they are found the diagnosis may be considered as positive.

In poisoning with strychnine, there are symptoms which at first may be more confusing. This form of poisoning usually occurs in dogs where tetanus is rare, and again in strychnine poisoning the suddenness of the attack, the rapidity of the course and the increased reflex irritability are valuable diagnostic features. In differentiating tetanus from other affections in the newly born, the bacteriological examination of cover-glass preparations made from the end of the umbilicus may be of much assistance. 
$\$$ I96. Prevention. Owing to the wide distribution of tetanus bacilli, precautions can consist only of the careful and thorough disinfection of all wounds. With animals at pasture, it is impossible often to know of the wounds until it is too late to apply this measure. In stables where the disease becomes prevalent, the floors and siding should be thoroughly disinfected and special watchfulness exercised to find at the earliest moment any injury by which infection could occur. The practitioner should learn as soon as possible the tetanus infected lands and stables in his community and, knowing these, give wise instruction to his clients to take such precautions as are possible. In case operations are to be performed on animals in such stables an immunizing dose of tetanus antitoxin may be administered. This practice is followed in many places in Europe. If the present knowledge of this disease is properly availed of, there should be only occasional cases which as yet there seems to be no way to avoid.

\$ 197. Tetanus antitoxin. It was first pointed out by von Behring and Kitasato that animals could be made immune to tetanus by using cultivations of the tetanus bacilli which had been attenuated with iodine trichloride. The blood serum of such immunized animals has the power to immunize healthy animals against the disease and to render the toxin in animals affected with tetanus inert. The antitoxin is prepared now, however, by injecting horses with the filtrate of bouillon cultures, either alone or with a quantity of antitoxin. After the first dose the animal becomes tolerant to a certain degree so that by repeated and constantly increasing doses complete resistance to the toxin is acquired. When this point is reached the serum usually possesses a strong antitoxic power. As a practical remedy for the disease in animals the recorded results from the use of this antitoxin are somewhat contradictory. In human practice the results are similar. Moschcowitz has collected 290 cases in man where it has been used subcutaneously, with 173 recoveries and II7 deaths or a mortality of 40.33 per cent. In a total of 48 cases where the 
antitoxin was injected intracerebrally 23 recovered and 25 died, a mortality of 52.08 per cent.

Some interesting experinents suggested by Krokiewitz directed toward the finding of a specific treatment consist in the injection of an emulsion of brain substance. Primarily this method of treatment is based upon the hypothesis, set up by Goldscheider and Flatau, who, as a result of their research came to the conclusion that "The morphological changes in the nerve cells are the expression of a chemical process, i. e., of the chemical combination of the toxins with the nerve cells. Every nerve cell possesses atom groups which have a certain affinity for the atom groups of the tetanus toxin and are able to combine with them." Wassermann and Takaki substantiated this hypothesis experimentally. These observers injected into experimentally tetanized animals an emulsion of spinal cord, obtained from a freshly killed animal, to test, if possible, whether the nerve cells of the dead animal also have this affinity for the tetanus toxin, like the nerve cells of the living animal. By this experiment, they have come to the conclusion that every part of the nervous system, particularly the brain of the examined animals including man, has a definite and positive tetanus antitoxic power; and that the injection of normal brain substance into experimentally tetanized animals has the power to save life. Further work in this direction is necessary to fully demonstrate the efficiency of this procedure.

REFERENCES.

I. Vox BEHRIN; UND Kitasato. Ueber das Zustandekommen der Diphtherie-Immunität und der Tetanus-Immunität bei Thieren. Deutsche Med. Wochenschrift, Bd. XVI (IS9o), S. II 3.

2. Kitasato. Uber den Tetanusbacillus. Zeit. f. Hygiene, Bd. VII (18S9), S. 225 .

3. Kitasato. Experimentelle Untersuchungen iiber das Tetanusgift. Zeit. f. Hygiene, Bd. X (1891), s. 267.

4. Moschcowitz. Tetanus, a study of the nature, excitant, lesions, symptomatology, and treatment of the disease, with a critical summary of the results of serum therapy. Studies from the Dipart- 
ment of Pathology of the College of Physicians and Surgeons, Columbia University, Vol. VII (I899-1900). (M. gives pathology and antitoxin treatment, summary of cases and full bibliography.)

5. MCFARIAND. Tetanus and vaccination. The Jourual of . Medical Research, Vol. VII (I902), p. 474. (New Series Vol. II).

\section{BLACK LEG}

Synonyms. Black quarter; symptomatic anthrax; quarter ill; quarter evil; gangrenous emphysema; charbon symptomatique; Rauschbrand.

S 198. Characterization. Black quarter is an acute infectious disease of cattle characterized by the development of an emphysematous swelling of the subcutaneous tissues and muscles. These lesions are usually located upon and ordinarily extend over the greater part of a hind quarter or of a shoulder. The disease does not spread from animal to animal by simple contact but the infection takes place apparently from a common source, the soil. The virus seems to exist in the soil in certain localities only. Like tetanus, it is a disease following a wound infection.

Symptomatic anthrax is a disease of cattle, sheep and goats, although the two latter species are rarely attacked. Guinea pigs are very susceptible to inoculation. It is reported that horses, asses and white rats develop local lesions when inoculated subcutaneously with the virus. Other animals seem to be immune. In cattle, it rarely occurs in the very young, under six months, and in adults after the fourth year.

I99. History. It is supposed that black quarter has existed for hundreds of years, although it was not until late in the last century that it was positively differentiated and recognized as a distinct and specific "disease. The descriptions given to many of the earlier epizoötics designated as anthrax correspond more exactly with the present knowledge of black quarter than they do of anthrax.

In 1782 , Chabert classified the various anthracoid dis- 
eases recognized at that time into thrce groups, (I) anthrax fever, where the disease manifested itself without external swelling, (2) true anthrax, where the lesions consisted at first of small, hard and very painful swellings followed or accompanied by fever and other general symptoms, and ( 3 ) symptomatic anthrax, where the swelling was preceded by a rise of temperature, loss of appetite and symptoms of general depression. This classification was held for nearly a century: Boutrolle, in 1797 , refers to a disease which he called mal de cuisse (quarter evil) because it affected the animal in the thigh. Viborg described the disease in Denmark. where it has long been known to the laymen and designated by them as raslesyge ("rattle disease"). Its clinical features were very accurately" described by Walraff in 1856 . In 1879 , Arloing, Cornevin and Thomas proved the causal relations of a certain microörganism to this disease and thus established its specific nature. A year later (1880) they described the specific microörganism and demonstrated that the disease could be produced by inoculating susceptible animals with it. Since that time both the organism and the disease itself have been studied by many investigators. In this country, it has been under investigation during the last few years by the Bureau of Animal Industry.

\$ 200. Geographical distribution. Black quarter exists to some extent in nearly every country in the world. It is reported as occuring in the most northern latitudes in which cattle are kept, as well as in the temperate aud tropical zones.

In Europe, it occurs on the pastures on the Alps, where for five months in the year the ground is covered with snow and ice and in America it is quite common in certain northern districts. It has been reported from Asia and from Northern and Southern Africa.

In the United States, it prevails to a greater extent than is generally supposed. The states and territories which, according to the reports of the Bureau of Animal Industry, suffer most from it are Texas, Oklahoma, Kansas, Nebraska, Colorado, North and South Dakota and Indian Territory; but 
a number of the other Western States are badly infected. Many of the states east of the Mississippi river have infected localities, but in a few of the Eastern and Southern states it seems not to exist. During the last few years infected localities have been found in New York where there has been an annual loss from this disease, but where prior to recent investigations the cause of death has been attributed to poisoning.

$\$$ 201. Etiology. Black leg is caused by Bacillus chaureaui. This organism varies from 3 to $6 \mu$ in length and from 0.5 to $r . \mu$ in width. The ends are rounded and it produces spores. It stains readily with ordinary aniline dyes and also after the gram method. In cultures long involution forms are often observed. It is anaërobic. In suitable culture media under anaërobic conditions or in animal tissues (other than

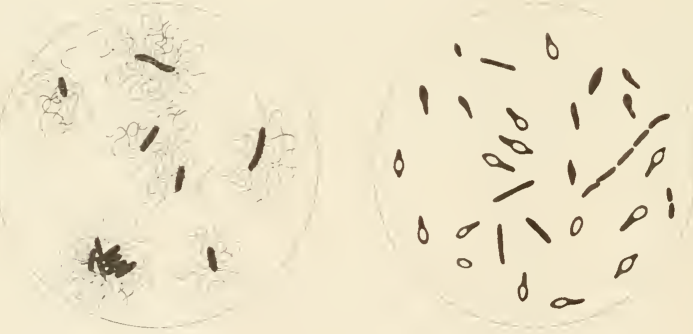

FIG. 63. Bacillus of black leg with flagella and with spores (after Hutyra).

blood) it multiplies rapidly with the evolution of gas. The presence of spores renders it very resistant to natural destructive agencies and to the commori disinfectants. The bacillus of black leg or its spores are supposed to gain entrance to the tissues of animals through abrasions of the skin or, possibly, the mucous membranes of the mouth or intestine.

The period of incuhation is not known in cattle but it is supposed to be very short. Guinea pigs inoculated with a culture of the organism die in from one to three days. 
$\$$ 202. Symptoms. The first symptoms may be either general or local in character. Arloing, Cornevin and Thomas believe that general symptoms always precede the local manifestations. Nörgaard reports finding cattle with marked local lesions but few animals suffering from general symptoms, although the latter may have preceded the former and have subsided.

A general symptom is elevation of temperature, reaching in some cases $107^{\circ} \mathrm{F}$. It usually falls to the normal or even subnormal before death. There is loss of appetite, loss of rumination and pronounced depression. Respiration becomes accelerated, reaching 140 per minute or even higher. The animal moves with difficulty and lies down frequently. At first the visible mucous membranes are congested and within twelve to fifteen hours they have a dirty leaden or purplish color.

The local symptoms may appear on different parts of the body except below the knee or hock joints and on the tail. They are less frequently found about the head. They usually appear on the thighs, neck, shoulders and lower region of the chest. The swelling is at first small and painful. It spreads rapidly and may in a few hours attain to a large size, when it becomes characterized by a crackling and a gurgling sound when the hand is passed over it. On percussion it gives a clear, tympanic sound due to the collection of gas in the affected tissues. At the center of the larger swellings the skin becomes dry and parchment-like, cool to the touch and painless upon pressure. If lanced, a dark, reddish, frothy fluid flows from the wound. It emits a disagreeable odor. In some cases there is but one swelling but usually there are two or more which may become confluent. The lymph glands adjacent to the swellings are much enlarged. There is usually trembling of the muscles, which, as death approaches, may develop into violent convulsions.

Hun has pointed out the interesting fact that in a very large percentage of cases the swellings appear on the right side. There seems to be no explanation given for this local- 
ization. In this country, records are wanting of observations on this point.

Arloing has called attention to a mild form of this disease in which the symptoms are slight debility, loss of appetite and slight local swelling.

$\$$ 203. Morbid anatomy. After death the carcasses of animals which have died of this disease soon become distended with gas. This is due in part to the fermentation in the digestive tract and in part to the formation of gas in the subcutaneous tissues due to the presence of the specific bacillus. The subcutaneous distension is especially marked in the region of the swellings but it extends for a considerable distance from these foci in the direction of least resistance. The tympanitic condition often causes the two legs on the upper side of the carcass to extend out straight without touching the ground. A dark, blood-colored, frothy discharge flows from the nostrils and anus. Decomposition takes place very rapidly except in the affected muscles, which retain a sweetish-sour odor for a considerable time after other parts of the carcass have become putrid.

The skin covering the swelling is often affected with dry gangrene. The subcutaneous connective tissue is yellow, gelatinous, infiltrated with blood and bubbles of gas which escape if the tumor is incised. The muscles underneath the tumors are of a dirty brown or of a blackish color. At other places they are dark red or dark yellow and, when exposed for some time to the air, they may have a golden lustre. They are brittle, putrid and very rich in fluids. They crackle on palpation. When incisions are made into them, blood of a frothy, greasy, tarry appearance and of a sickish, fetid odor issues from them when they are squeezed. The fibres of the muscles show extremely varied degenerative changes. The gases that are present in the inuscles are inflammable and burn with a bluish flame on being ignited. They are said to have but little odor, on which account it is assumed that they consist of carburetted hydrogen. They are also said to contain carbonic 
acid but no oxygen. An exact chemical analysis of these gases seems not to have been made. The lymph glands near the tumors are enlarged and full of blood. They contain hemorrhages and are infiltrated with a serous fluid. The afferent lymph vessels are sometimes distended with gases, giving them the appearance of strings of beads. Clianges similar to those of the external muscles appear in the muscles of the tongue and pharynx when the disease, as may happen in rare cases, is localized on the oral and pharyngeal mucous membranes.

A large amount of blood-red exudate is frequently found in the abdominal cavity. In other cases only a small quantity of a serous fluid is present. In still others no changes at all appear. The abdominai changes seem to be determined by the swelling of the muscles, that is, whether it has or has not spread to the peritoneum. Yellow gelatinous and hemorrhagic infiltrations are often met with on the omentum, mesentery and in the neighborhood of the kidneys. The mucous membrane of the stomach and small intestines is frequently swollen, congested and infiltrated with hemorrhages, in which case the contents of the intestine are bloody. The liver is lyperemic, but the spleen is usually normal.

In the thoracic cavity, the pleurae in the neighborhood of the swollen parts of the skin and mediastinum are sometimes hemorrhagic. The pleurae may also show large ecchymoses. in which case the thoracic cavity contains a sero-sanious exudate. Hemorrhages are sometimes present in the lungs, pericardium, myocardium and under the endocardium. The muscular tissue of the heart is very soft, but the other muscles show only slight changes. The mucous membrane of the bronchi is sometimes hyperemic and sprinkled with hemorrhages.

The blood is of a normal color and coagulates readily. The fluids of the muscles have, according to Feser, an acid reaction, and the flesh becomes rapidly putrid. The bacilli of blackleg are found only in small numbers if at all in the 
blood during life, but abundantly a few hours after death. They are numerous in the local lesions.

The duration of the disease is from one to three days. Occasionally it is longer. The prognosis is grave.

$\$$ 204. Differential diagnosis. Black quarter is to be differentiated from anthrax, the "corn stalk" disease, septicemia hemorrhagica and various forms of poisoning. Usually the localized subcutaneous lesions are sufficient to differentiate black quarter from these other affections. It of ten happens, however, that post-mortem changes have so modified the carcass before it can be examined that the diagnosis is questionable. In this and all doubtful cases or where only small portions of tissue are sent for examination, it is necessary to resort to a more definite method or methods, such as the microscopic examination, cultures and animal inoculation.

I. Microscopic examination. Cover-glass preparations made from the fresh tissues will ordinarily exhibit the specific bacteria. They are easily distinguished in case of anthrax, black quarter and often with septicemia hemorrhagica, while in the "corn stalk" disease and cases of poisoning characteristic bacteria are not found. It is important to eliminate putrefactive bacteria, when the animals have been dead for some hours.

2. Cultures. Ordinary culture media inoculated with the tissues from a case of anthrax will give growths of the anthrax bacterium, and from cases of septicemia hemorrhagica that of Bact. bovisepticum, but with the other two diseases they will remain clear if uncontaminated. The black quarter bacillus will grow on these media only when placed in anaërobic conditions. In case of the "corn stalk" disease the media will continue to be clear.

3. Inimal inoculation. In guinea pigs inoculated in the deeper subcutaneous tissues with pure cultures of black leg bacteria or with bits of tissue from the affected area of another animal dead from the disease, death ensues in from one to two days. It is preceded by a raise of temperature, loss of appetite 
and general indisposition. The site of inoculation is swollen and painful and drops of bloody serum may sometimes be seen exuding from it. At autopsy the subeutaneous cellular tissues and underlying muscles present a condition of emplnysema and extreme edema. The edematous fluid is often blood stained and the muscles are of a blackish or blackish brown color. The lymphatic glands are narkedly hyperemic. The internal viscera present but little alteration visible to the naked eye. In the blood stained serous fluid about the point of inoculation short bacilli are present in large numbers. These often present slight swellings at the middle or near the end. They are not seen as threads but lie singly in the tissues. If the autopsy is made immediately after death, these organisms may not be detected in the internal organs, but if not made until after a few hours, they will be found there also. In early autopsies only the vegetative forms of the bacilli may be found, but later (in from twenty to twenty-four hours) spore-bearing rods may be detected. With the " corn stalk" disease the inoculated animals will remain well.

$\$$ 205. Prevention. In checking the spread of the disease it is very important wherever it is possible to remove the well animals from the infected field and to restrict the sick ones to a small one. The swellings should not be opened and the discharge scattered over the field. The dead animals should be burned if possible, otherwise buried deeply and covered well with lime as soon as possible after death. Birds and other animals should not be allowed to feed upon the carcasses and - the skin should not be removed. Every precaution to restrict the spread of the bacteria of this disease should be taken. It is very desirable to thoroughly disinfect the ground where the animal lay at the time of death. The spores are very resistant both to disinfectants and the natural destructive agencies such as sunlight and drying. It is not wise to use land upon which animals have contracted the disease for grazing purposes for susceptible species.

\$ 206. Preventive inoculation. Several methods of 
fortifying exposed animals against the infection of symptomatic anthrax virus have been proposed. In I880, Arloing, Cornerin and Thomas demonstrated at Chaumont that animals injected with the filtrate of cultures of this virus into the jugular vein were protected against inoculation with the strong virus. It was found, however, that this nethod was difficult, as the vein had to be exposed and the greatest care was necessary to prevent infection of extra vascular tissue in introducing and withdrawing the syringe. Later these investigators attenuated the virus by heating it to a temperature of 100 to $104^{\circ} \mathrm{C}$. and injecting it into the subcutis of the shoulder. This gave a partial immunity which was reinforced after eight or ten days by a second inoculation of a virus that had been heated from 90 to $94^{\circ} \mathrm{C}$. for six hours. They injected the virus where the subcutis is quite dense, such as at the end of the tail where only local swellings would occur. This process is known as "the French method," Arloing's or the "Lyons method."

In 1888, Kitt of the Veterinary College in Munich, after a careful investigation of the subject, proposed a single injection method using a virus attenuated by heating at a temperature of from 85 to $90^{\circ} \mathrm{C}$. for six liours. A single injection of this vaccine would usually confer immunity. He further modified Arloing's method by making the injections in the shoulder regions where the skin is looser and the operation easier. Later, Kitt made further important investigations concerning preventive vaccines for this disease.

In the fall of 1896 , investigations looking to the preparation of a black quarter vaccine were begun in the Bureau of Animal Industry at Washington by Dr. Nörgaard under the direction of Dr. Salmon. The various European methods were tried. The one finally adopted consists of a single vaccine, the Arloing principal with Kitt's modification.

The material used for the vaccine is obtained from a fresh blackleg tumor, by pounding the muscle tissue in a mortar with the addition of a little water and squeezing the pulp through linen cloth. The juice is spread in layers on plates 
and dried quickly at a temperature of about $35^{\circ}$ C. This temperature does not in the least affect the bacteria, and the dry virus obtained in this way retains a high degree of virulence for two years or longer.

When vaccine is to be prepared, the dried material is pulverized and mixed in a mortar with two parts water until it forms a semifluid homogeneous mass. This is spread in a thin layer on a suitable glass dish and placed in an oven, the temperature of which may be regulated with exactness. The reason for mixing the dried muscle with water is to insure a quicker and more uniform attenuation. The temperature of the oven is previously brought up to $95^{\circ}$ to $99^{\circ} \mathrm{C}$., and the virus is allowed to remain in it for six hours. When removed it appears as a brownish scale, which is easily detached from the dish. This scale is pulverized and put up in packages containing ro doses each. Before it is used, it is mixed with IO c. c. water, filtered and the filtrate injected in doses of one cubic centimeter.

\section{REFERENCES.}

I. FISHER. Blackleg in Kansas, and protective inoculation. Kan. State Agric. Exiper. Station, 1901.

2. LEWIS. Symptomatic anthrax. Bulletin No. 27. Oklahoma State Agric. Exper. Station, 1897.

3. Mayo. Blackleg. Bulletin No. 69. Kan. State Agric. E.rper. Station, I $\$ 97$, p. IoS.

4. NörgaARD. Blackleg in the United States and the distribution of vaccine by the Bureau of Animal Industry. Annual Report of the Bureau of Animal Industry U. S. Dept. Agric. 189 S.

5. NöRGAARD. Blackleg. Its nature, cause and prevention. Circular No. 23. U.S. Bureau of Animal Industry, ISgS.

6. Paquin. Blackleg. Bulletin No. 12. Mo. Agric. Exper. Station, ISgo.

7. PETERs. Blackleg. Its nature, cause and prevention. Bulletin No.65. Neb. State Agric. Exper. Station, 1900.

8. Salmos. Black quarter. Annual Report bureau of Animal Industry, U. S. Dept. of Agric. ${ }^{1893-4}$. 
$\$$ 207. Characterization. Malignant edema is an acute, wound infection disease of domesticated animals, which is especially characterized by edematous, later crepitating tumors at the place of infection due to Bacillus oedematis maligni.

\$ 208. History. Crepitating tumors following wounds, withdrawing of setons, castration, and the like have long been known. It was pointed out by Girard in I8I8, that creptitaing tumors in sheep could be caused by subcutaneous injection of animal tissue taken from putrefying tissue. Chauveau (1873) showed by experiments performed on goats that the development of the disease stood in a close relation to living organisms present in injected putrescent blood. Pasteur, in 1887 , studied more closely the organism and named it I'ibrion septique. He obtained it in pure culture. Later Koch and Gaffky (I88I) studied exhaustively the disease caused through contamination by contact with the ground, which they named malignant edema. Since then Kitt, Jensen, Sand and Leclainche have studied its bacteriology, while Jensen and Sand, v. Rátz, Fröhner, Carl and others have made valuable contributions to the appearance of the malady among domesticated animals. Malignant edema is a wide spread but not a common disease.

$\$$ 209. Etiology. Maligant edema is caused by Bacillus oedematis maligni Koch (Vibrion septique Pasteur). It is described as a bacillus resembling that of anthrax, but somewhat more slender, rod-shaped, and spore bearing. The ends are rounded. It is an anaërobe. In artificial cultures as well as in the animal body, after the death of the latter the bacilli grow into long filaments. Exceptionally, living animals contain the spore bearing bacilli in the edematous fluid (Jensen and Sand). The bacilli stain very readily with aqueous aniline dyes. In culture media containing sugar gases are formed, which have a characteristic disagreeable odor. The inoculation of a pure culture into the deep connective tissue of mammals and birds produces a tumor quickly spreading from 
the place of inoculation and later crackling on account of the formation of gas.

Of the domestic animals, the horse is the most susceptible

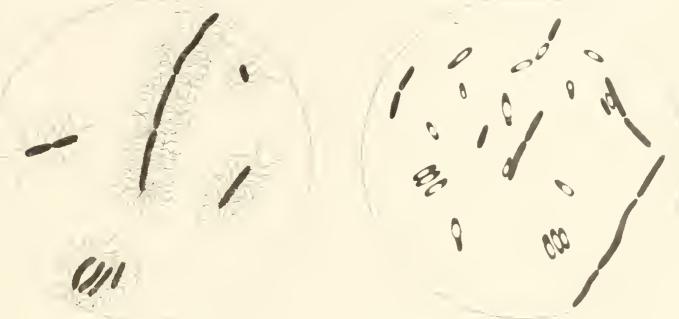

FIG. 64. Bacillusoedematis maligniwith flagella and spores (Hutyra).

to natural infection; the cow, the sheep and the goat are less susceptible. The pig, dog and cat are rarely attacked.

Infection sometimes follows contusions or lacerations, sometimes delivery, when in the latter help is given with hands or instruments not clean, while in other cases it occurs such as smallpox vaccination, castration, shearing, bleeding, drawing setons, subcutaneous injections where unclean syringes are used.

$\$$ 210. Morbid Anatomy. On the expansion of a tumor appearing in any part of the body, the connective tissue is distended and infiltrated with yellow or reddish fluid containing many small gas bubbles, which emits a characteristic odor. These gelatinous infiltrations of the connective tissue follow between the deeper layers of the muscle. The muscle itself is often sallow or dark red in color and is very brittle. The connective tissue in places seems to be strewn with larger or smaller hemorrhages. In the intestinal cavity there is a little reddish, serous fluid; the peritoneum is deeply injected. In the cases in which malignant edema has deveioped in con1. nection with parturition the uterus is insufficiently contracted, the subserous connective tissue of the true pelvis and the walls of the uterus are edematously infiltrated. 
The spleen is usually not affected. Occasionally acute tumors with gas formation are found in the pulp (Fröhner). The liver may show tumefaction. The mucous membrane of the intestinal canal may show signs of acute catarrh. The lymph glands are swollen. The lungs are hyperemic and for the most part edematous. The muscular system of the heart shows usually a high degree of parenchymatous degeneration. The blood clots very little. The body quickly becomes putrefied. The fluid pressed out of the crepitating tumor contains edema bacilli in great number, associated possibly with other bacteria.

The presence of the bacilli of malignant edema in the tissues of a dead animal does not of itself prove that it died of this disease. These bacilli appear very often in the intestinal contents of animals which feed on plants in company with other bacteria and on that account are able after the death of the animal to multiply in its tissues, especially when the blood remains fluid for some time, as for example after a sudden death by suffocation.

S2II. Differential Diagnosis. Malignant edena, if it occurs in cattle, can be easily confused with symptomatic anthrax. As distinguishing malignant edema are the occurrence of the disease in a region where symptomatic anthrax is not native, further the often very advanced age of the patient, the occasional localization of the tumor on parts of the body poor in muscle, and besides the insignificant affection of the muscular system in comparison to the severe affection of the connective tissue.

In horses and sheep the development of a crepitating tumor with a fever indicates malignant edema. The crepitation distinguishes the disease from anthrax edema as well as from the inflammatory edemas often following wounds and caused by streptococci. In simple subcutaneous emphysema, following skin or lung wounds, ferer rarely occurs. Finally care must be taken that on section a simple emphysema caused by putrefaction is not confused with a crepitating tumor formed during life. 
\$212. Prevention. In the prophylaxis of the disease the wounds of the skin and the mucous nembrane are to be kept from infection with the soil, those which are already in fected are to be disinfected, while after difficult delivery in which the genital passages have been injured a thorough cleansing of the latter and of the uterus check the development of the trouble. Test animals can be immunized against the virulent infection by injection of tissue juices containing spores after heating it to $92^{\circ} \mathrm{C}$. for 7 hours (Leclainche and Vallée). These inoculations protect only against malignantedema and not at the same time against symptomatic anthrax, as Leclainche and Vallée have proved in contradiction to the earlier experiences of Roux and Duenschmann.

\section{FUOT-ROT IN SHEEP}

\$ 213. Characterization. Foot-rot in sheep is an infectious disease characterized by a specific inflammation of the tissues just above the horny part of the cleft of the foot, which extends downward, undermining the horny portion. It appears in epizoötic and enzoötic forms. Sheep are most often attacked, although other species are reported to be susceptible.

\$ 214. History. Foot-rot has been recognized for more than a hundred years. It has been described from various parts of Europe by Chabert, Pictet and Gohier. It seems to have first appeared in this country late in the eighteenth century. It has recently been investigated by Mohler and Washburn. They found a specific organism, and thus differentiated it from the streptococcic infection.

S 215. Etiology. The cause of this form of foot-rot is, according to Mohler and W'ashburn, an anaërobic organism, Bacillus necrophorus. This organism is isolated with difficulty. from these lesions because of the association with it of other bacteria. The most satisfactory method is by inoculating white mice or rabbits subcutaneously with the diseased tissue 
from their organs it can be obtained in pure culture. The time required to kill these animals is usually from four to

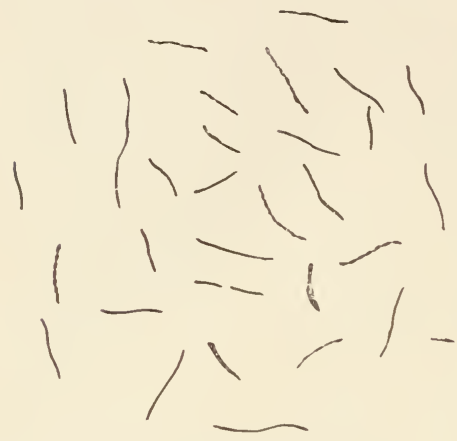

FIG. 65. Bacillus necrophorus (after Mohler). twelve days.

The period of incubation in small animals is but a few days. In the naturally contracted disease in sheep it is uncertain. In cases produced by inoculation of the specific bacillus from three to ten or more days elapse before symptoms appear.

\$ 216. Symptoms. Lameness is the first symptom noted. If examined prior to this, Mohler reports a moist area of the skin just above the horny part of the cleft of the foot. The inflammatory condition extends rapidly to tissue beneath the horny part. There is often a discharge of a thin, purulent fluid. Mohler states that

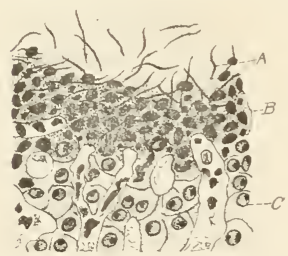

Fig. 66. Necrotic area in the liver of a rabbit; $C$, liver cell, $B$, inflammatory zone, $A$, necrotic center (Mohler). the discharge emits a pungent, disagreeable odor which is characteristic of this infection. There is emaciation which may be due quite as much to the inability of the lame sheep to procure food as from the specific action of the bacillus.

The duration of the disease varies from a few weeks to several months. The cases are said usually not to terminate fatally.

\$217. Morbid anatomy. The tissue changes are those of a purulent exudative inflammation. As the process undermines the horny portion of the hoof it 
may slough, and granulating tissue, commonly called "fungoid growths," develop. The invasion of the organism and the extending of the necrosis may continue until the tendons, ligaments and even the bones may be attacked. There is going on at this time reparation processes which usually terminate in a peculiar growth composed of horny elements, dense epithelial cells, and granulation tissue (Mohler).

$\$ 2$ 18. Differential diagnosis. Foot-rot in sheep is to be differentiated from inflammation of the feet caused by streptococcic infection, purulent inflammation of the interdigital space, the stoppage of the duct of the interungulate or biflex gland, and contagious foot-and-mouth disease.

\section{REFERENCES}

I. ERNST. Ueber nekroses und den nekrosebacillus (streptotlirix necrophora). Monatsheft f. prakt. Tierheilk, Bd. XIV (1902), S. I93.

2. Mohler AND IVASHbURn. Foot-rot of sheep, its nature, causes, and treatment. Bulletin No. 63. L. S. Bureau of Animal Industry, I 904 .

\section{MISCELLANEOUS INFECTIONS WITH BACILLI}

$\$ 219$. Enzoötic in cattle caused by a bacillus of the enteritidis group. In 1902, Mohler and Buckley* described an outbreak caused by $B$. enteritidis among cattle in a stable of 2 I animals of which 8 contracted the disease and died. Three others exhibited the early symptoms.

The symptoms were first refusal of food, suspension of urination and diminution in lactation. There was excessive salivation in some cases. The temperature varied from $102.7^{\circ}$ to $104 . \mathrm{I}^{\circ} \mathrm{F}$. The visible mucosae were congested. There was a wild expression in the eyes and the animals were very.

* Mohler and Buckitey. Report on an enzoötic among cattle caused by a bacillus of the enteritidis group. (Illustrated and bibliography). Annual Report of the Bureau of Animal Industry, I902. 
excitable. The gait was irregular. Convulsions set in prior to death.

The duration of the disease varied from two days to several weeks.

The morbid anatomy varied. In the acute cases the anatomical changes were very slight. The most noticeable and characteristic lesion observed consisted of petechial hemorrhages under the endocardium. These were present in every case. There were occasional blood extravasations in the intestinal mucosa. There was marked injection of the blood vessels of the meninges and blood tinted fluid in the cavity. The chronic cases presented a wider range of lesions in the organs.

Cultures of the bacillus were obtained from the different organs. The bacilli were found in small numbers in coverglass preparations made from the organs. The organism was fatal to experimental animals and to calves. It was more virulent than the bacillus of hog cholera obtained from hogs dead of that disease.

Since Gaertner first discovered this organism in 1888 in the meat of a diseased cow, it has been isolated by others from both animals and man. It has been found to produce toxic properties that are pathogenic for animals, and several people have been reported to have become ill from eating broth made from meat containing this organism. During the last few years several bacilli differing slightly from Gaertner's bacillus have been isolated from cases of meat poisoning.

Bacilli of this group, or at least of closely related groups, have frequently been found to stand in a causal relation to the lesions with which they were associated. The more important of these are Bacillus typhi murium obtained by Loeffler in I 890 from an enzoötic among mice, the bacillus isolated by Mereshkowsky in 1895 from the ground squirrel, and Bacillus psittacosis isolated by Nocard in 1893 from the organs of parrots.

In addition to these, other bacilli have been found apparently as the etiological factor in isolated cases among animals. 
$\$$ 220. Grouse disease. In I 887 Klein described a disease of grouse characterized by congestion of the lungs, liver and kidneys with small necrotic areas in the liver and areas of redness in the intestines. The disease was found to be due to a bacillus which has been found to belong to the colon group. [The author has studied the bacillus of the Grouse disease a culture of which was obtained from Krahl and found it to be $B$. coli communis.] Migula designates it B. scoticus.

Quail disease (Colibacillosis tetraonidarum). In May I907, Morse (Circular No. Iog, Bureau of Animal Industry) described a disease of quail characterized by congestion of the lungs, focal necrosis of the liver, and intestinal ulceration. He found the cause to be a member of the colon group of bacteria. This seems to have several centers of infection in this country. Several species of quail and grouse are susceptible. While there are strong resemblances between this affection and the grouse disease described by Klein, Morse assumes that they are not identical. 


\section{DISEASES CAUSED BY BACTERIA \\ FAMILY SPIRILLACEÆ.}

$\S 22 \mathrm{I}$. General Consideration of Spirillaceæ. This family of bacteria has thus far revealed very few species that are pathogenic for domesticated animals.

$\$ 222$. Diseases of fowls caused by spirillaceæ. The disease of fowls reported to be caused by these organisms has not been found in this country. It is not unlikely that

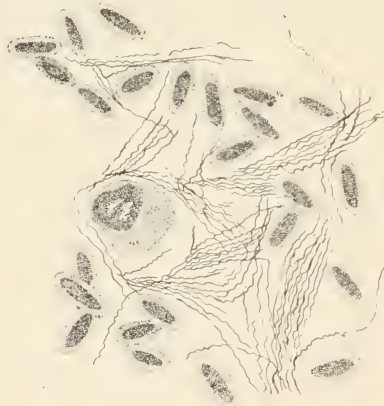

FIG. 67. Spirochaete anserina from the blood of a goose (after Cantacuzène). some one or more of the many as yet mysterious diseases of poultry may be caused by members of this family. It is interesting to note that spirilla are not uncommon in the bacterial contents of the intestines. It is believed that many of these are anaërobes, which would explain the difficulty encountered in trying to isolate them in pure culture.

Sakharoff studied, in I891, a peculiar disease of geese and showed it to be caused by a spirillum. It was designated spirochaete anserina. Cantacuzène has studied the mode of destruction of the spirilla. He found that they are destroyed by and within the macrophages of the spleen.

The morbid anatomy in the affections caused by the spirilla appear to be largely engorgement of the spleen and 
swelling of the liver with fatty degeneration of the parenchymatous tissue. The heart muscle is sometimes affected. Areas of necrosis have been described in the solid viscera.

It is stated that the blood of the diseased fowl is not infectious 48 hours after it has been removed from the fowl but that if injected into a healthy fowl it will confer immunity against a virulent infection. Marchoux and Salimbeni found that if the fresh blood of the diseased fowl was heated for 5 minutes at a temperature of $55^{\circ} \mathrm{C}$. it would confer immunity but if it was heated for 10 minutes this property was lost.

S223. Spirillosis of cattle. Theiler found spirilla in a few cattle in South Africa. The animals were suffering with "red water" with possibly one exception. He sent preparations of these to Laveran who designated then Spirillum Theileri. Theiler made a number of inoculations with the blood of animals infected with the spirilla with negative results. The following description of the spirillum is quoted from 'Theiler's report :

"The microörganism in question is a typical spirillum, and varies considerably in its length. The longest microbes measure from 20 to $30 \mu$. They are somewhat thinner at both ends, otherwise the thickness is about the same throughout the whole length-viz., about .25 to $.40 \mu$. The corkscrew-like forms are, as a rule, predominant, but there are other forms which are atypical in appearance and also shorter. For instance, the parasite may show itself as a simple curred line without any spiral curves, representing sometimes the shape of S ; it may also be completely doubled up, both ends nay meet and take the shape of a ring, or both ends may cross each other and also form a loop. These loops may be of different shapes and sizes. Double loops may also be found. It is somewhat difficult to describe all the various forms, but they can be easily imagined, considering that the spirillum is a very flexible and agile parasite.

"In preparations made by placing a cover-glass on a drop of fresh blood the microörganisms are easily detected. Some 
of the red corpuscles show a slight irregular motion, and when closely watched it may be noticed that this disturbance may proceed in a certain direction, or again whirl round in the same place. When examined under a high power (I-I2th inch obj.) the agile spirillum is usually seen attached to one or more red corpuscles. Sometimes it is curled all round a red or white corpuscle. As soon as the organism becomes free and begins to travel through a clear space, a characteristic undulating movement is visible, which continues until it finally attaches itself to some other blood corpuscle. This motion may be noticed for some time; it then becomes relaxed, and finally slaskens down completely. I have observed the movements in preparations which were twenty-four hours old.

"Staining of the organism may be obtained with any of the aniline dyes used in bacteriology, viz., methylene-blue, fuchsin, thionin. Good preparations were obtained with Laveran's modification of Romanowsky's stain, and also with Azur II. In using the last two mentioned methods no chromatic body could be traced, such as is present in parasites belonging to the protozoa.

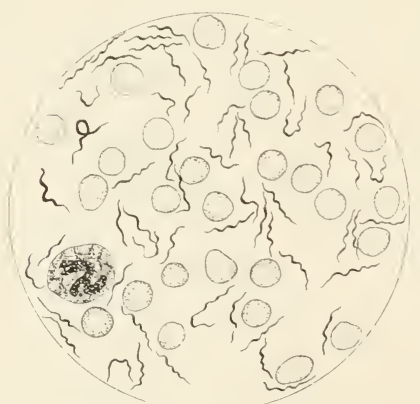

FIG. 68. Spirochaetes from the lesions in the skin of a pig (after Dodd).

"Cultivations on the usual artificial necia were repeatedly tried, but always with negative results. The same has been found to be the case with all the above-mentioned different spirilla found in men and birds."

$\$$ 224. A disease of the pig due to spirochaetes. Dodd has recently described a spirochaete which he found in a pig sent to the government laboratory in Pretoria. The examination showed very few morbid changes in the tissues 
but the skin was sprinkled with dark hemorrhagic-like spots, From scrapings of these lesions he was able to find the organism. It is described as long and very slender, its length varying from 9 to $26 \mu$. Both extremities are pointed. The spiral forms predominate but in the same preparation curved or simply long straight threads were observed. They appeared singly, in pairs and in clumps. It was difficult to distinguish it in the unstained preparation. It stains well with any of the ordinary aniline dyes but does not retain the coloring matter after being treated by the Gram method.

$\$ 225$. Other spirochaetes found in animals. Bonhoff (1905) described a spirochaete found in the pustules of vaccinia of the calf. Martoglio and Carpano found a spirochaete in the blood of the Abyssinian sheep. It exhibited from three to ten regular spirals and measured from 10 to $20 \mu$ in length and from 2 to $4 \mu$ in breadth. The extremities were tapered and it did not stain by Gram's method. It could not be cultivated on any media used. Neither flagella, spores nor chromatin were discovered. Two spirochaetes were often seen attached throughout their length and apparently fused together at one extremity as through they had been produced by longitudinal fission. This parasite was present in the blood plasma. As in the case with the Sp. Theileri the disease could not be reproduced in any of the animals inoculated with the infected blood or even in sheep. This organism was described by Blanchard as Sp. ovina.

According to Bizzozero the stomach of the dog always contains numbers of extremely slender spirochaetes formed of from three to seven turns and from 3 to $8 \mu$ in length lodged in the interior of the gastric cells. These were found in the Norway rat, cat and dog. In the latter they have been found to be coustantly present.

The principal species of the spirochaeta that have been described are the Sp. plicatilis Ehrenberg, in $18_{3} 8$. It is common in stagnant water and often attains a length of 100 to $200 \mu$. In 1875 , Cohn described Sp. buccalis which is tapered at both extremities and common in the dental tartar and in the 
saliva. In the same year the $S p$. Obermeieri was named by Cohn after its discoverer as the cause of recurrent fever in man. This organism varies from 15 to $30 \mu$ in length, is very thin and tapered at both extremities. In I 905 Schandinn and Hoffmann described a spirochaete which is believed to be the cause of syphilis. It is known as Treponema pallidum.

\section{REFERENCES}

I. Cartacuzise. Recherches sur la spirillose des oies. Ann. de l' Inst. Pasteur, Vol. XIII (1S99), p 529.

2. Dond. A disease of the pig, due to spirocliaeta. Jour. Compar. Path. and Thera, Vol. XIX (I906), p. 216.

3. GABRITSCHEwskv. Beiträge zur Pathologie und Serotherapie der Spirochäten-Infektionen. Centralb. f. Bakter., Bd. XXIII(I8gS), S. 365 , und 778 .

4. LeVAdite ET MANoNeliax. Nouvelles recherches sur la spirillose des poules. Ann. de l' Inst. Pasteur, Vol. XX (1906), p, 592.

5. SAKHAROFF. Spirochaeta anserina et la septicémie des oies. Inn. de l' Inst. Pasteur, Vol. V' (IS9r), p. 564.

6. THeiler. Spirillosis of cattle. Jour. Compar. Path. and Thera., Vol. XiII (I904), p. 48. 


\section{CHAPTER VII}

\section{DISEASES CAUSED BY FUNGI.}

\section{ACTINOMICOSIS.}

Symptoms. Lumpy jaw ; wooden tongue; big head.

\$ 226. Characterization. Actinomycosis belongs to the class of affections known as the infectious granulomata. It is a chronic disease determined by the presence of a specific cause-the ray fungus-which by irritation stimulates the formation of new growths consisting of round cells, epithelioid cells, giant cells and fibrous tissue. The neoplasms appear as tumors having either a tendency to develop into large and hard masses or to suppurate. It has been suggested that the suppuration was due to a secondary infection by pyogenic bacteria.

Cattle (genus Bos) are most often attacked. Horses, dogs, pigs, sheep and elephants are slightly susceptible and a few cases have been reported in each. Men are susceptible but this disease is rarely found in the human subject. Other species seem to be immune.

$\$ 227$. History. The early history of this disease is quite obscure. Prior to the discovery of its specific cause, it was much confused with other diseases resembling it more or less closely in certain gross appearances. It was designated by a variety of names, the more common of which are swelled head, lumpy jaw, big head, fibroma, sarcoma and osteosarcoma. It is popularly known in the United States as "lumpy jaw" and in Europe as "wooden tongue." The popular names were probably suggested by the character of the lesions, which differ to a marked degree. It was recognized as a specific disease by Rivolta in I868, by Perroncito in 1875 and 
by Bollinger in 1877 . The ray fungus was undoubtedly observed prior to this by Lebert and Robin, both of whom failed to recognize it as a vegetable parasite.

The fungus was carefully described by Dr. Harz, a botanist, who gave it the name actinomyces or ray fungus. Bolinger was the first to carefully study the disease in cattle and to demonstrate the power of the ray fungus to produce disease. With this discovery of Bollinger in 1877 , actinomycosis became recognized as a definite, specific disease which could in most cases at least be differentiated from the other affections with which it had hitherto been confused. In $18+5$ von Langenbeck of Kiel observed and made drawings of peculiar bodies in a case of vertebral caries in man which it is now believed were rosettes of the ray fungus. In 1878 , Israel demonstrated the disease in man. Since that time it has been carefully studied and described by a number of investigators.

$\$$ 228. Geographical distribution. Actinomycosis is quite widely distributed throughout North and South America and Europe. It is much more prevalent in certain countries and districts than in others. The observation has been made that animals pastured upon low lands and in river valleys are more liable to contract it than those feeding upon high and dry ground. It has also been noted that cattle fed upon rough or coarse forage are more prone to the disease on account of abrasions of the buccal mucosa than those kept upon less harsh food.

It is very difficult to procure reliable statistics concerning the extent to which it occurs. The observations which have been made at the union stock yards, Chicago, show one case of actinomycosis in from 1600 to 1700 cattle. The statistics from the abattoirs in Berlin show one case to 4 I5O cattle and one in 8000 pigs. These figures do not, however, indicate the extent of the disease among the farm animals, as they are collected from those animals presented for slaughter only. At the clinic of the New York State Veterinary College there is presented for treatment a very few cases each year. In the 
Mississippi Valley and in the South-west it seems to he more prevalent than it is east of the Alleghany Mountains.

S29. Etiology. Actinomycosis is produced by a fungus, Cladothrix actinomyces, commonly known as the "ray fungus." $*$ The disease is the result of its multiplying in the tissues and not from the elaboration of a toxin. Undoubtedly
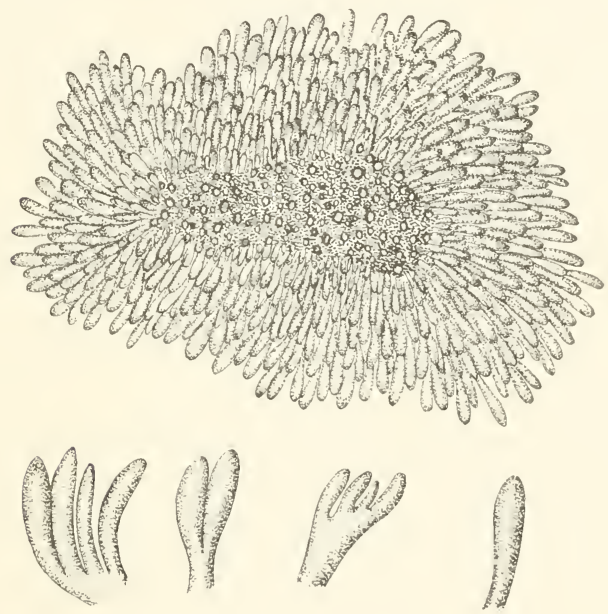

Fig. 69. A rosette of the ray fungus together with difficent forms of the single cluh ends. - 300. (. tfter (rookshank).

the bacteria often associated with the fungus in suppurating lesions are of some significance. Wright states that he believes they play an important part in the extension of the disease. The fungus appears as minute, yellowish granules in the lesions. When examined microscopically, these granules are

"The cladothrix is placed among the higher bacteria. There are many varieties of the actinomyces. Until they are better understood it seems better to group them with the fungi. 


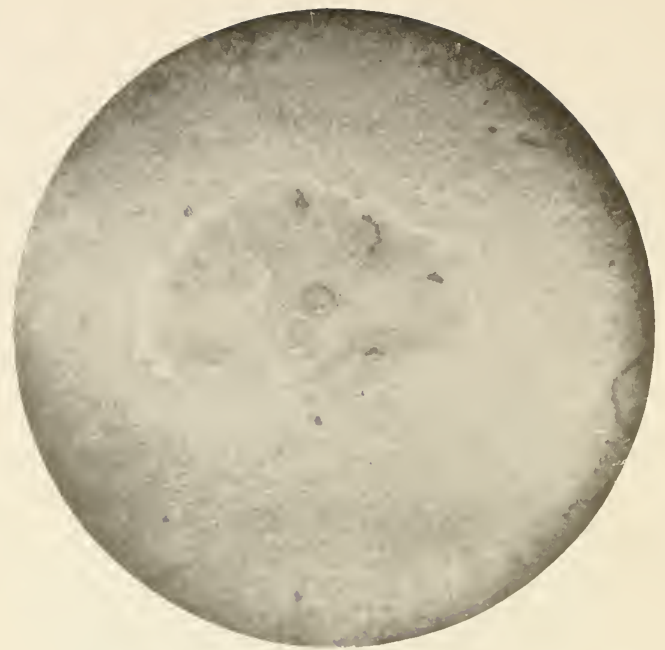

FIG. 70. Photograph of a young actinomycotic growth under low power, showing clumps of the ray fungus.

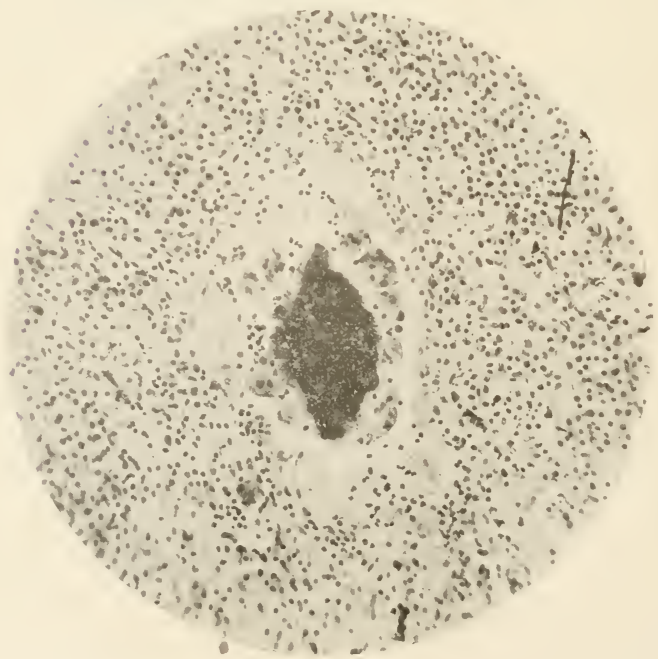

FIG. 71. Photograph under higher magnification of one of the clumps of the ray fungus showing giant cells about the clump of fungi. 
found to be made up of rosettes varying in size from 10 to $200 \mu$ in diameter, the average size ranging from 30 to $40 \mu$. This fungus can be cultivated on artificial media. It stains somewhat feebly with the aniline dyes.

The rosettes are composed of a number of club-shaped structures (rays), radiating from the central mass which is composed of the mycelial part of the fungus. The club-shaped bodies vary in size but usually they are from I to $10 \mu$ long. The rays are connected with the central portion by fine threadlike structures which are not readily demonstrated. In tearing or crushing the rosette, the clubs break off at or near their junction with the mycelial threads. Some investigators have mentioned a polymorphous form of actinomyces in which coccoid and rod-shaped structures are found. These are doubtless the ends of the clubs which first appear in focusing on a rosette.

The mycelial threads are wider in some portions than in others. In the narrowest places the walls seem to touch each other. Whether this irregularity is natural or the result of twisting the mycelial thread is not determined. The mycelium is much more difficult to stain than the clubs. In some cases it seems to branch. The filaments can rarely be seen in the rosettes as they occur in the suppurating lesions.

The natural habitat of this fungus is said to be on certain plants. According to Brazzola, they vegetate on the grasses, chiefly on Hordeum murinum. He discovered quantities of the fungi between the regetable fibres of barley which were imbedded in the gums of animals. Johne, Piana, Bostroem and others have found it on the awns of corn which were imbedded in the tonsils of pigs and in the tongues of cattle. Mayo, after making a careful study of this disease, states that the actinomyces are probably a degenerative form of some fungus which grows naturally upon food stuffs or grain. Bostroem entertains the view that they develop exclusively on grains, particularly on the awns of barley.

The period of incubation is not known. 
$\$ 230$. Infection. While actinomycosis is an infectious disease it does not seem to be transinitted directly from one animal to another. Numerous investigators have tried to produce the disease by inoculating cattle, calves, sheep, goats, pigs, dogs, cats, rabbits and guinea pigs with actinomycotic lesions. The results have almost invariably been negative when pus was used, but the disease has developed after inocu-

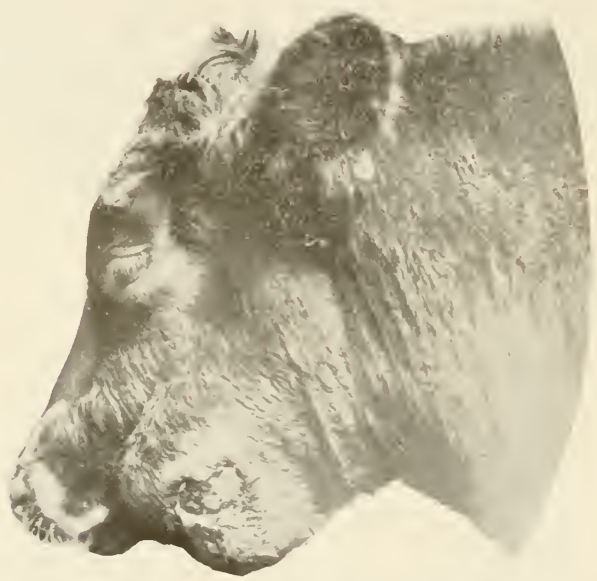

FIG. 72. Head of a steer with actinomycosis of the lower jaw. (Pholographed by Hopkins).

lating cattle with pieces of tissue containing the fungus in its regetating state.

It is believed that the infection occurs in susceptible species by the introduction of the fungus on food stuffs. The supposition is that the parasite gains entrance to the living tissues througli slight wounds of the mucous membrane of the mouth or throat and perhaps the alveoli of diseased teeth or during the shedding of the milk teeth. It multiplies and extends from the points of entrance. After the infected awns 
once gain lodgment, especially between the teeth, they are removed only witl difficulty. The farorite points for the actinomyces to enter the tongue is on tle upper surface midway between the dorsum and the tip. The lungs may be the seat of primary infection due to the inhalation of the fungus. The disease has been rarely observed primarily in the udder but frequently in the subcutaneous tissue about the head. In man the source of infection is more obscure. Many cases have been reported where the individuals did not come in contact with diseased animals and were not occupied in agricultural pursuits or in handling grain but were glaziers, tailors and various sliop tenders. There are a few cases reported, however, where the circumstantial evidence points to direct infection from diseased animals.

The present knowledge of this fungus indicates that it must attain to a certain stage or period in its development before it will live and multiply in living animal tissues. It has been observed that, as a rule, cattle become infected when they are kept upon dry food.

\$ 231. Symptoms. Actinomycosis is manifested by a firm swelling or tumor usually situated in the region of the head or throat. It is first recognized as a slight swelling of the affected part resembling somewhat the result of a bruise. It is stated by those who have had much experience with the disease that many cases of actinomycosis seem to be caused by blows or injuries received while struggling in stanchions. The enlargement gradually increases in size. It is ordinarily. sharply defined from the surrounding tissues.

Upon manipulation the tumor feels hard and dense. In the region of the throat it may be fluctuating. After a variable length of time, the tmmor-like mass may soften in one or more places, rupture and discharge a rather thick, yellowish and more or less sticky, purulent substance. The discharge may continue or, as often happens, the opening heals temporarily only to rupture again. The discharge often takes place into the cavity of the mouth or throat. Sometimes the 
neoplastic tissue increases in amount until it gradually forces its way through the opening, resernbling somewhat a cauliflower in appearance. The actinomycotic growth frequently increases rapidly in size after it has discharged. In later stages the teeth may become ulcerated and loose.

When the tongue is affected the animal finds it difficult to eat. The organ is swollen and in advanced cases hangs from the mouth. There is in these cases profuse salivation. When

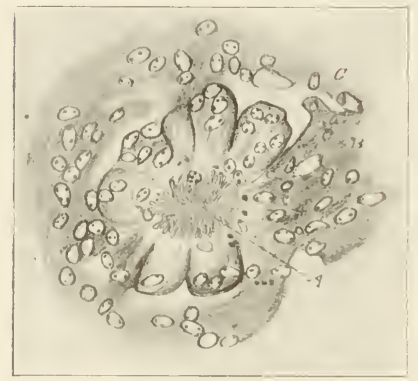

FIG. 73. It drawing of a very young actinomycotic growth. $A$, actinomyces; B. giant cell: C, surrounding reactionary zone. the pharynx is affected there is difficulty in swallowing and when the larynx is attacked there is difficulty in breathing. In this country the tumor is most frequently seen on the external surface of the jaw. It is stated by Salmon that it usually begins in the connective tissue beneath the skin but soon extends to the bone, which it penetrates. Actinomycosis of the cervical vertebrae may cause spinal paralys is. When the lungs are attacked the animal may present the appearance of one suffering from a chronic pulmonary disease such as tuberculosis.

Actinomycosis is not a rapidly fatal disease. Animals rarely if ever die from its immediate effects. The length of time during which they survive depends very largely upon the location of the tumor and the rapidity of its development. If the tumor is situated where it does not interfere seriously with prehension, mastication or swallowing of food or where it does not occlude or press upon the respiratory passages the animal usually survives for several years. When death occurs it is usually due to inanition, the animal being unable to take sufficient food, although the drain upon the system by the 
long continued discharge of pus must be severe. Mayo reports several cases where the disease was watched for five or six years and where it would possibly have continued several years more had not the animals been destroyed. Most animals which become affected with actinomycosis are either destroyed, treated or slaughtered for beef in the early stages of the disease.

\$232. Morbid anatomy. The new actinomycotic

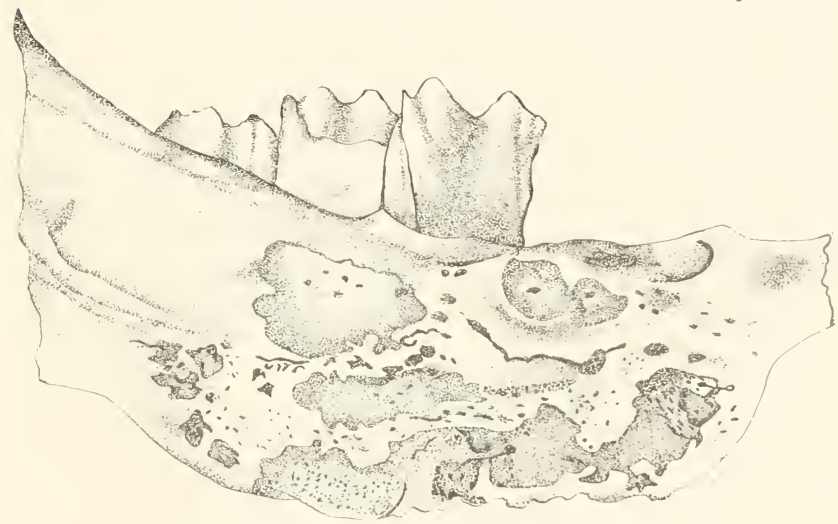

Fig. 74. A drawing of an actinomycotic jaw.

growths have in or near their centers rosettes of the ray fungus surrounded usually by giant cells. These in turn are surrounded by tissue consisting principally of epithelioid and spindle shaped, connective tissue cells, among which giant cells may appear. As these cells increase in number they press against the surrounding tissues, thus producing the hard and dense tumor-like growths. This is especially true when they are located in the connective tissue. In certain other positions, such as the liver, the inflammatory cells are surrounded by a fibrous tissue frame work whicl gives to the lesion a honeycomb appearance. On section a disagreeable "nutty" odor is given off which Mayo considers to be quite characteristic of the disease. The outside of the tumor is 
usually composed of a dense layer of fibrous connective tissue. Extending from the periphery toward the center, the tissue becomes less dense and is composed largely of epithelioid cells. In the softer tissue there are often cavities of greater or less size filled with a viscid purulent substance in which the small, yellowish granules of the ray fungus can be found. If this pus is spread in a thin layer on a smooth surface granules composed of the "ray fungus" can often be seen with the unaided

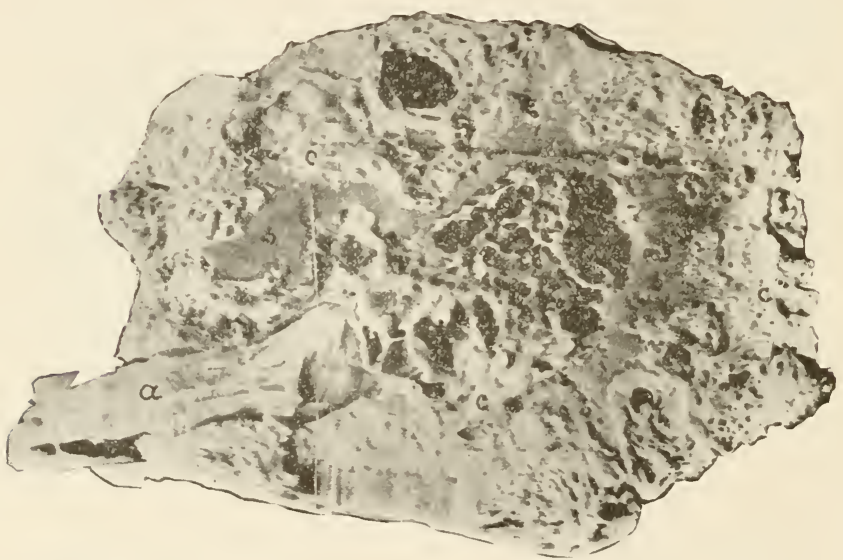

FIG. 75. Photograph of a section through an actinomycotic jaz'; (a) tooth, (b) bone, (c) actinomyrotic tissue.

eye. These pus cavities are usually connected with each other by small sinuses but sometimes they are separated by bands of fibrous tissue.

If the disease is in the bone, usually in the head, as it is when the specific organism gains entrance and begins to grow in the interior of the jaw, the bone tissue about the organism becomes in places disintegrated and absorbed and pockets are formed containing the fungus. While the interior of the bone is being broken down and absorbed by the action of the acti- 
nomycotic growth within, its diameter is being increased by the deposition of new tissue until it may become several times its normal size.

The lesions spread in most cases by gradual invasion of the tissues surrounding the infected point. At the seat of infection, minute, inflammatory points appear, which extend at their periphery and unite to form larger areas of diseased tissue. These masses tend to extend in one direction and to heal in another, leaving behind bands of cicatricial tissue.

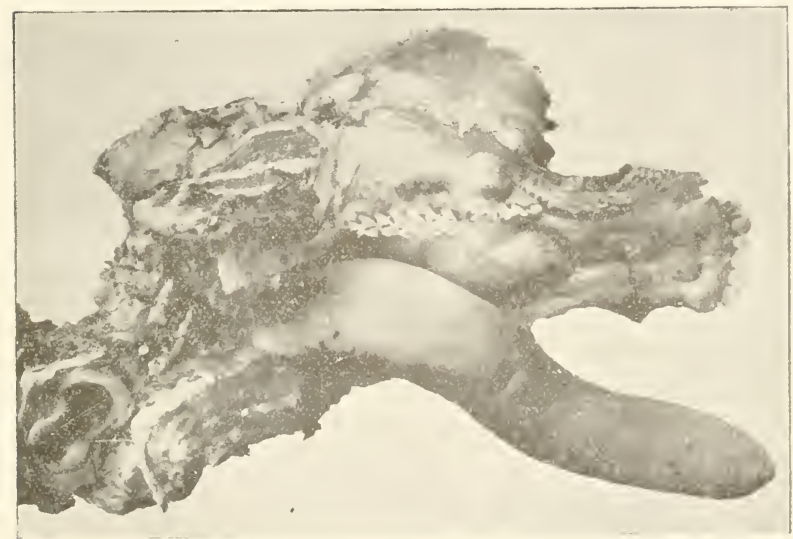

Fig. 76. Actinomycosis of the upper jain. (Photographedby Hopkins).

The process usually differs widely from that of a simple inflammation. In its progress the disease shows no preference for structures but invades one tissue after another so that all may be involved alike.

The lymphatics show no constant tendency to becone involved. Metastasis occurs in a very small proportion of the cases. When it does, as reported by Ponfick, large areas may be simultaneously affected. He reports a case in the human 
subject in which the left jugular vein was perforated by a mass of the fungi resulting in the formation of actinomycotic infarcts in the lungs, spleen, brain, and heart.

In cattle, actinomycosis usually appears in one or more of the following locations.

1. In the maxillary bones. Here it generally results in large tumor-like growths. Actinomycosis of the jaw usually commences with flat granulation of the gums and mucous membranes in the neighborhood of the teeth and spreads finally to the medullary tissues of the bone and to the periosteum, soon giving rise to the osseous tumor. From the maxillary bone the disease may advance either to the subcutaneous connective tissue and the skin or to the oral cavity in the direction of the molar teeth, which become displaced.

2. In the tongue. When the lesions appear in this organ the disease takes the form of an indurating glossitis. The tongue becomes thickly sprinkled with round or oval, hard,

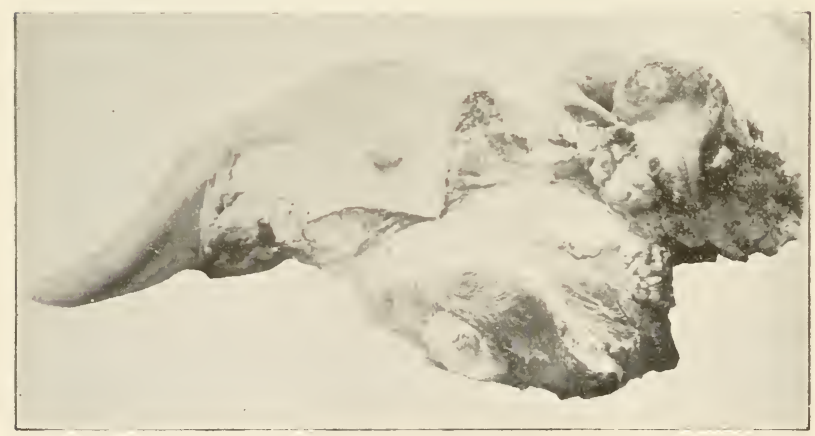

FIG. 77. Actinomycosis of the tongue, "wooden tongue". (Photographed by Hopkins).

fibrous nodules which finally become purulent or chalky at the center. Around these there is a considerable increase of connective tissue which leads to the atrophy of the muscle fibers. 
Upon section the tongue is found to be hard and often gritty. The indurated tongue is often eroded from friction and various deformities of this organ are reported.

3. In the pharynx. Here the disease usually takes the form of soft polypoid or fungoid nodules or lumps with a smooth surface and short peduncle. These nodules vary in size often reaching that of a goose's egg. These polypoid growths may cause great difficulty in swallowing and likewise interfere with respiration. Tumors of this kind may form in the esophagus or trachea. Rarely actinomycotic growths occur at other places in the alimentary tract. There are some cases in which the lesions are not restricted to the digestive tract.

4. In the skin and subcutaneous tissue. The lesious of the skin and subcutis are found chiefly on the head and neck. They usually consist of firm nodules from the size of a hazel nut to that of a man's fist or even larger. Sometimes these nodules are pedunculated and at others they are attached to the skin by a broad base. Instead of the hard tumor there may occur soft granular fungoid proliferations covered with a brown crust or with a purulent secretion. At other times minute nodules appear in these proliferations and the skin becones thickened and indurated. However, the skin lesions may become very large. In this organ, the disease may be either primary or secondary.

5. In the lymph glands. Actinomycosis often appears in the lymph glands of the head, larynx and plarynx. The parotid and submaxillary glands are sometimes involved as secondary infections. It is reported that the sub-parotid glands are most frequently affected.

6. In the lungs. The lesions in the lungs vary. They may consist of firm, somewhat yellowish nodules which eventually become calcareous in their center and vary in size from mere specks to that of a pea. This form is spoken of as miliary actinomycosis. In the second form the actinomycotic foci soften and become filled with a gray muco-purulent fluid. 
The lesion may spread to the pleurae and even reach to the surface of the body by penetrating through the thoracic wall. The bronchial glands and the mucosa of the air passages may also become affected.

7. In other organs. Actinomycosis has been reported rarely as attacking the udder, spermatic cord, brain, spleen, liver, muscle, diaphragm, peritoneum, inguinal glands, vagina, uterus and cervical vertebrae.

Assmann has recently summarized the literature on the dissemination of the lesions and has concluded that general-

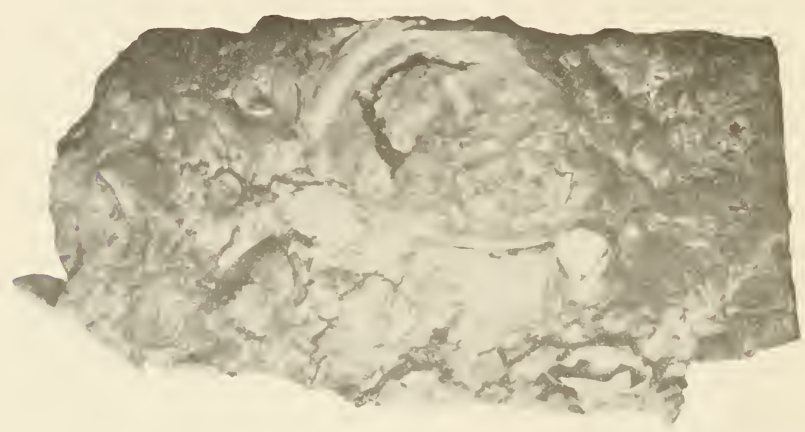

FIG. 78. I'hotograph of a portion of a cou's lung, show'ing area of actinomycotic tissue surrounded by a wall of connective tissue. Natural size.

ized actinonycosis is not rare in occurrence. He gives a detailed description of eleven cases in cattle and hogs.

It is stated by Salmon that in England the disease appears most often in the tongue, in Denmark the soft parts of the head are affected most frequently, while in some parts of Germany it is most frequently found in the pharynx. In the United States it usually appears in the lower jaw. In man as in cattle, the appearance of the lesions varies according to the part infected. In some cases the lesions closely resemble those of chronic inflammation but in others, such as the liver 
or skin, they are often characteristic. In the lungs the lesions have frequently been mistaken for tubercle. Usually the disease affects the head and if the maxillary bones are attacked the teeth are usually lost.

Actinomycosis in swine. Actinomycosis appears in this species in the lower jaw, larynx. lungs, wounds caused by castration, in the mamnary gland, muscles and bones. The character of the lesions does not differ to any marked extent in swine from those in cattle or man. In case of bone infection purulent cavities and sinuses are formed in which the yellow granules of the fungus occur. It is reported that occasionally pigs suffer from generalized actinomycosis. Duncker has found in the muscles of the pig a variety of the ray fungus which has been called Actinomycosis muscolorum suis, to distinguish it if possible from the bovine species. Its relation to the actinomycosis bovis has not been clearly determined. It is reported to have been found frequently.

Actinomycosis in horses and shecp. In the horse, actinonycosis of the bones, tongue, trachea, spermatic cord and submaxillary glands has been observed. The disease is reported to have been mistaken for glanders. The affection known as scirrhous cord seems to be due in rare cases to an infection by the ray fungus. One such case has occurred in the clinic of this institution. A very few cases of this disease have been reported in sheep, the lesions being restricted to the lungsi or muscles.

S 233. Differential diagnosis. In cattle actinomycosis is to be differentiated (I) from tuberculosis, especially of the lungs, glands of the throat, head and the udder, (2) various forms of glossitis, polypoid growths in the pharynx, fibroma, sarcoma and osteosarcoma of the jaw, parotitis and cellulitis. The writer has seen a few cases of bacterial infection of the maxillary glands giving rise to the formation of large quantities of caseous matter which caused swelling and firmuess suggestive of actinomycotic tumors. In one instance a specimen reported to be actinomycosis was examined and found to 
contain a piece of bone about three inches long which had become wedged between the teeth and cheek and surrounded by inflammatory tissues. Fröhner calls attention to contagious diseases as possibly being mistaken for this disease.

The affection recently described by Lignières as actinobacillosis is to be distinguished from actinomycosis of the skin. It is thought, however, by many workers that actinobacillosis is a variety of actinomycosis.

In making a positive diagnosis of actinomycosis it is necessary to make a microscopic examination of some of the diseased tissue or of the discharged pus in which the ray fungus may be found if the disease is actinomycosis. It is impossible to obtain this positive proof from the living animal when the disease is situated in the internal organs. With these it is necessary to depend largely upon the history and general condition of the animal. In preparing the discharged pus for a microscopic examination it is usually sufficient to crush one or more of the yellowish granules between a slide and cover-glass. It is of advantage to wash it with a dilute solution of caustic soda to clear away the pus cells. The rosettes are easily recognized with a low magnification.

In man, actinomycosis is to be differentiated from certain forms of tuberculosis and the Madura foot disease which was described by Carter, in I 860 , as a "fungus disease." This is a chronic, locally spreading inflammation of the foot, rarely of the hand, causing the destruction of the part involved and giving rise to a great overgrowth of connective tissue. Mycetoma almost invariably attacks the hand or foot and according to Carter there are no secondary deposits in the viscera. In actinomycosis the extremities are rarely attacked and the viscera are often the seat of the disease ; further the mycetoma is a disease of hot climates while actinomycosis is a disease of the temperate latitudes. The fungus of the two affections seem to be closely related but as yet their identity has not been established.

5234. Specific treatment. The investigations of Thomassen, Nocard, and Nörgaard and the experience of a 
large number of reterinarians have proved very conclusively the specific, curative effect of iodide of potassium. According to Salmon the iodide of potassium is given in doses of from I. 5 to 2.5 drams dissolved in water and administered in a drench, once a day. The dose should vary somewhat with the size of the animal and with the effects that are produced. If the dose is sufficiently large there appear signs of iodism in the course of a week or ten days. The skin becomes scurvy, and the eyes moistened. There is nasal catarrh and loss of appetite. When these symptoms appear the medicine may be suspended for a few days and afterwards resumed in the same dose. The cure requires from three to six weeks' treatment. Some animals do not improve with the administration of iodide of potassium and these are generally the ones which show no signs of iodism.

If there is no sign of improvement after the animals have been treated four or five weeks and the medicine has been given in as large doses as appears desirable, it is an indication that the particular animal is not susceptible to the curative effects of the drug and the treatment should be abandoned.

It is not, however, advisable to administer iodide of potassium to milch cows, as it will considerably reduce the milk secretion or stop it altogether. Furthermore, a great part of the drug is excreted through the milk making it unfit for use. It should not be given to animals in advanced pregnancy, as there is danger of producing abortion.

$\$$ 235. Sanitary considerations. The literature upon this subject is largely to the effect that actinomycosis is rarely if ever either contagious or infections in the sense that it can be transmitted from one animal to another or from one of the lower animals to man. There seems to be no indisputable case on record of such a transmission, although a few cases are very suggestive. It is the opinion of most pathologists that when the disease is restricted to small tumors and these are localized, that the affected parts should be destroyed but the remainder of the carcass may be used for human consumption. In Bulletin No. 2, of the Board of Live Stock Commis- 
sioners of Illinois, published in I89I, is the report of the somewhat famous trial in the Peoria county circuit court of the case of J. B. Greenhut et al. vs. John M. Pearson et al. to recover damages for the rejection and destruction of certain actinomycotic cattle, in which is given the testimony of a large number of distinguished veterinarians and sanitarians concerning the wholesomeness of the meat of cattle affected with this disease. Although at that time there was a strong popular sentiment against the use of such animals, the jury after a forty hours' consideration reported their inability to agree and were discharged by the court. The most conspicuous feature of this evidence was the inability of the witnesses to produce satisfactory evidence of the communicability of the disease from animal to man. This evidence did much to show that the danger from this disease in eating meat of affected animals was after all a matter of opinion, fear or sentiment rather than a demonstrated fact. Mayo, in his bulletin upon the subject, states that there is no danger of persons contracting this disease from eating the flesh of affected animals provided the visibly diseased portions are removed.

\section{RFFERENCFS}

I. BostrokM. Untersuchungen über das Aktinomykose des Menschen. Bcitrag. zur path. Anat. u. zur allge. Pathologie, Bd. IX $\left(18_{9}\right.$ I), S. 1.

2. IsRaEl. Neue Beobachtungen auf den Gebeite des Mykosen des Menschen. I Trchow's Archiv, Bd. LXXVI (187S), S. I1.

3. Maro. Actinomycosis bovis or "lumpy-jaw." Bulletin No. 35, Lansas State Agric. Exp. Station, 1892.

4. MoOre Actinomycosis mistaken for tuberculosis at postunortem following the tuberculin test. Am. Vet. Kevieu', Vol. XXX (1906), p. ISI.

5. NocARD. Notes sur l'actinomycose des animaux. Recueil de Míd. V'étér. Vol. LXIX (1S92), p. 167.

6. SALuON. Treatment of lumpy-jaw or actinomycosis in cattle. Bulletin No. 2, U. S. Bureau of Animal Industry, 1893.

7. Saliox. Actinomycosis or lumpy-jaw. Annual Report, Bureau of Animal Industry, I\$93-4, p. 88. 
8. WOLFF UND ISRAEL. Ueber Reincultur des Actinomyces und seine Uebertragbarkeit auf Thiere. Wirch. Arch. Br. XXVI (I89I), S. II .

9. WRIGHT. The biology of the microörganism of actinounycosis. The Jour. of Med. Researh, Vol. XiII (1905), p. 349.

ACTINOBACILLOSIS.

\$236. Characterization. Actinobacillosis is described as an infectious disease of cattle, characterized by its clinical resemblance to actinomycosis. It is caused by an organism which "resembles, in marked degree, the bacterium of Fowl Cholera." It arranges itself in the tissues in "rosette" or ray-like forms. It is thought by some workers to be a variety of actinomycosis. It is described as an independent and distinct disease.

\$ 237. History. Lignières and Spitz described, in I 902 , a disease in cattle resembling actinomycosis but which was caused by a bacterium. Until 1900-o this affection was not differentiated from actinomycosis. Nocard, in I902, identified the disease in France. In 1904, Higgins described four cases in Canada. These appear to be the only records we have of this affection.

$\$$ 238. Geographical distribution. It is reported by Lignières and Spitz to be epizoötic in Argentine Republic. It has been described in France, and in Canada.

$\$$ 239. Etiology. This disease is caused, according to its investigators, by a bacterium which arranges itself in the tissues in a rosette or ray-like appearance. It is aërobic, facultative anaërobic, non-motile and of a variable size, ranging between 1.0 and $\mathrm{I} .8 \mu$ in length and from $0 .+$ to $0.6 \mu \mathrm{in}$ breadth. According to Higgins, it has a distinct polar arrangement of the protoplasm as observed in the hanging drop prep- 
aration. It stains with the ordinary aniline dyes.* It does not take the Gram stain.

In the fresh tissues or in sections it appears in granules the same as in actinomycosis.

The actinobacillose is virulent for guinea pigs and rabbits. When inoculated into the abdominal cavity with pure

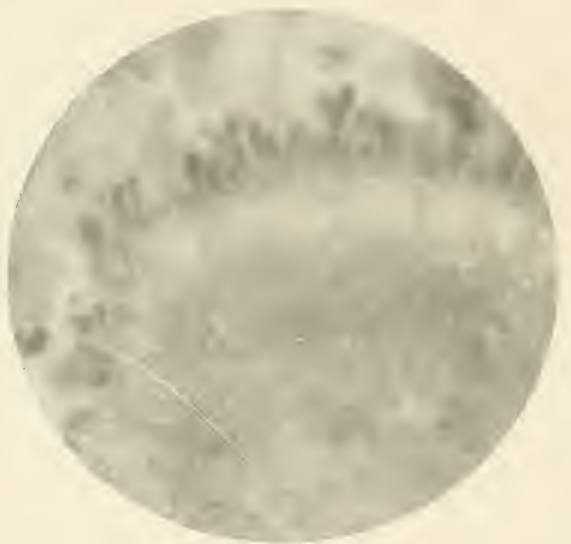

FIG. 79. A photograph of a section of a tumor stained by Gram's method but not fully decolorized. $\times$ abont 1,0oo. (After Higgins).

* Higgins recommends the Romanowsky stain as modified by Dutton and Todd for sections or preparations from pus. The formula for the stain and method for its use are as follows :

Stain: Eosin, aqueous solntion $\begin{aligned} & \text { Borrell's Blue } \\ & \text { Water }\end{aligned}$

Mix just before using and filter. Suspend the prcparations (sections fixed to the slide) upside down on the stain to saturate them from below, to avoid precipitate. Stain in this solution for thirty minutes. Wash thoroughly in water, then in a $10 \%$ solution of tannic acid, which will brighten the color, and again wash in water. Dehydrate in alcohol, clear and mount in xylol balsam. The stain as above prepared spoils quickly. 
cultures guinea pigs die in from nineteen to thirty-one days (Higgins) of generalized actinobacillosis. 'These are reported to be characteristic and different from those of any of the other observed infective agents. According to Higgins, "Surall pearly-white nodules appear just beneath the peritoneal and pleural membranes, varying from r.o to $5.0 \mathrm{~mm}$. in diameter. The liver presents lesions thronghout its subtance, the surface being mottled. The spleen slows, usually, a varying number of nodules. The great mesenteric fold of the omentum has in every instance been the seat of extensive lesions. The kidneys present nodules beneath their serous covering, but none have been observed in the substance of the organ. The stomach and intestines usually present nodules on their serous surfaces, varying from 1.0 to $0.5 \mathrm{~mm}$. in diameter." There are other lesions such as inlcers in the stomach, nodules in the heart and pericardium. Subcutaneous inoculations are usually followed by similar lesions.

Rabbits are said to react the same as guinea pigs. Nocard found an intravenous injection fatal to dogs in 24 hours. In horses a local abscess resulted which healed rapidly.

The method of infection has not been fully explained, but it is supposed that the organisms are taken with food as in cases of actinomy cosis.

The organisms are said to agglutinate in serum of animals affected with actinobacillosis.

It is destroyed in ro minutes at $62^{\circ} \mathrm{C}$. It grows best at incubator temperature $\left(37^{\circ} \mathrm{C}\right)$. It is not rapidly destroyed by freezing.

$\$ 240$. Symptoms. They do not appear, in cattle, to be differentiated from those of actinomycosis.

5 241. Morbid anatomy. The lesions are very similar to those of actinomycosis. The location of the affected parts varies. Lignières describes it as attacking the skin, lymphatic glands, tongue, pharynx, mammary glands, the viscera and bones. The tissue changes appear to be an infiltration of purulent material, and the new formation of connective tissue. 
The skin is often affected. In the single specimen which the writer has had an opportunity to study, the ray-like arrangement of the organism and the tissue immediately surrounding it, could not be easily distinguished from a section of actinomycosis.

\$ 242. Differential diagnosis. Actinobacillosis is to be differentiated from actinomycosis, tuberculosis, perhaps certain parasitic diseases of the skin, and localized bacterial infections.

The diagnosis is made from the various locations of the lesions. The more important of these is the apparent selection of the skin. The examination of the fresh pus does not reveal the yellow granules as observed in actinomycosis but when squeezed between two cover-glasses they are said to be distinct. The actinobacillosis does not take the gram stain, it is infectious for guinea pigs and rabbits, and it is readily cultivated on artificial media. It appears to be transmitted more often in cattle by cohabitation than actinomycosis.

The differentiation from any parasitic trouble is made by the finding of the animal parasite. The nature of the lesions and the finding of tubercle bacteria in the discharge by microscopic examination, or by producing tuberculosis in guinea pigs by inoculations, would differentiate it from tuberculosis.

$\$$ 243. Prevention. As the natural habitat of actinobacillose is not known, the source of infection is undetermined and consequently effective preventive measure are not known. The fact that it seems to spread from infected to healthy cattle necessitates the isolation of the infected. It is more desirable when possible to separate the well from the infected animals.

REFERENCES.

I. Higgins. Actinobacillosis. Bulletin No. I, Biological Laboratory, Department of Agriculture, Dominion of Canada, I904. Also Proceedings Amer. Vet. Med. Asso., 1904.

2. LIGNIÈRES AND SPITz. Actinobacillose. Contribution à l'étude des affections connues sous le nom d'actinomycose. Buenos Aires, 1902. 
3. LigniÉrES AND SPIT\%. Actinobacillose. Recueil de Médicine l'̈l'rinaire, 1903.

4. Nocarn. Actinobacillose der Zunge. Jahr. des Vet. Med. Berlin, Bd. I,VI (IgO3), p. 695, (abstract).

\section{IEECHES.}

Synonyms. Summer sore ; leeching : barsati, barsáti, barsattee, barsatti, bausette, bursati, bursatic, burusaltec, bursalti, bursautce, bursautic, bursautie, bursottce and burusauttce. These names have been derived from the Indian word bums or bursat, meaning rain or rain sore, it having been supposed that the malady was associated with the rainy season.

$\$$ 244. Characterization. "I Ieeches " or "leeching", is an infections disease quite prevalent among the horse kind in Florida with lesions localized on the skin or the mucosa of the head. It is thought by many that this affection is identical with the disease known as bursattee* in India.

245. History. Neal of Florida described this disease as affecting horses and cattle. He believes it to be peculiar to that section, where he states it is common and rery fatal to horses and mules. There are hundreds of ponds in the central portion of the state around the margins of which there is usually a belt of grassy prairie, water grass and water lilies. Into these grassy places the horses, mules and cows often go during the summer and feed all day in the water. He adds, "after a varying exposure to the influence, or whatever it may" be called, of the 'pond,' a slight lump or elevation of the skin may be found on some part of the body that has been submerged. To the touch it will feel as if a grain of shot were lodged beneath the skin. In eight or ten days the skin slotighs off centrally over this hard spot, leaving a bloody,

*Il seems to be true that an entirely different affection is known by the same name in the northern portion of the United States. The term "Leeches" is also applied to the condition following the invasion of ths liver fluke (Fisciola hepatica). 
bruised-like surface. This rapidly grows in size till in a few weeks there is a raw surface from four inches to a foot square. This oozes blood and serum and no pus. An examination will usually show a mass of yellow, gritty growth, coral-like in sliape, embedded in a mass of bruised, bloody tissue, dark in color with the edges roughened, elevated above the skin, and the skin decaying at the outside of the ulcer. The leech invades almost any tissue, but seems most common on the legs, abdomen and sides. Occasionally it is found in the head. The invaded tissues decay slowly and apparently without pain. I have seen hoofs cut off, the abdomen opened, the eyes eaten out and the teeth destroyed."

In this country the disease has not attracted very much attention, nor has it been considered of much economic importance. An explanation for this may be offered on account of its seemingly non-contagious character and because it has been thought to be confined to comparatively linited areas, and because the animals, although infected, may be utilized for some purposes. On account of the chronic course of the disease the affected animals are often killed from a sentiment of mercy before the disease can terminate fatally.

Although this affection presents many points of similarity to the one fonnd in India, the question of their complete identity ought to be held in abeyance until a more thorough investigation can be made.

In a recent publication, Dawson, of the Florida Experiment Station, states 'that 'leeches' or bursattee is a conmon disease in Florida, which manifests itself in the formation of tumor-growths which have some of the characters of actinomycotic tumors. Its structure is fibrous, and contains many sinuses, which discharge a bloody, 'honey-like' fluid. It is a fatal, infectious disease, which has its origin in the skin and finally penetrates all the tissues. Here and there in the tumor tissue yellow bodies with root-like projections may be found. These bodies are called 'leeches' by the natives. They consist of the mycelia of the fungus which causes the disease. The only remedy is the complete removal of the tumor and adja- 
cent tissue at once. The application of caustics and disinfectants makes matters infinitely worse, as they stimulate the tissues to renewed growth-activity. In Florida the disease affects only the genus equinus."

In 1896, some of the diseased tissue from cases of this affection in Florida, were sent to the Bureau of Animal Industry for investigation. They were studied by Fish, who made an extended report on the results of his findings. He also gave a very complete review of the literature.

Hodgson, in 1853 , referred to the sores as cancerous ulcers and Hart, in 1872 , was strongly inclined to pronounce it cancer, although he could not confirm this view structurally by microscopic examination of the tissue. It seems to be generally accepted that the disease is peculiar to the Tropics, but cases have been reported in Kansas and Minnesota in the United States, not only during the summer months, but when the thermometer registered below zero. We might also expect that the disease would exist in Mexico and Central and South American comntries, where the conditions of temperature and moisture are favorable.

Reports show that a high temperature is essential for the development of the disease, although exceptional cases are noted as occurring during the cold season. Moisture does not seem to be uecessary, since many cases develop when the season is dry. It is, however, an important factor. Statistics show that cases are more numerons and that the disease assumes a more aggravated form during the wet season.

In India, native as well as foreign bred horses are susceptible, but according to some writers, none of the other equine species is affected.

In the United States mules and cattle are said to develop it, but not so readily as the horse. Outbreaks among cattle are comparatively rare. Thin-skinned animals are more susceptible than thick-skinned ones. Some discrepancy of opinion exists as to the kind of horses most likely to take the disease (assuming that bursattee and leeches are similar). Neal states that only horses of good blood leech, and the 
Cubau and Texan ponies are as a rule exempt. Anderson states that it is the coarsely bred and hard-worked horses that are the most susceptible. The well-bred ones, having the advantage of good hygienic surroundings, rarely contract it.

$\$ 246$. Geographical distribution. Bursattee has been reported from Burmah and Hindoostan. It is thought that the prevalence of the disease is associated with the principal river systems of India. In the hilly, rocky and consequently drier districts there is a very noticeable diminution or absence of it.

Outside of India there seem to have been no cases of this malady reported except in the United States, m1nless upon further investigation certain mycotic diseases which have been described in Europe should prove to be identical with it.

Lyford (1866) reported it in Minnesota, Anderson, (1889) in Kansas and Alabama, and Neal (1857) and Bitting (1894) in Florida. The latter writer states, that it is "now known all over the United States except in that region lying east of the Alleghany mountains and north of the Potomac river." A few cases have been presented for treatment in the clinic of the New York State Veterinary College.

5 247. Etiology. A sunmary of the literature shows that among the old theories "leeches" was believed to be a blood disease in many ways not unlike sypliilis, scrofula and farcy. The "fly theory" of the causation and dissemination of bursattee was $\in$ ntertained by the natives of India as early as I820. Jackson, in I $8+2$, seems to have been the first to believe that there was any connection between the disease and a fungus.

Jackson suggested, in 1842 , that the disease might be related to a fungus or to a regetable parasite. Collins, in 1874 , expressed a similar belief. F. Smith, in I879 and I884, seems to have been the first to have worked along this line. He was able to find fungi in every fresh specimen of the sores that he examined. Steel, in $\mathrm{r} 88 \mathrm{I}$, also found fungal elements in these sores. T. Snith, in 1893 , examined some 
alcoholic material and gave expression to the belief that the disease was caused by a fungus. Fish, in 1896, found a fungus embedded in the diseased tissue. He did not name it neither did he obtain it in pure culture, but his illustrations are rery clear in showing the existence of the fungus. Fish gives in detail the methods he employed. It is to his work that we are indebted for the more careful description of the morbid changes.

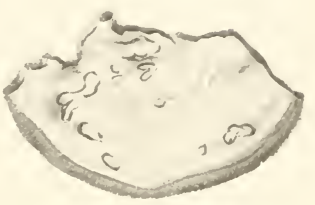

Fig. So. A piece from the lip of an affected horse, shor'-

\$248. Morbid anatomy. As ing sereral disersed foci a rule the lesions are near the (Fish).

surface. Where the diseased portion has become well developed there is usually a more or less complete detachment of the central inflammatory growth from the surrounding tissue. This nodular or "kunker" growth may vary in its density according to the stage of its derelopment. During the early stages it is soft and easily cut; later it becomes firmer and ultimately assumes a hard or "gritty" character.

In cutting sections it is generally the exception to cut through the nodule or kunker evenly and to have it retain its proper relations with the other parts. Even if successful in cutting, the nodule drops out after some of the other processes. In the specimens examined the lcsions were confined entirely to the skin and subcutaneous tissue; no traces of nuscular or glandular structure were observed. Around the central portion of the inflammatory growth there is a zone of leucocytes of the mononuclear and polynuclear varieties, the latter predominating. They are embedded in an abundant stroma of connective tissue which is in a greater or less stage of degeneration. The central portion of the zone is in some cases very closely packed with the lewococytes, while toward the periphery they are more loosely arranged and cause a marked irregularity of the margin from their uneven drifting into the tissue beyond. There is generally one and perhaps more 


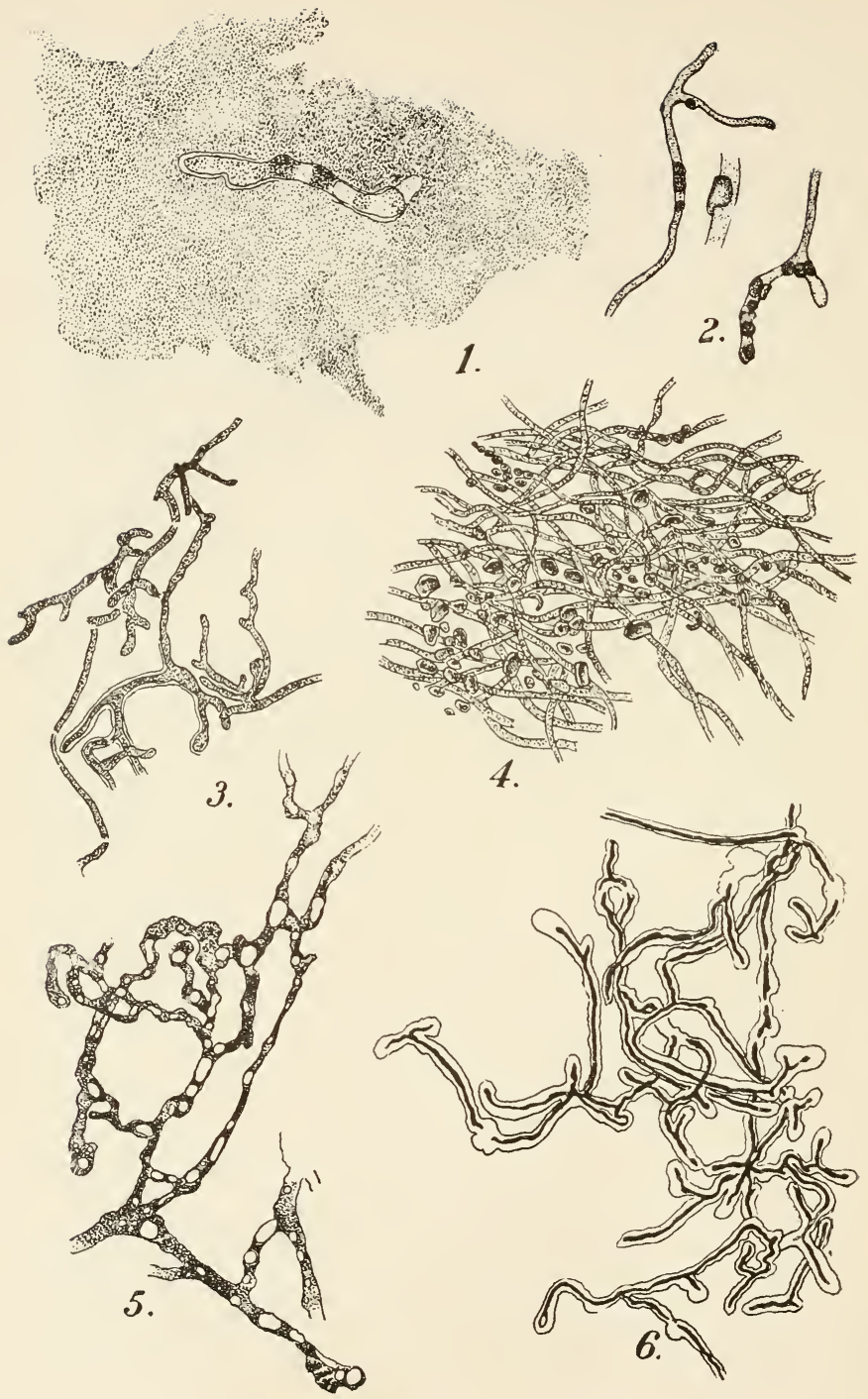

Fungus.

FIG. SI. I'arious forms of the fungus. 
points where this infiltration occurs quite extensively. In some of the preparations the wandering cells have been traced as far as the surface of the epidermis.

Occasionally there may be found a narrow area at the periphery of the nodule, as seen in cross section, which is lighter in color and less dense in texture than the central mass, evidently an extension of the growth.

In the specimens examined the parts where the lesions abounded were not characterized by a rich vascular supply. Fig 82 . From the same lip, but The few ressels that were en- showing a larger infected area countered were not of a normal (Fish).

character; their walls were thickened, and the endothelium, instead of presenting the usual flattened appearance, was irregularly cylindrical. Although the condition was not observed, it is not impossible that the hyphe of the fungus may develop to such an extent as to compass or actually penetrate the walls of the vessels, causing inflammatory changes sufficient to permit, in the course of time, a disorganization or absorption of a portion of the vessel itself, and that ultimately it may become incorporated in the nodule.

DESCRIPTION OF FIT, SI.

1. Showing a young fungus embedded in the tissues (lip.

2. Showing scale-like bodies embracing the filaments.

3. Showing young branches of the fungus, and in one place the transparent sheath. Hemalowylin preparation.

4. Mycelium with scale-like hodies lying among the filaments. Hematorylin.

5. Vacuolated filaments. Hematoxylin.

6. Branches showing a a'ell dezeloped, bansparent sheath. In places the axis of the branch is disconnected and occasionaly ther is a faint sign of a septum. Himatoxylin.

No. focular, $2 \mathrm{~mm}$. objectize. Cameralucida (. lfier Fish). 
The nodules are generally irregularly cone shaped and are of variable size. In section they reveal a very dense structure, the framework of which forms a close reticulum.

Within the meshes are what appear to be

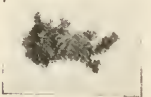

Fig.83. An isolated nodule showing the characteristic roughened, coral-like appearance of the mass (Fish).

delicate filament. leucocytes in various stages of disintegration, and free nuclei: Among these, at places, there can be seen small bodies of nearly the same size as the nuclei and taking the stains in the same way, but differing in form. At one portion of its circumference the substance of the body is seen to draw itself toward a point and in favorable preparations that point has been followed some little distance as a stained, or, as observed in a Gram-eosin preparation, the club end may stain blue and the filament red. Exceptionally one may find a clear area or vacuole in one of the clubs. From the fact that the filament is not usually traceable to its central comnection a more or less flagellate appearance is given to the fungus, which represents a condition not believed to exist.

Not infrequently small spherical bodies are found not far from the clubs, which take the stain readily and whose size is sufficiently small to admit of the possibility of their being spores. The free ends of many of the clubs point toward the periphery of the nodule, but this is not a constant feature.

The framework of the nodule stains very slightly or not at all and shows among the enmeshed corpuscles as a very irregular, distorted and somewhat glistening network. It is this portion of the nodule that gives the hard, gritty feeling, and is probably due to a greater or less deposition of lime salts along the reticulum. It appears that the framework of the nodule is composed of a mycelial net, which in the course of development has become more or less calcified.

As a result of the treatment of the nodules with a ro per cent cold solution of caustic potash, a very profuse and intricately branched fungus became apparent. The branching is of an irregular order. In places there is seen in the filament a 
central axis, which takes the stain, and around this appears a transparent or hyaline sheath of varying size.

In certain of the teased preparations (Biondi-Elnlich stain) the wall of the filament, instead of being smooth and homogeneous, appears roughened, as if covered with very minute but numerous spinous processes.

In the sections of the tissue in which the fungus appeared the substance of the filament was not uniform. In places it was drawn together in an irregular manner, with intervening clear spaces of greater or Jess area.

In some places the filaments show distinct septa, but the latter are not common. Some of the club-like endings,

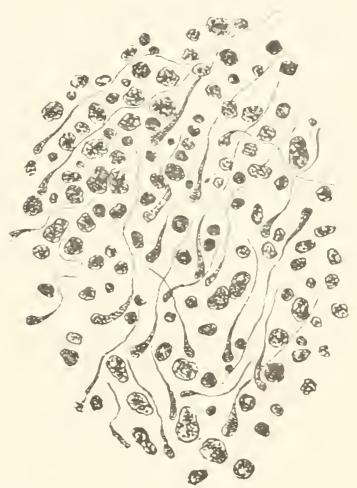

Fig. 84. The fungus. Toluidin blue preparation (Fish). especially those that are elongated, show a septum at the union with the filament proper. Scattered among and coiled around the ordinary filaments there have been observed much more slender ones apparently devoid of any external sheath.

There have also been observed numerous small circular bodies of inconstant size. They have been seen lying freely in the meshes of the mycelium and also closely applied to the filaments. These bodies are not spherical, but thin and flattened, and some of then present a curved appearance, convex on the outer side and concave on the inner side. They suggest the possibility of having been closely applied to the filaments and have something of a scale-like arrangement. With possibly one exception, no trace of blood vessels has been found in the nodules. 
In the circumnodular tissue pathologic conditions exist, consisting of certain areas of tissue necrosis.

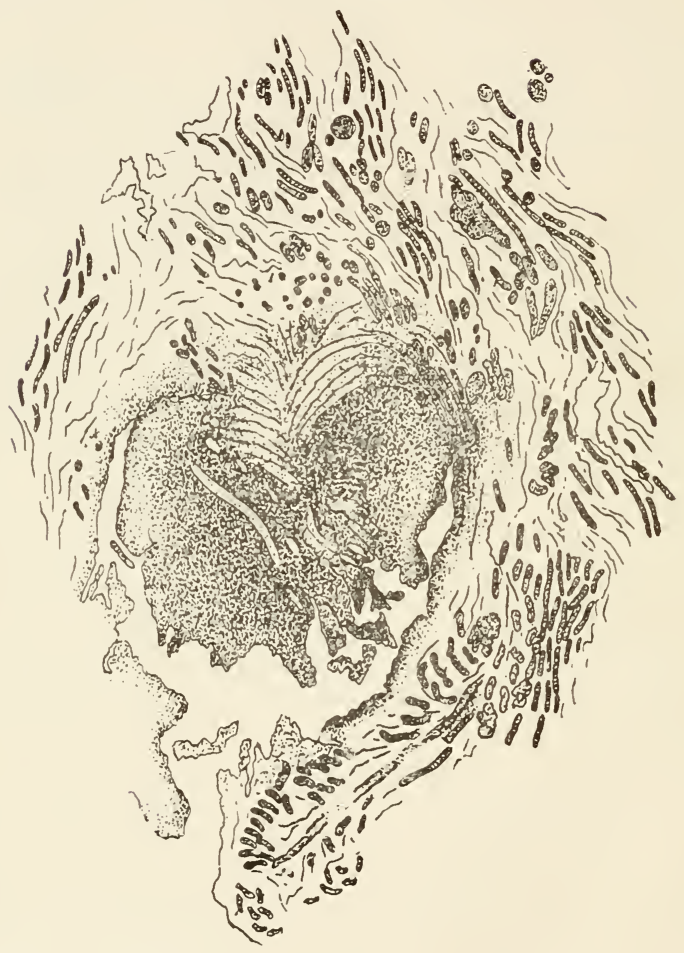

FIG. 85. A section through a nodule showing its dense texture, with a portion of its peripheral zone made up of hypha with lencocytes interspersed. Methylene blue and eosin stain. No. + ocular, smm. objective. Camera lucida drawing (Fish).

There is an infiltration of the connective tissue with a great number of wandering cells. In some places there are 
well-defined nests in the stroma of the connective tissue, sinulating, perhaps, a cancerous appearance. The character of the cells, which present a curiously vacuolated condition, would, however, tend to eliminate this view. 'The vacuoles very in number and size, the average number being is to 12 in a cell.

In some preparations numerous lencocytes, of the mononuclear and polynuclear varieties, had drifted away from the nodule. They were for the most part elongated, and in all the nucleus or nuclei appeared to be in a healthy condition. The cells contained numerous eosinopliiles, which took a deep orange color with the Biondi-Ehrlich stain. In places adjacent to these leucocytes there were frequently noticed a number of these small bodies apparently lying free in the tissue. No definite cell wall was distinguished in the leucocytes.

The vacuolated cells are present in greater numbers than the lieavily laden leucocytes. In the former nuclei were present and presented various phases of change. In some there is a single nucleus, which may be circular, crescentic, or in the form of a dumb-bell; in others there may be two or more nuclei which in advanced cases appear only as remnants. In extreme cases no nuclei at all are visible. The wall of the wandering cell differs from that of the lencocytes proper in possessing an appreciable thickness. This thickened boundary apparently gives considerable rigidity to the cells, as nearly all of them are approximately circular in form. Their average diameter is about 8 microns. In one specimen there appeared to be large giant cells, measuring from 12 to 18 microns and apparently possessing quite a distinct cell wall. Within each giant cell there is some appearance of vacuolated cells, each with a single nucleus and fairly well-defined cell boundary. As many as eight or ten of these nuclei luve been counted in a single giant cell. There is the possibility that these apparent giant cells are simply sone of the vacuolated cells fused together, but the nuclei are well defined and take the stain very intensely, which is not commonly the case in the ordinary vacuolated cells.

The connective-tissue cells surrounding the nodule show 
marked signs of degeneration, their cytoplasm in most cases being extremely vacuolated. Among these connective-tissue cells, which for the most part are quite brauching and elongated, is another class of cells which are in general of an oval or elliptical form. The noteworthy appearance of these cells is the presence of numerous dots in the cytoplasm which take the methylene blue and toluidin blue stains very deeply. The appearance is, indeed, very much as if the cells were filled with micrococci. These are the granule cells of Waldeyer, or still further differentiated as the plasma cells, in contradistinction to the "mastzellen " or "food cells," which indicate an exalted degree of nutrition. The nucleus of the plasma cell takes the stain very slightly, or not at all, and is almost entirely obscured by the numerous " granules" in the cytoplasm. These cells are well differentiated by the toluidin blue stain, as they take a deep purple color, while the surrounding cells are blue.

Bitting has figured the jaw bone of a horse quite extensively affected with this disease. He belieres that the lesions about the mouth result from the animal biting the affected areas on the body.

Neyrick reports finding the inflammatory growths in the lungs of an affected subject, and Burke has reported them in the liver. There are no other lesions described in the internal organs although Neal writes that any tissue may be invaded.

\$ 249. Treatment. On the ground that the fungus supposed to be the cause of this disease may be closely related to the ray fungus of actinomycosis, the use of iodide of potassium has been recommended. It is reported to be fairly successful. The efficiency of this drug as a specific needs further confirmation.

REFERENCESS.

1. Bitring. Leeches or leeching. Bullelin No. 25, Florida Agricultural Experiment Station, 1894.

2. Fish. A histological investigation of two cases of an equine mycosis, with a historical account of a supposed similar disease called bursattee occurring in India. Annual Report, Bureau of Animal In- 
dustry, U. S. 1)ept. of Agriculture, 1895-6, p. 229. (This report contains a bibliography on Bursattee.)

3. NFan. Jeeching of horses and cattle. Annual keport, Burean of Animal Industri, U. S. Dept of Agriculture, 1887-8. p. 489 .

\section{PNEUMONOMICOSIS.}

$\$$ 250. Species of fungi. The literature contains a number of reports of cases of mycosis in the lower aninals as well as in man due to infection with different moulds. The genus Aspergillus seems to infect and to produce lesions in animals more frequently than the menbers of other genera. In fact, Aspergillus fumigatus seens to be the only important pathogenic species. The lesions encountered as a result of its invasion are largely restricted to the respiratory tract. Pnetumonomycosis has been reported in a number of cases. Cadéac, Schneidemühl, Friedberger and Fröhner, Ostertag and Kitt have all called attention to mycotic pneumonia. Renon considers the lesions resulting from aspergillus infection as a pseudo-tuberculosis which he would designate as "Aspergillar tuberculosis." Aspergillar pueumonia is, however, quite rare.

$\$ 251$. Description and method of cultivation of the mould. The aspergillus fungus is readily cultivated artificially. It grows on most of the ordinary culture media used in bacteriology if the reaction is acid; it develops poorly in alkaline media. The well-known Raulin's fluid is reported to be the best medium for its cultivation, especially where the aspergillus must be isolated from mixed growths, as in the examination of sputum. Sabourand's* solution of maltose also gives good results.

The formula recommended by Ravenel is as follows :

$\begin{array}{lr}\text { Maltose, } & 370 \text { grams. } \\ \text { Peptone, } & 0.75 \text { grams. } \\ \text { Distilled water, } & \text { I00.00 c. c. }\end{array}$

To this may be added gelatin or agar to solidify it, the latter being preferable, as the aspergillus grows best, and forms fruit best at $37^{\circ}$ to $39^{\circ} \mathrm{C}$. 
For ordinary use potato, with or without glycerin, gives excellent results. A paste made by rubbing up crumbs of stale bread in water is also a good medium. Growth is said to be more rapid, however, in Raulin's fluid than in any other medium, the mycelium appearing in from five to twelve hours and spores forming in from twelve to fifteen hours. The growth is first a velvety white, soon becoming a delicate bluish green, which grows darker. On Raulin's fluid it changes after some days to a dark brown. Cultures on potato retain the green color for a long time, while those on bread paste become brown.

The fungus retains its vitality in cultures for many months unimpaired. Its development has been reported when inoculated from cultures three or four years old. Spores do not form in a temperature below $20^{\circ} \mathrm{C}$. and like the mycelium they require fresh access to oxygen for their best development. They measure 2.5 to $3 \mu$ in diameter. In nature the spores are widely distributed but seem to be especially abundant in grain and vegetable matter. They have considerable power of re-

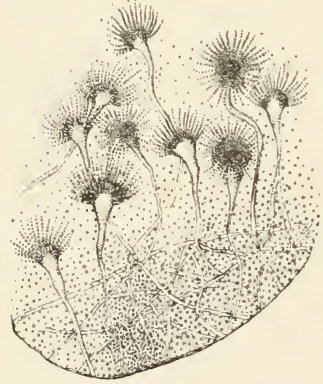

FIG. S6. Aspergillus fumigatus in fruit. sistance to heat and to chemical agents. They are killed by a temperature of $60^{\circ} \mathrm{C}$. in five and onehalf hours. In moist heat and in solution of bichloride of mercury I to $\mathbf{I}, 000$ they are destroyed in fifteen minutes.

Aspergillus fumigatus is differentiated from other species by its color in cultures, the high temperature at which it grows, the size of the spores and by its pathogenesis. Aspergillus glaucus is the one most likely to be confounded with it. It may be differentiated from $A$. fumigatus by its ability to grow at low temperature, its delicate green color, the large diameter of its spores -9 to $15 \mu$-and its lack of pathogenic power. 
The mode of infection is through the respiratory tract. Only a sulall number of the spores inspired are able to reach the alveoli, the greater number of them being arrested in the tracheal and bronchial secretions. Hildebrant has shown that, liaving reached the alveoli, they penetrate the epithelial lining without difficulty. Both animals and man seem to possess immunity to intestinal infection. Renon has produced it only a few tines experimentally.

The aspergillus does not form toxin. Its pathogenic power is due entirely to lesions produced by the masses of mycelium which causes a necrosis of the cells and a leucocytic reaction which diminishes the functions of the organs, the final result being an enfeebled condition of the animal and a lessened resistance to hurtful influences. When fruit hyphae can form, the myriads of spores given off by them may be carried to other parts of the organ. In this way the foci rapidly multiply and practically the entire organ becomes invaded. The opinion held by some authors that in the mould mycoses there is "no fructification or actual multiplication" of. the infected agent and that the "number of the diseased foci corresponds exactly with the number of spores introduced," is erroneous both for the disease naturally contracted as well as for the experimental form. In the produced lesions, fruit formation of the fungus is exceptional. It has been observed by Renon to take place only where there is full communication with the air. It has been observed only in the lung. It is extremely rare for aspergillosis to pass from one animal to another. The infection can only take place with the spores.

Pneumonomycosis in cattle. Recently Pearson and Ravenel have described a very interesting case of pneumonomycosis in a cow due to $A$. fumigatus. As this seems to be the only carefully described case in this species of animals listed in this country their description of the symptoms and lesions is very largely incorporated here. 'The case was in a Jersey cow six years old. She had been in poor condition for six months prior to bringing her to the Veterinary Hospital where she was tested with tuberculin with no reaction. At this time sle did 
not eat, was weak and depressed, respiration labored and from 4o to 90 per minute. Pulse rapid. Percussion of the chest walls gave a sound that if anything was clearer and louder

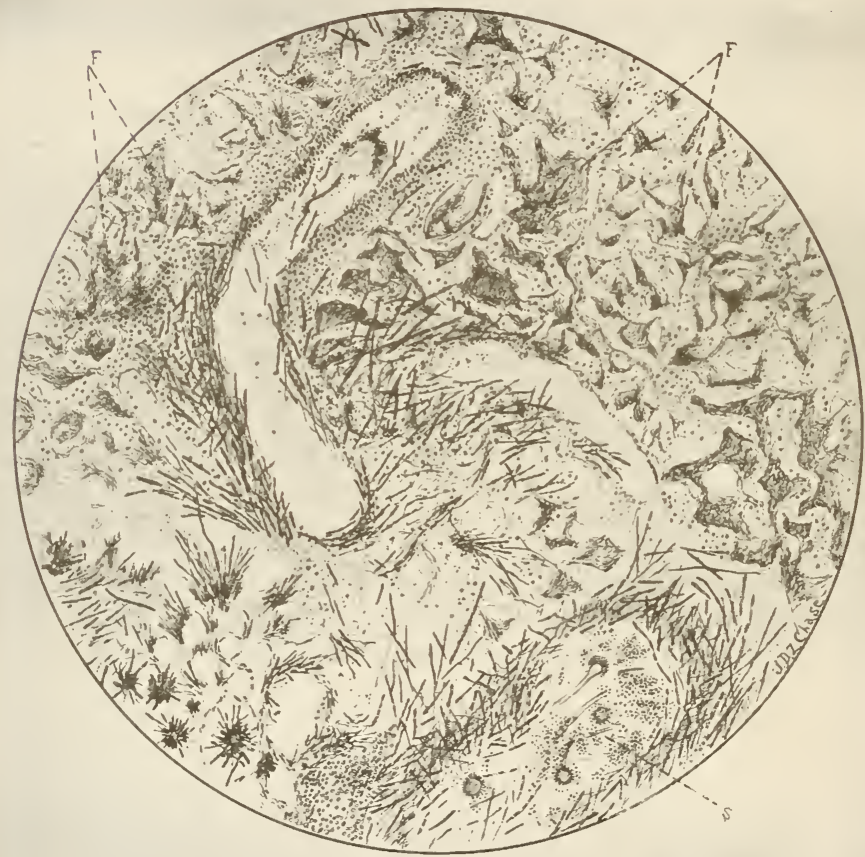

FIG. 87. Composite drawing of section of lung through nodule of aspergillus origin. F, fibrin in alveoli. S, fruit hyphae and spores of fungus (Ravenel).

than the normal percussion sound. Upon auscultation it was found that the vesicular and bronchial nurmurs were consider- 
ably increased in intensity and accompanied here and there by sibilant râles. She coughed violently at times. Six days after she came to the hospital the breathing became more rapid and difficult and the pulse very much accelerated. The animal did not eat, grew weak rapidly and died four days later, or ten days after admission to the hospital.

\$ 252. Morbid anatomy. The anatomical changes given liere are restricted to the case of Pearson and Ravenel. The animal was much emaciated. The mucous membrane of the small intestine was catarrhal and showed a small amount of erosion. All the organs were normal except the lungs. The most striking feature on external examination was the extreme amount of emphysema. The lobules were separated from each other by 3 to $5 \mathrm{~mm}$. and even at some distance from the borders one conld see through the crevices by transmitted light. On the surface, the sub pleural connective tissue was distended by large blebs. Upon palpation the lung crackled and numerous hard nodules could be felt. On section numerous dark red nodules appeared in the surrounding normal tissue. In each lung there were from fifty to sixty of these nodules, from 5 to $12 \mathrm{~mm}$. in diameter. Most of them were dark red and closely resembled partially organized blood clots. However, on crushing a portion in glycerin between two slides and examining it under the microscope, they were found to be made up almost entirely of a felted network of mycelial threads. Between these large nodules there were numberless smaller areas of much the same color, I to $2 \mathrm{~mm}$. in diameter, not perceptible to the touch as nodules but which were of the same character and were no doubt foci of recent origin. These were seen especially well in portions of the lung which were preserved by Pick's method, the slight bleaching of the tissue bringing them into relief. On opening some of the interlobular emphysematous spaces, small, whitish, monldy looking patches were noticed which bordered the cavity. Scrapings of these patches were made up entirely of perfect fruit hyphae, with myriads of spores. The diagnosis of a mould mycosis was in this way made at once and confirmed by cul- 
tures and examination of sections. Cultures were made on glycerinated potato, bouillon and plain agar, by opening a nodule with sterile instruments and tearing out a small portion of the center, whicl was transferred to the culture tubes and placed in an incubator at $39^{\circ} \mathrm{C}$. Abundant growth was ob. tained on the potato by the end of thirty-six hours, white at first but soon changing to a yellowish and later to a dark green color. The growth in the bouillon and agar was slow. Plates and flasks of bread paste were made, and these with potato were employed for all subsequent cultures. The formation of the fruit hyphae was studied. The spores measured from 2.5 to $3.5 \mu$ in diameter. By these means the culture was identified as the aspergillus fumigatus. The experiments on other animals were limited to the inoculation of one rabbit, into the aural vein of which one-half cubic centimeter of a suspension of the spores was injected. The animal died in forty-four hours and from the liver and kidneys cultures were recovered. All of the organs were examined in sections, but the mycelium was detected in two only.

Microscopic examination. The nodules were hardened and embedded, some in collodion and some in paraffin. Various staining methods were tried, hematoxylin and eosin, carbolthionine, Gram and lithium carmine with Weigert's fibrin stain. Good results were obtained with all, but the carmine and Weigert gave the most beautiful picture and by this method the fungus was most perfectly demonstrated, the spores and mycelium taking on a deep purple color. The histology was studied largely in sections stained with hematoxylin and eosin. The bronchial epithelium was normal in places, but, for the most part. the columnar cells had been replaced by a sort of membrane, which appears to be made up almost entirely of a felt-work of mycelial threads. From this membrane hyphæ grew out into the lumen of the bronchus, and here, owing no doubt to the supply of air, fruit hyphae arose, with perfect sterigmata and spores. There was no cellular nor other exudate and very little debris. The under surface of this membrane was of looser texture and contained some cellular 
infiltration made up of round cells, leucocytes, proliferated connective tissue cells and red blood corpuscles. The adjacent structures were closely filled with a cellular infiltration with a quantity of mycelium of the same description, this extended to the neighboring alveoli, which under low power appeared to have preserved their outline but with greater amplification were seen to have lost all their normal structure, showing clumps of homogeneous, irregular masses which stained faintly with eosin and were probably of connective tissue origin.

In these areas the mycelium followed the alveolar wall as a trellis, the tissue seeming to afford no obstacle to its advance. Within the alveoli was a finely granular debris, with some coarser particles, probably the remains of cells. In sections stained with carbol-thionine large numbers of mast cells were seen iu the alveolar walls. Bordering these degenerated areas were alveoli which had retained their normal structure and were filled with a network of fibrin holding in its meshes a few cells. In other parts of the sections were areas resembling those just described, but in which all anatomical landmarks had been destroyed, so that it was impossible to tell whether or not the spaces seen were bronchi.

Some sections showed a widespread interstitial and alveolar hemorrhage, the blood showing a considerable increase in the number of leucocytes. The capillaries were congested and areas of edema with thickening of the alveolar walls were not uncommon.

There were peribronchitis and arteritis, while in some sections arterial thrombosis was seen, the thrombus being penetrated by mycelium, thougls no fruit was found. Areas were also found in which the alveoli were filled with a cellular exudate producing consolidation and thickening of the alveolar walls.

Emphysema, both interstitial and vesicular, were marked and often extreme. Around the borders of the interstitial cavities was a distinct zone made up of red blood cells, letıcocytes and homogeneous material, which was yellowish in fresh as well as stained sectious. These areas contained very little 
mycelium. All sections showed a small amount of anthracosis. The appearance of sections varied in different nodules as they were taken further and further away from the center. In general the fungus was thickest at the center, so thick in many instances that the lung tissue was hidden entirely, and grew less as we went outward. The tissue changes noted took place in a zone beyond the greatest growth of the fungus. In other nodules the fungus was evenly distributed throughout, following the alveolar walls. In these the tissue changes were slight. At times the fungus grew in dense, brush-like clusters, closely resembling actinomycosis under low amplification.

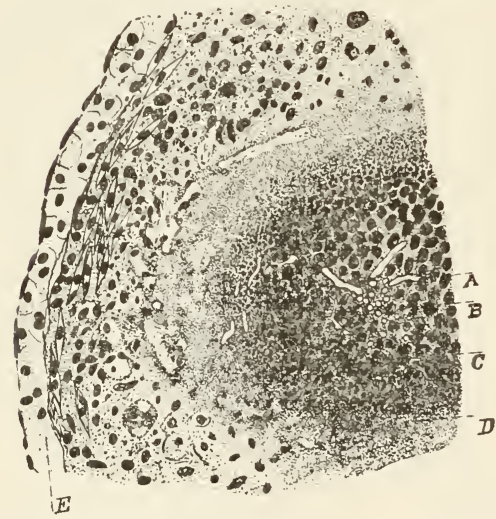

FIG 88. Necrosis in the kidney of a rabbit due to A. fumigatus; $\mathrm{A}$, fungus; $\mathrm{B}$ and $\mathrm{C}$, nuclei; D, necrotic tissue; $\mathrm{E}$, normal cells.

This form was considered to show a marked reaction and resistance on the part of the animal and a lowered vitality in the fungus. When found it indicated that the aspergillosis was a primary and not a secondary or terminal affection. No giant cells were found in any section.

Fruit formation was not observed in the substance of the tissues at any time. It was observed most frequently in bronchi, which were for the most part denuded of their epithelium, and next in emphysematous cavities. where it could be detected in clusters by the naked eye. Fruit was found in sections, in spaces the nature of which it was impossible to determine accurately. Whenever the formation of fruit was seen, there were innumerable free spores as well 
as those still attached to the sterigmata, but in no case were spores detected in the substance of the tissues.

In many sections, especially those from near the center of the nodules, the mass of mycelium was so dense that the structure of the tissues was obscured. Besides the dense growths resembling actinomycosis already described, other brush-like clusters not unlike them were frequently seen. These differ from the former in being somewhat less compact, and that from their periphery numerous hyphae run out into the sur. rounding tissues, whereas in the actinomycotic form the masses are sharply defined and only here and there a few threads grow out beyond the cluster. Their appearance suggests that they may be actinomycotic forms which have finally overcome the resistance of the tissues. Emplyysema is less marked in the neighborhood of the latter.

The cow was examined carefully for the lesions of tuberculosis and in one lung some four or fire caseous and calcareous nodules I cm. in diameter were found, in which tubercle bacteria were demonstrated, but no nuycelium could be detected. In no part of the lung was there coexistence of the two infections.

The fact that the animal did not react to tuberculin, although tuberculosis was present, is noteworthy and suggests that the mould infection may interfere with the test. It is probable that the tuberculous lesion was arrested in its progress.

$\S 253$. Pulmonary mycosis in birds. Moliler and Buckley have recently described a case of this affection in the lung of a flamingo which died at the National Zoölogical Park in Washington. In this case the bird was very much emaciated. The lungs presented lesions suggesting those of tuberculosis in their general appearance. The other organs (iver, spleen and kidneys) appeared to be normal. From the lung Aspergillus fumigatus was obtained. [The authors give a full description of the lesions with a historical sketch and results of experiments on the smaller animals.] 
REFERENCES.

I. ARWINE AND LAMB. A fifth case of "fungous foot" in America. The Amer. Jour. of Med. Siences, Oct. I899.

2. DrNwidik. On the toxic properties of moulds. Bulletin No. 1o, Arkansas Agric. Exp. Sta., May, 1896.

3. FLEXNER. Pseudo-tuberculosis Hominis Streptothricha. The Journal of Experimental Medicine, Vol. III (1898). (Bibliography).

4. MOHLER AND BuCKLEY. Pulmonary mycosis in birds-with a report of a case in a flamingo. Annual Report of the Bureau of Animal Industry, 1903. (. Hlso issued as circular No. 58.)

5. OpHïls axd Moffits. A new pathogenic mould. The Philadelphia. Med. Journal, June 30, 1900.

6. Pearson axd Ravexem. A case of pneumonomycosis due to the Aspergillus fumigatus. The University Medical Magazine, Aug. 1900. The Vet. Journal, New Series, Vol. II (1900), p. 229.

7. Ríxon. L'étude sur l'aspergillose chez les animaux et chez 1'homme. 1897 .

8. WEIs. Four pathogenic Torulie (Blastomycetes). The Jour. of .led. Research, Vol. VII (1902), p. 2 So.

\section{EPIZOÖTIC LYMPHANGITIS}

Synonyms. Japanese farcy; pseudo-farcy; equine pox ; equine syphilis : inundation fever.

\$254. Characterization. Epizoötic lymphangitis is described as a virulent infectious disease characterized by suppuration of the superficial lymphatic vessels, due to the presence of a specific organism. It is a disease of the solipeds, although Tokishige reports finding it in cattle in Japan.

5 255. History. This affection seems to have been known for a very long time and to have been confused with cutaneous glanders (farcy). French veterinarians have recognized the disease as river farcy, farcin en cul de poule, curable or benign farcy. In France these various forms were acknowledged to be identical, the " river farcy" being considered as an attenuated form of glanders (farcy) until i873, when Rivolta discorered the specific organism (Saccharomycosis 
farciminosus). This affection has been recognized at different times in Japan, China and India. It has been known in Algiers for many years and during the war in South Africa it seems to have been introduced there. From South Africa it has been imported into England and Ireland by government horses returning from the Cape. The first case in Eingland appears to have been detected in 1902. In 1907, Pearson discovered it in western Pennsylvania.

$\$ 256$. Etiology. This disease is caused by an organism described by Rivolta as Sacharomyces farciminosus. It is also called a cryptococcus. According to Pallin, it is found in large numbers in the diseased tissues and products, partly free and partly enclosed in pus corpuscles, which often contain from ten to thirty or more of them. It is characterized by its clearly defined contour and its very refractile double outline. It measures from 3 to $+\mu$ in diameter, and in the unstained preparations it is said to be best seen with an oil immersion and abbé condenser, under a magnification of not less than soo diameters. In stained preparations it can be recognized with a much lower magnification.

The classification of this organism has been much discussed by several workers. Canalis places it with the coccidia, Piana and Galli-Valerio consider it as belonging to the protozoa, and Formi and Aruch as a blastomycete. Tokishige and Marconi believe that it belongs with the saccharomyces. It is not easily stained by the aniline dyes, although Mettam has shown that by the Gram method, Nicolle's violet, Nicolle's thionine and others it is readily colored. It is cultivated with difficulty. Tokishige obtained cultures in bouillon, agar, gelatin and on potato. In bouillon it required seventeen days to obtain a growth.

The infectious material may be transported by contact between the diseased and well horses, by stall bedding, by stable utensils and harnesses and possibly by insects.

The period of incubation is placed at from three weeks to three months and in certain cases it may extend to even eight 
or ten months. In experimental cases symptoms have appeared after 32 days.

$\$ 257$. Symptoms. An infection takes place in wounds, the first symptom usually appearing at the seat of a pre-existing wound. The lesions usually appear in the skin, but they may occur on a mucous membrane. They consist of swelling and suppuration of the lymph vessels and glands. These break and discharge a thick, yellow pus, stained with blood. Pearson states that the horses do not, as a rule, show any general disturbance except in very advanced cases. Pallin describes the opened sores as follows :

" The buds, ulcers, or sores, by all of which names they are known, are characterized by their bright red exuberant granulations and their fungoid appearance, as well as by their indurated base and well-defined edges: the adjoining skin, which is partially inverted, has a peculiar shiny appearance; an opening exists in the center of the bud, from which the pus, at first creamy, and afterwards yellowish, oily, and curdled, is continually discharging."

These buds are quite different from those of glanders. The lesions are commonest in the limbs. The most usual location is on the fore-leg generally extending up along the fore-arm to the brachial region and point of the shoulder.

The sores vary in size from that of a pea to a hen's egg. Pallin reports lesions on the mucous membranes in from 7 to Io per cent of the cases. When these occur on the nasal mucosae they are liable to be confounded with those of glanders.

Usually the general symptoms are not conspicuous. The temperature remains normal and the appetite good. The disease seems to thrive best on animals in good condition.

Pearson describes its symptoms as follows: "The most common mauifestation consists in the presence of small, chronic, discharging ulcers in the vicinity of the hock joint of a thickened hind leg. In such a case, one may also find small scars showing where ulcers have healed and there 
will probably be some firm nodules beneath the skin and, perhaps, one or more nodules that have softened, forming fluctuating abscesses. The regional lymphatic ducts are corded and the glands inside the thigh are hardened and nodulated.

"The earliest observed symptom may be the occurrence of a firm nodule, from the size of a pea to that of a walnut, beneath the skin, anywhere on the body. Corded lymphatics extend from this lesion. In time, the nodule will soften and, at length, its purulent contents will break through the skin. The time required for these developments is most variable and may reach several weeks. Such pus is thick yellowish or greyish yellow and often it is mixed with blood. Sometimes it contains flakes.

"In other cases, the first symptom observed is an indolent sore, covered with pus and scab, surrounded by a slightly swollen zone and from which one or more firm cords extend beneath the skin toward the lymphatic glands. This condition is, no doubt, the first to develop, but such a sore often escapes special notice until nodules occur.

"Fresh ulcers may be surrounded by a slightly raised zone of bright red granulation tissues ('proud flesh'). The ulcers occur irregularly and they disappear slowly ; some heal in a fortnight, others continue to discharge for months, and, after healing, may break out again. From this long continued irritation and from the formation of scar tissue, the skin thickens and the affected parts become indurated.

"Ulceration sometimes occurs upon the conjunctiva and on the mucous membrane of the nostrils and upper respiratory act."

$\$$ 258. Morbid Anatomy. This disease consists in an inflammation of the lymphatics. On section the walls of the vessels are thickened, their internal nembrane is congested, and the ducts filled with thick-clotted lymph mixed with pus, which is followed by the formation of the abscesses (pustules) and granulating sores. The affected parts become indurated as the result of the formation of fibrous tissue due to the 
inflammation set up by the disease. On the mucosa, the ulcers have a round, well defined raised border. They are at first isolated but later they become confluent. Nodules are occasionally found in the liver and spleen. A few horses appear to recover spontaneously. A few are apparently benefitted by proper treatment. It is said to be fatal in from to to I 5 per cent of all cases.

$\S 259$. Differential diagnosis. This affection is to be differentiated from glanders, ulcerative lymphangitis, tubercular lymphangitis, bursatti, and the so-called botryomycosis. The finding of the specific organism in case of epizoötic $1 \mathrm{ym}$ phangitis affords a positive means for its differentiation and diagnosis.

REFERENCES.

I. METTAM. The staining of the organism of epizoötic lyuphangitis. The Vet. Record, Vol. XVI (1904), p. $8_{34}$.

2. PALLIN. A treatise on epizoötic lymphangitis. London, 1904.

3. Pearson. Epizoötic lynphangitis of horses and mules. Circular. No. 8, Pennsyläania State Livestock Sanitary Board (1907).

\section{MISCELLANEOLS FUNGOUS INFECTIONS.}

$\$$ 260. Farcy in cattle. This affection is described as being characterized by an inflammation tending to suppuration of the superficial lymphatic vessels and glands caused by a streptothrix. The descriptions of this affection, however, are not recent, those by Cruzel, I869, and Nocard in 1888 being among the latest, and consequently there is some question concerning its etiology. Nocard states that it is very closely related to actinomycosis.

This affection is said to be chronic, attacking the lymph vessels and glands, which become hard and often caseous. Tokiskye has described cases in which the lesions extend into the respiratory passages. In some cases abscesses occur. They are reported to occur on the ventral surface of the body. 
This disease does not appear to exist in this country. Until its differentiation from tuberculosis, actinomycosis and "botryomycosis" is made its real nature will remain in doubt.

I. Cruzer.. Traité des maladies de l'espèce hovine. 1869.

2. Mausis. Mrémoire sur le farcin. Ibid.

3. Nocard. Note sur la maladie des boeufs connue a la Guadeloupe sous le nom de farcin. Annales de l'lnst. Pasteur, Vol. II (ISSS), p. 293.

4. Soriflox. Exemples de farcin dans le boeuf. Recueil de míd. viétir., IS29, p. 65 I.

$\$ 261$. Mycotic stomatitis in cattle. Cattle sometimes suffer from stomatitis caused by fungi. The exact species that are involved in this form of infection are not clearly determined. A number have been incriminated. Mohler has recently described a stomatitis of this character. The symptoms are inability to eat, suspension of rumination, frequent movements of the lips, and in some cases dribbling of saliva. There is a desire to eat but prehension is difficult. The mouth is abnormally warm and the mucosa reddened, rarely small blisters will be seen which soon develop into ulcers. These vary in diameter from 3 to $25 \mathrm{~mm}$. The erosions, which may become confluent, are found on the gums, dental pad, inside of the lips and on the end of the tongue. They also occur on the cheeks. The ulcers are hemorrhagic at the borders. The central necrotic portion soon sloughs, and the place is filled with granulating tissue. There are often erosions and exfoliation of the epithelium of the muzzle. There are at times swellings about the feet.

The prognosis is good.

The course of the disease varies from 7 to 15 days, the average being, according to Mohler, about 10 days. IVard has diagnosed a mycotic stomatitis in California. This infection, which appears to occur in enzoötics, resulting from the eating of food containing irritant fungi, is to be differentiated from foot-and-mouth disease, ergotism, and necrotic stomatitis caused by B. necrosis. 
Mohler. Mycotic stomatitis of cattle. Circular No. 51. Bureau of Animal Industry, U. S. Dept. of Agric. r904.

$\S 262$. Blastomycetes infection in horses. Fermi and Aruch described a disease in horses resembling glanders except that it did not affect the lungs, which was caused by a blastomycete. It is known as Furcin d'Afrique. Centralblatt f. Bak., Bd. XVII (I895), p. 593.

Frothingham has described a tumor-like lesion in the lungs of horses caused by a blastomycete. The growth was about ten inches in diameter and on section resembled in appearance a myxosarcoma. The central portion was easily removed, the outer zone forming a firm border wall composed of fibrous tissue. A microscopic examination of the central portion showed it to consist of a fine meshwork of fibrous tissue, in the meshes of which were many cells and blastomyces. These were fatal to rabbits and guinea pigs. Jour. Compar. Med. and l'et. Archives, Vol. XXIII (1902), p. 593. 


\section{DISEASES CAUSED BY PROTOZOA \\ GENUS PIROPLASMA.}

$\leqslant$ 263. General discussion of piroplasma. There are several species of piroplasma. Their life history is not known. In the infected animal they live within the blood, often entering into and destroying the red blood corpuscles. They are transmitted from the infected to the uninfected animal by means of some insect usually a tick. The known species of this genus are parasitic and pathogenic in different species of animals. The term Piroplasmoses was introduced by Nocard to designate the diseases produced by these organisms. According to his classification Piroplasmoses are diseases resulting from infection with any species belonging to the genus Piroplasma. Nocard recognizes four species, but others have been described more recently.

Piroplasma bigeminum-the piroplasma of cattle.

Piroplasma oi'is-the piroplasma of sheep.

Piroplasma canis-the piroplasma of dogs.

Piroplasma equi-the piroplasma of horses.

To Americans, Piroplasma bigeminum, the form infecting cattle, is the most important.

TEXAS FEVER.

Synonyms. Bovine malaria; red water; Spanish fever; splenic fever; "bloody murrain;" southern cattle fever; tick fever. 
$\$ 264$. Characterization. Texas fever is an infectious blood disease of cattle, characterized by rise of temperature, hemoglobinuria, destruction of the red blood corpuscles and the presence in the blood of a protozoan parasite which is transmitted from animal to animal by means of the cattle tick.

It is believed to be identical with the hemoglobinuria in Roumania, tick fever in Australia, and "La Tristeza" in South America. It has been named malaria des bovides by Celli and Sentori and Malaria bovine by Lignières. Although it differs in many ways from human malaria, the analogy is so close respecting the specific cause, wide distribution and means of transmission, that bovine malaria seens to be a very suitable name for this affection. At least it has the advantage of not stigmatizing any locality.

The peculiar and interesting feature of this affection is the fact that cattle raised in the infected districts become immunized so that they do not suffer from the disease but they carry its specific organism in their blood. When imported into non-infected districts, they transmit the virus, by means of the cattle tick, to susceptible animals, but remain themselves perfectly well.

$\S 265$. History. There is little knowledge concerning the early history of this disease. With the development of commerce, however, the shipping and interchange of animals gradually came into prominence and, with it all, this disease which had long been known in certain localities was more widely scattered until finally it came to be an important barrier to the cattle traffic. In 1868 , this disease seems to have made its first important impression upon the American people. In June of that year, Texas cattle were shipped up the Mississippi river to Cairo and thence by rail into the states of Inlinois and Indiana, where they caused during the summer enormous losses from this disease. Cattle from these states shipped east brought the disease with them. The cattle commissioners of New York and the Board of Health of New York City endeavored to check the importation of such cattle. The disease was 
carefully investigated at that time but nothing beyond a very accurate description of the gross lesions was obtained. Later, Salmon determined the boundary line between the non-infected and the permanently infected districts, or what is now known as the Texas fever line. (See Plate II). In I889, the Bureau of Animal Industry undertook a systematic investigation into the nature of this disease, which resulted in the same year in the discovery of its specific cause by Dr. Theobald Smith and later the demonstration of the fact that the disease is transmitted from southern to northern cattle through the medium of the cattle tick. Prior to this (1888), v. Babes had found an intraglobular parasite in the blood of cattle suffering from an epizoötic disease (hemoglobinuria in Roumania. While at first these diseases were thought to be different in their etiology they are now beliered to be identical.

A number of investigations have been nuade by the Bureau of Animal Industry, the State Experiment Station and State Board of Agriculture of Missouri and Texas, the Louisiana Experiment Station and by the Queensland Government, Australia, for the purpose of obtaining a practical method for the production of immunity against Texas fever in susceptible cattle. The results that are being obtained are promising, as they have made it possible to take northern cattle into the infected territory of the south.

$\$$ 266. Geographical distribution. In the United States the distribution of Texas Fever corresponds with that of the cattle tick (Boöphilus annulatus). This includes, with possibly a few small exceptional areas, that portion of the country south of the "Texas fever line" which is shown by a red line on the accompanying map but which is changing constantly by virtue of the spread or elimination of the tick. It lias been identified with the tick fever of Australia which has become a source of great loss to the cattle industry of that country. Lignières has identified the disease in South America (Argentine Republic). It is also reported to be identical with a nalady affecting cattle along the Danube river, in the Balkan 
provinces and in South Africa (Rhodesia Rotwasser*). It is restricted, however, to those countries where the climate is not sufficiently severe to destroy the cattle tick during the winter season and where the animals are constantly infected. Cattle (genus $B o s$ ) are the only animals which suffer from it.

$\$ 267$. Etiology. Texas fever is caused by a microörganism belonging to the protozoa and named by Smith, the discoverer, Pyrosoma bigeminum. $\dagger \quad$ It is generally recognized

*The Rhodesian redwater or East African coast fever is according to Stockman's report a very different disease from the tick fever in America. The conclusions from Stockman's report are as follows :

I. That the disease is caused by a special blood parasite-a piroplasma.

2. That it is a disease peculiar to bovine animals.

3. That it is only indirectly contagious; that is to say, a sick animal will not infect another susceptible animal by contact, however intimate, or by any of the excretions or fluids of its body, as in the case of rinderpest and like diseases.

4. That the indirect agents of infections are the nymphal and adult stages of the brown tick (Rhisicephalus Appendiculatus) and the black tick (R. Simus?). The former however is the more important factor.

5. That only those ticks which in one of their intermediate stages have sucked on affected animals are capable of transmitting the disease to other oxen.

6. That the infecting agent does not pass through the egg of the tick to the second generation, as was at first thought probable, by reasoning from analogy with what takes place in the blue tick in case of Texas fever.

7. That the brown and black ticks existed in certain parts of the Transvaal long before the disease was imported and that the said ticks only become virulent after sucking sick animals recently introduced. These species of ticks exist to-day on many farms that are perfectly clean, and which will remain clean as long as sick animals are kept off them.

8. That the blue tick is not a carrier of the disease.

9. That the proportion of recoveries from the disease is five per cent. at the very most.

tThe genus of the parasite has been changed to Piroplasma by Patton, to Apiosoma by Wandelleck, to Aambosporidies by Bonome, and Porteus virulentissimus by Perroncito. Starcovici has named the organism described by Babes as Hematococcus, Babesia bigeminum bovis. 


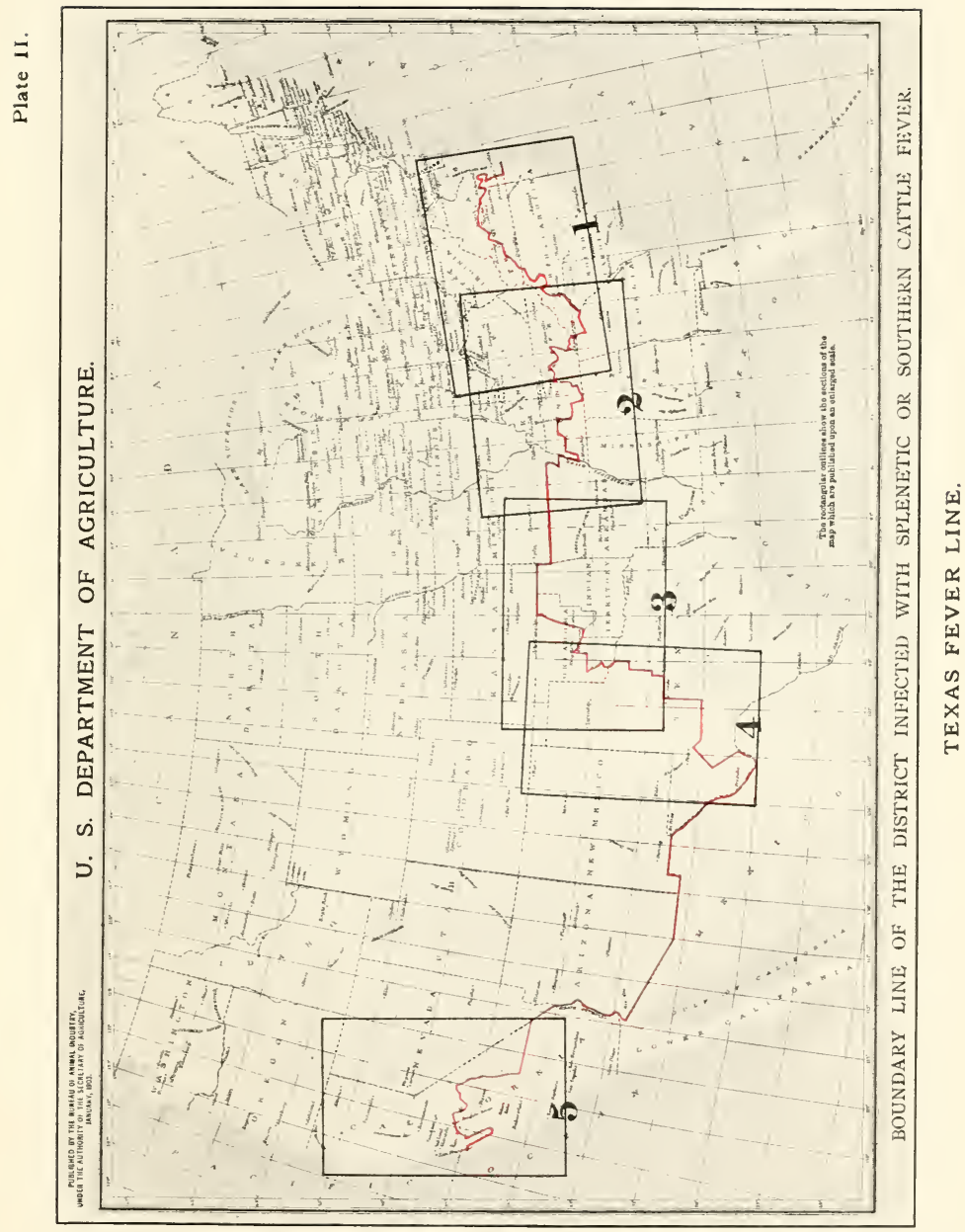



that Piroplasma is the proper generic term and this is used by writers on protozoa.

If Texas fever in America and hemoglobinuria in Roumania are identical, Babes was the first to call attention to the existence of this intraglobnlar
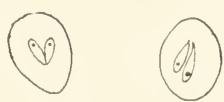

FIG. 89. Piroplasma bigeminum in red blood corpuscles.

parasite. It seems that Dr. Stiles, in 1867 , observed this organism but failed to recognize its significance. It is found in the blood in cases of Texas fever and it also exists in the blood of immune animals in the tick infested districts. The life history of this parasite is not determined. In the blood of the diseased animals they appear in the instained, fresh preparation, as minute or larger bright bodies which may be from 0.5 to $4.0 \mu$ in diameter according to the form of the disease. In the acute types of the disease certain of the red corpuscles contain pale or brighter pyriform shaped bodies. One end of each body is broad and rounded, the other tapering and pointed. Usually there are two of these bodies, both of the same size, in a corpuscle. More rarely there is but one, although four are occasionally observed (Fig. 9I). When two are present the tapering ends approach each other and usually they are joined while the other ends may point in any direction. Several forms have been noted varying from a round to a pyramidal outline. The small and often the larger bodies have been

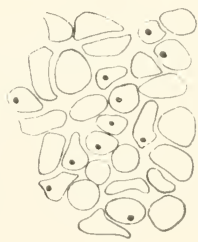

Fig. 90. Coccus form of Piroplasma bigeminum. observed to change their position within the red corpuscle. Smith has noted that the ameboid bodies observed were apparently single within the corpuscle. In dried and heated cover-glass preparations stained with alkaline methylene blue, these parasites are distinctly colored. They are also stained with carbol fuchsin and with hemo- 
toxylin. As a rule they stain more deeply in preparations made from internal organs than they do in those from the living blood.

In the capillaries of the congested organs, the blood cor-

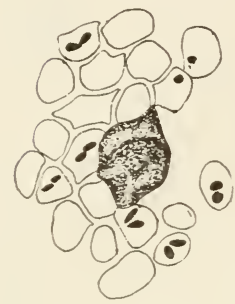

Fig, 9I. Blood from kidney shou'ing parasites of Teras fever (Smith). puscles contain many more parasites. Smith has noted in one case from 2 to 3 per cent of infected corpuscles in the circulating blood but in corer-glass preparations made at the autopsy quite different results were obtained. In those from the skeletal muscles, blood of the right heart, and blood from the bone marrow (sixth rib) very few infected corpuscles were found; in the blood from the left heart and lung tissue from 2 to 3 per cent of infected corpuscles; in the spleen 5 per cent; in the liver and kidney tissue from 10 to 20 per cent; and in the hyperemic fringes of the omentum and the heart muscle 50 per cent of the corpuscles were infected. In other cases the blood corpuscles in the capillaries were more and in still others less extensively infected. In the living blood the parasites were pyriform, but in the post-mortem specimens they were more nearly round. In the mild type of the disease from 5 to 50 per cent of the red corpuscles in the circ11lation are infected for a period of from oue to five weeks. The parasite is round (coccus form). In the fresh preparations it is seldom seen : rarely it can be detected as a pale spot about

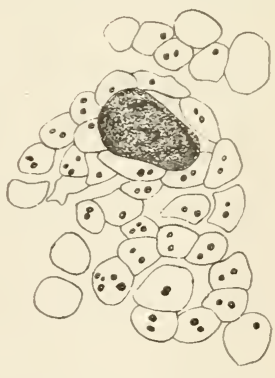

FIG. 92. Cover-glass prep aration from kidney. Corpuscles showing Piroplasma, coccus form (Smith). $0.5 \mu$ in diameter at the periphery of the corpuscle. In stained (alkaline methylene blue) preparations, the parasites appear as round coccus-like bodies from 
0.2 to $0.5 \mu$ in diameter. They are situated within the corpuscle on its border. As a rule only one is found in a corpuscle. Sometines a division was evident separating the parasite into two parts. They must be differentiated from somewhat similar looking bright bodies which are seen in the corpuscles of healthy blood during different seasons of the year.

Concerning the life history of this parasite, Smith considered the intraglobular stage hypothetically the swarming stage, which precedes the peripheral coccus-like bodies and the pyriform and spindle shaped bodies which develop from the divided coccus-like peripheral forms. The free bodies are the parasites set free after

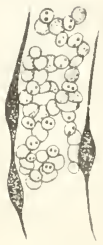

Fic.93. Blood in capillary of heart showing Piroplasma (Smith). they have reached the preceding stage by disintegration of the infected corpuscles. They are most commonly found in the kidney. The reproductive stage has not been recognized.

S 268. Infection. Although practical stockmen had long looked upon the tick as a source of infection, it remained for Smith and Kilborne to experimentally demonstrate that so far as known the cattle tick (Boöphi-

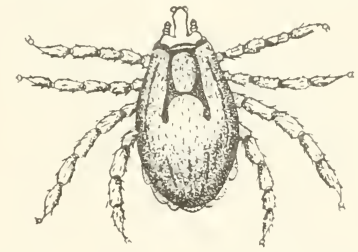

Fig. 94. Sermally mature male tick after the last moult, dorsal view (Smith).

lus annulatus)* is the sole carrier of the parasite. It was pointed out by them that when southern cattle were freed

*This tick was first described by C.V. Riley in I 868 as Irodes bor'is. Later, Cooper Curtice investigated this parasite (Biology of the Cattle Tick, Journ. Comp. Med. and Veterinary Archives, July, I89I, Jan., I892) and gave it the generic name of Boöphilus (ox loving). This seems to be the only genus of cattle ticks which transmits the parasite of Texas fever. Recently Karsch's genus Margaropus has been proposed as the correct name instead of Boöphilus. 
from ticks they would not when kept together in swall enclosures transfer the disease to susceptible animals, but that when susceptible cattle become infested with the ticks either by grazing in infested pastures or by having placed upon them young ticks hatched in the laboratory the disease appeared.

The infection of northern cattle with Texas fever by

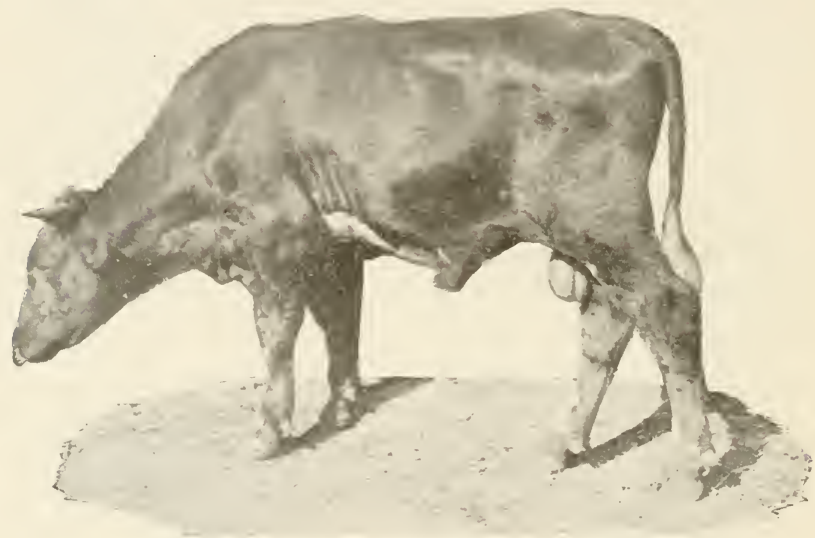

FIG. 95. Photograph of animal sick with Teras fever. (Photographed by Connaway').

southern animals consists therefore in first infesting them with the cattle tick.* The number of ticks necessary to carry the disease is small so that frequently they will not be observed unless the sick animals are carefully examined. The life

*It is interesting to add the results of an experiment conducted by Dr. Cooper Curtice in the Bureat of Animal Industry which shows the necessity of the tick in inoculating cattle. In a tick infested district in the south, a field was cleared of ticks by fencing and keeping cattle off for a year. Susceptible northern cattle were transported to and placed in this field where they thrived for a season. The second year they were placed in a second cleared pasture where they kept well for another year. The third year they were placed in a tick infested pasture where they died promptly of Texas fever. 
cycle of the tick will, therefore, explain the variation in the time elapsing between the exposure of northern to southern cattle and the appearance of the disease. Starting with tick infested animals placed with native cattle in a northern pasture the adult female ticks drop to the ground almost daily, so that the following life cycle may be assumed to begin at once.

r. Adult ticks drop to the ground in from $r$ to 3 days after the infested cattle are placed in the field.

2. Adult ticks lay their eggs in about 7 days after dropping to the ground.

3. Eggs are hatched in about 20 days after they are laid.

4. Young ticks crawl upon cattle from I to several days after they are hatched.

5. In about ten days from the time the young ticks crawl upon the susceptible cattle the rise of temperature appears.

The length of time that must elapse (period of incubation) from the

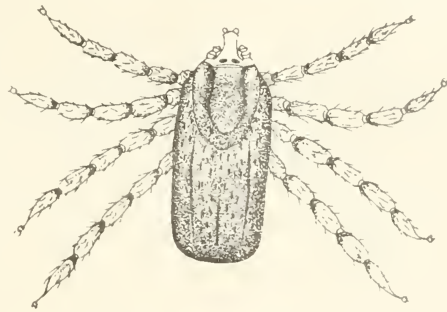

Fig. 96. Sexually mature female after the last moult, dorsal view (Smith).

exposure of susceptible cattle to the development of the disease depends on whether or not the whole life cycle of the tick must be passed or part of it has already gone by. If susceptible animals are placed in a pasture where the young ticks are just ready to crawl upon them the infection of the cattle is accomplished at once and the high fever appears in aboit ten days, practically the minimum time. It has been experimentally demonstrated that the young ticks are able to travel for a considerable distance in a pasture. In pastures where tick infested cattle are grazing, young ticks are very

* Mohler states that the time required for the hatching varies from I3 days to six weeks, depending upon temperature, moisture, soil, etc. He states further that the eggs may remain dormant for several months. 
liable to be on the ground continuously. In estimating the time to elapse after the exposure to the tick infested field, before the disease will appear, it is necessary, therefore, to determine the exact stage in the life cycle of the ticks at the time when the animals come in contact with them.

Small quantities of the blood from immunized cattle in the tick infested district, when injected into susceptible animals either intravenously or beneath the skin, will produce the disease. While this mode of infection rarely if ever occurs in the natural order_of events, it may happen that in

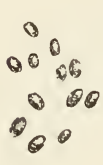

FIG. 97. Eggs and young tick, just hatched (Smith). case of certain operations bits of blood may be carried directly from a southern to a northern a nimal th us inoculating the latter with the disease.

In the fall of

I 898 two cases occurred in the practice of Dr. Ambler of Chatham, N. Y. The owner had his animals dehormed in December and soon afterward two fatal cases of Texas fever developed. The Piroplasma and the characteristic lesions were present. Inquiry revealed the interesting fact that the two animals which sickened and died were dehorned immediately after two imported southern cattle. The owner was not aware of the fact at the time that these were southern bred cattle, as he had bought then of a dealer in Vermont. More recently another case of this disease produced in the same way has been reported.

$\$ 269$. Symptoms. In the acute type of the disease which occurs during the hot summer months, the onset is sudden and usually all animals exposed to the same infection together come down at the same time. The first indication of the disease is a rise of temperature, at first higher in the after- 
noon than morning, but this oscillation is minimized later in the course of the disease when the temperature remains high. The temperature rarely rises above $107^{\circ} \mathrm{F}$. With a clinical thermometer the temperature can be detected two or more days before there are other symptoms. The respiration may rise to between 60 and roo and the pulse may range between 80 and I ro per minute. Iate in the disease there may be hemoglobinuria. Smith and Kilborne found it in 33 out of +6 fatal cases in which urine was found in the bladder. The passing of the colored urine before death was noted in but four of their cases. In one of these which showed hemoglobinuria four days before death, the urine in the bladder was clear at post-mortem. As this condition seems to depend upon the rapidity of the destruction of the red blood corpuscles, a slow disintegration may enable other organs to dispose of the coloring matter, while in rapid destruction of the blood much of it may be thrown into the urine. The urine contains small quantities of albumin. At first the specific gravity may be high but later it ranges from Iolo to 1020 and fails to effervesce with acids. The color varies according to the quantity of hemoglobin. As a rule there is marked constipation during the high fever. There is loss of appetite and nsually cessation of rumination with the high fever. The blood is thin and pale. The high temperature, hemoglobinuria and thinness of the blood are quite diagnostic symptoms of the acute type.

The course of the disease may vary, but the continuous high temperature does not usually last for more than ten days. Death often intervenes in from five to eight days. In the mild, nonfatal or chronic type which was first pointed out by Smith and Kilbourne and which occurs in the late summer or autumn, the general symptoms are similar to those of the acute type except they are not so severe and are prolonged for a greater length of time. The parasite is of the spherical or coccus form. The general symptoms are not manifested unless the temperature goes above $103^{\circ} \mathrm{F}$. Hemoglobinuria is not observed in this type. Cattle which have passed through an acute type owing to the heated season may have a relapse in 
the form of a mild type in the fall. The essential difference between the two types is found in the different stages of the parasite circulating in the blood. Unless the temperature is taken and the blood carefully examined, mild types of Texas fever would be either overlooked or mistaken for any one of a variety of disorders common among cattle.

$\$ 270$. Morbid anatomy. Cattle which die of 'Texas fever undergo post-mortem changes very rapidly. For this reasou the description of lesions made some hours after death may be misleading.

Externally the animal presents nothing abnormal or characteristic of the disease. Rarely dried bits of blood may be found and also some small slightly elevated areas of a bluish color. The skin between the thighs, upon and about the udder and possibly elsewhere may have cattle ticks attached. It is important under ordinary circumstances to look for this parasite. The subcutaneous tissue may be more or less yellow in color. Edema of the subcutis over the ventral portion of the body has been observed. The muscles are usually normal in appearance although frequently they are pale.

Very slight if any lesions have been recorded as occurring in the central nervous system and lungs. Blood extravasations usually occur beneath the skin and endocardium, especially of the left ventricle. On the external surface the petechiae occur for the greater part along the intraventricular groove near the base. The capillaries of the heart muscle are packed with corpuscles. Parenchymatous and fatty degeneration of the muscular fibers sometimes exists. The right ventricle is distended with blood either fluid or clotted and the left one firmly contracted.

In the abdominal cavity there are frequent edematous areas about the kidneys and in the portal regions between the duodenum and liver. The omentum is often sprinkled with peculiar hyperemic patches consisting of delicate shreds of vascular tissue. This condition, however, is not characteristic of Texas fever. 
['sually the most conspicuous changes are in the spleen. This organ is much enlarged and increased from two to four times its normal weight. The normal markings, Malpighian bodies and trabeculae, are hidden in the dark brownish-red, glistening pulp which distends the capsule. The pulp may be firm or it may be in a semi-fluid condition so that it oozes out if the surface is cut. The enlargement and color of the spleen are due to an engorgement of red blood cells. There may also be present a greater or less number of large cells containing granules, red corpuscles or clumps of yellowish pigment. Free pigment is much more abundant than it is in healthy spleens.

The liver is extensively affected. It is enlarged, congested, edges rounded, the bile ducts more or less distended and the parenchyma is usually in a state of fatty degeneration. The color is paler than normal and usually the surface is somewhat mottled. On section the color of the cut surface is brownish-yellow or it may be mottled like the surface. The mottling is due to a discoloration owing to degeneration of a zone bordering the intralobular vein. This zone varies in width and its peculiar color seems to be due to a tendency to necrosis. It is characterized by parenchymatous degeneration and the loss of the nuclens. It may involve a third or more of the lobule. This portion stains very feebly or not at all. The explanation for the necrosis of the liver cells is suggested by Smith as being due to the plugging up of the ultimate bile canals with solid bile which may interfere in some way with the nutrition of the adjacent liver cells. The bile stasis he considers as a result of the breaking up in the capillaries of the liver of enormous numbers of infected corpuscles. This results in an abnormal fluid containing an excess of solids which the bile ducts are unable to carry away. When examined in fresh condition or in sections of tissue fixed in Miiller's fluid the engorgement of the bile canaliculi is seen. The bile stasis may occur over a portion or a whole of the lobule. The gall bladder contains usually an abnormal quantity of changed bile. It is thick and often semi-solid in con- 
sistency, holding in suspension many flocculi. It imparts a deep yellowish tinge to all articles coming in contact with it. Owing to the mucus which is present it is quite viscid.

The changes in the kilneys vary. If death occurs early they are usually enlarged and uniformly darker than normal throughout. The capillaries are distended with red corpuscles. Parenchymatous and fatty degenerations are not common, although occasionally present in the epithelium of the tubules. The pelvis is often sprinkled with ecchymoses.

The bladder may contain ecchymoses.

It is important to note that throughout the kidneys, liver and spleen pigment may be more or less abundant.

In the digestive tract the lesions of this disease consist largely of congestion of the mucosa especially in lines corresponding to the summits of the folds of the mucons membrane. It is more marked in the cecum and rectum than in the colon. The cecum and less often the rectum contain dry, hard fecal balls. In some cases in the intestines lesions are not observable. In the older writings much emphasis is placed on certain lesions, mostly nodular or abrasions, in the digestive tract. Smith has shown, however, that most of these are due to animal parasites and have 110 relation to Texas fever.

As already stated, Texas fever is a disease of the blood and consequently it is in this fluid that the most constant and morbid changes occur. They are characterized by the blood becoming thin and watery with a destruction of the red blood corpuscles. In some of the cases the loss of corpuscles is rapid and continuous until death or convalescence, while in others there is a marked oscillation between destruction and regeneration. In some animals the loss is not continuous, but the course of the disease is marked by the periods of rapid blood destruction and periods of rest, or, as it were, where the blood destruction was holding its own. These points are best illustrated from actinal cases, three of which are taken from the report by Smith and Kilborne. 
(No. 129)

Date. $\quad \begin{gathered}\text { No. of } \\ \text { Corpuscles. }\end{gathered}$
(No. 142)

Date.

No. of Corpuscles.
(No. 56 )

I) ite.

No. of Corpuscles. $\begin{array}{lr}\text { Aug. II, } & 6,125,000 \\ \text { I3, } & 7,171,000 \\ \text { 16, } & 5,370,000 \\ 27, & 3,310.000 \\ 29, & \text { I, 675,000 } \\ \text { 30, } & \text { Died S P.Mr }\end{array}$

First high A.m. temp. Aug. 24 .

$$
\begin{array}{rrrrr}
\text { Sept. 16, } & 6,890,000 & \text { Sept. } 20, & 6,844,000 \\
22, & 5,430,900 & 22, & 5,640,000 \\
24, & 4,562,000 & 29, & 2,307,0.0 \\
& 29, & 5,274,000 & \text { Oct. } 9, & 5,436,000 \\
\text { Oct. } 4, & 3,902,000 & 22, & 4,666,000 \\
& 8, & 5,983,000 & 25, & 2,754,000 \\
22, & 4,333,000 & 30, & 2,720,000 \\
\text { Nov. } 4, & 5,586,000 & \text { Nov. } 6, & 2,344,000 \\
& & 8, & 1,984,000 \\
& & & 13, & 1,183,000
\end{array}
$$

As evidence of the diminution of the number of corpuscles within the body these authors point ( 1 ) to the loss of hemoglobin through the kidneys, (2) to the overproduction of bile which is abnormal in the abundance of pigment and (3) to the actual observation of their destruction by the micro-parasite under the microscope.

The regeneration of blood corpuscles is indicated perhaps by the count, but more surely by the forms of the corpuscles themselves. The abnormal forms are the very large corpuscles, "punctate" forms and lastly the diffuse stained or "tinted" forms and the erythroblasts. The first of these may appear when the blood count reaches 3.000,000 and the other forms when it is still lower. These various forms, however, are probably embryonic or immature corpuscles, which are forced prematurely into the circulation by the blood producing organs in trying to overcome the rapid destruction of corpuscles by the parasite. The action of the disease upon the leucocytes or the defensive activities of the white corpuscles in combating the parasite of Texas fever have not been determiued. In the work thus far performed and reported, they have received little attention. Suffice it to say that they have not been in evidence in this conflict and probably take little or no part in the morbid changes of Texas fever.

$\$ 271$. Differential diagnosis. Texas fever is easily 
differentiated from other disorders of infectious diseases by the presence of its specific parasite.

In the absence of a suitable microscope the differentiation can in most cases be made from the character of the lesions, the history of the animals, the presence of the cattle tick and the course of the disease. The lesions are not simulated by any other disease of cattle, although the enlarged, dark spleen may suggest anthrax and in a hasty diagnosis the two may be contused. From the fact that all animals exposed together usually come down with the disease together poisoning may be suggested, but here again a study of the symptoms and lesions are sufficient to eliminate toxic disorders.

$\$ 272$. Prevention. The discovery of the specific cause of Texas fever and of the cattle tick as the common means of its transmission has reduced the preventive measures to a direct warfare against the tick. The National government has determined the territory in which the tick naturally exists and from which cattle, on account of the parasite, cannot be shipped to uninfected districts, except under certain very restricted conditions. (See regulations for transmission of cattle, p. 618 , Report of the Bureau of Animal Industry for 1898). Likewrse susceptible northern cattle cannot be transported to the infested districts (south of Texas fever line) unless they can be placed in fieldis that have been freed from ticks. The elimination of the disease depends therefore upon the elimination of Boöphilus annulatus. Recently the government has undertaken to eliminate the ticks. Thus far the reports are most encouraging. There seems to be no reason why in the dairy districts of the South their eradication cannot be accomplished.

$\$$ 273. Immunizing susceptible cattle. A number of investigations have been undertaken directed toward the development of methods for immunizing northern cattle against Texas fever in order to enable the shipment, especially of breeding stock, into the South. In I895, the writer in conjunction with Schroeder, began an immunizing experiment which was continued and reported by Schroeder in 1898 . 
Young animals were selected and injected with blood taken directly from the jugular veins of southern animals. The injections were made in the fall and winter and in the spring the animals were placed in a highly infected field at Manchester, Va., where they remained for the summer. Inning this time they were under the inmediate observation of Curtice, who made a careful study of the blood, temperature and extent of tick invasion. The results of this experiment are shown in Schroeder's tabulation, which is appended. The animals were again exposed the following season without the development of Texas fever.

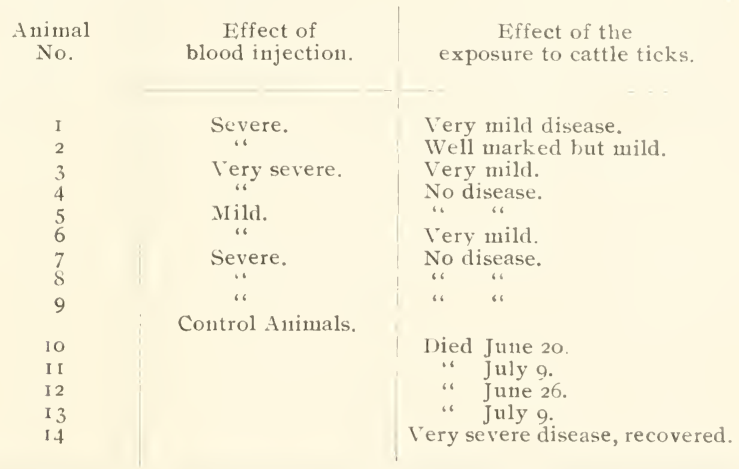

The inoculation disease appears in from eight to ten days after the injection of the blood. It lasts from one to two weeks. The symptoms are occasionally of a still shorter duration, but the altered condition of the blood persists in some cases for a much longer period.

Dalrymple, Dodson and Morgan, of the Louisiana Experiment Station, conducted experiments along this line. They showed that inmunity against a fatal attack of Texas fever can be conferred on susceptible cattle by inoculation with the blood of a native Southern animal or one which has recently been rendered immune. 
The Experiment Station of that state offers to immunize (free of charge) northern cattle, if they are shipped to the state, for its stock raisers.

In Missouri, Comnaway has immunized a few animals with the blood serum from immune (southern) cattle. In Mississippi, Robert has tried the serum for both prevention and treatment with somewhat similar results. In Virginia and Oklahoma the disease and its prevention have been studied. In Texas, Francis is immunizing cattle with most excellent results. He has pointed out the value of immunizing young ( 2 to 6 weeks old) calves by artificially infesting with ticks. In Australia the problem of immunizing cattle against the effects of the spreading of the cattle tick in order to save their stock from "tick fever" has become a matter of serious consideration. Certain European writers claim that immunity can not be permanently induced by artificial injections. Schroeder has shown that the parasite remains virulent in the blood of naturally immunized cattle for from io to 12 years.

The very limited knowledge of the life cycle of the parasite of Texas fever precludes a satisfactory explanation of the modus operandi in the production of immunity by these various procedures. On this point there is need for much extended investigation.

REFERENCES.

I. BABES. Die Aetiologie der seuchenhaften Haemoglobinurie des Rindes. V'irchow's Archiv, Jan. is89, S. 8I.

2. Connaway. Texas fever or acclimation fever. Bulletin No. 37. Mo. State Board of Agriculture, 1897 .

3. DALRYMPlE, MORGan AND DODSON. Texas or southern cattle fever. Bulletin 51. Louisiana Agric. Expt. Station, 1898.

4. Dinwiddie. Some Texas fever experiments. Bulletin No. 20 Ark. Agric. Exper. Station, 1893 .

5. Francis and Connaway. Texas fever. Bulletin No. 35. Texas Agric. Expt. Station, I899.

6. GaMGEE, DODGe, BILlings AND CuRTis. Diseases of cattle in the United States. Report of the Commissioner of Agriculture, II ashington, D. C., 1871 . 
7. Hughrs. The fight against Texas Fever. A review of the work being attempted in the sonth for the control and erarication of the disease. Am. Vet. Review, Vol. XXIX (1906), p. I309.

S. Hunt And Colmixs. Report on tick fever. Brisbane. (2neensland, Australia, IS99.

9. Kосн. Vorlaufiger Bericht über das Rhodesische Rotwasser oder "Afrikanische Kustenfieber." Archiz'. für a'iss. u. praktische Tierheilkund', Bd. XXX (1904) S. 281 .

10. LEwis. Texas fever. Bulletin No.39. Oklahoma Agric. E.rper. Station, 1899 .

11. LigxitiRes. La "Tristeza " ou Malarie Bovine dans la République Argentina. Buenos Aires, i8go. (Full bibliography).

12. MAvo. Texas fever. Bulletin No.6\%. Kan. Arric. Exper. Station, I 897

I3. MCCLLLCH. The prevention of Texas fever and the amended laws controlling contagious disease. bulletin No. 107. Virginia Agric. Erper. Station, rS99.

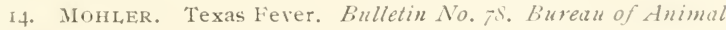
Iudustry, 1905.

15. Nilfes. Splenetic or Texas cattle fever. Bulletin No. 6I, I'irginia Agric. Exper. Station, IS96.

16. NörGaARD. Dipping cattle for the destruction of ticks. Annual Report, Burean of Animat Industry, 1\$95-6, p. Io9.

17. Paguin. Texas Fever. Bulletin No. Ir. Mo. Agric. E.rper. Station, ISgo.

1S. SalmoN, Contagious diseases of animals. Special riport No. 22, IV ashington, D. C.

19. Salmox. Report Commissioner of Agriculture. ISS1-2.

20. Sicmox. Annual Riports, Bureau of Animal Industry. I $88.4-5$.

21. SCHROEDER. Inoculation to produce immunity from Texas fever in Norther11 cattle. Ibid. I8g8, p. 273.

22. Schroener. Notes on cattle tick and Texas fever. Annual Report of the Bureau of Animal Industry, 1905. p. 49.

23. Schroeder Axp CoTros. Persistence of Texas fever organism in blood of southern cattle. Ibid., p. 7 I.

24. Smith. Preliminary observations on the microörganisu of Texas fever. The Hedical New's. Dec. 21, ISsg.

25. SMITH AND KilßorNk. Texas fever. Bulletin No. I, Jinreau of Animal Industry, U. S. Dept. Agriculture, ris93. 
26. SMith And Kilborne. Annual Report, Bureau of Animal Industry, I89I-2. (Issued I893).

27. Stiles. Report New York State Boart of Health, i868.

28. Stockman. Some points to be considered in connection with Rhodesian redwater. Jour. Comp. Path. and Thera., Vol. XVIII (1905), p. 64.

29. THEILER AND STOCKMAN. Some observations and experiments in connection with Tropical bovine piroplasmosis (East-coastfever or Rhodesian Redwater). Jour. Comp. Path. and Thera., Vol. XVII (I904), p. I93.

\section{ICTERO-HEMATURIA IN SHEEP}

Synonyms. Carceag; hemaglobinuria in sheep; Piroplasmosis in sheep.

274. Characterization. This is an enzoötic disease characterized by a rise of temperature with chill, and later icterus and marked changes in the blood due to a specific parasite invading its red blood corpuscles.

S 275. History. In 1892 , Babes pointed out the constant presence of an intraglobular parasite in the blood of sheep suffering from an enzoötic hemoglobinuria in Roumania. Bonome studied the same affection in Italy in 1895 . Williams described this disease in Montana in the same year. He did not, however, report the finding of the parasite or record its description.

S 276. Geographical distributions. The piroplasma infection of sheep has been found in several places in Europe. Its existence in the United States is in question, although the description given by Williams of the disease he found suggests very strongly a Piroplasma origin.

$\$ 277$. Etiology. Piroplasma ovis is the specific cause. This organism is very closely related to Piroplasma bigeminum of Texas fever.

$\$ 278$. Symptoms. At the beginning the syinptoms 
are said to be severe. There is a rise of temperature usually with a chill. After one or two days icterus appears. The urine is occasionally of a reddish brown color, due to the presence of hemloglobin. Death is preceded by a collapse in which the temperature is subnormal. The duration of the disease is usually but a few days.

$\leqslant$ 279. Morbid anatomy. The subcutaneous tissues are infiltrated with a yellowish colored liquid. The blood is thin and watery. The nuscles are pale and edematous. The mucous membranes of the pharynx and intestines are often hemorrhagic. The liver is small, soft and yellowish in color. The spleen is usually slightly enlarged. The kidneys are soft and friable. There usually occurs a parenchymatous nephritis.

$\$ 280$. Differential diagnosis. This disease is positively diagnosed by finding the piroplasma in the blood. It is to be differentiated from anthrax, in which the specific organ ism is readily found in the blood and organs.

REFE,RENCES

I. BABEs. L'étiologie d'une enzootie des moutons dénommée Carceag en Roumanie. Comp. $R$. de l'Aiad. des sciences, Vol. CXV (1892), p. 359 .

2. Boxome. Uber parasitäre Ictero-Haematurie der Schafe, Ein Beitrag zum Studium der Amöbo-Sporidien. Archia' für. path. Anatomie, Bd. CXXXIX, S. I.

3. WILLIAMS. The parasitic Ictero-Haematuria of sheep. Bnlletin No. 8, Won. Agric. Exp. Station, 1'95, also Amer. I'et. Revieu', 1897 , p. 377 .

EQUINE MALARIA

Synonyms. Piroplasmosis in horses; South African horse sickness ; "Biliary fever."

$\$ 28 \mathrm{r}$. Characterization. This affection of horses is characterized by a high temperature and a yellowish tint of the mucous membranes. The spleen is enlarged and the blood contains a Piroplasma equi. 
5 282. History. The disease appears to have been first described by Wiltshire in 1883 . Guglielmi discovered the parasite of this affection in 1899 , and Rickmann found it in a large number of horses that died of "horse sickness." A good description of this affection was given by Theiler in Igor.

283. Geographical distribution. This disease appears to be very largely restricted to Southern Africa and Europe. The disease known as malarial fever in the United States has not been demonstrated to be due to a piroplasma. Peters describes this disease in horses in the IVest but he did not find its specific parasite.

$\$$ 284. Etiology. Laveran who has studied this affection states that its cause is Piroplasma equi. It is closely related to $P$. bigeminum. It measures from 0.5 to $2.0 \mu$. During the invasion and multiplication of the parasites there is a high temperature. In the blood corpuscle the parasite is single, in pairs or in rosette form. The disease was believed not to be transmitted directly with the blood containing the parasite. Theiler, however, succeeded in proving that equine piroplasmosis is inoculable with the blood of immune horses into susceptible ones. The natural method of infection is not known, but it is believed by many to be by means of a tick.

Theiler's conclusions relative to the transmissibility of this parasite are as follows:

(I) The piroplasma found in the mule and the donkey is identical with the piroplasma equi first found in the horse.

(2) The disease caused by this piroplasma is inoculable with blood of imnune animals into susceptible ones belonging to the domesticated species of the genus equus.

(3) The horse shows the greatest susceptibility for this piroplasma; the donkey is less, and the mule the least, susceptible.

(4) The possibility of a practicable inoculation against the piroplasmosis stands in the reverse order of the susceptibility. The mule may be safely inoculated with immune 
blood of any of the three respective equines; the immune horse-blood produces the severest reaction, the immune muleblood causes little reaction, and so does the immune donkeyblood.

The period of incubation is stated by 'Theiler to be 21 days.

\$285. Symptoms. An acute and chronic type are recognized. The acute type begins with a high temperature. There is jaundice, appearing first in the eyes. Death follows rapidly, often at the time of the maximum temperature. In the chronic cases the symptoms are prolonged.

The duration of the disease is from a few to several days.

$\S 286$. Morbid anatomy. The animal is emaciated. The blood is said to be thin and watery. The conjunctival subcutaneous tissue is of a yellowish color. The muscles are of a reddish brown. All of the tissues are anemic. The spleen is very large. Theiler has found the spleen to be twice the normal size. The lymphatic glands, especially those of the spleen, liver and kidneys, are tumefied and often hemorrhagic. The liver is yellowish in color and engorged with blood. The bile capillaries are distended. The mucosa of the digestive tract is pale, or sprinkled with reddish areas. The glands in the thorax are enlarged and infiltrated with a gelatinous substance. Occasionally there are ecchymoses on the lungs and heart. The heart muscle, pericardium and valves are frequently infiltrated with a gelatinous substance. The blood clots are soft. The exuded serum is of a yellowish brown color. The parasites are found in all parts. Death usually follows an acute attack.

$\$ 287$. Differential diagnosis. Equine malaria is to be differentiated from (I) Brustseuche, (2) Nagana, and (3) anthrax. In the last two named diseases the finding of the specific organisms will determine the diagnosis. The finding of the piroplasma will distinguish it from Brustscuchc. 
I. Bowhill. Equine piroplasmosis or "biliary fever." The Jour. of Hygiene, Vol. V (1905), p. 7.

2. DALE. Piroplasmosis of the donkey. Jour. of Comp. Path. and Thera., Vol. XVI (I903), p. 3I2.

3. Gugliemin. Un caso di malaria del cavallo. Clinica Veterinaria, I899, p. 220.

4. LAVERAN. Contributions à l'étude de Piroplasma equi. Comp. $R$. de la Société de biologie, igor.

5. PeTERs. Malaria of the horse. Nebraska Agric. Exp. Station, Press Bulletin 22.

6. Pricoro. Beitrag zur Piroplasmose des Pferdes. La Clin. Vet., I906, p. 529.

7. Rickmaxi. Südafrikanische Pferdesterbe. Berliner thicrarztl. Wochenschrift, I902, S. 4 .

8. Theiler. Die Pferde-malaria. Thise de Berne. SchweizerArchiv für Thierheilkunde, 1901, S. 253.

9. THEILER. Further notes on Piroplasmosis of the horse, mule and donkey. Jour. Comp. Path. and Thera., Vol. XVIII (1905), p. 229 .

\section{CANINE MALARIA}

Symonyms. Piroplasmosis of dogs; malignaut malarial jaundice; malignant jaundice in the dog.

$\$$ 288. Characterization. This disease is characterized by a high temperature, rapid course, jaundice and anemia. These are due to the invasion of the blood with Piroplasma canis.

\$289. History. In I895, Piana and Galli-V'alerio found the piroplasma in the blood of dogs. In r 899, Hutcheon described a malarial fever in dogs that could be transmitted by inoculation subcutaneously with the infected material. Koch found the disease in Africa, and Celli mentions a modified form of the affection in Lombardy. In I9or, Nocard and Almy reported several cases of piroplasmosis in dogs presented at the clinic of the Alfort Veterinary School. Robertson 
described the disease under the name of malignant jaundice and pointed out its transmission by the dog tick (Hacmaphysalis leachi). In 1902, Nocard and Motas reported an experimental study of the specific parasite. More recently Nuttall, and Grahan-Smith lave investigated this affection.

$\$$ 290. Geographical distribution. This disease has been found in several places in Africa, in Italy and in Europe.

\$ 291. Etiology. The Piroplasma canis is the cause of this affection. Like Piroplasma bigeminum it appears in two forms, round and pear-shaped. They nearly always occur in the red blood corpuscles. It varies in its morphology. According to Marchoux Piroplasma canis in France is larger than Piroplasma bigeminum and single parasites occur more frequently. They vary in size from 2 to $4 \mu$. At the beginning of the disease usually single large round forms appear. It is said by Nocard and Motas not to be pathogenic for other species of animals. The parasite is said to be transmitted by means of certain insects. Lounsbury has demonstrated that Pulex serra liceps, which is very abundant in certain localities, piays a rôle in its transmission. In Italy Piroplasma canis is supposed to be transmitted by Ixodes reduitus. In France it is supposed to be conveyed by Dermacentor reticulatus. In South Africa it is conveyed by Hacmaphysalis leachi. The parasite appears in the blood in from two to four days after artificial infection.

Graham-Smith did not find the parasites in films from the peripheral circulation when stained by L,eishman's method until several days after infection. The earliest day on which they appeared was the sixth day and the latest the thirtysixth day. In most cases they were observed between the eighth and twelftl days after infection. In a few cases he worked ont the percentage of red blood corpuscles that were infected. He found that it varied from .3 to $1.4 \%$. Free parasites were seldom encountered in the earlier stages but later they became more numerous. The day before death he found one free parasite to 23 infected corpuscles, and the day 
of death the free parasites were still more numerous. $\mathrm{He}$ found little evidence of phagocytosis in the cases examined. Nucleated red corpuscles appeared in films from three dogs the day before death, and in three other dogs they appeared six days before death. Blood pigment was present in nearly all samples of urine.

The period of incubation after direct inoculation is about three days.

$\$$ 292. Symptoms. Two distinct forms have been described: the acute which is nearly always fatal, and the chronic which often terminates in recovery. In the acute form the dog is dull, drowsy and refuses food. It may be thirsty. The temperature is high $\left(\mathrm{IO}^{\circ}{ }^{\circ} \mathrm{F}\right.$.) but after two or three days it drops to subnormal. Icterus is not constant and the hemoglobinuria is not always present. The blood is pale and it coagulates slowly. The red corpuscles are reduced to 2,000,000 per cubic millimeter or below. The polynuclear leucocytes are increased in number. Death nearly always occurs in from three to six days.

In the chronic cases the fever remains high for from 36 to 48 hours, when it returns to nornial. The anemia is the most constant symptom. The mucosa become pale and the appetite is poor. The symptoms persist for from three to six weeks. Recovery is the rule.

$\$$ 293. Morbid anatomy. The mucous membranes are pale and the subcutaneous tissue and fat more yellow than normal. The spleen is 3 or 4 times the normal size. The liver is engorged with blood which is heavily charged with parasites. The gall bladder is distended with greenish bile. The mucosa of the digestive tract are slightly, if at all, changed. The kidneys are congested, often sprinkled with petechiæe or ecchymoses. The capsule is easily removed. The parasites are found in the blood in the early stages of the disease. They are more numerous in the capillaries than in the heart blood.

The lungs are in some cases edematous. In all young 
animals one finds edema of the lungs with blood stained mucoserous substance in the trachea and bronchioles. The lymphatic glands are rarely if ever altered in appearance.

The central nervous system presents nothing of note, except a slight congestion of the meninges.

The histological study of the lesions shows that the tissue changes start from greatly engorged capillaries. In these vessels containing masses of blood, a large part of the red corpuscles contains the parasite.

The histological examination of the organs when hardened in Mïller's fluid shows, according to Graham-Smith, the capillaries of the alveoli of the lungs to be dilated and in some instances a proliferation of the lining cells some of which are seen lying free in the air cells. In other alveoli the process is more advanced and proliferated cells, lencocytes, and in some cases red corpuscles are present in them. The lumen of many of the bronchioles frequently contains desquamated epithelium, leucocytes and mucus. There is no evidence of any increase in the connective tissue. No pigmentary or fatty changes were observed in the heart or skeletal muscles. The liver showed the most marked changes. The central vein of the lobule and the capillaries lying between the liver cells were dilated. The protoplasm of the liver cells stains feebly but the nuclei take the stain fairly well. The cells are distorted between the dilated blood ressels and in many cases almost destroyed, especially those in the central zone. The vessels in the interlobular spaces are dilated but the bile ducts are normal. There is no increase of fibrous tissue and the capsule is normal. The capillaries contain a large number of red blood corpuscles and the proportion of leucocytes is high. The latter are also very numerous in the larger vessels. In these vessels abont $10^{\circ} 0$ of the red corpuscles are infected. The parasites usually appear in small groups in the cells. The proportion of lencocytes to red corpuscles is about I to Io. In the capillaries from 23 to $53 \%$ of the red corpuscles are infected and in some instances the proportion of leucocytes to red corpuscles is as high as I to 3. In but one dog did he find fatty changes. The smear 
preparations showed that $98.9 \%$ of all infected corpuscles contained one to four parasites and the balance more than four parasites. Free parasites were found in the proportion of $\mathrm{I}$ to $2 \mathrm{I} / 2$ infected corpuscles. The spleen pulp contains in most cases a large quantity of blood and the vessesl in the trabeculae are dilated and contain numerous leucocytes. The proportion of infected corpuscles in the pulp is small ( 3 to $12 \%$ ) but in the small trabecular veins it is high $(48 \%)$. In the kidney there were no changes that were constantly present except dilatation of the blood vessels. In some cases about $46 \%$ of the red corpuscles in the vessels of the glomeruli were infected.

The duration in fatal cases is from 3 to 6 days.

294. Differential diagnosis. The positive diagnosis is made by finding the parasite in the red blood corpuscles.

\section{REFERENCES}

1. GRAHAM-S̀nTH. Canine piroplasmosis. Morbid Anatomy. Jour. of Hygiene, Vol. V (rgo5), p. 250.

2. Hutchén. Malignant malarial fever of the dog. The Viterinary Journat, Vol. XLIX (iSg9), p. 39 S.

3. LotxsBuRY. Transmission of malignant jaundice. Agricul. tural Journal, Nov. 21, 190I.

4. Marchoux. Piroplasma canis che\% les chiens du sénégal. Comp. R. de la Société de biologie, 1900, p. 97.

5. Nocard ET AlmY. Uneobservation de piropiasmose canine. Bulletin de la Société cent. de méd. Vétér., IgOI, p. I92.

6. NoCARD ET MOTAS. Contribution à l'étude de la piroplasmose canine. Ann. de l'Inst. Pastent, 1902, p. 257.

7. NetTAll and Graham-Smith. Canine piroplasmosis, Jou: of Hygiene, Vol. V' (I905), p. 237.

8. Nutral, Canine piroplasmosis, Jour. of Hygiene, Vol. IV (I904), p. 2 Ig.

9. Piana ET Galli-VAlERio. Il moderno Zooiatro. 1895 , p. 165.

10. RoBERTSON. Malignant jaundice in the dog. The Jour. of Comp. Path. and Thera., Vol. XIV (Igor), p. 327.

11. WEBB. Piroplasmosis in Fox-hounds in India. The lour of Comp. Path. and Thera., Vol. XIX (Igo6), p. I.

12. WETzI. Ueber die Piroplasmose der Hunde. Zeitschrift für Thiermed., Bd. X, S. 369 .

13. WRIGHT. Canine piroplasmosis (on certain changes in the bloor). Jour. of Hygiene, Vol. V (1905), p. 268. 
CHAPTER X.

\section{DISEASES CAUSED BY PROTOZOA GENUS AMEBA.}

$\$$ 295. General discussion of Ameba. The ameba belong to the class Sarcodina. They include the simpler forms of the protozoa. The genus ameba is provided with lobar or pointed pseudopodia. A few of these have become parasitic. So far as seems to be known, these parasites, with possibly a few exceptions, do not produce noxious products like bacterial toxines or ptomaines, but whatever danage they may cause is due to the mechanical disturbances set up by their presence and multiplication. The genus ameba has very few pathogenic species. The best known of them is Ameba coli, the supposed cause of a form of dysentery in man. In animals but few species have been found to stand in a causal relation to a morbid process. The term "amebiasis" has been introduced by Musgrave and Clegg to denote an infection with ameba.

INFECTIOUS ENTERO-HEPATITIS IN TURKEYS.

Synonym. Blackhead.

$\$ 296$. Characterization. This disease of turkeys is characterized by thickening of areas or of the entire walls of the ceca and areas of tissue degeneration and necrosis in the liver.

$\$$ 297. History. In the fall of 1893 , Prof. Salnuel Cushman of the Rhode Island State Experiment Station sent a few specimens of the affected organs of turkeys which had died of "blackhead" to the Bureau of Animal Industry, where 
they were carefully examined by Dr. Theobald Smith. In the summer of 1894 , Smith made a careful study of this disease at the Rhode Island Experiment Station. He found that it was caused by one of the protozoa (Ameba meleagridis, Smith). He published a full description of the disease which, in accordance with the lesions, he designated Infectious entero-hepatitis.

In 1895, the disease was further inrestigated respecting the mode of transmission of the infecting protozoa. The results showed that it could be transmitted directly from diseased to healthy turkeys without the intervention of an intermediate host. These results were published in 1896 . The place and the time of the first appearance of this disease are not clearly stated, but it seems that New England was the first to suffer from it.

Recently, Chester of the Delaware Agricultural Experiment Station has shown that a rery similar disease attacks chickens.

$\$ 298$. Geographical distribution. The available data bearing upon the geographical distribution of this disease indicate that it is widely distributed. The New England states, particularly Rhode Island and certain districts in the Middle and Western states, are affected. It has not yet been reported from the Southern states. For want of statistics the amount of loss to the poultry industry occasioned by this disease can not be accurately estimated, but the fact that it has caused many farmers and poultry men in New England to discontinue the raising of turkeys shows that it is of much economic importance. It is stated in the report of the Rhode Island Experiment Station for 1894 that "the eradication of this disease would be worth hundreds of thousands of dollars to the eastern farmers alone." These heavy losses in the East, together with the accumulating evidence that the entire northern third of this country is sprinkled with infected districts from which the disease is spreading, indicate that this malady is of more than ordinary significance to those engaged in the turkey industry. 
5299. Etiology. In 1895, Suith described a microorganism belonging to the protozoa which he found to be associated directly with the disease process. He designated it Amaba meleagridis. In those cases in which the disease was recent, or at its height, the parasites were very numerous in the affected tissues, while in those in which the disease process was far advanced and associated with degenerative or regenerative changes, the parasites were found with difficulty. Curtice finds that the chicken is a host for the causative parasites, and together with the aduit turkeys spreads them broadcast through the droppings. He has shown that the ameba are not transmitted through the eggs. The young turkeys become infected soon after being exposed to contaminated surroundings. The young are much more susceptible than the older turkeys.

The most frequent appearance presented by the parasites is that of round homogeneous bodies with a sharply defined, single-contoured ontline. Within these bodies and situated some what eccentrically is a group of very minute granules, probably representing a nuclear structure. They vary somewhat in size, measuring from 8 to Io $\mu$ in diameter in
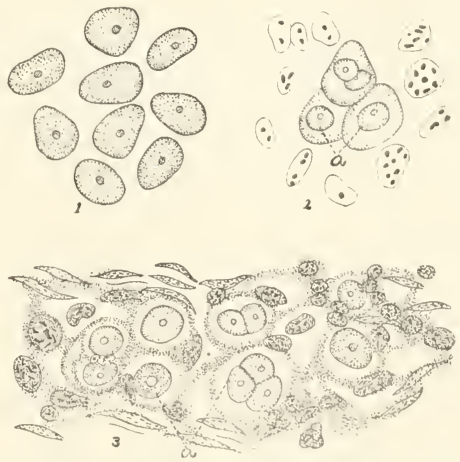

Fig 9S. Ameba meleasridis. (I) Isolated organisms, (2) single parasites, (3 gronps of the parasite (a) of the ameba in the mucons membrane of a turliey's cecum (Smith).

some cases, from 12 to $14 \mu$ in others. In the fresh tissues they are distinctly larger than the parasites within the tissues which have undergone the hardening process. The latter are from 6 to ro $\mu$ in diameter. The difference may be due to 
shrinkage, on the one hand, and on the other to a sliglit flattening of the bodies by pressure in the fresh preparations. These peculiar homogeneous bodies were found, as a rule, free in the crushed preparations, although occasionally giant cells were detected which contained a number of them. The cell nuclei of the giant cells are not visible in the fresh condition. Numerous coarse granules, less frequently fat globules, are embedded in its protoplasm.

Smith believed from the results of his investigations that the parasite lived in the interstices and lymph spaces of the tissue, but not within cells. This seems certainly true of the cecum. The liver cells become necrotic or else disappear so rapidly that it is impossible to determine just where the parasites begin to multiply. They do not live within the blood ressels, as they are not found within them excepting perhaps in a thrombosed ressel. They must. therefore, occupy the place of the liver cells. It is probable that they begin to multiply in the connectire tissue adjoining the blood vessel and simply crowd out the liver cells, learing the connective tissue stroma of the lobules in whose meshes they are found.

Their presence within giant cells is seen in almost every infected organ subjected to examination. In teased preparations the fresh tissues they are frequently found with remnants of the inclosing cells still attached. This intracellular condition is. however, a purely passive one so far as the parasite is concerned.

The microparasites within the tissue of the host seem to tend toward destruction. Both the death of the tissue itself and the repair seem to lead to the disappearance of the parasites. In most cases there may be seen in the same section a partial dissolution of some of the bodies, while others are still in good preservation. Evidently their life within the tissues is not very long.

A discharge of the microparasites which escape destruction probably takes place from the walls of the ceca, when these break down into the contents with which they are carried outward. A similar discharge may take place from the liver 
through the bile ducts into the intestine. Another way of dissemination is in the death of the diseased turkey and the dissolution of its body, whereby the organisus are set free.

The occurrence of amebre in intestinal affections of man was noticed by Lösch in 1875 . Since that time it has been the subject of many investigations.

'The points of analogy between the avian and the human disease are that in both there is an affection of the intestine (large intestine in man, ceca in turkeys) associated with liver disease due to amebæ.

The intestinal wall in amebic dysentery is greatly thickened, owing to an edematous condition. It is also thickened in crrcumscribed areas and contains cavities filled with gelatinous-looking pus. The amebæ vary much in size and contain vacuoles. They are found in variable numbers in the bottom of the ulcers and in the discharges. The large numbers of amebre found in the intestinal contents led Councilman and Lafleur to infer an active multiplication therein. The presence of the parasites within the submucosa is described by these authors in one case only.

In the turikey, the parasites are always present in the conmective tissue spaces of the mucous and submucous membrane. Their presence in the contents of the cecum is highly probable.

It differs from the Ameba dysenteric in being quite uniform in appearance, varying but slightly in size (from 6 to $10 \mu$ in diameter) and in being free from vacuoles. Movements characterized as ameboid have not yet been demonstrated.

The liver affection in man appears usually as an abscess. In turkeys it appears as a variable number of foci in which the microparasites may be present in great abundance. The difference in the nature of the lesions must be largely attributed to the different reaction of the tissues of birds toward injuries.

$\$$ 300. Symptoms. Diarrhea is the symptom which sooner or later may be expected to appear. It probably occu- 
pies the most prominent place among the objective manifestations. The disease of the ceca is presumably responsible for this. Diarrhea occurs with at least one other disease of the ceca and with the presence of tapeworms. Emaciation is pronounced in very chronic cases but it is sot constantly present. As it may accompany other wasting diseases, it can not be depended upon as an indication of this affection. As the disease progresses the turkeys become less active, lag behind their flock or do not go out with it. Later the comb, wattles and even the skin of the head become dark colored, hence the popular name "blackhead."

$\S$ 301. Morbid anatomy. Turkeys are attacked quite young. Smith found a turkey about three weeks old in which the disease had already made considerable progress. It seems, moreover, as if the disease is contracted only by the young, because in the examination of turkeys of different ages the oldest show lesions of the longest standing; that is, such as had undergone the most extensive transformation. In general it may be said that the age of the turkey corresponds with the age of the disease process. The most serious and extensive destruction of tissue occurs in the turkeys in the fall. In midsummer the disease is making most progress and the microparasites are present in greater numbers. It is probable that the delicate tissues of the young are best adapted for the temporary habitat and rapid multiplication of this parasite.*

The primary seat of the disease is the ceca. From these the liver is secondarily invaded. Other organs have not been found to be attacked.

The lesions of the ceca are in substance a thickening of the wall, followed in most cases by a destruction of the epithelium and deeper portions of the mucous membrane. This destruction results in the outpouring of a coagulable fluid into the tube. The thickening of the wall may vary considerably in extent from case to case.

"In this regard it simply follows the rule observed by large numbers of parasites whose most destructive action is visited upon the young. 
It may be uniform over the greater portion of the tube or it may be limited to circumscribed patches. 'The commonest seat of these lesions is near the blind end of the tube where it evidently starts and whence it spreads to other portions. Not infrequently only one cecum is diseased, the other remaining normal.

The affection of the cecum is due primarily to the multiplication of the microörganism which may take place chiefly either in the mucous membrane, or in the submucous tissue; it may, though rarely; extend into the muscular coat. The thickening of the wall is the result of several processes-the multiplication of the parasites, the increase of the normal tissue elements and later on the accumulation of masses of small cells and some giant cells.

In the early stages of the invasion, the adenoid tissue between the tubules and in the submucosa becomes greatly increased, owing to the presence of large numbers of micro-parasites of round or slightly oval ontline and from 6 to rom in diameter which stimulates the proliferation of the tissue cells. Numerous mitoses have been seen in this stage. The parasites seem to occupy the meshes of the adenoid tissue either singly or in groups or nests. In these meshes they are soon inclosed in cells acting as phagocytes, so that the appearance of an intracellular habitat of the parasites is suggested.

The presence of the parasites in this reticulum probably stimulates also the accumulation of lymph cells within the 
spaces, by virtue of which the mucous membrane is thickened. In this early stage of invasion the epithelium, both of the tubules and of the surface, remains unaffected. The parasites do not invade the epithelium at any time.

As the disease progresses there is a continued increase in cellular elements of the mucous and subnucous coats and a gradual invasion of the muscular coat. Here the bundles of fibers of the circular coat are thrust apart by masses of cells, so that this coat also becomes greatly thickened. The inflammation finally extends to the serous covering, where the blood ressels become greatly dilated and give the cecum a congested appearance. In cases of ordinary severity the wall of the cecum which is not more than 0.2 to $0.5 \mathrm{~mm}$. thick normally becomes 2 to $3 \mathrm{~mm}$. thick.

With the progress of the disease the mucous membrane may be shed and a coagulable fluid poured out into the cecum. In some cases it appears in isolated masses, which adhere to certain spots of the mucous membrane. In others, this exudate fills the entire tube with a yellowish-white mass, built up in

FIG. Ioo Diseased cecum, showing thickness of wall and ulcerated mucosa. concentric layers consisting of a mixture of blood corpuscles, fibrin and small round cells in variable proportion.

In the further progress of the local disease it is not improbable that bacteria are also concerned. The exudate con- 
tains innense numbers of them and the denuded mucosa furnishes a favorable place of entry. It is otherwise difficult to explain the continued increase in thickness of the walls of the cecum after the nucous membrane has been shed. This continued increase in thickness is due to an extensive infiltration of small round cells and the presence of some giant cells. Parasites in this advanced stage are scarce and usually recognizable only as vacuole-like bodies within the giant cells.

The thickening of the wall is associated in some cases with an extension of the inflammation to the contiguous wall of the intestine, which bec omes firmly attached to the cecum. Yellowish exudates are sometimes found outside of the diseased cecum on its serous covering and they bind it inextricably to the other cecum or to the intestine or attach it to the abdominal wall. In these stages, the micropara-

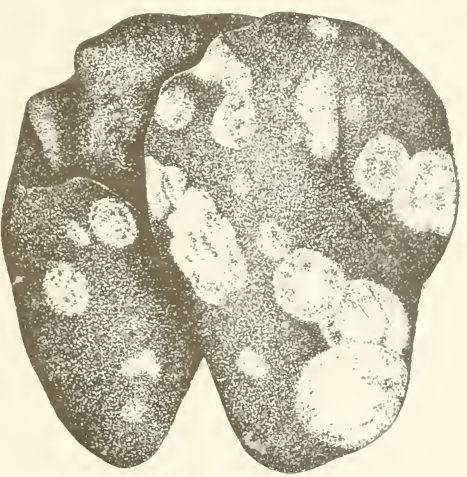

FIG, 101. Lizer showing diseased foci. site is not found. It seems to have done its work by destroy ing the mucous membrane and to have left the field for miscellaneous bacteria.

Other portions of the digestive tract are not affected. The secondary lesions are found in the liver, although in some cases they do not appear. The organ itself is enlarged to probably $t$ wice the normal size. Orer the surface are distrib. uted roundish, discolored spots, distinctly demarcated from the surrounding tissue. These may be distributed uniformly over the whole surface of the liver or they may be limited in number to a few. They vary from 3 to $15 \mathrm{~mm}$. in diameter. 
Several types of these spots appear corresponding to different conditions of the diseased tissue. We have in the early, most active disease process sharply defined circular areas of a lemon yellow, or a neutral gray or of an ochre yellow color. The spot is not homogeneous in structure, but made up of a delicate network of grayish yellow, dead tissue.

In another class of spots there is a mottled brownish color which contrasts only slightly with the surrounding liver tissue by its darker color. It may contain a central yellow nucleus of dead tissue and a narrow outer border of the same character, or the border may be a dark brownish circular line. The entire spot has an indistinct appearance and is flattened or even slightly depressed

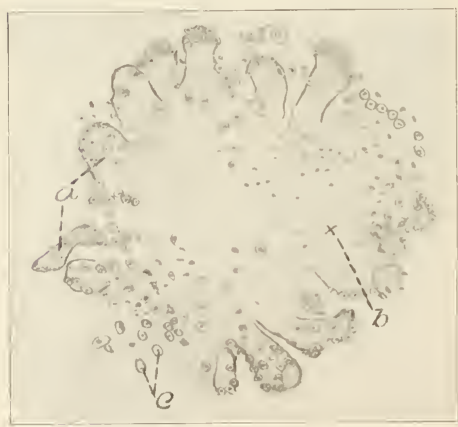

Fig. I02. Adrazing of a beginning necrotic mass. (a) Giant cells, (c) free nuclei, and $(b)$ disintegrated necrotic tissue. below the surface. In some cases they are uniformly whitish and shade off somewhat gradually into the surrounding tissue. In sections of the affected organ it will be found that the surface spots represent $\mathrm{m}$ asses of liver tissue in the same condition, the spots being simply the places where these diseased foci intersect the surface. Some are found deeply imbedded in the liver tissue, and therefore not visible on the surface. The lesion of the liver is thus represented by few or many foci of disease having in general a spherical form and appearing on the surface of the organ as round spots. Occasionally the lesions become more extensive and the death of large portions of liver tissue follows.

The changes in the liver are most easily explained by 
assuming that the microparasites are conveyed by the blood directly from the diseased ceca into the liver and there deposited in different places, where they begin to multiply and spread in all directions. In this way they form the spherical foci of disease which appear as circles on the surface of the liver. This theory is borne out by the results of the microscopic examination.

In sections of hardened tissue from the liver in which the disease has but recently begun, the affected regions are invaded by large numbers of protozoa which occupy a kind of reticulum formed probably from the connective tissue stroma. The liver cells have partially or wholly disappeared from these foci. The border of the necrotic tissue is surrounded by a zone of giant cells. The parasites occupy the meshes of the tissue either singly or in groups. The reticulum is provided with a small number of nuclei, some of which are closely applied to and curved partly around the parasite. The blood vessels are usually much dilated and filled with red corpuscles.

The yellow masses observed with the naked eye in the surface spots are shown to be patches of an amorphous substance which take nuclear stains very feebly, the aniline colors not at all. This may be described as a coarse network in the meshes of which small cells, and very rarely parasites, are seen. This substance is assumed to be the result of coagulation necrosis of the liver cells by which they have lost their nuclei and have become fused into a formless mass. It is probable that the plugging of blood vessels in the liver by parasites carried from the cecum is the cause of the necrosis, since such plugs or thrombi are not uncommon in sections of the diseased areas.

With the appearance of the nilicroparasites regenerative changes begin at once which complicate the process. We have at the outset an active multiplication of the microparasites which take the place of the original liver tissue and a process of coagulation necrosis going on at the same time. Soon multinucleated (giant) cells appear. Not infrequently they are grouped around what appears to be a plugged 
vessel or else they occupy the lumen of the ressel itself.

In still older cases the diseased areas are found more or less filled with small round cells which may have passed into the dead regions from the blood ressels. In all cases the latter are more or less enlarged and they seem to encroach upon the liver tissue, thus filling in part the void produced by the cell death and giving the surface of the liver a brownish, mottled appearance wherever the disease spots are. The processes of advancing disease and necrosis or death of tissue on the one hand and of repair on the other seem to go on side by side, now one, now the other, predominating.

The results of the investigations thus far made indicate that the disease may follow several courses.

I. After a certain period of disease, regenerative processes begin which tend toward a permanent recovery.

2. The disease may proceed so rapidly from the very start that the affected turkeys die early in life.

3. The cisease may come to a standstill but the amount of dead tissue in the ceca and liver may be so great as to favor the entrance of bacteria which are directly responsible for the death of the bird late in the summer or fall.

The description of the lesions of a turkey dead of this disease is appended. It is quoted from Smith's report.

"Turkey' No. 14.-A bout 5 months old. Taken from a flock August $S$ because of lack of strength to keep up with the rest when driven. Indications of diarrhoea. Placed in a coop, where it died during the night. Examined next morning.

"Slight odor of decomposition. A few small warts on skin of neck. The various organs were found normal, with the following exceptions:

"Nrucosa of duodenum almost blackish, from intense injection and pigmentation of villi.

"Both caeca diseased. The left is slightly distended. On serous aspect two yellowish spots, with markedly injected borders, corresponding to thickenings of the walls near the blind end of tube. The mucous surface of one is smooth; to the other an exudate is attached. Besides the thickening of these spots, the free half of this caecum is somewhat thickened uniformly.

"The right caecum is very much distended over two-thirds of its length. From the serous surface local thickenings are recognizable, 
which have a yellowish, mottled appearance. The small intestine is firmly attached to one of these. The disease has, however, not invaded the wall of the latter. The border of these spots is intensely lyyperiunic. When the caecum is slit open its width is three to four times that of the nudisturbed tube, and the thickness of the wall varies from one-eighth to one-half of an incli, being not less than one-eighth of an incli over three-fonrths of the entire length. When the brownish feces were washed away the increased local thickenings were fonnd covered witl firm exudates, 11sually attached in but one spot.

".Sections were examined of that portion of the caecal walls which was very much thickened, and to which the contignous small intestine was inseparably attached by the new growth.

"The mucosa of the caecal portion liad sloughed away, while that of the embedded sulall intestine was intact. The neoplastic tissue between caecum and intestine was fully I cm. (two-fiftlis inch) thick. Inasmuch as the infiltration probably followed the narrow mesentery between caecum and intestine the original boundary lines of the caecal wall are no longer recognizable. The nuscular coat of the caecum may be traced for only a slort distance into the neoplasm, when it appears. Microparasites were not seen distinctly in the diseased tissue.

"The liver is very much enlarged, and dotted everywhere with roundish spots of varying appearance. The majority are fronis 5 to 12 $\mathrm{mm}$. in diameter, round or slightly oval. The center of each is usually occupied by a group of yellowish dots and the circle is bounded by a narrow yellowish ring. The space of the circle is mottled brownish. Among these spots there are also circles of a conpletely yellowish color. On the convex surface of the left lobe there is a very firm, ring-like, yellowish mass, cutting like firm cheese.

"In crushed preparations of fresh liver tissue from within the brownish circles many giant cells are seen. They consist of a meshwork of protoplasin of a rather coarsely granular character inclosing splieres which appear homogeneous. The giant cells are $11 \mathrm{p}$ to $30 \mu \mathrm{in}$ diameter.

"Sections of liver tissue hardenerl in alcohol and in Foa's solution were also examined. The foci of disease contain necrotic areas in which are numerons giant cells each inclosing a number of nicro-parasites. In some portions there is wuch cell infiltration in the interlobular tissue around the portal vessels. Among the cells the protozoa are recognizable.'”

302. Differential diagnosis. 'This disease is to be differentiated from certain local affections of the cecum not especially uncommon in turkeys. Ziirn (Deutsche Zcit. $f$. Thiermed, $B d . \mathrm{I}\left(188_{3}\right)$, p. I 89 ) has described a cecal disease in water fowls and turkeys and von Ratz has described a 
cecal disease in turkeys in which the liver lesions seem to be absent. The lesions in the liver and the presence of the microparasite, as previously described, are sufficient to differentiate this disease.

$\$$ 303. Prevention. The present knowledge of this disease shows that the parasite is transmitted directly from diseased to healthy turkeys. This suggests that the first precaution is to avoid the entrance of diseased or seemingly healthy turkeys from a diseased flock into a healthy one. The discovery of Chester indicates that a like precaution must be taken with reference to fowls. If the disease exists the best, although most radical, method as suggested by Snith is the total destruction of the affected flock, thorough disinfection of the roosts and droppings under the same, and the introduction of healthy turkeys.

\section{RFFERENCES}

1. CHESTER. Report of the hacteriologist of the Del. College Agric. Exp. Station, 1899 1900. (C. reports disease in chickens).

2. CURTICL. Notes on experiments with blackliead of turkeys. Circular No. 119. Bureau of Animal Industry, 1907.

3. Cesmuax. Nature of blackhead in turkey. Report $R$. Island Agric. Exp. Station, i894, p. 199.

4. MOORE. The direct transmission of infectious entero-hepatitis in turkeys. Circular No. 5, limreau of Animal Industry, 1896.

5. Musgrave AND Cr.gG. Amebas: Their Cultivation and Etiologic Significance. Bulletin No. IS. Bureau of Gozernment Laboratories, Manila, 1904 .

6. Smrн. Infectious entero-hepatitis in turkeys. Bulleiin No. \&, U. S. Burean of Animal Industry, 1895 . 


\section{DISEASES CAUSED BY PROTOZOA GENUS TRYPANOSOMA.}

\section{$\$ 304$. Classification of Trypanosoma. The Trypan-} osoma belong to the protozoa, but their species diagnosis is not satisfactorily determined. A number of classifications of these organisms have been proposed. The one suggested by Salmon and Stiles is appended.

Protozoa, class Mastigophora, subclass Flagellata, order Monadida, family Trypanosomidac, genus Trypanosoma Gruby.

According to Stiles the family contains at present two genera, which are distinguished as follows:

I. One flagellum present, extending from the centrosome along the undulating memhrane and becoming free at the anterior

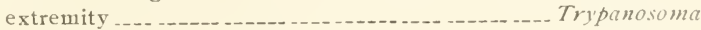

2. Two flagella, one extending anteriorly, the other posteriorly Trypanoplasma

Generic diagnosis of Trypanosoma. "Body fusiform, presenting a lateral, longitudinal, undulating membrane, the thickened border of which terminates posteriorly, in the posterior half of the body in a 'centrosome,' and is prolonged anteriorly in a free major flagellum; nucleus generally anterior: there is a tendency to agglomeration by the posterior extremity; divisions longitudinal and unequal. Parasitic in the blood of vertebrates."

In order that a somewhat definite idea of the structure of these organisms may be obtained the specific characters of Tr. Lewisi are quoted.

Trypanosonia: " 8 to $10 \mu$ long, 2 to $3 "$ broad, 24 to $34 \|$ long by I. 44 broad (Laveran and Nesnil, IgOI); a very refringent granule (near centrosome) in place of which a clear vacuole is seen in stained preparations. Animalcules exceedingly minute, alternate and vermicular nnder normal conditions, but highly polymorphic and capable of assuming a variety of contours; flagellum single, terminal, two or three times the length of the extented body. No contractible vesicle . . . as yet detected. Habitat, blood of the rat and hamster." 
\$ 305. General morphology of trypanosoma. Trypanosoma of all species are in general very similar. The morphology is said to vary greatly in the same species and to a greater extent in different species. In general the trypanosoma may be said to measure from $\mathrm{I}$ to $5 \mu$ in thickness and from I 5 to $45 \mu$ in length, including flagellum. They all show very

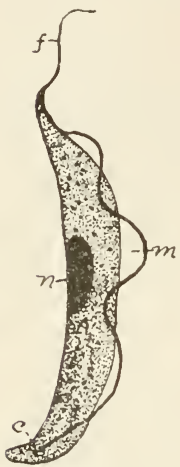

Fig.103. Trypanosoma Brucei : c, centrosome; $f$, flagellum; m,undulating membrane; n, nucleus. $\times$ about 2,00o. (After Laveran and Mesnil).

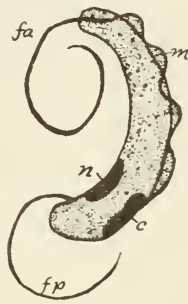

Fig. Io4. Trypanoplasma Eorrelli: c.centrosome; fa, anterior flagellum; fp,posterior flagellum; m,undulating membrane: $n, n u c l e u s$; about I,Soo. (Afler Laz'eran and Mesnil). active eel-like movements and some motility. The nature and extent of the motility varies. The fact as stated, that variations are occasionally found in one species, often, indeed, in a single preparation, which are nearly as great as those observed between different species, renders the specific determination difficult. The flagellum at the anterior end of the parasite varies greatly in length. It is actively motile, pointed and continuous, with the thickened margin of the undulating membrane ending at or near the centrosome. The undulating membrane extends along the border of the organism from near the centrosome in the posterior portion to the anterior end of the organisul, from whence it continues as the free flagellum. Its breadth and folds vary considerably.

The nucleus is usually situated in the anterior half of the parasite and varies both in size and shape. It is generally oval or round, and assumes other contours with the different stages of division. The centrosome as a rule is in the posterior and more blunt end, and it appears to have an intimate associ- 
ation with the flagellum and undulating membrane. Its location has been used as a diagnostic point in determining species.

The protoplasm is homogeneous or granular, depending upon the age of the parasite, its environment and, perhaps to a certain degree, upon the species. Few or many fine or coarser granules may be found scattered throughout the protoplasin.

Multiplication. Voges gives three forms of multiplication, namely, longitudinal, transverse fission, and segmentation.
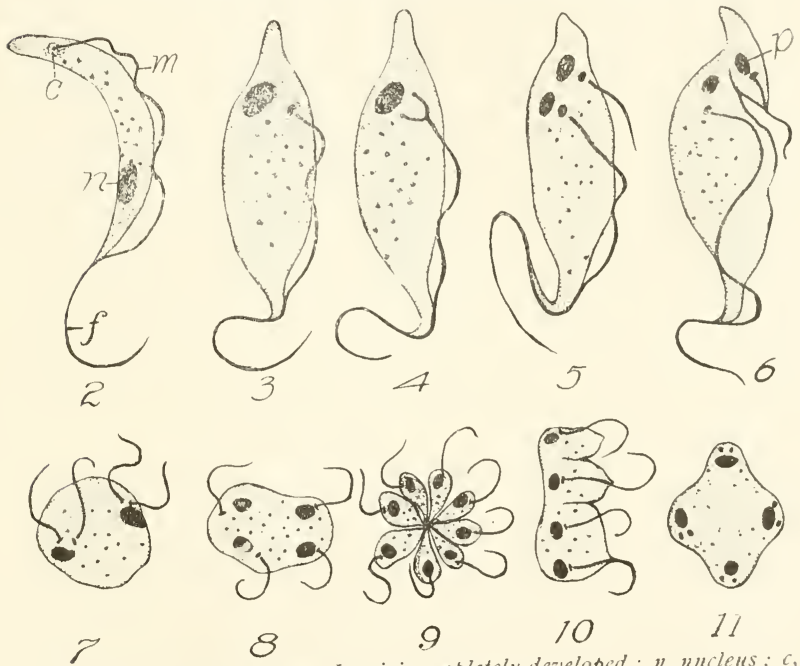

71

FIG. 105. 2, Trypanosoma Lewisi completely developed; n, nuclens; $c$, centrosome; m, undulating membrane; f, flagellum. 3-6 trypanosoma in process of division. 7 -10 other forms of multiplication of $\mathrm{Tr}$. Lewisi, II, flagella not stained. $\times$ about 2,000 ditumeters (after Lai'eran and Mesnil).

He did not observe conjugation. The chromatin divides into from 3 to ro segments, which assume irregular shapes and locations, some of which are often found well up in the flagellum. 
The nucleus usually divides into equal parts, but may break into several segments. After the nuclear division the protoplasm may assume various irregular forms. The young nuclei arrange themselves in groups, and the parasite twists and splits by longitudinal or more often by transverse fission (Fig. I04). The new forms resulting from the division soon assume the regular shape. Plimmer and Bradford consider longitudinal and transverse division the more frequent modes of reproduction. They observed conjugation, which consisted in the fusion of the micronuclei, followed by an amoeboid stage and division by segmentation. The order of division appears to be (I) centrosome, (2) flagellum, and (3) nucleus and protoplasm. Other forms of reproduction have been described by Martini, Laveran and Mesnil and others. Involution forms have been observed by a number of workers. Rodet and Vallet state that Tr. Brucei multiply principally in the blood and lymph. There is a difference of opinion concerning the agglutination of Trypanosoma. Musgrave and Clegg state as a result of their researches that the so-called phenomenon of agglutination is of no value from a diagnostic point of view, and it is too uncertain, if it is a reaction, to serve as an index of immunity or susceptibility.

$\$ 306$. Distribution in the body. It is the opinion of most students of the Trypanosoma, that in the infected animal they are found in all of the body juices, and are not present at the same time in great numbers in one part, with but few in another. Animals having many parasites in the blood when killed show them also in the organs; and if they are not demonstrable in a microscopic examination of the one they will not appear in the other. The blood of animals suffering from the disease is always infectious by animal inoculation, although the parasites may not be found microscopically at the time. Martini, however, regards the spleen, lymphatics, bone marrow, and to a less extent, the liver and kidneys, as the places for the destruction of Trypanosoma. It has been found that Trypanosoma injected into the peritoneal cavity multiply considerably before they enter the blood. 
Disappearance after death. Trypanosoma disappear very suddenly after the death of the host. Within two hours signs of degeneration begin; the parasites shrink, assume irregular shapes and then disappear. Motile forms are rarely found after two hours.

Distribution in nature. Trypanosoma are not known to) exist in nature outside of the bodies of living animals. They have been found in the blood of a large number of species. Novy has found them in the blood of many birds. They have been kept alive in blood or salt solution for a few hours. Novy has succeeded in cultivating them, $i . e$, getting them to multiply on an artificial culture medium.

$\$ 307$. Historical sketch. There is a voluminous literature on the trypanosoma from which the following brief summary was taken. In I84I, Valentin discovered hematozoa in trout (Salmo fario) and in $18+2$, Glugge found them in the blood of frogs. In 18+3, Gruby observed a flagellate infusorium in frogs which he named Tr. sanguinis. Gruby has generally been credited with the discovery of these forms. From $18+3$ to 1879 the organisms were found by many observers, not only in frogs but in birds as well.

In $1879-80$, Lewis described trypanosoma found in rats in India. Later he states that they are identical with Tr. Livansi.

In 1880 , G. Evans discovered trypanosoma in the blood of horses suffering with surra, the well known disease of India. He proved their causal relation to the affection. In 1885, Steele confirmed Erans' work, and named the parasite Spirocheta Eviansi.

The work of Evans and Steele was followed by many interesting discoveries of trypanosoma especially in fish and in man.

In 1896, Rouget described Trypanosoma found in the blood of a horse suffering from dourine. Wasilewsky and Senn, in I 899, confirmed Rouget's work and determined the pathogenic action of this parasite for the horse. Laveran and Nesnil proposed the name $\mathrm{Tr}$. Iougcti for the parasite of 
dourine. Doflein (July, I90I) named it Tr. equiperdum, which term was adopted by Salmon and Stiles.

In I 90 I, according to Voges, Elmassian first differeutiated the Trypanosoma of Mal de Caderas in South America. Voges described it the following year, demonstrated its pathogenic action, and named it Tr. equinum.

In 1902, Bruce and Laveran independently published articles inwhich they credit Theiler with the discovery of a

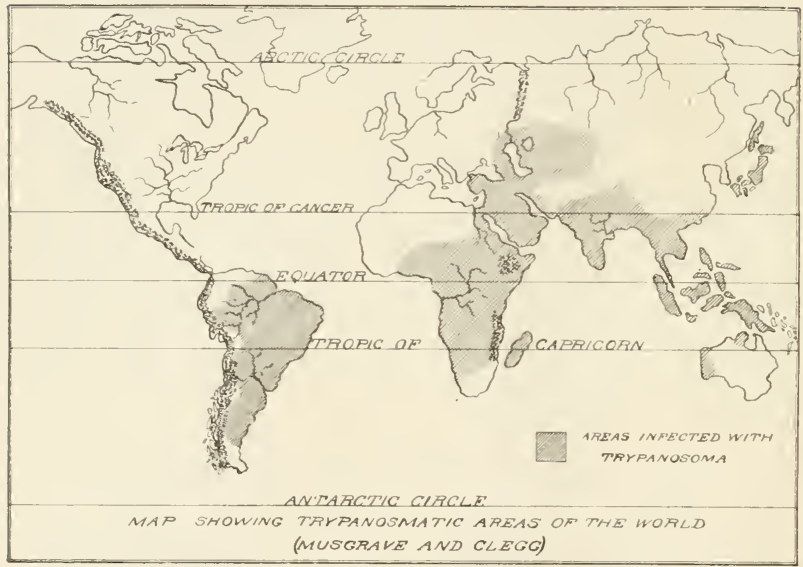

FIG. I06. A map showing the geographical distribution of Trypanosoma disease.

new Trypanosoma of cattle in South Africa. They each proposed the name $\operatorname{Tr}$. Theileri.

In Igor, Smith and Kinyoun described a parasite which had been observed by Jobling in the blood of a sick horse in Manila. Later in the year Smith described it as $T r$. Evansi.

$\$$ 308. Trypanosomiasis. Salmon and Stiles have introduced the term Trypanosomiasis to describe an infection 
with parasites belonging to the flagellate family Trypanosomidac. The term is analogous to Tcniasis and Coccidiosis. There are a number of different trypanosoniases now recognized, being caused by different species of Trypanosoma. Among these the following may be mentioned :

r. Surra. A disease of equines, camels, elephants and certain other animals in India, attributed to Trypanosoma Ezansi.

2. Nagana, nygana or Tsítséfly discase of Africa. Affecting cattle, horses, mules, asses, antelopes, camels and certain other animals. It is attributed to Trypanosoma Brucei.

3. Dourine or maladie du coüt of Algiers, France and Spain. It attacks the horse and the ass in particular, but may be transmitted to certain other animals. It is attributed to Trypanosoma equiperdum.

4. Mal de caderas of South America. It affects horses, asses, cattle, hogs and certain other animals. It is attributed to Trypanosoma equinum.

5. Rat trypanosomiasis attributed to Trupanosoma Lexisi. By some authors this parasite is alleged to be identical with the horse surra organism, but it is quite certain that rats may harbor a distinct species. Until the results of further investigations are recorded it is deemed best to consider these as distinct infections. Nusgrave and Clegg conclude that proof sufficient to establish the individuality of the Typanosoma causing trypanosomiasis in domestic animals has not yet been advanced. These anthors consider the trypanosoma found in domesticated animals in the Philippine Islands as Tr. Ezansi.

It is important to note the observation of Nusgrave and Clegg that "in all the forms of trypanosomiasis the infection seems to involve particularly the genitalia, the skin, and the organs of special sense. The skin symptoms consist of roughening of the hair, which also falls out in places: a thickening of the epidermis, often with exfoliation, and in some stages of the disease, various skin ermptions. There may be simple ery thema, and more rarely they may assume the severer forms, 
as urticaria, or in extreme cases a distinct localized ulceration may occur. The scrotum and penis in the male and the vulva in the female are often swollen, and ulcerations of the penis or vulva are frequent symptoms especially in dourine."

The geographical distribution of the trypanosomiases is shown in Fig. Io6.

The following table of trypanosoma compiled by Smedley gives the distribution, means of dissemination and the pathogenesis of the various species.

\section{REFERENCES.}

1. DutTon AND TODD. First report of the Trypanosomiasis Expédition to Senegambia (I902). Thomson Yates, and Johnson Laboratories Report, Vol. V.

2. LATERAN AND MESNiL. Recherches morphologiques et expèrimentales sur le Trypanosomi des rats (Tr. Leu'isi, Kent). Ann. de l'Inst. Pastcur Vol. X' ( Igor), p. 673.

3. LAVERAN ET MESNit. Trypanosomes et Trypauosomiases. Paris. 1904.

4. Nory, MCNeal, and Hase. The Cultivation of Tr. Brucei. The Jour. of Infectious Diseases, Tol. I (I904), p. I.

5. PETRIE. Observatious relating to the structure and geographical distribution of certain trypanosomes. Jour. of Hygiene, Vol. I ( I905), p. 19I.

6. RODET ET VALILT. Contribution à l'étude des Trypanosomiases. Arch. de Méd. Expér., Vol. XVIII (I906), p. 450.

7. SMEDLEY. The Cultivation of Trypanosomata. The Jour. of Hygiene, Vol. V (I905), p. 24.

8. Thiroux. Recherches morphologiques et expérimentales sur Trypanosoma Paddae. Ann. de l'Inst. Pasteur, Vol. XIX (I905), p. 65. 


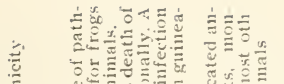

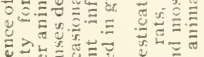

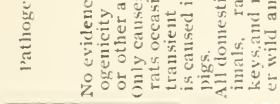

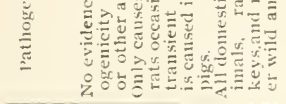

$\stackrel{2}{\frac{2}{2}}$

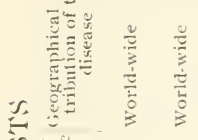

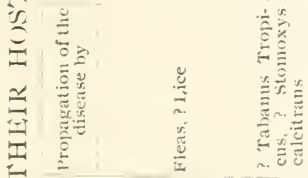

2
2
5
4
$=$
0
0
0 $\circ$

乙

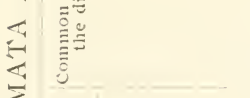

3
3
0
11
$\frac{1}{2}$
2
2
2

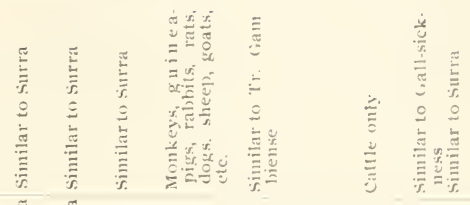

ए

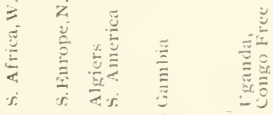

要要要

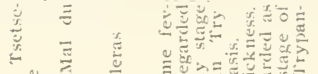

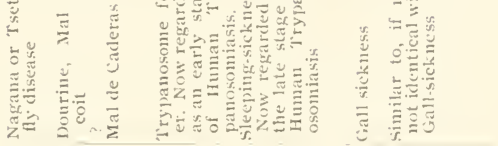

递

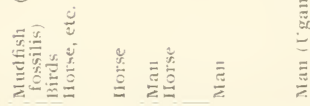

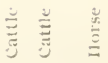

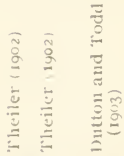

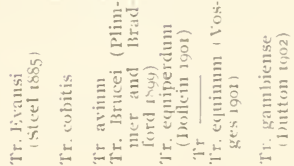

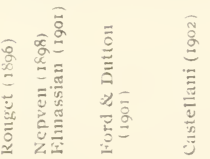

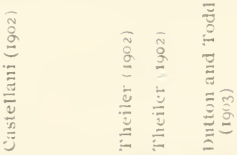
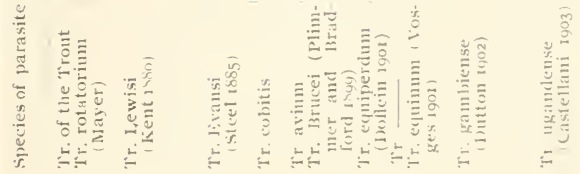

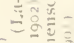

$\overline{5}$

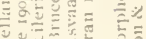

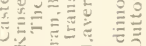


Synony'ms. Relapsing fever of equines; pernicious anemia of horses.

S 309. Characterization. Surra is an infectious disease of solipeds and camels caused by a flagellate protozoan. It is determined by a continuous fever with alternate paroxysms and intermissions, with a general or localized eruption of the skin, petechiae of the mucosae and more or less subcutaneous edema. There is rapid emaciation and great weakness. It is usually fatal. It attacks horses, asses, mules, cattle, goats, dogs, and rats. It can be inoculated into other animals such as rabbits, guinea pigs and mice. From an economic point of view it is reported to be essentially a disease of horses.

In India cattle are said to be infected with the trypanosoma of surra but they are not appreciably affected by them. It is reported that horses become infected by insects that have first bitten such cattle.

$\$ 3$ ro. History. This disease appears to have been known for many years to the natives of the low lands on both sides of the Indus on the nortliwest frontier of India. Haig appears to have observed it in Persia in 1876 . In 1880 , Evans found several cases of it in the Dera Ismael Khan county. He was the first to describe it and attribute its cause to an animal parasite which he discovered in the blood. In 1885 , Steel met with a disease among mules in Burma which he regarded as identical with Evans' surra, and which he believed to be relapsing fever. In 1888 there was an outbreak among the Bombay Tramway Company's horses. Since then surra has become epizoötic in Bombay; Lingard reports that thousands of ponies, horses, camels and asses died from it during the rains of 1893 and 1894 . Its ravages in the Punjab and Northwest Provinces during 1895 are reported to be appalling.

S 3II. Geographical distribution. It is a disease of Asia and Africa. It is reported that " the distribution of this malady seems to be entirely influenced by the physical aspect 
of this country; being far more prevalent in those parts where floods and inundations occur than in the higher and dryer portions" (Pease). If the identity of surra with tsétsé-fly disease proves to be true, which is still questioned, it has a wide distribution in Central Africa.

Surra does not exist in the United States, but because of its prevalence and long standing in the Plilippines it is liable to be introduced into this country. For this reason its nature should be understood by American reterinarians.

\$ 312. Etiology. There is little or no doubt that surra is due to the presence in the blood of a flagellated infusorian, Trupanosoma Ei'ansi.

"A motile trypanosoma 20 to $30 "$ in length to $\mathrm{r}$ to $2 "$ in breadth, somewhat blunt at the posterior end and gradually tapering at the anterior end. The undulating membrane is well defined, beginning at or near a small body centrosome) in the posterior portion of the parasite and extending forward as a free flagellum. It is provided with a nucleus and a granular protoplasm."

This organism is invariably found during the paroxysms of the disease in the blood of animals which have acquired surra either naturally or experimentally. Although blood containing these infusoria readily communicates the disease to susceptible animals it entirely loses its virulence when it is filtered through porcelain, so as to free it from the parasite. The disease can be transmitted to healthy, susceptible animals even of different species with the unfiltered blood of a diseased animal. The microscope reveals the infusoria in vast numbers moving with great activity in the blood. When this acute stage has passed the organisms disappear, the temperature falls, the severity of the symptoms abates, and there is an intermission, during which, at the beginning of the attack, the patient may appear in good health. Although the blood during an intermission may appear nnder the microscope to be absolutely free from the parasites, its inoculation into susceptible animals will, as a rule, produce the disease. The blood of surra affected horses loses its power of transmitting the disease by inoculation in about eighteen hours after deatl. 
Under the microscope, these parasites are detected in a drop of blood by an irregularly intermittent and characteristic quivering of some of the red blood corpuscles, which become much altered in form. The leucocytes remain unchanged in appearance. After a further and careful examination of this slightly quivering blood a minute thread-like organism with eel-like movements emerges from the mass of corpuscles. It may be seen apparently tugging with all its might at a red corpuscle endeavoring to detach it from its rouleau. The question of the manner in which these parasites interfere with the health of the affected animal has not yet been settled. When they are outside the animal body and in a dry state, they are killed or rendered inert by prolonged atmospheric action.

The period of incubation seems to be liable to great variation. It may be put from six to eight days after inoculation or ingestion of blood taken from an animal suffering from surra. It appears from Lingard's investigation that the period of latency may be prolonged to thirteen days, if the blood used for inoculation has been taken from a dead animal. When the parasites have been given in water, by the mouth, symptoms of surra may not appear for even seventy-five days. We have no exact data for determining the time required for the disease to manifest itself under natural conditions from drinking surra contaminated water.

$\$ 3$ 3. Means of transmission. The contagium of surra is fixed and can be conveyed only by inoculation or ingestion. Stagnant water and grass growing on recently iuundated land are said to form farorable resting places for this organism.

Lingard considers the ingestion of stagnant water and of grass from land subject to inundations a source of infection. Salmon and Stiles do not think this method of infection is sufficiently proven to look upon it seriously. Lingard stands almost alone in the belief that infection can take place through healthy mucosae.

The most common demonstrated natural niethods of 
transferring the virus from infected to non-infected animals is by means of insects, especially the biting flies. Of the flies, the tsétsé-fly (Glossina morsitans) is reported to be the most important. Musgrave and Clegg conclude concerning the rôle played by flies in transmitting this disease that " it has thus far been conclusively shown that the tsétsé-fly (Cilossina morsitans), at least one other variety of (ilossini, Stomoxys calcitrans, Musca brava (?), Taon, and at least one variety of Tabani transmit the virus. All other biting insects have been looked upon with suspicion, but absolute proof of transmission by them has not been furnished." The theory as to the method of transferring the parasite is that it is purely mechanical, although some have thought the Trypanosoma passed through one phase of its life cycle in the fly.

The spread of the disease from one locality to another is caused by the introduction of animals carrying the parasite.

\$14. Symptoms. The symptoms as given by Lingard are as follows: "The chief symptoms are the occasional appearance of an urticarial eruption, generalized or localized, closely following the first rise of temperature, but which may make its appearance at any time during the course of the disease; then the presence of petechiae on the mucous menbranes, chiefly that covering the membrana nictitans, lachrymation and the exudation of a seni-gelatinous material into the subcutaneous and other connective tissues. There is rapid wasting and great weakness, although in the majority of cases the appetite remains good throughout, no matter how high the fever. There is extreme pallor of the visible 111ucous membranes, and this is followed at a later period by yellowness. From first to last there is progressive anemia; the blood at first presents a normal character, but after a varying period of time it undergoes marked changes. The white corpuscles are increased in number and the red corpuscles usually: cease to form normal rouleaux, lose their individuality and run together forming irregular masses. They are at first dark, but gradually, as the disease advances, almost entirely lose their coloring matter and become pale." 
The respective duration of the paroxysms and intermissions is very irregular. Lingard puts it down as from one to six days. He states that in a few experimental horses the paroxysms lasted from eighteen to twenty-two days.

The duration of the disease is, according to Gunn, about fifty-two days. In the Philippine Islands the duration in horses is from fourteen days to three months. The prognosis is always unfavorable, the mortality in most species of animals being roo per cent. In cattle a variable percentage recover.

\$15. Morbid anatomy. As a rule there is great emaciation, enlargement of the liver and spleen, petechiae on various internal organs. A yellow or amber-colored jelly-like exudation occurs in the connective tissue of the throat, chest and abdomen, about the muscles and other tissues, and especially around the base of the heart. The lungs often show signs of inflammation. The mucous membranes and other tissues are frequently tinged yellow by the coloring matter of the bile.

It has been stated that the hide is often removed with difficulty. In the areas corresponding to the edema during life are found yellowish-tinged, gelatinous infiltrations. The serous membranes, especially the peritoneum and pleura, often show flakes of plastic, fibrous material. These are especially numerous over the liver. All of the organs have a dry, pale appearance. There are numerous sub-serous hemorrhages, particularly on the right side of the heart and over the lower portion of the lungs. The lymphatics are in general somewhat enlarged, often markedly so. The heart muscle shows parenchymatous changes, in degree depending somewhat on the duration of the disease.

In some of the lower animals the scrotum and even the testicles in the male and the vulva in the female are greatly swollen, and in the male rabbit the tension may be so great as to rupture the scrotum. Small preputial or labial ulcers are not uncommon.

Steel noticed ulceration of the stomach in about two-thirds 
of his cases among mules in Burma. In India this ulceration has not been observed among horses as a sequence of surra. In the Philippines changes in the intestine due to anemia with occasional ulcers are reported.

The clinical aspect of surra is essentially one of progressive anemia, accompanied by paroxysms and intermissions, during both of which there is a natural decrease in the number of the red blood corpuscles and in the amount of hemoglobin in the blood, with consequent anemia of the visible mucous membranes.

The importance of this disease renders it desirable to reprint "A preliminary note on a parasitic disease of horses," by Capt. Allen M. Smith and Dr. J. J. Kinyoun, from the Army Pathological Laboratory, Manila, October 17, I9or, as it gives a good idea of the appearance of the disease. The accompanying photograph showing trypanosoma was taken by Smith and Kinyoun at that time.

"()n October 15, I9or, information was given by J. W. Jobbing, Assistant Bacteriologist of the Board of Health of Manila, that an epidemic sickness of an undetermined nature was now prevailing in this city, and also that he had just taken a specimen of blood from a sick animal which on examination revealed the presence of a parasite, whether this was accidental or was the causative agent of the disease in question, be was unable to say. On investigation and inquiry it was learned from the Veterinarian in charge of the corral of the ()uartermaster's Department, and from the City Veterinarian, that there was 11ow, and had been, a fatal epidemic among the horses in Manila, the Quarter-master's Department having lost over 200 within the past four months.

"One of the corrals was visited by us on the 15 th inst., where we were shown, by the Veterinarians in charge, 20 horses and mules, ill with an undetermined disease. These animals presented the several stages of the malady, some were quite recently attacked, while others had been ill for over two months.

"The srmptoms first noticed are: impairment of appetite, constipation, fever and thirst. These are tollowed within a few days by a rapid and progressive emaciation.

"The temperature for the first few days ranges from $104^{\circ}$ to $107^{\circ} \mathrm{F}$. the pulse is full and strong. This may be termed the acnte stage. Then hegins an asthenic state, which may terninate fatally witlin a variable 
period, or by a slow convalescence. During this stage usually within Io days after the onset, there appears a commencing cedema above the belly, involving the soft parts, coincident with this, or soon after, the cedema extends to the feet and legs. The pulse becomes rapid, weak

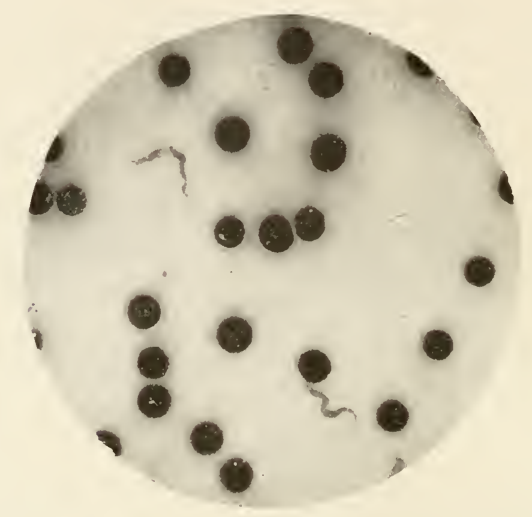

Fig. 107. Photograph of blood of horse conlaining Typanosoma. Taken by Smith and hinyoun.

and dichrotic, the respiration increased, shallow and jerky, the gait staggering. Emaciation is rapid and extreme.

"The disease has a tendency to relapse, this may occur at any time, even after convalescence appears to have been fully established. The relapses are invariably fatal.

"The mortality in this epidemic has been about 75 per cent for American horses and mules, and too per cent for native ponies.

"The gross pathology shows serous effusions into the pleuræ, pericardium, and sometimes the peritoneum. There is also a serous exudate into the cellular tissue of the legs and abdomen. The organs are pale, but otherwise normal in appearance.

"At the time of our inspection, five acute cases were examined, the duration of the attack being from six days to two weeks. All these animals presented the several clinical appearances as above described.

"Blood specimens were taken from the jugular vein of each and examined microscopically, shortly afterwards. In 4 of these a parasite 
was demonstrable. The other was negative, but a speciment taken the followiug day showed the presence of this same parasite.

" On the day following, specimens were obtained from 12 others, all chronic cases, with the result of finding this same parasite in the blood of four. In three there were very few, whilst in the fourth they were present in great numbers, as many as 20 could be seen in one microscope field. The animal from which the specimen was taken had suffered a relapse

"It would appear that the parasite may disappear from the peripheral circulation, or exists there in such few numbers that it is not easily demonstrable, after the acute stage has passed. It would require repeated blood examination to decide this point.

"Description of the parasite. The parasite resembles a wliplike worm, having much the appearance of the Trichocephalus 1)ispar, its lengtl is from ro to 14 mikrons, and is from $x$ to 1.2 mikrons in diameter through its body, the neck is nearly $I_{2}$ its length, tapering gradually to a point representing the month (?). It has a limiting membrane, which is well defined, the contour is in most cases symmetrical but in some the body line is quite irregular. The larger part of the parasite body) contains granular material and clear spaces, whicl latter vary in size and number; they are i.sregularly distributed, and may encroach on the wall so as to cause irregular outline. The granular material does not extend to the neck.

"The parasite is actively motile, having both a vermicular (contractile) and spiral movement. It moves forward in a very peculiar manner, the long whiplike process is thrust forward by a spirillar motion, followed by a coutraction of the body.

"We have not so far been able to determine its intimate structure, further than the limiting membrane, and the protoplasmic substance of the body.

"Two sizes of the parasite have been seen in all the specimens examined, the larger appears to be more numerous, and contains considerably more granular material than the smaller, and usually two or more vacuoles. Whether these two sizes represent male and female, has not been determined. We are inclined to believe from onr observations, that they do not represent the male and female, because we have observed in more than half the fresh specimens, the joining of a large and small parasite in such a way as to appear to be something more than accidental.

"The pathological changes caused by this parasite is a rapid destruction of the red blood cells, causing an acute ancmia. The changes occur in the blood coincident to the iuvasion of the parasite. In one horse which had been ill seven days, the red blood cells wumbered 
$3,500,900$, the white 14,500 . In another, ill six weeks, the red blood cells were $3,200,000$, and the white were 13,900 . The blood of a healthy horse, taken as a comparison, gave red blood cells 6,900,000, white 9, Soo. There is also a slight diminution in the amount of hxmoglobin, about 85 per cent.

"After convalescence has been fully established, no parasite can be found, the blood gradually assumes its normal constitution.

"The parasite is not confined to the blood, as it can be demonstrated in the serous eff usions.

"It is quite easy to detect, all that is necessary is to make a nicroscopical examination of fresh blood films, a in. objective will suffice. Dried films, fixed and stained with any of the nuclear dyes.

"The organism appears to be a strict parasite. It lives but a short time after renioval from the hody, the longest tinıe which it has been kept alive in blood serum was not more than ten hours.

"The parasite has many of the properities in common with the filaria, and resembles more nearly that of filaria perstans, only it is smaller, and its movenients dissimilar. Yet on the other hand, the clinical history of animals infested by it, the changes occurring in the blood, the lesions observed in post-mortem, point very strongly towards its classification with the spirochiete.

"The mode of transmission has not yet been studied. It does not appear to be highly contagious, as it does not appear to spread from one to another, exen under the most favorable circumstances.

"It more nearly resembles malaria in this respect. It is more than probable that its extra corporeal state is different, or anothersupposition equally tenable, is that its intermediate host is some insect, such as the fly or mcsquito.'

$\leqslant$ 316. Differential diagnosis. Surra is to be differentiated from anthrax and the other trypanosoma diseases. A history of the case or outbreak together with the chronic course and intermittent temperature in surra will usually suffice to determine the nature of the disease. A positive diagnosis can easily be made in the horse, in a majority of cases, by a microscopic examination of the blood. The trypanosoma are readily observed, and nsually they are in sufficient numbers to be quickly seen. In a suspicious case, where the organisms are not found, the examination should be repeated daily or small animals inoculated with the blood. For this inject about I c.c. of the blood into the abdominal cavity 
of a dog. In a few days the trypanosoma will be found in the usual way if the disease is surra. Althougl this requires some time the importance of a positive diagnosis demands that it should be done.

Surra may be complicated with broncho-pueumonia, Rinderpest and tuberculosis (especially in cattle), foot and mouth disease, pseudo-actinomycosis, neoplasms and septicemias as yet little understood.

If no history or symptoms are known, the diagnosis can be made post-mortem from the bacteriological examination of the tissues or blood, as Bact. anthracis is readily found in cases of anthrax.

S 317. Prevention. The importation of animals from infected contries should be prohibited. If the disease gains entrance, the infected animals should be destroyed. In framing regulations for quarantine particular attention should be paid to the wild animals and to circus animals.

Lingard found that arsenic has a decided effect in diminishing the number of surra organisms in the blood of affected animals. Thus far serum therapy is not successful.

From the latest results, it is very clear that infected animals must be destroyed and the healthy ones protected from the bites of insects.

REFERFINCES.

1. BIRKE. Surra or progressive pernicious anituia, let. Jour. London, Vol. XXV, 1887.

2. DURHAM. Tsetse disease. l'eterinurian, V'ol. LAXI (isg8).

3. IURRANT. A trypanosoma found in blood of catile in India. Jour. Comp. Path. and Thera. Vol. XYII (1904), p. 209.

4. Evaxs. Report on surra disease in the I)era Ismail Khan IDistrict. I8So. Military Department.

5. Exins. (In a horse disease in India known as "surra," probably due to a Hixnatozoon. l'et. Jonr. London. Vol. Xill (1sisi). July, Aug., Sept., Nov.

6. Hassal.t. Bibliography of surra and allied irypanosonatic 
diseases. Bulletin No. f2, U. S. Bureau of Animal Industry, I892, p. 132.

7. KANTHACK, DURHAM ANI BLANDFORD. On nagana or tsetse fly disease. Report made to the tsetse fly committee of the Royal socity, etc. Proc. Royal.Soc. London, Vol. LXIV, p. Ioo.

8. LIYGARD. Report on horse surra. I893. (Bombay.)

9. LANGARD. Report on "surra" in equines, bovines, buffaloes and canines, etc. Rec. de méd. vil. Par.s. Vol. VIII, p. 377.

IO. MisgraliE AND CLFGG. Trypanosoma and Trypanosomiasis, with special reference to surra in the Philippine Islands. Vo. 5. linreau of Gozernment Laboratories, .Manila, r903.

II. Musgrave and Cr.FGg. Reporl of the Superintendent of Gon'ernment Lahoratories in the Philippinc Islands, 1903.

12. NocARD. Sur les rapports qui existent entre la dourine et le surra ou le nagana. Comp. rend. Soc. de Biol. Vol. LIII (Igor).

13. RAxkixg. A prelininary note on the nature and pathology of the disease known as " surra" affecting horses and mules in India. l'et. Jour. London, Vol. XXXII (1891).

14. SALMON AND STrus. Emergency report on surra. Bullitin No. t2, L'. S. Burcau of Animal Induslry, 1892.

15. SCHILING. Bericht über die Surra-Krankheit der Pferde, Centralblattf. Bakteriologie u. Parasit. Bd. XXX 1902), p. 545:

i6. Smith AND Kinvotx. A pliminary note on a parasitic disease of horses. Army Pathological Laboratory, Manila, Oct. 17, I9or.

17. StenL. On relapsing fever of equines. Vel.Jour. London. Vol. XYII ( I8S6).

18. STEEL. Report upon an obscure and fatal disease anong transport mules in British Burma. 1885.

19. Strles. Trypanosoma in a new rôle. Am. Méd. Vol. III (1902).

DOURINE

Synonyms. Tenereal disease of solipeds; equine syphilis; chancerous epizoötic; breeding paralysis; epizoötic paraplegia; maladie du coït.

S 318. Characterization. A contagious affection of solipecis, transmitted by copulation and attended by specific 
lesions of the generative organs and nervous system, such as local venereal swellings, chancerous nlcers and cicatrices, dementia and paralysis.

The disease is essentially an equine one, although the following species are susceptible to experimental inoculation, namely: dogs, rabbits, rats, mice and asses. While the horse shows the greatest susceptibility, the ass is comparatively resistant to the infection.

$\$$ 319. History. Dourine seems to have first been recognized in Algeria. It was first clearly described in 1796 by Ammon who found it in the royal stud at Trakchnen in Northern Prussia. We have later, I80 I and 1807 , descriptions of the disease in the same locality. It was found in Bomberg in 1817 to 1820 , in Austria and Bohemia in $1821-8$, in Syria in 1821 , in Switzerland in 1830 , in France in $1830-32$, in Siberia in $1833-40$, in Italy in 1836 , in Russia in 1843 , in Poland in $1830-40$, in Algiers in $18+7-55$. In Syria and Asia generally it is reported to appear perennially.

It is not known to have invaded Belgium, Scandinavia, England, South America or Australia. All indications point to Asia and Northern Africa as the home of the disease where it still appears perennially.

It was found in De Witt Connty, I11., in I882. The first animal showing the disease was a brown stallion that had been imported from France. In this locality it spread to a considearble number of breeding mares and stallions. The disease was very largely stamped out of that region by a rigid quarantine of diseased and exposed animals. Some exposed animals had, however, left the district, and it is not surprising that isolated centers of infection are occasionally found.

$\$$ 320. Etiology. Thanhoffer found in the blood, vaginal mucus, testicle, semen, spinal fluid and roots of the dorsal and lumbar nerves, bacteria, especially streptococci and less constantly bacilli, to which he attributed the cause. More recently Schneider and Buffard have apparently demonstrated that one of the Trypanosoma is the specific pathogenic agent. 
Rouget in 1896, described a trypanosoma found in the blood of a horse suffering from dourine, and for over two years continued the study of this organism in susceptible animals. Wasilewsky and Senn confirmed Rouget's work, and determined the pathogenic action of this trypanosoma for the horse, passing it through other animals and back to the liorse, reproducing the disease. Laveran and Mesnil (1901) proposed the
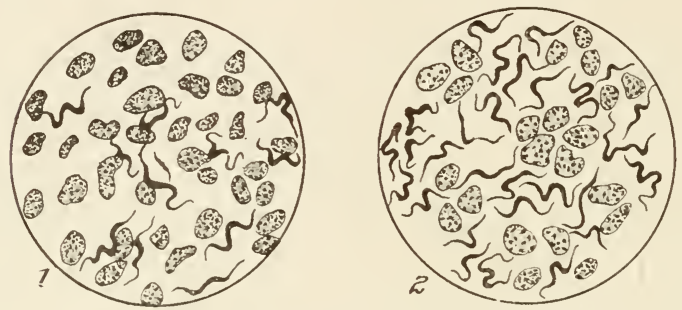

FIG. I08. Tr. equiperdum. I, in the blood of a mouse four days after inoculation, 2, same blood eight days after inoculation (aft:r-Rouget).

name $T r$. rongetii for the parasite of dourine. Doflein named it $T r$. equiperdum, which is the name used by Salmon and Stiles.

In its morphology and evolutionary forms, the trypanosona of dourine has not been shown to differ from that of surra. The granule form, the spherical, the club shaped or pyriform bodies, the fusiform with more or less stellate groupings seem to be generic characteristics. Baldrey states that it is smaller than the Trypanosoma of Surra. The specific distinction is found in the pathogenesis as shown by the two diseases (surra and dourine).

In the active stages, the parasite is usually found abundantly in edematous fluid, the blood, semen, milk, vaginal secretions and the erosions of the vaginal mucosa and penis. During intermissions, however, and in the absence of local lesions, the parasites are not found in the blood on microscopic examination, yet the inoculation of the blood into 
a dog will usually produce the disease. The parasite disappears from the blood and tissues very rapidly after death, so that, to prove successful, inoculations should be made from an infected individual before or immediately after death. They are not affected after forty-eight hours.

Schneider and Buffard, Nocard and others fount the trypanosoma in the blood and exudates of horses, asses and dogs suffering from dourine. They failed to find it in the same localities in animals of the same species which were free from dourine. The infected blood preserved for 24 hours in sealed glass tubes, and then inoculated into dogs produced characteristic symptoms and lesions with many trypanosoma in the blood. Inoculation into two other dogs, with the same material, but at the end of $4^{8}$ hours, produced a slight transient hyperemia only, without local lesions or propaga-

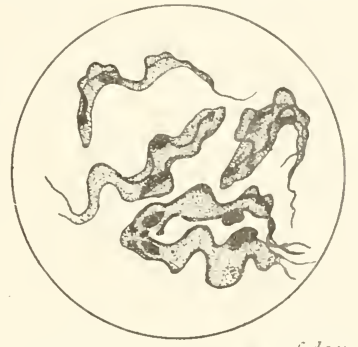

Fig. rog. Trupanosoma of dourine in the process of dizision (aiter Ligniires). tion of the parasite in the blood. The blood from the same animal inoculated after fifteen days gave negative results.

Baldrey found Romanowsky's and Wright's modifications of Leishman's method the best methods for staining the trypanosoma ; the latter is very useful and handy, as no mixing of solutions is necessary and no fixing required.

The following is Romanow'sy's Stain :

$$
\text { STOCK SOILTION NO. I. }
$$

Höchst's Medicinal Methylene Blue ..................... I part sodium Carbonate pure. 0.5 parts Ioo parts

Distilled water............... for two or three dars,

Place this solution in an incubator at $37^{\circ} c$ ages of the liquid; this when a purple color will be noticed at thelor-methylene red-which combined with eosin iorms the active principle of the stain and has a 
particular affinity for chromatin. Unless this polychromatophylic change takes place the solution is useless.

STOCK SOLETION NO. 2.

Eosin

I part

Water Iooo parts

For staining, the stock solutions are separately diluted with water, 5 parts of stock solution to 100 parts of water.

In order to obtain a smear, prick the center of the plaque and take a drop of blood on a slide, which should be chemically clean, having been taken from an alcohol bottle and dried with a clean piece of art muslin. Then, either in the ordinary way with a piece of cigarette paper, make a thin even smear over the slide, or, as an easier and equally efficient method, take a perfectly clean flat large-sized needle and place it edgeways on the drop, when the capillary attraction of the needle will cause the blood to stream right across the slide; then evenly and gently draw the needle down the length of the slide, and a very even smear may be obtained. Qnickly dry the smear in the air by waving rapidly about, which prevents the red corpuscles from crenating; the slide can then be kept indefinitely or used at once. The advantages of using a slide instead of a cover-glass are that you get a much larger field on which to work, it is much more easily manipulated and it can be kept without any mounting. Place the film in absolute alcohol or alcohol and ether, for fifteen minutes to half an hour, to fix. This coagulates the albumen and makes a permanent film in which the corpuscles and organisms are retained. Remove from the alcohol, wash in water, and then apply the stain. This is made by mixing equal parts of the above two solutions, freshly prepared, in a small glass measure or porcelain dish. It is important that the admixture should be as fresh as possible. Apply the stain to the whole of the film and let it remain for seven to ten minntes; wash in water and dry in the air, no heat being applied. The red corpuscles may have a bluish tinge, which may be removed by further washing. If the blood platelets appear bluish the film requires further staining; they should appear as ruby-red granular bodies. By continuous application of water the stain may be washed out, but the film may always be stained over again.

By this stain the protoplasm of the trypanosome is stained blue, the nuclear chromatin a carmine violet, and the flagellum and centrosome a brilliant red. The red corpuscles will be a pinkish colour, and the various forms of leucocytes will be well differentiated. In examining the smear, time may be saved by looking along the edge of the film, as it is here that the parasites will be most numerous if they are present, as they, being like the leucocytes of less density than the rest of the blood, tend to run to the periphery when the smear is made.

A film made in this way requires no cover-glass, but if the cedar oil 
is left on it tends to withdraw the color; however, if it be carefully blotted and wiped off with a soft rag after use the film may be kept indefinitely.

321. Symptoms. The first local changes in the genital organs begin after a period of incubation, according to Maresch, of from eight days to two months. The first symptom in the stallion consists in the swelling of the glans penis. Reddish spots, vesicles and ulcers may occur on the outer surface of the organ. The meatus urinarius is reddened and swollen and exhibits a mucous discharge. The animal lias a continuous desire to micturate and frequently manifests sexual excitement. The swelling also spreads from the penis to the sheath and scrotum in which case the testicles become inflamed. Finally, the inguinal glands and lymph vessels become involved. These local affections may, as the disease advances, almost entirely disappear. In some cases the external changes are absent, as the mucous nembrane of the urethra is first affected, the only visible symptoms being strangury and a mucous discharge from the urethra.

In mares, the disease begins with a donghy or tense swelling of the pudenda, which frequently spreads to the udder and inner surface of the thighs. 'The mucous membrane of the vagina is red in spots and swollen, sometimes thickened by gelatinous elevations and covered with a turbid and orange colored secretion. Sometimes nodules, vesicles and ulcers are observed on the mucous membrane. They are, however, frequently absent. In mares, the local manifestations are often insignificant. The mucous membrane in the neighborhood of the clitoris is more congested than at other points and the clitoris itself is swollen and erect. It is devoid of pigment and unnaturally dry. Williams states that this depigmentation is " peculiar and characteristic." The spots of discoloration are not caused by previous ulcers. At the same time affected mares show excessive sexual excitement. They frequently suffer from strangury and after considerable straining urine is discharged in small jets. In his report on the Illinois outbreak, IVilliams states that in mares, "The open vulva and 
enlarged, protruding, unnaturally dry clitoris, especially in young and otherwise healthy mares is quite pathognomonic."

Instead of urine small quantities of sticky, discolored mucus are discharged. The animals incessantly shake their tails and open and close the vagina in rapid succession, showing the clitoris as mares do in season. The discharge often exerts a corrosive action on the tail and legs. In severe cases the neighboring lymph glands become inflamed and swollen as well as the udder, on which abscesses may appear. The swelling may even extend to the hypogastrium.

The general symptoms develop only after weeks or even months; their appearance is often delayed until the local symptoms have disappeared. At first the animals are depressed and weak, they frequently continue to lift up their bind feet, alternately, so as to try to avoid putting weight upon them, knuckle on their fetlock joints and lose control over the movements of their hind legs while walking. The temperature is not so high as in other forms of Trypanosma infection.

It is reported that stallions especially suffer from an urticaria in the form of sharply defined, round, flat eminences which may be'raised the breadth of a finger above the surface and which may vary in size from two to four centimeters or more in diameter. These eminences are caused by a serous infiltration of the papillary layer of the skin in the neighborhood of a small artery and are evidently of a vaso-neurotic character. They often appear and disappear very rapidly and may shift their position. Usually they persist for several weeks during which time they become moderately hard and then slowly disappear. Their farorite sites are the croup, neck, shoulders, chest and abdomen.

Later in the course of the disease, a progressive paralysis of the hind quarters combines with excessive emaciation. The animal has a staggering gait and often gives way on the pasterns and at the knees, can raise itself from the ground only with difficulty, and sometimes falls down unexpectedly. The affected stallion is unable to cover, as he can neither mount a 
mare nor get an erection. Some patients exhibit permanent tremblings over the whole body or local paralysis as for instance, that of the lips, ears and eyelids. Hyperesthesia of the skin is observed particularly in stallions and with it is extensive pruritis, so that the animal continually rubs itself, bites the affected parts and thus produces extensive sores on the skin. The patient becomes extremely emaciated especially in the hind quarters so that the outlines of the pelvic bones and ribs become very prominent. The skin becomes dry, the hair is ruffled and loses its gloss. Some animals manifest pain when the lumbar region is pressed. The senses become more and more blunted and the eyes assume a staring and expressionless appearance. As the end approaches the patient persistently maintains a recumbent position and finally dies from the effect of secondary lesions such as hypostatic inflammation of the lungs, septicemia or perhaps general cachexia. Sometimes in the final stage the patient suffers from nasal catarrh with swelling of the submaxillary glands and conjunctivitis. Severe internal inflammation of the eyes has been observed. The appetite continues longer than any of the other normal functions.

Baldrey has divided the symptoms into three different stages, as suggested by Nocard. These stages are distinct, and may, if the case is carefully watched, be recognized comparatively easily. They are :-

Primary. In which occur the local manifestations of discharge and urethral irritation, and ulceration of the penis and sheath.

Secondary. In which the exanthematous eruptions appear in the skin-the so-called "plaques".

Tertiary. Characterized by the formation of lesions in the central nervous system, and by nervous disturbance with ultimate paraplegia.

It was probably on account of these three periods that the older writers coufounded the disease with syphilis, and it is also possible that the ulcerations and chronic enlargements of 
the sheath and penis gave rise to the idea that it was a form of localized glanders.

The duration of the disease is stated by Williams to extend from three months to as many years. The prognosis is unfavorable.

$\$$ 322. Morbid anatomy. In the early stages there are phlegmonous or edematous swellings of the sheath, scrotum, penis and inguinal glands and a yellowish liquid effusion into the scrotal cavity. The skin covering the parts may show a papular or vesicular eruption or if this has passed a mottling with white spots shows where these lesions have been. Later, the inguinal glands shrink and become firm, owing to the development of fibroid tissue. The testicles, which are either swollen or shrunken, contain foci of suppuration or caseation. The connective tissue of the epididymis and the cord is the seat of a gelatinous exudate. The walls of the scrotum may be greatly thickened and be the seat of abscesses or of caseous degenerations. In advanced cases the testicles are usually abnormally small, even if the scrotal mass is enormously distended. The sheath and penis may be the seat of more or less numerous ulcers and swellings. Contraction and contortions of the penis are not uncommon. It may, however, retain its normal dimensions. The walls of the lymphatics in the inguinal region may be the seat of hyperplasia; the thickening causes them to stand out like cords as in glanders. In the advanced stages the muscles, especially those of the hind limbs, become pale and atrophied. The nerve centers undergo profound changes which have been studied by Thanhoffer. The pia mater in the affected part of the spinal cord is the seat of active congestion and thickening. The central canal of the cord is dilated more at one point than another, contains more than the normal amount of liquid and the neuroglia around it is thickened and fibrous. The substances of the cord, both white and gray, show congestion, blood staining, and points of softening and of hyperplasia of the neuroglia. The nerve cells are modified in various ways, some being granular, some discolored by fine granular pigment, some hav- 
ing enlarged and multiple nuclei and some show vacuoles. The nerve filaments often show a granular degeneration extending from the nerve cell to the axis cylinder. The latter is liable to be varicosed or enormously enlarged. In the affected portion of the cord, leucocytes are numerous and there is often hyperplasia. The neuroglia tends to increase, and apart from the foci of softening tends to give a special firmness to the substance. The subarachnoid and subdural fluid is increased and there may be at the roots of the spinal nerves, especially in the dorsal and lumbar regions, a gelatinoid exudate investing the nerve, distending the connective tissue beneath the neurilemma and even occupying the interval between the nerve filaments. Sometimes large corpuscular bodies are found between the nerve fibers.

Weber and Nocard state that sections show cachexia and hemorrhagic softening of the spinal marrow. The parasites found in these areas and in the serous effusions resemble those of surra and nagana.

The cerebral meninges are congested and opaque. Foci of softening are by no means uncommon and the cerebral rentricles contain an abnormal quantity of fluid.

The bony tissue generally has lost its consistency and the medullary matter may be unduly reddened. The large joints contain an excess of synovia of a somewhat pinkish color. The ligaments of the hip joint are often congested, thickened and softened. The articular cartilages may even show areas of blood staining.

The intestines are usually nearly empty, soft, pale and flaccid. Ruthe has in one case observed rounded nlcers on the mucosa.

The mesentery is thickened with an infiltration and it has a yellowish discoloration and the mesenteric glands are usually enlarged, softened and friable, though sometimes firm and contracted. The lymph glands adjoining the generative organs are often swollen, pigmented and studded with foci of caseation, varying in size from that of a pea upward. The liver is softened, hyperemic or fatty. The spleen is small. 
The kidneys are usually large, pale and blackened. The thoracic organs may show little change, though hypostatic congestions and foci of caseation or suppuration may be present. The blood is light colored and forms a loose, pale clot. There is a diminution in the number of red blood cells and a relatively large increase in the number of lencocytes.

In the mare, in addition to the lesions in the internal organs and blood, the following may be noted in connection with the generative system. Phlegmons or edematous swellings, or ulcers on the lips of the vulva and on the vulvar and vaginal mucosae. The parts become variously distorted. A crop of pustules or vesicles which run into ulcers may appear on the urethral orifice, the vulva and adjacent skin. The mammary glands are sometimes inflamed, edematous and tender, with suppurative or necrotic foci. The adjacent lymph glands are enlarged by infiltration or contracted by sclerosis.

In the dog the symptoms and the lesions resemble those in the horse.

$\$$ 323. Differential diagnosis. Dourine is to be differentiated from the other forms of Trypanosoma disease, and also from " Benign venereal disease."

Dourine is characterized throughout by its intermittence. As each fresh crop of parasites appears in their cycle of existence, there is an exacerbation of symptoms, but, in contradistinction to the malarial hematozoon of man and the piroplasma of cattle, there is no marked rise of temperature and a correspondingly low fall.

Williams describes a benign venereal disease of mares all of which had been bred to an imported French draft horse. He states that "the margins of the vulva retain their natural color in this disease, except at the seat of eruptions, when the color quickly returns. The vulva remains naturally closed, and does not gape, "as in maladie du coit. The clitoris retains its natural color, size and appearance." The duration of this affection is stated to be from two to six weeks, but may persist 
for a longer time if neglected. The cause is not known. He reports that when it becomes established it is highly contagious. It appears to be spread by copulation.

$\leqslant$ 324. Prevention. The prevention of this disease seems to rest in the isolation of all affected animals. It is important, therefore, that its diagnosis be made at the earliest possible moment. As it is not spread except by copulation, it is a comparatively easy disease to control if taken in time.

Prophylaxis.-In Austria where the disease has existed for a long time, the following rules are observed. Baldrey states that they sum up the necessary preventive measures. It is understood that they apply to a country in which the disease is prevalent :-

"( ( ) Eren when there is nothing to lead to the supposition that the disease exists, every mare about to be put to the horse shall be carefully inspected, and refusal made to old and weakly mares, or to those which have a discharge from the vulva, or have that organ enlarged or swollen, or which do not present the ordinary manifestations of oestrum. It is also suggested that an edematous swelling, no matter where situated, should negative covering.

“(2) The stallion's penis to be carefully and frequently examined, and on no account is the animal to be used if there is the slightest lesion upon it. He is to be kept secluded until all doubt as to the nature of the lesion has passed away.

"(3) Give every information possible to breeders as to character, etc., of the disease.

"(4) Immediate information is to be given in all cases of stallions in the least suspected, and the necessary steps taken.

"(5) To prevent extension, the sale of all mares in the affected areas to be stopped during the prevalence of the disease.

"(6) If the malady has spread in a district, all breeding stallions to be stopped employment, whether Government or private property. Those already diseased to be sequestrated 
under police supervision, whether private or Government property.

"(7) Affected animals to be separated from healthy, to have their own attendants, and no interchange of clothing, utensils, etc., to take place. Those deemed curable to be treated, those incurable to be destroyed.

“(8) All horses attacked to be castrated, as well as those which, notwithstanding their apparent good health, have transmitted it to mares they have served, and also those which have been put to infected mares.

"(9) Mares that have been in the least affected and apparently cured not to be covered the following year, or until certified by a veterinary surgeon as cured. It is even better to exclude all such mares entirely, and brand them as having had the disease."

REFERENCHS.

r. Baldrey. Dourine. Jour. Comp. Path. and Thera., Vol. XVIII (I905), p. I.

2. BUFFARD AND Schneider. Prophylaxie de la dourine et exposé de faits nouveaux intéressant cette maladie. Jour. de . Véd. I'ét. et de Zootch, igor.

3. Favil, E. Extirpation of maladie du coit. Annual Report, Bureau of Animal Industry, r895-6, p. 13 and 62.

4. Mohler. Cultivation of Trypanosoma Equiperdum. Proceedings Am. Vet. Hed. Asso., I905, p. 363 .

5. RovGET. Contribution à l'étude du trypanosome des mammifères. Amer. de l'Inst. Pasleur, Vol. X ( I896), p. 716.

6. ThanhoFfER. Über Züchilähme. Wien. Iss8.

7. Williaus. Maladie-du-Coit, or equine syphilis. Annual Report of the Board of Live Stock Commissioners, for the State of Illinois Fiscal Year ending Oct. 31, I857. (A full report of the disease and its eradication in Illinois.)

8. Willians. Benign venereal disease-equine chancroid. Ihid. p. 84 .

9. Wilson-BARKER. Maladie du coït in Nebraska. Vet. Jour. Lond., Vol. XXXY (1892). Vol. XXXVI, (1893). 
MAL, DF; CAIHEAS

325. Characterization. Mal de caderas (disease of the rump) is a disease essentially of the horse kind, characterized by an intermittent fever, a progressive paralysis of the posterior parts, rapid emaciation and death. It is a "wet weather" disease, as it is reported to almost entirely disappear in the dry season. Horses, mules and asses are said to suffer from it. Horses are said never to recover.

$\$ 326$. History. Rebourgeon studied this disease in I889. He made a bacteriological investigation into its cause without success. Leclerc described it clinically in $1899 . \mathrm{He}$ believed that he had found its pathogenic bacterium. In I 901 , Eilmassian showed that this disease was caused by one of the trypanosoma. Toges and Lignières confirmed his discovery.

\$ 327. Geographical Distribution. Mal de caderas is a disease of tropical South America.

\$ 328. Etiology. EImassian differentiated the trypanosoma of this affection in Igor. Voges pointed out its pathogenic action and named it Tr.equinum. In length it is 3 or + times the diameter of the red blood corpuscles. Its width is one-third to one-half the diameter of a red blood cell.

The anterior end is provided with a flagellum about as long as the body of the parasite. It extends backward about two-thirds the length of the body as a somewhat thickened margin of a distinct undulating membrane. The posterior end of the parasite is about one-third the length of the flagellum. It is contracted and somewhat beak shaped.

Its motion resembles that of an eel, but its actual motility is not great, the whole body taking part in an excessively active wriggling motion with the flagellum and beak ends moving in opposite directions. The nucleus is toward the anterior end, a very small centrosome near the posterior end, and there is a granular protopiasm.

It is found in the blood of horses, mules, asses, hogs and 
water hogs suffering from mal de cadcras. It is transmissible to white and gray rats and mice, rabbits, dogs, goats, sheep, chickens, turkeys, ducks and certain monkeys found in South America. Cattle are said to be immune.

The parasites are most numerous in the circulating blood during the rise of temperature. Upon its reaching $40-4 \mathrm{I}^{\circ} \mathrm{C}$ they gradually disappear, but reappear with the next rise of temperature.

$\$$ 329. Mode of infection. Unlike dourine, the virus of mal de caderas is not transmitted by copulation. It has been proven that the virus is disseminated and animals are infected with it by means of certain insects. Stomoxys calcitrans has been incriminated and several other insects are under suspicion.

$\$ 330$. Symptoms. The first symptom is an elevation of temperature which rises slowly, but suddenly falls to normal. Emaciation is rapid. The urine is dark colored and usually coutains albumin, and perhaps blood. The blood changes so that it gives the picture on microscopic examination of pernicious anemia. There is an increase in the lymphocytes and in the eosinophiles. The most obvious symptom is said to be a symmetrical or asymmetrical paresis of the hind legs. Defecation and urination are difficult (coinciding with paralysis of the sphincters). The paralysis gradually extends to other parts of the body. Edema is often present. The appetite remains good until near the end when there is extreme thirst.

The duration of the disease is variable. Some animals die after a month, others live for a year or longer. Stiles states that it lasts from two to five months in horses and from six to twelve months in mules and asses.

\$3 33. Morbid anatomy. The muscles are pale and atrophied in the posterior part of the body. The intermuscular tissue is infiltrated with a gelatinous serous-like substance. Hemorrhagic foci appear in the muscles of the rump. 
The spleen and lymphatic glands are enlarged. The liver is enlarged and congested. The lieart muscle is soft and flabby. The lungs often contain ecchymoses and subpleural emphysematous areas. There is a serofibrinous exudate in the body cavities, especially in the pericardial sac and pleural spaces. There are conflicting statements concerning the morbid anatomy and it is difficult to select those that are not contradicted. The pathological histology and the lesions in the nervous system do not appear to have been described.

\$332. Differential diagnosis. This affection is to be differentiated from the other forms of trypanosoma infections. There seems to be no other specific disease with which it would be confused. The diagnosis is made from the intermittent fever, emaciation, progressive paresis, anemia, and the finding of a parasite. The inoculation of experimental animals (mice or dogs) with the blood is of value when the parasite is not found on microscopic examination in the blood of the horse.

\section{REFERENCHS.}

1. Fimassiax. Mal de Caderas. Anales de la Uniũorsidud Naional. Isuncion, Vol. V (1901).

2. LACLkRC. El mal de Caderas. Puenos Ayres, is 99.

3. Lignitires. Contribución al estudio de la trypanisomiasis de los Equideos Sud Américanos. Buletin de agriultura y yanaderia (K'epublic Argentina) rgo2, p. 843 .

4. Rebotrgeox. Note sur le mal de Cadera. Reilleil de míd. i'citér. $\quad$ I8S9, p. 85 .

5. SivOri AND Licler. Le surra Américain ou nial de Caderas. Anales del ministerio de agricultura, igo2. Cientralbl. für allg. Path. 1902, ‥ 963 .

6. loges. Das mal de Caderas. \%eitschrift f. Mygine, Bd. XXXIX (1902), p. 323 .

See also literature on other trypanosoma. 
Synonym. Tsétsé-fly disease.

$\$ 333$. Characterization. Nagana is a disease characterized by anemia and rapid emaciation caused by one of the trypanosoma. It attacks horses, mules, zebras, cattle, and sheep. A number of the smaller animals are susceptible. It is known to all dialects as the tsétsé-fly disease.

$\$ 334$. Geographical distribution. This disease is found in central and southern parts of Africa. There seems to be some doubt about its identity with the disease of a similar nature in the Transvaal.

$\$ 335$. History. Livingston pointed out the existence of this disease in Central Africa. In i 886, Bruce studied it in the Zulu Land. He found constantly in the blood of the sick animals a trypanosoma similar to that found in surra. It has been carefully studied by Kanthack, Durham and Blandford, Koel, Plimmer and Bradford, Theiler, Schilling, Laveran and Mesnil.

$\S 336$. Etiology. This affection is caused by Trypanosoma Brucei. It is from 28 to $33 \mu$ in length with the flagellum and about $I \mu$ in width. It is closely related to $\mathrm{Tr}$. equiperdum. Some investigators have been unable to satisfactorily differentiate the $t$ wo species, while others recognize them as distinct.

The trypanosoma are transmitted from the diseased to the healthy animals by means of the tsétsé-fly (Glossina morsitans), which exists in certain parts of Africa. It appears that this is the only species of insect responsible for the transmission of the virus. The affection is extended into uninfected areas by the introduction of diseased animals.

The period of incubation, in artificially produced cases, is reported to be about 4 days in the horse.

$\$ 337$. Symptoms. The first indication of the disease is a rise in temperature which lasts for 3 or 4 days, when it 
suddenly drops. After this time the temperature oscillates between $35^{\circ}$ and $41^{\circ} \mathrm{C}$. Emaciation is rapid, the hair becomes rongh and may fall out. There is a tendency to diarrhea. There is edema of the abdominal walls. In cattle the symptoms are not usually so acute as in the horse.

The duration of the disease is said to vary from a week to six months or more. The appetite remains good until near the end. According to Bruce recovery is rare.

$\leqslant 338$. Morbid anatomy. There appear to be no distinctive anatomical changes for this affection. The tissues generally are reported to be anemic and infiltrated with a serons exudate. If the edematous portions are incised a clear amber or citron colored fluid escapes. The spleen may be enlarged but the color and consistency are normal. The liver and kidneys are said to be slightly affected.

$\$$ 339. Differential diagnosis. The diagnosis is made clinically from the progressive anemia and edema, coincident with a good appetite. The finding of the parasite in the blood is positive eridence. This disease is to be differentiated from the other affections caused by trypanosoma.

\section{RFFERENCES}

I. BRUCE. Preliminary report on the tsétsé-fly disease or nagana, in Zululand. Durham, 1 \$95.

2. KANTHACK, DURHAM AND BLANDFORD. On nagana or tsétséfly disease. Proceedings of the Royal Society, Vol. LIIV (189S), p. 100.

3. LAIERAx AxD MEsxil. Recherches morphologiques et expérimentales sur le trypanosome du nagana ou maladie de la mouche tsétsé. Inn. de l' Inst. Pasteul, 1902, p. I.

4. PliMMER AND BRADFORD. A preliminary note on the morphology and distribution of the organism found in the tsétsé-fly disease. The Veterinarian, Vol. LXXII (1899), p. 64 s.

5. Thender. Die Tsétsé-K rankheit. Siha'izer-Alihiz fur Thic'heilk., 1901. S. 97 .

340. Differentiation of surra, dourine, mal de caderas and nagana. The divergence of opinion concern- 
ing the nature of these affections and the specific identity of the exciting cause, render a differentiation or unification of these most interesting diseases exceedingly difficult. Very few investigators have had the opportuuity of studying all of them in their natural environment. The conclusion of Musgrave and Clegg in their recent report is worthy of consideration. They say: "In summing up the whole matter it appears to us, when we take into consideration the work done by others and add our own results, that we are justified in believing surra, nagana, mal de caderas, and probably dourine. the same disease, and that all are caused by Tr. Evansii."

Koch, who worked with surra and nagana, considered the parasites and the resulting infections identical. Many others have formed similar conclusions. Other investigators such as Voges, Laveran and Mesnil and others maintain that certain differences exist. The evidence is convincing that dourine and mal de caderas are different in some respects from the other two. Voges' reasons for this are:

I. "Dourine and mal de caderas can not be transmitted to cattle.

2. "In regions where mal de caderas exists cattle do not die of surra.

3. "We have no reason to believe that trypanosoma show the same irregularities of virulence as bacteria, so that the different forms of the disease may be said to be produced by different degrees of virulence in the same trypanosoma. On the contrary, during our four years of experimentations, the latter have shown a constant virulence."

4. The fourtl reason which he considers decisive is based on the morphological differences in the parasites.

Voges concludes by saying, "I think these four proofs are entirely sufficient to establish for all time the difference between surra and dourine as well as between surra and mal de caderas." Laveran and Mesnil give extensive consideration to the differences between surra and nagana. A summary of their considerations is appended. 
1. "'The same animals are susceptible to buth diseasesthe horse, ass, mule, goat, sheep, cow, camel, dog, cat, monkey (long-tailed macayo), rabbit, guinea-pig, and rat.

2. "In the horse the course of the disease is the same, whether surra or nagana. The aninual dies at the same time, in 30 days on the average. In inoculation cases the period of incubation is the same, and the same symptoms and lesions supervene.

3. "The other equides, the goat, slieep and dog, die of the two diseases in the same length of time and with similar symptoms and lesions.

+. "Rabbits, guinea-pigs and rats succumb to the infection in a like manner.

5. "Cows rarely survive nagana, and they rarely die from suma. They become emaciated with surra but recover in health and a subsequent inoculation does no harm. This is a marked difference between them but it may be explained when further experiments are made."

Laveran and IIesnil believe that the paralysis of the posterior extremities, a marked symptom in mal de cadcras, is less marked in surra and nagana, although they believe the three affections very closely related. Dourine differs from the other three in two distinct points: (I) The morphology of the parasite is different. (2) In dourine contagion by coition seems to be the only natural mode of infection.

Much additional investigation will be necessary before the question of either the identity or the non-identity of these affections can be positively determined. As these diseases are not liable to become of great economic importance in this country, further discussion of the voluminous literature seems unnecessary. 
CHAPTER XII.

\section{INFECTIOUS DISEASES FOR WHICH THE SPECIFIC CAUSE IS NOT DETERMINED.}

$\$ 34 \mathrm{I}$. General consideration. It was not until a comparatively recent date that the nature of the infectious diseases began to be understood. They were, however, differentiated in so far as that could be done by clinical evidence alone. With the work of Pasteur, overthrowing the "spontaneous generation" theory; the introduction of the aniline dyes by Weigert in 1877 ; the discovery of solid culture media by Koch in I88I; together with the finding of the specific causes of anthrax, Asiatic cholera, tuberculosis and other diseases, there naturally came new methods for the study of the etiology of these affections. By the use of newer methods and better instruments of precision and the closer study of these affections the cause of one after another of the infectious diseases was revealed until the etiology of a large number of them has been made known. These have already been grouped and studied. There are remaining still a number of well recognized diseases for which a specific cause has not been found. The methods for the investigation of the cause of disease that have been effective in case of other diseases have failed here. Until other procedures are devised, the specific causes of these affections will undoubtedly remain undetermined. Their study, however, has revealed much concerning their nature, so that measures for their prevention have been found that are quite as effective as they are with those of known etiology.

RINDERPEST.

Synonyms. Contagious typhus; steppe murrain; cattle plague. 
S 342. Characterization. Rinderpest is the most fatal disease affecting cattle. It is a specific eruptive ferer, occurring both sporadically and in epizoötics. It is characterized by a more or less typhoid condition, with lesions largely located in the mucosa of the digestive tract and skin, and by the infectious nature of all the tissues, secreta and excreta. It is a disease peculiar to cattle, although other ruminants are susceptible to it.

$\$$ 343. History. Rinderpest seems to have been brought to western Europe by the importation of cattle from central Asia as early as the fourth century. It is supposed that it had long existed on the steppes of central Asia and eastern Europe. The first great epizoötic of which there seems to be records occurred about 1709 and spread over nearly all of the countries of Europe. It is reported that $\mathrm{I}, 500,000$ cattle died from its effects during the years from i7i to i7I4. Ramazzini seems to have been the first (I 7II) to accurately describe the symptoms and lesions.

It was in connection with this disease that the first veterinary police regulations were instituted, and it is stated that because of the ravages of this affection Veterinary Colleges were first established with government aid. In the latter half of the eighteenth century, rinderpest was prevalent in nearly all of the countries of Europe. During the years from 1740 to $175^{\circ}$ it was estimated that three million cattle died. The importance of this disease is shown in the fact that in Italy alone during the year 1792 from three to four million cattle died from its effects. In the years 1844 and $18+5$, Russia is said to have lost a million of cattle from this disease alone. Nearly all the countries of Europe have from time to time lost heavily from it. It is stated, however, that England and (iermany have practically freed themselves from it. Preventive inoculation against this disease was introduced into England by Dodson as early as 1744 and later by Courtivon into France.

344. Geographical distribution. Rinderpest is a well-known cattle plague in Russia and the steppes of central 
Asia. It has extended from time to time from its home in Russia and Asia to nearly every country in Continental Europe and Asia. More recently it has occurred in southern Africa. In $\mathrm{I} 882$, * it appears to have been introduced into the Philippines. It has not been introduced into the United States or other American countries. At present, it is not known to exist in England, although in the past she has suffered many destructive epizoötics.

$\$ 345$. Etiology. The specific etiological factor of rinderpest is not known. Several investigators have isolated and studied various species of bacteria from the tissues of animals dead from this disease. Semmer of Dorpat has always found the same organism in the lesions. His results do not appear to have been verified. There seems to be no doubt in the minds of those who have worked on this disease that it is caused by a specific microörganism, most likely a species of bacteria. Koch makes the following statement concerning the etiology of rinderpest in the second report of his investigations in South Africa in 1897 : "All efforts to find by means of the microscope, as well as through cultivation, a specific microorganism in the blood have as yet been fruitless. I also did not succeed in finding any specific nicroörganism amongst the microbes which the mucus from the nose, the secretions from mucous membranes, and the contents of the intestines naturally contain in large numbers." Jobling reports that 0.1 cc. of blood taken from a sick animal and injected under the skin of a healthy one will produce the disease.

Nicoll and Adil-Bey found that the virus would usually pass through the porous Berkfeld cylinders, but not through the denser form or the Chamberland tube.

The virus may be transmitted from the sick to the healthy individuals in a variety of ways, both direct and indirect. It is said to be present in the various excreta of the diseased animal, stich as the discharge from the nose, the saliva, the urine and

*No authoritative evidence of its occurrence there prior to that time has been found. 
the feces. It retains its vitality outside of the body in a moist state for months, even a year or more, according to some anthorities. Hence, feces and the fodder and bedding soiled by the discharges may conrey the disease. When dried, however, its ritality is said to be lost in a few days. Persons may carry the virus on their shoes, clothing and farm inplements. Even small animals such as cats and rats, which frequent barns and stables, have been looked upon as carriers of the infection. The hides of animals dead of the disease may transmit the infection. The virus is destroyed, according to Hutcheon, by complete desiccation. Kraiewsky found that the virus was destroyed in hides soaked in corrosive sublimate I- IOOO for 24 hours, or in 2.4 per cent carbolic acid for the same time.

It is also clained that animals after having passed through one attack of the disease are able to resist successfully future attacks. Inoculation with the virus is said to produce immunity, but the process of inoculation itself is followed by death in many cases. The disease is reported to have developed after feeding hay a year after it has lain in an infected stable. It is destroyed at a temperature of $\mathrm{I}_{3} \mathrm{I}^{\circ} \mathrm{F}$. but in animal tissues it is said by some to resist putrefaction. Hutcheon, however, states that putrefaction appears to destroy it.

The period of incubation is stated to be from three to ten days. In animals inoculated with virulent blood it is from sixty to ninety-six hours.

S 346. Symptoms. The symptoms of rinderpest are those of a severe, acute, infectious disease. At first the temperature rises to 105 to $106^{\circ} \mathrm{F}$. and remains near that point with but slight variations mutil other symptoms develop. The pulse is small, beating from 160 to 120 per minute. There is great debility, decrease in the yield of milk and loss of appetite; rumination becomes disturbed and the animal may have slight attacks of shivering.

After these preliminary symptoms there are well marked rigors, respiration becomes accelerated and the visible mucous nembranes assume a scarlet color. There is entire loss of 
appetite, arrest of the function of rumination, thirst, constipation with the feces dry and covered with mucus. Sometimes there is slight colic. Later there is a discharge which is first serous and subsequently sero-mucous from the eyes, nose and vagina. The saliva flows from the mouth. The feces gradually become thinner until violent diarrhea accompanied by colic sets in. The evacuations become fetid, viscid and sometimes mixed with blood. The animal becomes rapidly emaciated, staggers when walking, is rery sensitive to pressure on the loins and lies down a great deal. In exceptional cases the patient manifests nervous symptoms. Others exhibit violent dyspnea and symptoms of severe inflammation of the lungs.

As the disease advances characteristic changes are to be seen in the mucous membranes. Red patches which nay be flat or in the form of wheals and which quickly become covered with a grayish white, loose crust appear on the mucous membrane of the lips, tongue, cheeks, gums, nostrils and vagina. The uppermost epithelial layer consequently becomes opaque and yellowish gray spots develop on it. Less frequently crusts are formed from the tumors by their caseous disintegration. The crusts on being shed leave dark red hollow places, the so-called erosion ulcers, which readily bleed. In slight cases of the disease there may be no crusts or erosions. It is stated that sometimes an eruption in the form of very minute pimples and pustules occurs on the abdomen, inner surface of the thighs, perineum and udder. In these cases it may be confused with that of variola. Pregnant animals frequently abort.

In sheep and goats the disease is milder, and its infectiousness is said to be less than in cattle, although the symptoms are essentially the same. Sheep are reported to suffer frequently from pneumonic affections when attacked by rinderpest.

347. Morbid anatomy. Authors differ somewhat on the lesions characteristic of this disease. Walley has pointed out the fact that none of the morbid changes are constant and consequently they vary with the stages of the epizoötic, the 
condition of the animal and the treatment. There is always emaciation, the muscular tissue is dark and the capillary congestion is marked. All the tissues of the body may be the seat of effusions, exudations and blood extravasations. If symptoms referable to the nervous system have occurred, brain lesions will be found at post-mortem.

The muscle of the heart is pale and relaxed. Blood extravasations beneath the endocardium are not rare. The kidneys are usually the seat of congestion or ecchymoses either beneath the capsule or in their structure. There are also parenchymatous changes. The liver is congested, often giving a mottled appearance. It is often bile stained. There are more or less parenchymatous changes in the liver cells. The lymphatic glands are usually enlarged and the mesenteric glands are often hyperemic or even hemorrhagic.

The structures most often affected are the mucous membranes of the digestive, respiratory and genito-urinary tracts and the skin.

Nodules and pustules are sometimes found on the skin, especially of the udder. The mucous membrane of the mouth and pharynx is congested in spots, swollen and exhibits rounded, yellowish gray, caseous plates or deposits. The removal of plates discloses ulcerous and highly congested depressions in the mucous membrane, the so-called erosion ulcers. These changes are best marked on the inner surface of the lips, lower surface of the tongue, buccal mucous membrane and gums of the inferior maxilla.

In the first three stomachs the mucous membrane is usually normal or slightly congested in spots, and the epithelium is so loose that it can be easily detached. The contents of the rumen and reticulum are soft and those of the omasum are often dried, rarely they are fluid. Generally the abomasum is empty and contains only a small quantity of tough, mucopurulent, yellow or sanious material. Its mucous membrane is highly congested, especially in the neighborlood of the pyloric orifice. The congestion is partly diffuse, partly in spots, in the form of points or streaks. Its color may be 
purple or reddish-brown with a tinge of slate-gray. The epithelium exfoliates. On the mucous membrane may be found small, brownish-yellow, caseous deposits, in the form of plates, which become detached in shreds, leaving indented, highly reddened areas which are studded with petechiae. The glands (peptic and mucous) of the stomach are swollen and show considerable cellular hypertrophy. Like changes are present in the small intestine, where there is a good deal of swelling and congestion of the mucous membrane with isolated scab-like caseous deposits and erosions. In very serere cases these deposits form tube-like casts of the intestinal canal. At the same time there may be considerable infiltration of the solitary glands and of Peyer's patches, which become enlarged. Jobling states that he nerer saw them ulcerated.

In the large intestine the inflammatory changes are much less pronounced. They are greatest in the cecum.

The nasal mucous membrane is of a dark red color and covered with grayish-yellow, soft scabs. After they are removed, the true tissue of the mucous membrane lies bare. Similar changes are found in the larynx and trachea, where the deposited masses are frequently purulent and of a creamy consistence. The lungs are sometimes hyperemic, sometimes edematous, hepatised or emphysematous. Pneumothorax and subcutaneous emphysema may be present.

The duration of the disease is usually from 2 to 10 days, the average period is about 6 days. The prognosis is not favorable. The mortality ranges from 60 to 90 per cent.

$\$ 348$. Differential diagnosis. It is very difficult to diagnose rinderpest from the first cases that occur, especially if there is no history of infection. The diagnosis is based upon the symptoms, morbid anatomy, progress of the epizoötic and the history. The most characteristic diagnostic symptoms are the rise in temperature (which often occurs some days before other symptoms), formation of red spots and a yellow coating on the visible mucous membranes and later the development of erosion ulcers. A mucous discharge from the mouth, nares, eyes and vagina with symptoms of severe intestinal disturb- 
ances and excessive emaciation are of differential value.

Rinderpest is to be differentiated from "foot and mouth disease,' and malignant catarrh if complicated with emphysenta of the lungs. Anthrax, Texas fever, and other affections such as contagious pleuropneumonia and enteritis may be mistaken for $i t$. The differentiation may be made from the specific nature of eacin disease.

\$349. Prevention. In this connection the proclamation for the prevention of the spread of rinderpest in Cape Colony recently issued by the British Government authorities is of interest. It is as follows :

"Disinfection of hides, hoofs, homs, skins and fiathers. 1. Hicles skins, hoofs, horns and feathers will only be allowed south of Orange River and will only be accepted for conveyance by rail after being thorongbly disinfected in the manner hereafter described at ranlway stations and the anthorized crossing places in terms of Regulation 5 issued under Proclamation No. 387 of 1 isg , or at each of them as shall hereafter be notified.

2. No hilles, skins, horns or hoofs shall he passed by the supervising Officer unless accompanied by a declaration signed by the consignor (or his agent) that they are from animals that have not died from rinderpest. Any hides, skins, horus or hoofs not accompanied by stuch declaration, shall be immediately destroyed by the supervising Officer at the consignor's expense.

3. Disinfection shall be supervised by the officer appointed by the forernment for the purpose, but shall be performed by the owners or consignors or their agents.

4. Inried hides, horns or hoofs sliall be inmersed in a liquid disinfectant for at least 30 minntes.

5. Cireen hides and skins slatl be immersed in a liquid disinfectant for a period of at least 15 minutes.

6. The disinfectant used may be either a two per cent solution of carbolic acid or a five per cent solution of Jaye's Disinfectant, Odam's Disinfectant or Izal.

7. Feathers shall be hung up for three hours in a chanber charged with sulphurous acid producerl by buruing an excess of sulphur in a closed chamber.

S. Hides, skins, horns, hoofs and the packages containing feathers when disinfected, shall be marked for the guidance of the railway officials, and shall he accompanied by a certificate that disinfection bas 
been efflciently performed, signed by the supervising officer without which the railway officials shall refuse to receive the articles.

9. When disinfection is completed, the articles disinfected shall be loaded direct into a previously disinfected railway truck.

ro. Drying, salting or any other subsequent treatment of the hides or skins shall be done by the owners or their agents at their own risk."

"Disinfection of tracelers or passengers. I. Travelers and passengers shall be disinfected at railway stations and at authorized crossing places, in terms of Regulations 7 and $S$ issued under Proclamation No. 587 of 1896 , by the police or other persons duly authorized by the Secretary of Agriculture in the manner hereafter described.

2. Natives shall strip and enter a bath containing 2 per cent solution of carbolic acid; they shall then be provided with a blanket or other suitable clothing until the clothes they are wearing have been disinfected.

3. The clothing of all natives, and the blankets, rugs, karrosses, wraps, etc., of all Europeans, whether from disinfected areas or not, shall be subjected to sulphurous acid fumes produced by burning an excess of sulphur in a closed chamber for at least 15 minutes, pending arrival and erection of a proper steam disinfecting apparatus.

4. Europeans coming from an infected farm or place or who have otherwise rendered themselves liable to infection from contact with natives or their huts or kraals, shall be disinfected in such a manner as, in the discretion of the disinfecting officer, may be deemed necessary and their clothing as provided by clause 3 .

5. The disinfectant to be used shall be

2 per cent solution of carbolic acid or

5 per cent solution of Jaye's Fluid or

5 per cent solution of Odam's Disinfectant or

5 per cent solution of Izal.

6. Boots of Europeans and natives shall be well dry brushed, and then the uppers and soles well wiped with the disinfecting solution by means of cloths.

7. Europeans on coning from an infected farm or place and all natives presenting themselves at a railway station, siding, halt or other place north of the Orange River, shall, before the station master, clerk, guard or other officer pernits them to obtain a traveling ticket, hand to the station master or booking clerk a certificate signed by the disinfecting officer in terms of Form A, to the effect that they and their clothes have been properly disinfected as well as such articles and things in their possession as are intended to be carried by rail, not being articles or things actnally prohibited to be carried south of the Orange River. 
8. Any European not coming from an infected farm or place or who luas not in any way been liable to infection, shall sign a certificate to that effect in terms of Form B, and without such certificate shall be deemed as coming from an infected farm or place, or otherwise been liable to infection, and shall be subject to all provisions and regulations attached to persons coming from infected areas or liable to infection : and if the above certificate contains any false statement, the person signing the same will be liable to a penalty not exceeding 100 pounds or, in default of payment, to imprisonment with or without hard labor, for a period not exceeding six n1onths."

\section{Rinderpest}

FORM A

This is to certify that together with his clothes and the articles or things in his possession, authorized to be carried by rail, have been properly disinfected as required by the Government Regulations,

Disinfecting ()ficer.

Rinderpest. FORM B.

I do liereby certify that I have not come from any farm or place infected with rinderpest, and I have not in any way, to the best of my knowledge and belief, come in contact with infection.

(signed).

\$ 350. Immunizing cattle. Koel found that the serum of an animal that had suffered from rinderpest and recovered possessed immunizing powers. This fact being demonstrated, its utility has been availed of in immunizing animals for procuring the serum. The method given by Jobling and which is used extensively in the Philippines is appended.

The animal first receives an inoculation by the "sinultaneous method"' of Kolle and Turner. 'This consists in injecting under the skin on one side from is to $5.5 \mathrm{cc}$. of serum from an immune animal and on the other side I cc. of virulent blood from a sick animal. If the reaction from this double injection is good, i. e., a rise of temperature after the proper period, it is given rooocc. of virulent blood after the tempera- 
ture again drops to normal. This is followed, under the same circumstances, by $500 \mathrm{cc}$. and again $1000 \mathrm{cc}$. After this the animal is bled for serum. They are bled with a trocar and canula from the jugular rein. The animals are bled three times at intervals of a week, after which they are injected again with $1000 \mathrm{cc}$. of virulent blood.

In using the serum from 50 to $100 \mathrm{cc}$. should be injected subcutaneously by aseptic methods.

The advantages of this method of immunizing cattle are : (I) It produces no reaction, (2) it does not check the flow of milk, (3) it confers immunity almost immediately, (4) if the disease has just begun it will modify the attack resulting in a milder form, (5) no deaths follow its use, (6) pregnant animals do not abort, and ( 7 ) the serum can be prepared in any quantity and it can be kept for seven or eight months.

The disadvantages of this methed are ( 1 ) the short period of immunity -2 to + months, (2) skill required to obtain the serum, (3) occasionally, according to Jobling, very little immunity is conferred.

The other methods that have been tried with more or less success are: inoculation with attentuated virus; injection of the bile of animals dead of the disease: injecting the bile associated with virulent liquid; the injection of the serum from immune aninals.

\section{REFERENCES.}

I. IAxisz, BRoder Axn Theiler. The l'it. Journal. Vol. XLII (1898), p. 298

2. EDIxgtox. Report of investigation. The l'eterinary Journal, Vol. XLVI (rSgS), p. 64.

3. GAMGEF. The cattle plague. London. IS66.

4. Holmes. Some diseases complicating rinderpest among cattle in India. Jour. Comp. Path. and Thera., Vol. XVII (1904), p. 317.

5. Joвirig. Report of the Director of the Serum Laboratory. Fourth annual cport of the Philippine Islands. 1903. Ibid. Bulletin No. t, Bureau of Government Laboratories. Manila, Igoz.

6. Косн. Report. The l'eterinary Journal, Vol. XLV (1897), p. 204. Also Centralblf. Bakteriol. Bd. XXI (1897), S. 526. 
7. KoIt.E UND TIRXER. Lber Sichntzimpfungen und Heilserum bei Rinderpest. \%il. f. Hy gienc, Bd. XXIX (1898), \&. 309.

s. RAMAzZrNi. Dissertatio de Contagiosa Epidemica, I'arlua, 17 I 1 .

9. TIRNER AND Kolli. Report of investigations. The l'el. low). Vol. XII (1897), p. 462 .

IO. WALLFY. The four bovine scourges. London. itipg.

I i. WAIKkR. The prophylactic trealment of rinderpest by means of preventive inoculations, more especially considered in regard to the conditions prevailing in India. Jour. Comp. Path. and Thera., Vol. XVII (I904), p. 326 .

\section{CONTAGIOL'S PLEURO-PNEUAIONIA IN CATTLH}

Sinonyms. Lung plague; pleuro-pneumonia zymotica ; Peripneumonie contagieuse: Lungenseuche.

$\leqslant 35^{1}$. Characterization. Contagious pleuro-pneumonia of cattle is a specific epizoötic disease which affects bovine animals and from which other species are exempt. TThen the disease results from exposure in the usual manner, it is characterized by an inflammation of the luugs and pleurae, which is generally extensive and which has a tendency to invade portions of these organs not primarily affected and to cause death of the diseased portion of the lung.

S 352. History. The first account of the appearance of contagious pleuro-pnemmonia dates from the end of the seventeenth century. It is stated that it was observed in Hesse for the first time in 1693 , and that its earliest appearance as an epizoötic was in 1713 and 1714 , when it prevailed chiefly in Switzerland and the neighboring conntries of II ürtemberg. Baden and Alsace. There are detailed reports of its occurrence from the year 1743 . In 1773 . Haller published an essay on this disease, which was raging severely at that time. He described the symptoms, anatomical characters and protective measures laid down at that time by the sanitary police. In I 735, the disease appeared in England and in 1765 in France. From 1790 it spread over the whole of Germany. France and 
Italy. At the commencement of the nineteenth century it visited all the countries of Western Europe.

South Africa was infected by a bull brought from Holland in 1854 , and Australia received the contagion with an English cow in 1858 . It is also reported as existing in various parts of the continent of Asia; but the time of its first appearance and the extent of its distribution are very uncertain.

Some countries which have only been infected for a short time, such as Norway, Sweden and Denmark, have succeeded in eradicating the disease without much difficulty by slaughtering all affected and exposed animals. Other countries long infected and in which the contagion was thoroughly established, like Anstralia, South Africa, Italy, France, Belgium and parts of Germany, have labored long, in some cases making no progress and in others being only partially successful. Holland was one of the first of the thoroughly infected countries to free itself from the contagion.

The disease has been brought to the Lnited States several different times. Probably its first introduction was in a diseased cow sold in Brooklyn, N. Y., in $r 8_{43}$. It came to New Jersey by importing affected animals in 1847 . Massachusetts was infected in the same way in 1859 . Massachusetts eradicated pleuro-pneumonia diring the period from is6o to 1866 . New York and New Jersey made an attempt to eradicate it in I 879 but were not successful. Late in 1883 the contagion was carried to Ohio, probably by Jersey cattle purchased in the vicinity of Baltimore, Md., to which place it had extended previous to I 868 . From the herd then infected it was spread by the sale of cattle during 1884 to a limited number of herds in Illinois, to one herd in Missouri and two herds in Kentucky. By coöperation between the United States Department of Agriculture and the authorities of the affected states, it was found possible to prevent its further spread and to completely. eradicate it after a few months.

In I886, pleuro-pneumonia was discovered in some of the large distillery stables of Chicago and among cows on neighboring lots. This led to renewed efforts to secure the com- 
plete extirpation of this disease from the country. Congress, in 1887 , enlarged the appropriation available for this purpose and gave more extended authority. During the same year the disease was stamped out of Chicago and has not since appeared in any district west of the Allegheny Mountains.

The work of eradication was at the same time commenced in all of the infected States. Before the end of the year 1889 Pennsylrania, Delaware, Maryland, the District of Columbia, and Virginia had been freed from the disease. More difficulties, however, were encountered in the States of New York and New Jersey on account of the larger territory infected and the density of the population. The long struggle was crowned with success, however, and the last animal in which the disease appeared in the State of New York was slaughtered early in $189 \mathrm{I}$ and the last one affected in New Jersey met the same fate early in the spring of 1892 .

On the 26 th day of September, I 892 , the following proclamation was issued, declaring the United States to be free from this disease.

PROCLAMATION-ERADICATION OF PLELRO-PNECIIONIA.

[. S. DEPARTMENT OF AGRICILTURE,

()FFICF OF THE SICRIETARS.

TO ALL WHOM IT MAY CONC1:RN :

Notice is hereby given that the quarantines heretofore existing in the counties of Kings and Queens, State of New York, and the counties of Essex and Hudson, State of New Jersey, for the suppression of contagious pleuro-pneumonia among cattle, are this day removed.

The removal of the aforesaid quarantines completes the distolving of all quarantines established by this Department in the several sections of the [nited States for the suppression of the above-named disease.

No case of this disease has occurred in the state of Illinois since December 29, 1857 , a period of more than four years and eight months.

No case has occurred in the state of Pennsylvania since September 29 , I 888 , a period of four years within a few days.

No case has occurred in the state of Maryland since september is, I 889 , a period of three years. 
No case has occurred in the state of New York since April 30, 1891 , a period of more than one year and four months.

No case has occurred in the state of New Jersey since March 25. 1892 , a period of six months, and 110 case has occurred in any other portion of the Inited States within the past five years.

I do therefore hereby officially declare that the Inited States is free from the disease known as contagious pleuro-pneumonia.

\section{J. M. RLSK, Secretarr.}

Done at the City of Washington, D. C., this 26 th day of September, A.I., 1892 .

The time required for its eradication was only about five years and the total expenditure was but a little in excess of $\$$ I , 500, OOO.

\$ 353. Etiology. The specific cause of contagious pleuro-pneumonia has not been fully demonstrated. The infection may be introduced either by diseased cattle, or, less commonly, by bearers such as cattle dealers, attendants, utensils, fodder, dogs, etc. The sheds in cattle markets are very dangerous centers for the dissemination of the disease. All cattle are not equally susceptible. It is generally supposed that about one animal in four is inmune. The virus is spread principally by the respired air. Infected cattle are reported to be able to transmit it even during the period of incubation, before the symptoms are apparent. The disease is particularly infectious when it is at its height and the animal remains capable of transmitting the disease for eight or ten weeks or even longer after the infection, especially when necrotic foci remain in the lungs. Walley estimates the duration of infectiousness in cases of encapsulated necrotic foci to be as long as fifteen months. It is said, but the evidence is not given, that the virus may be conveyed by the respired air for as great a distance as forty yards or more. In exceptional cases, the contagium is transmitted from the pregnant cow to the fetus.

Pöls and Nolen, in 1886, at Amsterdam, found micrococci alway present in the exuded matter of the lungs. These micrococci were about $0.9 \mu$ in diameter and occurred either isolated or in chains up to six in number. In the unstained 
preparation, the cocci were surrounded by a distinct envelope which could be stained only with great difficulty and which was absent from cultivated micrococci.

Arloing believed that he had found the existing cause of the disease in various bacilli, especially in one which he calls Pneumo-bacillus liquefaciens bovis, which forms short nonmotile rods. Arloing believes that lis experiments prove that the pneumo bacillus is the cause of pleuro pueumonia.

In 189 s, Nocard and Roux succeeded in obtaining a very feeble growth of an exceedingly minute organism in bonillon containing cow or rabbit serum in proportion of one part serum to 25 parts bouillon, when cultivated in collodion sacs within the abdominal cavity of rabbits. The rabbits which received the inoculated capsules become enaciated, and some of them died. Those inoculated with uninoculated capstules remained well. Rabbits inoculated with the pleuro-pneumonic lungs were not affected. With the cultures obtained in the collodian sacs the disease was produced in cattle. The virus passed through a Berkefeld filter and Chamberland F crylinder but it was held back by a Chamberland filter B.

S 354. Symptoms. The symptoms are such as would be expected with inflammation of the lungs and plenrae, but they vary considerably according to the course which the disease runs. If the attack is an acute one, as is frequently seen in hot weather, the symptoms appear suddenly. The breathing becomes rapid and difficult, the animal grunts or moans with each expiration, the shoulders stand ont from the chest, the head is extended on the neck, the back is arched, the temperature ranges from 104 to $107^{\circ} \mathrm{F}$, the milk secretion is suspended, there is loss of appetite, rumination is stopped. the animal may bloat and later be affected with a severe diarrhea. Such cases are generally fatal in from seven to twenty days.

Very often the attack comes on slowly and the symptoms are more obscure. In the mildest cases there is a cough for a week or two but no appreciable loss of appetite or elevation of temperature. The lungs are but slightly affected and recovery 
soon follows. Such animals may disseminate the virus for a long time without being suspected and for that reason are the most dangerous of all.

A more severe type is commonly seen. The cough is frequently more or less painful, the back somewhat arched and the milk secretion diminished. These symptoms increase, the appetite is affected, the animal loses flesh, the breathing becomes more rapid, the cough more painful, pressure of the fingers between the ribs produces evidence of tenderness, the hair loses its gloss and stands erect, the skin becomes adherent, the temperature rises to $\mathrm{IO}_{3}$ to $105^{\circ} \mathrm{F}$. Animals thus affected may continue to grow worse and die in from three to eight weeks or they may after a time begin to improve and make an apparent recovery. The inflammation of the lung does not, as a rule, subside and the organ does not return to normal condition as in ordinary pneumonia, but with this disease the life of the affected portion of the lung is destroyed, the tissue dies and a fibrous wall is formed around it to shut it away from the living parts. The tissue, thus encysted, gradually softens, becomes disintegrated into a purulent-like substance. The recovery, therefore, is only partial.

By those accustomed to examining the lungs of cattle, other and extremely important symptoms may be detected during the course of the disease. By auscultation an area of a certain extent may be found where the natural breathing sound is diminished or entirely lost. This represents the diseased portion of the lung. In other cases a loud blowing sound may be heard, quite different from any sound produced when the lung is in a healthy condition. In some cases crepitation is heard near the border line of the diseased area and friction sounds produced by the roughened pleura may be detected. By percussion an area of dullness may be discovered corresponding to the portion where the respiratory murmur has disappeared. This loss of respiration detected by auscultation and the dullness brought out by percussion are the most important evidences of an area of inflamed or consolidated lung. 
Seriously affected animals remain standing if they have sufficient strength, but those which lie down are said to always lie on the affected side.

The proportion of animals that become affected after being exposed varies according to the virulence of the outbreak, the susceptibility of the animals and the length of time during which exposure is continued. Sometimes not over 15,20 or 30 per cent of the animals exposed will contract the disease, while at other times 80 or 90 per cent may be infected. The proportion of cases in which the disease proves fatal also varies greatly, it may not exceed ro per cent and it may reach 50 per cent. In general it may be said that about 40 per cent of the exposed animals will contract the disease and about onehalf of these cases will prove fatal.

$\$$ 355. Morbid anatomy. Anatomically, contagious pleuro-pneumonia is characterized by a progressive interstitial pneumonia with secondary hepatization of the lungs and exudative pleuritis. Usually only one lung, the left as a rule, is affected. The anatomical changes vary according to the duration of the disease.

The otherwise healthy lung shows, in the initial stage, small, circumscribed, inflammatory centers from the size of a hazelnut to that of a walnut. The interlobular tissue in it is hyperemic, permeated by single hemorrhages and infiltrated with serum. The reddened lobules of the lungs are surrounded by bright margins, which are $\mathrm{I}$ to $2 \mathrm{~mm}$. broad and which are filled with a serous or $1 y m$ phatic fluid. When the deposits are superficial, the plure become opaque and covered with slight clots.

At the height of the disease there is a lobular pneumonia with pleuritis which is usually spread over the greater part of one lobe of the lung. The lung is considerably enlarged, of firm consistency, very heavy (weighing up to one hundred pounds), sinks in water and does not crackle when cut. Its section appears marbled, in consequence of the interstitial connective tissue having become thickened into broad lines which 
vary in color from orange to dirty white and which surround the dark colored lobules of the lung. The larger lobules have a thickness of from .2 to $5 \mathrm{~cm}$.; and the smaller ones of from .25 to $.50 \mathrm{~cm}$. The color of the enclosed lobules of the lungs depends on the duration of the process and varies from brown-red to dirty yellow. The recently infected lobules have a blood-red, reddish-brown or dark brown color (stage of red hepatization). The color of the older ones varies from orange to yellow (yellow hepatization) and that of a still older date is gray (gray hepatization). The central foci, because they are the oldest, are usually in a stage of yellow or gray hepatization. Some of the enclosed lobules of the lungs are normal or only compressed, while others are merely hyperemic. If we closely examine the bright interstitial lines, we find that they consist at first of an edematous infiltration, which later on becones plastofibrinous, gelatinous, indurated and finally tends to the formation of adventitious connective tissue. The lymph-spaces in the lines are dilated like lacunae and filled with a serous or fibrinous fluid. In robust animals, the exudate in the alveoli is firm; but is of a more serous character in animals of a weak constitution. In the former case, a section made through the lung will be found to be granular. Besides these changes, the other lymph vessels of the lungs are dilated, their walls are infiltrated with cells and their lumen is in a state of thrombosis. The blood ressels frequently show thrombi and small hemorrhagic infarcts. The contents of the finer bronchi are often infiltrated with numerous white corpuscles. The bronchial glands and frequently the mediastinal glands are inflamed and swollen.

The pleurae are covered with soft, membranous, fibrinous masses, which are sometimes lumpy or crumbled and which can easily be detached. These deposits have a reticular surface and may attain a thickness of $2 \mathrm{~cm}$. If we remove them, we shall find the pleural vessels highly injected with ecchymoses, and the surface of the pleurae in a rough and uneven condition. In the thoracic cavity we generally find, in varying quantity, an inodorous fluid exudate, which may be clear 
or opaque and which contains flakey or lumpy masses. Similar fibrinous masses often lie on the outer surface of the pericardium.

After the disease has existed for some time, the affected parts of the lungs undergo induration, cicatrization, caseation, calcification, necrosis or suppuration. At first the interstitial infiltration becomes dense, solid and dry and changes into firm connective tissue which nakes a crunching noise while it is being cut with the knife. In other places we have fatty degeneration, caseation, calcification or suppuration, in which the enclosed lobules of the lungs, in consequence of the existing suppuration, become gangrenous, and form sequestra surrounded by sequestral cavities which have smooth walls. The dead portions of the lungs may remain unchanged in these cavities for a long time. Frequently they become softened to the cousistency of a greasy, yeast like paste. Sometimes, when they are comparatively small, they become absorbed, and a scar is formed. The hepatized lobules of the lungs rarely regain their normal condition after the absorption of the exudate. More frequently they atrophy or collapse, undergo atelectasis, calcification or softening, become necrotic or suppurating or form cavities. On the pleurae we find thick and wart-like hypertrophies of connective tissue, which frequently cause the lungs to adhere to the sides of the chest.

The changes in the lungs and pleurae are the most important general changes in cases of pleuro-pneumonia. It is stated that we may sometimes meet with an interstitial fibrinous exudate in the liver with atrophy of the liver cells ; serofibrinous effusions into the articulations, tendon sheaths, subcutis, dewlap and brisket; intestinal catarrh; areolation of Peyer's patches and ulcers on the gastro-intestinal mucous membrane.

The views of pathologists differ as to the nature of the earliest changes in contagious plenro-pneumonia and it is not within the scope of this work to present imperfectly developed or controverted theories. Without entering into a discussion of the varions views, it is clear that there is an inflammatory 
condition of the connective tissue between the lobules, resulting in the exudation of coagulable $1 \mathrm{ymph}$. This inflammation is equally marked around the blood vessels and air tubes. It leads to inflammatory changes in the inner wall of the veins and these cause a deposition of thrombi or plugs in the vessels, which prevent the return of the blood. The blood pumped into the lung tissue leaves the meshwork of capillaries around the air vesicles, enters the latter and produces the firm hepatized condition so characteristic of this disease. It will be easily understood how the different shades of color from dark red to grayish or yellowish red are produced if we bear in mind that the veins in different parts of the lung tissue are plugged at different times and that the affected regions are in different stages of the disease.

One of the most conspicuous features in a microscopical section from a lung affected with acute contagious pleuropneumonia is the presence of intensely stained foci and lines. These lines, to which Welch seems to have been the first to call attention, are visible to the naked eye and when riewed with a hand lens suggest by their peculiar curres the contour lines of a map. They are situated at the margin of and within the inflamed connective tissue which surrounds the large vessels and separates the lobules from one another. A closer examination of these lines indicates that they coincide with the boundaries of the lobules and of the individual $1 \mathrm{ymph}$ spaces of the interlobular tissue. Under a high power of the microscope they are resolved into dense masses of leucocytes in various stages of degeneration. These dense bands are presumably attracted to the connective tissue boundary of the lobules and to the walls of lymph spaces within the connective tissue by the unknown cause of the inflammation, presumably the cause of the disease itself. The space between the lines is filled with fibrin, in which very few leucocytes are found.

S 356. Differential diagnosis. It is extremely difficult to form an exact diagnosis of the disease during its development, because the synptoms which are present are few in 
number and by no means characteristic. The slight ferer and congh are the only symptoms of diagnostic importance in the prodromal stage. In the second or acute stage a positive diagnosis intra vitam can be made only when cases of pleuropneumonia have previously occurred or when several occur simultaneously. As a rule, a correct diagnosis can only be made by a post-mortem examination. The following diseases are to be differentiated from it :-

I. Non-infectious inflammation of the lungs. This may be distinguished clinically, as a rule, by its more acute and more typical course and by its sporadic and sudden appearance and, anatomically, by the fact that the parts which have undergone hepatization are practically all of the same age and that the interstitial lung tissue and pleurae are but slightly involved. Nocard states that in exceptional cases pleuro-pneumonia may run a very acute course and show hepatization of equal ages.

2. Tuberculosis. The disease cannot be positively distinguished clinically from pleuro-pneumonia. Tuberculin may be used as a diagnostic agent, although it is not at all certain that animals which have suffered for some time from pleuropneumonia do not react to tuberculiu. After all, an anatomical examination is the only real test. Tuberculosis and contagious pleuro-pneumonia have occasionally appeared simultaneously in the animal. See description of lesions in tuberculosis.

3. Traumatic pneumonia or pneumonia due to foreign bodies may exhibit the same symptoms as pleuro-pneumonia. Evidence, during life, of changes in the heart caused by traumatic carditis will be conclusive in making the differentiation.

4. Broncho or interstitial pneumonia. In making a diagnosis between contagious pleuro-pneumonia, based on the lung lesions alone, it should always be borne in mind that the entire lung should be subjected to examination. Attention should be given to signs indicating injury to the chest wall, to the possible presence of foreign bodies and to severe inflammation of the air passages which may result from the aspiration of 
irritant or corrosive fluids. Where these agents may be excluded special attention should be paid to the condition of the pleura and to the distribution of the disease, careful notes being made of the lobes involved. Next in order come the peculiar perivascular and interlobular thickening and the thrombosis of the veins. Care should be taken not to confound mere clots with adhesive thrombi. In acute pleuropneumonia, after death, the arteries are usually distended with clots. The different features of the hepatized and edematous portions of the lung tissue should be carefully noted. Lastly, the peculiar exudation and infiltration in the connective and fatty tissue of the dorsal mediastinum and of the embedded glands should not be overlooked. With the microscope the peculiar dense cell masses of the diseased connective tissue should be looked for and the nature of necrotic tissue determined in case microscopical appearances are no longer reliable owing to hardening processes.

Finally it should be borne in mind that the lesions of broncho-pneumonia and the interlobular changes which may follow it may coexist with contagious pleuro-pneumonia, and that both kinds of lesions may be encountered in the same lungs. Hence, great caution must be exercised in expressing an opinion when only a.small portion of the lungs are presented for examination, because only that portion which is affected with broncho-pneumonia may have been submitted.

$\$ 357$. Preventive inoculation and eradication. In Europe inoculation has been practiced for a long time as the principal means for combating pleuro-pneumoria. As early as the beginning of the last century it was proposed in Germany by Hausmann and others. Its employment was greatly. increased by the investigations which were made in 1850 by Wilhelms in Holland and which were published in 1852 . Since that time these inoculations have been practiced in nearly every country. The literature on the subject is very copious.

The advocates of inoculation, among whom we may 
mention Haubuer, Bouley, Schiitz and others, start from the well known fact that one attack of pleuro-pneumonia successfully passed through confers immunity for the remainder of the animal's life. By inoculation, a local, specific, inflammatory process which is analogous to that in the lungs, is produced and is followed by subsequent immunity of the whole body. Haubner calculates that the mortality from the inoculation is from is to 2 per cent and that the tips of the tails are lost in from 5 to 10 per cent of the cases. In Holland, among 59,180 cattle inoculated in 1578 and 1879 , the mortality amounted to only 0.66 per cent.

The opponents of inoculation, among whom we may mention Rolof, Zündel. Kitt, MI'Fadyean and others, assert that np to the present no positive case of immunity has been proved to have been obtained from inoculation. They also point to the fact that eren the advocates for inoculation are unable to give the exact duration of the immunity and consequently make several inoculations. Dujardin-Beaumetz finds that the inoculation in the tail with a bouillon culture of the organism gives a local swelling. It confers immunity quite as well as the injection of the serous fluid. Already he reports its use in 675 cattle, of which $1+$ died as a result of the inoculation. The best procedure seems to be the stamping out of the disease by means of thorough disinfection or destruction by fire of all infected sheds and barns. The success of this method is illustrated by the eradication of the disease from the United States.

\section{REFEREXCES}

I. DUJARDIX-BEAUMET\%. Le microbe de la péripneumonie et la culture. Thisis. Paris, I9oo.

2. Nocard hit Roux. Le nicrobe de la péripneumonie. Recueil de Med Vitinaire, March 2.4, $189 \mathrm{~S}$, p. 212 . Trans. in the l'eterinary Journal, Loudon, Vol. XLVII (ISgS . p. 147. Ann. di l'Inst. Pasteur, Yol. XII (1898), p. 240.

3. SAlawox. Annual Reports of the Bureall of . Inimal Industry, I $884^{-1} \mathrm{I} 92$.

4. Smith. Annual Reporl of the Bureau of Animal Industry, $1895-6$, p. 143 . 
5. WaLLEY. The four bovine scourges. $1 S_{79}$.

6. WILHEI,Ms. Memoire sur la péripneumonie epizoötique du bétail, I 852 .

FOUT AND MOUTH DISEASE

Synonyms. Eczema epizoötica ; epizoötic aphtha; vesicular aphtha; vesicular epizoötic; aphthous fever; murrain; cocotte; Maul-und Klauenseuche.

$\$ 35^{8}$. Characterization. Foot and mouth disease is a highly infections disease of animals. It is determined by the eruption of vesicles in the moutl, around the coronet of the foot, on the udder and between the toes. It is said to be more common among cattle, but swine are quite susceptible; sheep, goats, horses, dogs, cats and fowls are said sometimes to be attacked. The human species is also susceptible. People may be infected by drinking the unboiled milk of animals suffering from the disease. The mortality is not high.

$\$ 359$. History. Foot and mouth disease was quite accurately described in the eighteenth century. Very destructive outbreaks are reported in 1809 and in the early part of the nineteenth century it was the sonrce of much loss in southern Europe. In $188_{3}$, Great Britain lost heavily from its ravages. In 1892, Prussia is reported to have had $8,000,000$ cattle affected. It was during the years 1890 and 1893 that the last severe epizoötic appeared in Germany.

\$36. Geographical distribution. This disease seems to be very largely restricted to Europe, although it has been introduced into almost every cattle raising country. In is7o, it was brought to the United States from Canada. At that time it spread into New York and New England. It appears that this disease was mild and its spread was quickly and easily checked. This according to Law was accomplished so easily because the cattle mere in winter quarters. In 1880 , a few infected animals were brought to the United States, but the disease did not extend beyond the animals introduced. In 
185 , there was a small epizoötic at Portland caused by imported cattle.

The most serious ontbreak in the United States was in 1902. The first herds affected were at Chelsea, Mass., in the vicinity of the docks, to which place the infection was probably carried from shipping. It is not known exactly how the infection was introduced, but it is highly probable that it came through some one of the many possible channels other than infected imported cattle. In this outbreak, the disease appeared in Massachusetts, New Hampshire, Vermont and Rhode Island. A total of 4,712 cattle were affected. The comparative treedom of the United States from this disease is attributed to the enforcement of rigid quarantine measures.

$\leqslant 36 r$. Etiology. The specific cause of foot and mouth disease has not been clearly demonstrated. It has been shown, however, that it is caused by a specific infection and that every outbreak starts from some previous case or cases. The virus is contained in the eruptions and given off from the mouth and feet, causing its wide distribution. Loeffler and Frosch have shown that the cause-presumably a germ of some form-would pass through a Berkefeld filter. Later Loeffler showed that it did not pass through the finer $K$ itasato filter. Aninals may be infected directly by coming in contact with the disease, or indirectly by being exposed to the virus in stables, cars or other places recently occupied by infected animals. It is stated that the virus is destroyed in a short time by drying, but some writers maintain that it will persist for several months. Penberthy states that under ordinary circumstances the virus does not retain its effectiveness long. Animals that have passed through the disease may carry the virus for several months. The infected matter may be carried on the clothing or hands of human beings and thus be transmitted to animals or men. Milk is often the carrier of the virus.

The period of incubation is short, from $2+$ to 72 hours in inoculated cases. It may be longer than this. 
$\$ 362$. Symptoms. The symptoms of foot and mouth disease vary greatly in different epizoötics, sometimes they are quite mild and at others very severe. The first evidence of the disease is a rise of temperature which in cattle rarely exceeds $104^{\circ} \mathrm{F}$. The mucous membrane of the mouth becomes reddened, the appetite is diminished, and rumination ceases. The mouth is usually kept closed and the quantity of saliva is increased. A smacking sound is not infrequently made by the animal. These symptoms are chiefly due to the pain accompanying the disease in the mouth. After two or three days the eruption appears. This consists of small yellowish-white vesicles or blisters, varying in size from a hemp seed to a pea, on the gums and inner surface of the lips, the inside of the cheeks, the border and the under surface of the tongue. They may become half an inch or more in diameter. In some cases the back of the tongue may be the seat of large blisters.

These vesicles burst soon after their appearance, sometimes on the first day. More rarely they may persist for two or three days. After they have ruptured the grayish-white nembrane forming the blister may remain for a day or nore or disappear speedily and leave deeply reddened areas or erosions which are very painful. These exposed areas may son become covered again with the normal epithelium or they may be converted into ulcers. In this stage the saliva forms in large quantities and hangs in strings from the mouth. In eight to fourteen days the disease may have entirely disappeared.

In addition to the changes in the mouth, one or more feet may become diseased. The skin around the coronet and in the cleft between the toes becomes hot and tender and may swell. Blisters appear as in the mouth, but they are speedily ruptured and the inflamed, exposed areas are covered with a viscid exudate.

The udder, more particularly the teats, may be the seat of lesions. Some authorities regard the udder disease merely as the result of infection during milking. The vesicles are broken by the hands of the milker and the teats become cover- 
ed with reddened areas deprived of the superficial layer of the skin and are very tender. The healing, however, goes on quite rapidly. The milk is said to be somewhat changed in appearance and unfit for making butter or cheese. T'luese are the main symptoms accompanying the uncomplicated cases of foot and mouth disease. In all such cases recovery is usnally rapid and complete. In certain other cases, however, complications arise which are not only injurious but may be fatal. Thus the month lesions may be accompanied by nasal catarrl or pneumonia. The feet may become rery much swollen and the inflammation and suppuration extend to the tendons and bones, resulting in the loss of the hoof. Such cases are usual1y fatal. As a result of the general affection young calves may succumb to a secondary inflammation of the stomach and bowels and older animals may abort or suffer from inflammation of the udder.

The duration of the disease in uncomplicated cases varies from Io to 20 days. When complications occur either with the regular course or as sequelae the duration becomes indefinite. The mortality varies with the severity of the attacks. the age and condition of the animals and the treatment. Ordinarily the mortality is not high, excepting in very young animals.

$\leqslant$ 363. Morbid anatomy. The tissne changes found at post-mortem vary to a marked degree. There are in certain cases hyperemia and edema, catarrh of the nares and mucosa of the lungs and dilatation of the heart. There may be fatty degeneration and hemorrhagic infarcts in the heart muscle. In other cases there is severe gastro-enteritis with intestinal hemorrhage. In the stomachs of cattle oval reddish areas which ultimately form ulcers appear. These often become confluent. The involved portion of the mucous membrane becomes thickened. The areas of necrotic tissue in which the ulcers appear become surrounded by a reddish line of demarcation which, in the healing process, forms a cicatrix. The lesions on the mucons membrane rarely extend deeper than 
the mucosa. Ulcers of a nature similar to those found in the stomach occur in the intestines. On the feet inflammations may follow the simple vesicles about the coronet. These may extend deep iuto the tissues, pass under the hoof and cause it to slough off, extend into the bone producing necrosis or permanent arthritis. It is stated by some authorities that in the mild non-fatal cases the obrious lesions are so slight that frequently they escape notice. In sheep and swine the lesions are more frequently restricted to the feet.

The period of duration of the disease varies from 9 to It days. The immunity resulting from a natural course of the disease is placed by Penberthy as being brief, probably not to exceed six months.

$\leqslant$ 364. Differential diagnosis. Foot and mouth disease must be differentiated from (I) various forms of stomatitis caused by different fungi and often referred to as sporadic aphthae, (2) from stomatitis due to drugs and injuries. (3) from actinomycosis of the tongue and (4) from variola. It must also be differentiated from simple cellulitis, often of streptococcic origin, in the subcutaneous tissue about the coronet and from the sloughing of the hoof resulting from the extension of the inflammatory process, and from eczemas due to dietary causes. The means of differentiating these must be found largely in the history of the cases and in the study of the nature of the lesions themselres.

\$365. Prevention. Preventive inoculations do not seem to have given satisfactory results. The isolating of the diseased animals and the placing of the well ones in non-infected fields and stables tend very largely to the checking of the spread of the disease. The milk of the diseased animal should be sterilized before it is used.

In England the slaughter of infected animals has frequently been resorted to in recent years to stamp out the disease. In the recent outbreak in the United States, the prompt destruction of all infected and exposed animals proved to be very satisfactory. The failure in the past to control the dis- 
ease in Europe by quarantine and disinfection necessitated the radical measure of slaughter of infected and exposed animals in order to eliminate the disease from our country.

Loeffier has recently produced artificial immunity against this infection by a method which promises to be successful for practical immunization.

\section{REFERFNCHS.}

I. Copk. Foot and month disease. Keport, th Internatimul Congriss of l'et. Surgeons. Fad'n Baden, Vol. I (1899). p. 184.

2. LOEFFI,ER UND FRosCH. Berichte der Kommission \%ur Firforscluung der Maul und Klanensenche bei dem Institut fiir Infektious Krankheiten in Berlin. Cent. f Bakt. Bd. XXIII (18́gs), \$. 371.

3. I,OEFFLFR. Ibid. Bd. XXIV (ISgS), S. 569 .

4. LOEFFLER. Ein neuer Verfahren der Schutzimpfung gegen Maul und Klauenseushe. Mümih. Med. Mochenschr., I906. ‥ 1036.

5. Pfixberths: Foot and moutli disease. four. Comp. Path. and Thera., Vol. XVI ( $190 \mathrm{~s})$, P. I6.

b. Priters. Foot and mouth disease. Second tiemi-ammul Report of the Chief of the Catlle burcau. Mass. State board of algrit. 1903 , p. 321 .

7. Sismox. Foot and nouth disease. Ieal liooli U. S. I Dpt. of Agric. rgo2. p. 643. Thid. Annuat Report lintean of Inimal Industru, Igo2, p. 39I.

S. WALLES: The four bovine scourges. 1 879 . 1). 61 .

\section{RABIFS}

Synonyms. Hydrophobia ; canine madness ; lyssa; Rage : Tollu'ut; Wutkrankhcit.

$\leqslant 366$. Characterization. Rabies is an acute infectious disease transmitted from animal to animal or from animal to man by the bite of the rabid individual or by direct inoculation. It is not known to be contracted or transmitted in any other manner. It is characterized by a long and variable period of incubation, followed by symptoms referable to the nervous system, lasting from one to ten days and ending in 
paralysis and death, without recognizable gross anatomical changes.

The dog is the animal most commonly affected, although all of the canine and feline races seem to suffer from rabies more than other species. All warm blooded animals appear to be susceptible. It is a serious disease in man, cattle, sheep, horses and swine. An explanation for its greater frequency among dogs is found in their tendency to bite. A very large percentage, in fact nearly all, of the cases in man and in the domesticated animals are caused by inoculation from the bites of rabid dogs.

$\$ 367$. History. Rabies was described by Aristotle in the fourth century B. C. He wrote, "Dogs suffer from madness that puts them in a state of fury, and all the animals that they bite, when in this coudition, become also attacked by rabies." Cornelius Celsius, who lived in the first part of the Christian era, seems to have been the first to refer to human rabies and to employ the term "hydrophobia."

The transmission of the disease by wolves to man was recorded in 1591 . In 1803 , and for a number of years following, it was epizoötic among foxes in Southern Germany and Switzerland.

During the latter part of the eighteenth and the beginuing of the nineteenth century the disease extended over Europe and about this time it appeared in America. The first outbreak in this country was reported from Boston in 1768 . In I 770 and $177 \mathrm{I}$ it was observed in dogs and foxes in the vicinity of Boston; in the year 1779 it appeared in Philadelphia and in the state of Maryland; in $1 ; 85$ it was prevalent throughout the Northern States and soon after it spread to the Southern States. During the last century it has caused heavy losses among farm animals throughout Europe and America.

It has called forth careful study from many of the ablest men in the medical professions. Among them may be mentioned John Hunter in England, Viborg in Copenhagen, Waldinger in Vienna, Hertwig in Germany and Pasteur in France. 
Without detracting in the least from the great work of other investigators, we may say that to Pasteur and his co-laborers, Nocard and Roux, we owe much of the knowledge of the nature of rabies which we possess at the present time.

$\leqslant$ 368. Geographical distribution. Rabies is known to exist in almost every country on the globe. Australia is the largest area which is said to be absolutely free from it. This exemption is the gratifying result of a rigid quarantine enforced against dogs inmported on that island. Rabies is very common in France, Belgium and Russia. In the latter country it is perhaps more often seen in wolves than in any other part of the world. In Holland, Denmark and Sweden it is very rare. In England, it has from time to time been widespread, but at present it is practically eradicated. Salmon has found that rabies exists in nearly every part of the United States.

Inquiries which the writer has made during the last few years, by verifying current newspaper reports of rabies, show that the larger number of cases come from certain districts in which the disease seems to have become established. Newly infected districts are constantly springing up, due presumably to the introduction in some manner of an infected dog.

The prevalence of the disease cannot be accurately determined, as there are no reliable statistics concerning it. Ravenel has reported that the State Live Stock Sanitary Board of Pennsylvania has investigated 82 cases of rabies since 1897 . Of these there were $5^{8}$ dogs, 4 horses, 17 cows, I cat and 2 human beings. During r 900 -'o4 the New Jork State V'eterinary College investigated 64 cases of rabies, of which +7 were in dogs, I i in cattle, 2 in horses, 1 in sheep, 1 in swine, and 2 in men. In 1907 a nuch larger number of cases were presented for diagnosis. Salnon states that in the District of Columbia from 1893 to August 1900 rabies has been positively: diagnosed in animals in 9 I cases. These consisted of 80 dogs, 5 cows, 2 horses, 2 foxes and 2 cats. In addition to these the records of the health department of the District of Columbia show that since 1874 there have been seven deaths from rabies 
in the human species. These illustrations from the experiences of a few laboratories could be duplicated from the records of many others.

In Europe the disease seems to be more prevalent. In I 898 the official reports show I, 202 cases of rabies in animals (mostly dogs) in Germany. In $1899,2,374$ rabid animals were reported from France and $44+$ cases from Belgium.

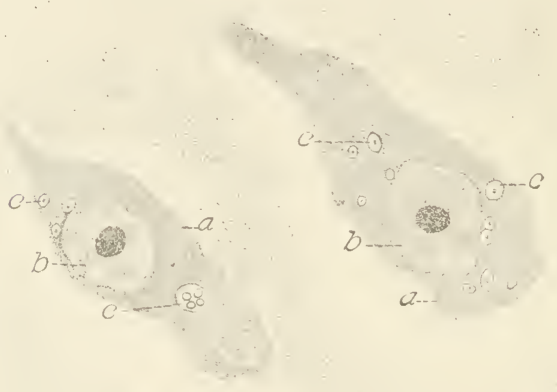

FIG. IIO. A drawing from a section of a rabid brain, showng large nerve cells containing Negri bodies. (a) Nerie cell, (b) mucleus of nerve cell, (c) Negri hodies. Wuch enlarged.

$\$ 369$. Etiology. Although rabies has long been recognized as a specific disease, its primary etiological factor has but recently been discovered by Negri in the brain and spinal cord of the affected animal. In certain instances the presence of the virus has been reported in the salivary glands, pancreas and milk. It has not been found in the blood.

In 1903, Negri, of the University of Pavia, described small bodies or cell inclusions, since called Negri bodies, which he found in the Purkingie cells of the cerebellum and in the 
large ganglion cells of the Ammons horn. Negri believed these bodies to be the etiological factor of the disease and classified them among the protozoa.

He believes the bodies are specific microörganisms which are characteristic of the disease, found only in animali affected with rabies. They appear early in the course of the disease. They occur in larger numbers and are of greater size as the disease progresses. They are most numerous and largest at the time of death. Smears or sections are stained in saturated alcololic solution of eosin for from 10 to 30 minutes after which they are counter-stained in alkaline methylene blue. No special technique is necessary to demonstrate these bodies. Their constant appearance in cases of rabies forms a basis for a positive opinion and diagnosis and they are affected very little by beginning decomposition of the surrounding nervous tissue.

Williams and Lowden state concerning the channels of infection that "in whatever way the virus enters the body, so far as we know, there is no development of the organism, or none, to any appreciable extent, until it reaches the central nervous system, and not until after a certain amount of development there does it infect the peripheral organs. Before the disease was well studied it was thought that the salivary glands were the chief site of the infection. But it has been shown that these glands are not alway's infective, and when they are, not until comparatively late in the disease and that when the virus is inoculated into them the animal seldom comes down with the disease and probably never if the centripetal nerves are cut (Bertarelli). This means that the parasite does not grow in the salivary glands, that it is only carried there incidentally by its spread from the central nervous system along the nerve branches. That the organisms escape into the blood and are carried in this way in small numbers is shown by the fact that the blood in large quantities has been found infective (Marie). Principally by the nerve channels, secondarily by the blood and lymph channels, the organisms are carried in small numbers to all parts of the body.- With other investigators, we have found the suprarenal cepsules infective." Their 
conclusion relative to the nature and diagnostic value of the Negri bodies are as follows :

I. The smear method of examining the Negri bodies is superior to any other method so far published for the following reasons: (a) It is simpler, shorter and less expensive ; (b) The Negri bodies appear much more distinct and characteristic. For this reason and the preceding one, its value in diagnostic work is great ; (c) The minute structure of the Negri bodies can be demonstrated more clearly ; (d) Characteristic staining reactions are brought out.

2. The Negri bodies are shown by the smears as well as by the section are specific to hydrophobia.

3. Numerous "bodies" are found in fixed virus.

4. "Bodies" are found before the beginning of visible symptoms-i. e., on the fourth day in fixed virus, on the seventh day in street virus, and evidence is given that they may be found early enough to account for the appearance of infectivity in the host tissues.

5. Forms similar in structure and staining qualities to the others, but just within the limits of visible structure at ( 1,500 diam. magnification) have be seen. Such tiny forms, considering the evidence they give of plasticity, might be able to pass the coarser Berkefeld filters.

6. The Negri bodies are organisms belonging to the class Protozoa. The reasons for this conclusion are: (a) They have a definite, characteristic morphology ; (b) This morpho$\operatorname{logy}$ is constantly cyclic, i. e., certain forms always predominafe in certain stages of the disease, and a definite series of forms indicating growth and multiplication can be demonstrated; (c) The structure and staining qualities as shown especially by the smear method of examination resembles that of certain known Protozoa, notably of those belonging to the sub-order Microsporidia.

7. The proof that the "Negri bodies" are living organisms is sufficient proof that they are the cause of hydrophobia ; a single variety of living organisms found in such large num- 
bers in every case of a disease, and only in that disease, appearing at the time the host tissue becomes infective in regions that are infective, and increasing in these infective areas with the course of the disease, can be no other, according to our present views, than the cause of that disease.

The Negri bodies or cell inclusions vary in shape. The most common forms are round or oval. The round bodies are from .5 to $2.3 \mu$ in diameter, while the oblong ones vary from .5 to $1.5 \mu$ to 5 to $27 \mu$. The round or oval forms are by far the most common. Irregular forms are occasionally seen. In preparations stained with eosin and methylene blue they appear as bright red bodies containing one or two nuclear-like structures which are surrounded by a number of other small circular, regular bodies. They are said to preserve their form even when the brain tissue has undergone marked degenerative changes, after prolonged immersion in glycerin and after several days' drying. A number of workers report finding them quite uniformly. Schïder does not consider them as the cause, largely because his virus passed through a filter that retained the cholera spirillum.

Remlinger and Riffat-Bey found that the virus would pass through a Berkefeld filter "Y,", but its passage was not constant, as rabbits inoculated with the filtrate did not all die of rabies. The filter which he used held back the organism of chicken cholera, which was used as a check on the filter. Remlinger more recently stated that the virus will pass through the more porous Berkefeld filter only. The firmer Berkefeld and Chamberland filters keep the virus back.

Babes states that the Negri bodies are not always present. He seems to consider them as a result of the local reaction of the cells to the cause of the disease.

$\leqslant$ 370. Method of invasion. When introduced into au animal either experimentally or by the bite of a rabid dog, the virus remains for a time without producing either local or general symptoms. The period of incubation varies within quite wide limits. The virus penetrates the nervons system by following the nerve trunks from the site of infection to the 
spinal cord, then through the spinal cord to the brain. This has been proven by inoculating an animal in one of the legs with virulent material. After a suitable time, but before the symptoms of rabies appear, the virus will be found, on killing the aninal, in the nerves of the limb, and even in the part of the spinal cord into which the nerve enters, while the upper part of the cord and the brain are still uninfected. This explains the fact why the earliest symptoms, both in man and animals, such as itching, tingling, numbness and other nervous sensations, often appear in the part of the body which received the virus. In the case of a bite about the face and head the route along the nerve to the central nervous system is much shorter. While the nerves seem to form the main route by which the virus travels, the circulation may at times assist, especially in small animals. Inoculation into the large nerve of the leg is almost as certain to produce the disease, as inoculation directly into the sub-dural space, while injection beneath the skin of the leg is not so sure. Nicholl finds that the virus passes from the point of infection to the brain exclusively through the nerves. He also finds that it is rapidly destroyed in the blood.

Resistance of the vinus. The action of the virus is destroyed by drying and by the action of light. In dry air, protected from light and putrefaction, the virulence of the spinal cord of rabbits is destroyed in fourteen to fifteen days. When spread in thin layers it is entirely destroyed by drying in from four to five days. Sunlight destroys it in about forty hours. The loss of virulence by drying is gradual but quite regular, which fact was taken advantage of by Pasteur in the preparation of his vaccine. The virus may be preserved in neutral glycerin at ordinary temperature for a long time. Roux found that after four weeks in glycerin at $30^{\circ} \mathrm{C}$., the virus in a rabid brain had the same power as when perfectly fresh. The writer has found that rabbits inoculated with rabid brains that had been kept in glycerin from three to four weeks did not develop the disease as quickly as those that were inoculated with the freshly removed brain. 
It is quite resistant to putrefaction. Galtier found the virus active in the central nervous system of rabbits that had been buried for twenty-three days, of sheep buried thirty-one days and of dogs buried forty-four days. Other observers have found it still active in animals buried for twenty-four days.

It is destroyed completely by a temperature of $50^{\circ} \mathrm{C}$. in one hour or $60^{\circ} \mathrm{C}$. in one-half hour. It is uninjured by exposure to extreme cold, resisting the prolonged application of a temperature from 10 to $20^{\circ} \mathrm{C}$. below zero.

Its activity is destroyed in one hour by a five per cent. solution of carbolic acid, or by a I to 1 , ooo solution of corrosive sublimate. Water saturated with iodine destroys it in ten minutes.

$\$ 37 x$. Period of incubation. The period of incubation is quite variable, depending on the site of the wound, which is almost always a bite, the amount of virus introduced and its virulence. In general it may be said for all animals that the period of incubation seldom exceeds sixty days, although in man and in some larger animals, it sometimes, though very rarely, reaches one year. A few cases of a longer period have been reported. The average period as given by Ravenel is as follows:

In man, 40 davs.

In dogs, 2 I to 40 days.

In horses, 28 to 56 days.

In cats, 14 to 28 days.

In pigs, I 4 to 2 I days.

In goats and sheep, 2 I to 28 days.

In birds, if to 40 days.

In rabbits inoculated subdurally with the brain from rabid animals, the writer has found the period of incubation to vary from 12 to 62 days and the duration of the disease to range from a few hours to three days. Westbrook reports a period of incubation in rabbits to extend in one case over a hundred days. In the disease as it is naturally contracted from the bites of rabid animals, the period of incubation varies with 
reference to the location and extent of the bites. If the individual is bitten about the head the period of incubation is much shorter than if the injuries are on the extremities.

In the dog, the period of incubation in I 44 cases was clearly determined by Peuch. His table with the addition of percentages is appended.

PERIOD OF INCEBATION OF RABIES IN THE DOG.

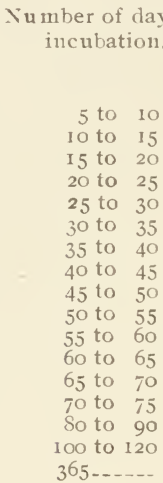

Total

5 to 10
10 to 15
15 to 20
20 to 25
25 to 30
30 to 35
35 to 40
40 to 45
45 to 50
50 to 55
55 to 60
60 to 65
65 to 70
70 to 75
80 to 90
100 to 120
$365 \cdots-\cdots--$

\section{Number of cases.}

Per cent.

\section{s of}

(1)


CASES (1) RABIHS IN DOGS, BY MONTHS

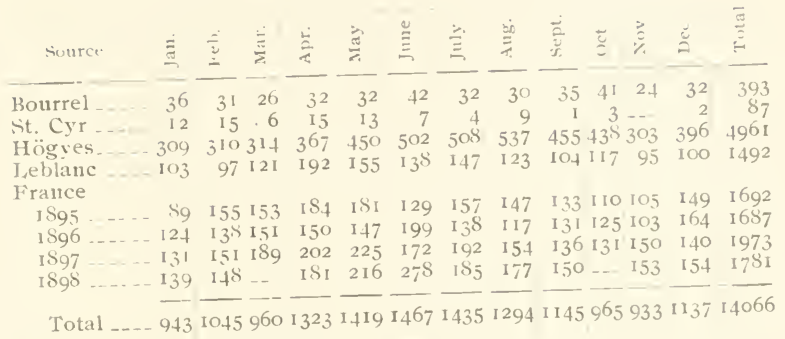

\$ 372. Symptoms. Rabies is generally divided into two forms, furious and dumb. In the first the animal is irritable, aggressive and bites nearly every object which comes in its way : in the second the muscles of its jaws are paralyzed almost from the beginning and being unable to bite the animal remains more quiet and tranquil. Essentially the two forms of the disease are the same, but probably owing to the parts of the brain attacked or the acuteness of the attack or both, paralysis appears much sooner in the dumb form than in the other. The saliva from a case of dumb rabies is just as dangerous and virulent as that from a case of furious rabies. Dogs affected with dumb rabies are less dangerons simply because they are unable to bite and thus to infect others.

I) umb rabies and furious rabies do not always represent two distinct types of disease. The typical cases belong to the two extremes of symptoms and there are always graduations between them. In fact, almost every case of furious rabies sooner or later changes to the dumb form, that is, the final stage of the disease is almost invariably paralytic. In the typical development of the dumb form, the paralysis occurs on the first day of the disease. It may not appear, however, until the second or third or even a day later.

Again, a dog does not necessarily bite everything about it even if it has rabies and its jaws are not paralyzed. It may be combative and furious all of the time or only part of the time, 
or not at all. There is perhaps no other disease in which the symptoms may vary more than in rabies of the dog.

Furious rabies. The symptoms appear very gradually. The animal's habits and behavior are changed. It may be more restless or affectionate than usual, seeking to be near its master or mistress, fawning, licking the hand or face and apparently seeking sympathy and assistance. Such caresses are, however, extremely dangerous, for the animal's tongue, moist with virulent saliva, coming in contact with a part where the skin is thin, abraded or wounded, may fatally infect the person to whom it is endeavoring to demonstrate its affection. The reported cases in which rabies have developed from such inoculations are quite numerous.

In most cases dogs first become dull, gloomy, morose, seeking solitude and isolation in out-of-the-way places or retiring under pieces of furniture. But in their retirement they cannot rest, they are uneasy and agitated, they lie down and assume the attitude of repose, but in a few minutes they are up walking about "seeking rest, but finding none." Occasionally this restlessness may disappear for a time and the animal becomes lively and affectionate; oftener it sinks into a sullen gloominess from which even its master's voice rouses it but temporarily. At this period dogs may have aberrations of the senses which cause hallucinations and lead them to think they are being annoyed by something or that some animal or person is endeavoring to injure them. They crouch ready to spring upon the enemy; they rush forward and snap at the air ; they throw themselves, howling and furious, against the wall as though they heard sounds beyond it.

While at first the affected dog may not be disposed to bite, it becomes more dangerous as its hallucinations and delirium increase.

The disturbance of the sensations leads to chills and itching. If the place where the bite occurred is accessible, the dog licks the scar and later may bite and tear the tissues. In this case it bites into its own flesh with apparent pleasure and satisfaction. Food is taken at first if it is something that can 
be swallowed without mastication, otherwise it is soon dropped. Difficulty in swallowing is an early symptom. Mad dogs have no fear or dread of water, they continue to drink until paralysis prevents them from swallowing.

When the furious symptoms appear, the dog may leave his home and start upon a long chase with no apparent object in view other than to be traveling. He trots at a rapid pace, eyes haggard and tail depressed. He is indifferent to the surroundings. He often flies at and bites persons whom he meets, but usually he does not search for them or even notice then if they remain quiet. Dogs in this condition may travel many miles and finally drop from exhaustion and die. (Often after an absence of a day or two they return to their homes, exhausted and emaciated, presenting a most forloru and miserable appearance. Those who have pity for such an animal and try to make it clean and comfortable are in great danger of being bitten, as the disease has advanced to a point where the delirium or insanity is most marked and where a treacherous bite is most common.

If the animal, instead of being allowed to escape, is kept confined, the paroxysms of fury are seen to occur intermittently or, in the absence of provocation, they may be entirely wanting. If excited it howls, rushes upon objects that are thrust toward it or throws itself against the bars of its cage and bites with great fury.

As death approaches the animal becomes exhausted and is scarcely able to stand. The eyes are dull and sunken and the expression is that of pain and despair. Paralysis appears in the jaws or in the posterior extremities and extends rapidly. to other parts of the body. The animal, being unable to stand, lies extended upon its side, the respiration becoming more and more difficult. There are spasmodic contractions of certain groups of muscles, complete prostration and finally. death.

The usual course of the disease is four or five clays. It may be as short as two or as long as ten days.

Dumb rabies. When this form of the disease is typical, it 
comes on with restlessness, depression, a tendency to lick objects and paralysis of the muscles which close the jaws. As a consequence of the paralysis, the lower jaw drops, the animal is unable to close the mouth, the tongue hangs out and an abundance of saliva escapes. The mucous membrane of the mouth becomes dry, discolored and covered with dust. The animal remains quiet, it does not respond to calls and appears to understand its helplessness. Bouley states that the animal cannot bite and does not desire to bite. When dumb rabies follows the furious form, the desire and tendency to bite may be retained even after the jaw is paralyzed.

The course of the disease is short, death usually occurring in from two to four days.

\$373. Morbid anatomy. One of the striking characteristics of rabies is the absence of constant, recognizable lesions. The mucosa of the pharynx and larynx are congested. The spleen is sometimes enlarged and dark colored. In dogs the stomach often contains a variety of foreign matter such as earth, stones, pieces of iron, bits of leather, wood, etc. Axe reports finding such foreign substances present in 90 per cent. of 200 cases he examined. Galticr reports such findings in from 50 to 70 per cent. In experimental animals and cattle the writer has rarely found them. It seems to be true that the obvious lesions are not constant and it is probable that the pronounced changes occasionally found in a single organ are accidental or secondary rather than primarily related to the disease. The lesions in the brain and spinal cord are likewise variable. In some cases there is a marked hyperemia, while in others the brain appears to be normal.

Certain investigators, however, have found histological changes which to their minds have been pathognomonic of the disease. The close simulation of the nervous lesions to those due to other diseases, and the possibility of greater or less post-mortem changes will foster an element of doubt in the miuds of the nuajority of working histologists. This doubt instead of diminishing shows a tendency to grow when a review 
is taken of the conflicting results and opinions held by those who have already investigated this field. It also appears that some portions of the nervous system may exlibit lesions of a pronounced character, other portions very slightly, and still others none at all, thus presenting additional difficulties.

One of the most common lesions that has been observed is of an inflammatory character, the congested blood ressels frequently showing diapedesis and, according to some, a perivascular exudation of a granular or a hyaline substance. Hyperemia and lymph-stasis, although of not so much significance when taken by themselves, have been taken into consideration along with other changes. The blood vessels quite as much or even more than the nerve structures have been noted as the focus of some of the most marked changes, anong which are the proliferation of the epithelial cells and of the comnective tissue elements of the outer coat, with the infiltration of lymphoid cells. Such lesions may be nodular primarily, but later become diffuse. The inflammatory process may progress to such an extent as to obliterate certain vessels.

Pathological miliary centers have been noted not only in the axial portions of the nervous system, but in the gray matter as well. These centers were formed by lymph cells which accumulate notably around the blood vessels perivascular) and the nerve cells (pericellular) as well. The lesions, when present, are observed most frequently in the notor centers of the oblongata and spinal cord.

The following observations were made by Babes, in is8 7 :

I. "In animals dead from street rabies there are found usually a hypercmia and an acute generalized redema of the cerebral meninges, acute hemorrhages localized around certain vessels, as well as inflammatory lesions. On microscope examinations we find an increase of the plasma cells, angmentation of the reticular substance, fibrinous in character, between the several layers of the meninges.

2. "The epithelium of the cerebro-spinal central canal has proliferated. In the gray matter which surrounds the 
canal, and especially in that of the floor, hemorrhages, sometimes symmetrical, are often found. Microscopically, we often find an obliteration or thrombosis of a vessel by a reticulated, hyaline, pigmented material or by leucocytes or hyaline globules, and sometimes a hyaline degeneration or even inflammation of the vascular tunic. The extravasated blood also contains much of the hyaline material. The hemorrhages are often limited by the lymphatic sheath of the ressels. At the same time the epithelium of the ventricles and central canal may be partially lost. This last is occasionally filled with blood or plugs, either granular or hyaline in character.

3. "With the naked eye small centers of degeneration may sometimes be noted in the gray matter, but often they may be sought for in rain.

4. "The most constant lesions are microscopic in charter: they are found more especially in the gray matter surrounding the cerebro-spinal canal and in the motor centers of the medulla and spinal cord. These lesions consist at first in hyperæmia and accumulations of embryonic cells around the small ressels, perithelial or migratory in origin, often showing indirect division; finally there are also found lesions of nerve cells.

5. "The lesions of the nervous elements of the parts indicated is quite characteristic ; it consists of signs of proliferation, namely, in the presence of several small cells in place of one large one, or in a uniform degeneration aud often in the appearance of vacuoles with a reduction in size or disappearance of the nucleus, or again, its chromatic network disappears. These cells frequently contain pigment. Round uninuclear, more rarely multinuclear, elements of a lymphatic origin often invade the protoplasm even of the cell and fill out the dilated pericellular lymphatic spaces by a multiplication of small nuclei.

6. "The lesion of medullary substance is less pronounced, it consists chiefly of an edema of the medullary sheath of the nerve fibers. 
7. "In certain plasma cells, in the interior of and around vessels, sometimes in leucocytes, in lymphatic spaces, in the altered parts of certain nerve cells, and in the dilated sheath of nerve fibers may be seen round or ameboid granules about I $\mu$ in diameter, pigmented or stainable by aniline dyes, and which in part seem to possess the power of movement. "'

More recently Babes has noted, besides the lesions above mentioned, that the alteration of the nerve cells is usually accompanied by a modification of their protoplasmic network and concludes that "IV hilst admitting that the lesions of rabies are not absolutely characteristic, and that it may be that in a case of diffuse, very acute myelitis similar lesions may be found, it is necessary all the same to state, that neither in writing nor in my personal experience have I ever met with a similar case, so that at present we may consider the lesion of rabies as characteristic. In other infectious diseases there have also been found histological lesions characteristic as a whole, although composed of elements not absolutely specific."

Golgi draws attention to the following morbid changes in rabies :

(I) Changes in the structure of the nucleus, all the various phases of karyokinesis may be simulated, yet no true unclear division may take place. (2) Changes in the body of the cells, such as vacuole formation, bladder-like transformation of the cells. Changes may also be recognized by methods directed to the study of the outer form of the cell. Here varicose appearances of the cell processes may be seen. Granular fatty changes may also be present. An important change lies in the displacement of the nucleus. 'The periphery' of the cell becomes homogeneous. (iramular fatty changes are also seen in the neuroglia cells. (3) Changes in the intervertebral ganglia. The author would look upon these anatomico-pathological changes found by him as characteristic. while here not only the sum total of the changes, but also their order of occurrence and mutual interdependence are taken into consideration.

The morbid process is parenchymatous encephalo-myel- 
itis, of which the exact exciting cause is as yet unknown. The changes are thus grouped: (1) appearance of nuclear chromatin, peculiar cell division (neuroglia cells and vascular endothelium), nuclear movements also in nerve cells, diffuse vascular distension and leucocyte infiltration, revealing a condition of irritation; (2) swelling, vacuolation, changes of form, granular appearance of nerve cells and neuroglia; and (3) more advanced changes in the nerve elements. The changes in the first group may be seen as early as five days after inoculation.

In a more recent article by Germano and Capobianco. attention is called to the fact that the destruction of some of the nerve cells in rabid animals is not accepted by everybody, but that in their researches they have been able to confirm the statements made by Golgi, that instances of the complete disappearance of nerve cells have been observed, while other cells show fatty degeneration, and partial destruction of the irentirety represent intermediate stages between the normal cell and its total disappearance. The alteration of the nucleus may precede or follow that of the cell body.

The nerve fibers, either in the white or gray matter, undergo a certain amount of change. In a longitudinal section of the myel, especially through the ventro-lateral columns, there are noted marked changes in the axis cylinders. In some cases they appear uniformly swollen for their whole length, while in others there are varicose enlargements. In the swollen portions there were frequently observed small vacuoles which interrupted the continuity of the axis cylinder.

During the year 1900 , the discovery of changes distinctive of rabies was announced by Van Gehucten and Nélis. These changes are found in the peripheral ganglia of the cerebro spinal and sympathetic systems and are especially marked in the plexiform ganglion of the pneumogastric nerve and the gasserian ganglion. Normally these ganglia are composed of a supporting tissue holding in its meshes the nerve cells, each one of which is enclosed in a capsule, made up of a single layer of endothelial cells. The action of the rabic virus seems 
to exercise its effect on these cells particularly, bringing about an abundant multiplication of the cells forming this capsule, leading finally to the complete destruction of the normal ganglion cell and leaving in its place a collection of ronnd cells. Ordinarily a considerable number of ganglion cells will be found which have undergone only a slight change, bnt under certain conditions the process is so widespread that all the ganglia cells are destroyed. The intensity of these changes varies in different animals; they are perhaps most pronounced in the dog, less marked in man and still less in the rabbit.

Much of the practical value of these findings consists in their making it possible to make a sure and quick diagnosis. It is possible to complete the examination within six hours after the death of the animal, and under ordinary circumstances a positive opinion can be given in from $2+$ to 36 hours. It is important that the animal should be allowed to die, and not be killed prematurely, as where the disease is not permitted to run its full course ending in death, the changes may be absent or only slightly developed.

$\leqslant$ 374. Differential diagnosis. From the often obscure manner of infection, the long period of incubation, the variable symptoms and the absence of gross morbid changes characteristic of the disease, it is easy to mistake rabies for various other nervous disorders and vice zersa, unless a definite method of diagnosis can be availed of.

Diagnosis by animal inoculation. The method which the experience of pathologists has shown to be the best, is the subdural inoculation of rabbits or guinea-pigs with a suspension of the brain or spinal cord of the suspected aninual. The subdural inoculation with the brain tissue of rabid animals was first demonstrated by Pasteur to be more reliable and more rapid in its results than the subcutaneous injections. The procedure is simple. The brain of the suspected animal is removed with aseptic precautions as soon as possible after death. A small piece of the brain or spinal cord is placed in a sterile mortar and thoronghly ground with a few cubic centi- 
meters of sterile water or bouillon. This forms the suspension to be injected.

The hands of the operator and all instruments are carefully disinfected. The rabbit is etherized, the hair clipped from the head between the eyes and ears, and the skin thoroughly washed and disinfected. A longitudinal incision is then made, the skin and subcutaneons tissue held back by means of a speculum, a crucial incision is made in the periostenm on one side of the median line, to avoid hemorrhage from the longitudinal sinus, and the four parts of the periosteum reflected or pushed back. By the aid of a trephine a small button of bone is easily removed leaving the dura mater exposed. With a hypodermic syringe a drop or more of the rabid brain suspension is injected beneath the dura, the periosteum is replaced, the skin carefully sutured and disinfected and the rabbit returned to its cage. As soon as the influence of the anesthetic* has passed off the rabbit shows no appearance of discomfort. If the operation is performed in the forenoon the animal partakes of its evening meal with the usual relish. The inoculation wound heals rapidly, and the rabbit exhibits every appearance of being in perfect health until the beginning of the specific symptoms, which occur ordinarily in from fifteen to thirty days after the inoculation. Occasionally the symptoms appear earlier than fifteen days and in some cases the rabbits are not attacked for from one to three months.

The symptoms following the inoculation are quite uniform. There is, however, a marked difference in the length of time the rabbits live after the initial manifestation of the disease. The fact should be clearly stated that rabbits do not ordinarily become furious. In some instances they are somewhat nervous for a day or two preceding the paralysis. There appears to be marked hyperesthesia. Usually the first indication of the disease it a partial paralysis of one or both hind limbs. This gradually advances until the rabbit is completely

*Ether should be used in preference to chloroform for rabbits, as the latter frequently causes death, while the former can be administered with comparative safety. 
prostrated, the only evidence of life being a slight respiratory movement. The head occupies different positions. In some it is drawn backward as in tetanus : in others it is drawn down with the nose near the fore legs; and in still others it is extended as if the animal were sleeping. The period of this complete paralysis varies from a few hours to a few days, but ordinarily it does not exceed twenty-four hours. Although these animals are unable to move voluntarily, there is a reflex action of the limbs until a very short time before death.

During the period of incubation the temperature of the rabbit is normal. As the time approaches for the first symptoms to appear there is an elevation of temperature of from I to 2 degrees, which continues for a variable length of time, but rarely longer than two days. This is followed by a gradual or usually a more rapid drop to the subnormal, which continues to the end.

The differential diagnosis in experimental animals is not difficult. Rabbits inoculated with several varieties of pathogenic bacteria frequently exhibit symptoms of paralysis for a brief period preceding death. In cases of injury to the brain or spinal cord there may be paralysis, which in the absence of the history of the case might be taken for that of rabies. In these cases, however, the symptoms appear very soon after inoculation. This is especially true when the paralysis is due to mechanical injury of the brain or to irritation of septic substances. In the case of the pathogenic bacteria if paralysis occurs at all it is almost invariably preceded by marked disability. This method of diagnosing rabies requires that the inoculated animals remain apparently well for a considerable length of time after the subdural inoculation and before the paralytic symptoms appear.

The lesions found on the post-morten examination are also of much assistance in making a diagnosis. If the animal died from septicemia or brain injury there will be lesions almost invariably recognizable in the brain or viscera. In the case of septicemia a bacteriological examination will reveal the presence of microörganisms. If the death was caused by 
rabies the inoculation wound in the head should be healed perfectly, there should be no abscess and the menings should be free from exudates and the brain should appear perfectly

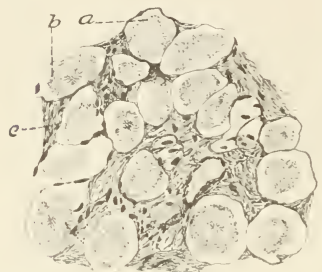

FIG. III. Section of a normal plexiformganglion; (a) and (b) ganglion cells, (c) intercellular substance.

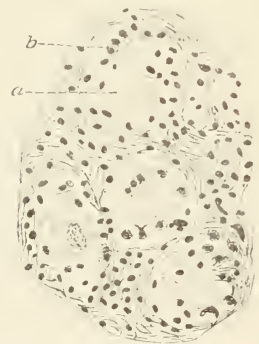

Fig. 112. Section of pleviform ganglion from a case of rabies; (a) ganglion cell, (b) cells infiltrating the ganglion cell and space. normal, except that in rare cases there may be a slight injection of the blood ressels. The viscera are ordinarily normal in appearance, with possibly the exception of the liver, which we have frequently found to be deeply reddened and the gastric mucosa, which not infrequently shows dark patches, indications of disintegrated hemorrhagic areas. A bacteriological examinatiou fails to reveal the presence of microorganisms in either the tissues or blood. Another import a $11 \mathrm{t}$ point which has been noticed is an intense rigor mortis following death from rabies. Kinyoun states that this was a constant feature of this disease in all of the produced cases which have come under his observation. Wesbrook did not observe this condition.

Animals other than rabbits have been used and a number of of other methods of inoculation have been proposed.

Diagnosis by histological examination of the ganglia. The rapid diagnosis by means of the histological changes pointed out by VanGehuchten and Nélis has been very successful in the experience of a number of workers. Ravenel was the first to publish upon this method in this country. He used it very 
successfully in the Laboratory of the Pennsylvania State I,ive Stock Sanitary Board. He reported its use in 52 cases. IVe have used this method with success.

VTe have found the plexiform ganglion, which is situated just outside of the cranial cavity near the foramen lacerm basis cranii, on the pnetmogastric nerve, the most convenient and the most desirable for study. The removal of this ganglion is comparatively easy and simple.

There are two ways by which this ganglion can be easily found:

1. Take up the pneumogastric nerve and trace it anteriorly to the point where it enters the cranium. Near this point a slight enlargement, the ganglion of the trunk of the vagus, will be fonnd.

2. Cut through the skin from the mandibular symphysis posteriorly along the neck and reflect it back. An incision is then made through the mylohyoid muscle near the inner face of the mandible posteriorly past the digastric muscle and superiorly until the lingual nerve going to the tongue is exposed. Trace this posteriorly until the point where it enters the cranium together with the vagus is reached. In this way it is easy to locate the vagus nerve and the plexiform ganglion. We have found either one of these methods or a combination of the two very convenient, and with a knowledge of the location of these parts there is no reason why the ganglion should not be removed quickly and easily.

After the ganglion is removed there are a variety of methods which may be used in fixation and staining. The following we have found to be very satisfactory. As soon as the ganglion is removed it is placed in Flemming's fluid or in a standard aqueous solution of mercuric chloride for a few hours, washed in water, carried through the alcoliols and sectioned by the paraffin method. With this method of fixation it is almost imperative that the sections be stained with iron or Delafield's hematoxylin, of which we have found the latter the most convenient. Alcohol, either 95 per cent. or absolute, may be used as a fixer, in which case other staining methods may be used. However, the fixation by this method is not as good, but it admits of a trifle more haste.

Normally this ganglion is composed of a fibrous capsule from which a supporting fibrous tissue extends into the interior, holding in its meshes the nerve cells, each of which is enclosed in an endothelial capsule. The changes characteristic of rabies consist in the atrophy, the invasion and the destruction of the ganglion cell as a result of 11 ew formed cells, evidently from the endothelial capsule. These cells appear 
first between the nerve cell and its capsule. These changes are quite uniform through the entire ganglion and in advanced cases of the disease nearly all of the nerve cells are often times destroyed.

Robineaux examined 37 cases that died of rabies with positive results. In animals killed during the course of the disease the results varied. In to such cases, he found the lesions in it and they were absent in 29. The rapidity with which ganglionic changes appear seems to vary greatly in different individuals.

The fact must be kept $i_{11}$ mind that this is a method for rapid diagnosis in case the animal dies and mot a means for an early diagnosis.

Diagnosis from the presence of Negri bodies. The presence or absence of Negri's bodies is used as a means of diagnosis in most if not all laboratories. These bodies, which are often quite large, are readily brought out by proper staining. These bodies, whether the cause or specific degenerations, appear to be of much value in making a rapid diagnosis. Unlike the gauglion changes they appear early in the course of the disease, and consequently they are of ralue in making an early diagnosis when the animal is killed soon after the appearance of the first symptoms. Thus far these bodies, or those easily mistaken for them, have not been found in the brains of animals dying from other diseases except one report of their possible presence in a case of tetanus.

Bohne uses for diagnosis of rabies a piece $I_{2}-3+\mathrm{mm}$. thick from the Ammons horn which after $30-40$ minutes of fixing and hardening in aceton for $60-75$ minutes he puts it in paraffin. In this way it is possible for them by the aid of a short staining after the Mann method to get stained sections in the course of three hours.

In his 170 investigations ( 157 dogs, 6 cows, + people. 3 cats) he found the later discoveries of Negri and Volpino confirmed according to the presence of the Negri bodies and their finer structure.

Besides he investigated 50 dogs attacked with other diseases without finding Negri bodies or similar forms. He therefore holds the Negri bodies as specific for rabies and the diagnosis as assured by a positive find. Their parasitic nature seems to him for the present still doubtful. 
$\$$ 375. Prevention and treatment. The prevention of rabies infection resolves itself into two procedures. (1) The destruction of all ownerless and vagrant dogs, and (2) the nuzzling of all dogs that appear upon the streets or in public places. In thus preventing the propagation of the virus, as shown by the results obtained in Germany and Great Britain, the disease will be practically exterminated.

There is no treatment for rabies except the preventive inoculation known as the Pasteur treatment by which an immunity is produced by the subcutaneous injection of the virus of rabies in an attenuated form, beginning with the mildest virus and going gradually up to one which possesses nearly or full virulence. The attenuation of the virus is brought about by drying at a fixed temperature and the action of the atmosphere. Depending upon the length of time the virus is exposed to the influences, we can obtain any degree of virulence desired, the loss of virulence under fixed conditions being quite uniform.

The disease as seen in dogs infected naturally was called by Pasteur " street rabies" and the virus of such animals is known as the "virus of street rabies." Such virus will as a rule produce the disease in rabbits by intra-cranial inoculation in from three to four weeks. By inoculating rabbits in series one from the other, a reduction of the period of incubation is obtained. After about roo passages rabbits will die with certainty and great regularity on the sixth or seventh day after inoculation. Beyond this point no increase of virulence has been obtained. This is the fixed virus of Pasteur.

The simultaneous method which consists in the injection simultaneously of a strong virus and the serum of an imnune animal is now being used with reported success in the Pasteur Institute of Paris.

RFFERENCFS

I. BABks. Sur certains caractères des lesions histologiques de la rage. Ann. de l'Institut Pasleur, Vol. VI (IS92), p. 299.

2. Babrs. Untersuchungen ïber die Negrischen Körper und ihre 
Beziehung zu dem Virus der Wutkrankheit. Zeitschr. f. Hygiene, Bd. LVI (1907), S 435.

3. BoHNE. Beitrag zur diagnostischen Verwerthbarkeit der Negrischen Körperchen. Zeitschr. f. Hygiene, Bd. LII, S. 87.

4. CABOT. Report on experimental work on the dilution method of immunization from rabies. Jour. Experimental Med., Vol. IV ( 1899$), \mathrm{p} \quad$ I81.

5. DULLES. Disorders mistaken for hydrophobia. Trans. of the Med. Soc. of the State of Penn., 1884.

6. Fleming. Rabies and hydrophobia.

7. Frothingham. The rapid diagnosis of rabies. Jour. Med. Research.

S. KEIRLE. A report on the autopsies on four recent cases of rabies and a bacteriological examination of a rabid dog, together with the recent laboratory experiments. Maryland Med. Jour., Vol. XXXVIII ( 1897 ).

9. LAw. Rabies. A System of Practical Medicine by American Authors, Vol. III ( 1898 ).

Io. Maccure. Rabies-hydrophobia. Supplement to the Annual Report of the Michigan Board of Health, 1894.

I I. MoHLER. Pathological report on a case of rabies in a woman. Annual Report, U. S. Bureau of Animal Industry, 1903, p. 54.

12. MOORE AND FisH. A report on rabies in Washington, D. C. Annual Report, U. S. Bureau of Animal Industry, 1895-6.

13. MOORE AND WAY. A rapid method for the diagnosis of Rabies. Anerican l'eterinary Reviea', Oct., 1904.

14. Negri. Beitrag zum Studium der Aetiologie der Tollwuth. Zeit. f. Hygiene, Bd. XLIII (1903), S. 507.

15. Poor. Recent studies in the diagnosis of rabies. Medical Record, Apr. 15, 1905.

i6. Public Healtith Commission, District of Columbia. Rabies. Bul. 25, U. S. Burean of Animal Industry, I9oo.

17. RAVENEL, AND MCCARTHY. The rapid diagnosis of rabies. Univ. of Penn. Med. Magazine, January, igor.

I8. Ravenet. Rabies. But. 79, Dept. of Agr., State of Penn., 190 I.

19 REMLINGER. Le passage du virus rabique à travers les filtres. Ann. de l' Inst. Pasteur, Vol. XVII (rgo3), p. 834.

20. Reminger ent RifFat-Bey. Sur la perméabilité de la bougie Berkefeld au virus rabique. C. R. Soc. de Biol., Vol. LV. (1903) p. 974. 
21. Sis,mox. Rabies, its cause, frequency and treatment. Jear liwok, Dept. of Agriculture, Washington, 1). C. I900.

22. Salmox. Rabies in the District of Columbia. Circular No. (1), L'. S. Bureau of Inimal Industry, tgoo.

23. Simor. Hydrophobia. An account of M. Pasteur's system. I 887.

24. Schïner. Der Negrische Erreger der Tollwuth. Deul. Med. Hochenschrift, 1903, No. 39, S. 700 .

25. VAx (iEHUCHTEx AND Nisis Diagnostic listologique de la rage. Annales de Mid. Vít., Vol. XLIX (1900). p. 234.

26. Was. The Negri bodies and the diagnosis of rabies. Amer. l'et. Reviere, Vol. XXIX (1905), p. 937.

27. WrsBrook AxD Wilsox. Preliminary report on the laboratory diagnosis in twenty cases of suspected rabies. Trans. Am. Public Health Assn., 1 sos.

28. WILLAMS Axil Lowde. The etiology and diagnosis of hydrophobia. Jour. of Inficlions Diseases, Vol. 3, 1905, p. $45^{2}$.

\section{DIPHTHERIA IN FOWLS.}

Synonyms. Roup*; pip; canker; swelled head.

$\leqslant 376$. Characterization. Diphtheria of birds is an infectious disease the lesions of which first appear on the unucous nembrane of the nasal passages, the eyes, the mouth, the pharynx and larynx, and which may extend to the trachea, bronchi, the air sacs, the intestines and possibly to other abdominal organs. The disease is determined by a grayishyellow, fibrinous exudate which forms upon the mucous surface of one or more of the parts mentioned. The exudate may be so abundant as to obstruct tie air passages. In some outbreaks, it is very acute, progresses with great rapidity and destroys most of the birds attacked.

Fowls (genns (jallus) and pigeons (genus Columba) are most conmonly attacked and they are the only ones considered

The origin of this term is somewhat obscure, but it is supposed to be a corruption of croup, and its application explained on account of a peculiar hoarseness accompanying the respiration of the affected birds. 
in this discussion. Avian diphtheria is reported, however, to attack turkeys, ducks, pea-fowls, pigeons and pheasants. It is presumed that wild birds may be affected.

Avian diphtheria is quite distinct from human diphtheria. There are cases on record, however, which indicate that the diphtheria of fowls may be communicated to children and cause a serious and even fatal sore throat. On the other hand, it is asserted that diphtheria of children is sometimes communicated to fowls and that the virus may be thus preserved for a considerable time and again be transmitted to children. Concerning this point additional investigations are needed.

$\$ 377$. History. The history of this disease is somewhat obscure. It is evident from the literature, that fowls have always been subject to various affections of the head but the first investigation of this class of maladies seems to have been made by Loeffler*in $188_{4}$. Since that time Klemmer $\uparrow$, Babes and Puscarin +, Eberlin \|, Loir and Ducloux and others have studied diseases known as diphtheria in pigeons, fowls and other birds. The disease was investigated by the Bureau of Animal Industry in 1893-4. It has more recently been studied in California by Ward, in New York by Mack, and at Guelph, Ontario, by Harrison and Streit.

$\$$ 378. Etiology. In 1884, Loeffler discovered a bacterium which he believed to be the specific cause of diphtheria in fowls and with which he could produce the disease. It differed from the diphtheria bacterium in man. Loir and Ducloux isolated a still different organism. The writer found in the exudates of the earlier stages of the disease a bacterium belonging to the septicemia hemorrhagica group. It was rapidly fatal to rabbits but the diphtheritic lesions could not be produced by inoculation in fowls. In the examinations of the

*Mitt. aus dem Kaiserlichen Gesundheitsamte. Bd. II (1884), S. 2 I 4. $\dagger$ Berliner theirärzt. Wochenschrift. ISgo, No. Ib, S. 138.

Zeitschrift f. Hygiene. Bd. VIII (1890), S. 374 .

\|Monatshefte f. Thierheilkunde. Bd. V (1894), S. 433.

-Ann. de l'Inst. Pasteur. Tome VIII (I894), p. 599. 
last three years this organism has not been found in the diphtheritic lesions of fowls. King found a bacterinm on the conjunctiva of a healthy fowl that belongs to this group. Ward failed to find it in his study of the disease in California. Harrison and Streit have described an organism, Bacillus cacosmus, which they consider specific. Ps. pyocyaneus has also been obtained in pure culture from the exudates. Mack, who has made a careful study of this disease, has failed to find any

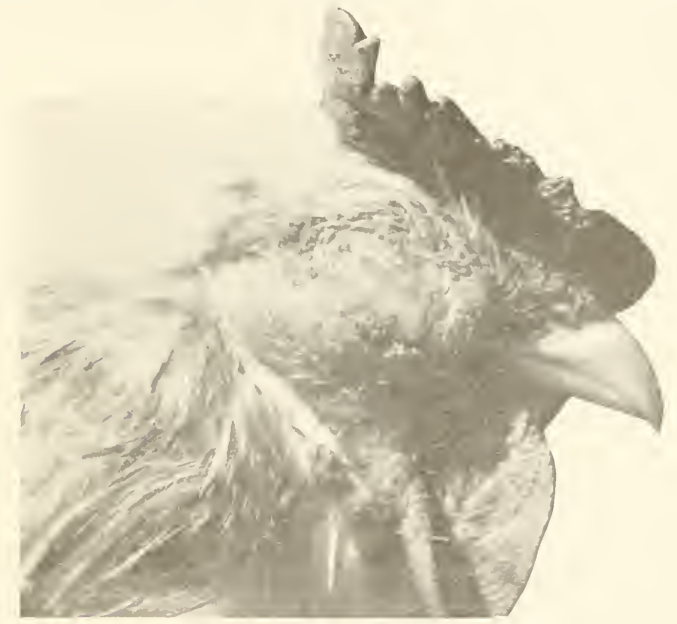

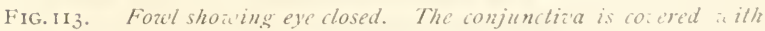
a thick erudate (II ard).

organism constantly present in the lesions. He also failed to produce the disease with $B$. cacosmus. It is not positive, however, that the same disease was studied by the different writers. Roup is usually introduced into a flock by the exposure of the birds to sick ones at shows or by bringing affected fowls on the premises. The contagion may be carried by birds which have the disease in so mild a form that they show no 
symptoms of it. There is a general belief that the disease may be developed by exposure of birds to draughts of air or by keeping them in damp, filthy and badly-ventilated houses. It is presumable that this belief in its etiology is not well founded because of confusion existing concerning the early symptons of acute diphtheria and those of all stages of the chronic form, and those of simple colds and catarrhs. Ward was unable to produce the disease by exposing fowls to unfavorable conditions, but when infected fowls were introduced

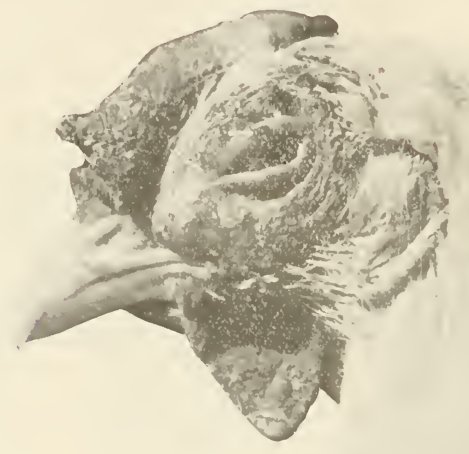

FIG. IIt. Foall showing the suborbital sinus distended. The eye is parlially closed.

the disease spread rapidly. Dampness and lack of ventilation no doubt favor the maintenance of the virus when introduced.

The specific cause of the disease known as diplitheria or roup in chickens and pigeons, in the opinion of the writer, is not known. It is not impossible that a number of organisms may share in the production of the lesions of this affection.

Guérin considers it a general disease caused by a coccobacillus (resembling the fowl cholera organism). This is not unlike the bacterium of septicemia hemorrhagica. He finds 
it in the blood and organs. Moore, Mack and II ard have failed to find this organism in the tissues.

$\$$ 379. Symptoms. There is a watery secretion from the nostrils and often from the eyes, with general weakness and prostration greater than would be expected from simple catarrh. The birds sit with the back arched, the head and neck drawn out towards the body, the plumage rougliened; the respiration is more or less obstructed, rapid and audible. the vision is inpaired and swallowing is difficult. There is

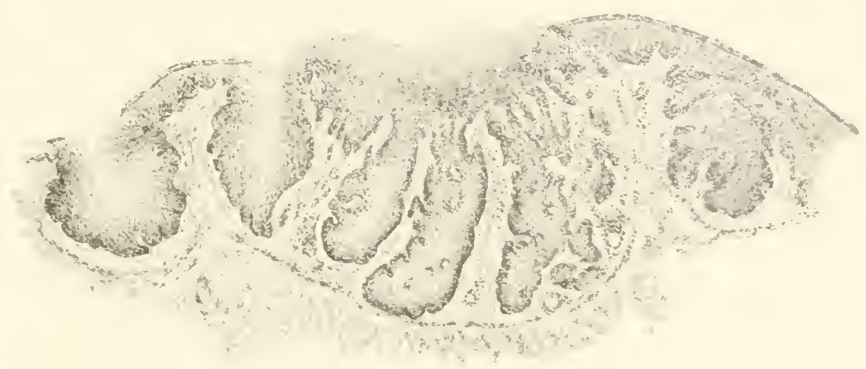

FId. I15. Early stages of diphtheritic necrosis in the throat of a pigeon.

frequent shaking of the head, sneezing and expectoration of mucous secretions. If the mouth is examined at this early period the tongue is found to be pale. while small grayish spots, shaded with black and slightly projecting abore the surface, may be seen along the border, the upper surface or at the base.

The following day the condition is aggravated, the temperature is several degrees above normal, the appetite has disappeared and there is diarrhea with greenish or yellowish evacuations. From the open beak there escapes a thick, stringy, grayish mucus. The eyes are unnaturally dilated. projecting and possibly party covered with the thick secretion which has accumulated between the lids. The nostrils are obstructed by the thickened and dried secretion. Malking is 
irregular and difficult. The nucous membrane of the mouth and pharyn is congested and shows numerous dark red elevations covered with fibrinous exudate. The patches on the tongue have increased in size, they are gray in color, dried along the edges of the tongue but soft and flattened upou its upper surface. They are covered with membranous deposits. The voice often fails.

$\$ 380$. Morbid anatomy. The lesions are largely localized on the mucosa of the head. With the exception of ema-

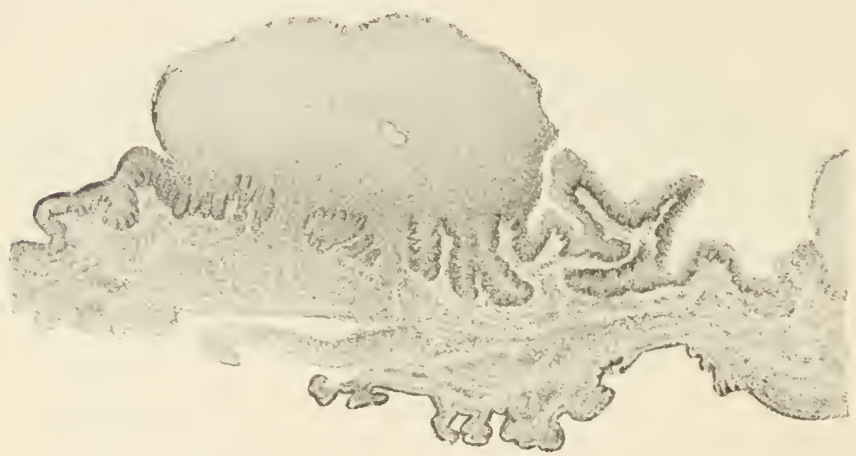

FIg. II6. A section through a diphtheritic erudate, late in the course of the disease, from a pigeon's throat.

ciation, there are no lesions or evidence of organic disease. The cause of death and the extreme emaciation are difficult to explain in those cases where the lesions are confined to one eye or to the mucosa of the nares, excepting on the supposition that some poisonous or toxic substance was absorbed from the seat of the disease. In those cases where the lesions are in both eyes, or in the mouth and throat, difficulty in finding or swallowing food affords a rational explanation.

In some cases the exudate is of a croupous character, in others of a diphtheric nature. Three stages or varieties of lesions, which represent the types of this disease as en- 
countered in this country, may be more definitely defined as follows :

I. An exudate of a serous or muco-purulent character in the conjunctiva and nasal cavities. Ordinarily this condition cannot be recognized in the mouth. The mucosa in these cases is apparently but slightly altered.

2. The mucosa over a small or larger area is covered with a spreading exudate of a grayish or yellowish color. It is firmly attached to the mucous membrane and when removed leaves a raw, bleeding surface. Sections through this exudate and the subjacent tissues show that the epithelial layer is destroyed and the unlerlying tissue infiltrated with cells. The extent of the infiltration varies in different individuals.

3. The mucosa is covered with a thick mass of exudate, varying in color from a milky white to a lemon yellow or brown. It is easily removed, leaving a more or less granular and healed surface. This sloughed mass is frequently dried at its margins to the adjacent tissue. It emits a strong putrid odor, due to decomposition. The drying of the margins prevents the fowl from expelling the exuciate after it becomes separated from the underlying tissue.

The evidence to support the supposition that the three forms or types of exudate described are different stages in the same morbid process, as gathered from the post-mortem notes and bacteriological study of the cases investigated, may be summarized as follows :

(a) Abnormal conditions, representing the intermediate and connecting links between the types of lesions, are frequently encountered.

(b) Although at the time of examination (post-mortem) but one form of exudate is usually present in a single fowl. there are exceptions, in which two and oscasionally the three forms are coincident. Thus the eye is covered with a sloughed exudate, the posterior nares contains a layer of muco-purulent substance and on the mucosa of the mouth are areas of diphtheritic exudate. 
In fowls which die, the exudates are for the greater part in the advanced stage, although fatal cases occur in which the lesions are restricted to an abuormal quantity of a serous or muco-purulent, more or less viscid, exudate in the conjunctiva or nasal cavities. The best illustration of the diphtheritic

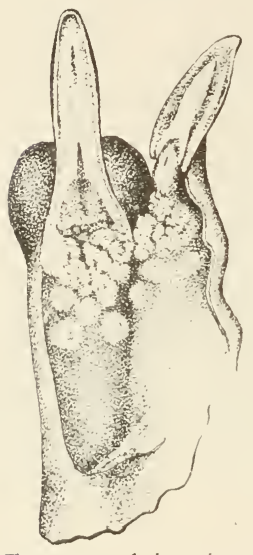

FIG. II7. A drazing showing areas of diphtheritic ex udate in the throat of a pigcon. process is found in fowls killed for examination in the second stage of the disease. The distribution of the lesions shows that the conjunctiva is most frequently affected. The exudate in the nasal cavities is in some cases undoubtedly the result of the coagulation of the liquid which has passed during the course of the first stage from the conjunctiva through the lachrymal duct into the nares. In certain cases, however, the lesions appear in the nares primarily. In some cases the exudate appears in the larynx and extends down into the trachea. In these cases the fowls are liable to die from suffocation. It occasionally happens that the lesions are restricted to the larynx and as the fowls die suddenly the canse of death is not suspected. Sections of the exudate with subjacent tissues from the cornea and the mouth, show that there is a cell infiltration into the mucosa which destroys the epithelial layer and frequently the submucous tissues to a cousiderable depth.

The fact should not be overlooked that the disease in the eye is usually confined to the conjunctiva and the cornea, the posterior portion remaining apparently normal.

Mack in his work on thirty-three cases found 40 per cent had lesions in the conjunctiva; in 44 per cent the nasal mucosa was affected; in $4 \mathrm{I}$ per cent the mouth was involved and in 33 per cent the suborbital sinuses were distended with exudates. 
From the observations thus far made the provisonal theory is entertained that the three forms of the exudateserous or muco-purulent, diphtheritic and sloughed mass-represent three stages in the course of the same distase. It is easily understood that fowls examined in the first stage would be said to be affected with a catarrhal condition of the mucosae of the eyes or nares. It is highly probable that in many cases the disease never reaches the second stage and if these cases alone were examined the diphtheritic condition would not be

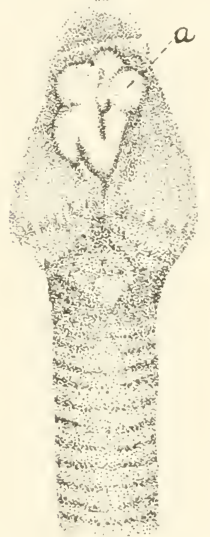

FIG. I18. Diphtheritic erudate in the laryn.r of a fowl: (a) the grayish-white erudate projecting from the glottis.

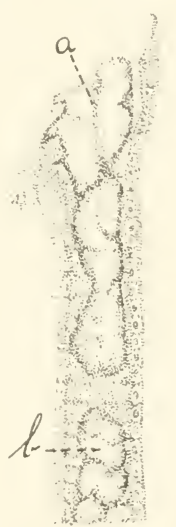

lig. IIg. Alongitudinal seition through the larynx and trachica of a firel (same as IIS), showing the exudate: (a) in the lar ynir and (b) in the trachea.

suspected. It appears, however, that in the majority of cases the disease runs its course and membranes are formed, slough and recovery follows. It is furthermore presumable that the disease in question appears sometimes in a virulent and destructive form. I am in possession of statements from poultry raisers which show that there are occasionally epizoötics of a disease characterized by exudates in the eyes, nose or mouth. 
which run a rapidly fatal course. It appears that it is such outbreaks which have been reported in Europe as diphtheria and not the low form of chronic inflammation which has been studied in this country.

$\S 381$. Differential diagnosis. The differential diagnosis of diphtheria in fowls cannot be made until we are possessed of a knowledge of its cause. At present all affections of the head characterized by the range of lesions admitted by the description of the morbid anatomy are accepted as cases of diphtheria or roup. Chicken pox is separated by the nodular character of the lesions. Manson's eve worm (oxyspirura Mansoni) of chickens produces lesions that might be mistaken for roup. The finding of this worm would determine the diagnosis.

\$ 382. Relation of diphtheria in man to that in fowls. A comparison of the bacillus of diphtheria in man (KlebsLoeffler) with those described from diphtheria in fowls shows that morphologically and in their pathogenesis for experimental animals the organisms are in no way alike. There is also a marked difference in the nature of the exudates in fowls and in man. The non-identity of these diseases has been clearly pointed out by Ménard.* Although these maladies are show11 by several observers to be unlike in their etiology and the character of their lesions, the transmission of fowl diphtheria to the human species, and vice versa, is affirmed by several writers.

Gerhardt reports 4 cases of diphtheria in Wesselhausen, Baden, among 6 workmen who had charge of several thousand fowls, many of which died of diphtheria. There were no other cases of diphtheria in the neighborhood and the evidence was quite conclusive that the disease was contracted from the affected fowls.

Debrie reports briefly the transmission of human diph-

*Revue d'Hygiene. Tome XII (IS90), p. 4 Io.

\# Reviewed in Centralblatt f. Bakteriologie. Bd. IIII (I893), S. 730 . 
theria to fowls. He is inclined to the view that human diplntheria is transmissable to fowls and fowl diphtheria to man. Cole* reports a case of supposed transmission of the disease from a fowl to a child.

The diphtheritic disease of fowls reported by Loir and Ducloux in Tunis, in I 894, spread to the people of that place, resulting in an epidemic of serious proportions. Ménard refers to the fact that men employed to feed young squabs contracted diphtheria by blowing the masticated food into the mouth and crop of squabs suffering with that disease. Sichrevenst reports several cases of diphtheria in children in which he traces the source of infection to certain poultry.

Guérin has pointed out with emphasis that there is no relation between diphtheria in man and in fowls.

Although the number of reported cases of the transmission of fowl diphtheria to the human species and vice versa is small in comparison with the extent of the disease in poultry, the evidence that such a transmission is possible is quite sufficient to discourage the careless handling of diseased fowls. It is a quite common practice, especially in the rural districts, to bring the sick chickens into the house for treatment, where the children of the household are allowed to fondle them at will. It is not improbable that when this disease is thoroughly investigated the number of cases of direct infection from this source will be found to be much less than it is at present supposed. Until such investigations are satisfactorily completed the indiscriminate handling of diphtheritic chickens especially by children and the exposure of fowls to the infection of diphtheria in the human species, whereby they may become carriers of the virus, should be strenuously avoided.

$\leqslant$ 383. Prevention. In order to prevent this disease it is evident that many conditions must be strictly complied with. The character of the food and the general sanitary con-

* Archives of Pediatrics, NI (1894), p. $3^{\text {sil. }}$

Bulletin de l' Acad. Royale de Méd. de Belgique, Vol. VIII [1894, p. 380 . 


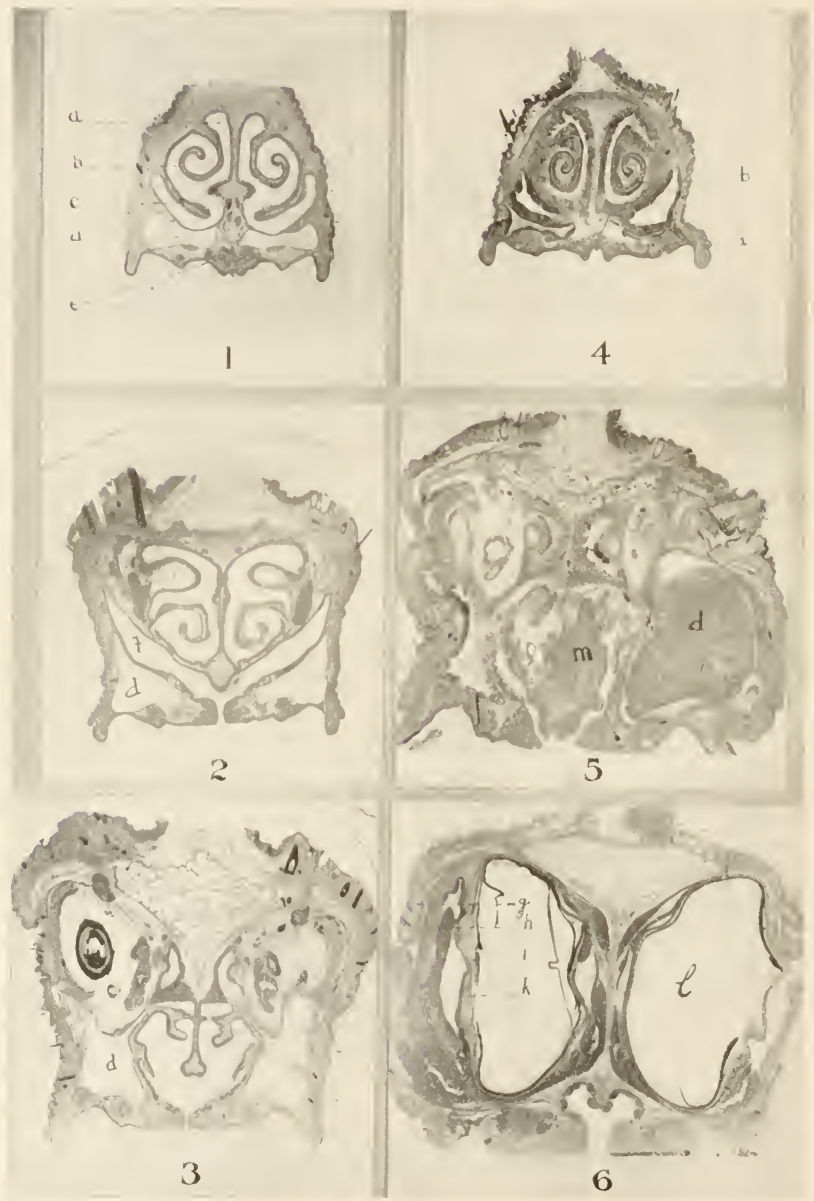

FIG. I20. Sections of the heads of a normal and of a diphtheritic foul. 
ditions, including cleanliness, ventilation and the temperature of the poultry houses, must be considered. Undoubtedly there is much to be learned in comnection with the proper sanitary care of poultry. In addition to the general sanitary methods, the following rules should be observed.

I. Fowls which have an exudate on any of the mucous membranes of the head or which have come from flocks in which such a disease exists or has recently existed, should not be placed among healthy pothltry.

2. If the disease appears in one or more fowls of a flock they should be immediately separated from the weil ones. If

Fig. I20. Photograpls of transections of fowl's head.

I, 2 and 3 . Sections from a normal hearl.

4, 5 and 6 . Sections from approximately corresponding levels from the heads of fowls suffering with diphtheria.

1. Cross-section of a chicken's head just posterior to the nasal openings. $a$ Nasal passage, $b$ turbinated bone, $c$ portion of the wall of the false nostril, $d$ sub-orbital sinus, $e$ palate.

2. Cross-section of a chicken's head midway hetween the nasal openings and the eves. $d$ Sub-orbital sinus, $d^{1}$ superior portion of the sub-orbital sinus, which conuects with $d$ posterior to the lachrymal duct, $f$ lachrymal duct opening into the mouth through the cleft palate.

3. Cross section of a chicken's head on a level with the anterior part of the eyes. $d$ Sub-orbital sinus and the duct connecting it with the nares.

4. Cross-section of a chicken's head just posterior to the nasal openings, showing the swollen condition of the nasal mucosa in the first stage of the disease. The nasal passages are nearly occluded. I Turbinated bone with swollen mucosa, $d^{7}$ sub-orbital sinus containing a small amount of exudate.

5. Cross-section of a chicken's head nidway between the nasal openings and the eyes, showing extensive exudate in the left suborbital sinus $d$ and nasal passage extending into the cleft palate $m$. The exudate is crowding upon the turbinated bones and nasal septum.

6. Cross-section of a chicken's head through the eyes, showing exudate in the conjunctival sac, inflammatory thickening of the eyelids and membrana nictitans, and ulcerated cornea. $g$ livelid, $h$ meubrana nictitans, $i$ exudate in the conjunctival sac, $k$ ulcerated cornea, $/$ eve.

All sections are magnified two diameters. 
possible, the source of the infection should be determined and remored.

3. The quite common practice of allowing fowls from different flocks to run together during the day should be discouraged.

4. Care should be taken to avoid the possibility of bringing the virus of the disease from affected flocks in the dirt or excrement which naturally adheres to the shoes in walking through an infected chicken yard. The same care is necessary in the interchange of working implements, such as shovels, hoes and the like.

Ward has found that this disease can be prevented by keeping infected fowls away.

It is evident to any careful observer that the fact is too often overlooked that fowls, owing to their method of living, are more liable to infection than other farm animals. This is especially true when they are allowed to run at random, picking their living from the garbage pile and barnyards, or securing even more unwholesome food. There is little doubt that many so called outbreaks of contagious disease among fowls are simply enzoötics brought about by various infections to which they have been exposed.

The wide distribution, the large number of fowls affected and the usual chronic course of this disease render it one of the few poultry affections for which curative measures promise to be of some practical value. The most certain of the known methods of treatment is the local application of disinfectants, among which a weak solution of carbolic acid appears to be the most satisfactory. The dipping of the heads of fowls in a solution of $\mathrm{I}$ to 2 per cent of permanganate of potash, or a 3 per cent solution of creolin is reported to be very effective in cases where the lesions are external and in the early stages. The fact that the lesions are so much exposed renders the disease especially favorable for topical applications. When the exudates are in the suborbital sinus or in the nares there is less opportunity for treatment. 


\section{REFERHNCHS.}

I. Givisix. Sur la non-identité de la diplitherié humaine et de la diphthérie. Recueil de .1Mid. l'̈́t., 1903, p. 20.

2. GRATIA HiT Lrivalx. Contributions à l'ćturle bacteriologique de la diphtérie. Annalés de Mid. Vét., Vol. XI.VII (ISgs), p. for.

3. Harrison and Strkit. Roup. Am. Vet. Review, Vol. XxviI (1903), p. 26.

4. HARRISON AND STREIT. Roup: An experimental study. liulletin 132. Onturio Arric. Coll. and Exp. Farm, 1903.

5. Hot.nks. An outbreak of diphtheria associated with a similar disease anong fowls and a vesicular eruption on the udders of cows. wur. of Comp. Path. and Thera., Vol. XVII (I904), p. I.

6. LOEFELER. Untersuchungen über die Bedeutung der Mikroorganismen für die Entstehung der Diphtherie beim Menschen, beim Tanbe und beim Kalbe. Mitthiel. a. d. Kaiserlichen Gesundheilsamtc, Bd. II ( $\left.1 S S_{4}\right)$, S. 421 .

7. Loir it Duclotx. Contributions à l'étude de la diphtérie aviare en Tunisie. Inn. de l' Inst. Pisteur, Vol. VIII (IS94), p. 559.

8. MAck. The etiology and morbid anatomy of diphtheria in chickens. Am. I'el. Rev., Jan., I905.

9. Mooke. A preliminary investigation of diphtheria in fowls. Bullitin No. S. U. S. Bureau of Animal Industry, Is95.

Io. Raxsom. Manson's eye worm of chickens. Bulletin No. oo. l'. S. Bureau of Animal Industry, Igot.

in. SAlmox. The diseases of poultry, 1899, p. 2 I6.

12. WARD. Poultry diseases in California. Proceedings of the Aner. Vet. Hed. Asso., igot, p. 164.

\section{INFLLEN\%A.}

Synonyms. Epizoötic catarrhal fever; epizoötic catarrh ; horse distemper; pink eye; mountain fever ; shipping fever.

$\leqslant 384$. Characterization. Influenza is an acute infectious disease characterized by a rise of temperature and a catarrhal condition of one or more of the mucous membranes. more especially of the head. One or more of the interual organs may become affected. It usially appears in epizoötic form. It is a disease of horses, although asses and mules are 
susceptible and a few cases are reported of its being transmitted to man and to dogs. It appears sometimes in sporadic form and often in epizoötics.

Influenza is a generic term employed to designate a large variety of symptoms. A somewhat careful analysis of its manifestations suggests that possibly it includes a number of etiologically distinct diseases, $i . e$, morbid conditions brought about by different causative factors. The term has long been employed to designate a considerable variety of equine epizootics, the independence of which could not be established. The disease, as it is seen in the horse, suggests further that possibly it is in its beginning a general affection because of the early rise of temperature and that later in its course it becomes, to a limited extent, localized. At present influenza is restricted to groups of symptoms and lesions in the horse that are not very unlike those of la grippe in man. Its symptoms, lesions and sequelae warrant such a view at least for a working hypothesis. As it is not usually fatal, little progress seems to be made in acquiring knowledge concerning the nature of its morbid anatomy. There is much need for careful investigation of this very common malady.

$\$ 385$. History. According to the writings of Falke, influenza was recognized in very early times. There is evidence that it was known in the fourth and fifth centuries. It was described by Löw in 1729 in an equine epizoötic which had spread over Southern Europe. It is also stated that cases of its having been transmitted to man had occurred. Gibson observed it in 1872 in London and in different districts of England. It raged in epizoötics in 1760,1776 and 1803 . The disease was widely disseminated during the last century. The more important epizoötics are reported in the years from $I_{S_{3}}$ to 1815,1825 to 1827,1836 to I $840,1846,1851,1853,1862$, $1870,1873,1881$ to 1883 , and 1890 . Anker, who described influenza in Switzerland in 1826 , laid stress on its contagious nature and stated that in his opinion "a volatile infectious matter was the cause."

Influenza spread as an epizoötic in 1872 to 1873 over the 
greater part of the Lnited States where it received the name of "pink eye"' (French, fiire typhoide). It started in Canada and extended sonth and west, reaching into Britisl Columbia to the north and Mexico at the sunth. The last great epi\%ootic raged in Europe from 1881 to 1883 during which time it is said to have spread over nearly the whole continent. In the Prussian army, 3, 44 horses became affected in $1890 ; 2,497$ in ISgi; and $3,6+5$ in 1892 . In Copenliagen, 3, ooo horses were affected in 1890 and 189 I.

\$ 386. Geographical distribution. Influenza seems to be known in nearly if not all of the countries of Europe and Anerica In certain sections of the United States it is almost a constant affection. This is especially true of certain cities, orving to the constant introduction of "green" horses.

$\leqslant 387$. Etiology. Influenza seems to be produced by a specific infection the nature of which has not yet been deternined. A number of bacteria have been described as the probable cause but thus far none of them have been found to be sufficiently constant to warrant their acceptance as the etiological factor. It spreads rapidly among horses. 'The virus appears to lose its virulence quickly outside of the animal body, but within the body it seems to be preserved for a long time. According to the observation of Jensen and Clark, stallions which have liad the disease may transmit it to the mares they serve for months after apparent recovery. Dieckerhoff succeeded in transmitting the disease to healthy auinals by subcutaneous and intravenous injections of the blood of infected horses, but Friedberger and Arloing failed to do so. Horses are most susceptible. Sex, breed, stable managenent and feeding appear to have little or no influence on their individual susceptibility.

Infection usually takes place from horse to horse. The virus appears to be carried by infected luman beings, litter, harnesses and thermometers. In many cases one attack confers immunity but a second infection or a relapse frequently occurs. Toward the end of an epizoötic the disease is usually 
milder in form, probably due to a gradual attenuation of the virus.

The period of incubation varies from two to seven days. Siedamgrotzky places it at from four to five days and in rare cases from $\mathrm{I} 2$ to $2+$ hours. In some cases symptoms have not appeared until from two to five weeks after the latest known exposure.

$\$$ 388. Symptoms. The disease appears suddenly and may attain its highest point of intensity within twenty-four hours. The organs of circulation, nervous centers, digestive and respiratory mucous membranes and conjunctiva are especially affected. There is partial or entire loss of appetite and depression. The temperature rises suddenly from 3 to $4^{\circ} \mathrm{F}$. or even more. It remains high with but slight variations for from three to six days and then falls rather quickly, often within trienty-four hours, to the normal. At first the frequency of the pulse is but little increased in comparison to the elevation of the temperature, but later it rises to from 60 to 70 and in fatal cases from so to 100 or more. It generally continues high for some time even after the temperature has fallen. The fever is characterized by unevenness in distribution of the external temperature of the body. The early rise of temperature, while the affected horses appear to be healthy, is of much diagnostic value.

Usually the nervous depression coexists with the fever. The animal may hold its head down and appear to be coniatosed. Extreme muscular debility is frequently: associated with this stupor. Tremors may occur, the hind legs may give way while walking and paralysis of the hind quarters appears in a few cases.

The oral mucous membrane is greatly congested, hot, dry or covered with mucus. There is sometimes difficulty in swallowing. The animal frequently yawns. There is usually constipation in the beginning of the disease which may be accompanied with colic. The feces are formed into small hard balls and are covered with masses of mucus. Later diarrhea 
with considerable tenesmus usually occurs The feces are of a thin. pulpy and even fluid consistence and sometimes have a fetid odor. At the beginning of the attack the urine is alkaline but it becomes acid when the intestinal lesions are developed. It rarely contains albumin but desquamated epithelial cells of the bladder are often present in large quantity.

A severe affection of the eyes is quite a constant characteristic symptom of influenza. At first it consists chiefly of a catarrhal and later of a plilegmonous conjunctivitis with considerable swelling of the eyelids, which may be followed by keratitis and possibly by an exudative or hemorragic iritis. Usually botlı eyes are affected. The first indications are the presence of tears, intolerance of light, intense hyperemia of the conjunctiva and contraction of the pupil. The eyelids swell, are hot, painful and kept more or less continually closed. A grav, muco-purulent secretion accumulates between the eyeball and eyelids and the eyeball becomen very sensitive to pressure. The cornea, which at the beginning of the keratitis has a greasy lustre, first becomes iridescent, but later in the course of the disease it may be opaque. It is considerably injected with blood at its edge; the iris becomes swollen and yellowish in color. Often these inflammatory changes of the eye disappear in a strikingly short time.

During the further progress of the disease, strellings appear on the extremities, sheath, epigastrium and lower part of the chest. It may be concluded that these swellings are due to edema caused by passive congestion. Less frequently the swellings are of an inflammatory nature. The swelling of the extremities causes the gait to be stiff and unwieldly. Inflammation of the sheaths of the tendons is sometimes observed.

The respiratory mucosae are congested. At first there is a serous and, later on, a muco-purulent discharge from the nose, slight swelling of the submaxillary glands, moderate acceleration of respiration and a cough. As a rule the animal becones emaciated during the course of the disease. Pregnant mares may abort.

In certain cases complications may arise, such as cardiac 
debility, grave cerebal symptoms, severe gastro-intestinal inflammation, laminitis and petechial fever, all of which have been described as accompanying complications.

The duration of the disease is from six to ten days, althongh severe cases may run for two or three weeks and very mild cases may recover in from three to six days.

The mortality varies at different times and in different places. The average appears to be from 0.4 to 4 per cent. Dieckerhoff saw a loss of 4 per cent among I,700 horses; Aureggio, one of 3 per cent among 800 horses; Friedberger, one of 9 per cent ; and Siedamgrotzky, one of 10 per cent. It is stated that in 1872 , in Philadelphia, 7 per cent of 30,000 infected horses died.

\$ 389. Morbid anatomy. The principal tissue changes of influenza are met witl in the organs of digestion. The nucous membrane of the pyloric portion of the stomach and of the intestines is hyperemic, swollen and sprinkled with slight hemorrhages. The subnucosa is yellowish in color and infiltrated with a gelatinous substance causing the membrane to form thick, somewliat translucent, elevations containing a fluid which coagulates. Peyer's patches are enlarged, especially those in the neighborhood of the ileo-cecal valve. The mucous membrane of the mouth and sometimes that of the pharynx show similar changes.

The mucous membrane of the upper air passages is hyperemic and swollen. In rare cases, the mucosa of the larynx is inflamed, also tlie subcutis when inflanmatory swellings appear on the skin. Schütz found that in the brain and spinal cord the arachnoid spaces are filled with a fluid which is generally clear, although it may contain leucocytes. $\mathrm{He}$ reports one case in which the lateral ventricles contained a large quantity (2o c. c.) of fluid. The other lesions which may be found depend upon the extent or localization of the disease. Usually the spleen is slightly enlarged; small hemorrhages in the intestines, under the serous membranes and in the lungs, eyes and brain; gelatinous infiltration of the 
renal connective tissue and mesentery ; swelling of the lymph glands; yellowish serous exudates in the larger cavities of the body and imperfect coagulation of the blood. (Ine or all of these changes may appear in a single aninal.

\$ 390. Differential diagnosis. Influenza must be differentiated from strangles and contagious pueumonia. The differentiation between pleuro-pneumonia and influenza is difficult only at the beginuing, when merely general symptoms, such as ferer, loss of appetite and weakness are present. It should be mentioned that the two diseases may affect the horse simultaneously. When the skin is greatly swollen, influenza may resemble petechial fever, from which it can, however, very soon be distinguished by the absence of petechiae, by the mildness of its course and its greater contagiousness. In case of strangles, the lesions in the lymphatics may serve as distinguishing characters. If abscesses are in evidence the finding of the streptococcus of strangles would be quite conclusive. It would be positive providing streptococcus equi could readily be distinguished from the pyogenic streptococci.

IVith these diseases, a diagnosis, save in the nore typical forms, is difficult. Without a definite, recognizable, etiological factor or other exact tests, a positive diagnosis in doubtful cases can not be made.

\section{REFEREALES}

I. LigNìnes. The etiology of equine influenza or infectious pneumonia. Jour. of Comp. Path. and Thera., Vol. XI (1895), p. 312.

2. M'FADYEAx. Influenza of the horse-what is it? Jonr. of Comp. Path. and Thera., Vol. II is89), p. 105.

3. Marsnex. Influenza. The Vet. Jomr. Nea series, Vol. II 1950), p. 3I5. (MI. describes three forms, (I) catarrhal fever, (2 bilious fever, (3) epizoötic cellulitis.)

4. Nersox. Influenza. Bulletiu 22. Stali .1:ric. Frpir. Station, Washington. ISg6. 
DOG DISTEMPER.

Synonyms. Dog plague; dog disease; bench show disease; typhus fever in the dog; typhoid fever in the dog.

$\$ 391$. Characterization. Distemper is an infectious disease appearing in sporadic cases or in epizoötics. It is usualiy determined by a rise of temperature, loss of appetite and lassitude, followed by a catarrh of the conjunctiva, respiratory passages and digestive tract. Frequently there are serious disturbances of the nervous system. It is the most important canine disease. It is reported that cats, wolves, foxes, jackalls, hyenas and monkey's suffer from it.

392. History. This disease of dogs was known in quite early times. Its history shows that possibly it was introduced into Southern Europe from Peru, South America, about the middle of the eighteenth century. It was regarded as being closely allied to a number of diseases of the human species such as the plague and typhus. Trasbot believed it to be closely allied to, if not identical with, small-pox.

$\$$ 393. Geographical distribution. Distemper in dogs is a widespread disease. It is exceedingly common in the United States and its ravages extend throughout America and seem to be no less in Europe. It is stated that there is no country or climate in which the dog is exempt from distemper.

$\$$ 394. Etiology. The specific cause of distemper has not been demonstrated. A large number and variety of bacteria have been thought by different investigators to stand in a causal relation to this disease. Schantyr stated, in Is9r, that canine distemper should be divided into three different diseases and that each is produced by a distinct species of bacteria. More recently (189y) Jess has isolated a bacillus from the catarrhal secretions, blood, serous exudates and organs. He reports having reproduced the disease in dogs with pure cultures of this organism. The writer has not been able to find this bacillus in the few cases which he has examined, but a 
streptococcus has often appeared in pure cultures from the various organs. Carré has shown that the serous discharge obtained at the outset of the disease possesses great pathological power, and that its virulence was due to the presence of an organisun sufficiently small to pass through certain filters. There is much need for further investigation into the etiology. of this malady. That it is produced by a specific cause is very clearly indicated by the reported results of investigations to the effect that dogs inoculated with the nasal discharge of affected animals derelop the disease.

$\$$ 395. Symptoms. The symptoms appear after a period of incubation of from four to six, possibly eight days. They vary to such a degree that it is impossible to refer to all of the manifestations. In some cases the symptons suggest a general clisorder. In others they are referable to certain parts or organs such as the mucosa of the digestive and respiratory tracts, the brain or integument. As a rule several organs are implicated.

The initial symptoms such as depression, roughened condition of the coat, loss of appetite and elevation of temperature are suggestive of a general disturbance.

In a large majority of cases, conjunctivitis is the primary ocular symptom. Tears flow from the eyes and photophobia is present. The nucous nembrane of the eyelids becomes conjested and a purulent exudate may appear. The exuded matter consists of pasty mucous or dirty yellowish pus. This exudate collects under the lower eyelids, chiefly at the inner canthus of the eye and soils the edges of the eyelids, upon which it frequently dries and causes the lids to adhere, especially during the night. Ulcers form on the cornea in consequence of the action of the accumulated and decomposing pus and the patient wiping and rubbing the eyes with its paws. The epithelium of the cornea sometines suffers nore or less from shallow flat lesions which give the surface of the cornea a rough and uneven appearance. Frequently smaller and deeper ulcers form especially toward the center of the cornea. 
In other cases, there is a diffuse, parenchymatous keratitis which renders the cornea, to a considerable extent, opaque and gives it the appearance of ground glass. These extensive opacities sometimes develop in a comparatively short time. This affection of the cornea, the so-called " distemper of the eyes," is frequently the only evidence of distemper with the exception of the high temperature.

There may be romiting, well marked congestion and dryness of the oral mucosa. There is usually constipation at first, but later a diarrhea in which the feces, as a rule, are very fetid, often slimy and frothy. Hemorrhagic intestinal catarrh sometimes exists. The urine frequently contains albumin and bile pignent, especially when the patient is weak or in an advanced stage of the disease.

The nasal discharge is serous at first, mucous or purulent later on. It is followed by sneezing, panting and a nasal pruritis, which causes the animal to rub its nose with its paws. The purulent discharge from both nostrils may be very copious. It is sometimes mixed with streaks of blood, and varies in color from a dirty yellow to a dirty green. Later, it may become fetid and even watery. Ulcers may appear on the nasal mucosa

Laryngeal catarrli usually accompanies the nasal catarrh and manifests itself by a cough, which comes on in paroxysms and which is at first hoarse and dry, but later moist and accompanied by a discharge of phlegm. The cough excites vomiting. The catarrh spreads from the larynx to the trachea and bronchi. The resulting bronchitis is followed by an increased rate of breathing and manifests itself by a cough and hoarse, sharp, resicular, respiratory murmurs. Frequently there is a catarrh of the mucous membrane of the smaller bronchi. There may be difficulty in breathing and a feeble cough which the patients try to suppress. The cough may be excited by percussion of the thoracic walls, by the animals getting up and by their being taken out of their kennels. Young and weak animals that cannot remove the accumulated phlegm from the bronchi by coughing become affected with 
catarrhal pneumonia. The puemmonia can be recognized by the elevation of the temperature.

Distemper often begins, especially in anemic animals, with great depression and dullness. Strong animals, however, more usually exhibit symptoms of acute hyperenia of the brain. such as excitement, restlessness, yelping and even attacks of fury, which give way later on to manifestations of cerebral pressure. Spasms frequently occur either generally or confined to particular limbs which swing backward and forward as if affected by chorea. The animal may fall down as if suffering from epilepsy, bark, becone unconscions and exlibit spasms of the muscles generally. The sphincters of the anus and bladder become relaxed and consequently feces and urine are involuntarily passed. There is a gradual return of consciousness which in a short time is complete and the dog manages to get up, although he is very weak. Such an epileptiform attack may pass directly into long continued conna.

Paralysis may follow the convulsions or it may come on simultaneously with them. It seldom occurs at the beginning of the disease. It may be confined to certain groups of muscles, as those of a limb, the whole of the lind quarters or even the entire body in the form of paresis, especially of the motor nerves, combined with excessive muscular weakness. The sick dog staggers and his hind quarters sway from side to side or he becomes incapable of supporting himself on his hind legs. Frequently he knuckles on all four legs and in severe cases is unable to stand. Permanent paresis of the hind quarters with paralysis of the bladder and rectum is a frequent result of distemper. In some cases there may be paralysis of the muscles of the tongue.

A characteristic pustular exanthenua is frequently observed on the inner surface of the thighs and abdomen and in abortive cases it may be the only symptom of distemper. It first appears in the form of minute red spots, which after twentyfour hours derelop into miliary nodules that are surrounded by a red ring. These nodules change into vesicles and pustules which may become as large as a pea or bean. They dry into 
a yellowish brown crust or burst, leaving a raw surface. Healing takes place with desquamation of the epidermis after about eight days, leaving pigmented, pale reddish areas which persist for some time. Generally, there are only a few pustules present. The exanthema may spread in the form of a scabby eczema over the whole body, to the membrane of the external auditory meatus and less frequently to the mucous membrane of the mouth and eyes. This eruption, contrary to that of sarcoptic mange, is accompanied by only slight pruritis. Intense catarrh of the prepuce may appear simultaneously with the skin eruption.

The temperature, which is usually very irregular, is higher during the initial stage than when local manifestations appear. It often falls with remarkable rapidity below normal towards the approach of death. If the disease runs a protracted course, the patient becomes emaciated and the hair loses its lustre, the body exhalations have a very fetid odor, the eyes are sunken, the mucous membranes become pale and the patient grows weaker, staggers when walking or lies in a state of coma.

In abortive cases recovery may take place in eight or ten days, although the disease usually lasts three or four weeks. With severe complications, especially those of the nervous system, distemper assumes a protracted course and is frequently followed by sequelae, such as paralysis or convulsions at longer or shorter intervals, which may persist for months and even longer. The average mortality appears to be from 50 to 60 per cent.

396. Morbid anatomy. The anatomical changes in the respiratory system are those of rhinitis, laryngitis, bronchitis and catarrhal pneumonia. The nasal mucous membrane is either very pale or greatly congested, swollen and covered with a thick, purulent, grayish green or dull reddish inflammatory exudate which is mixed with coagulated blood and collects chiefly between the lamellae of the turbinated bones and in the frontal sinuses. Hemorrhagic ulcers are some- 
times present. The mucous membrane of the larymx and bronchi is hyperemic, swollen, often infiltrated with hemorrhages and covered with pus. Sometimes catarrhal ulcers appear. The large bronchial tubes often fail to exhibit changes which might have been expected from the symptoms. The smaller bronchi are on the other hand frequently filled with a dirty gray and even bloody, viscid pus. There are areas of congestion on the surface of the lungs, some parts of which may contain but little air. There may be areas of collapse or those abnormally filled with air. The inflammatory foci of the lungs are nsually consolidated. In very young animals there may be a fibrinous exudate which is very soft and which readily liquefies. The hepatization frequently. involves an entire lobe. The hepatized parts are frequently studded with small suppurating foci, or are diffusely infiltrated witl pus. The pleura over the affected parts is often inflamed. The bronchial glands are swollen or infiltrated with a serous fluid or with pus.

In the digestive system, the mucous membrane of the stomach and intestines, especially that of the small intestine, is hyperemic and swollen. It may be covered with a tough mucus and is often sprinkled with hemorrhages. In other cases it is very pale, swollen and easily torn. Frequently the contents of the intestine are blood stained and the mesenteric glands enlarged and edematous.

The brain is anemic and often there is a serous effusion into the lateral ventricles and subarachnoid spaces. In a few cases there are signs of a purely venous, cerebral hyperemia, as for instance, great congestion of all the sinuses, venous plexuses and ressels of the pia and the appearance on the cut surfaces of the brain of numerous blood points which can easily be wiped off. Kolesnikoff found microscopically the brain substance, especially the walls of the vessels, infiltrated with leucocytes. Krajewski noticed dilation of the vessels, cellular infiltration of their walls, filling of the perivascular spaces with lymphoid cells and migration of lymphoid cells into the stroma of the brain and into the protoplasm of the ganglionic 
cells. The changes in the spinal cord, which are not well marked, consist chiefly of anemia and slight edema, especially in the lumbar region. Mazulewitsch states that in acute paralysis there are changes in the walls of ressels, with an exudate along the vessels and in the interstitial tissue of the gray matter of the spinal cord. In chronic distemper, there is a localized interstitial myelitis with partial atrophy of the cord. Hadden found groups of emigrated blood corpuscles in it. In serere cases, according to Trasbot, the spinal cord and its membranes are often considerably injected with a serofibrinous exudate in and under the arachnoid and even into the substance of the spinal cord.

Among the other changes which have been described we may mention decrease in the total quantity of the blood of the body, combined with a certain degree of hydremia. There may be fatty degeneration of the liver and kidneys. The muscular tissue of the heart is discolored in consequence of cloudy swelling and fatty degeneration of the fibers. The lymph glands may be edematous.

$\leqslant$ 397. Differential diagnosis. Distemper is to be differentiated from :

I. A simple catarrh, such as that of the eyes, nose, lungs, stomach or intestines. The differentiation is often difficult at first, as distemper frequently manifests itself in a single mucous membrane or in one organ. In general the diagnosis is obtained from the epizoötic nature of the disease, age of the patient, high temperature, simultaneous implications of several organs and the unfavorable course of the malady. The finding of the pustules of dog distemper is of much diagnostic value.

2. Rabies. The symptoms of cerebral irritation which occur at the beginning of the disease may give rise to the suspicion of rabies. The characteristic aggressive behavior of animals suffering from rabies is, however, absent in cases of distemper. The further course of the disease soon enables a diagnosis to be made. 
3. The eruption of distemper if widely distributed orcr the body may resemble that of mange. The mild character of the pruritis, the presence of pustules on the hypogastrium and inner surface of the thighs, the rapid spreading of the exanthema over the whole body and the development of other symptoms of distemper and those of mange, however, often occur simultaneously in the same animal, in which cases certain precantions are necessary in making the correct diagnosis.

4. Epilepsy. The epileptiform attacks in distemper are distinguished from true epilepsy, essentially by their being less acute.

5. It must also be differentiated from simple coryza, bronchitis, chorea and paralysis.

Until the specific cause is found and can be availed of in making the diagnosis, much doubt will necessarily exist respecting the nature of the disease where many of the symptoms and lesions are atypical. It may be found on further invest1gation and the discovery of the etiological factors that the symptom-complex of distemper may be differentiated into two or nore distinct affections.

S 398. Prevention. The lack of knowledge conceruing the specific cause has rendered it impossible thus far to close all chaunels of infection, but its spreading can be checked to a considerable degree by isolation and the use of disinfectants. It has been stated that the inoculation with the virus from very mild cases, which produces a mild attack, will immunize an animal for several years. This method is as a rule not to be recommended.

RFFERENCES.

1. Carrit. Sur la "Maladie des chiens." bul. de la Sic. Cintr. de llid Vit., Vol. I.IX (1905), p. 335.

2. HERTWig. Kranklieiten der Hunde. I88I. S. 48.

3. Jriss. Der Bacillus der Hundestaupe (Febris catarrhalis epizootica Canum.) (ent. f. Bak. u. Parasitenk., Bd. XXV (IS99), S. 541.

4. LAOSson. Ueber Gesclichte und Kontagiositït der staupe. Dorpat. I $\mathrm{S} 92$.

5. Nickorns. Dog distemper. Am. let. Fevieni, 19oo. p. 180. 
Synonyms. Staggers; crazy disease; forage poisoning; acute epizoötic leucoencephalitis.

399. Characterization. This is a disease that seems to be infectious in its nature, exhibiting symptonis referable to a disturbance in the central nervous system. It is called epizoötic cerebro-spinal meningitis because it often attacks a number of animals in the same locality. It often occurs in sporadic cases. Although the literature contains numerous accounts of its seemingly contagious nature, an analysis of the facts fails to bring forth conclusive evidence that it is ever transmitted directly from one horse to another. In nearly if not all outbreaks, the animals affected have been subjected to like conditions of life. This disease is, at the present time, peculiar in that its cause is not known, that obrious tissue changes are usually absent, and that it has a rery high mortality.

$\$$ 400. Etiology. The cause has been attributed to a great variety of conditions, such as fermented food, forage laden with fungi or toxic moulds, various unsanitary conditions and possibly other ill-defined ágencies. It seems to be true that in most outbreaks all of the animals that suffer have had at least some one thing in common either in surroundings, food or management. The bacteriological and other examinations which have been made to determine the cause have not resulted in finding a specific agent. Micrococci and various bacilli have been found associated with the disease. The writer has had an opportunity of making a careful examination of animals in two outbreaks. In one of them all inoculated media and histological examinations gave negative results, in the other pure cultures of a colon bacillus were obtained from the brain. No specific organism, therefore, is charged with its production. No virus has been isolated that is capable of producing it. The nature of the affection suggests a poison rather than a specific virus. 
$\$$ 40r. Symptoms. The mildest attacks are manifested by paresis or loss of perfect control over the limbs, loss of power over the tail, impairment of appetite and some difficulty in swallowing, together with areas of hyperemia and reddishbrown discoloration of the orbital and nasal nucosae. In other cases paralysis of one or more limbs may supervene but without marked fever or coma.

The more severe forms are ushered in by riolent trembling, or by stupor, apathy and extreme muscular weakness or actual paralysis. In sucl cases the animal may stagger or fall. The inability to swallow is of ten a marked symptom, the saliva falling in strings from the lips. Another common phenomenon is the rigid contraction of the muscles of the neck, back and loins, the parts becoming tender to the touch and a more or less prominent opisthotonos setting in. Twitching of the muscles of the shoulders and flanks may be noticed. Trismus is sometimes seen. The breathing is usually rapid and catchy and the temperature ranges from $104^{\circ}$ to $106^{\circ} \mathrm{F}$. The pulse may be accelerated and hard, soft and weak, or alternating. The eyes are usually violently congested, of a brownish or yellowish-red color, and the eyeballs may be turned to one side. Paroxysms of delirium may set in when the animal will push against the wall or perform any of the disorderly movements following meningo-encephalitis. Sooner or later coma and paralysis supervene and death occurs in from five to forty-eight hours. In the most acute cases the animal falls and dies in convulsions. On an average the disease lasts from eight to fourteen days. In the more favorable cases, improvement may begin on the third or fourth day. One attack does not protect the animal against a subsequent one.

402. Morbid anatomy. Mlost writers report lesions of leptomeningitis, hyperenia of the brain and spinal cord, with extensive effusion into the ventricles and subarachnoid spaces. Petechice and parenchymatous degeneration of the solid organs of the body are also mentioned. In the cases examined by the writer there has been an absence of lesions in the nervous 
system and other organs that could be detected by a gross examination. In one case the brain, spinal cord, and organs were studied histologically with like results.

MacCallum and Buckley have found in the brains of horses dying of this disease areas of soltening " in the frontal region on each side, anterior to the motor region of the cortex." This lesion was practically confined to the white matter immediately under the cortex. In the affected areas there was "complete destruction of the brain substance, in which the anatomical structures are disintegrated and largely replaced by a colloid-like material ". The neighboring blood vessels were acutely inflamed, with exudation of leucocytes and passage of red corpuscles into the peri-vascular lymph sheath and adjacent tissue. In a later epizoötic they failed to find the brain lesion but did detect the vascular changes.

McCarthy and Ravenel in a study of fifteen animals found certain lesions in the upper gastro-intestinal tract and in the central nervous system. These were (I) in the intervertebral and Gasserian ganglia where a peri-capsular, small round cell accumulation was present. The cells were all of the same type, the nucleus and protoplasm being about the size of a red corpuscle. There was no evidence that these cells were the result of proliferation of the original layer of capsular cells. (2) Cortical lesion. These consisted of congestion of the cerebellar and cerebral cortex. There were also capillary hemorrhages. The meninges were normal. (3) Changes in the choroid plexus. In three cases the choroid plexus was changed into a triangular, tumor-like mass, of a yellowish red color and of a firm consistency. The increase in size was found to be due to a proliferation of the elastic tissue surrounding the vessels. (4) Changes in the peripheral nerves. There was a distinct degeneration of the nerves supplying the larynx and neck. This was present in the nerve up to the ganglion, but was not found in the posterior roots. Other slight changes were detected.

These authors conclude that this disease is not a true meningitis, but that the evidence goes to show that it is caused 
by some poisonous substance contained in the forage. 'They propose the name "forage poisoning" for "cerebro spinal meningitis", and lencoencephalitis suggested by MacCallum and Buckley. It is highly probable that up to the present time, cases of uncomplicated meningitis and possibly cerebritis have been confused with the disease in question. T'lhe entire subject must await the results of further investigation.

$\$$ 403. Differential diagnosis. This disease is to be differentiated from other forms of cerebral affection and rabies. The differentiation can be made from the clinical history of the case, and from the character of the lesion in the intervertebral ganglia and if necessary by the results of animal inoculation.

\section{RFFERFNCES.}

I. Favilt. So-called spinal meningitis. Am. Vet. Rerieu', Vol. XVII, p. 9.

2. Hгсках. Epizö̈tic cerebro-spinal meningitis of horses. Ta'enty-therd annual report, liurau of Animal Industry, 1906.

3. Martin. Cerebro-spinal meningitis, Ibid. Vol. XXI, p. 289.

4. MCCALLum AND BUCKLEY. Acute epizoötic Leucoencephalitis in horses. Bulletin No. in, 1/d. Agric. E.r.p. Station, 1902.

5. MCCARTHY AND RAVEXEL. A pathology for forage poisoning, or the so-called epizoötic cerebro-spinal meningitis of horses. The Journal of . Vedical Research, Vol. X (1903), p. $2+3$.

6. SIEDAMGROT\%KY AND SCHLEGEL. Eipi\%ö̈tic cerebro-spinal meningitis in the horse. Archiv für a'iss. u. prakt. Thioheilk. Bd. XXII. (Abstract), Jour. Com. Path. and Thera., Vol. IX, p. 23.3.

CORNSTALK DISEASE IN CATTLE.

\$ 404. Characterization. The name "cornstalk disease" has been given to a somewhat mysterions affection from which cattle sometimes suffer while feeding in cornstalk fields late in the fall and early winter. The meaning generally accepted and intended to be conveyed by this term is, that an animal or a number of animals, usually cattle, have died suddenly after feeding in a cornstalk field from four to ten dars. From a 
pathological point of view, therefore, the term is meaningless. but it has served admirably as a general term to designate certain fatalities occurring under a given condition, which are not easily explained.

This disease is very insidious, frequently causing the death of animals before its presence is suspected. Cattle that act perfectly well at night are dead on the following morning. Usually all the animals in the herd that die of this affection perish in a single night or at the longest within a few days after the first death occurs. It is generally believed to be invariably fatal and its symptomatology has not been fully determined.

$\$ 405$. History. This affection of cattle has been known to exist for many years. The time and place of its origin, however, are not known, but it seems to be peculiar to the United States and to have first appeared west of the Allegheny Mountains. We are told of its occurrence in the Mississippi Valley forty or more years ago. It made extensive ravages in $1864-65$ and again in 1868 . From an historical standpoint, no positive statements can be made concerning it prior to 1868 , when the first recorded investigations into its nature and cause were made. After that time the disease seems to have escaped the attention of investigators until i 889 , when Billings, of the Agricultural Experiment Station of Nebraska, published the results of his investigations.

In 1868, Gamgee was employed by the United States Department of Agriculture to investigate this disease. The "smut theory" of its etiology appears to have been the prerailing one at that time and consequently Gamgee's report deals almost exclusively with the effect of improperly prepared food, smuts and the like. Corn smnt was unusually abundant in 1868 and he carried out experiments to test its etiological value with the conclusion "that smut is not a very active poison in combination with wholesome food."

In r889, Billings described the cornstalk disease as an "acute extraorganismal septicemia, due to micro-organisms 
belonging to the class of ovoid-belted germs, to which variety of disease also belongs the swine plague, southern cattle plague, Wildeseuche, hog cholera, and yellow fever in man.

From the organs of cattle dead from the disease he reported to have invariably isolated a bacillus which he affirms to be its cause. He identified the bacillus which he found in the animal tissues with the one described by Burrill as the cause of a disease in cornstalks. In I S93, Dr. Theobald Smith identified the bacillus described by Professor Burrill as Bacillus cloace.

Billings also found pneumonia to be one of the lesions characteristic of this affection and in a subsequent bulletin he places great importance upon this lesion, although he adds very few additional observations to sustain the claim.

In r 890 , a few animals from a shipload of American cattle landed at La Villette, France, died of pneumonia. They were examined very carefully by Nocard and other French veterinarians. From the diseased lung Nocard obtained a microorganism which corresponded very closely to the description of the bacillus of the cornstalk disease of cattle described by Billings in America. The publication of this fact gave rise to a temporary supposition that this American cornstalk disease might be a menace to the cattle of Europe and consequently initial steps were taken to require American cattle to be quarantined against it. The fact was subsequently determined that the bacillus isolated by Nocard belonged to the septicemia hemorrhagica group of bacteria which is usually fouml to be associated with a form of bovine pneumonia occasionally met with in America, but not known to be contagious, and the matter was dropped.

A single experiment was made at Champaign, Ill., in I889, in which the etiological importance of corn smut was tested with negative results. A bacteriological examination of the organs from an animal that died in a cornstalk field, supposedly of this disease, was made with negative restults by Professor Burrill in 1889 .

In 1892, Moore incestigated this disease and his report 
furnishes the information here given concerning the symptoms and morbid anatoniy of this affection.

\$ 406. Geographical distribution. Geographically, this affection is restricted very largely to those sections of the United States where the farmers harvest their corn by picking the ears from the standing stalks, after which cattle are turned into the cornstalk fields. At present, therefore, it is limited in its distribution to the middle and northern portions of the Mississippi Valley. It is believed that there are exceptions to this and that infrequently cattle die from its effects in the eastern part of the country.

$\$ 407$. Etiology. The definite cause of this disease has not been determined. It has been shown, however, that the former theories respecting salt, water and the bacillus of the Burrill disease of cornstalks are not substantiated. The hypothesis that the cause rests in the cornstalks themselves seems to be the most tenable. It is well known that cattle rarely if ever die from eating cornstalks in moderate quantities. However, the results of such investigations as have been made point as the cause to an intoxication from an excessive quantity of one or more elements existing in the cornstalks themselves.

\$ 408. Symptoms. The insidious nature and rapid course of the disease usually result in the death of the animal before its presence is detected. In a few instances, however, the sick animals have been observed very carefully by their owners, from whom all of our knowledge of the symptoms is obtained. One owner found a steer lying down and unable to rise. His head was extended, resting on the ground and moving continually from side to side; this was kept up for several hours, when he died. In the second place a steer was fonnd to remain behind the other animals when they were driven to water about I I A. M. At 3 P. M. he was found in a dying condition.

Another man reported that he found his animals apparently well at 5 A. M. At 7 A. M. a heifer was found resting squarely. 
on her knees, the head extended and resting upon the ground. She was frothing at the mouth and groaning as if in great distress. Slie died in about two hours.

Another report states that the sick animals were dull, exhibited great weakness and walked with a peculiar jerky movement of the hind legs. The animals trembled as if suffering from a chill. In a short time they fell down and appeared to be in great distress, heads moving continually backward and forward. A fourth owner observed a sick animal trembling violently for about two hours before it died.

$\leqslant$ 409. Morbid anatomy. In twelve animals which died in cornstalk fields and were examined, post-mortem changes were more or less advanced in the greater number. A few were examined soon after death. The structural changes in the organs were slight. This confirms the statement of many veterinarians that the organs of the cattle dying of cornstalk disease are normal in appearance.

The only gross pathological changes observed were those of a hemorrhagic nature. The hemorrhages were mostly confined to the serous membranes and especially those of the heart. Eicchymoses were more or less numerous, however, beneath the pleura and under the capsule of the liver and of the spleen. The mucosa of the intestinal tract showed areas in which the capillaries were deeply injected. Occasionally there were hemorrhages. In one case there were pronounced hemorrhagic areas in the heart muscle, aorta and plenra. In most cases the liver was pale in color and the acini presented deep reddish centers with pale peripheries. The inner and middle zones of the lobules were more densely congested than the peripheral ones. A layer several lobules in thickness immediately beneath the capsule was usually more engorged with blood than the deeper portions of the organ. In the more deusely injected areas not only the blood spaces were filled, but the liver cells were separated from each other by. a space of variable width containing blood corpuscles. In some cases there were slight changes in the appearance of the cellular protoplasin. 
In all of the animals examined, the hemorrhages were of recent origin and the blood normal in its microscopic appearance. There were no discolored areas indicative of old ecchymoses. The distribution and general character of the hemorrhages, which are the most conspicuous microscopic lesions observed, are very similar to those described in certain cases of vegetable poisoning, more particularly that of fern root.

Although certain symptoms described by the owners were referable to the nervous system, lesions were not discovered in the brain or spinal cord excepting in one case in which there was considerable hemorrhage beneath the pia mater.

In one animal certain of the lymphatic glands exlibited more or less blood extravasation, particularly in the interlobular tissue.

410. Differential diagnosis. This disease is to be differentiated from sudden deaths from accidental causes, deatbs directly due to engorgement, or to the consumption of too much corn, as occasionally happens during the first days that the cattle are in the stalk field. The diagnosis of the cornstalk disease must, for the present, depend upon the hemorrhagic lesions and the period of feeding upon the stalks. Mayo has pointed out the fact that occasionally cattle die from eating cornstalks excessively rich in nitrate of potash. It is not impossible that the hemorrhagic lesions are those of septicemia hemorrhagica. The only argument against this view is the negative results of the bacteriological examinations that have been made.

Of the specific infectious diseases which might be confused with the affection, acute anthrax, symptomatic antlurax and septicemia hemorrhagica should be mentioned. Each of these affections can be determined by its specific nature as pointed out under the description of each of these affections.

REFERENCES.

I. Biflixgs. The cornstalk disease in cattle. Bulletins No. 7,8 , 9 and 1o. Neb. Agric. Erper. Station, r886-88. 
2. Buthisis. The corn fodder disease in cattle and otler farm animals, with especial relation to contagious plenro-pneumonia in American beeves in England. Bulletins No. 22 and 23. I niz. of Nich. Agric. Exper. Station, 1 isg2.

3. DF: SснWrixiT\%. Chemical examination of cornstalks presumably the cause of cornstalk disease in cattle. Bulletin No. I0, I S. Burean of Animal Industry, isgh.

4. G.MGE1: Diseases of cattle in the [nited states. U.S. / e partmemt of Agriculture, 1869 .

5. MAso. Cattle poisoning by nitrate of potasli. Bulletin No. f?, kansas Aqric. Eirper. Station, 1895

6. Mavo. Cornstalk diseases in cattle. Ibid, isg6.

7. MOORL: An investigation into the nature, canse and means of preventing the cornstalk disease (Toxemia Nlaidis) of cattle. Bnlletin Vo. 10, L. S. Burean of Animal Industry, 1896.

\section{INFECTIOUS ABORTION.}

\$ 4II. Characterization. The lisease or condition known as infections abortion consists in the expulsion of the immature fetus, usually before it has sufficiently developed to live after birth, by a large proportion of pregnant animals that are kept together. Usually the abortion occurs in cattle between the fifth and eighth month of gestation. The disease as described by European writers is cliaracterized by certain morbid clianges in the uterine mucosa and fetal membranes. American observers have not described these changes. In cattle it usually affects the young cows. After two or three consecutive abortions cows, as a rule, become immune to it. Cows suffer most from this condition, although mares, ewes, and other species are occasionally reported to be affected.

In Norway infectious abortion is scheduled under the socalled "milder contagious diseases." The owner is obliged to report when such a disease appears in his herd, and he is not allowed to bring such animals to fairs or cattle sliow:

\$ 412. History. Abortions in epizuötic form have been recorded from very early times. Mascal, in 1859 , gives direc- 
tions in his work on cattle, "How to keep cows which are great bellied with calf." In Germany the disease seems to have existed in a somewhat severe form in the latter part of the eighteenth century. According to the "Veterinary Dictionary' (1897) this trouble existed in Great Britain. The literature on animal industry and agriculture of the last half century contains many reports of the existence of this disease in almost every cattle raising country. The most important scientific investigations that have been made into its nature are those of Nocard, 1885 ; in Great Britain, by a committee appointed in r 886 by the Highland Agricultural Society of Scotland consisting of Drs. Woodhead, Aitke11, M'Fadyean and Campbell; and in Denmark, by Bang and Streibolt. Some work was done on this disease in $1897-98$ at the New York State Veterinary College by Law and Noore. A number of the State Experinent Stations have published on this disease but the work reported has been more in the line of treatment then a study of its etiology.

$\$ 4$ I3. Etiology. Nocard found on bacteriological examination of cows that had recently aborted two different species of bacteria present in large numbers in the purulent substance. They were first a micrococcus, found abundantly in the fluid lying at the base of the cotyledons and which grew either singly. or in short chains. The second was a short thick bacillus which occurred most abundantly in the juice expressed from the follicles of the cotyledons. His inoculation experiments were negative.

Bang and Streibolt found an anaerobic bacillus which possessed somewhat peculiar properties and which they believed to be the specific cause of the disease. They found it in a number of cases and report positive results from inoculation experiments. The cultivation of this organism required a medium composed of agar, gelatin and blood serum. Bang considers the bacillus he discovered to be a purely pathogenic organism which has no saprophytic existence. The fact that when it is injected into the blood stream it grows only in the pregnant uterus and in the fetus is considered evidence of this. 
It is, however, able to live for a long time outside of the body. In a later article Bang has called attention to the infections nature of the uterine discharges of the aborted cows. He believes that copulation affords the most favorable opportunity of all for infection.

The investigations in the United States have failed to reveal the presence of Bang's organism, but instead a variety of B. coli communis has been found by Chester and by Law and Moore. Nocard showed that this organism is able to invade the uterus and provoke the expulsion of the fetus.

I.ignières, reported by Nocard, found in his investigation that the canse was an infection of the nother with a peculiar organism constantly present in the digestive tract. Prior to this he found the trouble to be caused by the secondary invasion of the fetus by various bacteria that are always recognized in variable numbers in multiparous cows.

The disappointing part of these investigations is that. with the exception of the Americans who have found a colon bacillus, the different workers have not verified the findings of each other. Nocard did not believe that abortion was due to a general infection of the dam, becanse the cow both immediately before and immediately after the act of abortion exhibits no symptoms of disease such as rise of temperature or changes in the urine, blood or milk. Smith found in an epizoötic of abortion anong mares a bacillus belonging to the hog-cholera group which appeared to stand in an etiological relation to the trouble. The weight of evidence seems to indicate that this form of abortion is caused by some organism that invades the uterus, and which seems to be transmitted from the infected to the uninfected animals by putting them together in stables and in some instances by the use of the same bull.

The poriod of incubation according to Bang is abont to weeks.

$\$$ 414. Morbid anatomy. The investigations and clinical observations reported in this conntry have not called 
attention to any definite lesions in the uterine mucosa or fetal membranes that differ materially from those normally found in the tissues. Nocard and Bang, however, describe very pronounced changes. Bang's description of the disease is as follows :

"The external surface of the uterus was normal. The os uteri was firmly closed and the cervical canal was filled with the normal thick mucus. After disinfection of the serous covering of the uterus by burning, I made a section through the uterine walls: when the mucous membrane was divided we saw between that aud the foetal cnvelope an abundant odorless exudate-a dirty yellow, somewhat thin, pultaceous material of a slimy, somewhat lumpy character. At some places where the fluid constituents had run out the exudate was of a semisolid nature; its reaction was alkaline. When it was allowed to stand in a glass it separated into two strata, namely, superiorly a reddish yellow cloudy serum, and at the bottom a thick greyish yellow precipitate.

"On cutting through the chorion we saw under that a thin, clear, apparently gelatinous substance, with very fine membranes runuing through it: closer examination showed that this was the fine connective tissue lying between the chorion and allantois, saturated with oedematous exudates. This was present over the entire extent of the foetal envelopes and formed a layer one and one-half centimeters thick. The allantoic fluid was natural in appearance, thin, yellowish, and containing fine flocculi. Nothing abnormal was observable in connection with the amniotic fluid. The umbilical cord was oedematous. The size of the foetus and degree of development of the hair on it indicated an age of seven months. It was quite fresh and on section it showed no striking alteration. The pericardium contained a little reddish fluid; the intestinal mucous membrane was, perhaps, rather redder than ordinary; the spleen was in very slight degree swollen and the blood was fluid.

"The examination of a cover-glass preparation made from the yellowish exudate and stained with Loeffler's methylene 
blue immediately showed the presence of a very small bacterium, apparently in pure culture. This organism was present in very considerable numbers: many individuals lay free, but most striking were the large dense clumps of bacteria. Closer exanination showed that these heaps were included within cells whose bodies were often in this way greatly distended. Sometimes the body of the cell was very indistinct, but as a rule one conld still recognize external to the heap a part of the cell body and often also the cell nuclens. Not seldom the cell body had assumed a peculiar homogeneous appearance.

"In the dense heaps the bacteria mostly had the appearance of cocci, but some of the free-lying individuals were of a longer shape, and these were at first regarded as short oval structures; closer examination, however, under very high magnification showed that we had in fact to deal with a small bacillus whose body contained one, two, or more rarely three, roundish or elongated granules. These granules most readily took up the stain. The length of the bacillus is very variable: the longest examples are about as long as tubercle bacilli. The granules may occur a little distance from the extremities but frequently they are at the end of the bacillus. They stain with the ordinary aniline dyes, but not by the method of Gram. The bacilli are non-motile. In the subchorial oedema I found no bacteria. In the heart blood of the foetus there were a few, and in the intestinal contents there were many staining granules; but it was not possible to say with certainty whether these were bacteria or not."

Bang states that the discovery of this particular organism indicates that epizoötic abortion ought to be regarded as a specific uterine catarrh, determined by a definite species of bacteria. While the uterine mucous membrane was not strikingly altered he affirms that chronic catarrh is not necessarily associated with striking anatomical alterations. He states further, "In my opinion the very abundant exudate which contained a quantity of shed epithelial cells, pus cells and detritus must necessarily lave been furnished by the uterine nucous membrane and not by the thin chorion, and 
consequently the disease must be regarded as a uterine catarrh."

4I5. Prevention. Dairyman have found that if they keep animals that abort away from their sound cattle the trouble does not appear. As it affects young cows, it is the practice in some places to keep the young animals separated from the others until they have become free from the disease or at least until they have passed the period when it is apt to occur after which they are admitted to the herd of older cows with impunity.

When the trouble appears in a herd the best prophylactic is thorough disinfection of the stable and frequent washing with a disinfectant of the vagina and external genitalia of the cows that have been exposed. The vagina and uterus of the aborted cows should be thoroughly washed with a disinfecting solution. Brauer has recommended the subcutaneous injection in the groin of twenty grams of a two per cent solution of carbolic acid. Immunizing experiments are in progress under the guidance of Professor Bang. but it is too early to speak of the results.

All new cows that are purchased should be isolated from the herd until after parturition has occurred at full term.

The disinfectants that have been used with success for external application are 5 per cent carbolic acid, 4 per cent creolin, I to Iooo corrosive sublimate, and a solution of copper sulphate containing forty grams per liter of water. The last two may be used for vaginal douches. Bang recommends lysol 0.5 to $\mathrm{I}$ per cent for this purpose. There is great need of further investigation into the control of this affection.

REFERENCES

I. BAxg. The etiology of epizoötic abortion. The Jour. of Comp. Path. and Thera., Vol. X (IS97), p. I25.

2. BAxg. Infectious abortion in cattle. The Jour. of Comp. Path. and Thera., Vol. XIX (1906), p. I91.

3. BRÄNER. Ueber das Epizootische Verkalben der Kühe. Deutsche Zeitschr fur Thier., Bd. XIV (I888), S. 95. 
4. CHestik. Th annual report, l)el. Asric. Exp. Station.

5. DArriardit. Bullelin No. to, and Sories, La. Agr. Exp. Stution, isgi.

6. GARDINiR. Contagions abortion in Montana. limlletin $\mathrm{N}$. 14, 1/on. Agr. E.1p. Station, 1903 .

7. Kir.13ORNE. An outbreak of abortion in mares. liullitin No. 3, U. S. Buriau of Animal Industry, Is93, p. 49.

8. IAw. Contagious abortion in cows. Report of the $\Lambda^{r}$. Y. State Commissioner of $\mathrm{Agricullure,} \mathrm{x} 897$.

9. II Arsha1.r. Special Bulletin No. 13, .Wich. . Igr. College, Ingg.

10. NErson, J. Reports of the Biologial Department of the Nea ferser Agricultural college and Experiment Stalion, 1897,1 ings and 1899 .

11. Nistsox, S. B. Fonth Biennial kepurt of the Slate literinarian of the Stale of $\mathrm{W}$ ashington, r9or and 1902 .

12. Niris. Bulletin No. I.3, Va. Erp. Station, 1902.

13. Nocard. Recherches sur l'avortment epi\%ootique des vaches. Recueil de llid. lílir., Vol. III (ISS6), p. 669.

14. I'FMBERTH: Epizö̈tic abortion. four of Comp. I'ath. and Thera., Vol. VIII (1\$95), p. 95. (A good summary of the history and a very complete list of references to the earlier literature is given.

15. SurTH. On a pathogenic bacillus from the vagina of a mare after abortion. Bullitin No. 3. liureau of Anumal Industry, 1 s.93. p. 53 .

16. Vanfes. Abortion in cattle. liulletin No. 5/, North Daketer Igricullumal College and E.rpirimenl Stalion, 1902.

17. NOODHEAN AN1 OTHERS. First Report of the Committee of the Highland and Agricultural Society of Sicotland. Transactions of the society for 1887 . Second Report of Committee. Jour. af Cimp. Path. and Thera., Vol. II 1889 ), p. 97.

\section{VARIOLA IN ANIMALS.}

Synonvms. T'ariola equinae: horse pox: íariola íacima. cow pox: z'ariola orina: sheep pox; variola caprima; goat pox: zariola suilla; swine pox.

S 416. Characterization. The disease in man and animals known as variola is characterized by a rise of temperature followed by a skin eruption consisting first of panules. 
then of vesicles and finally of pustules. It is common to horses, cattle, and man. Sheep suffer from a like or similar disease. Other species are said to be occasionally attacked.

\$17. History. Small pox in man has existed from very early times. It is reported to have been mentioned in the Chinese records of $1122 \mathrm{~B}$. C. It was quite fully and accurately described by an Arabian physician (Rhazesin) in the early part of the tenth century. The disease in animals has been known for many years. Slieep pox is reported by Joubert to have existed in 1567 . Cow pox has existed for centuries but since Jenner's discovery of vaccine it has received more attention. The same is true of horse pox.

The etiological relations of the pox of man and animals to each other are not yet clearly enough demonstrated. The constantly agreeing anatomical structure and the like development of the pustules characteristic of the disease speaks for the etiological identity of the various forms of pox, but yet what we know concerning their different infectiousness especially the susceptibility to them, as well as the appearance of the disease, accords little with this identity.

While in man and sheep the disease usually appears with severe general symptoms and with a diffuse pock eruption, the eruption is confined always in cattle and almost always in goats to single places on the body, and in its development is accompanied by very mild general symptoms. The disease among men on the one hand and sheep on the other spreads very easily, providing the acquired inmmunity of the individual does not interfere, while on the contrary among other animals the spread even in the case of favorable conditions becomes important only within narrow limits.

Doubtless the relations between the pox of men and cattle are very close. The latter is very easily inoculated into man yet the inoculation always produces a single eruption limited to the place of inoculation and never a general affection giving evidence of variola. On the contrary human pox is much less safely transmitted to the cow. In a part of such cases there appear in the cattle characteristic pocks at the place of inocu- 
lation, in other cases there develops after the inoculation firm nodules which without changing to vesicles heal without scab). bing (Chauveau) or else the inoculation remains without results.

The experimental evidence seems to show that the infecting element of human variola and that of cows (vaccina) offer two different modifications of one and the same pox contagion. Fischer as well as Eternod and Haggins tried also to prove this by the fact that the pox lymph inoculates back again into man after which, in many thousands of people inoculated in this manner, only a local pox eruption developed. The above named authors, as well as Roloff and Bollinger, draw the conclusion from this that variola in its transmission through the bodies of cattle clianges to vaccinia and that the latter therefore presents nothing but a weakened modification of the first. That this change does not always take place easily and in the above mentioned way is shown by the experiments of Chauveau, who after inoculating with the lymph taken from cows inoculated with variola saw the pox repeatedly appear in men as a severe general disease.

The very close relationship between human iariola and vaccina is shown through the fact that the vaccine produces a lasting immunity to the variola. Since the local illness in man following vaccination is a mild form of human pox, vaccine must be considered as a weakened form of variola virus. If one considers further that the transmission of the contagion from person to person, as stich inoculations were ustual in the past, in most cases produced only a local lesion, so that in cattle the pox as a rule, perliaps almost always, appeared as a result of the transmission of the virus from a person sick with inoculation pox, the conclusion is well founded that the contagion of cow pox really presents a weakened modification of the human pox virus.

Jenner was of the opinion that cow pox appeared as a result of infection by horses sick with pox and therefore concluded that it was identical with cow pox. Later Lafosst and afterwarls Bouley agreed with this opinion lnder the 
influence of the authority of the latter author as well as of Chauveau, this conception was commonly received in France until recently Warlemont and Hugues discovered that the horse is slightly susceptible to vaccine. Dieckerhoff and Rawitz have made the assertion that the contagious disease observed by certain of the former authors was not pox sickness but sometimes stomatitis, and sometimes dermatitis contagiosa pustulosa, which latter diseases are transmissible to other kinds of animals as well as to cattle.

Sheep pox as a result of natural infection usually spreads exclusively to sheep, not being transmitted to the closely related goats, and it is not dangerons to man. Human pox is only rarely inoculated into sheep. Efforts to immunize cattle with the contagion of sheep pox against cow pox have not been successful. According to Pound the sheep pox must be considered as a specific disease of sheep. The same conclusion has been entertained relative to goat pox.

The pox of other species of animals, as far as they generally appear, manifest themselves in consequence of an epidemic in man or an epizoötic in one of the species of animals and therefore cannot be considered as independent forms of the disease.

According to our present knowledge human pox, sheep pox and goat pox present symptoms independent of each other in their beginning and spread, while the pox of the other species of animals always stand in a casual relation to one of the cited forms of disease. But this conception does not agree completely with the relationship of these forms of disease. On the contrary the present agreement in the development of the otherwise specific pathological process makes the opinion probable that the pox disease was a specific entirely independent disease of one of the mentioned species of animals or of man which was also transmissible to other species of animals; but in the course of time the virus has passed through several generations of different species of animals and has become adapted to the life conditions in the bodies of the different species of animals. As a result of this the virus thus living in 
one species lost partly or entirely its pathogenesis for other species.

$\$$ 418. Geographical distribution. It lias been reported in animals from many places in lurope, in northern Africa and Asia. Cow pox has been reported in America.

$\$ 4$ Ig. Etiology. The cause of variola is not known. A number of different microörganisms have been isolated but thus far their discoverers have not been able to reproduce the disease with them. Some investigators believe the cause to be a protozoan which they believe they have found in the tissues. The work of Councilman stands foremost in this line. The virus is quite hardy and remains alive for a considerable time if not exposed to direct sunlight. The identity of the disease in horses, cattle, sheep and man has not, therefore, been positively determined, although the results reported by Hine, Simpson, Freyer and others suggest an etiological relationship if not an identity. If the identity is not established, then the diseases in the different species now called variola must be considered as distinct maladies. It seens desirable at this time to consider them under the generic name liariola, treating the disease as found in each species separately.

420. Symptoms. The symptoms vary somewhat in the different species, but the essential ones are a rise of temperature and the appearance of a definite eruption on the skin or mucous nembranes. This is at first papular, then vesicular and finally pustular. It is rarely a dangerous affection in animals and often it is very mild. The peculiar symptoms and lesions as recognized in each species of animals are appended.

$\$ 421$. Horse pox. The eruption occurs on the buccal membrane, nasal mucosa, coujunctiva (rarely), mucosa of generative organs, and upon the skin. In the latter case the pustules may occur over the entire body or be localized in certain regions. The lesions consist of the specific pustules. On the mucosae the pustule begins with the congestion of the 
skin followed by an initial ecchymosis and occasionally by an abundant exudate. The mucosa becomes opaque. The liquid accumulates in vesicles followed by a pustular condition with a crust or scab covering it. Upon the skin the eruption is characterized by ecchymosis with marked hyperemia. The histological changes have not been fully described. The descriptions published appear to be copied from those of human small-pox.

\$ 422. Cow pox. In the bovine species the eruptions are usually on the skin of the teats or udder. Other parts are said to be occasionally involved. The period of incubation is said to be about two days after inoculation. The first symptom is a tenderness of the skin of the teats or ndder, then follows the appearance of small reddish spots. A few days later these become vesicles, then pustules with a depressed umbilicated center. These are surrounded by a pinkish or reddish areola. The pustules crust over in a few days leaving a scab several millimeters in diameter. Usually many of the vesicles are ruptured by the hands of the milker. This often leads to scars that heal with difficulty. It may happen that eruptions in all the stages of development may appear on the teats at the same time.

The diagnosis of cow pox depends on the presence of regular pustules with a depression, and in many cases a similar exanthema on the hands of the persons occupied in the caring for the affected animals. The injuries and irritations caused by milking makes the diagnosis more difficult. It is possible to confuse it with the exanthema of foot and mouth disease, although here the nodules do not develop into pustules and are at the same time larger and less regularly formed and there are besides that similar vesicles even in the mouth and the split of the hoof of the sick animals. The mild eruption of vesicles is easy to recognize in the simultaneous affection of the genitals. In rinderpest, pustules are also sometimes formed on the udder, but this appearance is, in comparison with other general and local symptoms, of slight importance. 
$\$$ 423. Sheep pox. 'This affection, known as clavelée, is an acute febrile disease of sheep and goats occurring epizootically and existing in enzootic form in certain parts of Europe, Africa and Asia. It is usually not fatal but a mortality of from 7 to 20 per cent, according to the outbreak, is reported. It is marked by a rise in temperature and general disability followed by the appearance of a series of changes on the bare and merely hairy portions of the skin. These consist of papules, vesicles and pustules which are later covered with a scab. They dry up and drop off in from i5 to 20 days. Observers have distinguished two forms of this affection in sheep, namely, a discrete form and a confined variety. There may be hemorrhages giving the dark or black sheep pox.

Borrell found that when the scraping from a pustule was suspended in water (mixed) it remained virulent after much dilution. When this suspension was filtered through a Berkefeld cylinder the filtrate was still virulent. It did not pass through a Chamberland filter $F$. The filtrate retains its virulence for a long time. Borrell considers that his results show that the microbe of sheep pox is ultra microscopic and that the cellular inclusions described as parasites of vaccinia, of variola, of clacelée, cannot be the true cause of the disease. He believes that the researches should be directed along the lines of those made in connection with contagious pleuropneumonia and foot and mouth disease.

Pathogenesis. According to Hutyra and Marek the cutaneous inoculation of a small drop of pox lymph usually causes in susceptible sheep only a local pox eruption; in part of the cases, however, especially in lambs or when very virulent lymph is used, there also appears a general pox eruption. In the latter case there forms at the place of inoculation after $2-2 \frac{1}{2}$ days' incubation a dark red nodule which softens in from four to five days and changes into a vesicle. The latter attains the size of a dollar, its top later sinks, from the interior a little lymph oozes out which later becomes thick, until on the i 2 th or $13^{\text {th }}$ day after the inoculation a scab forms with a gradual drying of the pox content. With the beginning 
of the softening of the nodule the body temperature rises to $39.5^{-40.6^{\circ}}$, later to 4 I. $5^{-42.6^{\circ}}$ as a sign of the entrance of the virus into the circulation, in consequence of which nodules form on the mucous menbrane of the lips, around the nose and eyelids, later also in the axillary region, on the thighs, in the pubic and anal regions. Later these form into pock vesicles. At the same time the general symptoms of fever reach a high grade until at the beginning of the third week after infection or perhaps later death follows with symptoms of septicemia. After subcutaneous infection the temperature rises with the beginning of the local inflammation; the latter consists of a hard swelling the size of a fist, with countless nodules, later with pock vesicles running together on the surface, while the pock eruption generally follows on the 5 th or 6 th day after the infection and in a manner similar to that after cutaneous inoculation. Intraperitoneal injection of the lymph results directly in the formation of nodules on the peritoneun with swelling and painfulness of the abdomen, a specific inflammation of the mucous membrane of the trachea with exceedingly difficult breathing, to which is generally added a general pock eruption on the 6 th or 8 th day (Bosc). Injection of the lymph into the circulation generally causes a rise of temperature without skin eruption, but though the disease is slight and of short duration the sheep become as immune as after surviving the ty pical disease (Semmer and Raupach). After intracerebral inoculation fever occurs after 6 or 8 days, upon which the animals die within a week, while injection of the lymph into the lactiferous duct causes a pock eruption on the mucous membrane of the udder and the milk contains the infective material for two weeks (Nocard).

Natural infection. The contagion of sheep pox, which usually comes in the form of a general disease, according to all probability reaches the lungs with the inspired air and here passes from the alveoli directly into the blood, by which it is carried to the superficial vessels of the skin and mucous membrane. By injection or spraying of the pock lymph into the trachea of susceptible sheep the disease is sure to be reproduced, 
while feeding of the $1 \mathrm{ymph}$ is, according to Hicard, ineffective. Rickert has inoculated about 700 sheep in the last week of pregnancy. Repeated inoculations of the lambs born of them remained negative while of 36 lambs from others not inoculated pox occurred 9 days after the inoculation. After three years inoculations in the case of the former had positive results but in the latter no longer. In the same way Adacker has inoculated 60 , Peuch 3 , lambs born of sick mothers without any result the latter also 3 kids).

424. Goat Pox. I'ariola caprina. The goat pox was formerly observed in Sweden. It has been found in Italy, Spain. France, Germany and in Algeria. It has been reported that in Algeria it is occasionally very severe.

Etiolog 1 '. The contagion of goat pox can be transmitted to goats through the pock content and when the pustules are in the mouth through the saliva of the sick animals. After cutaneous inoculation a local eruption develops at the place of inoculation associated with very mild general symptoms. Man is not entirely unsusceptible, as there appears, especially on the hands and arms of people who care for the sick goats, an exanthema with little vesicles (Hansen, Marcone).

Natural infection takes place by direct touch and the disease in this way spreads quickly inte the herd of goats so that as a rule almost all the animals are infected (sheep kept with the goats are never affected). On the other hand the disease shows no inclination to spread to wider territories but usually stays confined to one herd.

The manifestation of the disease is very similar to the sheep pox. In connection with a moderate fever there develops large pustules partly confluent and with a depression, on the most diverse parts of the body, especially on the udder, the inner surface of the extremities, the face and around the lips and eyes. These leave radiating scars. In many cases abscesses form in the tissues of the udder, and at the same time the milk becomes bloody. In certain animals, especially nursing kids, there also appear in the mouth, as well as in the 
mucous membrane of the upper air passages, lesions whose development is accompanied by coughing, rapic breathing and a pus-like discharge from the nose.

The prognosis of the disease is generally favorable; at the site of the confluent pustules the skin sometimes dies and sloughs out, which retards convalescence. In very few cases the disease develops a severe form from the beginning and is accompanied by general infection and death.

This affection may be confused with foot and mouth disease because, according to Conte, in goats the pustules of the pox sometimes reach considerable size; however, the characteristic appearance of the pox exanthema as well as the fact that the claws remain unaffected, and the inability to transmit it to other animals, will prevent a mistake in diagnosis.

$\$ 425$. Swine pox. The occurrence of swine pox is not yet determined with positiveness. Because in common parlance all sorts of skin eruptions of swine are designated as pox the characteristic nature of many diseases described under this name is doubtful. After Chauveau hastransmitted cow pox in single cases to sheep: Gerlacli swine pox to goats, and Koch swine pox to calves, the occurrence of swine pox cannot reasonably be doubted and it is also probable that the disease passes from the cow, from man and perhaps also from the goat to swine, and once occurring easily spreads among the animals turned together. According to the descriptions the disease as a rule attacks only young pigs and for the most part manifests itself in an exanthema spread over the greater part of the body. Several days after its appearance the animal shows signs of weakness, loss of appetite, slow movements, stiff walk, tail hanging straight down, shivering and ruffled bristles. There immediately appear on the parts of the body with littie or no hair, such as the nose, the eyelids, the inner surface of the thiglss, the abdomen, seldom on the neck and back, little red marks which quickly increase in size. In the center of these there develops firm nodules and after two or three days the latter develop into pox the average size of a pea and filled at 
first with pure lymph, later with pus; these shortly dry to dark brown scabs which fall off after a few days. In more severe cases the pustules became confluent.

The diagnosis between this affection and the different forms of eczema. erysipelas and urticaria is not easy. There is much need of further investigation of this group of diseases.

REFFRHCHS.

1. BERRY. Contagious pustular dermatitis of sheep.

2. BorRei. Eitude expérimentale de la clavelée filtration du virus; Sero-clavelisation; Serothérapie. $4 n n$. de l'Inst. P'asteur, Vol. XVII (1903), p. 123.

3. Councilman, MatiRath axi BRINCKERHOFf. The pathological anatomy and histology of variola. The Journal of lledical Research, Vol. VI (1904), p. 12.

4. Dupuis. Colques cas de cow-pox: Erruption généralisée. Annals de Mid. I'él., 1889, p. Is\}.

5. EILERTS DE HAAX. Vaccine et rétrovaccine à Batavia. Annals de l'Inst Pasteur, 1896, p. 169.

6. Himk. successful transformation of small-pox into cow-pox. British Medical Journal, 1892, p. 116

7. Nocard. Eitudes expérimentales sur la clavelée. Bulletin de la Sociúlí Cent. Míd. l'ít., 1899, p. 263.

8. Simpsox. Vaccinia produced by passing the vaccine of sullpox. Indian. Hedical Gasette, 1896, p. 205.

\section{EPITHELIOMA CONTAGIOSLM.}

Sinonyms. Chicken pox ; la petite rerole; sore head.

$\$$ 426. Characterization. Epithelioma contagiosum, or chicken pox as it is more conmonly called in this country, is characterized by the development of nodular-like growths upon the mucosa and skin of the head and neck. It is readily transmitted among fowls. Other birds especially pigeons are said to be affected.

$\$ 427$. History. This affection of fowls has been known for a long time. It was thought in early times that it was re- 
lated to small pox. Spinola failed to produce it in fowls with cow pox. In 1873 , Bollinger gave a very full account of his investigations into its nature.

$\$$ 428. Geographical distribution. This affection has been studied in Europe. In the Lnited States, Salmon refers

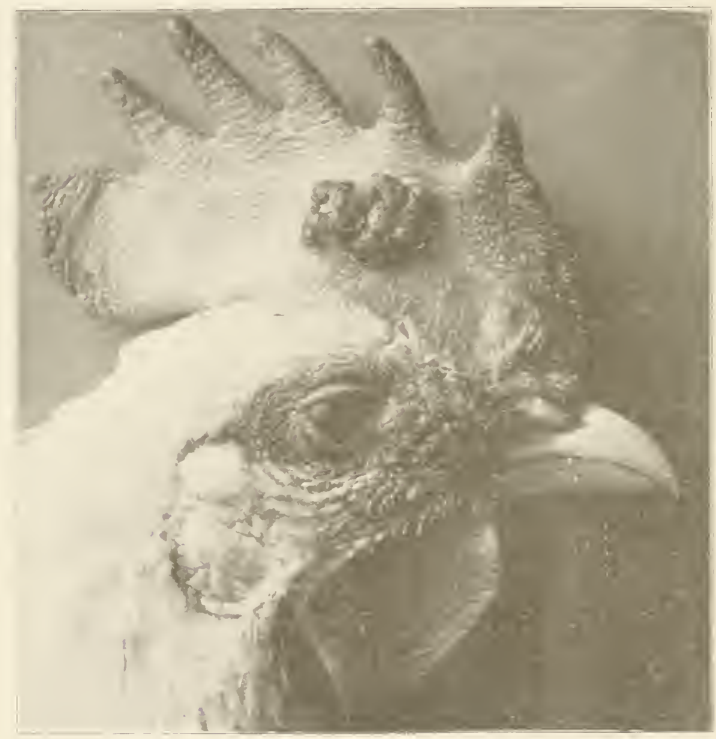

FIG. 12I. A photograph of the head of a fourl shou'ing epithelioma on the comb and in front of the eve after (I ard).

to it from the Southern States and Ward has described it in California. Sedgwick reports that it is one of the greatest obstacles to chicken raising in Hawaii.

$\$$ 429. Etiology. The cause of this disease is not satisfactorily settled. Rirolta and Silvestri considered coccidia to 
be the exciting cause. The disease is readily transmitted by inoculation. Ward has produced it by simply pricking the tumor with a syringe needle and then puncturing the skin on the head of a healthy chicken Marx and Stickler ground up the tumors or nodules in normal salt solution and passed this through a Berkefeld cylinder. The filtrate rubbed on the scarified combs of healthy chickens produced the disease. The virus did not pass through the porcelain filters.

$\$ 430$. Symptoms. The disease first manifests itself by a catarrh of the mucosa of the head. In the further course of the disease wart-like proliferations appear on the mucosa and extend to the skin. The epitheliomata are usually at first gray and glistening but later they are covered with a scab. The nodules may become so numerous, or if single so large, that the eyes are closed, in which case the fowls being unable to see may die from starvation. The growths may also interfere with the use of the beak. The lesions are usually local on the unfeathered part of the head. They are said at times to extend to the feather covered skin. The affected fowls are used for food unless there are objectionable secondary changes resulting from lack of ability to eat. Recovery often takes place in from three to fonr weeks.

$\$$ 431. Morbid anatomy. The nodules consist of epithelial cells. There is a cell infiltration of the skin and subcutaneous tissue. The epithelial cells are much larger than normal; they may be in scales or in more dense masses. Later in the conrse of the disease the nodules may drop off as scales.

RFFERENCES.

I. Boldriger. Ueber Epithelioma contagiosa bein Haushnlin nud die sogenannten Pocken des Geflügels. Archia'. für. Puth. Anat., Bd. LVIII (1873), S. 349.

2. Heusincitin. Recherches de Path. Comp., Vol. 1, (18+7), p. 649 .

3. Salmon. Diseases of Poultry.

4. SeDGwick. Chickens and their diseases in Hawaii. Bulletin No. I, Hazuaii Agric. Expt. Station, rgor. 
5. Spinola. Handbuch der. spec. Path. u. Thera. für. Thie rarzte, 1858 .

6. WARD. Poultry diseases in California. Proceedings of the Am. Vet. .Yed. Asso, 1904. p. 164.

INFECTIVE SARCOMATA IN DOGS.

$\$ 432$. Infective sarcomata in dogs. Smith and Washburn have described a series of tumors of dogs which spread from animal to animal as the result of coitus. These tumors which varied much in size appeared to start in the mucosa of the vagina. In some cases the walls of the vagina were deeply infiltrated, and the tumors often ulcerated. Death occurred frequently from cachexia or as the results of mechanical obstruction. They were enabled to successfully inoculate the tumors into two dogs. The following are their conclusions:

I. "The tumors in question are infective round.celled sarcomata occurring in dogs.

2. "The tumors can be transplanted from the genitals, where they naturally occur, to the subcutaneous tissue of dogs.

3. "The tumors can be transplanted from subcutaneous tissue to subcutaneous tissue through a series of dogs.

4. "The tumors after reaching the maximum of growtl may disappear spontaneously with or without ulceration.

5. "The tumors may continue to increase, and may cause death by secondary deposits forming in the viscera.

6. If the tumor should disappear the animal is then immune to subsequent inoculation."

Beebe and Ewing have studied these nodular tumors. They have been able to transplant it. From 122 plants by various methods they have produced tumors in 35 cases and there were 12 spontaneous recoveries. The course of the successful implantations is usually quite uniform. When inserted beneath the skin a period of 2 to 3 weeks elapsed before enlargement was noticed. Thereafter the nodules grew steadily in size for four or five months producing a well- 
circumscribed tumor the size of a hen's egg or larger. These authors did not determine the listological classification of the tumor.

\section{REFERENCES}

I. BEEBE AND EWING. A study of the so-called infectivus lymphosarcoma of dogs. The Jour. Med. Research, Vol. XV (1906), p. 209.

2. Surth AxD WashbuRx. British Medical Journal, Dec. 17. I 90 S.

FOWL PEST.

Synonyms. Vogelpest; Huhner-pest; exudative typhus.

5 433. Characterization. This is a very acute and rapidly fatal disease of fowls caused by an ultra-microscopic organism that passes through the Berkefeld and Chamberland filters. Pigeons succumb to inoculation. Guinea-pigs and mice are susceptible.

5 434. History. In I 580 , Rivolta and Delprato differentiated a disease from chicken cholera which they designated "exudative typhus." Perroncito called it a typical fowl cholera. It was investigated and described by Lode and Gruber in I9oI. It was found in the Tyrol where during the time from March until July it had attacked 2,300 hens with a mortality of from 80 to 95 per cent. Centanni described this disease and the nature of its virus. He states that it has been recognized as a distinct affection for more than ten years.

$\$$ 435. Geographical distribution. It has appeared in Belgium and the Tyrolean Alps and a few other places in Europe.

$\$ 436$. Etiology. This disease appears to be due to an invisible microörganism. The blood or aqueous suspension of crushed lungs or liver will usually produce the disease when injected in very small doses. It was found by Maggiora that 4 cc. of a dilution of virulent blood in which the blood was 
present in the proportion of I to $125,000,000$ destroyed a young hen.

The virus retained its virulence in blood for 15 days. It was destroyed in thirty minutes at a temperature of $60^{\circ} \mathrm{C}$.

$\$ 437$. Symptoms. According to Centanni the chicken acts dumpish the first day and refuses food on the second. The feathers are ruffied, the comb discolored and on the third day it dies. More rapidly fatal cases are mentioned by Lode and Gruber. The temperature is at first high but it falls to subnormal before death.

$\$ 438$. Morbid anatomy. The lesions vary. In some cases death follows so rapidly that autopsies reveal no change. Usually there is a slight pericarditis and ecchymoses in the heart muscle. There is pleurisy in some cases. The lungs are congested and occasionally there are pneumonic centers. The liver, spleen and kidney's are more or less congested. Microscopic changes are not described.

$\$ 439$. Differential diagnosis. This is to be differentiated from fowl cholera and typhoid. The diagnosis is made from the bacteriological examinations. The rapid course of the disease cannot be relied upon as a differential character, for both fowl cholera and fowl typhoid often run very rapid courses and likewise have a higl mortality.

\section{REFERHNCHS.}

I. Centanni. Die Vogelpest; Beitrag zu dem durch kerzen filtrirbaren Virus. Cent. f. Bakt. Bd. XXXI (I902), s. 145. u. IS2.

2. DuBors. Une maladie infectieuse des poules à microbes invisibles. Comp. Rend. Soc de biol. Vol. LIV (1902), p. 1162.

3. Lecharnche. Reálle Gínirale de Méd. Vétérinaire. rg04, p. 49. Abstract of article in Jour. Comp. Path. and Thera. Vol. XVII (Ig04), p. $S_{3}$.

4. LODE UND GRUBER. 'Bakteriologische Studien ïber die Aetiologie einer epidemischen Frkrankung der Hühner in Tirol (rgor). Central-blatt für Bakt. Bd. XXX (r90I), S. 593.

5. MAggiora UND VAlEnTr. Ueber eine Seuche von exudativem Typhus bei Hühnern. Zeit für. Hygiene, Bd. XIII (1903), s. I $8_{5}$. 
CHAPTER XIII.

\section{IMMUNITY AND PROTECTIVE INOCULATION.}

\$ 440. Immunity. In a broad sense, immunity is "resistance to disease." The term, however, is usually restricted to the infectious maladies and signifies a condition of the individual which enables it to successfully defend itself against the invasion of its tissues and organs with the infecting microörganisms or to resist the toxic effect of the invading organisms should they gain entrance and multiply within the body. While it usually applies to the action of pathogenic bacteria, the protozoa are not excluded. It will be seen that immunity is only relative; it is neither permanent nor constant but varies with natural and artificial conditions. According to the process by which it is established in the indiridual, immunity is recognized as natural or artificial.

$\$ 44 \mathrm{r}$. Natural immunity. The term natural immunity has been applied to that condition or ability possessed by some races or species of animals which enables them to resist the natural invasion of infecting organisms that attack other varieties or species of animals. In so far as we know, it is a condition inherent in the very nature of the individual, born with it and transmitted to its offspring.

There are a number of very striking examples of natural immunity. The Algerian race of sheep are immune to natural infection of anthrax, whereas other sheep are very susceptible to it. The equine species is susceptible to glanders but the ruminants are immune. Blackleg, which is very destructive to cattle, does not attack horses, the carnivora or nan. There are, however, instances where there seems to be a general immunity but where individuals are occasionally attacked. Thus, it is not usual to find tuberculosis in the carnivora, but 
now and then the cat or dog is found suffering with the disease. While it must be admitted that all species may be infected with tuberculosis there is much evidence to show that certain species are largely immune to it.

It sometimes happens that individuals belonging to a susceptible species resist infection. These are spoken of as possessing natural immunity; but this is not a satisfactory explanation, for in such cases it is practically impossible to state whether it is natural or acquired. In the present state of our knowledge of this subject it seems better to allow such cases to remain as examples of individual resistance.

It has also been found that in cases of marked natural immunity the resistance can be overcome and the animal infected by changing its normal physical condition. Thus fowls that are naturally immune to anthrax are said to be made susceptible to its bacteria by reducing their temperature by immersing them in cold water. Charrin and Roger found that fatigue would lessen the resistance of white rats to the same disease. Gibier found that frogs kept at a temperature of $37^{\circ} \mathrm{C}$. were susceptible to anthrax.

It has been stated that sewer and other poisonous gases predisposed animals to infection. Abbott concluded, after a careful experiment of exposing rabbits to sewer gas and gases of putrid meat, that they did not lessen the resistance of the animals to infection. Diet and drugs have been reported to have been successfully used in reducing the resistance to infection. The removal of the spleen has been thought by some experimenters to increase the susceptibility but others have reported different results.

Natural inmunity usually persists under ordinary conditions throughout life and in that respect it is much more permanent than artificial immunity.

$\S 442$. Explanation of natural immunity. There are a number of explanations of this phenomenon. In brief they deal with the supposed actions (1) of the cells of the body, and (2) of the serums or humors. 
Those who seek the cause for this condition in the cells find that phagocytosis, so ably described and demonstrated by Metchnikoff, is the source of the individual defence. 'Those who find the cause in the humors of the body rely upon the germicidal action of the serum itself or of the substances set free from the cells that are present in the liquids. Metchnikoff seems to believe that the microcytase elaborated from the leucocytes acts as a solvent directly upon the bacteria.

The lateral side-chain theory of Ehrlich assumes that the cells of certain animals do not possess the necessary combining molecules (receptors) with which the haptophore group of atoms of the toxin molecule could unite, thus the destructive action of the toxin upon the cell is prevented. This theory refers immunity to the resistance of the animal tissues to the toxin. A study of the subject, however, shows that while many interesting facts have been brought to light a satisfactory exposition of the cause of natural immunity has not appeared.

$\$$ 443. Artificial immunity. As the term inplies, this is immunity brought about in the individual after birth. The most common form of artificial immunity is found in individuals that have survived an attack of an infections disease. The most striking examples of this are cases of recovery from small pox and yellow fever in man and Texas fever in cattle. All of the exanthematous diseases leave the individual with more or less immunity. In some other infectious diseases like tuberculosis there seems to be very little if any increased power of resistance imparted to a patient who has recovered from the first attack. In such acute diseases as diplitheria, the duration of the immunity resulting from a natural attack of the disease is somewhat variable. In artificial immunity there is great variation in the period of duration.

The fact that individuals that had passed through certain diseases were rendered immune to a second attack led Pasteur, Salmon, Smith and others to inquire into methods for artificially immunizing animals against the infections diseases most 
destructive to them. The first experiments* of this kind on animals appear to be those of Pasteur, who found that inoculating animals with attenuated virus would immunize them against inoculation with a strong virus or naturally acquired infection. He promptly succeeded with swine erysipelas, chicken cholera, and anthrax. Later he succeeded with rabies. Arloing, Cornevin and Thomas, and Kitt introduced a successful method of preventive inoculation with attenuated virus against blackleg. The method has been tried with a number of other diseases with less satisfactory results.

The next procedure was a line of investigations directed toward the production of immunity by the use of toxins or heated cultures of the bacteria. The first of these was an immunization of pigeons against hog cholera by the use of heated bouillon cultures of the bacillus of hog cholera by Salmon and Smith in 1886 . This method was followed with similar results by Pasteur with chicken cholera. This line of investigation led eventually to the immunizing of animals experimentally with the toxins or heated cultures of certain virulent pathogenic bacteria such as diphtheria and tetanus.

Another method that has been extensively tried experimentally with the bacterial diseases, but usually without success, is the use of non-lethal doses of virulent virus. With certain of the protozoan diseases this method is more sticcessful, as shown by the excellent results that are being reported in immunizing cattle against Texas fever.

It has been found that the blood serum of animals that are immune to certain bacterial diseases possesses antitoxic properties by which it is able to impart immunity to healthy

*This principle was exemplified centuries before in the far East where inoculation with small pox virus (material from the pustules) was practiced whenever small pox occurred naturally in a very mild form. Lady Mary Wortly Montague is said to have introduced this practice into Europe about 1718 . Later, 1796 , Jenner, after thirty years of labor, introduced the practice of inoculating human subjects with the virus of cow pox. This is known to-day as vaccination and the vaccine is prepared at the present time from calves. In $18_{39}$, Thiele showed that the disease known as cow pox was small pox in cattle. 
susceptible animals, or to act as a therapentic agent for those affected with the same disease. Diphtheria antitoxin is the nost striking example.

\$ 444. Method for artificially producing immunity. The present knowledge of the subject shows that immunity may be produced in several ways other than by causing the individual to pass through an attack of the disease caused by natural infection. These methods may be summarized as follows :

I. By inoeulating the individual with a non-lethal dose of a strong virus. This is practiced in immunizing cattle against Texas fever, sheep pox and contagious pleuropneumonia.

2. By inoculating the individual with attenuated virus. This is practical in anthrax, blackleg, chicken cholera, rouget, and rabies and bubonic plague in man.

3 By inoculating the individual with a vaccine consisting of the virus of the disease modified by continual passage through another species of animal, as vaccine for small pox.

4. By the injection of toxins. In practice this is used for immunizing aninals such as horses against the virus of the diseases for the purpose of procuring antitoxin from their blood, as in diphtheria and tetanus.

5. By the injection of antitoxins. These are used to immunize animals against toxins, and children against natural infection, as in diphtheria.

$\leqslant$ 445. Active and passive immunity. In methods producing artificial immunity, most of them require the introduction into the body of the living virus or the injection of the products (toxins or heated cultures) of the living virus in repeated doses and constantly increasing quantities. Inmunity produced by any of these procedures or by the recovery from an attack of an infectious disease is called active immunity. When immunity is produced by the injection of the serum (antitoxin) of animals already imnune it is called passive immunity. 
Active immunity is slow in its appearance, is more or less dangerous to produce and is always attended with at least some discomfort. It varies in the time it lasts but usually it is quite persistent, lasting from a few weeks or months to several years. Passive immunity is quite rapidly produced, is attended with little or no danger and practically no discomfort. It is very limited in its period of duration. The most extensive use of passive immunity is in immunizing children against diphtheria. It is not enployed to any great extent in animal diseases. The immunizing of horses against tetanus before an operation is, however, practiced by many operators.

$\S 446$. Explanation of acquired immunity. A number of ingenious explanations have been offered for acquired immunity. The only ones that have withstood the test of their objectors are those of Metchnikoff, representing the cellular theory, and of Ehrlich, representing the humoral theory. The results from different lines of investigation indicate that the factors involved in securing immunity against infectious diseases are multiple in number and raried in character. As pointed out by Meltzer it is difficult to explain immunity as being due to one or even to a few anti-bacterial properties of the animal body. In the struggle against bacteria the defence of the body is carried on by the united action of each and every resisting influence. However, a number of theories have been proposed.

I. The exhaustion theory. This theory was suggested in I 880 by Pasteur, who thought that the microörganisms growing in the body used up some substance essential to their further existence and died out leaving the body unsuited for future occupation. The theory could not apply to passive immunity produced by the injection of antitoxin.

2. The retention theory. This was proposed by Wernich and Chauveau. This theory is based on the fact that bacteria elaborate some metabolic product that inhibits their further development and the future invasion in the tissues by the same species. This theory is illustrated with the facts shown in 
the cultivation of bacteria in artificial media. The bacteria often die apparently from the accumulation of metabolic products long before the nutriment is exhausted. After these cultures are filtered and the bacteria present are removed, other bacteria of the same species will not grow in it. This theory, however, does not explain immunity against lysins, serpent's venom and other poisons.

3. The phagocytosis theory. Metchnikoff has supposed that acquired immunity is brought about because of the action of the phagocytes upon the invading organisms. He has shown that in cases of infection with the Vibrio Metchnikovi, the phagocytes of unprotected animals do not take up the bacteria, but that in vaccinated animals they do. It appears from all the work that has been done on this subject that the phagocytes are active in proportion to the degree of immunity possessed by the individual. It has not been demonstrated, however, whether they are active because the animal is immune and the bacteria harmless to it, or whether the animal is immune because the phagocytes are destructive to the bacteria.

4. The humoral theory. This theory is based on the observations of Buchner, Nuttall and others that blood serum has the power of destroying a certain number of bacteria when introduced into it. Nuttall showed in addition to this that the bacteriolytic power ceased if the blood was heated to $55^{\circ} \mathrm{C}$. It is found, however, that the bacteriolytic serums occur only in cases where there is a high degree of forced immunity, their activity being in proportion to the degree of immunity obtained. An explanation for the action of these serums upon bacteria is given by Ehrlich in his lateral-chain theory.

5. Ehrlich's side-chain theory. According to Ehrlich, in every living cell there must exist an active central body and a number of other chenical gromps or side chains. These groups have the greater variety of function, especially those of nutrition and assimilation. This theory teaches that immunity depends upon the presence or absence of certain substances 
which he calls receptors or lateral chains which certain of the cells possess. These receptors are concerned in the normal uutrition of the cells and have affinities for various complex albuminous substances. Among these substances are the molecules of the toxin produced by certain bacteria and possibly other poisons. Every toxin has affinities described as haptophorus and toxophorus, that is, every molecule of the toxin is composed of two different groups of atoms, the one the toxophore or poisonous group, the other the haptophore or combining group of atoms. The haptophorus molecules of the toxin combine or unite with the receptors of those cells for which they have special affinity and through the haptophore group the toxophore part of the molecule is able to act upon the cell. It some cases the cells are destroyed and in others additional receptors seem to be produced because of the stinulation. These receptors may pass out of the cell into the serum, where they act as free receptors or immune bodies to lock up or neutralize the toxin. The free receptors are the active part of the antitoxin.

Ehrlich illustrated his theory by the use of diagrammatic figures to represent the cell throwing off " receptors," the receptors or antitoxin locking up or neutralizing the toxin and the effect of the anti-bodies on the toxin and its complement. The accompanying figures are taken from his work.

$\$$ 447. Hemolysins. Belfanti and Carbone, in 1898 , pointed out the fact that if horses were injected with the red blood cells of rabbits the serum of these horses would be more or less toxic for rabbits. This result was followed with some interesting experiments by Bordet in which he slowed that the blood serum of guinea pigs that had been injected several times with from three to five cubic centimeters of defibrianated rabbit's blood acquires the property of rapidly dissolving in a test tube the red blood cells of a normal rabbit's blood. The serum of an untreated healthy guinea pig will not do this. It was pointed out that this reaction was specific, that is, the serum of animals treated with rabbit's blood (specific serum) dissolves the red corpuscles of the rabbit's blood only. This 
property that had been demonstrated in the blood serum of guinea pigs treated with rabbit's blood was shown to hold for the sera of other species of animals treated with the blood cells of a different species. Wassermann has formulated this action as follows: "The serum of animals species A, after these have been injected either subcutaneously, intraperitoneally, or intrarenously with erythrocytes of species B, acquires an increased solvent action for erythrocytes of species $\mathrm{B}$, and only for this species. (There are a few exceptions to this general rule). We call this hemolysis, and the substances which affect the solution of the red cells, hemolysins or hemotoxins."

Bordet has been able to show that the solvent power of the specific hemolysins depended on the combined action of two constituents of the specific serum. Thus, when the fresh hemolytic serum was heated for a half hour at $55^{\circ} \mathrm{C}$. it lost its power. If to this inactive serum a very small amount of the serum of a normal guinea pig was added, the full hemolytic power was restored to this inactive serum. In other words, it had been reactivated by this addition. This experiment showed that the hemolytic action of the specific hemolytic serum depends upon two substances (I) the one destroyed by heating to $55^{\circ} \mathrm{C}$. and which is contained in the serum of the normal untreated animal as well as in the specific hemolytic serum, and (2) a substance that is able to withstand heating to $55^{\circ} \mathrm{C}$. and which is contained in the specific serum ouly.

The substance which is destroyed at $55^{\circ} \mathrm{C}$. and which exists in the blood of the untreated animal and in the specific serum constitutes the substances designed by Buchner as alexins. It is the substance which is not destroyed by heating to $55^{\circ} \mathrm{C}$. and which is brought about by the action of the blood of one species upon another and is known as the immune body, or as termed by Buchner substance sensibilatrice.

$\S 448$. Agglutinating power of hemolytic serum. It has been found in the experiments by Bordet that another property was increased in the hemolytic serum, namely, the 
power of clumping red blood corpuscles. This clumping or so-called agglutination of the red cells occurs previous to their

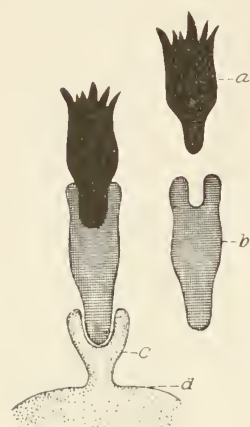

Fig. I22. $a$, Complement; $b$, intermediary body; c, receptor; $d$, part of the ccll.

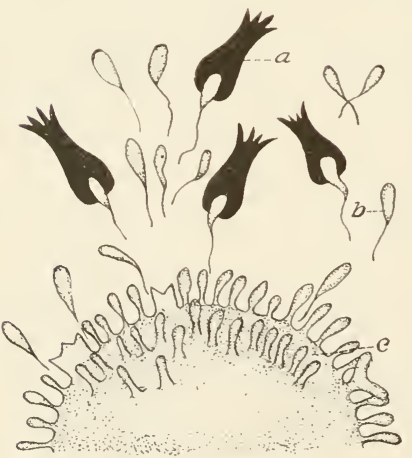

FIG. I24. A cell showing the separalion of the receptors or antitoxin and the combinalion of torin with free antitorins; $c$, cell; b, free receptor; a torin.

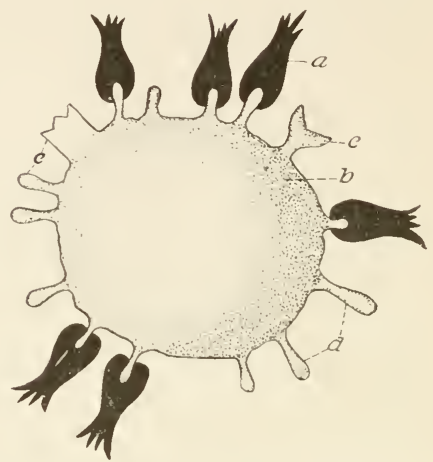

FIG. 123. A iell with different kinds of receptors; $b$, cell; $c, c$ and $d$, different kinds of receptors; a, bodies having but onc haptophore or combining group of atoms.

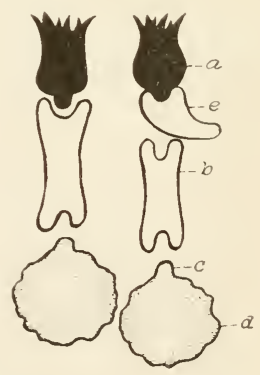

FIG. I25. A drawing showing the action of anti-complement; $a$,complement; b, intermediary bod' $y^{\prime} c$, receptor; $d$, call; e, anti-complement. 
solution. This action Bordet considers as a specific one. Wassermann has formulated this reaction thus, "if an animal, species $A$, be treated with blood of species $B$, the serum derived from A will have acquired an agglutinating power which differs from that of normal serum of $A$ in one very important particular, namely, in that it is specifically increased with respect to the red cells of species B or its nearest biological relative. This clumping must not be confounded with rouleaux formation in normal blood.'

For a more extended discussion of the subject of hemolysis and for cytolysis, cytotoxins, agglutinins and precipitins the student is referred to the special literature on these subjects.

$\$$ 449. Protective inoculation. The practical application of immunity in protective inoculations or vaccination has come to mean the establishment of partial or complete immunity in the individual against the disease in question. The vaccination against small pox introduced by Jenner in 1796 is a well known example of protective inoculation. Pasteur found that animals inoculated with attenuated cultures of anthrax and chicken cholera bacteria were subsequently immune to their respective diseases. From this there has developed many procedures for establishing both active and passive immunity against a number of diseases of animals. The methods that are now in use, together with the diseases against which they are employed, may be summarized as follows :

I. Active immunity.

I. The injection of non-lethal doses of the virulent virus. This method is employed most extensively in immunizing cattle against Texas fever and bovine contagious pleuro-pneumonia. It is used in France to immunize against sheep pox (clavelization) .

The fact that susceptible cattle can be immunized against Texas fever by the use of blood from immunized animals has been demonstrated. The method is being applied with success in several places in the tick infected district. It is a 
practicable method but, like the others, it should not be undertaken without a realization of the possible unfavorable outcome.

Since the 18 th century there has been practiced in France on a large scale the artificial immunization of sheep by the inoculation of the virus of sheep pox just as the variolization of man was practiced before the discovery of small pox vaccine. In France, the law requires the inoculation (clavelization) of flocks in which sheep pox appears, but it interdicts the practice in unattacked flocks.

2. The injection of animals with attenuated cultures of the bacteria of the disease against which inmunity is to be established. This method is used most extensively in anthrax, rabies, symptomatic anthrax, swine erysipelas and bovine tuberculosis.

The practical value of vaccination for rabies, over that of most other diseases, is the fact that it is effective if made early in the period of incubation. This vaccination taking advantage of the long period of incubation in rabies, constitutes a form or type of handling of an infectious disease intermediate between protective inoculation and a therapeutic method of treatment.

Many efforts have been made to procure a vaccine for tujerculosis. Pearson, of the University of Pennsylvania, and von Behring of Marburg, Germany, have done the most work along this line. A number of other workers have reported results, among whom de Schweinitz, Trudeau, M'Fadyean and Schütz may be mentioned.

The bovo-vaccine of von Behring consists of living human tubercle bacteria. The results reported by von Behring and others who have tried his vaccine are, for the greater part, encouraging, but as yet the method is in the experimental stage.

II. Passive immunity. This consists of a temporary immunity produced by the injection of the blood serum of an animal that has been immunized to the disease. It is em- 
ployed as a prophylactic in swine erysipelas, tetanus, and diphtheria.

The use of the tetanus antitoxin to immunize horses against tetanus before subjecting them to operations, sucli as castration, or after receiving punctures of the skin or hoof ("farrier's puncture") is becoming more and more prevalent in those countries and localities where tetanus is common. In France it seems to be used more than elsewhere. The extent to which it is employed is indicated by the fact that in 1896 there were sent out from the Pasteur Institute of Paris I,5 I I bottles of ro cc. each of tetanus antitoxin; in 1898 the number rose to $24,95^{\circ}$ bottles; and in 1900 it exceeded $+3,000$. The most of this was for the protection of injured animals against tetanus. It is given in two injections from io to 12 days apart. Large animals receive $20 \mathrm{cc}$. but small ones from 6 to ro cc. at each injection.

The value of diphtheria antitoxin as an immunizing agent against diphtheria in children is a well-known fact.

III. The simultancous method. This consists in using a strong virus together with an immunizing serum. The process is of comparatively recent date. It is used quite extensively against rinderpest, anthrax, and in rabies.

In case of rinderpest the animals are injected with a protective serum simultaneously with the virulent blood. The immune serum is obtained from animals that have recovered spontaneously from rinderpest or from cattle that have been immunized by bile or some other method. The serum alone of animals that have recovered spontaneously possesses very slight protective properties unless very large doses are given. Kolle and Turner showed that if animals just recovering from an attack were injected with large quantities of the blood coming from animals suffering with a fatal attack, the protective power of their serum was markedly increased. This serum may be kept for a long time by adding a small quantity of carbolic acid.

In rabies the method is reported to be most successful. Its essential advantage over the other process is that it can be 
used with good results much later in the period of incubation. It has the additional practical feature that the number of injections is minimized.

In anthrax it is reported to be giving much better results than the double inoculation with a weak and stronger vaccine as followed in the Pasteur method.

\section{$\$ 450$. Difficulties and dangers to be considered in} vaccination. The results of the efforts that have been put forth during the last twenty years to obtain control over the infections diseases of animals show that with the victories there have been many failures. Because of the few diseases for which vaccines have been successful, animal owners often look upon vaccination as a safe and sure means of heading off all infections. Because of their strong faith in its efficiency and the ease of its application, it is often chosen rather than the more difficult and perhaps immediately more expensive procedures of prevention or eradication. For a few diseases there is a well-established natural basis for vaccination, but with others such a foundation does not appear to exist. The reasons for occasional failures in vaccination are not difficult to find. The analysis of the principles underlying vaccination shows that it means the establishing of immunity by the introduction into the body of non-lethal doses of virulent virus or the use of a virus that has been attenuated.

It is not always easy or even possible to know the exact degree of virulence possessed by the vaccine, and again the resisting forces of animals vary even in different individuals of the same species. If the virulence is too great or the resistance below the supposed normal the vaccine may produce disease in excess of the amount required to establish immunity and perhaps it may kill the animals it was intended to protect. This is a result that has been experienced. On the other side, if the attenuation of the virus is too much, or the natural resistance unusually high, there is not disease (reaction) enough produced to cause any immunity. In this case the results are negative. In cases where the virulent virus is used in small 
doses, accidents have happened by way of producing a fatal disease instead of a mild attack that was anticipated. The difficulty rests in the procuring of a raccine or the quantity of a virus that possesses just the amount of disease-producing porrer that is necessary to bring about immunity and no more. This is a balance of vital forces that it is exceedingly difficult to strike.

A glance at the diseases for which active immunity has been attained will show that they are acute toxic affections and not those in which the disease consists of extensive tissue destruction. Toxic immunity has been attained in several disorders but a bacterial immunity is much more difficult to acquire.

As vaccination rests upon the production of artificial immunity, the extent to which it can be applied depends upon the efficiency of methods to produce immunity in different diseases. In deciding upon the action to be taken in the presence of an infectious disease, the selection of a vaccine should be guided by the fullest knowledge possible of the nature of the disease itself and the extent to which natural and acquired immunity against it exists or is made possible.

The dangers in vaccination as applied especially to animals at large may be summarized as follows:

I. The vaccine may be too much attenuated, resulting in the failure to establish immunity.

2. The vaccine may be too strong (virulent) so that it will produce more disease than is desired, possibly causing fatal results.

3. The attenuated virus of which the vaccine cousists many regain its virulence. The distribution of living pathogenic microörganisms among animals is of itself not to be recommended. They may be the starting point of subsequent outbreaks.

4. In using non-lethal doses of a virulent virus, the danger of producing fatal results because of the susceptiblity of the individual treated is always present.

5. In the simultaneous method the danger of accident 
resulting from too strong a virus, too weak a serum, or the high resistance or unusual susceptibility of the individual are possible conditions to be kept in mind.

$\$ 45$ I. Prevention. The prevention of the specific dis. eases of animals, when considered from the point of riew of etiology, is not so difficult as is often supposed. Infectious diseases are simply parasitisms. If the infecting organisms can be kept away from animals the diseases they would produce cannot appear, and if the individuals already suffering from the disease are properly isolated, their stables and pens disinfected, and their bodies properly destroyed if they die, the infecting organisms must perish. The great Pasteur said, "It is within the power of man to make all infectious diseases disappear from the world." The fact that the bacteria of these diseases are parasites restricts their breeding places. so to speak, to the animal body. If, therefore, the channels through which these microörganisms escape from the infected body are properly guarded, and if the channels through which they enter the healthy body are intelligently protected, the spread of infectious animal diseases will be minimized, it not entirely prevented.

Since the discovery of a specific etiology the life history and possibilities of the virus of the different infectious diseases have been diligently studied and much has been learned concerning them. The result is that frequently by taking advantage of the present knowledge of the infecting organism, preventive measures may be taken that will give equally as good results as vaccine, without its dangers, and often with as little trouble and expense. The prevention of these diseases is well illustrated in many instances where owners of animals have protected their herds against the sources of infection when surrounded with widespread epizoötics. Ithole countries have been kept free from certain maladies by enjoining the same methods, as shown in the absence of rabies in Australia. This was accomplished by prohibiting the entrance of dogs until after they had been quarantined for a sufficient time. The eradication of infectious diseases by holding rigidly and 
simply to the guarding of the cliannels of dissemination and infection has been accomplished a number of times on a large scale as instanced by the eradication of contagions pleuro-pnenmonia in cattle from this country and from Great Britain. The elinination of foot and mouth disease from New England is another striking illustration of active decisive efforts in this direction. The eradication of infectious diseases from individual herds is being accomplished repeatedly by adhering to the same methods. The Bang method of handling borine tuberculosis, as already mentioned, enables one to protect the well animals and to save all there is of value in the others.

The isolation of the well from the sick and the thorough disinfection of the houses and yards containing the sick has resulted in stopping many outbreaks of disease. This is followed very generally even where vaccination and serum prevention treatment are resorted to. Several times in the writer's experience success in. checking the spread of the disease by vaccination was not attained until rigid methods of isolation and disinfection were carried out. Just what these methods are to be in each particular case will be indicated by a definite knowledge of the cause and the nature of the disease in question.

The methods for immunization that give the greatest promise in aiding in the solution of the problem of the control of infectious diseases are those productive of a passive immunity. Although these are temporary in duration they are effective immediately and consequently tend to save individuals when they are applied in the period of incubation or before a possible exposure. They protect the animal until the virus can be elininated and its environment made safe.

The advantages of introducing preventive measures are:

1. The tendency to eliminate the virus of the disease if it is present, and to keep it away if it has not already appeared.

2. The animals are free from the virus and there is no danger of their subsequently developing lesions due to the localization of the attenuated microörganisms. 
3. The separating of the well animals from the sick ones and from the infected stables, pens, yards, or fields is not usually an expensive procedure. The stables and yards can be disinfected and the infected fields can be utilized for other purposes until the virus has been destroyed by its own limited life cycle. In this connection, it is well to call attention to efforts that are being put forth to eliminate the cattle tick from the Southern States and thus prevent Texas fever.

REFERENCES.

I. ERNST. Modern theories of Bacterial Immunity. Boston, I903.

2. MFтсникоFғ. Immunity in Infective Diseases. Cambridge. 1905 .

3. Nutrall. Blood Immunity and Blood Relationship. Cambridge, I 904 .

4. Sobfrnhim. Deutsche Med. Wochenschrift. Igo4, No. 26, s. 27.

5. STERNBERG. Immunity, Protective Inoculations in Infectious Diseases and Sernm-Therapy. New York, 1895.

6. WASSERMANx. Immune Sera, Hrmolysins, Cytotoxins, and Precipitins. New York, 1904.

7. Vaughn and Norr. Cellular toxins or the Chemical Factors in the Causation of Disease. 


\section{CHAPTER XIV.}

\section{DISINFECTION.}

$\$$ 452. Disinfection. By disinfection is meant the destruction of infectious disease-producing organisms. For this purpose, nature has provided very important agents, such as sunlight and drying, but these are not available or sufficient to destroy all infecting bacteria in all infected places within the necessary time limits. To supplement these natural forces, a large number of chemical substances possessed of germicidal powers have been brought into service. If, however, the results of the test experiments with these different substances are reviewed, one is impressed with the discrepancies, if not contradictory conclusions, recorded concerning their value. In view of these facts the practitioner is often at a loss to know just what chemicals to use, or how to apply them under different conditions and for the destruction of different species of organisms. The failure resulting from the many efforts to disinfect stables, pens, kennels and yards has caused much skepticisn1 concerning the efficiency of many reported disinfectants. In order to rightly understand the reason for the differences in results of the test experiments or the lack of uniformity in the application of the various disinfecting substances, it is well to take into account certain fundamental facts.

I. The bacteria used by different investigators to test the efficiency of certain substances have not been the same. The vital resistance of the various species is very different. The results obtained in testing disinfectants on the spirillum of Asiatic cholera or the bacterium of bubonic plague give but little information relative to the value of the same disinfectants when used for the destruction of the bacteria of glanders, tuberculosis or hog cholera. Thus the difficulty in accepting the results of many of the older experiments is that the 
organisms were used which are very unlike those for which these disinfectants are now wanted. The practical value of the more recent experiments is greater because they have more generally dealt with species of bacteria with which most of the work of disinfection has to do.

2. The power of resistance of the same species of bacterium varies greatly under different conditions. For instance, Bear found that a freshly inoculated culture of the bacterium of diphtheria was destroyed with r:5000 of nitrate of silver, but that a twenty-four hour culture required $\mathrm{i}: 1000$ of the same agent to kill it in the same space of time. In sone work done by Esmarch he nuade use of anthrax spores from seventeen different sources. They were destroyed by steam at $212^{\circ} \mathrm{F}$. in from one to twelve minutes and by a five per cent solution of carbolic acid in from two to forty-two days.

3. The medinm in which the bacteria exist influences the results of the disinfectants. The bacterium of tuberculosis from an aqueous suspension dried upon threads may be promptly destroyed by mercuric chloride, but in fresh, purulent, tuberculous discharges it cannot be trusted to destroy them. Again Behring says that sporeless anthrax bacteria in water are killed by corrosive sublinate, 1:500,000; in bouillon, by I :40,000; but in blood serum not with certainty with a solution of $1: 2000$. Some disinfectants are influenced very much by the character of the material which contains the infectious organism, while other disinfectants are influenced to a comparatively slight degree. The experimental work which does not take the influence of the media upon the disinfectant into account is not of much practical value and failures are to be expected in the work of the disinfector who does not act in accordance with this fact.

4. The temperature under which the disinfecting agent acts influences very much the rapidity and the certainty of its action. Thus Heider found that anthrax spores that survived the action of a five per cent solution of carbolic acid thirty-six days at ordinary room temperature, were killed in from one to 
two hours at $131^{\circ} \mathrm{F}$. Some investigators have failed to state the temperature under which their disinfecting experiments were made.

5. In many of the results the inhibitory action of the agent in question has been mistaken for its germicidal action. After the bacteria have been subjected to the influence of a disinfectant for a given time, though not killed, their vegetating aud pathogenic capabilities may be modified but still able, under favorable conditions, to return to their former vigor.

The rules and recommendations of the varions cattle commissions and those having authority in methods for prevention of infectious diseases of animals do not very clearly define the procedures best adapted to the various places and conditions requiring disinfection. The many chemicals possessed of germicidal powers and the numerons commercial disinfectants, recommended largely from the results of certain definite tests, which in point of fact may be of no value in determining their efficiency for the conditions in question, render further inquiry into the hest methods for disinfecting after animal diseases a matter of much scientific interest and great practical value.

$\$ 453$. Conditions to be taken into account in practical disinfection. In the effort to destroy the microörganisms in such places as yards, stables, cattle cars and the like, it is necessary to consider before applying a disinfectant the following conditions :

I. The resistance of the particular organism to be destroyed.

2. The medium or material in which it exists.

3. The nature of the place containing the organism to be destroyed.

4. The chemical action of the material surrounding the microörganisms on the disinfectant itself.

If the disinfection is for anthrax or Texas fever (cattle tick) a more powerful substance or solution must be employed than would be required in disinfecting for the bacteria of 
septicemia hemorrhagica or hog-cholera. If the infecting organisms are mixed with fecal matter, dirt or fodder, the problem is a different one than where they rest on a comparatively clean surface. It matters again whether the infecting organisms are in the soil (on surface), on a stable floor that is tight and hard or on one containing cracks of various sizes and made up of boards more or less shattered or destroyed, thus forming deep crevices for the hiding away, as it were, of the specific organisms.

In the disinfection of human dwellings the fumigation with formaldehyde has proven to be one of the cheapest and ordinarily the most efficient procedures, but it requires a tightly closed room. It is erident that such a method cannot be trusted for the disinfection of most barns, stalls or stables which are usually large compared with dwelling rooms, and what is of far more importance, they are too open. In the disinfection for animal diseases the agents used must from the nature of the buildings in most cases be applied in the form of a solution.

Jaeger's investigations brought out very clearly the necessity of adapting the disinfecting agent to the specific kind of organism to be destroyed. For instance, while brushing the surface with a $1: 3$ milk of chloride of lime destroyed anthrax spores, it was untrustworthy as a disinfectant for the bacteria of tuberculosis and of glanders. For the destruction of the bacterium of tuberculosis he found carbolic acid and the other coal-tar phenols very efficient, especially when acidulated with hydrochloric acid. For this purpose he recommended especially Laplace's 4 per cent solution of crude carbolic acid with two per cent of hydrochloric acid. In the hands of Jaeger, the power to destroy anthrax spores with certainty has been shown only by solutions of carbolic acid and the thick chloride of lime mixture.

A thick milk of lime applied once with a brush Jaeger found efficient in the destruction of the microörganisms of chicken cholera, hog cholera, swine erysipelas, typhoid fever, glanders, anthrax (without spores) and Staphylococcus pyogenes aureus. 
Giaxa, in a similar line of work to that of Jaeger's, found that in the disinfection of walls even a five per cent lime wash acting forty-eight hours failed to destroy anthrax spores, the bacterium of tuberculosis and the bacillus of tetanus.

A strong solution of the chloride of lime may be classed as one of the rapidly acting disinfectants for most bacteria, but Jaeger's report of its failure when applied to the infection of tuberculosis and glanders should be borne in mind. For the cleansing of cattle cars Gruber advises scrubbing them out with hot water or washing with a two per cent solution of soda at $50^{\circ} \mathrm{C}$., although this has no particular disinfecting power. If the cars are infected he sprays with a 5 to Io per cent solution of formaldehyde.

$\$ 454$. Disinfectants of value in the practical disinfection of stables and pens. For disinfecting pens, stable floors and the like the following solutions have been recommended and their careful and intelligent use has shown them to be very efficacions.

1. Corrosive sublimate (mercuric chloride), $I$ ounce in 8 gallons of water (one-tenth of I per cent). The water should be put into wooden tubs or barrels and the powdered sublimate added to it. The whole must be allowed to stand for twentyfour hours, so as to give the sublimate an opportunity to become entirely dissolved. Since this solution is poisonous, it should be kept covered and well guarded. It may be applied with a broom or mop and should be used freely on all woodwork. Since it loses its virtue in proportion to the amount of dirt present, all manure and other dirt should be first removed before applying the disinfectant. The manure should be covered with lime or burned. Its very poisonous nature for man and animals renders it less desirable for general use than some other solutions.

2. Carbolic acid. A 5 per cent solution of carbolic acid is one of the best disinfectants for mangers, feed boxes and fixed watering basins. It should be applied in quantity sufficient to thoroughly wet all parts and soak deep into the cracks and crevices if there are any. 
3. Chlorinated lime. Five ounces of chloride of line to a gallon of water ( 4 per cent). This should be applied in the same way as the corrosive sublimate.

4. A mixture of crude carbolic and sulphuric acid. The following disinfectant has been found to be very serviceable. It is not poisonous, but quite corrosive, and care should be taken to protect the eyes and hands from accidental splashing :

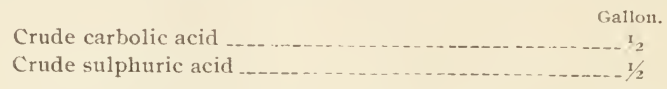

These two substances should be mixed in tubs or glass vessels. The sulphuric acid is very slowly added to the carbolic acid. During the mixing a large amount of heat is developed. The disinfecting power of the mixture is heightened if the amount of heat is kept down by placing the tub or glass demijohn containing the carbolic acid in cold water while the sulphuric acid is being added. The resulting mixture is added to water in the ratio of $I$ to 20 . One gallon of mixed acids will thus furnish 20 gallons of a strong disinfecting solution, haring a slightly milky appearance.

5. Formalin. Formalin is being highly recommended as a disinfectant when used in a 5 per cent solution. The floors and walls should be thoroughly wet with it.

6. Ordinary slaked lime. Although it does not possess the disinfecting power of the substances given above, slaked lime is nevertheless very useful. It is well adapted for disinfecting the surface of yards and pens. It is very good to apply. to the ceilings and walls of stables.

There are a number of other substances that may be used, such as a solution of blue vitriol or creolin.

In disinfecting stables and pens all litter which has accumulated should be remored before applying the disinfectant. As the litter itself is infected it should be disinfected as well as the stable floor and walls. The most efficient method for disinfecting the litter is fire. The practice of washing the floors and cenling with water before applying the disinfectant 
has in most instances the disadvantage that the water carries the nicroörganisms to be destroyed into cracks and possibly through the floor, where they will not be affected by the later application of the germicide. It is deemed safer to simply use a dry cleaning, avoiding dust as much as possible, and to burn the sweepings or to thoroughly wet them with a strong disinfectant. The disinfectant is then applied in sufficient quantity to thoroughly saturate the surfaces, including the adhering particles of dirt. The solutions available for stable disinfection are cheap enough to admit of this precaution,

In the application of disinfectants it is well to use a broom and thoronghly scrub the floor and lower part of the walls. This is necessary in order to get the disinfectant through the dirt and into the crevices of the floor. The disinfectants can be applied to the ceilings and upper parts of the side walls with a spray pump.

It is often desirable to disinfect yards where infected animals have been kept. It is well in such cases to carefully scrape together and burn the litter, after which the surface of the soil must be disinfected. For this the milk of lime or a very liberal coating of slaked lime has been recommended. The burning of the surface sucl as can be done by covering it with a layer of old straw and burning, is a more certain destroyer, especially if animal parasities are to be eliminated. The method of disinfecting with a flame as described by Ferbusch in 1896 , and recently recommended by Stiles for disinfecting kennels, pens and yards offers possibilities not found in other means. The procedure consists of a "Cyclone burner" attached to the end of a long iron tube with a wooden shield. This is connected with a short piece of hose of the kind made for the delivering of oil attached to a spray pump. A tank of suitable size is taken and paraffin gas oil is used. The spray of oil is ignited, giving a very hot and effective flame, which is run over the surface to be disinfected. The flame destroys all living things on the surface. This method seems to be applicable to the disinfection of floors and stables as well as yards, when the conditions are permissible and when the flame can 
be applied with the necessary care. Experiments are being made to determine more definitely the extent to which this method can be applied with safety.

The practical use of disinfectants is a matter requiring much attention if good results are to be attained. It is not wise to trust the disinfection of pens and stables to their owners, unless they are men well versed in the knowledge of disinfection. The failure to properly disinfect stalls and stables is frequently the secret of the failure to stop the ravages of infection.

In the employment of commercial disinfectants, it is necessary also to know the destructive value of the solutions for the organism to be destroyed. There are many so-called disinfectants that, in the strength of the solutions recommended, are little if any better than a poor antiseptic. In the destruction of pathogenic microörganisms it is important to ever keep in mind that the disinfectant must be able to kill the organisms in the condition under which they are then existing.

REFERENCES.

I. BRACKEN. Disinfection and disinfectants. IgOI.

2. RIDEAL. Disinfectants and disinfection. London. I895.

3. Rosenau. Disinfection and disinfectants. Igoz.

4. STILES. The disinfection of kennels, pens and yards by fire. Bulletin No. 35, U.S. Bureau of Animat Industry. I902, p. I5.

5. Younc. Notes on disinfectants and disinfection. Reprinted from the roth Report of the State Bourd of Health of Maine. I8gs. (Contains full bibliography on disinfectants and results of experiments.) 


\section{INDEX.}

\section{A}

A specific infectious disease ... 3 Actinobacillosis ............... 3 17

Characterization _...-317

Differential diagnosis _ _ 320

Etiology _._.

Geograplical distribution-3I7

History _.............. $3 \mathrm{I} 7$

Morbid anatomy ....... 319

Prevention ............ 320

Symptoms ... _... _...319

Actinomycosis . _...........299

Characterization _........ 299

Differential diagnosis ..... 3I 3

Etiology _......... 301

Geographical distribution -300

History _._._._._._. 299

Infection_ _... _....... 304

Norbid anatomy _..._._. 307

Sanitary considerations _- 3 I5

Specific treatment .........314

Symptoms ............ 305

Agglutinating serum .......-- 553

-tmeba, genus _._._..._._. 377

Ameba dysenteriae ...........38i

Ameba meleagridis..._._. 379

Anebiasis ................ 377

Anthrax ................... 129

Animals attacked _....... 133

Blood in ............. I4 I

Channels of infection _... 133

Characterization .......... 129

Differential diagnosis _._._1 45

Disposition of animals dead of anthrax .......... 150

Duration_.............. I44

Etiology _ . . . . . . . I I

Geographical distribution_I 31

History _._._._._._._. I 29

M'Fadvean's stai11_........ I46

Morbid anatomy _.......139

Pasteur's vaccine method__I47

Period of incubation_..._.133

Prevention _.... ........ 149

Prognosis _... _.......... 1.44

Protective inoculation ..... I 47

Simultaneous vaccine niethod _...... 149

Symptoms _.............. I 135
Apoplectiform septicemia in chickens _......... 57

Characterization _........ 57

Differential diagnosis ..... 59

Etiology ............ $5 \mathrm{~S}$

Geographical distribution - 58

History _.............. 57

Morbid anatomy ......... $5 \mathrm{~S}$

Prevention _............ 59

Symptoms _............ 58

Aspirgillus fumigatus _... 334 glaucus _... . . 334

Cultivation _......... 333

Asthenia in fowls and pigeons 243

Characterization _........ 243

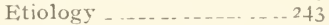

History ............. 243

Morbid anatony ......... 244

Symptoms _... _....... 243

Avian tuberculosis _......... 203

Bacteria _............. 205

History .............. 203

Morbid allatomy _..._._._. 206

Symptoms _............. 204

\section{B}

Bucillus, genus..............246 of blackleg.......... 278

Bacillus aur septicus _.......... 106 bozisepticus ......... 96 cholerw suis _.... 249, 260 description of .... 250 cloaiae .......... 519 coli communis _...29, 525 enteritidis . .........29I necrophorus _......... 289 oedematis maligni_...2S6 letani__... _ _ 266, 267

Bacterenia ................ 3

Bacteria causing wound infection _._. 8

Bacterium, discussion of genus 69 Bacterium anthracis...... I31, 1.45 asthenice _.......... 243 of Preisz. . ......... 236 sangnuarum II4,I15, I22 septicemiae hemorihagicue, 29,70, 72, 57, 96, 113 tuberculosis ..... 175, ISo 
Cultivation of

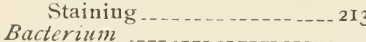
180

tuberculosis (avian) 205

Bacterium of swine plague $-72,260$

Of fowl cholera

Bang's method_..................... 224

Black head (see infectious entero-hepatitis).

Black leg .._._. 276

Characterization _..._._. 276

Differential diagnosis _... $2 \mathrm{~S}_{2}$

Dnration ........... 282

Etiology _................. 278

Geographical distribution 277

History ................ 276

Morbid a natomy ........... 280

Period of incubation ....... 278

Prevention .............. $2 \mathrm{~S}_{3}$

Preventive inoculation .... $2 \mathrm{~S}_{3}$

Syniptonis _..._. _..._. 279

Blastonycetes infection ...... 34.5

Boöphilus annulatus _........ 355

Botryomy cosis ............... 23

\section{C}

Canine malaria _....... 372

Characterization ........... 372

Etiology _... . .

History …… .

Morbid anatomy _........ 374

Symptoms _............. 374

Cellulitis (infections)_....... 29

Cerebro-spinal meningitis_... 514

Characterization _..._....5I4

Differential diagnosis....-517

Etiology _..._......... 514

Morbid anatomy .........-5I5

Symptonis _..._......... 515

Channels of infection....... 5

Chicken cholera (see fowl cholera).

Cladothrix actinomyces _...... 30I

Consumption (see tuberculosis)

Contagious pleuro-pneumonia in cattle

Characterization

Differential diagnosis

Eradication _.......... 452

Etiology ....................

History .......................

In the U. S. ............... 442

Morbid anatomy _......... 447

Preventive inoculation .... $45^{2}$

Symptoms ............... 444
Cornstalk disease _ _ _ _ _. 517

Characterization ... ... 517

Differential diagnosis _... 522

Etiology _. _ _._._. 520

Geographical distribution -520

History _............... 518

Morbid anatomy ....._...521

Symptoms _..._....... 520

Cow pox _..._.

Cytodites nudus _.............. 212

\section{D}

Diarrliea in calves (see white scours).

Diphtheria in calves and swine. 244

Diphtheria in fowls ........... 485

Characterization _......... 485

Differential diagnosis..... 494

Fitiology _............ 486

History ................ 486

Morbid anatomy ........... 490

Prevention _............-495

Relation to human diphtheria ................ 494

Symptoms .................. 499

1)iscomyces equi .............. 24

Disinfectants ................ 567

Application of _._._. 569

Value of _........ 567

Disinfection ................ 563

Practical _......... 565

Dog distemper................... 506

Cliaracterization _..._._. 506

Differential diagnosis _... 512

Etiology _...... 506

Geographical distribution_506

History - ......... 506

Morbid anatomy ........ 510

Prevention _..._.........-513

Symptoms _.............. 507

Dourine _................ 4 IO

Characterization .......... 4 Io

Differential diagnosis.....420

Eitiology .............. 4 I I

History .............. 4 II

Morbid anatomy _.........4IS

Prevention _................ 42 I

Symiptoms _............ 415

E

Ehrlich's side-chain theory ... 552

Epithelioma contagiosum _...539

Characterization ..........539 
Fitiology _._. 540 (ieographical distribution 540

History ..... . _. _. 539

Morbid anatomy ......... 541

Symptonus ............ $54^{1}$

Epizoötic lymplangitis ....... 342

Characterization ........-342

Differential diagnosis _... 346

Etiology . . . . . 343

History _.................... 342

Morbid anatony _..._. 345

Period of incubation _..... 343

Symptoms .............. 344

Equine contagious pleuro-pneumonia _............ 49

Characterization ......... 49

Differential diagnosis.... 56

Duration . ............... 56

Etiology ............ 50

(Seographical distribution. 49

History _.............. 49

MIorbid auatomy ........... 53

Mortality. ............ 56

Period of incubation ...... 52

Prevention ............... 56

Symptoms _.............. 52

Equine malaria.

Characterization _.......369

Differential diagnosis .... 37 I

Etiology _... . - . - 370

Geographical distribution -370

History ….......... 370

Morbid anatomy _........ 371

Symptoms _........ 37 I

Etiology .................

\section{F}

Farcy (see glauders).

Farcy in cattle ............ 346

Fistulous withers ........... 31

Foot and mouth disease ....... 454

Characterization _......... 454

Differential diagnosis .... 458

Etiology _ _ _ _... 455

Geographical distribution -454

History ............... 454

Morbid anatomy _......... 457

Period of incubation ..... 455

Prevention .................. 458

Symptoms _.......... 456

Foot-rot in sheep _.......... 289

Characterization ......... 289

Differential diagnosis .... 29I

Etiology .............. 28q
History a... 289

Morbid anatomy _. $\quad 290$

Symptomis .... 290

Forage poisoning _... $\ldots-517$

Fowl cholera _..._..... 105

Blood counts _..._._. IO9

Characterization _.._ 105

Iifferential diagnosis _. $\quad$ I10

Duratio11 . . . ............ 1 I0

Etiology ........... 106

Geographical distribution_106

History _............... 105

Morbid anatoll1y _...........107

Period of incubation _._._. 106

Prevention _............... 110

Prognosis ............... 110

Symiptonis _............. 106

Fowl pest ........... 543

Characterization _..__._. 543

Differential diagnosis .... 544

Etiology ….......... 543

Geographical distribution $-5+3$

History _... _...

Morbid anatouly _._. _..._. 54.4

Symptoms _... . . $5+4$

Fowl typhoid ............ 114

Characterization .......... I14

Differential diagnosis ...... I20

Etiology - . . . _..._... I I5

Geographical distribution_114

Historv ................... 114

Iorbid anatomy .......... 116

Prevention _.............. 122

Srmptoms _.......... 115

\section{G}

Glanders ....................... 151

Agglutination method _. . _ i68

Animal inoculation ...... 165

Characterization ......... 15 I

Differential diagnosis ..... $16_{4}$

Disposition of reacting horses _._._. _._. . . 172

Etiology

Geographical distribution_-152

Glanders in man ........ 163

History ................ 15

Iallein _................ 165

Morbicl anaton11 _._... _ _ 55

Period of incubation _...... I.54

Prevention _._._. _..._... 15.53

Serm11 diagnosis ........... 168

Symptoms ........... 154

Goose septicemia ............ III 
Characterization .......... 111

Differential diagnosis .....113

Etiology ............... I I I

History ................. II II

Morbid anatomy .......... 112

Post-mortem notes ........113

Prevention .............. II

Symptoms .................. 112

Grouse disease .............. $28_{3}$

\section{$\mathrm{H}$}

Hemolysins _............ 552

Hemorrhagic septicemia in cattle ............... 94

Characterization ......... 94

Differential diagnosis.... 103

Duration _..._._......... 99

Etiology .... ............ 96

Geographical distribution_ 96

History _.......... .... 94

Morbid anatomy _......... 99

Period of incubation ..... 97

Prevention ................. I03

Prognosis ............... 99

Symptoms ..._........ 97

Hog cholera ................ 246

Characterization ......... 246

Differential diagnosis _.._-259

Duration _..._..._._._. 259

Etiology _. . . . . . _... 249

Geographical distribution_248

History -... . . . . . . 247

Morbid anatomy ....... 254

Period of incubation ......253

Prevention ............. 262

Proguosis ............ 259

Specific treatment ....... 264

Symptoms .......

Horse pox ............ 533

\section{I}

Ictero-hematuria in sheep _-..-368

Characterization _........-368

Differential diagnosis _...-369

Etiology _... _.

Geographical distribution 368

History ................ 368

Morbid anatomy

Symptoms _. - . - _ - - 368

Immunity

Active and passive

Artificial _..._._.

Explanation of ....--550
Natural _.

Explanation of -

Production of .......... 549

Active _._. . .

Passive ............ 556

Infection

Miscellaneous, $36,244,29 \mathrm{r}, 346$

Umbilical ....... 29

Infectious abortion .......... 523

Characterization _........ 523

Etiology _.

History _.... .......... 523

Morbid anatomy

Prevention _............. 52S

Infectious cerebro-spinal meningit is (see cerebro-spinal neningitis).

Infectious diseases........... 14

Dissemination of .......... If

Prevention ........... 560

Infectious entero-hepatitis ...-377

Characterization _..._._. 377

Differential diagnosis..... 389

Etiology _..._.

Geographical distribution -378

History -

Morbid anatomy _._._._. 382

Post-mortem notes......... 388

Prevention _...

Symptoms _........... $38 \mathrm{SI}$

Infective sarcomata in dogs .. 542

Infectious suppurative cellulitis 29

Influenza_ _.._._._._._. 499

Characterization _........ 499

Differential diagnosis _... 505

Etiology _.........

Geographical distribution.5or

History -............. 500

Morbid anatomy

Symptoms _... .

Ixodes bovis .

\section{$J$}

Johne's disease .............. 230

Characterization ......... 230

Differential diagnosis _._.233

Etiology _...

History ................. 230

Morbid anatomy .........231

Period of incubation ...... 231

Prevention ................ 233

Sympton1s _............... 23I 


\section{L}

Leeches ................. 32 I

Characterization .... 321

Ftiology _...

Geographical distribution-324

History _................ 32 I

Morbid anatomy ......... 325

Treatment _........... 332

Leucoence phalitis _..._... . . 517

Lockjaw (see tetanus).

Lnmpy jaw (see actinomycosis).

\section{M}

Malaria, bovine (see Texas fever).

Canine .............. 372

Mal de caderas ............... 423

Characterization ......... 423

Differential diagnosis ..... 425

Etiology _. _ _...... 423

Geographical distribution 423

History ..... . . . . ._._... 423

Mode of infection ... .... 424

Morbid anatomy _......... 424

Symptoms ... .......... 424

Malignant edema_............. $2 \mathrm{~S} 6$

Characterization _........ 286

Differential diagnosis ..._. 288

Etiology _...

History _.............. 286

Morbid anatomy ............ 287

Prevention ............... 289

Mallein _..._........ 165

Margaropus anmulatus _._._- -355

Mastitis, infectious _........ 32

Mastitis, streptococcic ....... 60

Characterization ........ 60

Differential diagnosis .... . 6I

Duration ........... 61

Etiology ........... 60

Geographical distribution. 60

History ................ 60

Morbid anatomy _....._._. 61

Period of incubation _...... 61

Symptoms .............. 6I

Micrococcus, discussion of ... 63

Hicrococcus ascoformans _..... 24

botryogenes ........... 24

caprinus _.......... 64

lanceolatus _..._...... 73

pyogenes aureus, 8, 24, 63

Migula's classification of bacteria I 8,19 1/usca domestica ........... 135

Mycotic stomatitis _...... 347

\section{N}

Nagana _.... _._. . . 426

Characterization _......... 426

Differential diagnosis _.... 427

Etiology _..._.

Geographical distribution- 426

History .............. 426

Morbid anatomy _......... 427

Symptoms _. _ _._. 426

Navel-ill _................ 25

Negri bodies.........462, 464, 482

Normal temperature of cattle 218

Effect of drinking water on -22I

\section{(Esophagostoma Columbianum}

Omphalophlebitis_.... 212, 239

Omphalophlebitis $1 \mathrm{mph}$ adenitis 234

Characterization ........... 234

Differential diagnosis _... 242

Etiology _...

Geographical distribution 234

History _.... . . . . 234

Morbid anatomy ........... 233

Symptoms ................. 236

\section{$\mathbf{P}$}

Pasteur's anthrax vaccine_... 147

Pasteurelloses ............. 69

Pictou disease ..... . . . . 13

Piroplasmoses _...... . . . 349

Piroplasma in horses........ - 369

Piroplasma bigeminum _...--352

canis _................. 373

equi _...

ovis_................ 368

Plenro - pneumonia (see contagious pleuro-pneumonia).

Pneumonomy cosis _ _...... 333

Morbid anatomy _..._._. 337

Species of fungi _.......-333

Pneumonomy cosis in birds _...34 I

Poll evil ... .................. 31

Protozoa

Protective inoculation _....... 555 
Pseudo-tuberculosis(see Johne's disease).

In sheep ................ 234

Prrosoma bigeminum ....... 352

\section{Q}

Quail disease .

(Yuarter-ill (see black leg).

\section{$\mathbf{R}$}

Rabies $-459$

Characterization ........... 459

Differential diagnosis ....-477

J) umb _.............. 471

Iitiology

I'urious … ............ 470

Geographical distribution 461

History - ........... 460

Method of invasion _..... 465

Morbid anatomy ........ 472

I'eriod of incubation ..... 467

Prevention and treatment 483

Resistance of virus.... $\quad 466$

Svmptoms _.......... 469

Ray fungus _..... _....... 301

Rhorlesian rerlwater .... 352

Rinder jest _.............. 430

Characterization ....... 4.31

Inifferential rliagnosis $\quad 436$

Etiology _... _ _... 432

Geographical distribution 43 I

History _- ac a -...431

Immunizing cattle. $\quad . .4439$

Morbid anatomy .......... 434

Prevention ... . . ....4.4. 437

Simptonis _..._... ... . 433

k'inderseuche....._._._._._. 94

\section{S}

Saccharomycosis farciminosus -343

Sapremia …......... _ 3

Senerio jacobea ............. 13

Septicemia ................ 3

Sheep pox … 535

Simultaneous vaccine method 149

Specific infectious rlisease.... 3, it

Canse of variation in _.. 15

I)ifferential characters of _ II

I)issemination of _........., I4

(irouping of ........ 16
Spirillaceae _... . . _. _._._. 294

Diseases of fowls caused by -294

Spirillosis of cattle .... _.....295

In animals ............ 297

Disease of pigs ........ 296

Spirochaete anserina _._._._._. 294

Strangles_............... 44

Characterization _......... 44

Iifferential diagnosis ..... is

Duration ............... 47

Etiology _.......... _ 45

Geographical distribution - 45

History _............. 44

Morbid anatomy _........ 46

Mortality _........... 4 is

Period of incubation ..... 45

Prevention _.............. 4s

Symptomis _._.......... 45

Strauss nethod of inoculation. 55

Streptococci ..... .......... 38

Classification of ........ 40

Diseases dlue to _..____ 33

Distribution in nature .... +1

General discussion of _.... $3 \mathrm{~S}$

Pathogenesis of ........ 43

Surra .............. _.. 400

Characterization _.........400

I) ifferential diagnosis ..... 408

Etiulogy ................. 401

Gengraphical distribution .400

History … .... . - 400

Means of transmission _._. 402

.1\%rbicl anatomy___. $\ldots 404$

l'eriorl of incubation ..... 402

Prevention _..... -409

Report of Smith and Kinyoun

Symptomis _............ 403

Swine erysipelas............ 123

Characterization ......... 123

I)ifferential diagnosis ..... 127

Juration ................ 127

I:tiology _._._._. 124

( reographical distribution_124

History _..._....... 123

Morbirl anatomy _..... 126

Periorl of incubation _._._ 125

P'reventive inoculation _... $2 \mathrm{SS}$

I'rognosis ........... 127

Symptoms_..._._._. 125

Swine fever (see hog cholera).

Swine plague. …..... $7 \mathrm{r}$

Autopsy notes _....... $\quad 84$

Bacterium of ......... 74

Characterization _......... 71 
Differential diagnosis _ 86

Etiology _... . 72

Geographical distribution $7^{2}$

History _............. $7 \mathrm{I}$

In rabbits ............... SS

Modification of, in rabbits 60

Morbid anatomy _...... 77

Prevention _.......... 87

Specific treatnient ........ SS

Symiptoms _._._._._._. 76

Symptomatic anthrax (see blackleg).

\section{$\mathrm{T}$}

Tabanidue .......

Takosis .................... 63

Characterization ......... 63

Differential diagnosis _... 60

Etiology _._. . _. _. _ 64

Geographical distribution 04

History ................ 63

Morbid anatomy _._._..... 65

Prevention _........... 67

Symptons _........... . . 64

Tetanus _... _...

Characterization _..._... 265

Differential diagnosis . _. 273

I) uration _............ 273

Etiology - .

Geograplical distribution_260

History _..._. . 266

Mode of infection _.......268

Morbid anatomy _._._._. 271

Period of incubation ..... 268

Prevention _...... _._. 274

Srmptoms _. _...2. 269

Tetanus antitoxin _.......274

Texas fever ........

Characterization _....... 350

Differential diagnosis _... -363

Etiology - _.. _ _ 352

Geographical distribution 350

History -........... 350

Imnunizing susceptible cattle . - .

Infection _...... _.. 355

Morbid anitomy ........-360

l'revention _._.

Symptoms _...... _ _ 35 .

Toxemia

Trypanoplasma_..._... 39 39 , $39^{2}$

Trypanosoma .......... 391

Classification _..._. 391

Disappearance after deatli-395
Distribution in the body -394

History _.. 529

Historical sketch _._. 395

Morphology _....... 392

II ultiplication _._._. _ _ _ 393

Staining _....... +13

Trypanosoma Brucei, 394, 397, 426 equillum _ - 396, 397, +23 equiperdum $-396,397,412$ Evansi _.... 397, 401 Leaisi $\ldots 391,397$ Theilerei _... $\quad-396$

Trypanosomata and their hosts -399 Trypanosomiasis _.... 390

Differentiation _._. $\ldots 427$

Tse-tse fly disease (see Nagana).

Tuberculin ... _........ 15

Application of _......217

Preparation of _._. 215

Tuberculosis _.................. 175

Characterization _....... 175

Control of, in cattle _.....224

Differential diagnosis _...211

Animal inoculation ...214

Microscopic exam'tion, 213

Tuberculin test .......2 15

Etiology _............ ISO

Extent of, in cattle and swive _............ I75

Generalized _........197

Geographical distribution_ $; 79$

History 176

Localized ..........__ 196

Iorbid anatomy _..... $18 \mathrm{SS}$

l'revention $\quad 223$

Symptoms _..._. _... $1 S_{2}$

'Tubercle, structure of . ... 191

Vaccination _._._. 225

Tuberculosis in fowls _.... 203

Symptoins _._. _... 204

Tuberculosis in swine....... $19 \mathrm{~S}$

Clannels of infection ..... rgs

Mlorbid anatomy ..... 200

Svmptoms _ $\quad 199$

Tuberculosis in other mammals_ 203

\section{V}

Vaccination _................. $55^{8}$

Dangers of ......... $55^{\mathrm{S}}$

Variola in animals _...... 529

Characterization ....... 529

Etiology _._. 533

Geographical distribution -533 
Symptoms

Variola in horses

in cows

in goats

in sheep

in swine.

W
Wildsenche .........._-_. 94

Wound infection_........... 3, 6 Bacteria _.............. s

Morbid anatomy

Prevention .............. 10

\section{Z}

White scours

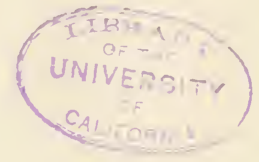




\section{The Pathology and Differential Diagnosis of Infectious Diseases of Animals.}

By Veranus Alva Moore, B.S., M.D., Professor of Comparative Pathology, Bacteriology and Meat Inspection, New York State Veterinary College, Cornell University, Ithaca, N. Y. With an introduction by Daniel Elmer Salmon, D.V.M., former Chief of the Bureau of Animal Industry, United States Department of Agriculture.

The Profession will gladly welcome this new book, which brings the subject right up to the present state of the wonderful progress made in the study of infectious diseases. * * The book deals with the important infectious diseases of animals that occur in this country.-Am. Vet. Review.

Dr. Moore has rendered an invaluable service in bringing together in convenient book form a lucid, interesting and accurate account of the infectious diseases of animals. - Am. Med.

Third Edition. Revised and Enlarged. \$4.00 net Postpaid.

\section{Examination of the Urine of the Horse and Man}

BY PIERRE A. FISH, D.Sc., D.V.M.

Simple directions are given for performing the tests necessary to determine the normal or abnormal conditions of the urine.

Price, $\$ 1.50$ net postpaid.

TAYLOR \& CARPENTER

VETERINARY PUBLISHERS AND BOOKSELLERS

ITHACA, N. Y. 


\section{General Surgery}

B Y DR. MED. EUGEN FRÖHNER-Professor in the Royal Veterinary High School in Berlin. Authorized Translation from The Third Revised Edition, by D. HAMMOND UDALL, B.S.A., D.V.M., Associate Professor of Surgery and Obstetrics, Ohio State University, Columbus, Ohio.

The translation of Frohner's General Surgery has been undertaken to meet the need of an English text-book on the subject. This textbook is Vol. II. of a hand book of seven volumes written by various authors and edited by the late Prof. Joseph Bayer, of Vienna and Prof. Eugen Frohner of the Berlin Veterinary School. One other volume of this hand book, De Bruin's Obstetrics, is already well known to English speaking veterinarians.

The reputation of Prof. Frohner as a writer of text-books is too well known to require explanation. This translation is from the 1905 edition; the subject is presented in a scientific manner; is both concise and complete, and based on the experience of many years of carefully prepared stastics from the largest clinic of its kind in the world.

The translator has earned our thanks for making available to Non-German reading Veterinarians one of the best of the numerous works on General surgery. The name of Professor Fröhner is a sufficient guarantee of the excellence of the matter and the convenience of its arrangements. The work contains much information not to be found, or indifferently treated of, in othets of the same class and some chapters, notably those on tumour, fractures and luxations, are admirably written. "

THE JOLRNAL, OF TROPICAL, VETFRINARY SCIENCE,

Calcutta.

"I beg to tlank you for the copy of Fröhner's Ceneral Veterinary Surgery which I received from you a short time ago. It is an excellent work, the hest of its kind, in my opinion, in the English language.

(signed) J. J. O'CONNOR, M. R. C. V. S.,

Professor of Sirgery, Royal Veterinary College of 1reland."

"The original work of Fröhner is of course of an nunsually high class and I have found your translation of it highly satisfactory. You have rendered a distinct service to veterinary students in America by your admirable translation of this work which in excellency is unsurpassed in Veterinary literature.

(Signed) W. L. WILI,IAMS,

Professor of surgery New York State Veterinary College, Ithaca, N. Y.'

\section{$\$ 3.00$ net postpaid}

\section{TAYLOR \& CARPENTER}

VETERINARY PUBLISHERS AND BOOKSELLERS

ITHACA, N. Y. 
RY PIERRE A. FISH, D.Sc., D.V.M. Professor of Veterinary B Physiology and Pharmacology, New York State Veterinary College, Cornell University, Ithaca, N. Y.

\section{Veterinary Doses and Prescription Writing}

A full list of drugs with their doses for the different domestic animals. Therapeutic terms and a list of terminations of medical terms applicable to Veterinary medicine. Prescription writing is discussed in some detail, with illustrative prescriptions. Thermometric equivalents. Weights and measures. Latin words and phrases used in prescription writing. Incompatability. Poisons and their antidotes. Classification of medicines according to their physiologic actions. Pages for selected prescriptions.

Red Leather Flexible Covers, 160 pages. Third Revised and Enlarged Edition $\$ 1.50$ net Postpaid.

* * * A small volume which will be of indispensable value to practitioners and students. $* * *$ It will return the investment with interest every other day.American Veterinary Review.

\section{Elementary Exercises in Materia Medica and Pharmacy}

BY PIERRE A. FISH, D.Sc., D.V.M.

A.laboratory manual treating of the more commonly used inorganic and organic drugs. Charts are included, upon which are to be plotted physiologic action of many of the drugs. The pharmaceutical section includes examples of the different preparations in the U.S. Pharmacopoeia.

Second Edition. Revised and Enlarged. \$1.50 net Postpaid.

There are features in this book which betoken a graleful advance in the medical and pharmaceutical professions. We congratulate Prof. Fish on his work.-Alkalodial Clinic.

\section{TAYLOR \& CARPENTER. \\ VETERINARY PUBLISHERS AND BOOKSELLERS} ITHACA, N. Y. 


\title{
Exercises in Physiology
}

\author{
BY PIERRE A. FISH, D.Sc., D.V.M.
}

A laboratory manual. Part I, Chemical Physiology. Part II, Experimental Physiology.

Second Edition. Revised and Enlarged. \$1.50 net Postpaid.

The work is modern. Its directions are admirably concise and clear. It will aid teachers as well as students.-Jour. of Applied Microscopy and Laboratory Methods.

\section{Veterinary Medicine}

\section{By Professor James Law, F.R.C.V.S.}

\author{
Director N. Y. S. Veterinary College, Ithaca, N. Y.
}

VOL. I. General Pathology: Diseases of the Respiratory and Circulatory Organs. pp. 566. 8 vo. 2nd Ed. Revised and enlarged. Price $\$ 4.00$.

VOL. II. Diseases of Digestive Organs, Liver, Pancreas and Spleen. pp. 595. 8 vo. 2 nd Ed. Revised and enlarged. Price $\$ 4.00$.

VOL. III. Diseases of Urinary and Generative Organs, Skin, Eye and Nervous System. pp. 611. 8 vo. 2nd Ed. Revised and enlarged. Price, $\$ 4.00$.

VOL. IV. Infectious Diseases, Sanitary Science and Police. pp. 675. 8 vo. 2nd Ed. in Press. Price, $\$ 4.00$.

VOL. V. Parasites and Parasitism. 1st Ed. pp. 532. 8 vo. Price, \$4.00.

Destined to become a standard authority. - Am. Vet. Review.

No beller work of reference could be.-Veterinary Record.

Of Professor Law's latest volume (IV), we can speak in terms of warm praise. With its companion volumes, will form a valuable addition to the literature of veterinary medicine.-Jour. of Comp. Path. and Thera.

Published by the author. Sent, express prepaid, on receipt of price.

TAYLOR \& CARPENTER

VETERINARY PUBLISHERS AND BOOKSELLERS

ITHACA, N. Y. 


$$
\text { . }
$$



THIS BOOK IS DUE ON THE LAST DATE STAMPED BELOW

AN INITIAL FINE OF 25 CENTS WILL BE ASSESSED FOR FAILURE TO RETURN THIS BOOK ON THE DATE DUE. THE PENALTY WILL INCREASE TO 50 CENTS ON THE FOURTH DAY AND TO \$1.0O ON THE SEVENTH DAY OVERDUE.

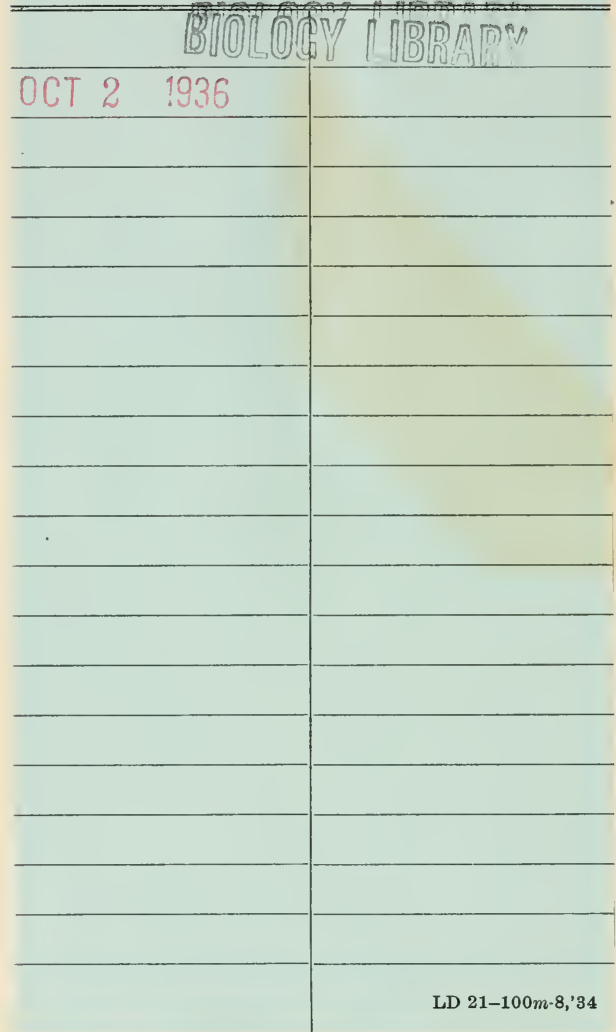




$$
2
$$


